\title{
Jean Meynaud
}

Directeur d'études

à l'École Pratique des Hautes Études

Professeur à l’Université de Lausanne

(1965)

\section{LES FORCES POLITIQUES EN GRÈCE}

\author{
avec le concours de P. MERLOPOULOS \\ ET G. NOTARAS
}

\footnotetext{
Un document produit en version numérique par Mme Marcelle Bergeron, bénévole Professeure à la retraite de l’École Dominique-Racine de Chicoutimi, Québec Courriel: mailto:mabergeron@videotron.ca

\section{Page web}

Dans le cadre de la collection: "Les classiques des sciences sociales" Site web: http://classiques.uqac.ca/

Une collection développée en collaboration avec la Bibliothèque Paul-Émile-Boulet de l'Université du Québec à Chicoutimi Site web: http://bibliotheque.uqac.ca/
} 


\section{Politique d'utilisation de la bibliothèque des Classiques}

Toute reproduction et rediffusion de nos fichiers est interdite, même avec la mention de leur provenance, sans l'autorisation formelle, écrite, du fondateur des Classiques des sciences sociales, Jean-Marie Tremblay, sociologue.

Les fichiers des Classiques des sciences sociales ne peuvent sans autorisation formelle:

- être hébergés (en fichier ou page web, en totalité ou en partie) sur un serveur autre que celui des Classiques.

- servir de base de travail à un autre fichier modifié ensuite par tout autre moyen (couleur, police, mise en page, extraits, support, etc...),

Les fichiers (.html, .doc, .pdf, .rtf, .jpg, .gif) disponibles sur le site Les Classiques des sciences sociales sont la propriété des Classiques des sciences sociales, un organisme à but non lucratif composé exclusivement de bénévoles.

Ils sont disponibles pour une utilisation intellectuelle et personnelle et, en aucun cas, commerciale. Toute utilisation à des fins commerciales des fichiers sur ce site est strictement interdite et toute rediffusion est également strictement interdite.

\section{L'accès à notre travail est libre et gratuit à tous les utilisateurs. C'est notre mission.}

Jean-Marie Tremblay, sociologue

Fondateur et Président-directeur général, LES CLASSIQUES DES SCIENCES SOCIALES. 
Un document produit en version numérique par Mme Marcelle Bergeron, bénévole, professeure à la retraite de l'École Dominique-Racine de Chicoutimi, Québec. Courriel : marcelle_bergeron@uqac.ca

Jean MEYNAUD

avec le concours de P. Merlopoulos et de G. Notaras

Les forces politiques en Grèce. Lausanne : Jean Meynaud, 1965, 530 pp. Collection : Études de science politique, $\mathrm{n}^{\circ} 10$.

[Autorisation formelle accordée parles ayant-droit de l'œuvre de Jean Meynaud, son épouse, Mme Meynaud-Zogrphos, Michel Meynaud (fils) et Hélène-Yvonne Meynaud (fille) le 19 octobre 2008 de diffuser toutes les œuvres de Jean Meynaud dans Les Classiques des sciences sociales.]

Qf. Courriels des ayant-droit :

Mme Meynaud-Zographos (épouse) : meynaud-zographos@orange.fr

Hélène-Yvonne Meynaud (fille) : $\quad \underline{\text { helene-yvonne.meynaud@edf.fr }}$

Polices de caractères utilisés : Times New Roman, 12 points.

Édition électronique réalisée avec le traitement de textes Microsoft Word 2008 pour Macintosh.

Mise en page sur papier format : LETTRE (US letter), 8.5'’ x 11'’)

Édition complétée le 9 janvier 2011 à Chicoutimi, Ville de Saguenay, Québec. 


\section{Jean Meynaud (1965)}

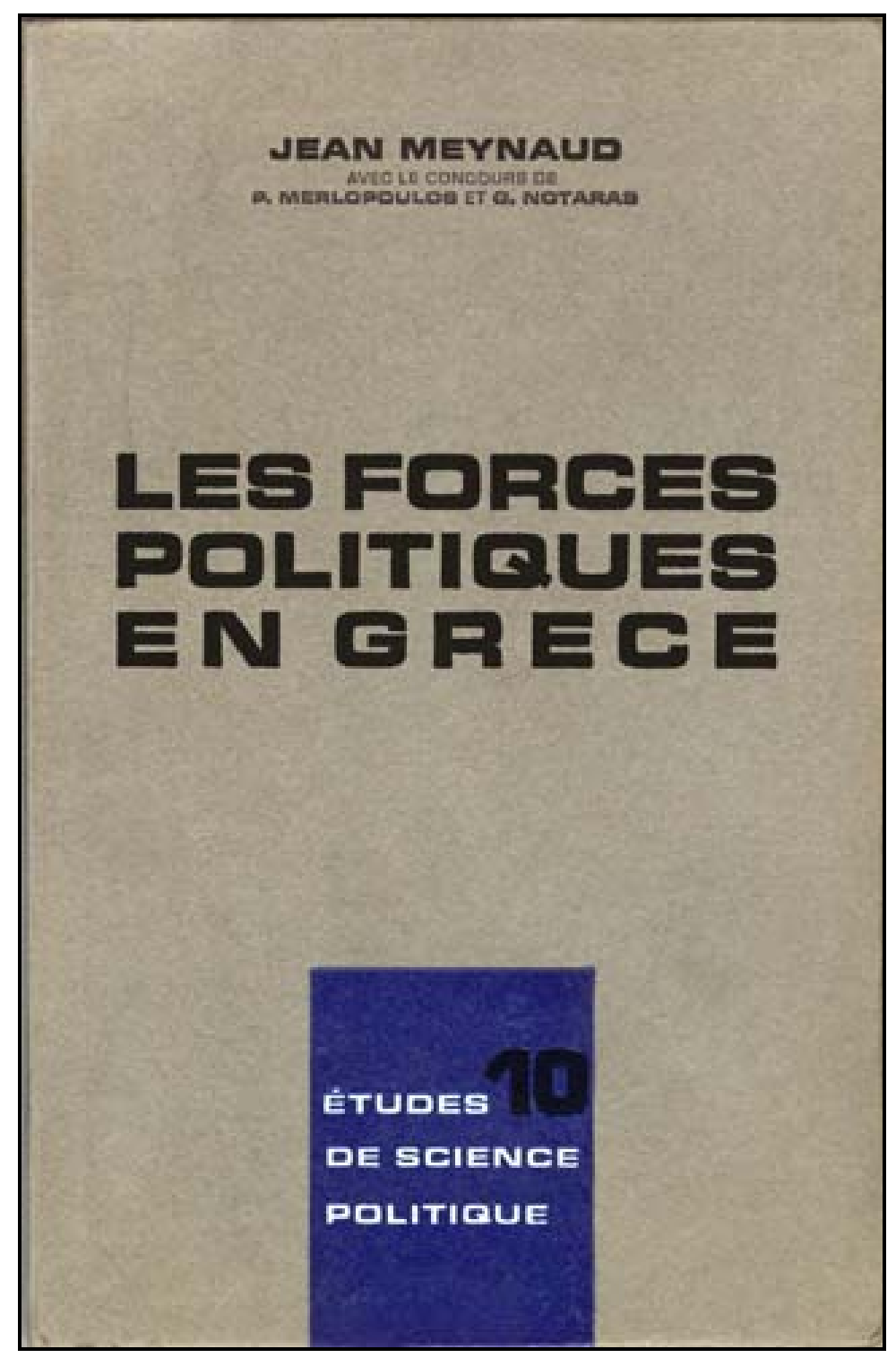

Les forces politiques en Grèce. Lausanne : Jean Meynaud, 1965, 530 pp. Collection : Études de science politique, $\mathrm{n}^{\circ} 10$. 
[p. 2] *

\section{DU MÊME AUTEUR}

La science politique au XXe siècle, 64 p., Lausanne, 1956, épuisé.

Aspectos Attuais da Emprêsa publica na França, 88 p., Rio de Janeiro, 1957.

Les groupes de pression en France (FNSP), 372 p., Paris, 1958, épuisé.

Introduction à la science politique (FNSP), 376 p., Paris, 1959, $2^{\mathrm{e}}$ édit.

L'élaboration de la politique économique, 228 p., Aix-en-Provence, 1959.

La science politique : fondements et perspectives (ESP), 228 p., Lausanne, 1960, épuisé.

Technocratie et politique (ESP), 116 p., Lausanne, 1960, épuisé.

Les groupes de pression (QS), 128 p., Paris, 1960, $2^{\mathrm{e}}$ éd.

Les groupes de pression internationaux (ESP), 560 p., Lausanne, 1961.

Destin des idéologies (ESP), 164 p., Lausanne, 1961.

La participation des Français à la politique (QS), en coll. avec A. LANCELOT, 124 p., Paris, 1961.

La médiation : tendances de la recherche et bibliographie (1945-1959), en coll. avec B. SCHRÖDER, 112 p., Amsterdam, 1961.

Acheter mieux. L'information objective du consommateur, 144 p., O.E.C.E., 1961.

Nouvelles études sur les groupes de pression en France (FNSP), 468 p., Paris, 1962.

Les savants dans la vie internationale (ESP), en coll. avec B. SCHÖDER, 220 p., Lausanne, 1962.

Les attitudes politiques (QS), en coll. avec A. LANCELOT, 128 p., Paris, 1962, $2^{\mathrm{e}}$ édition.

L'action syndicale et la Communauté Économique Européenne, 70 p., Lausanne, 1962.

Planification et politique (ESP), 192 p., Lausanne, 1963.

Les organisations professionnelles en Suisse (Payot), avec le concours de A. KORFF, 344 p., Lausanne, 1963.

La révolte paysanne (Payot), 310 p., Paris, 1963.

I gruppi di pressione in Francia e Italia, en coll. avec C. RISÉ, 140 p., Naples, 1963.

Le syndicalisme africain (Payot), en coll. avec A. SALAH-BEY, 264 p., Paris, 1963.

Études politiques vaudoises (ESP), sous la direction de J. MEYNAUD, 320 p., Lausanne, 1963.

La technocratie : mythe ou réalité, (Payot), 300 p., Paris, 1964.

Rapport sur la classe dirigeante italienne (ESP), Lausanne, 1964.

ABRÉVIATIONS :

ESP ..... Études de Science Politique, Mornex 6, Lausanne.

FNSP ... Cahiers de la Fondation Nationale des Sciences Politiques, Armand Colin, Paris, QS ...... « Que sais-je », Presses Universitaires de France, Paris.

\footnotetext{
* [Les numéros entre accolades réfèrent aux numéros de pages de l'édition de papier, MB.]
} 
[p. 523 530] *

\title{
TABLE DES MATIÈRES
}

\section{LES FORCES POLITIQUES EN GRÈCE}

$\underline{\text { AVANT-PROPOS }}$

\author{
CHAPITRE PRÉLIMINAIRE \\ COMPOSANTES DE L'EXPÉRIENCE HISTORIQUE
}

I. Une nation difficilement rassemblée

II. Une économie longtemps stagnante

III. Une société marquée par la pauvreté

IV. Un système politique inadéquat

$\underline{V}$. Un état soumis à la dépendance

VI. Répercussions de la seconde guerre mondiale

VII. Remarques sur le comportement politique grec

TITRE PREMIER

PARTIS ET ÉLECTIONS

CHAPITRE I : PRÉSENTATION DES RÉGIMES ÉLECTORAUX

I. Fixation du cadre

A. Partage des sièges à pourvoir

B. Délimitation géographique des circonscriptions

II. Mécanisme de distribution des sièges

A. Distribution des sièges entre les répartitions successives

B. Conditions d'accès aux répartitions successives

C. Modalités de distribution des sièges à chaque répartition

III. Conditions de mise en œuvre

A. Désignation de gouvernements de service

B. Taux d'inscription et niveau de participation

C. Vote des militaires

\footnotetext{
* [Les numéros entre accolades réfèrent aux numéros de pages de l'édition de papier, MB.]
} 
CHAPITRE II : ANALYSE DES RÉSULTATS ÉLECTORAUX

I. Préparation du retour au régime parlementaire

II. Élections du 31 mars 1946

III. Élections du, 5 mars 1950

IV. Élections du 9 septembre 1951

V. Élections du 16 novembre 1952

VI. Élections du 19 février 1956

VII. Élections du 11 mai 1958

VIII. Élections du 29 octobre 1961

IX. Élections du 3 novembre 1963

X. Élections du 16 février 1964

CHAPITRE III : TRAITS GÉNÉRAUX DE L'ÉVOLUTION

I. Exposé des changements

A. Analyse statistique

1. Fréquence des interventions électorales

2. Modalités des interventions électorale

3. Résultats des interventions électorales

B. Contenu politique

II. Influence du système électoral

A. Mécanisme d'intervention

B. Effets de l'intervention

1. Effets sur les résultats électoraux

2. Effets sur le système des partis

TITRE DEUXIÈME

ÉTAT DES PARTIS

CHAPITRE IV : PARTICULARITÉS DU CONTEXTE

I. Facteurs d'ordre socio-économique

A. Distribution de la population active

1. Secteurs d'occupation

a) surabondance paysanne

b) faiblesse des effectifs industriels

c) pléthore des activités de distribution ct de service

2. Rapports de production

B. Mouvements de la population

1. Ampleur de l'émigration

2. Dimensions de la croissance urbaine

C. Centralisation économique et pratique politique

II. Facteurs d'ordre socio-politique 
A. Situation du Parti Communiste

B. Dispositif de lutte anti-communiste

1. Exposé des mesures d'exception

2. Nature du régime

C. Faiblesse du mouvement syndical

III. Position de la presse

CHAPITRE V : GAUCHE DÉMOCRATIQUE UNIFIÉE (EDA)

I. Structure et direction

A. Mode d'organisation

B. Composition socio-professionnelle des organes centraux

C. Principaux leaders du parti

II. Idéologie et programme

A. Programme de base

B. Prises de position récentes

III. Stratégie et tactique

A. Action parlementaire

B. Activité extra-parlementaire

C. Appareil de communication

D. Situation financière

IV. Dimension du parti

A. Implantation territoriale

B. Les élections municipales de juillet 1964

V. Évaluation d'ensemble

\section{CHAPITRE VI : PARTI PROGRESSISTE}

\section{CHAPITRE VII UNION NATIONALE RADICALE (ERE)}

I. Structure et direction

A. Direction centrale du parti

1. Assemblée générale

2. Chef du parti

3. Autres organes centraux de direction

4. Secrétariat général

5. Groupe parlementaire

B. Structure organique du parti

C. Situation personnelle du chef du parti

1. Le cas de C. Caramanlis

2. Le cas de P. Canellopoulos

D. Parlementaires influents de la Droite

II. Idéologie

III. Stratégie et tactique

A. Pratiques de l'ERE 
B. La droite face à l'offensive de l'opposition

IV. Dimensions du parti

V. Évaluation d'ensemble

CHAPITRE VIII : UNION DU CENTRE (EK)

I. Structure et direction

A. Direction centrale du parti

1. Chef du parti

2. Congrès du parti

3. Groupe parlementaire

4. Conseil de discipline

B. Structure organique du parti

C. Situation personnelle du chef du parti

1. Le parti dans l'opposition

2. Le parti au pouvoir

3. Personnalité de G. Papandréou

D. Parlementaires influents du Centre

II. Programme et idéologie

A. Rétablissement de la Démocratie politique

B. Mise en œuvre de la formule démocratique

1. Création de l'État de Droit

2. Politique économique

3. Politique extérieure

III. Stratégie et tactique

A. Position de l'Union vis-à-vis de la Droite

B. Position de l'Union vis-à-vis de la Gauche

IV. Dimensions du parti

V. Évaluation d'ensemble

CHAPITRE IX : ESQUISSE D'UN BILAN

I. Traits caractéristiques du système des partis

A. Permanence des structures traditionnelles

B. Maintien des clivages anciens

II. Développement économique et modernisation politique

TITRE TROISIÈME

PARTIS ET GROUPES DIRIGEANTS

\section{CHAPITRE $X$ : LES FORCES EXTRA-PARLEMENTAIRES DE LA VIE PUBLIQUE}

I. Place de la Monarchie

A. Traits du comportement de la Monarchie en Grèce

1. Facteurs du retour du Roi

2. Relations de la Couronne avec la Droite 
3. Activités sociales du Palais

4. Le Clan Royal

B. Chances d'avenir de la Monarchie

II Rôle de l'armée

A. Exposé des interventions

B. Marge de manœuvre du pouvoir civil

III. Situation de l’Église

\section{CHAPITRE XI — LES GROUPES D’AFFAIRES NATIONAUX}

I. Présentation des groupes

A. Secteur bancaire

1. Banque de Grèce

2. Banques commerciales

a) Banque Nationale de Grèce

b) Banque Commerciale

3. Organismes d'investissement

4. Établissements spécialisés

5. Observations générales

B. Secteur industriel

1. Rythme de la croissance industrielle

2. Personnalités influentes de ce secteur

3. Secteur publie industriel

C. Secteur de la navigation

II. Influence des groupes

A. Sécurité politique et sociale

B. Sécurité économique et financière

1. Établissement de l'infrastructure

2. Protection douanière

3. Régime fiscal de faveur

4. Facilités de crédit

III. Problèmes de l’agriculture

\section{CHAPITRE XII : LES PUISSANCES ÉTRANGÈRES}

I. Efforts d'orientation politique

A. Action de la Grande-Bretagne

B. Action des États-Unis

1. Rappel historique

2. Traits de l'intervention américaine

3. Clan américain

C. Action d'autres pays

II. Essais de mainmise économique

A. Assistance économique

1. Assistance fournie par les États-Unis 
2. Assistance fournie par les autres pays

3. Assistance fournie par des institutions internationales

4. Observations générales

B. Investissements directs

1. Régime juridique

2. Ampleur des opérations effectuées

3. Discussion des contrats signés

a) contrat Esso-Papas

b) contrat Péchiney-Niarchos

4. Capital étranger et avantage national

a) prise de possession de l'appareil industriel

b) obstacles à la planification économique

c) entraves au progrès social

d) prélèvement sur les ressources nationales

e) stagnation du secteur ancien

f) pouvoir corrupteur du capital étranger

C. Capital étranger et services d'utilité publique

III. La route de la servitude

\section{CONCLUSION}

I. Qualité de l'appareil gouvernemental

II. Valeur de la politique économique

III. Nature des problèmes à résoudre

Lexique des partis politiques grecs

Tableau des coalitions électorales

Annexe I : Évolution de la force parlementaire des diverses tendances

Annexe II : Projets de loi soumis par l'EDA au cours de la période 1956-1961

Annexe III : Balance de paiement de la Grèce

Appendice statistique

Index

Appendice cartographique 
[p. 3, page titre, p. 4]

La cartographie de ce volume a été gracieusement établie, sur des brouillons de G. Notaras, par le Laboratoire de Cartographie de l'École Pratique des Hautes Études, auquel nous adressons nos vifs remerciements. 
[p. 5]

\section{AVANT-PROPOS}

$\underline{\text { Retour à la table des matières }}$

LA PRINCIPALE justification de ce livre est qu'il n'existe pas en langue française d'analyse de la politique grecque à l'époque contemporaine. La civilisation de la Grèce antique a fait l'objet, jusque dans ses plus petits détails, de recherches étendues qui se renouvellent sans cesse. Les Grecs de notre époque n'ont jamais bénéficié certes d'un semblable intérêt.

La situation n'est pas sensiblement meilleure dans les pays de langue anglaise. On y trouve quelques ouvrages sur la guerre civile mais il s'agit, en moyenne, de simples récits ou témoignages dépourvus d'inspiration générale. En dépit d'un dépouillement bibliographique minutieux, je n'y ai pas découvert de tableau ou d'exposé global de la vie politique grecque. Cette lacune est surprenante si l'on connaît l'ampleur et la diversité des domaines actuellement couverts par la science politique américaine.

Il faut dire aussi que la bibliographie en langue grecque n'est pas très satisfaisante. L'analyse politique n’étant pas encore inscrite au programme des universités helléniques, il n’y a pratiquement pas en Grèce sur ces sujets de travaux de facture ou de style universitaire. À l'exclusion des ouvrages ou brochures de pure polémique, les livres consacrés aux forces politiques sont en tout petit nombre et relèvent davantage de la chronique ou du journalisme que de l'essai d'interprétation systématique.

Dans ces conditions, la seule voie ouverte pour examiner la vie politique dans la Grèce d'aujourd'hui était de procéder à une enquête directe sur le terrain. Cette méthode implique que l'on interroge les acteurs du jeu gouvernemental et que l'on procède à un dépouillement de sources brutes: elle présente des risques et des servitudes dont la [p. 6] plus lourde pour le chercheur universitaire est de ne pouvoir appuyer ses dires ou ses appréciations sur les habituelles références bibliographiques. Mais l'on ne saurait traiter d'un champ encore largement inexploré comme l'on rend compte d'une question déjà abondamment discutée. 
Je n’aurais certainement pas entrepris la rédaction de ce livre si ma vie de famille ne m'avait mis en contact immédiat avec les choses de la Grèce depuis une vingtaine d'années. Par ailleurs, je n'aurais probablement pas pu mener à bien ce projet sans disposer de l'appui dévoué et éclairé de plusieurs Grecs à l'égard desquels j'ai contracté une dette que les remerciements usuels ne sauraient suffire à éteindre.

Je veux citer en premier lieu C. Notaras, d'abord mon élève, puis mon assistant pour les problèmes grecs dans le cadre de la Chaire de science politique de l'Université vaudoise. Parmi les multiples contributions de Notaras à ce livre figurent le dépouillement du matériel documentaire relatif aux partis politiques et l'établissement du lexique de ceux-ci. Compte tenu de la dispersion des sources d'information et de la médiocrité des renseignements fournis par les partis euxmêmes, ce travail, qui s'est étendu sur plusieurs années, a demandé beaucoup de compétence et d'application. Ayant au surplus discuté de ces questions avec G. Notaras pendant une si longue période, je ne me sens pas en mesure de dire tout ce que je lui dois.

J'ai également une grande dette vis-à-vis de P. Merlopoulos qui m'a toujours fait bénéficier avec une totale générosité de sa précieuse connaissance, théorique et pratique, de la vie politique grecque - connaissance attestée par un mémoire de recherche sur les élections de 1956 et 1958 pour la Faculté de Droit de Paris et dont j'ai souvent utilisé les résultats. Merlopoulos m'a donné l'occasion de rencontrer, spécialement durant l'été 1963, de nombreux hommes politiques grecs de premier plan. Il a suivi de près mes recherches sur les groupes dirigeants et m'a fourni de nombreux éléments d'information originaux. C'est certainement au titre de la troisième partie de ce livre que je lui suis le plus redevable.

Il m'est aussi agréable de remercier G. Cladakis qui, plusieurs années de suite, s'est prêté avec une parfaite gentillesse à mes interrogations sans cesse reprises et élargies sur les ressorts de la vie politique [p. 7] grecque. Les innombrables séances de discussion que nous avons eues ensemble ont constitué pour moi un précieux stimulant.

Je dois enfin remercier mon épouse Hélène Zographos qui a pratiquement supprimé pour moi tout obstacle linguistique et a bien voulu consacrer beaucoup de temps à la collecte des nombreux documents nécessaires à l'établissement de ce livre - tâche plutôt complexe dans un pays où les règles habituelles de la gestion administrative ne sont encore qu'imparfaitement reconnues. Je ne saurais dire ce que je dois à son dévouement et à son art d'obtenir des papiers apparemment non destinés à la publicité.

Il ne m'est pas possible de remercier ici, car la liste serait trop longue, toutes les personnes ou services qui ont apporté leur contribution, à l'établissement de ce livre (secrétariats de parti, bureaux ministériels, services de documentation de banques, organismes d'information d'ambassade...). Sans le matériel ainsi communiqué matériel difficile à faire entrer dans le cadre d'une bibliographie de type classique ce volume aurait manqué de plusieurs éléments importants. 
Ce livre sera sans nul doute critiqué et même contesté en plusieurs de ses développements par ceux dont il décrit les activités ou par leurs adeptes. C'est là un risque inséparable de tout, effort pour présenter, selon une expression à la mode, l'histoire immédiate. Je cours aussi le danger dans certaines des constatations ou affirmations présentées en cet ouvrage fassent l'objet d'une utilisation polémique.

Sans fuir de telles responsabilités, je voudrais simplement dire que ce livre a été préparé et écrit de bonne foi. J'accepte d'avance que l'on m'impute des insuffisances de documentation ou des erreurs d'interprétation : il faudra, après le mien, bien d'autres travaux pour que l'on parvienne à une vue exhaustive de la vie politique grecque. Cependant, bien qu'ayant repoussé les facilités du compromis intellectuel, j'ai fait de mon mieux pour ne pas verser dans la partialité.

Les conclusions auxquelles cet essai aboutit manquent certes d'optimisme à l'égard du destin de la Grèce. Il m'a semblé que le meilleur service à rendre à ce pays, pour lequel j'éprouve tant d'amitié, était de les formuler sans complaisance.

Lausanne, décembre 1964.

[p. 8, sans texte] 
[p. 9] *

\section{CHAPITRE PRÉLIMINAIRE \\ COMPOSANTES DE L'EXPÉRIENCE HISTORIQUE}

Retour à la table des matières

CET OUVRAGE porte sur la vie politique grecque depuis la fin de la seconde guerre mondiale mais, faute d'un rattachement à l'expérience historique, la période considérée ne serait pas intelligible. La démarche est au surplus nécessaire si l'on veut éviter de tenir pour une nouveauté la simple répétition du passé.

La difficulté au titre de la Grèce moderne est de savoir quand l'histoire commence. Selon quelques-uns, le comportement des Grecs d'aujourd'hui dériverait encore dans ses grandes lignes de celui des Anciens (passion pour la controverse publique, habitude de hausser le ton dans la dispute, propension à se diviser sur n'importe quel problème en deux factions irréconciliables). D'autres, plus nombreux certes, mettent l'accent sur l'héritage de Byzance et l'on sait que la reconstitution de l'Empire byzantin a longtemps représenté l'une des idées-force de la vie politique grecque.

Cependant, bien plus proches de notre époque que ces réminiscences illustres, il y a les conséquences de l'occupation turque, une situation qui a duré plusieurs siècles. Encore que l'impérialisme ottoman ait différé sous plusieurs aspects des impérialismes contemporains, l'exercice d'une si longue domination ne pouvait manquer d'influer sur le destin des peuples qui en furent l'objet. Sans oublier pour autant les implications négatives de la conquête, il est connu que diverses formes de l'Hellénisme, en particulier celles liées à la religion et au commerce, ont connu quelque épanouissement au sein de cet Empire ${ }^{1}$.

[Les numéros entre accolades réfèrent aux numéros de pages de l'édition de papier, MB.]

Le point est bien mis en lumière dans l'ouvrage de STAVRIANOS (L.S.), The Balkans since 1453, New York, 1958. Pour une première initiation historique se reporter à Svoronos (N.G.), Histoire de la Grèce moderne, Paris, 1953. 
[p. 10] En réalité, si le poids de l'expérience historique dans la formation des attitudes contemporaines est incontestable, nous sommes mal équipés pour en déterminer et en évaluer les facteurs constitutifs. Or ce sont de tels facteurs qui donnent à chaque unité nationale son élément d'originalité et interdisent ou rendent périlleux de lui appliquer mécaniquement les schémas d'explication universels.

Tout en demeurant dans le cadre de la Grèce moderne, cette introduction a pour objectif d'identifier les facteurs du passé susceptibles d'éclairer les comportements présents. En raison du domaine propre de ce livre qui est d'analyser le jeu politique actuel, le recours à l'histoire se limitera à un simple rappel de notions acquises sans aucune prétention d'originalité.

\section{UNE NATION DIFFICILEMENT RASSEMBLÉE}

\section{$\underline{\text { Retour à la table des matières }}$}

C'est en février 1830, à la suite d'une insurrection remontant au début de 1821, qu'est reconnue à Londres l'indépendance de la Grèce sous la garantie des trois puissances dites protectrices (France, Grande-Bretagne, Russie). Compte-tenu de la légère rectification de frontière effectuée en mai 1832, le nouvel État comprend environ 800.000 habitants. On estime à près de 2.500.000 le nombre des Grecs que cet arrangement maintient sous la juridiction de la Turquie et de la Grande-Bretagne (Îles Ioniennes). La cession de ces dernières en 1863, puis la remise par la Turquie en 1881, à la suite du Congrès de Berlin, de la Thessalie et d'une fraction de l'Épire réduiront quelque peu cet écart. Mais il faudra attendre la signature du traité de Bucarest en août 1913, à l'issue des guerres balkaniques, pour que la Grèce doublant approximativement son territoire (Macédoine, Crète, îles de la Mer Égée), trouve en gros sa consistance actuelle. Depuis lors, en effet, les seules acquisitions définitives seront celles de la Thrace Occidentale (cédée par la Bulgarie en 1918) et de l'Archipel du Dodécanèse (remis par l'Italie en 1947).

La lenteur de ce rassemblement s'explique par le fait que la constitution de la Grèce moderne est un aspect de la liquidation de l'Empire Ottoman en Europe. Au $\mathrm{XIX}^{\mathrm{e}}$ siècle certes, cet empire est défini comme " l'homme malade » de l'Europe mais les puissances, la Grande-Bretagne en tout premier lieu, redoutent que le partage des dépouilles [p. 11] n'entraîne des modifications dans le rapport des forces. D'où une propension à favoriser le maintien du statu quo qui suscite de graves obstacles au mouvement des nationalités.

La formation de l'unité nationale grecque sera considérablement retardée par cette tendance. Au point de départ, la politique britannique a pour principe de réduire autant que possible le territoire attribué au nouvel État. Au titre des remaniements engendrés par le Traité de Berlin, la Grèce ne parvient à faire admettre finalement qu'une partie de ses revendications. Le cas de la Crète illustre parfaitement cette 
tendance des grands États à subordonner la réalisation des aspirations nationales à l'accomplissement de leurs propres combinaisons. Dès 1821, en liaison avec l'insurrection sur le continent, les Crétois se soulèvent contre les Turcs et en mai 1822 une assemblée proclame le rattachement de l'Île à la Grèce. Mais c'est seulement en 1913, après beaucoup de troubles et de révoltes qui constitueront autant de sujets de préoccupation pour les chancelleries européennes que s'effectue l'Enosis — une certaine forme d'autonomie ayant toutefois été attribuée à l'Île à compter de novembre 1898.

La conséquence inévitable de ces atermoiements est que, durant près d'un siècle, l'achèvement de l'unité nationale restera au centre des préoccupations de la politique grecque. Ce souci empêchera que toutes les énergies et ressources disponibles soient consacrées à l'œuvre, si indispensable pourtant, de modernisation. La promotion de l'unité fournira à des politiciens démagogues comme Théodore Déliyiannis un argument de poids pour s'opposer à l'activité rénovatrice d'hommes plus réalistes dont le meilleur exemple reste celui de Charilaos Tricoupis. La primauté attribuée par beaucoup à l'objectif national, primauté en contradiction avec le vœu des puissances, entraînera ce pays dans des aventures qui provoqueront la ruine des finances publiques et susciteront d'humiliantes défaites (la plus grave étant celle subie devant les Turcs en avril-mai 1897). La révolte militaire de 1909, que l'on rangerait probablement aujourd'hui dans le cadre des mouvements d'inspiration nassérienne, sera le prix payé par le régime pour son impuissance et ses erreurs de manœuvre.

Sur la plus large part de son territoire actuel, la Grèce n'a pas eu à affronter les situations d'hétérogénéité ethnique qui ont tellement compliqué la liquidation des empires austro-hongrois et ottoman. Cependant de telles difficultés ont surgi à propos des régions du Nord [p. 12] (Épire, Macédoine, Thrace). Dans cette zone sensible (rappel de la question macédonienne), la Grèce n'a pas obtenu à l'issue du congrès de Berlin et des deux guerres mondiales que toutes ses revendications (notamment vis-àvis de l'Albanie) soient prises en considération et elle a dû, par ailleurs, faire face à des revendications de ses voisins. Notons toutefois que l'acuité du problème ethnique en Macédoine a été considérablement réduite par les accords gréco-bulgare et grécoturc d'échange de population.

Actuellement, l'état des alliances et la distribution des forces ont considérablement réduit et même, à l'exclusion d'éventuels développements du conflit chypriote sur la frontière gréco-turque en Thrace, pratiquement annulé la perspective de guerres locales en cette partie du monde. Mais, probablement, témoignerait-on de trop d'optimisme en considérant que, dès à présent, tous les États intéressés, malgré de récentes promesses de bonne volonté, tiennent pour intangible la répartition territoriale existante.

À la veille de la première guerre mondiale, l'unification de la nation grecque avait donc fait de considérables progrès. Cependant, même si on lui ajoute les territoires acquis par la suite, l'État ainsi délimité était très loin de coïncider avec l'aire d'expansion de l'Hellénisme. Marins et commerçants par excellence, les Grecs avaient au cours des âges fondé de solides colonies en plusieurs des régions qui devaient 
constituer l'Empire Ottoman et dans les pays adjacents (Russie notamment). Nulle part, ces colonies n'étaient plus nombreuses et plus denses que sur le territoire turc proprement dit. Pour des raisons aisément compréhensibles les statistiques en ce domaine - en particulier celles de l'Administration turque et du Patriarcat Ecuménique de Constantinople - ne coïncident pas totalement. Mais tous les dénombrements présentés, y compris celui de source officielle turque, mettent en lumière l'ampleur de la présence grecque en ces régions. En fait, les estimations du peuplement hellénique effectuées au titre de l'Anatolie varient entre 1.500 .000 et 2.000.000, celles relatives à la Thrace orientale et à Constantinople se situant entre 650.000 et 730.000. Ce sont là des chiffres considérables si l'on observe que le recensement officiel grec de 1920 donnait pour l'ensemble du pays un chiffre de l'ordre de 5 millions d'habitants.

Ces populations solidement attachées à la nation grecque par des liens spirituels très puissants, constituaient à l'époque une partie essen-[p. 13] tielle de l'Hellénisme. Elles étaient à tous égards, intellectuellement et économiquement, plus avancées que les populations ayant initialement formé l'État grec. Au XIX ${ }^{\mathrm{e}}$, siècle, si Athènes est la capitale politique de la Grèce, Constantinople en représente de facto la métropole économique et elle constitue pour tous les Grecs, soucieux de compenser leur médiocrité présente par l'évocation d'un passé prestigieux, un phare d'un incomparable éclat. Pour comprendre l'attrait qu'exerce la Ville sur les cœurs et les esprits, il suffira de rappeler qu'en 1830 Athènes est une petite bourgade de quelques milliers d'habitants (le chiffre de 50.000 n'étant atteint qu'aux environs de 1870).

De telles considérations permettent de comprendre le rôle de la « Grande idée » dans la politique grecque, c'est-à-dire du rassemblement en un seul ensemble politique de tous les Grecs vivant autour de la Mer Égée. Tout au long du XIX ${ }^{\mathrm{e}}$ siècle, un tel dessein sera le facteur d'une démagogie préjudiciable aux tâches austères du relèvement national et il est clair que la volonté de faire de la Mer Égée un lac grec comportait des aspects impérialistes. Mais, sans oublier l'immense résonance affective du problème, ces populations représentaient une solide réalité et, du seul point de vue économique, leur destin avait pour la Grèce une importance capitale. Cependant, dans la mesure où la «Grande idée » mettait en cause l'existence même de la Turquie, sa réalisation était inconcevable en dehors de vastes bouleversements internationaux.

La volonté de promouvoir la « Grande Grèce » tiendra une place majeure dans les mobiles ayant conduit Éleuthère Vénizélos à préconiser, dès le commencement de la première guerre mondiale, l'entrée de son pays dans la lutte aux côtés des puissances de l'Entente. La Grande-Bretagne tenta d'encourager cette attitude en donnant à penser qu'une telle participation ouvrirait à la Grèce la perspective d'importantes concessions territoriales sur la bordure occidentale d'Asie Mineure. On sait que le Roi Constantin sortant de son rôle de souverain constitutionnel s'efforça de contrecarrer les démarches du Premier Ministre qui suscitaient également l'opposition de l'État-major. Il en résulta un grave conflit entre la Couronne et les partisans de l'intervention dont il n'est pas sûr que toutes les conséquences sur la vie politique aient été encore épuisées. 
Les thèses vénizélistes ayant fini par l'emporter, au prix, il est vrai, d'une ingérence notoire des puissances de l'Entente dans les affaires [p. 14] du pays, la Grèce se trouve en 1918 dans le camp des vainqueurs. Et le traité de Sèvres, fruit d'une intense activité diplomatique de Vénizélos ${ }^{1}$, consacre pour une bonne part le triomphe de la "Grande idée » : cet instrument donne à la Grèce la Thrace orientale ainsi que les îles Imbros et Ténédos qui commandent rentrée des Détroits. De plus, il lui accorde l'administration de la région de Smyrne dans laquelle ce pays avait été autorisé à débarquer des troupes dès le 15 mai 1919 : il est prévu que la Grèce pourra annexer ce territoire au bout de 5 ans sous réserve que par plébiscite les habitants acceptent le transfert.

Pour que l'opération réussisse, il eût fallu que les puissances alliées appuient complètement la position grecque. Or, très tôt, la France et l'Italie vont se désolidariser de cette politique. Quant à la Grande-Bretagne, après avoir fortement soutenu les revendications grecques, elle n'interviendra pas pour empêcher ou limiter la défaite de son allié devant les armées de Mustapha Kémal. La déroute d’Asie Mineure (août-septembre 1922) va constituer pour le destin de l'Hellénisme hors des frontières de la Grèce un désastre majeur et irréparable. Non seulement le traité de Lausanne annule les avantages territoriaux donnés à la Grèce par le traité de Sèvres mais, de plus, il entraîne l'échange obligatoire des minorités entre les deux pays : en exécution de la convention gréco-turque incorporée au Traité de Lausanne environ 1.300.000 Grecs prennent le chemin de la mère patrie tandis que 500.000 Turcs suivent le chemin inverse ${ }^{2}$.

Dès lors, la «Grande idée » ne représente plus qu'un espoir à jamais déçu. En somme, avec beaucoup de difficultés et au prix de nombreux combats, la Grèce a réalisé son unité nationale mais ce lent processus s'est accompagné d'une réduction de la zone de l'Hellénisme dont les limites tendent de plus en plus à coïncider avec les limites de l'État grec actuel. Depuis cette époque, le mouvement s'est accentué sous le coup des nationalismes contemporains (liquidation graduelle des derniers éléments de la présence grecque en Turquie ; démantèlement de la colonie grecque d'Alexandrie, particulièrement active et prospère). Certes il existe encore d'importantes colonies grecques ou d’origine [p. 15] grecque en plusieurs pays (notamment aux États-Unis, où, selon certaines estimations, le nombre des habitants de descendance hellénique serait de l'ordre de deux millions) : mais il s'agit en de nombreux cas de populations vouées à une complète assimilation et qui, comme telles, même si des attaches sentimentales et des liaisons économiques sont maintenues avec la vieille mère-patrie, échappent totalement à l'emprise des autorités grecques.

1 On trouvera une excellente analyse de cette activité in : KYTSIKIS (D.), Propagande et pressions en politique internationale. La Grèce et ses revendications à la Conférence de la Paix (1919-1920), Paris, 1963.

2 Pour l'étude de ce problème, renvoi au récent ouvrage de PENTZOPOULOS (D.), The Balkan exchange of minorities and its impact upon Greece, La Haye, 1962. Sur la diversité des évaluations concernant le chiffre des réfugiés, voir pp. 96-103. 
La situation a un avantage : les Grecs qui durant tout un siècle ont ignoré la consistance territoriale définitive que prendrait leur pays, sont désormais fixés sur l'ampleur de leur domaine. À une exception près toutefois : celle de l'île de Chypre, passée sous juridiction britannique à l'occasion du Congrès de Berlin. Mais, bien que la revendication chypriote d'union avec la Grèce soit ancienne, c'est surtout durant la période étudiée en cet ouvrage que la question de Chypre a marqué la politique grecque et, dès lors, c'est plus loin que nous aurons à en parler.

\section{UNE ÉCONOMIE LONGTEMPS STAGNANTE}

$\underline{\text { Retour à la table des matières }}$

Au moment de la proclamation de l'indépendance, l'économie grecque se trouve encore dans l'ensemble à un stade primitif. Les faibles actifs dont elle disposait ont été en une large mesure ravagés lors des combats de la révolution. Le système des transports est rudimentaire et l'équipement public réduit à sa plus simple expression. Pratiquement, tout est à faire en ce domaine mais, initialement, il n'existe pas de force ou de groupe susceptible de promouvoir les tâches du développement économique.

En réalité, la modernisation du pays ne débutera vraiment qu'après plusieurs décennies de stagnation et le cours en sera ralenti ou entravé par les efforts accomplis au titre de la libération nationale. À la veille de la seconde guerre mondiale, l'économie grecque, malgré les progrès accomplis, occupe toujours un palier très inférieur, quantitativement et qualitativement (productivité) à celui des économies d'Europe occidentale. Il est juste de reconnaître d'ailleurs qu'à cette date les pays voisins souffrent, en gros, des mêmes lacunes et insuffisances.

L'un des signes les plus clairs de cette situation est la lenteur de la croissance industrielle. Il semble bien que l'on ne puisse parler d'industrialisation avant les années 1880-1890 durant lesquelles trois facteurs [p. 16] vont déclencher le mouvement : le lancement d'un premier programme systématique de travaux publics, un afflux de capitaux étrangers et l'établissement d'un tarif protecteur. Encore s'agit-il pour l'essentiel d'industries de biens de consommation (notamment industries textiles) qui importent une très large part des matières premières nécessaires à leur fonctionnement.

Entre les deux-guerres, la croissance industrielle, favorisée par l'arrivée des réfugiés et par un protectionnisme croissant, sera sensiblement plus rapide - le repliement autarcique qu'impose à la Grèce durant les années trente la désorganisation des échanges internationaux ayant eu pour effet d'accentuer le mouvement. Cependant, malgré des résultats substantiels, l'industrie grecque reste, à peu d'exceptions près, vouée à la satisfaction de la demande intérieure et demeure pour l'essentiel au stade d'un capitalisme de très petites unités, faiblement équipées et médiocrement efficientes : on estime que plus de $90 \%$ des usines sont en fait de 
simples ateliers n'employant qu'une main-d'œuvre très réduite (de 1 à 5 personnes) et n'utilisant que de faibles quantités d'énergie. Parmi les plus graves lacunes, mentionnons celle des industries mécaniques qui ne purent s'établir solidement à l'époque et dont la grande médiocrité constitua un sérieux obstacle à l'expansion de l'industrie toute entière.

On s'est naturellement interrogé sur les causes d'un tel retard. L'argument traditionnellement avancé est relatif à la faiblesse des ressources naturelles : en vérité, à l'exception de quelques sociétés étrangères travaillant dans des zones déterminées (ainsi celle du Laurion) il n'apparaît pas qu'une prospection systématique de ces ressources ait jamais été effectuée. On a également mis en avant la préférence des détenteurs grecs de capitaux pour les activités et spéculations proprement mercantiles, c'est-à-dire pour les opérations susceptibles de rapporter des bénéfices substantiels en un temps relativement bref. Un point renforce la portée de cette observation : l'habileté manifestée par les Grecs à diverses époques pour s'insérer dans le circuit des échanges, spécialement de ceux empruntant la voie maritime.

Signalons un dernier point de grande importance : la médiocrité de la politique économique suivie par la plupart des gouvernements et leur incapacité de créer, du moins à la dimension nécessaire, les instruments de tous ordres indispensables ou utiles à un développement industriel étendu. C'est un fait que le politicien grec traditionnel n'a [p. 17] jamais été très au courant des exigences du développement économique ni même très intéressé par les problèmes de cet ordre.

Durant toute cette phase, l'agriculture demeure la base essentielle de l'activité économique et l'on admet qu'à la veille de la seconde guerre mondiale près de $60 \%$ de la population en tirait encore sa subsistance. Les opérations de redistribution des terres intervenues à diverses époques ont entraîné la formation d'une couche nombreuse de petits propriétaires. Cette paysannerie souffre d'une surpopulation que les autorités s'efforcent d'atténuer en procédant à des travaux de bonification agraire (ainsi durant les années 1920 travaux d'assèchement et de protection contre les inondations en Macédoine). La production agricole fait des progrès mais par suite de la faiblesse de l'équipement (1.500 tracteurs environ pour toute la Grèce vers 1940), les rendements restent à des niveaux médiocres.

L'agriculture grecque se caractérise au surplus par une sorte de distorsion entre les catégories d'articles produits et celles qui sont nécessaires à l'alimentation du pays. Elle fournit en quantités appréciables des denrées dont l'écoulement est subordonné à l'exportation (raisins de Corinthe, olives et huiles d'olive, tabac) mais elle est déficitaire au titre des produits alimentaires de base (céréales et produits d'élevage). La Grèce doit donc vendre à l'étranger assez des premières pour compenser les lacunes de son ravitaillement et, aussi, pour payer les matières premières nécessaires à son industrie. Or les produits qu'elle est susceptible d'exporter correspondent à des consommations de luxe ou de demi-luxe dont le niveau est nécessairement fonction des fluctuations de la conjoncture économique internationale.

Les progrès de la production agricole et industrielle, même lents et limités, s'accompagnent normalement d'une expansion des activités de la distribution et des 
secteurs annexes à celle-ci. On sait au surplus que les pays insuffisamment développés tendent à souffrir d'une hypertrophie de l'appareil commercial. La Grèce ne manque pas à cette norme mais elle possède à ce propos un avantage singulier : sa participation au trafic maritime mondial. Durant une période, on pourra craindre que la survenance de la navigation à vapeur ne porte un coup fatal à la marine grecque mais, dès les premières années de ce siècle, le courant sera renversé grâce, il est vrai, aux capitaux de Grecs installés à l'étranger.

L'un des résultats essentiels de ces transformations sera le développement des classes moyennes qui ira s'accentuant à partir des guerres [p. 18] balkaniques. Ce n'est certes pas là un phénomène nouveau pour la nation grecque, diverses circonstances d'ordre politico-économique ayant suscité l'expansion et la consolidation d'une telle catégorie au sein même de l'Empire ottoman dans le courant du XVIII ${ }^{\mathrm{e}}$ siècle. La base de ces classes est constituée par l'activité commerciale mais le modeste développement industriel enregistré au début du $\mathrm{XX}^{\mathrm{e}}$ siècle va élargir quelque peu ce fondement. Pour la première fois dans l'histoire, l'extension des classes moyennes grecques cesse de reposer uniquement sur des entreprises purement mercantiles.

Admettons d'ailleurs que l'expression « classes moyennes », spécialement si on la prend dans le sens anglais de middle class, manque de clarté et peut conduire à des erreurs d'interprétation. Au sein des classes dites moyennes il y a, d'une part, d'authentiques éléments de bourgeoisie appelés à jouer un rôle essentiel dans la direction de la vie nationale et, d'autre part, une masse de personnes d'un rang socioprofessionnel beaucoup plus modeste. Un point facilite la confusion : la tendance de ces couches relativement inférieures à lier leur sort, notamment dans l'ordre politique, à celui des éléments plus élevés de la pyramide sociale. Il serait certes d'une grande utilité d'effectuer une décomposition de cette vaste catégorie mais nous ne disposons pas des études sociologiques indispensables à cet effet. On peut toutefois avancer, si du moins les mots sont pris dans leur sens fort, que durant cette première phase de transformations socio-économiques (1890-1940) la création d'une bourgeoisie à base industrielle et commerciale n'interviendra qu'avec lenteur.

Assez rapidement, nous le verrons mieux par la suite, le poids de ces nouvelles couches se fera sentir dans la vie politique, ce changement aboutissant à une mise en cause de la monopolisation du pouvoir par les meneurs traditionnels du jeu — ce que des auteurs Grecs appellent l'oligarchie et dont la puissance reposait sur les milieux ruraux. À plusieurs égards, ces couches vont représenter l'élément moteur de la modernisation qui avait fait défaut jusque-là. Selon un mécanisme bien connu, les premiers bénéficiaires de la croissance seront un facteur d'accélération et d'amplification de celle-ci. Mais la conversion du vieux monde politique grec aux idées et disciplines de la révolution industrielle constituera une tâche de longue haleine dont il serait illusoire d'admettre qu'elle est aujourd'hui complètement achevée.

[p. 19] Parmi les difficultés les plus graves que rencontreront les partisans ou adeptes de la modernisation, on doit mentionner l'extrême dépendance économique de la Grèce vis-à-vis de l'étranger. L'observation vaut en premier lieu pour l'ordre 
commercial. Tenu d'exporter pour vivre et n'ayant à offrir qu'une gamme de produits très limitée, le pays éprouve les plus vifs embarras dès qu'un seul de ses marchés importants tend à se fermer on à se contracter substantiellement. C'est ainsi que la chute profonde des ventes à la France de raisins de Corinthe en 1893 (due à l'adoption par celle-ci d'un dispositif protectionniste) suscita une grande détresse.

Cependant, la dépendance a un second aspect au moins aussi lourd : l'obligation de faire appel au capital étranger pour combler les insuffisances de l'accumulation nationale. À plusieurs reprises, la Grèce sera tenue de payer d'un prix très élevé sa subordination au capital financier international dont les grandes puissances ont toujours appuyé, avec des moyens variant selon les époques, les exigences parasitaires - cet adjectif de prime abord sévère trouvant sa justification dans le fait que les États contraints par leur pauvreté d'emprunter sur le marché extérieur se voient tenus d'acquitter au titre du seul service de l'emprunt des sommes sensiblement plus élevées que celles effectivement perçues.

La Grèce fera l'expérience de cette exploitation dans les années 1880-1890 durant lesquelles se réalise la première entrée massive de la finance internationale dans ce pays. Ainsi qu'on l'observe habituellement dans le cas d'une grande disproportion de forces entre le prêteur et l'emprunteur, le nominal des emprunts, c'est-à-dire le montant dont le débiteur se reconnaît redevable est très supérieur aux sommes, effectivement encaissées (prélèvement massif effectué par les banquiers au titre de diverses commissions d'intervention ; fixation d'un prix de souscription inférieur au pair...). Les conséquences observées en tant d'autres pays se produisent quasi immédiatement: affectation au service de l'emprunt d'une part considérable des ressources budgétaires ; utilisation des fonds acquis pour la couverture de dépenses ordinaires ou le service des emprunts antérieurs, les travaux productifs ne bénéficiant que d'une petite fraction des sommes reçues; subordination de l'action gouvernementale aux conseils ou exigences des banquiers étrangers. Un point aggrave encore la situation : l'obligation faite à la Grèce de verser aux Turcs une somme de 4.000.000 de livres sterlings à l'issue de la malheureuse campagne d'avrilmai 1897.

[p. 20] Le processus trouva son aboutissement dans l'installation à Athènes d'une commission financière internationale chargée de surveiller les finances grecques et ayant le droit de prélever directement un certain nombre de recettes publiques (celles des monopoles gouvernementaux, les droits d'entrée dans le port du Pirée). Ainsi, la Grèce fut-elle réduite, avec bien d'autres États de l'époque, à un statut de type semicolonial.

Le développement industriel ultérieur continuera de s'accompagner d'un lourd endettement vis-à-vis de l'étranger. À la veille de la seconde guerre mondiale, la dette publique extérieure atteint des niveaux considérables et, par la suite, bien que le pays ait été ruiné par dix ans de guerre étrangère et civile, les grandes puissances intéressées parviendront à obtenir la reprise du service de cette dette dans des conditions avantageuses pour les porteurs de titres. Ainsi le contribuable grec d'aujourd'hui est-il tenu, au titre de sommes entièrement englouties dans les désastres 
successifs de son pays, de verser une dîme qui bénéficie pour une large partie à quelques-uns des pays les plus riches du monde. Il serait difficile de trouver un épisode plus expressif des servitudes qu'oblige à accepter la solution de l'appel à étranger pour assurer le développement de l'économie nationale. C'est pourtant la voie qu'empruntent à nouveau et de façon massive les gouvernements grecs de ce temps.

\section{UNE SOCIÉTÉ MARQUÉE PAR LA PAUVRETÉ}

\section{$\underline{\text { Retour à la table des matières }}$}

Sous n'importe quel aspect, la société grecque, de l'accès à l'indépendance jusqu'à la veille de la seconde guerre mondiale, reste en proie à la pauvreté. Certes les progrès de l'économie nationale susciteront quelques améliorations du sort des masses en divers domaines mais divers facteurs limitent la dimension de cet allégement de la condition humaine (en particulier l'ampleur des inégalités entre les classes dans la distribution du produit national) ${ }^{1}$.

La population de cette époque a une base très largement rurale. Un mouvement d'urbanisation s'amorce dans les dernières décennies [p. 21] du XIX ${ }^{\mathrm{e}}$ siècle (l'agglomération d'Athènes atteignant le niveau de 200.000 habitants vers la fin de ce siècle). Ce mouvement s'accentue durant les années 1920 en raison de l'arrivée des réfugiés. Mais les derniers recensements effectués avant la seconde guerre mondiale font ressortir l'importance massive du peuplement rural :

\begin{tabular}{|c|c|c|}
\hline & \multicolumn{2}{|c|}{ Pourcentage de distribution } \\
\hline & 1928 & 1940 \\
\hline $\begin{array}{l}\text { Population urbaine (agglomérations de plus } \\
\text { de } 10.000 \text { habitants) }\end{array}$ & 31,1 & 32,8 \\
\hline $\begin{array}{l}\text { Population semi-urbaine (agglomérations } \\
\text { de } 2.000 \text { à } 10.000 \text { habitants) }\end{array}$ & 14,5 & 14,8 \\
\hline $\begin{array}{l}\text { Population rurale (agglomérations inférieures } \\
\text { à } 2.000 \text { habitants) }\end{array}$ & 54,4 & 52,4 \\
\hline
\end{tabular}

\footnotetext{
La plupart des données présentées sous cette rubrique sont extraites des documents ou volumes suivants : Statistical Yearbook of Greece, 1963 ; KAISER (B.), Géographie humaine de la Grèce, Paris, 1964 ; STAVRIANOS (L.S.). op. cit., pp. 683-687 ; Commission Économique pour l'Europe. Étude sur la situation économique de l'Europe en 1953, Genève, 1954 (contient un long développement sur l'Europe méridionale).
} 
D’un recensement à l'autre les différences sont minimes : encore l'accroissement de la part relative de la population urbaine est-il essentiellement dû à l'augmentation rapide de l'agglomération athénienne. Les autres villes restent pratiquement stationnaire (Patras) ou n'augmentent que faiblement (Salonique).

La population grecque de cette époque a un niveau de vie médiocre. Voici quelques chiffres relatifs aux années 1934-1938, les chiffres grecs étant rapprochés des chiffres britanniques en vue d'illustrer les dimensions de l'écart qui séparent un pays pauvre d'un pays riche. Ces comparaisons appellent bien des réserves dont la première est que la présentation de moyennes nationales dissimule d'importantes inégalités régionales : même quand l'Athénien vit mal, il vit habituellement mieux que le paysan de l'Épire. Cependant les chiffres retenus et qui sont tirés d'un tableau établi par la Commission Économique des Nations-Unies pour l'Europe ne sont pas sans signification pour le propos de cet ouvrage :

[p. 22]

\begin{tabular}{lrr}
\hline & Grèce & Grande-Bretagne \\
\cline { 2 - 3 } Nombre de calories journalières & 2.551 & 3.125 \\
Pourcentage de calories d'origine animale & 13 & 38 \\
Consommation d'électricité non industrielle & & \\
$\quad$ (en kWh par habitant et par an) & 9 & 147 \\
Consommation apparente de papier journal $\quad$ (en kg par habitant et par an) & 1,4 & 181 \\
Voitures de tourisme et autobus par millier d'habitants & 1,6 & 43 \\
Nombre de lettres intérieures par an et par habitant & 15 & 158 \\
Abonnés au téléphone par millier d'habitants & 6 & 64 \\
\hline
\end{tabular}

La situation sanitaire est mauvaise : la mortalité infantile est de 112 0/00 d'enfants nés vivants en 1934-1938 (le chiffre correspondant pour la Grande-Bretagne étant de 55). L'un des plus graves fléaux est la malaria, la Grèce important en certaines années jusqu'à 5\% de la production mondiale de quinine. Le taux de mortalité par tuberculose est dix fois plus élevé qu'aux États-Unis. Certes l'Université forme un nombre important de médecins mais ils ont tendance à se concentrer dans un petit nombre de villes, les habitants des campagnes étant dans l'incapacité d'acquitter le coût de leurs services.

Le taux de l'analphabétisme est considérable. Voici les pourcentages de personnes ne sachant ni lire ni écrire dans la population âgée de 10 ans et plus, selon les statistiques officielles (qui en de tels domaines ne pêchent généralement pas par pessimisme). 


\begin{tabular}{lccc}
\hline & Total & \multicolumn{2}{c}{ Décomposition par sexe } \\
\cline { 3 - 4 } & & Hommes illettrés & Femmes illettrées \\
\cline { 2 - 4 } $\mathbf{1 9 0 7}$ & 61 & 40 & 80 \\
$\mathbf{1 9 2 0}$ & 52 & 34 & 70 \\
$\mathbf{1 9 2 8}$ & 42 & 24 & 59 \\
\hline
\end{tabular}

Durant la décennie 1930-1940, à la suite d'un effort très important effectué au titre de l'instruction primaire, le taux d'analphabétisme a considérablement diminué, n'atteignant plus qu'environ 27\% en 1940. Mais ces données établissent bien le retard pris par la Grèce dans l'ordre de l'éducation.

[p. 23] C'est d'ailleurs tout le système de l'enseignement qui se révèle inadapté aux nécessités du monde moderne. En 1938, le pourcentage des titres juridiques dans le total des diplômes attribués est de $45 \%$. À la même époque, les écoles de théologie et de philosophie de l'Université de Salonique ont deux fois et demi plus d'étudiants que l'école consacrée aux problèmes de l'agriculture et de la forêt. Certes, les campagnes auraient grand besoin d'un nombre plus considérable de vétérinaires et d'ingénieurs agronomes, mais, sur la base de l'économie de marché, elles ne sont pas en mesure d'assurer leur entretien.

L'un des effets immédiats de cette pauvreté est de stimuler l'émigration. C'est là en vérité une vieille pratique qui aux $\mathrm{XVIII}^{\mathrm{e}}$ et $\mathrm{XIX}^{\mathrm{e}}$ siècles conduisit de nombreux Grecs à s'établir dans des pays voisins comme la Russie et la Roumanie ainsi qu'en Égypte. Dès le début du $\mathrm{XX}^{\mathrm{e}}$ siècle, le phénomène connaît un accroissement soudain et change de sens, l'essentiel de l'émigration se dirigeant désormais vers les ÉtatsUnis. Selon les statistiques officielles, le nombre des émigrants durant les années 1901-1921 s'est élevé à près de 400.000 personnes, plus de $95 \%$ de celles-ci empruntant le chemin des États-Unis. Le flot de l'émigration diminue ensuite considérablement, le total de la période 1922-1940 ne s'élevant qu'à 93.000 environ dont une part encore très importante (environ les deux tiers) est destinée, aux ÉtatsUnis. On peut admettre que les barrières placées par ce pays à l'immigration constituent l'une des causes de la réduction particulièrement forte durant les années 1930 du courant partant pour l'étranger.

Pour saisir la portée socio-économique de ces chiffres il faut observer qu'en 1901 la population de la « Vieille Grèce » — qui ne comprend encore ni la Macédoine ni la Crète - est de l'ordre de 2.500.000. Or, l'on estime que l'essentiel des émigrants de la période 1901-1921, même après l'élargissement territorial de 1913, est précisément originaire de cette partie du pays. L'émigration de cette époque est donc pour le pays un phénomène humain d'une considérable portée - la saignée ainsi subie étant encore aggravée par les pertes dues aux diverses guerres de cette époque. 
Dans les pays pauvres, l'émigration joue au moins un double rôle. D'une part elle constitue une sorte de soupape de sûreté qui diminue la pression politique des milieux déshérités et, donc, facilite la défense de l'ordre social. Par ailleurs, les envois d'argent des émigrants à leur [p. 24] famille améliore d'autant la situation de la balance des paiements, tout en augmentant le revenu à la disposition des couches les plus pauvres.

Les pays donnant naissance à un large mouvement d'émigration ont vite pris l'habitude de recevoir de tels avantages qui ne représentent d'ailleurs qu'une bien faible fraction des gains réalisés de ce chef par les pays d'accueil. En considérant le coût de la formation physique et intellectuelle d'un homme, même si celle-ci est médiocrement assumée, on se rend compte qu'en dépit des gains acquis par la suite, le pays d'émigration est généralement lésé dans l'opération. Plus exactement, il ferait une bien meilleure affaire en fournissant sur place à ses ressortissants un poste de travail productif. À tout prendre, la fourniture de force de travail constitue l'un des moyens, il y en a bien d'autres, par lesquels les pays riches obtiennent des pays pauvres qu'ils contribuent à augmenter leur richesse. Dans cette vaste partie entre les États parvenus à des degrés différents de développement économique, la Grèce était, et elle est toujours d'ailleurs, du mauvais côté.

\section{UN SYSTÈME POLITIQUE INADÉQUAT}

$\underline{\text { Retour à la table des matières }}$

La démarche habituelle est d'expliquer les défauts et retards de la vie sociale ainsi la médiocrité du système d'enseignement ou du cadre sanitaire — par les erreurs et insuffisances du système politique. Cette position, qui peut se réclamer du bon sens, a le tort de surestimer l'autonomie de la politique par rapport au système social. En une large mesure, l'autorité dont disposent les gouvernants et la qualité de leur activité sont sous la dépendance des structures et pratiques sociales. Sans adopter pour autant le postulat d'allure moralisante - et finalement peu équitable pour les catégories sociales dirigées - qu'un peuple a nécessairement le gouvernement qu'il mérite, il est impossible de repousser l'idée d'une certaine correspondance entre l'état de la vie sociale et l'esprit du système politique, entre la valeur des minorités dirigeantes et l'efficacité de la machine gouvernementale.

L'expérience du monde contemporain établit que les relations entre la modernisation économique et la modernisation politique sont complexes. Nous examinerons plus tard la contribution que le cas de la Grèce d'aujourd'hui apporte à ce débat. Observons seulement, c'est le fil directeur de cette rubrique, que durant le premier siècle d'existence [p. 25] de l'État grec peu d'efforts ont été accomplis pour élever l'aptitude de la machine gouvernementale à moderniser la société.

La Constitution de 1864, votée au lendemain de la montée sur le trône grec de la maison danoise des Glücksburg - le souverain actuel Constantin étant l'arrière petitfils du fondateur de la dynastie, Georges I — est d'inspiration démocratique. Le roi a 
la qualité de chef de l'État non en vertu d'un droit divin mais par consentement du peuple dont il est le serviteur. En bref, c'est un monarque constitutionnel qui ne peut accomplir de démarches ou d'interventions hors de la volonté de ses ministres. Un tel système entend bannir toute politique propre ou personnelle du souverain et écarter toute ingérence de la Couronne dans la gestion des affaires publiques. Selon la formule consacrée, le roi règne mais ne gouverne pas.

Un peu plus tard (1875), on procède à l'introduction du régime parlementaire en établissant que le roi est tenu de constituer un ministère qui jouisse de la confiance de la Chambre - disposition qui, pour fonctionner correctement, suppose la présence, en permanence, d'une majorité parlementaire et donc l'existence de formations partisanes d'une stabilité suffisante.

Telle est la règle mais, en pratique, on observe des écarts plus ou moins importants selon les époques, entre le schéma constitutionnel et la marche réelle de la politique. De tels décalages s'étant encore manifestés depuis la fin de la seconde guerre mondiale, il est utile d'en rechercher les facteurs et les modalités. Nous soulignerons trois points : la faiblesse et l'instabilité des regroupements partisans ; l'adoption par la Couronne d'attitudes non constitutionnelles; les interventions de l'armée dans la politique.

Observons, en premier lieu que, même après l'acceptation du régime parlementaire, les partis grecs continuent en une très large mesure à reposer sur l'attachement à des personnes. Certes à partir de 1880 on voit se constituer deux grandes formations : l'une qui trouve son ferment dans l'ascension progressive des classes moyennes et dont Tricoupis sera initialement le leader ; l'autre, d'inspiration plus conservatrice et qui, liée aux vieux notables de la politique, se rassemblera autour de Déliyiannis. Plus tard, nous aurons l'opposition entre les Vénizélistes, c'està-dire les partisans de la personne de Vénizélos et les Populistes attachés à la personne du souverain. En réalité, les formations ainsi identifiées ne constituent pas des organisations bureaucratiques centralisées mais de [p. 26] simples rassemblements de parlementaires qui se groupent autour de la personne d'un chef. L'allégeance faite de la sorte à un leader n'est pas forcément définitive et ne s'étend pas nécessairement au successeur de celui-ci (ainsi après l'assassinat de Déliyiannis en 1905 son parti éclate-t-il en deux fractions rivales).

Ces groupements englobent des notables ou caciques disposant de solides situations locales. Ceux-ci, qui forment au sens propre du mot les cadres des divers rassemblements parlementaires s'efforcent de constituer ou de maintenir autour de leur personne un réseau de relations et de solidarités. Un tel réseau, dans une société encore traditionnelle, se fonde nécessairement sur des rapports de clientèle et trouve son meilleur ciment dans la pratique du patronage. Le politicien grec traditionnel travaille avec l'aide de son propre bureau dont la tâche essentielle est de veiller à la défense des intérêts de la circonscription et des électeurs individuels. Le politicien y gagne un ensemble de suffrages qui, dans le cas où il vient à changer, durablement ou provisoirement, d'allégeance parlementaire, ont bien des chances de lui rester acquis. 
Et il arrive fréquemment que le bénéfice d'une telle situation soit transmissible dans le cadre d'une famille.

Telle est la base d'un certain nombre de pratiques constantes dans le monde politique grec : propension de chaque politicien ou aspirant-politicien ayant quelque envergure ou quelque ambition à fonder son propre parti ; effort pour faire de ce parti un noyau de rassemblement de parlementaires dont le principe tient autant, et parfois davantage, à des relations de personne qu'à des convergences idéologiques ; tendance des groupes ainsi constitués à glisser d'une formation parlementaire à l'autre. En l'absence d'une organisation bureaucratique capable de discipliner les adhérents, la solidité des grandes formations dépend uniquement du prestige et de la capacité manœuvrière de la personnalité leader. Ce ne sont pas là les facteurs idéaux de la stabilité partisane sans laquelle le fonctionnement du régime parlementaire est vicié par l'instabilité gouvernementale.

Les divers traits que l'on vient d'esquisser ne sont certes pas propres à la seule expérience grecque. Un rapprochement par exemple avec d'autres pays méditerranéens durant la même époque révèlerait bien des similitudes. Mais le retard pris par la Grèce dans la modernisation des structures socio-économiques a eu pour conséquence la survie de telles pratiques de manière plus durable et plus massive qu'ailleurs. Aujour-[p. 27] d'hui encore, le système partisan de ce pays reste marqué par certaines des habitudes traditionnelles : et dès lors, nous aurons à déterminer les moyens par lesquels des hommes politiques sont parvenus, en dépit de ces tendances centrifuges, à obtenir ou à imposer la stabilité gouvernementale autour de leur personne (exemple, en particulier, de la longue occupation du pouvoir par C. Caramanlis).

Une autre condition de fonctionnement du régime parlementaire est que le souverain se garde soigneusement d'intervenir dans les luttes partisanes. Les historiens sont en général d'accord pour estimer que Georges I, qui monte sur le trône à 17 ans et règnera pendant cinquante ans (1864-1913), aura pour principe de s'en tenir au rôle de monarque constitutionnel dans le domaine des affaires intérieures et évitera de constituer un parti de la Cour. Il est vrai que le souverain tendra à considérer la politique étrangère comme un domaine réservé et, en tout cas, comme un secteur ouvert au veto royal (rappel, en particulier, de son rôle au titre du problème crétois).

Son successeur Constantin adoptera un comportement bien différent. Impressionné par l'exemple de l'empereur Guillaume II dont il a épousé la sœur, la princesse Sophie de Prusse, il tend à se considérer comme investi, spécialement dans le domaine des affaires internationales, d'une responsabilité particulière devant Dieu - responsabilité lui permettant éventuellement de s'opposer à la volonté populaire telle que l'incarne le chef du parti ou du rassemblement majoritaire au Parlement. Soucieux de faire prévaloir sa politique dans les occasions où il l'estime indispensable, le roi Constantin s'efforcera d'obtenir des points d'appui ou leviers d'intervention. Il les trouvera parmi les courtisans et l'état-major de l'armée de terre (la marine demeurant au contraire en grande partie fidèle à Vénizélos). 
Notons au passage un problème de terminologie. Beaucoup emploient pour désigner un tel réseau le mot « parti ». Encore que cet usage n'ait rien de choquant du point de vue linguistique, on peut craindre qu'il n'engendre la confusion dans la mesure où le groupe d'hommes ainsi défini est bien différent d'un parti proprement dit. D'autres auteurs emploient le mot de "clique " mais il a en français un sens nettement péjoratif. La même remarque vaut quoiqu'à un degré moindre, pour le terme «faction ». En réalité, il n'y a pas de mot ou d'expression susceptible de traduire exactement et objectivement le phénomène évoqué, le terme «clan » étant probablement le moins imparfait.

[p. 28] Lorsque la guerre éclate entre les grandes puissances, Vénizélos est au pouvoir tout auréolé de la grande victoire remportée sur la Turquie et la Bulgarie. La nation grecque est unie sous son égide comme elle ne l'avait probablement jamais encore été. Au Parlement, le Parti Libéral qui le soutient ne rencontre guère d'opposition. C'est dans ces conditions que va éclater le conflit entre le Roi et le Premier Ministre - conflit d'autant plus paradoxal qu'en réalité comme nous allons le voir, c'est Vénizélos qui, quelques années auparavant, a sauvé la monarchie. Après diverses vacillations le Roi, se prononçant dans le même sens que le colonel Métaxas, déclare rejeter le projet du Premier Ministre d'associer la Grèce aux opérations alliées dans la région des Détroits (projet que combat également la Russie inquiète des visées grecques sur Constantinople). Vénizélos n'a alors d'autre possibilité que de donner sa démission qui est acceptée par le souverain (6 mars 1915). Ce dernier choisit pour le remplacer D. Gounaris qui forme un gouvernement bien moins favorable à l'Entente que le précédent.

Quelques mois après (13 juin 1915), des élections tenues dans des conditions défavorables pour le Parti Libéral redonnent à celui-ci la majorité au Parlement. Malgré sa défaite, le cabinet Gounaris refuse de démissionner pendant plus de deux mois. Vénizélos redevient Premier Ministre en date du 10 août, le problème le plus urgent étant désormais celui d'une attaque que l'on tient pour imminente de la Bulgarie contre la Serbie. Vénizélos manifeste ouvertement la volonté de soutenir la seconde en exécution des engagements pris. Bien que cette position ait reçu l'appui du Parlement par 147 voix contre 110, le Roi refuse de l'accepter et envoie à Vénizélos en date du 5 octobre 1915 un message l'informant de son désaccord. Une nouvelle fois celui-ci se trouve contraint de donner sa démission bien qu'il soit le chef d'un gouvernement disposant de la majorité parlementaire.

En vue de légitimer sa politique, le Roi organise presque immédiatement (19 décembre 1915) de nouvelles élections qui, tenues avec la participation et sous le contrôle de l'armée, se déroulent dans une atmosphère de pression et d'intimidation. Vénizélos demande au Parti Libéral de s'abstenir d'y prendre part. N'ayant pas d'adversaire, les Monarchistes remportent la victoire mais le nombre des électeurs ne s'élève qu'à 200.000 (contre 750.000 en juin). Le Parti Libéral entre ainsi dans une opposition extraparlementaire dont l'aboutissement sera la formation du Mouvement de Défense Nationale et la constitution à [p. 29] Salonique en octobre 1916, sous la protection des puissances de l'Entente d'un gouvernement provisoire opposé à celui d'Athènes. C'était le schisme. 
Sans nous prononcer ici sur l'opportunité de la politique du roi — politique dont les vacillations traduisent l'indécision d'esprit du souverain - constatons que dans des circonstances d'une gravité exceptionnelle, la Monarchie grecque est sortie manifestement de son rôle constitutionnel et qu'il en est résulté une rupture de l'unité nationale. L'événement va donner au Parti Populiste fondé dès 1902 par D. Gounaris le caractère d'un parti monarchiste qui rassemble les éléments conservateurs du pays en vue d'assurer la défense de la Couronne. En faisant appel à Gounaris pour remplacer Vénizélos, la Couronne prenait en fait la tête de la droite grecque et, comme nous le verrons, c'est un rôle qu'elle a continué d'assumer par la suite.

Cette attitude s'explique en quelque mesure si l'on observe qu'à plusieurs reprises l'existence même de la Monarchie a fait l'objet de graves controverses. Bien que Georges I se soit efforcé d'être un monarque constitutionnel, la dynastie sera très critiquée et sérieusement menacée après l'échec de l'aventure de 1897 . Un historien rappelle que durant cette période la famille royale fit plusieurs fois ses bagages en vue de s'embarquer sans délai sur un destroyer britannique si la nécessité s'en faisait sentir ${ }^{1}$.

Lorsque Vénizélos prend le pouvoir à la suite de la révolte de la Ligue militaire, beaucoup espèrent qu'il va mener la lutte contre la dynastie danoise : mais celui-ci choisit de sacrifier l'anti-dynastisme à la volonté de faire autour de sa personne l'union du pays contre les Turcs. La Monarchie gagne ainsi un répit dont Constantin fera l'usage que l'on vient de dire. Cependant, l'institution monarchique, affaiblie par le schisme de 1915, ne résistera pas au désastre d'Asie Mineure. Sur l'initiative du comité révolutionnaire dirigé par le colonel Nicolas Plastiras, six hommes d'État du parti monarchique seront fusillés le 28 novembre 1922 — événement qui devait laisser des traces très profondes dans le monde politique grec. Notons que Georges II, monté sur le trône à la suite de l'abdication en sa faveur de son père Constantin, laissa s'accomplir l'exécution des fidèles de la Monarchie - attitude que les Populistes ne lui pardonneront jamais complètement. Finalement la [p. 30] République sera proclamée le 25 mars 1924 par un vote de l'Assemblée, cette décision étant confirmée par un plébiscite en date du 13 avril 1924 qui donne 758.742 voix au nouveau régime contre 325.322 à la monarchie.

Un peu plus tard, il est vrai, les partisans de la Monarchie parviendront à obtenir le retour du roi en la personne de Georges II. Ce retour s'effectue le 25 novembre 1935 à la suite d'un plébiscite organisé par l'armée avec un luxe exceptionnel de moyens - ce qui explique probablement que la monarchie ait alors obtenu la presque totalité des suffrages. N'oublions pas, parmi les facteurs de cette restauration, la capitulation des dirigeants de la République (Vénizélos lui-même, de son lieu d'exil, conseillant aux partisans de la République de se prononcer pour le retour du Roi).

L'armée en effet joue depuis plusieurs décennies déjà un rôle important en politique et c'est le troisième des facteurs qui tend à réduire la portée du régime parlementaire en Grèce. Nous avons déjà évoqué le rôle de la Ligue militaire en 1909,

FORSTER (ES), A short history of modern Greece 1821-1956, third edition, Londres, 1958, p. 248. 
le plus clair résultat de son intervention étant de faire accéder E. Vénizélos aux leviers de commande. Il s'agit de jeunes officiers au nombre d'environ 500 qui, sous la conduite du colonel Zorbas dénoncent l'impuissance des politiciens : ils réclament une réorganisation de l'appareil gouvernemental affaibli et compromis par le spoils system.

Nous avons vu également que pendant la guerre l’État-major de l'armée se rangera aux côtés du souverain dans sa lutte contre Vénizélos : le premier n'hésitera pas alors à utiliser l'armée comme levier d'intervention politique et des historiens vont jusqu'à mentionner l'existence d'un «parti militaire » opposé aux puissances de l'Entente. Rappelons enfin la constitution, après le désastre d'Asie Mineure, d'un Comité révolutionnaire composé d'officiers qui, au lendemain de la défaite, avaient cherché refuge dans l'île de Chios. De là, ils adressent un ultimatum au roi Constantin et c'est cette intervention qui conduira le roi à abdiquer au profit de son fils Georges II pour tenter de sauver l'institution monarchique.

D'autres interventions conduites par des militaires en activité ou dégagés des cadres se produiront durant la période allant de l'établissement de la République au déclenchement de l'attaque allemande sur la Grèce. Mentionnons en particulier : la courte dictature exercée par le général républicain Théodore Pangalos (janvier-août 1926) ; les deux [p. 31] tentatives de coup d’État effectuées en mars 1933 et surtout en mars 1935 par des officiers républicains en vue de " sauver la République » (les élections du 5 mars 1933 ayant redonné une majorité à la Chambre au Parti Populiste champion de la monarchie) ; l'action menée par l'armée au titre de la restauration monarchique,

Cette période chaotique devait s'achever par l'institution de la dictature du général Métaxas désigné par le roi comme Premier Ministre le 13 avril 1936 au lendemain de la mort de C. Démértzis sans aucune consultation mais aussi sans opposition des chefs de partis. Au départ ces derniers n'aperçoivent pas le danger de dictature qui menace le pays et Th. Sophoulis lui-même facilitera la mise en congé du Parlement pour une période de 5 mois. Or Métaxas, ultra-royaliste de toujours, va profiter de la situation pour procéder à la destruction des institutions et garanties démocratiques. Une fois le dessein du général devenu évident, Th. Sophoulis et P. Tsaldaris, respectivement leaders du Parti Libéral et du Parti Populiste offrent au Roi de constituer un gouvernement de coalition qui, comme tel, aurait bénéficié d'une majorité parlementaire. Mais le souverain ne tiendra pas compte de cette offre, à la vérité un peu tardive. Ainsi Georges II acceptait-il, finalement, de lier le sort de la Monarchie à un pouvoir dictatorial.

L'intervention des militaires après avoir joué en faveur des institutions républicaines aboutissait dès lors à la restauration de la monarchie et à l'établissement d'une dictature d'inspiration conservatrice. Ce changement résulta des sévères épurations effectuées après l'échec des deux coups d'État en faveur de la République. Le souci de la droite fut d'éloigner de l'armée tous les officiers soupçonnés de sympathies républicaines ou d'inclinations progressistes - cette épuration touchant près de 900 officiers au lendemain du coup d’État de mars 1935. L'opération ayant été 
encore répétée par la suite on ne s'étonnera pas qu'aujourd'hui l'armée soit le plus ferme soutien de l'ordre monarchique établi.

En définitive, la faiblesse des partis, les immixtions de la Couronne dans la vie politique, les interventions ou pressions de l'établissement militaire, tous ces facteurs ont combiné leurs effets pour empêcher l'établissement d'un authentique régime parlementaire en Grèce — régime [p. 32] au surplus peu en harmonie avec les structures socio-économiques du pays. On en trouvera une preuve significative dans le refus de participer aux élections qu'affiche à plusieurs reprises l'un des grands adversaires en présence. Nous avons déjà rencontré le cas du Parti Libéral en 1915. Lors des élections du 16 décembre 1923, ce sera le Parti Populiste qui, face aux Vénizélistes et aux Républicains, choisira de s'abstenir. Même phénomène mais en sens inverse lors des élections du 9 juin 1935, les Vénizélistes restant à l'écart face au Parti populiste de P. Tsaldaris et aux Ultra-royalistes de Métaxas. Une telle attitude signifie que les intéressés n'ont pas confiance dans la probité des autorités chargées d'organiser la consultation électorale et récusent d'avance les résultats enregistrés. Il est à peine besoin d'écrire qu'un régime représentatif ne saurait fonctionner dans de telles conditions.

Déjà très affaibli par ces discordes, le régime politique grec comportait un autre défaut fondamental: la médiocrité de la bureaucratie administrative dans le recrutement de laquelle les relations de «clientélisme » et l'application du système des dépouilles ont toujours tenu une place éminente. Rares ont été durant l'époque de la Grèce Moderne les hommes politiques ayant une vue claire des mesures à adopter pour assurer la modernisation du pays : cependant, une fois prises les décisions nécessaires à cet effet, les résultats en étaient inévitablement affaiblis ou compromis par l'inaptitude des services ou bureaux à les mettre en œuvre correctement.

On a pu définir la bureaucratie grecque actuelle comme l'« alarmant reflet de la politique » et souligner son " proverbial manque de conscience professionnelle » ${ }^{1}$. Ce qui s'avère vrai aujourd'hui ne l'était pas moins dans le passé. Il en va de même de la corruption qui sous des formes diverses a toujours constitué l'une des plaies endémiques de la vie publique grecque. La lutte contre de telles pratiques - qu'elles aboutissent à de simples complaisances ou à des trafics d'influence caractérisés était déjà l'un des thèmes de la Ligue militaire en 1909. Mais comme nous le verrons plus tard, la nécessité d'une telle moralisation n'a rien perdu de son actualité.

En observant la longue période qui va de l'indépendance à la seconde guerre mondiale, on s'aperçoit que deux hommes politiques ont à la fois véritablement

1 In «L'avenir politique de la Grèce », Bulletin Sedeis, 20 octobre 1963. Supplément Futuribles, $\mathrm{n}^{\circ}$ 65, pp. 10-11 (étude anonyme, mais solide et fort documentée). 
compris les exigences d'un État moderne et [p. 33] effectivement engagé la lutte pour perfectionner le système politique : Charilaos Tricoupis et Éleuthère Vénizélos. L'un et l'autre pourtant n'obtiendront sur ce plan que des résultats insuffisants.

Tricoupis gouverne la Grèce de 1882 à 1895 à l'exception de quelques intervalles durant lesquels son rival Déliyiannis parviendra à se saisir du pouvoir. Il s'efforce de réformer l'appareil d'État (administration, justice, armée) et entreprend de lutter contre la corruption qui dénature le fonctionnement du régime parlementaire. Il s'attache aussi à la constitution de l'équipement public qui commande la modernisation de l'activité économique. Son ambition suprême est de consolider la situation financière du pays, ce que selon lui, exige l'établissement de rapports corrects avec les Turcs. Tricoupis, qui fonde sa politique sur la venue de capitaux étrangers, obtiendra des résultats notables dans l'ordre des travaux publics mais il ne parvient pas à empêcher la banqueroute des finances grecques.

La carrière de Vénizélos ne se résume pas aussi aisément. Il arrive de Crète à Athènes en janvier 1910 comme conseiller politique de la Ligue militaire et sa dernière période de gouvernement date de 1928 à 1932 (les élections du 25 septembre lui faisant perdre sa majorité à la Chambre). Lors du coup d'État républicain de 1935, il se place en tête du mouvement, ce qui lui vaut une condamnation à mort par contumace. Il meurt à Paris le 18 mars 1936.

Beaucoup de Grecs tiennent Éleuthère Vénizélos pour le fondateur de l'État moderne ou encore de l'État de droit. Et il est vrai que, durant toute sa carrière, l'homme d'État crétois se vouera à des tâches de cet ordre (essai de purification de l'administration réforme de l'armée et de la marine; amélioration du sort des paysans; perfectionnement de l'éducation publique). Mais sa grande pensée reste l'unification politique de l'Hellénisme : sa politique en ce domaine vaudra à la Grèce l'éclatant succès de 1913 mais Vénizélos porte aussi la responsabilité initiale des décisions ayant finalement conduit au désastre de 1922 — désastre qui sera d'ailleurs entièrement imputé à la Monarchie et à ses hommes.

Loin d'être, ainsi qu'on le considère parfois à l'étranger, l'ardent prophète du républicanisme hellénique, Vénizélos a, en plusieurs occasions, traité la Monarchie avec ménagement et l'on ne saurait dire que ses dernières années de chef de gouvernement, aient contribué à renforcer les institutions républicaines. Peut-être le prestige dont, il a joui [p. 34] auprès de ses compatriotes et dont sa mémoire bénéficie vient-il de ce qu'il sut s'imposer sur la scène internationale et donner à un pays, souvent humilié et bafoué par les interventions des puissances étrangères, un sentiment de fierté nationale. 


\section{UN ÉTAT SOUMIS À LA DÉPENDANCE}

Retour à la table des matières

Il n'est pas besoin de longues recherches historiques pour s'apercevoir que dans la société internationale la notion dite de souveraineté nationale s'apparente à un simple mythe pour les petits États à faibles ressources. L'analyse la plus superficielle ne peut manquer de faire ressortir la densité et la profondeur des interventions étrangères dans la vie politique de ceux-ci. Il arrive certes que le petit État tente de se soustraire aux règles du jeu : une telle insubordination risque de lui valoir une cuisante leçon. De semblables servitudes ont toujours existé et au $\mathrm{XIX}^{\mathrm{e}}$ siècle leur mise en application s'affirme ouvertement. La Grèce moderne, sans oublier la profonde dépendance de son économie vis-à-vis des forces extérieures (supra) représente à cet égard un cas exemplaire.

La dépendance de l'État grec vis-à-vis des puissances de l'époque a déjà été évoquée si souvent qu'il suffira ici d'en donner une présentation très générale. Ce sont les puissances qui dictent le rythme et les dimensions du rassemblement de la nation grecque en fonction de leurs propres préoccupations ; ce sont elles qui, conformément à une pratique de l'époque, imposent le recours à l'institution monarchique et choisissent le représentant de la maison appelée à occuper le trône : la bavaroise d'abord (1833-1862), la danoise ensuite ; ce sont elles aussi qui imposent le respect des obligations, en bien des cas léonines, souscrites au profit de leurs ressortissants.

Il n'est pas injuste d'avancer que durant cette période chacune des puissances intéressées tient la Grèce pour un pion sur l'échiquier international et s'efforce, en conséquence, d'orienter la politique de ce pays dans un sens qui lui soit favorable. Au départ, l'un des instruments de ce rôle est la présence d'un certain nombre de partis de l'étranger ou pro-étrangers, c'est-à-dire de groupes de politiciens voués à l'exécution des suggestions ou directives de la puissance à laquelle ils sont liés. Tout en faisant les mêmes réserves terminologiques qu'à propos de la [p. 35] notion de parti royal, on peut dire que ces partis ou clans forment de véritables têtes de pont de l'étranger dans la vie politique du pays et il n'est pas exceptionnel que les services rendus vaillent aux exécutants divers avantages matériels.

C'est ainsi que dès le début de l'indépendance trois clans de ce type apparaissent en Grèce: le français, le russe et l'anglais (respectivement dirigés par Colettis, Colocotronis et Mavrocordatos). Les programmes de ces partis ne sont que le reflet des préoccupations des puissances qui les dirigent et dès lors l'essentiel de la vie politique du pays se ramène aux luttes que les puissances se livrent par personne interposées sur le territoire national. Ajoutons pour compléter le tableau qu'Othon, premier roi de Grèce, âgé seulement de 17 ans, comme plus tard Georges I, lors de son accession au trône, s'en vint régner accompagné de trois régents bavarois qui considéraient les Grecs comme un peuple totalement infantile. À cette époque l'armée grecque se compose de volontaires bavarois généreusement payés et les textes 
officiels sont rédigés en grec et en allemand. C'est seulement en 1843 à la suite d'un soulèvement populaire qui ne fit pas de victime qu'Othon consentira à expulser du pays la clique bavaroise.

Le roi est durant cette période en proie aux critiques des autorités britanniques qui lui reprochent de ne pas gouverner constitutionnellement et à celles des autorités russes qui lui font grief de son appartenance à la religion catholique. Il gouverne alors en s'appuyant sur le chef du parti français dont les aspirations expansionnistes coïncident avec les siennes. La guerre de Crimée suscitera un autre alignement : Othon embrasse alors les sympathies de ses sujets pour la Russie qui lutte contre la Turquie alors que la France et la Grande-Bretagne soutiennent cette puissance. Soucieuses d'éviter des désordres sur leurs arrières, celles-ci envoient alors une flotte occuper le port du Pirée (mai 1854-février 1857).

Par la suite, les interventions se feront, sauf circonstances exceptionnelles, un peu plus discrètes et les clans de l'étranger deviendront de simples réseaux de personnalités agissant en marge des formations partisanes ordinaires. Mais les ingérences ne cesseront pas de se produire et nul ne saurait sérieusement contester les relations privilégiées entretenues par la dynastie actuelle avec la Grande-Bretagne.

En installant une nouvelle maison sur le trône de Grèce, les hommes d'État britanniques, échaudés par l'indiscipline d'Othon, lui confient la [p. 36] mission de contenir les ambitions nationales de ses sujets, celles-ci allant à l'encontre de la politique alors suivie par la Grande-Bretagne dans la question d'Orient. La cession des îles Ioniennes constitue en somme le tribut qui doit conduire les Grecs à témoigner de patience dans la lutte pour leur unité. Mais si forte est la poussée du nationalisme grec — spécialement à l'égard des régions du Nord sur lesquelles les Slaves présentent aussi des revendications - que le roi ne pourra empêcher l'explosion de 1897 et devra s'associer au mouvement. Notons pourtant que, contrairement à ce qui devait arriver en 1922, la Grèce sera alors sauvée du désastre par l'intervention des puissances qui provoqueront la signature d'un armistice.

Plus tard, la politique britannique en ce domaine s'étant modifiée, Vénizélos pourra mener à bien la formation de la Ligue balkanique qui fut à l'origine des victoires de 1912 sur la Turquie. Durant toute sa vie politique d'ailleurs, l'homme d'État crétois considèrera que la clé de l'unification politique de l'Hellénisme réside dans l'acquiescement et l'appui de la politique anglaise à cette ambition.

Les Britanniques n'ont eu avec la monarchie grecque qu'une seule déception grave: celle provoquée par l'attitude du Roi Constantin lors du premier conflit mondial. Tout en évitant de refaire l'histoire, on peut admettre que sans l'assassinat de Georges I en 1913, Vénizélos serait parvenu bien plus vite, malgré les résistances de l'État-major, à faire prévaloir sa politique. Des liens familiaux attachaient ce monarque à la Grande-Bretagne et à la Russie alors que, pour Constantin, c'étaient les liens forgés avec l'Allemagne qui prédominaient. Il est probablement injuste de dire que la conduite du roi fut exclusivement dictée par sa germanophilie et il faut reconnaître que, surtout au début, la cause de la neutralité n'était pas dépourvue de valeur. Au surplus, le scepticisme de plusieurs dirigeants militaires quant à la capacité 
de la Grèce de réaliser la « Grande idée » n'était pas dépourvue de fondement. Tout ceci admis, on doit noter l'existence à Athènes durant les premières années de la guerre d'un parti ouvertement pro-allemand qui encourageait le roi dans sa résistance aux projets vénizélistes — parti lié au groupe, de l’État-major hostile aux puissances de l'Entente.

Gardons-nous, par ailleurs de considérer que ces dernières eurent à l'époque le moindre respect pour l'indépendance nationale de la Grèce. Stavrianos observe qu'il est rare qu'un pays indépendant ait été traité [p. 37] de façon aussi humiliante que le fut la Grèce à cette époque et il ajoute que ce pays devint une sorte de "place publique » dans laquelle chaque puissance se sentait libre d'agir à sa convenance ${ }^{1}$.

Un aspect de cette dépendance est l'adoption spontanée par les politiciens grecs à l'égard de problèmes d'intérêt national de l' "attitude correcte », c'est-à-dire d'une position qui n'offense pas les grandes puissances protectrices et en tout premier lieu la Grande-Bretagne. En voici deux manifestations concernant le destin de la Crète et de Chypre.

La Crète d'abord. En 1908, lors de la révolution des jeunes Turcs, les Crétois estiment le moment opportun pour débarrasser l'île des derniers vestiges de la suzeraineté ottomane et réaliser l'union avec la Grèce. En l'absence du Haut Commissaire de Crète A. Zaimis, la Chambre crétoise proclame cette union. Le gouvernement de Georges Théotokis adopte alors l'« attitude correcte » en affirmant qu'il ne lui est pas possible de prendre officiellement connaissance de l'activité déployée par le gouvernement provisoire constitué en Crète et qui a déclaré gérer l'île au nom du roi Georges I. Une telle démarche contribua à ancrer dans l'opinion publique l'idée que les politiciens trahissaient les intérêts de la nation grecque et l'on peut y voir l'une des causes du soulèvement militaire de 1909.

L'opération devait se répéter à diverses reprises à propos de lî̂le de Chypre formellement annexée par la Grande-Bretagne le jour même où l'empire ottoman lui déclara la guerre, soit le 5 novembre 1914 (la Turquie devant ensuite reconnaître cette annexion lors du Traité de Lausanne). En octobre 1915, les autorités britanniques offrirent l'île à la Grèce en échange de son entrée en guerre aux côtés des Alliés. Les Britanniques étaient alors parfaitement au courant des sentiments de la population de l'île en faveur de l'Enosis. L'offre n'ayant pas été acceptée fut tenue pour caduque et à l'issue de la guerre la Grande-Bretagne ne manifesta nulle intention de modifier le statu quo. Or, bien que Chypre subit alors un colonialisme du type le plus classique et que la Grande-Bretagne ne fit rien pour en assurer le développement, les négociateurs grecs se bornèrent à poser très discrètement la question qui ne fut pas discutée à la Conférence. Vénizélos lui-même n'éleva jamais la voix à ce sujet. Apparemment, chacun admettait qu'il eut été [p. 38] incorrect de la part de la Grèce d'exprimer publiquement une revendication à l'égard du grand pays allié. Chacun acceptait l'idée

Op. cit., pp. 567-568. 
que si la cession devait intervenir ce ne pourrait être que par l'effet d'un acte de générosité britannique, d'un « cadeau » pour utiliser le propre mot de Wilson ${ }^{1}$.

L'adoption de l' "attitude correcte " est l'une des formes de cette censure spontanée que les faibles s'imposent si souvent dans leurs rapports avec les puissants. Elle représente l'un des aspects les plus subtils et en même temps l'une des manières les plus solides de l'exercice de l'influence. Il serait souhaitable que la science politique accorde plus d'attention qu'elle ne l'a fait jusqu'à présent à l'analyse de tels comportements.

\section{RÉPERCUSSIONS DE LA SECONDE GUERRE MONDIALE}

$\underline{\text { Retour à la table des matières }}$

Assez rapidement, l'attaque italienne plongera la Grèce dans le conflit et l'intervention allemande lui vaudra trois ans et demi d'occupation militaire. Ces événements auront pour conséquence d'aggraver la situation de ce pays sous chacun des aspects examinés en cette introduction. Plusieurs de ces répercussions devant être analysées par la suite (en particulier la guerre civile), nous nous limiterons ici à une très brève présentation générale.

Voyons d'abord le problème de la consistance territoriale de l'État hellénique. La Grèce, qui se trouve dans le camp des vainqueurs, présente diverses revendications dont la liste définitive comporte trois articles : cession par l'Italie de l'Archipel du Dodécanèse, acquisition sur l'Albanie de l'Épire du Nord ; rectification de la frontière bulgaro-grecque. Les Grecs auront satisfaction sur le premier point mais échoueront complètement sur les deux autres. Ainsi, durant des années, le meilleur des efforts diplomatiques du pays aura-t-il été consacré à une ambition vaine ${ }^{2}$.

[p. 39] Vis-à-vis de Chypre cependant, c'est l'attitude correcte qui continue de prévaloir. Le problème est fréquemment mentionné dans les cercles gouvernementaux et les forces de gauche, qui n'ont pas de raison de ménager la puissance britannique réclament ouvertement la cession de 1'Île. De leur côté, les Chypriotes dont, à la demande de la Grande-Bretagne, plus de 30.000 combattirent avec les armées alliées, revendiquent l'union avec la Grèce au nom des principes de la Charte Atlantique. Mais le 17 mai 1946, à la tribune de la Chambre, le premier ministre C. Tsaldaris déclare que la question de Chypre n'est pas une revendication, ne doit pas être posée

KITSIKIS (D.), op. cit., p 78. Kitsikis observe à juste titre que « dans la bouche du défenseur du droit des peuples à disposer d'eux-mêmes ce terme de "cadeau" n'était pas particulièrement beau ».

2 Ces négociations ont été racontées en détail par XYDIS (S.G.), Greece and the great powers, 19441947. Prelude to the "Truman Doctrine », Salonique, 1963. Encore que la démonstration de ce point n'entre pas dans l'esprit de cet ouvrage, il en ressort que durant la période considérée la Grèce fut un simple protectorat britannique, les hommes placés à la tête de l'État acceptant cette subordination comme une situation absolument naturelle. 
de manière vindicative : c'est un sujet qui concerne seulement la Grèce et son amie la Grande-Bretagne. En somme, l'homme politique grec, prisonnier de l'«attitude correcte », ramenait le destin d'un peuple à une sorte d'affaire de famille.

Sur le plan économique, les ravages causés par la guerre et l'occupation furent immenses. Durant ces trois ans et demi, la Grèce perdit environ 30\% de sa richesse nationale et près de $7 \%$ à $8 \%$ de sa population. Or, au lendemain de cette terrible épreuve, le pays, au lieu d'entreprendre immédiatement les tâches de la reconstruction allait passer par les affres d'une guerre civile qui provoquera de nouvelles ruines et bloquera durant des années tous les efforts de reconstitution de la substance nationale. On ne s'étonnera dès lors pas qu'en 1951, sur de nombreux points (par exemple dans les domaines de l'alimentation et de l'éducation), la situation ait empiré par rapport à celle de 1934-1938 qui n'était pourtant pas très brillante.

$\mathrm{Au}$ moment où va s'achever la guerre mondiale, en vertu d'un marché entre Churchill et Staline - un de ces marchés où les grandes puissances règlent le sort des hommes comme s'il s'agissait de marchandises à leur disposition — la Grèce est placée dans la sphère d'influence britannique. Très rapidement (décembre 1944), un premier conflit armé se produira entre les troupes britanniques débarquées à Athènes et les forces de gauche de la Résistance groupées dans le Front de Libération Nationale (EAM) — front dans lequel le parti communiste grec joue un rôle primordial. Après une trêve précaire, la lutte reprendra, cette fois, entre les seules forces communistes et les troupes régulières grecques que soutiennent désormais les États-Unis.

Ces affrontements auront de graves conséquences politiques. Ils susciteront de profondes divisions dans l'esprit public, un nouveau clivage, d'une virulence particulière, venant s'ajouter aux oppositions tradition-[p. 40] nelles du monde politique grec. La volonté d'abattre la révolte communiste mènera les gouvernants de cette époque à l'adoption de mesures de sauvegarde de l'ordre public qui sont autant de violations des libertés individuelles et dont beaucoup resteront en vigueur jusqu'à la chute de la Droite en fin 1963. Par ailleurs, la tournure prise par ces luttes aura pour conséquences d'entraver le renouvellement, pourtant si nécessaire, de la classe politique.

L'un des objectifs essentiels de la Grande-Bretagne sera que Georges II, qui en 1941 avait quitté la Grèce devant l'invasion allemande et qui était de tendance anglophile, conserve son trône - perspective que dans un premier temps les Américains eux-mêmes ne considèrent pas avec beaucoup de sympathie. La réussite de l'opération, dans des conditions que nous examinerons plus tard, s'accompagne d'un retour en force des partis et groupes conservateurs. En 1946, lors des premières élections de cet après-guerre, la Droite grecque prendra le pouvoir et, à l'exception d'un bref intervalle, le conservera, sous des incarnations diverses, jusqu'à la fin de 1963.

Il est vrai qu'entre temps, le contrôle de la politique grecque sera passé des mains des Britanniques à celles des Américains. Nous aurons à examiner par la suite les modalités et les conséquences de ce transfert. 


\section{REMARQUES SUR LE COMPORTEMENT POLITIQUE GREC}

\section{Retour à la table des matières}

Jusqu'à présent, cet exposé n'a pas pris en considération les traits de caractère que l'on attribue habituellement aux Grecs pour expliquer les vicissitudes de la vie politique de leur pays. Parmi ces traits que l'on fait volontiers remonter à la Grèce Antique, mentionnons, au premier chef, l'individualisme dans les conduites quotidiennes et l'instabilité dans les allégeances partisanes ou les prises de position. Dotés d'une grande lucidité politique et d'un sens atavique de la démocratie, les Grecs témoigneraient par contre d'une exubérance et d'une inconstance difficilement compatibles avec une quelconque stabilité de rapports partisans. Selon d'autres évaluations du même ordre, la passion des Grecs pour la politique - ce «vice national » déclare $\mathrm{D}$. Pentzopoulos - dégénèrerait en une sorte de fanatisme, chacun s'efforçant de faire préva-[p. 41] loir son opinion avec un zèle apostolique et manquant totalement de la modération indispensable au compromis.

Le résultat de ces prédispositions serait d'empêcher le fonctionnement d'un véritable système parlementaire. Dans la mesure où le parlementarisme a pu avoir quelque réalité en Grèce, le fait trouverait son origine dans l'allégeance des politiciens à la personne de certains leaders, seul facteur capable de réduire l'indiscipline naturelle des Grecs. Comme ces jugements seraient mieux fondés s'il était possible de citer un seul pays pauvre où le régime représentatif soit autre chose qu'une simple caricature du modèle idéal de la démocratie politique !

L'observateur étranger ne peut manquer d'éprouver quelque amusement en constatant la tendance à définir les Grecs par des traits qui sont certes bien loin de leur appartenir en propre : ainsi la propension de tout citoyen à discuter de n'importe quel problème de gouvernement et à émettre un avis sur la question sans connaître les éléments du dossier. Les Grecs auraient-ils donc le monopole des discussions du Café du Commerce ou des bavardages de salon ? Quant à l'individualisme, on sait que les bons auteurs n'ont cessé d'y voir une particularité originale du génie français — trait de comportement difficile à concilier pourtant avec l'ensemble des phénomènes liés au gaullisme. Il n'est pas impossible que l'individualisme généreusement attribué aux Grecs soit finalement de la même veine.

Ces jugements superficiels et, somme toute, assez niais, sont en bien des cas acceptés par les Grecs eux-mêmes. Beaucoup de ceux-ci, en tout cas, se satisfont de telles explications pour rendre compte des défauts de leur organisation sociopolitique. On s'oriente ainsi vers ce qu'il semble possible d'appeler une interprétation folklorique de la politique et dont le principe est de prendre l'apparence pour la réalité, l'effet pour la cause. 
L'interprétation folklorique est, par essence, favorable aux bénéficiaires de la situation sociale. Elle leur permet en particulier d'expliquer la misère des déshérités par de prétendues déficiences de ceux-ci (ainsi la nonchalance des indigènes aux colonies). Un autre rôle de l'explication folklorique est de dériver l'attention des différences sociales qui sont la base de l'existence humaine vers des particularités soidisant propres à tous les membres de la communauté. Et, dans la mesure où l'explication folklorique flatte le nationalisme en attribuant un caractère ori-[p. 42] ginal et même unique à la communauté en cause, il est fréquent que les membres des classes inférieures tombent dans le piège.

Il existe certes une originalité ethnique qui est sous la dépendance de facteurs multiples, y compris probablement de facteurs biologiques et climatiques, que nous ne savons en réalité ni reconnaître ni, a fortiori, mesurer. Un Grec n'est pas un Anglais. Le fait reste pourtant que bien des Grecs implantés en Angleterre finissent par s'y conduire comme des Anglais. On peut à l'inverse citer des colonies grecques installées à l'étranger qui ont su conserver, au cours des âges, des particularités originales. La cause de telles situations est que ces Grecs, malgré l'individualisme qu'on attribue à leur ethnie, surent et purent accepter les relations communautaires sans lesquelles l'étranger dans un pays quelconque est voué à une assimilation rapide.

Ces observations suggèrent une conclusion simple : en aucun cas, l'étude des traits de comportement d'un peuple — c'est-à-dire des traits effectivement observés et non de ceux impliqués dans les stéréotypes habituels - ne doit être séparée de l'analyse du milieu social au sein duquel ces conduites se manifestent. Même si ce mode d'analyse ne permet pas d'appréhender l'intégralité des facteurs, il donne une base irremplaçable pour l'examen de la situation ${ }^{1}$. Il conduit à observer que la Grèce n'est pas aussi moderne que les Athéniens ont propension à le croire et les étrangers à l'envisager sur la base d'un petit nombre d'endroits relativement atypiques.

Examinons par exemple la question du patronage qui joue un rôle important dans la vie politique grecque, spécialement quoique non exclusivement, dans les régions montagneuses du pays. Il est fréquent que l'individu accorde son suffrage sur la base d'avantages reçus ou promis et non en vertu de convictions idéologiques. Il est possible que le commentateur ressortissant d'un pays développé dénonce l'opération comme une tricherie et y voit l'indice d'un amoralisme foncier chez ceux qui s'y livrent ou en profitent. Mais ceci est le point de vue d'un homme pour lequel la continuation de l'existence ne pose pas de difficultés matérielles élémentaires. En réalité, les populations considérées vivent parfois dans une telle misère que le patronage peut s'analyser en [p. 43] une nécessité de l'existence. Le vote étant l'un des rares biens que leur concède la société, il est normal que ces groupes déshérités s'efforcent d'en tirer le prix maximal.

1 Dans cette perspective on ne saurait que recommander la lecture du beau livre de CAMPBELL (J.K.), Honour, Family and Patronage. A study of institutions and moral values in a Greek mountain community, Londres, 1964. 
En des pages classiques, R. K. Merton a montré que les machines partisanes américaines remplissaient un certain nombre de fonctions sociales. Le principe d'une telle analyse s'applique parfaitement, mutatis mutandis, au cas du patronage grec. Dans un pays aussi pauvre que l'est demeurée la Grèce rurale, les services de tous ordres que peut rendre un député jouent un rôle considérable qu'il s'agisse pour celuici de trouver des fonds pour la commune, d'obtenir un travail pour tel jeune garçon ou simplement d'autoriser les électeurs à utiliser son téléphone. L'importance de ces services est naturellement accrue par l'état de sous-administration qui caractérise inévitablement de telles régions. Aujourd'hui encore c'est le député qui devra s'occuper d'obtenir le visa d'émigration et le billet pour l'Allemagne au profit du jeune paysan désireux de s'expatrier. En somme, le patronage est une sorte de compensation à l'isolement, à la défectuosité et à l'insuffisance du marché du travail, à l'impuissance matérielle et à la pauvreté de tous les Grecs qui n'ont pas encore été touchés par les formes de l'économie moderne.

Les relations traditionnelles entre l'élu et l'électeur sont ainsi cimentées par des rapports de patronage dont il est difficile de donner une juste idée en raison de leur multiplicité et plus encore de leur extrême hétérogénéité (la question de l'emploi ayant de nos jours une importance croissante). À divers égards, le patronage n'est pas un aspect ou un moyen de la politique : il est la politique au sens où c'est le seul moyen d'obtenir des éléments essentiels de la vie individuelle ou familiale. Et dans la mesure où le député rend les services que l'on attend de lui, l'électeur ou la collectivité d'électeurs n'a pas de raison d'en changer. Les hommes en place étant les plus aptes à rendre de tels services, on comprend, toute autre considération mise à part, que le citoyen soit porté à leur garder sa confiance. Ainsi le patronage se traduitil par une double relation de fidélité — de l'élu à l'électeur, de l'électeur à l'élu — dont le maintien signifie que chacun effectue les actes que l'autre attend de lui.

Vu sous cet angle, le rapport politique entre le député et le citoyen s'analyse en une sorte de marché tacite - caractéristique que l'on retrouve d'ailleurs en bien des circonstances de la vie moderne. Ce marché [p. 44] peut être exclusif de toute préoccupation idéologique. Mais, en principe, comme aussi dans l'ordre des faits, patronage et idéologie ne sont pas incompatibles : il est parfaitement concevable que les hommes élus au bénéfice d'une tradition rendent aussi à leurs électeurs les services attachés à la technique du patronage. L'attachement commun à une cause renforce certes la position des premiers à l'égard des seconds, le lien de fidélité se maintenant même dans le cas où le parlementaire ne parvient pas à procurer tout ce que l'on attend de lui.

En définitive, par suite de l'extrême imprécision qui, malgré les études à prétention scientifique du caractère national continue d'affecter la psychologie ethnique - une imprécision susceptible de provoquer de sérieuses mystifications - 
la manière la plus raisonnable d'aborder la vie politique de ce temps reste de partir des facteurs collectifs de l'expérience, tels que nous avons tenté de les analyser dans ce chapitre. Même si l'évaluation que nous avons faite de ces facteurs et la signification que nous leur avons attribuée peuvent être discutées, leur présence n'est pas contestable. On ne saurait entreprendre l'analyse de la période considérée et moins encore procéder à l'évaluation des résultats acquis sans tenir compte du legs des époques précédentes.

Ainsi ne saurait-on aujourd'hui encore expliquer le comportement électoral grec sans prendre en considération le degré d'ancienneté des différentes régions dans l'État grec moderne. Le régime socio-économique sous lequel vivait chacune de ces régions - ainsi que la nature des circonstances dans laquelle chacune a rejoint la mère-patrie — ont influé et influent toujours sur le comportement des habitants. Autrement dit, l'expérience historique reste un facteur de la couleur politique- prise par les différentes parties du pays.

C'est ainsi que la vieille Grèce, et spécialement le Péloponnèse, a toujours témoigné d'une nette propension au conservatisme et au soutien de la Monarchie comportement que l'on ne saurait séparer de la survivance de diverses influences féodales. L'adjonction de la Thessalie au lendemain du Congrès de Berlin allait modifier quelque peu la situation en provoquant chez les travailleurs de la terre une vive agitation pour le partage des chifliks (domaines dont la propriété était passée après le départ des Turcs aux mains des familles grecques fortunées). [p. 45] Mais ce sera l'introduction de la Macédoine et de la Crète dans l'État grec qui modifiera le plus profondément l'équilibre des forces : Vénizélos trouvera un soutien considérable dans les régions du Nord qui le tiennent pour l'artisan de leur libération et aussi, bien entendu, en Crète dont il est originaire. Ainsi sera-ce en définitive l'issue victorieuse des guerres balkaniques qui donnera au Parti Libéral l'assise territoriale de départ indispensable.

Autre facteur essentiel de l'expérience historique : l'arrivée en Grèce des réfugiés d'Asie Mineure en conséquence de l'échange obligatoire des minorités ayant sanctionné le désastre militaire d'août-septembre 1922. Bien que les statistiques en ce domaine n'aient pas toute la précision désirable, on a pu calculer que le nombre parmi ces réfugiés des hommes de plus de 20 ans était de l'ordre de 300.000. Ce chiffre peut ne pas sembler très considérable en valeur absolue mais il représentait environ $20 \%$ du corps électoral grec de l'époque. En réalité les réfugiés constituaient un facteur suffisamment massif pour peser de manière décisive sur l'orientation politique du pays ${ }^{1}$.

L'action des réfugiés avait d'autant plus de chances, d'affecter la politique grecque que ceux-ci témoignaient dans leur ensemble de positions concordantes. Les réfugiés étaient anti-monarchistes parce qu'ils attribuaient à la Couronne la responsabilité du désastre qui les avait frappés et aussi parce qu'élevés hors de Grèce ils n'avaient aucun attachement affectif à l'égard de la personne du Roi. Ils témoignaient en

Pour une analyse détaillée de ce problème, voir PENTZOPOULOS (D.), op. cit., pp. 171-195. 
revanche d'un extraordinaire attachement à E. Vénizélos parce qu’il demeurait pour eux l'homme qui avait su obtenir des puissances alliées la réalisation de la « Grande idée » : cet attachement se fondait sur une profonde reconnaissance à l'égard de Vénizélos et impliquait une grande confiance dans les capacités d'homme d'État de celui-ci.

Les historiens estiment que les réfugiés ont joué un rôle éminent dans la condamnation à mort des six ministres monarchistes et la proclamation de la République. Par ailleurs les sentiments pro-vénizélistes des réfugiés devaient les conduire à donner leur soutien au Parti Libéral — les tentatives faites pour créer un parti propre aux réfugiés lors des élections de 1926 ayant complètement échoué.

On a reproché au Parti Libéral d'avoir procédé à l'établissement des réfugiés d'une manière qui favorise ses intérêts électoraux (ainsi cons-[p. 46] truction de larges quartiers d'accueil autour d'Athènes). Les politiciens libéraux auraient en somme créé un nouveau type de gerrymandering consistant à altérer l'orientation politique d'une collectivité quelconque non par manipulation de ses frontières géographiques mais par installation de groupes «hommes témoignant de préférences partisanes déterminées.

Il n'est pas du tout impossible que de telles manœuvres aient été accomplies. Notons toutefois qu'aux élections de 1933 les réfugiés mécontents de certains refus ou retards gouvernementaux à leur égard semblent avoir fait pencher la balance du côté des Populistes (le phénomène jouant notamment en divers quartiers d'Athènes).

Sous l'angle des conséquences durables, le point essentiel reste que l'implantation des réfugiés affecta de manière très inégale les diverses régions du pays. La région la plus touchée à cet égard fut la Macédoine où, à l'issue des opérations de transfert, les réfugiés représentaient $45 \%$ du total de la population. Autres grandes régions d'accueil : la Thrace, la Grèce Centrale et les Îles de la Mer Égée — régions pour lesquelles la part des réfugiés dans la population atteignit respectivement 35\%, 19\% et $18 \%$.

Au total, sans constituer nulle part une force politique indépendante, les réfugiés se trouvaient en mesure d'influer sur la position respective des vieux partis en de larges secteurs du territoire et, réserve faite du flottement observé en 1933, ils le firent généralement dans le sens de la gauche. De plus, la concentration d'une large part de réfugiés dans le Nord du pays renforçait considérablement la force de l'Hellénisme en des régions partiellement convoitées ou disputées par les pays voisins. Bien que le passage du temps ait nécessairement affaibli l'action propre des réfugiés et de leurs descendants, on ne saurait dire que ces grands événements historiques ont cessé d'exercer une influence sur le comportement politique des Grecs, notamment dans l'ordre électoral.

Telles sont les composantes de l'expérience historique que nous souhaitions mettre en évidence avant d'aborder l'analyse de la période couverte par ce livre. En lisant la suite de cet ouvrage, le lecteur, pensons-nous, se rendra facilement et rapidement compte que l'établissement de cet exposé n'a pas représenté une activité gratuite eu 
égard à notre objet propre mais une démarche nécessaire pour la bonne compréhension des phénomènes de notre temps. 
[p. 47] *

\section{TITRE PREMIER}

\section{partis et élections}

$\underline{\text { Retour à la table des matières }}$

DURANT LA PÉRIODE étudiée en cet ouvrage, on a pu observer l'intervention de 95 partis sur la scène politique grecque. Nous donnons en annexe, sous forme de lexique - suivi d'un lexique des coalitions - , une brève analyse de chacune de ces formations dont le nombre même suggère une pulvérisation irrémédiable des forces partisanes.

Cette vue globale est pourtant trompeuse. S'il est vrai que 44 partis, intervenant à titre isolé ou comme membres d'une coalition, s'affrontèrent lors de la consultation de 1950, la lutte électorale de 1964 s'est limitée à 4 formations (dont 2 rassemblées en une coalition). Au cours des années considérées, la propension au regroupement l'a emportée sur les tendances à l'émiettement.

L'objet essentiel de ce chapitre est d'examiner les étapes et les modalités de ce mouvement dont nous aurons à étudier par la suite la signification et les chances de consolidation. La raison d'être des partis en régime représentatif étant la conquête de mandats parlementaires, il semble légitime d'analyser cette évolution à travers les consultations électorales. Depuis la fin de la guerre, les élections au Parlement grec qui est monocaméral ont eu lieu à 9 reprises : 1946, 1950, 1951, 1952, 1956, 1958, 1961, 1963, 1964.

L'un des traits distinctifs du système politique grec pendant cette période est l'incessante modification de la loi électorale. À l'exception de la dernière, chaque élection a été tenue sous un régime différent, [p. 48] les changements d'un cas à l'autre étant tantôt légers et tantôt drastiques. Il est à peine besoin d'écrire que de

[Les numéros entre accolades réfèrent aux numéros de pages de l'édition de papier, MB.] 
telles transformations ont eu généralement pour objet de favoriser les partis dont les hommes tenaient les leviers de commande gouvernementaux.

Il est donc nécessaire de donner en commençant une brève présentation des régimes électoraux mis en œuvre. Nous examinerons ensuite les résultats obtenus par les formations partisanes lors de chaque élection successive. Il nous restera enfin à donner une vue générale des modifications intervenues dans le système des partis au cours de cette période *.

En acceptant le risque d'une vue un peu schématique, on peut dire que, depuis la fin de la seconde guerre mondiale, trois grandes tendances se manifestent sur la scène politique grecque la Droite, le Centre et la Gauche (que divers milieux, pour des raisons que nous exposerons, qualifient d'Extrême-Gauche). Actuellement, ces tendances, à l'intérieur desquelles on rencontre bien des nuances, sont représentées par l'Union Nationale Radicale (ERE), l'Union du Centre (EK) et la Gauche Démocratique Unifiée (EDA). Nous nous efforcerons plus loin de préciser le sens et la portée de cette division tripartite dont l'allure géométrique est quelque peu fallacieuse (de nombreux éléments qui se rattachent au Centre étant d'inspiration aussi conservatrice que la Droite). En attendant cet effort de clarification, nous utiliserons ces termes avec le même sens et dans les mêmes conditions que la pratique politique habituelle.

Nous nous bornons dans ce titre à l'analyse des mécanismes et résultats électoraux, l'étude des programmes des partis et de leurs positions sur les événements en cours relevant du Titre II.

\footnotetext{
Sauf indication contraire, les données numériques mentionnées dans ce titre sont extraites des volumes officiels de statistiques publiés à l'occasion de chaque consultation. Les volumes relatifs aux élections de 1963 et 1964 ne sont pas encore parus ; toutefois, nous avons pu obtenir certains tableaux du Ministère de l'Intérieur. À l'occasion des élections de 1964, les services du Ministère à la Présidence du Conseil ont publié une brochure en anglais et en français sur les élections d'aprèsguerre dont nous utiliserons certains chiffres.
} 
[p. 49]

\section{CHAPITRE I \\ PRÉSENTATION DES RÉGIMES ÉLECTORAUX}

Retour à la table des matières

DEPUIS L'INSTAURATION du système représentatif jusqu'à l'avènement de la Dictature Métaxas, la Grèce a utilisé divers modes de scrutin, la plupart d'entre eux toutefois étant de type majoritaire à un tour. Il faut attendre l'année 1926 pour trouver la première consultation tenue sous un régime proportionnel (loi $n^{\circ} 3363$ de 1926). Cette loi met en œuvre le procédé dit de Hagenbach-Bischoff selon lequel le quotient électoral est obtenu en divisant le total des suffrages exprimés par le nombre de sièges à pourvoir augmenté d'une unité. Les sièges non pourvus lors de cette distribution font l'objet de deux répartitions ultérieures l'une d'assiette régionale, la dernière dans le cadre national. Point important : la loi limite l'accès à ces deux répartitions aux seuls partis ayant rassemblé un certain quantum de suffrages. Conçu pour éviter l'émiettement de la représentation parlementaire, ce régime favorise, de la sorte, les plus grands partis.

Cette expérience ne suffira pas pour établir une pratique constante puisque dès les élections de 1928 l'on revient au mode majoritaire. Lors de la consultation de 1932 la représentation proportionnelle est adoptée pour la seconde fois: mais c'est de nouveau le scrutin majoritaire qui est employé pour les élections de 1933 et 1935. Enfin une nouvelle utilisation de la représentation proportionnelle intervient lors des élections de 1936 qui sont les dernières à être tenues pour une période de 10 ans ${ }^{1}$.

[p. 50] Les débats de l'époque montrent que, dans l'ensemble, les grandes formations, Vénizéliste comme Populiste, sont peu favorables à la représentation proportionnelle. Elles y voient une menace de désagrégation et en redoutent la

1 On trouvera un tableau des systèmes électoraux utilisés durant cette période in LAKEMAN (E.), LAMBERT (J.D.), Voting in democracies. A study of majority and proportional electoral systems, Londres, 1955, p. 191. 
formation de dissidences. Lors d'une discussion à la Chambre, E. Vénizélos se prononcera pour la représentation des seules minorités ayant obtenu un pourcentage relativement important des suffrages (ainsi le quart). Par contre sont favorables au mode proportionnel les leaders des formations minoritaires qui risquent d'être écrasées par les grands partis dans une contestation d'inspiration majoritaire : citons en particulier A. Papanastasiou fondateur de l'Union Démocratique (parti républicain à tendances socialisantes). Le parti communiste se prononce dans le même sens.

Durant cet après-guerre, c'est en principe le régime proportionnel qui a prévalu, le mode de scrutin majoritaire (à un tour) n'étant utilisé que pour la consultation de 1952. Toutefois, le principe majoritaire a été largement employé dans le régime électoral de 1956 dont la caractéristique était de combiner plusieurs modes de scrutin en vue d'assurer la victoire du parti au pouvoir sur tous ses rivaux.

Sept élections ont donc été organisées avec des règles proportionnelles. Cependant, conformément à l'inspiration de la loi de 1926, il ne s'est jamais agi d'une proportionnelle pure mais d'un système favorisant les partis de tête. On a l'habitude en Grèce d'utiliser l'expression "proportionnelle renforcée » pour désigner un tel système. Le point significatif est que le niveau de ce « renforcement » a sensiblement varié durant la période considérée.

Les normes essentielles à cet égard sont celles qui déterminent le nombre des sièges attribués lors de la première distribution et fixent les règles de participation aux deux suivantes. Assez libérales au titre des élections de 1946 et 1950, ces règles seront nettement alourdies dans le régime de 1951. Le maximum de "renforcement » est atteint pour les élections de 1958 tandis qu'un desserrage des normes intervient lors des élections suivantes (le régime demeurant toutefois plus rigoureux pour les coalitions des partis que pour les partis simples).

Grosso modo, on peut diviser la période étudiée en deux phases que sépare le régime hybride de 1956. De 1946 à 1952, le régime électoral évolue d'une proportionnelle relativement favorable aux formations moyennes à un mode de scrutin purement majoritaire, le mécanisme de 1951 formant transition par la prime qu'il donne aux plus impor-[p. 51] tantes formations. De 1958 à 1964, c'est un mouvement inverse qui s'observe : on part d'une proportionnelle très renforcée pour aboutir à une proportionnelle d'inspiration plus stricte.

Au bénéfice de ces considérations générales, nous voudrions mettre en évidence de manière plus explicite les mécanismes utilisés par les auteurs des lois électorales successives en vue d'orienter les résultats de la consultation dans un sens déterminé. Mais, bien entendu, le fonctionnement de ces mécanismes dépend du cadre dans lequel ils sont appelés à jouer. Au surplus, quel que soit le système adopté, il faut tenir compte de ses conditions de mise en œuvre (en particulier question de la fraude électorale).

Tels sont les trois points que nous allons étudier pour établir, mais seulement dans ses grandes lignes, la consistance des régimes électoraux de 1946 à 1964. Cet exposé portera principalement sur les techniques électorales, l'analyse des motivations et conséquences politiques relevant normalement des chapitres suivants. 


\section{FIXATION DU CADRE}

\section{Retour à la table des matières}

On doit considérer à ce titre le partage des sièges à pourvoir entre les circonscriptions et la délimitation géographique de celles-ci. La manipulation de chacun de ces éléments ou des deux à la fois suscite des inégalités de représentation et permet des manœuvres intéressées dont la pratique grecque, sans en avoir nullement le monopole, offre de nombreux exemples. Il est nécessaire d'évoquer le principe de ces phénomènes pour donner une vue authentique des affrontements partisans en cet après-guerre.

\section{A. PARTAGE DES SIÈGES À POURVOIR}

Il a été fait de 1946 à 1952, sur la base d'un quotient fixé à l'avance, chaque circonscription disposant d'autant de sièges que sa population contient de fois le quotient et bénéficiant d'un siège supplémentaire au cas où l'opération laisse subsister un reste inemployé d'un certain montant. Montant du quotient : 20.000 en 1946, 30.000 en 1950 et 1951, 25.000 en 1952. Depuis 1956, le chiffre des sièges n'a plus varié (300) et le [p. 52] quotient est obtenu en divisant le chiffre de la population par le nombre de sièges à pourvoir dans l'ensemble du pays. Dans les deux cas, le problème revient finalement à distribuer un certain montant de sièges plus ou moins rigidement fixé en fonction d'une certaine population ; le point essentiel est dès lors celui de la convention adoptée pour la détermination de cette population.

L'art 68 de l'actuelle Constitution dispose que « le nombre des députés de chaque circonscription électorale est fixé ... en proportion de sa population » ${ }^{1}$. L'objectif de cette norme est de proportionner le nombre des députés élus par chaque circonscription à la population qu'elle contient. Il s'agit d'obtenir que chaque membre du Parlement y représente un nombre de citoyens aussi égal que possible ou, si l'on préfère, « éviter que le jeu politique ne soit faussé par de trop flagrantes inégalités de représentation territoriale. Pour y parvenir, il faut que le chiffre retenu au titre du partage des sièges suive d'aussi près que possible les changements survenus dans la population respective des diverses circonscriptions. Ainsi se trouve posé le problème du recensement de référence, c'est-à-dire du recensement dont les résultats servent de base au partage.

1 L'Institut Hellénique de droit international et étranger a publié (Athènes, 1955) une excellente traduction de la Constitution actuelle (qui est entrée en vigueur le $1^{\mathrm{er}}$ janvier 1952). 
Admettons d'emblée qu'il est difficile, le voudrait-on avec une parfaite sincérité, d'obtenir et surtout de maintenir une concordance parfaite entre la population réelle des diverses circonscriptions et la population servant de base au partage des sièges. Les recensements démographiques sont des opérations complexes que les autorités publiques ne peuvent envisager de réaliser qu'à des dates relativement éloignées les unes des autres (ainsi en Grèce tous les 10 ans). Dans l'intervalle, on peut moderniser en quelque sorte les chiffres du recensement antérieur par la pratique de sondages. Mais l'on ne saurait modifier une distribution de sièges à partir des résultats d'un échantillonnage statistique. Au surplus, l'élaboration des données d'un recensement exige des calculs minutieux et, par conséquent, nécessite du temps. À mesure que l'on s'éloigne de la date du recensement de référence, le risque d’inégalité de représentation grandit, le danger s'aggravant dans les périodes d'importantes migrations internes.

[p. 53] Quel que soit le recensement de référence, la question se pose de choisir la notion de la population ou, en d'autres termes, la manière de sélectionner celle qui convient le mieux à la distribution des sièges. La méthode évidemment la plus simple serait de fonder cette répartition sur la population présente ou de fait, c'est-à-dire sur l'ensemble de personnes se trouvant dans la circonscription au jour du dénombrement, qu'elles y résident habituellement ou y soient seulement de passage. Le choix d'une autre notion nécessite une ventilation statistique et, par conséquent, recule la date où il devient possible d'ajuster la distribution des sièges aux variations démographiques. Cependant il paraît préférable d'effectuer cet ajustement sur la base d'un critère de rattachement des hommes à la circonscription plus rigoureux ou plus significatif que la seule présence au moment du comptage périodique.

La réglementation électorale grecque prend en considération à cet égard la notion de citoyen (dimotis), notion qui se détermine à partir de l'inscription sur les registres d'une municipalité ou d'une commune ${ }^{1}$. En vertu de cette pratique, qui est demeurée constante durant toute la période couverte par cet ouvrage, la répartition des sièges s'effectue selon le nombre de citoyens des municipalités et communes de chaque circonscription au jour du recensement de référence. Le passage de la population de fait aux chiffres retenus pour la distribution des sièges se réalise donc par la mise en œuvre d'un lien de type juridique.

Observons que l'art. 68 de la Constitution peut s'accommoder d'une telle manière de procéder mais ne l'implique pas nécessairement. C'est ainsi que l'on aurait pu faire choix pour déterminer la population de l'art. 68 de la notion de résidence habituelle telle que mentionnée par les intéressés eux-mêmes le jour du recensement. Il est vrai que si le système des inscriptions municipales fonctionne correctement, la différence entre les inscrits et les résidents habituels doit être minime. Le décalage peut toutefois être assez sensible, spécialement au titre d'une collectivité qui constitue un grand centre d'attraction, quand la réglementation impose l'accomplissement d'un délai minimal de résidence avant l'inscription sur les registres. Tant que court le délai, une

1 La législation grecque organise deux régimes d'administration locale selon l'ampleur de la population des collectivités considérées. 
personne qui a choisi de résider habituellement dans une collectivité reste juridiquement membre d'une autre.

Le point est important sous l'angle de l'égalité territoriale de la repré-[p. 54] sentation parlementaire. Si l'on fait abstraction de tout formalisme, la véritable population d'une circonscription quelconque est celle des personnes qui y sont établies à demeure. Par conséquent, tous les facteurs de discordance entre les inscrits au registre et les résidents habituels sont susceptibles, si le registre sert de base à la répartition des sièges, de créer autant d'entorses au principe de l'égalité territoriale de la représentation. il peut en aller de la sorte si le délai minimal de résidence est trop long, si les personnes remplissant les conditions requises éprouvent des difficultés à obtenir leur inscription ou au contraire évitent de procéder à cette formalité en vue de se soustraire aux obligations locales ... En somme, si l'on veut obtenir un fonctionnement optimal du registre, il est nécessaire de prévoir une sorte d'inscription d'office garantissant que tous les ayants-droits à l'inscription sont en mesure de se faire inscrire et qu'il n'y a pas d'échappatoire.

En principe, la législation administrative grecque répond correctement à ces exigences, la loi de codification en ce domaine considérant comme citoyen (dimotis) d'une municipalité ou commune toute personne effectivement inscrite sur les registres mais aussi toute personne ayant le droit de demander son inscription. Or ce droit existe au bout de deux années de résidence permanente, ce délai étant un peu long certes mais ne pouvant être tenu pour excessif. Donc, sous la seule réserve, qui est d'ailleurs de taille, que le calcul des citoyens d'une circonscription soit effectué conformément aux prescriptions de la loi municipale ou communale, on peut admettre que le registre municipal ou communal est suffisamment représentatif de la population de résidence habituelle.

Durant la période examinée, la législation grecque a toutefois comporté une complication supplémentaire tenant à l'impossibilité pour le citoyen de modifier son inscription électorale dans le cas où il aurait changé son lieu de résidence après le $1^{\mathrm{er}}$ janvier 1948. Ce problème concerne apparemment l'exercice du droit de vote et non la distribution des sièges mais il faut en parler dès maintenant car, par certains aspects, il se rattache à la question de l'égalité territoriale de la représentation parlementaire.

Cette disposition étrange trouvait officiellement son origine dans la volonté de préserver les registres électoraux des remous produits par la guerre civile - qui selon certains calculs aurait entraîné le «déplacement » d'environ 700.000 personnes sur tout le territoire. Pensant qu'un certain nombre des personnes ainsi déplacées finiraient par rejoindre [p. 55] leur ancien domicile, le législateur estima souhaitable d'empêcher que les listes électorales ne soient artificiellement perturbées par le jeu de mouvements partiellement temporaires. Ce type d'instabilité ayant pris fin depuis longtemps, la disposition considérée aurait dû être annulée. En réalité, il a fallu attendre jusqu'aux élections de 1963 pour qu'il en soit ainsi. Désormais toute personne ayant changé de résidence peut se faire inscrire sur les registres électoraux de sa nouvelle résidence dès lors qu'elle remplit les conditions pour l'accès au titre de citoyen (dimotis), de cette communauté, en particulier le séjour de 2 ans. 
Ainsi donc, pendant plusieurs années il y a eu en somme deux notions différentes et même contradictoires de citoyen : celle relative à la participation municipale ou communale dans son ensemble et celle ayant trait à la seule participation électorale. Une personne ayant changé de résidence depuis 1948 pouvait selon la codification municipale devenir membre de la collectivité où elle avait installé sa nouvelle résidence permanente sans pour autant acquérir le droit d'y voter. On pouvait donc en principe concevoir que des citoyens ne puissent voter au titre de sièges pour l'attribution desquels ils avaient été pris en considération. Disons tout de suite que beaucoup ont illégalement obtenu, sous réserve que leurs opinions soient favorables au parti gouvernemental, la possibilité de voter au lieu de leur nouvelle résidence. Mais on ne saurait racheter une incohérence juridique par un ensemble d'irrégularités teintées de favoritisme partisan.

Tels sont les principes ayant régi la matière mais, en pratique, ces principes ont été compromis sinon totalement annulés par le choix systématique de données démographiques strictement périmées comme base de répartition des sièges parlementaires. Considérons en effet les données choisies comme base du partage des sièges de 1946 à 1964 :

\begin{tabular}{|c|c|c|c|}
\hline $\begin{array}{l}\text { Consultations } \\
\text { électorales }\end{array}$ & Nombre de citoyens & & $\begin{array}{l}\text { Recensement } \\
\text { de référence }\end{array}$ \\
\hline 1946 & 7.232.543 & 1940 & \\
\hline 1950, 1951, 1952, 1956, 1958 & 7.395.219 & 1940 & plus Archipel du Dodécanèse \\
\hline 1961 & 7.643 .808 & 1951 & $\begin{array}{l}\text { sauf pour } 13 \text { circonscriptions } \\
\text { dépendant encore de } 1940\end{array}$ \\
\hline $1963,1964 \ldots \ldots \ldots \ldots \ldots \ldots$ & 8.404 .080 & 1961 & \\
\hline
\end{tabular}

[p. 56] On voit donc que jusqu'en 1958 (et même pour partie jusqu'en 1961) la répartition des sièges a été effectuée sur la base de la distribution des citoyens en 1940. Déjà susceptible de provoquer de sérieuses inégalités dans une phase d'évolution normale de la population, un tel retard dans la prise en considération des changements ne pouvait manquer de créer de profondes distorsions au titre d'un pays ayant subi des bouleversements démographiques exceptionnels. Sans entrer ici dans une analyse de ces transformations, il est indispensable pour notre propos d'en esquisser le sens ${ }^{1}$.

De 1940 à 1951, la population, par suite des lourdes pertes subies, connaît une réelle stagnation. Cependant, la croissance des villes se poursuit, l'augmentation de la population urbaine étant de l'ordre de $20 \%$. Durant cette phase, la totalité du faible

1 Pour une étude détaillée de ces phénomènes, renvoi à KAYSER (B.), op. cit., spécialement chap. II. Les observations présentées sont tirées de cet ouvrage. 
accroissement démographique que connaît le pays est absorbée par les villes qui attirent au surplus, notamment comme lieux de refuge, une partie de la population des campagnes. Un vide démographique se crée sur toute la périphérie du pays (départements de la frontière septentrionale ; régions insulaires non seulement dans la mer Égée mais encore en mer Ionienne ; départements méridionaux du Péloponnèse). Bien que les conditions de vie y soient alors très dures, Athènes continue de se développer quoiqu'à un rythme moindre que par le passé.

Au cours de la période 1951-1961, la population recommence à s'accroître mais ce sont les villes qui bénéficient le plus de cette augmentation. Ainsi l'équilibre villescampagnes continue-t-il de se modifier au détriment des secondes, la concentration athénienne absorbant plus de 60\% de l'accroissement intervenu. Mais, selon Kayser, le phénomène le plus important de cette période est la transformation de l'équilibre des dynamismes interrégionaux. Ce mouvement déjà amorcé dans la période précédente aboutit à la formation d'une « Grèce vivante », selon un axe approximatif Athènes-Salonique, dans laquelle s'affirme un progrès simultané de la population urbaine et de la population rurale (cas de la Thessalie orientale et de la Macédoine). En sens inverse, des régions comme la Grèce insulaire, le Péloponnèse, ainsi qu'en une certaine mesure la Thrace et l'Épire montagneuse sont en déclin absolu sans que leurs villes bénéficient de l'exode rural.

[p. 57] Ces transformations accusent sans cesse davantage l'incapacité du recensement de 1940 de donner une image fidèle de la distribution des citoyens sur le territoire. Admettons que durant toute une période le gouvernement n'était pas en mesure de tenir compte de ces mutations, la désorganisation provoquée par la guerre civile en plusieurs régions interdisant même d'envisager un redressement de la situation. La ventilation des citoyens entre les circonscriptions exigeant une élaboration particulière, il était peut-être difficile d'utiliser dès 1952 les résultats du recensement de 1951. Il semble par contre que dès 1956 et a fortiori à compter de 1958, les ajustements indispensables auraient dû et pu être accomplis. On peut admettre sans injustice que si de tels ajustements avaient été susceptibles de favoriser la Droite, les autorités auraient apporté plus de zèle à les réaliser.

Au total, durant toute cette période, la Droite qui n'était pas en mesure de bloquer l'évolution sociale, et particulièrement l'exceptionnelle croissance de la concentration athénienne, s'est efforcée d'en limiter ou d'en éluder les conséquences sur le plan électoral. La volonté de figer la distribution des sièges sur les positions périmées de 1940 en est le meilleur témoignage. Mais on peut admettre que l'obligation faite à un grand nombre d'électeurs d'aller voter là où ils se trouvaient avant 1948 relève de la même inspiration. Ce sont là les différentes pièces d'un plan, non dépourvu de cohérence dès qu'on en admet le principe de base, par lequel le parti gouvernemental — spécialement lors des consultations de 1956 et 1958 — s'est efforcé en matière électorale de conserver autant d'éléments que possible du passé.

La même observation n'est plus valable pour les élections de 1963 et 1964 puisque la distribution des sièges a été effectuée sur la base du recensement de 1961. Cependant la consultation des statistiques disponibles fait surgir un autre problème : 
l'aptitude des registres municipaux, tels qu'établis par les autorités, à exprimer de manière valable la distribution permanente (résidence habituelle) de la population entre les diverses circonscriptions électorales.

Selon le recensement organisé le 19 mars 1961, la population totale de la Grèce s'élevait à cette date à 8.388.553. Considérée de facto, c'est-à-dire selon le lieu de présence au jour du dénombrement, cette population se répartissait comme suit :

[p. 58]

\begin{tabular}{|c|c|c|c|}
\hline 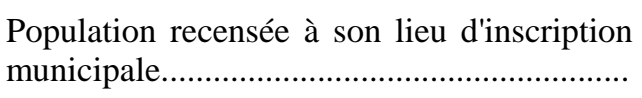 & 6.466 .732 & soit & $77,09 \%$ \\
\hline 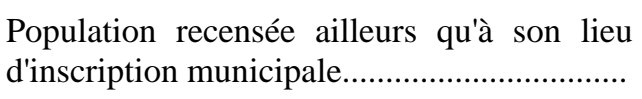 & 1.867 .085 & soit & $22,26 \%$ \\
\hline \multirow[t]{2}{*}{ 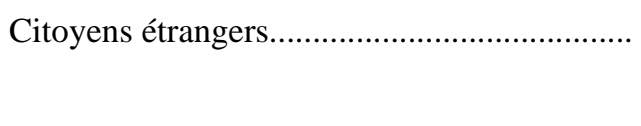 } & 54.736 & soit & $0,65 \%$ \\
\hline & 8.388 .553 & & 100 \\
\hline
\end{tabular}

Il paraît difficile d'admettre qu'au jour du recensement plus d'un cinquième des Grecs se soient trouvés en déplacement occasionnel ou en séjour de courte durée hors de leur résidence permanente. On doit donc tenir pour très probable qu'un nombre appréciable d'habitants de ce pays ont en réalité leur résidence effective dans des collectivités locales sur les registres desquels ils ne sont pas inscrits. Cette situation tient certainement pour partie au fait que le droit d'être inscrit sur le registre est subordonné à l'accomplissement d'un temps de résidence (deux ans en principe) sur le territoire de la collectivité considérée. Elle résulte aussi de ce que les services municipaux compétents ne mettent pas toujours une égale bonne volonté à satisfaire les postulants (les opinions politiques présumées de ceux-ci pouvant en certains cas constituer l'un des éléments de la position prise par ces services). Il existe certes une procédure d'appel auprès des autorités de l'État mais tous les intéressés ne sont pas également en mesure d'y avoir recours. Enfin, on ne saurait exclure qu'en diverses occasions les citoyens eux-mêmes ne soient pas désireux de devenir officiellement membres de la collectivité dans laquelle ils résident effectivement.

Quoi qu'il en soit, c'est pour l'agglomération dite Grand-Athènes que le pourcentage dans la population de fait (1.820.036) des personnes non inscrites sur un registre municipal est le plus grand: il s'élève en effet à 42,11\%. Certes, l'agglomération est susceptible de comprendre à tout moment un certain nombre de citoyens d'autres communes en séjour temporaire (voyages d'affaires, visites familiales...). Mais la catégorie des personnes présentes sans être inscrites est bien trop importante (780.201) pour qu'on soit fondé à expliquer son ampleur uniquement par des facteurs de cet ordre.

Observons maintenant le chiffre des citoyens retenu pour le calcul des députés revenant à cette agglomération lors des élections de 1963 [p. 59] et 1964 — chiffre, 
on le sait, établi sur la base des citoyens inscrits sur les registres - ce que les documents grecs appellent la population légale. Il s'élève à 1.413.395, c'est-à-dire qu'il se situe pratiquement à mi-chemin entre le total des inscrits dénombrés le 19 mars 1961 soit 1.039 .838 et celui du total des citoyens recensés dans le GrandAthènes en cette occasion soit 1.820.036. Si l'on raisonne à partir des normes fixées pour le calcul de la population, il faut admettre l'absence de l'agglomération athénienne, au jour du dénombrement, de 373.557 citoyens y ayant leur point d'attache juridique. L'importance même de ce chiffre suggère qu'une partie au moins de ces citoyens, quoique effectivement inscrits dans l'agglomération athénienne, possède ailleurs sa résidence permanente.

Si ce raisonnement est correct, des personnes qui habitent réellement l'agglomération athénienne ne sont pas prises en considération pour le calcul des députés lui revenant tandis que d'autres qui, en fait, n'y résident pas sont intégrés dans le calcul. En considérant le problème de l'égalité territoriale de représentation, on pourrait être tenté de faire état d'une certaine compensation entre ces deux séries de situations dont l'une joue effectivement en sens inverse de l'autre. Il serait cependant fallacieux de compter sur une telle compensation pour rétablir l'équilibre dans la représentation parlementaire entre l'agglomération athénienne et le reste du pays.

Au total, l'évolution de la population grecque depuis le déclenchement de la seconde guerre mondiale n'a été prise en considération qu'imparfaitement et tardivement pour la distribution des sièges entre les circonscriptions. Comme on l'observe d'ailleurs en tant d'autres pays, les décalages intervenus de ce fait ont défavorisé les villes et spécialement l'agglomération athénienne. En règle générale, ce sont les régions économiquement dynamiques qui, constituant des pôles d'attraction pour le reste de la population, souffrent le plus de ces défauts ou retards d'ajustement. Il est bien connu que dans l'ensemble, ce sont les partis conservateurs qui profitent au premier chef de telles distorsions.

[p. 60]

\section{B. DÉLIMITATION GÉOGRAPHIQUE DES CIRCONSCRIPTIONS}

\section{$\underline{\text { Retour à la table des matières }}$}

Les manœuvres que permet un découpage ad hoc des circonscriptions sont trop bien connues pour qu'il soit utile d'en rappeler ici les modalités. Disons seulement que le principe de telles opérations est de prendre en considération dans le dessin des circonscriptions non pas seulement l'importance numérique de la population mais les caractéristiques sociales de ses habitants ou, ce qui revient pratiquement au même, leur orientation politique présumée. Durant la période examinée, des préoccupations de cet ordre se sont manifestées dans la pratique électorale grecque.

Mettons à part les élections de 1952 (scrutin majoritaire à un tour) pour lesquelles on utilisera 99 circonscriptions constituées sur deux bases différentes : le ressort de la 
Cour de première instance pour les nouvelles régions (Épire, Macédoine, Thrace et quelques îles) ; la province pour les vieilles régions, c'est-à-dire le reste de la Grèce. Pour toutes les autres élections, ce sont les départements administratifs, au nombre de 50, y compris celui du Dodécanèse, qui ont constitué les circonscriptions de base quant à la première répartition. Mais, selon les consultations, l'assiette territoriale des circonscriptions a subi des modifications dont voici l'essentiel.

Au cours d'une première phase (élections de 1946, 1950, 1951 et 1956), le nombre des circonscriptions est demeuré inférieur à celui des départements, certaines des premières étant composées chacune de plusieurs des seconds. Pour 1946, on a ainsi 36 circonscriptions dont 25 composées d'un département, 9 de deux et 2 de trois. Ce chiffre passe à 37 en 1950 par suite de l'annexion du Dodécanèse. En 1951, le chiffre des circonscriptions est porté à 39 (trois départements précédemment groupés en une seule circonscription formant désormais chacun une circonscription séparée). Le même découpage est adopté pour l'élection de 1956. Si l'on ajoute que durant cette période les villes d'Athènes et du Pirée qui sont situées dans le département de l'Attique représentent l'une et l'autre une unité électorale séparée, le nombre total des circonscriptions est le suivant : 1946, 38 ; 1950, 39 ; 1951, 41 ; 1956, 41.

Un nouveau découpage est institué pour les élections de 1958. Désormais chacun des 50 départements constitue une circonscription électorale. [p. 61] De plus, les circonscriptions d'Athènes et du Pirée sont chacune dédoublées en deux circonscriptions, l'une embrassant la ville proprement dite, la seconde rassemblant les banlieues de celle-ci. Enfin, Salonique est détachée de son département pour former une circonscription indépendante. On a donc en tout 55 circonscriptions : les 50 départements, Athènes-Ville, Athènes-Banlieue, Le Pirée-Ville, Le Pirée-Banlieue, Salonique. Ce découpage n'a pas subi de modification pour les élections suivantes.

Le dédoublement des circonscriptions d'Athènes et du Pirée, ainsi que la séparation de Salonique d'avec son département trouvent certes une justification raisonnable dans l'importance numérique de ces agglomérations - le Grand-Athènes qui couvre l'ensemble urbain Athènes-Le Pirée ayant aujourd'hui 22,3\% de la population de la Grèce. On doit pourtant observer que l'opération, dans les conditions où elle a été accomplie, traduisait la volonté d'isoler certaines tendances politiques défavorables au parti gouvernemental: établissement d'une séparation entre les faubourgs ouvriers du Pirée, secteur le plus «rouge » du pays, et la circonscription plus bourgeoise formée par les vieux quartiers de la ville et un certain nombre d'îles (réunion qui, ayant un fondement historique constitue néanmoins un cas typique de découpage $a d$ hoc) ; constitution en unité électorale séparée d'Athènes-Banlieue qui est la circonscription la plus dynamique du pays sous l'angle démographique et comporte de solides bastions de la Gauche. 


\section{MÉCANISME DE DISTRIBUTION DES SIÈGES}

$\underline{\text { Retour à la table des matières }}$

Depuis son introduction en Grèce, le système proportionnel y est fondé sur la mise en œuvre de trois répartitions successives : première répartition dans le cadre des circonscriptions de base dont le nombre et l'assiette ont varié durant la période considérée ; deuxième répartition dans le cadre de neuf circonscriptions majeures qui n'ont pas subi de changement au cours de la période considérée (ressorts des neuf Cours d'Appel) ; troisième répartition au titre d'une circonscription unique formée par l'ensemble du territoire.

Sous n'importe quelle élection tenue avec un système de cet ordre, les résultats électoraux dépendent finalement de trois séries de règles : celles qui président à la distribution des sièges à pourvoir entre les ré-[p. 62] partitions successives ; celles qui fixent les conditions d'accès des formations en présence (partis et coalitions) à chacune des répartitions ; celles qui, pour chaque répartition fixent les modalités du partage des sièges devant être distribués entre les formations ayant accès à la dite répartition. Disons d'emblée que sur chacun de ces points, sans même parler du régime hybride de 1956, les lois électorales considérées ont connu d’importantes variations.

\section{A. DISTRIBUTION DES SIÈGES ENTRE LES RÉPARTITIONS SUCCESSIVES}

$\underline{\text { Retour à la table des matières }}$

Le régime proportionnel grec ayant toujours comporté une limitation, plus ou moins forte il est vrai, de l'accès aux deuxième et troisième répartitions, certaines formations n'ont de ce fait accès qu'à la première répartition. D'où l'importance pour celles-ci, qui sont normalement les plus petites, des règles fixant le nombre des sièges attribués lors de la première répartition.

Ce nombre est déterminé par la «mesure électorale », c'est-à-dire le chiffre des voix permettant d'obtenir un siège dès la première répartition. Le nombre des sièges reporté aux distributions suivantes est en proportion inverse de l'importance numérique de ce quotient électoral. Autrement dit, l'augmentation de la mesure défavorise les petites formations au profit des grandes.

En cinq élections (1946, 1950, 1961, 1963, 1964), la mesure électorale a été obtenue en divisant le total des bulletins valables par le nombre de sièges de la circonscription augmenté d'un. En deux occasions, par contre, (1951, 1958), on a augmenté la valeur de la mesure en divisant les bulletins valables par le nombre des sièges lui-même. 
Le calcul de la mesure électorale au titre des deuxième et troisième répartitions à également subi des changements selon les consultations. Dans certains cas (1958, 1961), le mécanisme de la troisième répartition ne prévoyait pas de mesure électorale (attribution des sièges non affectés lors des première et deuxième distributions au parti détenant la majorité relative dans chaque circonscription majeure).

[p. 63]

\section{B. CONDITIONS D'ACCÈS AUX RÉPARTITIONS SUCCESSIVES}

Retour à la table des matières

Le point essentiel ici réside dans les conditions exigées pour l'accès des partis à la seconde répartition - les participants à celle-ci étant le plus souvent habilités ipsofacto à prendre part à la troisième. Ces conditions consistent pour l'essentiel dans l'obtention d'un pourcentage minimum de voix. Assez légères au départ (1946, 1950), soit un siège ou $10 \%$ des voix dans la circonscription majeure, ces conditions ont été sensiblement aggravées sous le régime de la proportionnelle renforcée (obtention d'un pourcentage au plan national), le point maximum de sévérité étant atteint aux élections de 1958. Elles ont toujours été plus sévères pour les coalitions que pour les partis simples comme le montre le tableau suivant :

\begin{tabular}{cccccc}
\hline $\begin{array}{c}\text { Nature } \\
\text { de la formation }\end{array}$ & \multicolumn{5}{c}{$\begin{array}{c}\text { Pourcentage de voix requis au plan national de la formation } \\
\text { pour participer à la 2ème répartition }\end{array}$} \\
& $\mathbf{1 9 5 1}$ & $\mathbf{1 9 5 8}$ & $\mathbf{1 9 6 1}$ & $\mathbf{1 9 6 3}$ & $\mathbf{1 9 6 4}$ \\
\cline { 2 - 6 } & & & & & \\
Partis simples........................... & 17 & 25 & 15 & 15 & 15 \\
Coalitions quelconques........... & 20 & - & - & - & - \\
Coalition de 2 partis.................. & - & 35 & 25 & 25 & 25 \\
Coalition de plus de 2 partis.... & - & 40 & 30 & 30 & 30 \\
\hline
\end{tabular}

La sévérité du régime de 1951 était aggravée par le fait que seuls les trois premiers des partis remplissant les conditions requises pouvaient participer à la deuxième répartition. En revanche, l'extrême sévérité de celui de 1958 était adoucie par le fait que deux partis, au moins, devaient participer à cette répartition même si le quorum n'était pas atteint.

Notons que les normes de participation ont été sensiblement réduites dès 1961. De plus, au titre des élections de 1961, 1963 et 1964, des dispositions ont été insérées dans la loi au profit des partis simples. Pour les élections de 1961, il a été décidé que dans le cas où deux partis seulement auraient obtenu les pourcentages requis par la loi, le parti simple venant en troisième position sans avoir le quorum serait [p. 64] 
fondé à prendre part à la deuxième répartition. Enfin, pour 1963 et 1964, la loi dispose que participent à cette répartition tous les partis simples ayant obtenu un siège ou $10 \%$ des voix dans une circonscription majeure donnée.

En somme, si les coalitions sont toujours pénalisées, les barrières mises à l'accès des partis simples à la deuxième répartition sont progressivement réduites de 1958 à 1963 (le système en usage pour les élections de 1963 et 1964 se rapprochant ainsi, sur ce plan, de celui des élections de 1946 et 1950). Tout se passe désormais comme si l'objectif du renforcement de la proportionnelle, objectif lié à la lutte contre la Gauche, était de décourager l'établissement de coalitions électorales en subordonnant à un quorum relativement sévère leur participation à la deuxième répartition.

\section{MODALITÉS DE DISTRIBUTION DES SIÈGES À CHAQUE RÉPARTITION}

Retour à la table des matières

Le mécanisme de la première répartition a toujours consisté dans l'attribution à chaque parti au sein de chacune des circonscriptions d'autant de sièges que le nombre de bulletins valables reçus contient de fois la mesure électorale. Par contre les règles de distribution au titre des répartitions suivantes ont subi diverses modifications.

Toutefois, au titre des quatre dernières élections (1958, 1961, 1963, 1964), le mécanisme de la seconde répartition pour les partis y ayant accès n'a pas subi de changement. On part d'une mesure électorale qui résulte de la division du total des bulletins valables des partis participants dans la circonscription majeure considérée par le nombre de sièges de la circonscription. Chaque parti participant obtient autant de sièges que la dite mesure est contenue dans le nombre des bulletins valables reçus.

Une modification a par contre été inscrite dans la loi au titre de la troisième répartition. Lors des élections de 1958 et 1961, le parti venant en tête dans chaque circonscription majeure y emporte les sièges non encore attribués. Le régime de 1963 et 1964 rétablit à ce niveau le système de la mesure électorale (les partis participant étant les mêmes que ceux déjà admis à la deuxième répartition). 
[p. 65]

\section{CONDITIONS DE MISE EN EUVRE}

$\underline{\text { Retour à la table des matières }}$

Rares sont les pays dans lesquels lors d'une consultation électorale le parti au pouvoir ne profite pas de sa position pour se rendre les électeurs favorables. Par ailleurs, les formations battues ont tendance à expliquer leur défaite par le jeu de fraudes, d'irrégularités et de pressions. À supposer qu'elle remporte la victoire, l'opposition, une fois en place, n'hésite pas en général à se livrer aux manœuvres dont elle s'était précédemment faite la dénonciatrice. Cette tendance se manifeste particulièrement pour tout ce qui concerne le patronage au sens le plus large du terme.

En définitive, l'expérience suggère de n'accepter qu'avec réserves et, en tout cas, sous bénéfice d'inventaire, les dénonciations ou protestations faites par les perdants. Il semble cependant qu'en Grèce, lors de diverses consultations, les manœuvres du parti au pouvoir aient revêtu assez d'ampleur et de force pour fausser les résultats du scrutin. Tel fut semble-t-il, le cas pour les élections de 1961 à propos desquelles les partis de l'opposition parlèrent de « coup d'État électoral ».

Renvoyant à plus tard l'étude de ces accusations, nous voudrions simplement mentionner ici quelques points susceptibles de donner une vue générale du climat dans lequel se déroulent les luttes électorales grecques.

\section{A. DÉSIGNATION DE GOUVERNEMENTS DE SERVICE}

L'objet de ces gouvernements est en principe d'assurer l'impartialité de la consultation électorale. Il s'agit d'éviter que, durant la campagne électorale, les moyens dont dispose le gouvernement ne soient mis au service de l'un des adversaires en présence. Ces gouvernements sont composés de personnalités extraparlementaires : on y trouve en particulier des titulaires d'importants postes publics de nature administrative ou judiciaire ainsi que des personnalités appartenant au monde de la culture et des professions libérales.

En règle générale, la nomination du gouvernement de service intervient au moment de la dissolution du Parlement. Citons toutefois au [p. 66] titre de la période étudiée l'exception du Cabinet C. Georgacopoulos qui, constitué en date du 5 mars 1958, fut chargé d'obtenir du Parlement le vote d'une loi électorale.

Le rôle des Cabinets de service est d'assumer la tenue de la consultation électorale et de procéder à la gestion des affaires courantes en attendant la formation d'un 
nouveau gouvernement politique. Ces cabinets, sur la signification politique desquels nous reviendrons, fonctionnant en l'absence d'une représentation parlementaire, les Ministres qui en font partie sont de la sorte dispensés d'avoir à rendre compte de leurs actes devant l'Assemblée.

Il existe une controverse entre juristes sur la légalité des gouvernements de service - dispute venant de ce que la Constitution de 1952 est muette sur l'institution. Cependant le recours à cette formule — dont la première application remonte au 17 décembre 1867 (élections du 21 mars 1868) — représente désormais une pratique bien assise. Durant cet après-guerre, des gouvernements de service ont été désignés au titre de six élections (1950, 1952, 1958, 1961, 1963, 1964). En trois occasions par contre (1946, 1951, 1956), les élections ont été conduites par le gouvernement politique en place. Notons toutefois que lors des élections de 1951 et 1956 plusieurs ministères (Défense Nationale, Intérieur, justice et Grèce du Nord) furent confiés à des personnalités non politiques.

Disons dès maintenant qu'il est arrivé aux partis d'opposition de mettre en cause l'impartialité des gouvernements de service. Il en est allé ainsi tout particulièrement pour le gouvernement du général $C$. Dovas qui avait reçu mission d'organiser les élections de 1961 et que l'opposition a publiquement accusé d'avoir présidé le « coup d’État électoral » ayant permis à la droite de conserver le pouvoir.

\section{B. TAUX D'INSCRIPTION ET NIVEAU DE PARTICIPATION}

\section{Retour à la table des matières}

Le système des inscriptions électorales a certainement représenté l'un des points faibles du régime représentatif hellénique durant la période considérée. Par ailleurs, le chiffre des électeurs inscrits n'ayant pas toujours fait l'objet de communication officielle ou étant, quand indiqué par les autorités, manifestement entaché d'erreurs grossières, il est [p. 67] difficile, à moins de procéder à des ventilations complexes et nécessairement hasardeuses, de présenter des observations fondées sur le niveau de participation.

Le chiffre des électeurs inscrits fait entièrement défaut pour trois consultations : celles de 1946, 1950 et 1961 (le recueil publié par les services du Ministères à la Présidence du Conseil et auquel l'on ne peut attacher le caractère d'un dénombrement officiel, donnant pour cette consultation le chiffre de 5.693.000 inscrits). Pour les autres, les données officielles sont les suivantes :

1951

1952

1956
2.224 .246

2.123.150

4.507.907
1958

1963

1964
5.119 .148

5.662 .965

5.662 .965 
Le brusque doublement survenu de 1952 à 1956 trouve son origine, pour la plus large part, dans l'inscription des femmes sur les registres électoraux. Celles-ci disposaient depuis 1930 de certains droits électoraux au niveau local (facultés généralisées par la loi n 959 de 1949). C'est la loi nº 2159 de 1952, prise sur la base d'une déclaration interprétative de la nouvelle Constitution qui étend aux femmes le droit jusqu'alors réservé aux hommes de participer aux élections parlementaires. Le temps ayant manqué pour réaliser cette extension dès les élections de 1952, c'est seulement lors de la consultation de 1956 que les femmes dans leur ensemble exerceront ces droits.

Notons au passage que, conformément à ce qui se passe ailleurs, les femmes n'en profiteront pas pour envoyer beaucoup des leurs siéger au Parlement. Le nombre des députés de sexe féminin dans les législatures successives est très faible : 1956, 2 ; 1958, 4 ; 1961, 3 ; 1963, 1 ; 1964, 1. Il n'existe pas d'étude du comportement électoral féminin en Grèce. On sait que l'Église Orthodoxe n'intervient pas dans la politique courante et qu'il n'y a pas dans ce pays de querelle sur les rapports entre l'Église et l'État : dès lors disparaît l'un des facteurs essentiels de la divergence que l'on observe en pays catholique entre suffrage féminin et suffrage masculin.

Considérons maintenant l'augmentation de 611.341 électeurs inscrits intervenue de 1956 à 1958. Les techniciens estiment que cet accroissement manque pour une bonne part de légitimité et que lors de la consultation de 1958 le chiffre officiel des inscrits était sensiblement supé-[p. 68] rieur aux citoyens en droit de s'inscrire. La même observation s'applique aux chiffres de 1963 et 1964 qui, au moment où ces lignes sont écrites, n'ont pas encore fait l'objet d'une publication officielle. Observons que le chiffre des inscrits lors de ces deux élections représente plus de $67 \%$ de la population recensée en mars 1961 (proportion que l'on peut sans risque d'erreur tenir pour excessive).

Si l'on admet que dans l'état actuel de la pyramide démographique en Grèce le pourcentage normal des ayants droits à l'inscription est de l'ordre de $60 \%$ de la population totale, le montant des inscriptions non légitimes atteindrait grosso modo le niveau des 500.000. Une telle situation n'est pas incompatible avec l'existence des lacunes dans les registres dues à l'arbitraire gouvernemental (radiation ou refus d'inscription d'adversaires politiques...). Sur la base de divers exemples, l'on peut admettre que sous le gouvernement Caramanlis la Droite a commis de telles irrégularités (en nombre limité certes, mais de portée morale très fâcheuse).

À la lumière des expériences étrangères, il n’est pas difficile d'envisager les facteurs de gonflement excessif des inscriptions: par exemple le retard dans l'élimination des citoyens décédés ou encore le maintien sur les registres des émigrants. On connaît les abus que de telles situations sont susceptibles de provoquer. N'oublions pas non plus l'existence de doubles inscriptions au nom de certains électeurs. La double inscription peut résulter de deux impulsions différentes : l'une d'intention proprement frauduleuse, c'est-à-dire conçue par l'intéressé pour s'assurer effectivement la possibilité de voter deux fois ; l'autre résultant seulement du désir du 
bénéficiaire de voter dans des conditions plus commodes que celles fixées par la loi. On peut tenir pour certain que la disposition bloquant le domicile électoral là où il se trouvait au $1^{\mathrm{er}}$ janvier 1948 a multiplié les situations de double inscription résultant de la seconde inspiration.

Imaginons en effet le cas des citoyens placés dans une telle position. Il est probable qu'une partie d'entre eux ont accepté de s'imposer un déplacement pour exercer leurs droits électoraux. Mais il est vraisemblable qu'une autre partie n'a pas eu le désir ou les moyens matériels de se conduire de la sorte. Il existait il est vrai une troisième possibilité : celle d'obtenir malgré l'interdiction légale, une inscription électorale au lieu du nouveau domicile (sans que l'ancienne inscription soit pour autant éliminée).

[p. 69] Il semble que lors des élections de 1958 et de 1961 les autorités publiques aient accueilli de telles demandes avec libéralisme dès lors qu'elles émanaient d'électeurs manifestant l'intention de voter en faveur du gouvernement de droite au pouvoir. Encore qu'il soit difficile d'évaluer l'ampleur d'une telle pratique, on ne saurait en contester sérieusement l'existence. L'opposition a fourni trop d'exemples de telles domiciliations électorales, réalisées avec l'aide de la police, parfois même avec le concours de l'armée, pour que l'on puisse éprouver des doutes sur la réalisation de l'opération.

Considérons maintenant le rapport entre le chiffre officiel des inscrits, du moins quand il existe, et le total des électeurs ayant voté. On a la série suivante :

\begin{tabular}{|c|c|c|c|}
\hline & $\begin{array}{c}\text { Nombre } \\
\text { des inscrits }\end{array}$ & $\begin{array}{c}\text { Total des électeurs } \\
\text { ayant voté }\end{array}$ & $\begin{array}{c}\text { Pourcentage } \\
\text { de participation }\end{array}$ \\
\hline 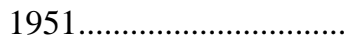 & 2.224 .246 & 1.717 .012 & 77,11 \\
\hline 1952 & 2.123 .150 & 1.600 .172 & 75,36 \\
\hline 1956 & 4.507 .907 & 3.379 .445 & 74,97 \\
\hline 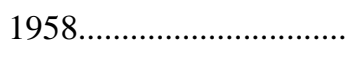 & 5.119 .148 & 3.863 .982 & 75,4 \\
\hline $1963 \ldots \ldots \ldots \ldots \ldots \ldots \ldots \ldots . .$. & 5.662 .965 & 4.708 .851 & 83,15 \\
\hline $1964 \ldots \ldots$ & 5.662 .965 & 4.626 .990 & 81,07 \\
\hline
\end{tabular}

Si l'on considère que la loi fait obligation aux citoyens de voter et que de toute manière, même si les sanctions prévues ne sont pas appliquées, la présentation d'un certificat de vote est nécessaire pour obtenir diverses pièces administratives (ainsi passeport), si l'on admet aussi que les Grecs n'ont pas l'habitude de s'abstenir par principe de la participation électorale, il devient légitime d'avancer que l'ampleur relativement grande de l'abstention tient à la surabondance des inscriptions. Nous avons suggéré que cet état de choses a trois causes principales: le retard dans l'ajustement des inscriptions aux mouvements de l'État-civil (spécialement les décès) ; le maintien sur les listes des émigrants dont le nombre s'est considérablement accru au cours des dernières années ; les entorses à la disposition figeant au $1^{\mathrm{er}}$ janvier 1948 le domicile électoral. 
[p. 70] Si l'on accepte l'idée que l'ampleur de l'abstention est fonction de la surabondance des inscriptions, il paraît légitime d'admettre que cette surabondance est particulièrement grande dans les campagnes. Observons en effet le taux de participation dans les très grandes agglomérations aux élections de 1964 :

\begin{tabular}{lcccc}
\hline & $\begin{array}{c}\text { Nombre } \\
\text { des inscrits }\end{array}$ & & $\begin{array}{c}\text { Total } \\
\text { des votants }\end{array}$ & $\begin{array}{c}\text { Pourcentage de } \\
\text { participation }\end{array}$ \\
\cline { 2 - 2 } $\begin{array}{l}\text { Ensemble de l'agglomération } \\
\text { athénienne }\end{array}$ & 963.549 & & 894.817 & 92,86 \\
Ville de Salonique & 190.772 & & 178.068 & 93,34 \\
\hline
\end{tabular}

Ces chiffres suggèrent que le système des inscriptions électorales est plus proche de la réalité dans les grandes villes que dans les circonscriptions rurales. On peut tenir pour probable que dans un certain nombre de cas, la réalisation d'une nouvelle inscription au lieu de résidence habituel — irrégulière jusqu'en 1963, légitime depuis — ne s'est pas accompagné de la radiation correspondante sur le registre d'origine. C'est le phénomène des doubles inscriptions d'inspiration non frauduleuse.

Ces considérations ne permettent nullement de rejeter l'idée qu'en divers cas l'existence d'une double inscription a pour objectif ou pour conséquence l'émission d'un double suffrage. En vue de prévenir de telles manœuvres, la Gauche, et également le Centre, ont demandé qu'au moment du vote un doigt de chaque électeur soit marqué au moyen d'une matière indélébile (pratique actuellement en vigueur dans certains pays africains où l'on va jusqu'à utiliser à cet effet des crayons au nitrate d'argent). Les autorités responsables n'ont pas retenu cette suggestion en faisant valoir — sans oublier les aspects fâcheux du procédé quant à la respectabilité internationale — que la Grèce ne disposait pas d'un stock de tels produits dont au surplus l'innocuité n'est pas prouvée. Pour le moment, on se borne à combattre les doubles votes au moyen de la perforation des cartes d'identité.

Nous ne disposons d'aucun moyen qui permette d'évaluer, même de manière très approximative, l'ampleur du double vote. Il nous paraît [p. 71] impossible toutefois d'admettre que la totalité des doubles inscriptions ou inscriptions régulières s'accompagne d'un double vote. S'il en allait ainsi, le taux de participation serait, sans nul doute, sensiblement plus élevé que ce n'est le cas. 


\section{VOTE DES MILITAIRES}

Retour à la table des matières

Lors de plusieurs des consultations électorales de la période étudiée, les militaires accomplissant leur temps légal de service ont été autorisés à voter sur des listes dressées au titre de leur unité d'appartenance. Il est à peine besoin de souligner que cette facilité constituait un avantage par rapport à ceux des citoyens obligés de retourner dans leur circonscription d'origine pour voter en vertu du blocage du domicile électoral au $1^{\text {er }}$ janvier 1948. Notons que les mêmes facilités ont été accordées aux fonctionnaires d'État se trouvant en service dans un autre lieu que leur domicile électoral, Encore qu'à divers égards les deux situations soient assimilables, c'est surtout le suffrage des militaires du contingent qui a retenu l'attention et suscité des polémiques.

En ce qui concerne l'affectation de ces votes, deux systèmes ont été employés : l'un consistant à additionner les résultats du vote des militaires aux suffrages émis dans la circonscription de stationnement, l'autre aboutissant à ajouter ces votes aux suffrages de leur circonscription électorale d'origine. Le premier système utilisé en 1961 comporte un danger : celui que les autorités ne tentent de modifier la géographie des opinions par un déplacement ad hoc d'unités militaires. Le second système employé en 1963 et 1964 présente un autre risque : celui que l'envoi des suffrages dans la circonscription d'origine n'ait pour résultat de dévoiler l'appartenance politique des intéressés. Pour neutraliser ce risque, on a mis sur pied un système complexe de centralisation et de redistribution dont l'application a été confiée à la Cour d'Appel d'Athènes.

On peut tenir pour acquis que durant la période examinée, la Droite a bénéficié dans une large mesure du vote des militaires. Cette situation s'explique aisément si l'on observe que, dans l'ensemble, le corps des officiers, ne serait-ce qu'en raison des épurations successives qui l'ont frappé, est d'opinion clairement conservatrice. L'Armée considère que, tant sur le plan externe qu'interne, sa tâche essentielle est de lutter contre le communisme et ses alliés. Or les officiers ont de multiples [p. 72] moyens d'influer sur le vote des soldats placés sous leurs ordres. Les statistiques disponibles à ce propos et dont nous mentionnerons quelques-unes dans le prochain chapitre, établissent que beaucoup de militaires ont suivi les consignes ou suggestions conservatrices de leurs chefs - le risque d'interférence des chefs étant maximal dans le cas où la réglementation électorale prévoit l'aménagement de bureaux de vote spéciaux pour les militaires.

On commettrait certes une sérieuse erreur et une grave injustice en considérant que la Grèce a un quelconque monopole des pratiques analysées ou mentionnées dans ce chapitre. Même si l'on s'en tient aux pays économiquement avancés de démocratie 
représentative, il en est bien peu qui puissent se déclarer totalement indemnes des injustices et irrégularités qui ont caractérisé la situation électorale de la Grèce depuis la fin de la seconde guerre mondiale. Le trait regrettable de la politique grecque n'est donc pas de comporter tel ou tel défaut électoral mais en quelque sorte de les cumuler.

Initialement, les autorités n'étaient pas sans excuses, la désorganisation entraînée par dix ans de guerre étrangère et civile ne pouvant manquer d'entraîner de nombreux désordres dans les opérations électorales. Par la suite cependant, les efforts de remise en état ou plus simplement de mise en ordre n'ont pas été poursuivis avec assez de vigueur. Sur plusieurs points au contraire, la situation est allée s'aggravant, les conditions dans lesquelles s'est déroulée la consultation de 1961 ne pouvant manquer de laisser à l'observateur une impression vraiment pénible.

On 'a proposé divers remèdes pour supprimer ou réduire les imperfections les plus voyantes : ainsi l'établissement du partage des députés entre les circonscriptions non plus d'après le nombre de citoyens mais en fonction de la population électorale, c'està-dire de la répartition effective des inscriptions électorales. Mais à supposer qu'un tel système soit compatible avec la norme constitutionnelle, son utilisation se heurterait aux défectuosités et irrégularités du système des inscriptions électorales. Il semble bien que la réfection de ce système, sous réserve qu'elle soit entreprise de manière à rapprocher autant que possible la [p. 73] liste des citoyens ayant juridiquement droit à être inscrits de la liste des citoyens effectivement inscrits, constitue l'étape initiale de tout effort d'amélioration de la situation.

L'emploi de machines électroniques est certes susceptible de faciliter une semblable tâche. Pourtant n'oublions pas qu'en définitive, la vigilance des citoyens constitue un facteur irremplaçable de la régularité électorale. 
[p. 74]

\section{CHAPITRE II}

\section{ANALYSE DES RÉSULTATS ÉLECTORAUX}

Retour à la table des matières

L’OBJET de ce chapitre est d'examiner les étapes et les modalités de l'évolution des partis à travers les consultations électorales de l'époque. Bien que l'exposé mentionne divers événements et problèmes, il ne représente en aucune manière une histoire politique de la période retenue. Seules nous intéressent pour le moment les transformations apparentes ayant affecté le système des partis.

Ce système se caractérise, spécialement durant les premières années, par une multitude de partis dont il n'est pas toujours facile de préciser l'orientation. La question se pose spécialement pour les partis étroitement liés à des personnes et qui, comme tels, ont reflété les variations ou fluctuations tactiques de leur leader. Pour le classement de ces situations, nous avons choisi un critère simple et relativement sûr : la prise en considération de la totalité d'une carrière ou d'un itinéraire et non d'un moment ou aspect particulier de celle-ci.

Soit le cas de l'actuel Premier Ministre G. Papandréou. Nous avons invariablement rattaché au Centre ses démarches et activités. Or certains estiment que, pendant toute une période, il a pris des attitudes relevant plutôt du Centre Droit : ainsi, en particulier, son refus de revenir au Parti Libéral lors des élections de 1950 et, un peu plus tard, ses relations avec le Rassemblement Hellénique du Maréchal Papagos. Ces indices ne sont pas dépourvus de signification mais on aurait tort de leur attribuer une importance décisive. Tout politicien grec ayant de l'ambition tente de se présenter en tant que chef de parti et, ne pouvant être alors leader du Parti Libéral, Papandréou était conduit à garder sa propre formation. Quant à sa « coopération» avec le Rassemblement Hellénique, elle traduisait simplement le souci de retrouver le [p. 75] siège parlementaire perdu aux élections de 1951. Il s'agit davantage d'opportunisme personnel que de fluctuation idéologique. Plus tard, C. Papandréou mènera un combat très violent contre l'ERE et, sur la base de ses actes les plus importants (y compris sa collaboration avec E. Vénizélos) il paraît légitime de 
voir en lui un homme du Centre (que des nécessités tactiques ont pu pousser à des accommodements provisoires avec la Droite).

Raisonnant de la même manière, nous avons choisi de classer invariablement le Parti Progressiste parmi les forces de Droite (avec une nuance « jeune droite » ou « droite moderne »), sans oublier cependant que S. Markézinis a parfois contracté des alliances avec le Centre et passe même pour avoir eu à une époque quelques contacts avec l'EDA.

L'analyse des résultats électoraux sera effectuée selon l'ordre chronologique des consultations. Afin d'alléger les développements, nous avons rassemblé dans un appendice statistique les chiffres de base relatifs à chacune d'entre elles.

\section{PRÉPARATION DU RETOUR AU RÉGIME PARLEMENTAIRE}

$\underline{\text { Retour à la table des matières }}$

Quand ont lieu les premières élections de cet après-guerre (mars 1946) le pays a perdu depuis une dizaine d'années l'habitude de vivre sous un régime parlementaire. On peut diviser cette période en trois phases : une phase de régime autoritaire qui commence avec l'établissement de la Dictature Métaxas (août 1936) et dure jusqu'à l'invasion du pays par l'année allemande (avril 1941), le général étant lui-même décédé le 19 janvier 1941 ; une phase d'occupation militaire qui prend fin avec le départ des troupes allemandes (octobre 1944) ; une phase de transition durant laquelle le pays est sous l'autorité de gouvernements provisoires. Le retour à une vie politique démocratique qui de toute manière, aurait été rendue difficile par ce long intervalle extraparlementaire se trouve compromis par les troubles et luttes dont le déclenchement suit de manière quasi immédiate le rétablissement de la souveraineté nationale. Ces événements ayant exercé une profonde influence sur le fonctionnement ultérieur du système des partis, il est nécessaire d'en donner une brève évaluation.

[p. 76] Pour notre propos, le fait central est l'insurrection proclamée à Athènes en décembre 1944 par le Front National de Libération (EAM) qui constituait sous l'occupation la plus puissante des organisations de résistance et qui, à la Libération, contrôle la plus large part du territoire. En août 1944, des représentants de l'EAM sont entrés dans le gouvernement qui fonctionne toujours à l'étranger. Le mobile du soulèvement est le refus par le Front de désarmer immédiatement ses troupes conformément à l'ordre donné par le commandement britannique. Durant plus d'un mois, un sanglant conflit qui dégénère parfois en actes de terrorisme et prises d'otages par les insurgés, se déroule dans la ville: cependant les forces sous direction britannique, dont le nombre sera progressivement augmenté, réduisent peu à peu les insurgés. Finalement l'accord de Varkiza (12 février 1945) met fin, de manière d’ailleurs précaire, à ce premier conflit. 
Cet événement a, bien entendu, fait l'objet d'évaluations divergentes. Les uns interprètent l'ordre de désarmement des troupes de l'EAM rassemblées dans l'Armée Nationale Grecque de Libération (ELAS) comme un effort de la Grande-Bretagne pour renforcer sa position internationale et imposer le retour de la monarchie contre la volonté du peuple. Les autres voient dans le soulèvement de l'EAM une tentative pour instaurer un gouvernement dominé ou orienté par les communistes : intervenant à titre préventif, la décision britannique aurait eu simplement pour effet de contraindre les partisans d'une telle opération à dévoiler leurs batteries.

Cette seconde interprétation comporte d'ailleurs deux variantes. Selon les uns, l'insurrection aurait été décidée par le Parti Communiste de son propre chef et sans consultation des autorités soviétiques: il se serait agi d'une manifestation d'autonomie, sinon d'indiscipline à l'égard de l'URSS. Pour d'autres, au contraire, l'Union Soviétique aurait approuvé la rébellion, si, même elle ne l'a pas directement suscitée. Dans son ouvrage sur le rôle des grandes puissances vis-à-vis de la Grèce, S. C. Xydis nous dit qu'après avoir adopté la première version, il s'est rangé à la seconde (notamment sur la base d'une meilleure compréhension du « Code opérationnel » du Politburo soviétique ${ }^{1}$ ).

La première interprétation, qui met en cause le soutien systématique accordé à la Droite monarchique par Churchill, bénéficia à l'époque [p. 77] d'une large audience dans les pays alliés, le gouvernement américain lui-même adoptant, au début du conflit, une position de neutralité. Il faut convenir, la suite l'établira sans équivoque, que les partisans de la restauration monarchique n'avaient qu'un souci fort relatif des garanties démocratiques. Cependant l'histoire, désormais bien connue, de l'établissement d'un pouvoir communiste dans les pays voisins - occupation progressive des centres gouvernementaux sous le couvert de rassemblements d'inspiration anti-fasciste — donne a posteriori quelque poids à la seconde interprétation.

La principale objection faite à cette dernière thèse est la faiblesse de la proportion des communistes parmi les membres de l'ELAS. Cette situation n'a rien de surprenant si l'on considère la médiocrité de l'implantation du communisme avant l'installation de la Dictature Métaxas qui lui portera de nouveaux coups (environ 6\% des suffrages et 16 sièges aux élections de janvier 1936). Par ailleurs, l'EAM dont dépendait l'ELAS n'était pas constitué du seul parti communiste mais d'une coalition de partis et de formations, d'ailleurs d'importance numérique mineure, qu'unissaient le souci de lutter contre les occupants et la volonté de réaliser des réformes sociales. Pourtant, il n'est pas contestable que les communistes tenaient une place prépondérante dans la direction de l'EAM (l'une des raisons de cette supériorité étant l'absence d'une tradition ouvrière socialiste).

Bien que nous n'ayons pas toutes les pièces du dossier - et peut-être n'auronsnous jamais l'intégralité de celui-ci — il est désormais possible de présenter quelques observations relativement sûres. Ainsi, malgré toutes les spéculations de la

Op. cit., pp. 528-529. 
«Kremlinologie » sur le code opérationnel du Politbureau, il est pour le moins douteux que l'URSS porte une responsabilité dans le déclenchement de la rébellion. Staline, fidèle au marché conclu avec Churchill, considère apparemment à cette époque que la Grèce est une "affaire britannique »; il laisse en conséquence les mains libres à la Grande-Bretagne dans l'espoir que les puissances anglo-saxonnes adopteront la même position à l'égard des territoires qu'il contrôle. Durant le soulèvement, le poste de Radio-Moscou lui-même demeure très prudent et modéré dans son évaluation de l'action britannique, se bornant à mentionner les très vives critiques que cette action suscite en Grande-Bretagne.

L'hypothèse d'un soulèvement voulu et organisé par l'EAM ne résiste guère finalement à l'analyse. Contrairement à Tito, les chefs de l'EAM [p. 78] ont accepté le débarquement de troupes britanniques - troupes si peu nombreuses au départ qu'il eut été très aisé de les rejeter à la mer. Alors qu'il se trouvait en position de force, le Front s'est prêté à des négociations sur le niveau respectif du désarmement des divers éléments en présence - négociations dans lesquelles le Premier Ministre de l'époque, C. Papandréou, ne semble pas avoir montré beaucoup de résolution propre. Au moment où éclate la crise, l'ELAS se trouve dans un état d'impréparation et de confusion: la démobilisation des forces de l'Armée populaire a commencé et à l'intérieur d'Athènes l'État-Major ne dispose que d'une quantité limitée d'hommes sous les armes. Loin que le soulèvement ait répondu à un plan concerté, il est possible que les dirigeants de l'EAM — dont les représentants au gouvernement avaient admis le principe du désarmement de l'ELAS - aient eu, au départ, la main forcée par une révolte de la base.

La décision britannique de désarmer les forces de gauche de la Résistance avait un fondement strictement politique : elle traduisait une préférence sans équivoque pour la restauration de l'ordre ancien et la remise du pouvoir aux anciens leaders politiques, le retour de Georges II en Grèce étant en quelque sorte l'élément-clé de ce programme et la garantie de son exécution. Que la direction de l'EAM ait eu d'autres plans pour la reconstruction de la vie nationale, personne ne le conteste certes. Et dès lors le refus d'obéir de l'EAM constituait la riposte à une décision qui entendait, avant toute consultation du peuple, préjuger le destin national: bien des éléments d'information portent à croire qu'elle s'accompagna de provocations.

Nous savons aujourd'hui que, conformément à la politique dite des sphères d'influence, la ligne de partage entre les armées alliées a finalement constitué, de manière durable, le principe de distribution des régimes politiques. Dès le début, la Grèce a dû payer un prix élevé pour connaître cette vérité devenue banale (le coût de l'insurrection en vies humaines ayant été de 11.000 dont 6.000 non combattants).

On peut penser que les choses auraient pris une tournure différente si la GrandeBretagne avait initialement accepté de faire un effort militaire correspondant aux responsabilités assumées. L'EAM aurait peut-être hésité à s'opposer à une puissante force armée et, de toute manière, la réduction d'une éventuelle révolte aurait été plus rapide. Il est possible que Churchill ait péché par sous-estimation de la puissance des éléments de gauche, la faiblesse du dispositif britannique conduisant [p. 79] l'EAM à 
mettre en doute la volonté et la capacité des Britanniques d'exécuter rigoureusement leur politique. Des diverses critiques que l'on peut adresser à l'action de la GrandeBretagne en Grèce, la volonté d'agir au moindre coût n'est certes pas la moins grave.

L'accord de Varkiza dont l'une des dispositions reconnaissait la légalité de l'EAM et du Parti Communiste en tant qu'organisations politiques n'aurait pu en tout cas fonctionner correctement que si les gouvernants de l'époque avaient été en mesure de préparer une consultation loyale du pays sur le sens de ses institutions. Admettons que le soulèvement de décembre rendait de toute manière difficile l'instauration d'un tel climat. De plus, que ce soit par impuissance ou connivence, les autorités laissèrent le champ libre aux organisations d'extrême-droite qui, surtout dans les campagnes, se livrèrent à de nombreux excès qualifiés de «terreur blanche " par les partisans de l'EAM. Le point a été attesté par des hommes politiques n'appartenant pas aux formations de Gauche. Mentionnons à ce propos une note en date du 5 juin 1945 signée par plusieurs chefs politiques du Centre (Sophoulis, Cafandaris, Plastiras... : cette note souligne l'amplification dans tout le pays de la terreur instaurée par les organisations d'extrême-droite (dont certaines avaient collaboré avec les Allemands ${ }^{1}$ ).

Dans l'incapacité d'obtenir un redressement de la situation, les partis de l'EAM et une fraction de la vieille garde vénizéliste (en particulier le groupe Cafandaris) décidèrent de manifester ouvertement leur opposition en s'abstenant de participer aux élections de mars 1946. C’était là, dès le début, un coup sérieux porté au rétablissement de la légalité démocratique.

Interprétée avec le recul du temps, cette décision dont on trouve de nombreux précédents dans la tradition parlementaire grecque peut être tenue pour malheureuse. Certes les circonstances de l'époque n'étaient nullement propices à la libre expression d'une volonté démocratique mais l'expérience montre qu'un tel refus de participation a souvent pour effet de nuire à la cause défendue. Cette abstention est un aspect de la politique du pire qui culminera avec le déclenchement ultérieur de la guerre civile dont les conséquences pèsent toujours sur la vie politique grecque.

SVORONOS (N.), op. cit., p. 120. 
[p. 80]

\section{II. ÉLECTIONS DU 31 MARS 1946}

$\underline{\text { Retour à la table des matières }}$

Le tableau officiel des statistiques relatif à ces élections reste muet sur le chiffre des inscrits. Seul nous est donné le nombre des électeurs ayant voté soit 1.121.696 : déduction faite de 13.223 bulletins nuls, le montant des suffrages exprimés s'élève à 1.108.473. Les sièges ayant été répartis sur la base d'une population de jure de 7.232.543, on doit admettre, sans oublier toutefois le caractère encore masculin du suffrage, que le total effectif des électeurs est très inférieur au nombre des citoyens ayant juridiquement le droit de vote. Ignorant le chiffre des inscrits, du moins n'en ayant pas d'estimation officielle, nous ne pouvons décider si cet écart résulte des lacunes du registre électoral (électeurs ne pouvant pas voter) ou d'une abstention volontaire de la Gauche (électeurs inscrits mais refusant de participer). Les deux phénomènes ont probablement joué dans des proportions que nous ne pouvons établir.

Ces élections avaient été placées sous le contrôle d'une Commission internationale d'observateurs dont la plupart ignoraient tout de la Grèce et de la langue hellénique. Celle-ci déclara que la consultation s'était effectuée dans des conditions loyales et fixa à 15\% des électeurs inscrits le taux d'abstention (pourcentage très inférieur à celui avancé par la Gauche et certainement au-dessous de la réalité). Compte tenu de la composition et des modalités de fonctionnement de la Commission, il serait très naïf de voir dans la délivrance de ce certificat de bonne conduite démocratique autre chose qu'une démarche tendant à renforcer la position internationale d'un gouvernement entièrement acquis aux puissances anglo-saxonnes.

Quoi qu'il en soit des très sérieuses réserves qu'appelle cette consultation, observons que les vieux adversaires de l'avant-guerre sont toujours présents mais dans des conditions certes bien différentes. Tandis que le Parti Populiste, champion de la cause monarchique, se présente comme le pivot d'une coalition des nationalistes, l'ancien Parti Libéral est divisé en six tronçons : Parti Libéral National (S. Gonatas) et Parti Réformiste (A. Alexandris) qui collaborent avec la droite; Parti Libéral Vénizéliste (S. Vénizélos fils cadet d’E. Vénizélos) et Parti Démocratique-Socialiste (G. Papandréou) qui participent à une coalition dite Union Politique Nationale ; Parti Libéral (Th. Sophoulis) qui se présente seul ; un groupe de Vénizélistes réuni autour de M. Cafandaris qui s'abstient de prendre part aux élections.

[p. 81] Comme on pouvait aisément le prévoir dans un tel climat, la Coalition des Nationalistes vient en tête remportant 206 sièges sur les 354 en contestation : le Parti Populiste arrive le premier avec 156 sièges mais sans obtenir à lui seul la majorité absolue. La coalition dite Union Politique Nationale vient ensuite avec 68 sièges. Le Parti Libéral et le Parti National de Grèce qui se présentaient seuls n'ont respectivement que 48 et 20 mandats. Les autres sièges sont ainsi répartis : 9 au Parti des Nationalistes qui figurait dans la coalition dite Union des Nationalistes, 1 au Parti 
Agraire de Grèce qui se trouvait dans la coalition dite de l'Union des Partis Agraires et 2 à des listes d'indépendants.

Le mode de scrutin adopté pour cette consultation comportait trois répartitions. Conditions de participation à la deuxième répartition : 1 siège ou $10 \%$ des voix dans la circonscription majeure. Pour la troisième : le dixième du total des voix dans tout l’État ou le douzième du total des sièges lors des deux premières répartitions.

Voici pour chacune des formations ayant obtenu des sièges le nombre acquis à chacune des répartitions :

\begin{tabular}{|c|c|c|c|c|}
\hline & $1^{\mathrm{re}}$ & $2^{\mathrm{e}}$ & $3^{e}$ & Total \\
\hline Coalition des Nationalistes.......... & 192 & 12 & 2 & 206 \\
\hline Union Politique Nationale............ & 57 & 11 & - & 68 \\
\hline 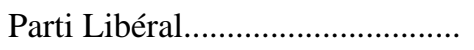 & 42 & 6 & - & 48 \\
\hline Parti National de Grèce................. & 17 & 3 & - & 20 \\
\hline Union des Nationalistes................. & 8 & 1 & - & 9 \\
\hline Union des Partis Agraires.............. & 1 & - & - & 1 \\
\hline \multirow[t]{2}{*}{ Liste d'Indépendants........................... } & 2 & - & - & 2 \\
\hline & 319 & 33 & 2 & 354 \\
\hline
\end{tabular}

Comparons maintenant le Pourcentage des voix et des sièges obtenus par les formations en présence :

[p. 82]

\begin{tabular}{|c|c|c|c|c|}
\hline & \multicolumn{2}{|c|}{ Pourcentages } & \multicolumn{2}{|c|}{$\begin{array}{l}\text { Différences entre } \\
\text { le \% sièges-voix }\end{array}$} \\
\hline & Sièges & Voix & En + & En - \\
\hline Coalition des Nationalistes....... & 58,19 & 55,12 & 3,07 & - \\
\hline Union Politique Nationale........ & 19,21 & 19,28 & - & 0,07 \\
\hline 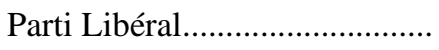 & 13,55 & 14,39 & - & 0,84 \\
\hline Parti National de Grèce............. & 5,65 & 5,96 & - & 0,31 \\
\hline Union des Nationalistes............. & 2,55 & 2,94 & - & 0,39 \\
\hline Union des Partis Agraires......... & 0,28 & 0,67 & - & 0,39 \\
\hline Listes d'Indépendants................. & 0,57 & 1,08 & - & 0,51 \\
\hline \multirow[t]{2}{*}{$\begin{array}{l}\text { Éléments non représentés } \\
\quad \text { au Parlement.......................... }\end{array}$} & 0,00 & 0,56 & - & 0,56 \\
\hline & 100,00 & 100,00 & 3,07 & 3,07 \\
\hline
\end{tabular}

Ce tableau montre que le régime électoral de 1946 a produit des résultats que l'on peut sans hésiter qualifier de proportionnels. Les partisans d'une telle équité dans la distribution des sièges seront ainsi portés à émettre un jugement favorable sur le mécanisme utilisé en cette occasion mais ce point ne doit pas faire oublier que les 
résultats acquis par la Coalition des Nationalistes, soit plus que la majorité absolue, l’ont été avec seulement 610.995 suffrages pour une population de plus 7.000.000.

Compte tenu du refus de participation de la Gauche, seules les tendances de Droite et du Centre sont représentées à la Chambre. En principe, il devrait être relativement aisé d'apprécier la force parlementaire respective de chacune de ces tendances sur la base des préférences idéologiques manifestées par les formations en cause ou, plus exactement peut-être par les chefs qui les dirigent. Cependant il n'en va pas totalement ainsi, la position de certains de ces partis étant affectée de quelque ambiguïté ${ }^{1}$.

Entrent indiscutablement dans la Droite le Parti Populiste et le Parti des Nationalistes. Quatre autres partis peuvent être rattachés au Centre [p. 83] (Parti Libéral, Parti Libéral-Vénizéliste, Parti Démocratique Socialiste et Parti Agraire de Grèce). En revanche, les hésitations sont permises pour les autres partis.

Le Parti Libéral National et le Parti Réformiste ont fait campagne aux côtés du Parti Populiste dans le cadre de la coalition des nationalistes : mais leurs chefs sont d'anciens libéraux qui ont peut-être gardé, des sympathies pour leur formation d'origine. Le chef du Parti National Unioniste, P. Canellopoulos, a commencé sa carrière par l'affirmation de préférences républicaines et il participe aux élections de 1946 dans le cadre d’une coalition d'inspiration libérale : mais, après avoir fait volteface sur la question dynastique, il prendra place dans la droite. Quant au Parti National de Grèce, son chef $\mathrm{N}$. Zérvas, de provenance vénizéliste, $\mathrm{a}$, sous l'occupation, dirigé l'Armée Grecque Démocratique Nationale (EDES) d'inspiration opposée à celle de l’EAM mais néanmoins d'ambition franchement républicaine. Militaire de carrière, il passe du fait de sa position vis-à-vis de l'ELAS, pour un homme de droite.

En réalité, il est résolument opposé à la Monarchie et lors des élections de 1951, il sera candidat sur les listes du Parti Libéral.

Sur ces bases, il paraît expédient de classer dans la Droite le Parti National Unioniste. Quant aux trois autres partis en cause (Parti Réformiste, Parti National de Grèce, Parti Libéral-National) il semble préférable de les ranger dans une rubrique de Centre-Droit - le Parti National de Grèce dont le chef est centriste nous paraissant relever de cette catégorie par suite de la nature de sa clientèle.

Compte tenu de cette distribution qui, nous l'admettons, peut susciter quelques réserves ou réticences, la force de la Droite dans l'Assemblée de 1946 s'élève à 51,6\%, celle du Centre-Droit atteignant 16,9\%. Encore que de telles controverses n'aient pas une importance considérable, soulignons que d'autres commentateurs, raisonnant selon des critères un peu différents, fixent à 60\% la force de la Droite.

Quelques mois plus tard, le $1^{\text {er }}$ septembre 1946, se tient le plébiscite relatif au retour de Georges II sur le trône de Grèce. En réalité, le problème du régime était

L’évolution de la force parlementaire des diverses tendances est donnée élection par élection dans l'annexe I. 
posé depuis longtemps, la Gauche et plusieurs milieux d'inspiration centriste étant alors hostiles à ce retour, ne serait-ce qu'en raison de la collusion manifeste de la Monarchie avec la Dictature Métaxas. Les Populistes eux-mêmes, qui reprochent au roi de les avoir tenus à l'écart sous la Dictature Métaxas, signent dans leur majorité la pétition revendiquant un référendum sur le régime (C. Tsaldaris [p. 84] figurant toutefois parmi les non-signataires). Après la Conférence du Liban (mai 1944) durant laquelle tous les partis décident de renvoyer au peuple la question du régime, Georges II devra finalement accepter que son retour fasse l'objet d'un plébiscite (point expressément mentionné dans l'accord de Varkiza). Rappelons qu'à l'époque le gouvernement américain était peu favorable à cette restauration. Voici les résultats de la consultation du $1^{\text {er }}$ septembre ${ }^{1}$.

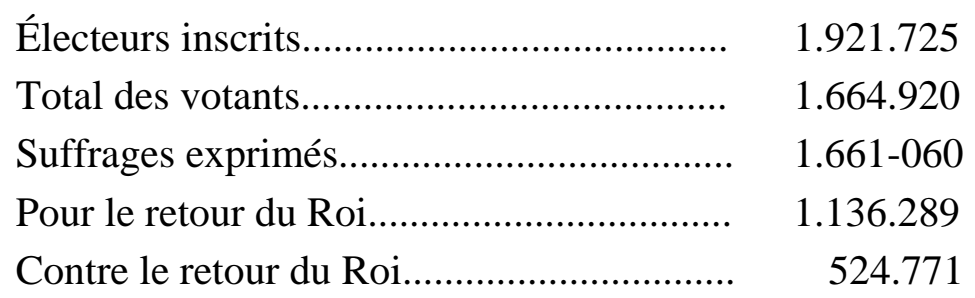

Notons que les autorités avaient effectué une révision des registres électoraux avec le concours d'observateurs américains et britanniques. Quelques-uns de ceux-ci étaient présents le jour du vote mais à titre simplement officieux. Aucun rapport international ne fut établi cette fois sur la validité de l’opération.

Nous reviendrons plus tard sur les mobiles ayant pu inciter un peu plus de 68\% des votants - soit un peu moins de $60 \%$ des inscrits - à se prononcer en faveur de la Monarchie. Disons tout de suite que l'assimilation du retour du monarque à la lutte contre le communisme et au maintien de l'amitié britannique a, sans doute, lourdement pesé sur le scrutin. En dépit du succès ainsi remporté par la dynastie, à laquelle se sont ralliées finalement plusieurs des politiciens républicains de l'entre deux guerres, il reste que plus de $30 \%$ des votants ont pris position contre l'institution monarchique dans un climat rendant cette attitude difficile. On peut admettre qu'une telle opposition est trop nombreuse pour que la Couronne puisse alors se présenter ou être présentée comme un facteur d'unité nationale.

L'événement capital de cette période est le déclenchement de la guerre civile par le Parti Communiste qui, cette fois, ne sera pas suivi par ses anciens alliés de l'EAM mais bénéficiera d'un soutien ouvert du bloc soviétique. La rébellion déjà diffuse prend une consistance nouvelle en [p. 85] octobre 1946 avec la création dans les montagnes de l'Armée Démocratique de la Grèce et c'est seulement à l'automne 1949 que les troupes nationales, sous le commandement du Maréchal Al. Papagos

1 D'après la brochure du Ministère de l'Économie Nationale, Statistiques du Plébiscite du $1^{\text {er }}$ septembre 1946, Athènes, 1947. 
parviendront à la réduire définitivement, l'un des facteurs de la défaite communiste étant la fermeture par Tito de la frontière gréco-yougoslave après sa rupture avec Moscou. L'un des premiers effets du conflit sera de faire passer la Grèce dans la sphère d'influence américaine (voir la déclaration Truman en date du 12 mars 1947), la Grande-Bretagne, qui avait une telle part de responsabilité dans la situation, se déclarant hors d'état de continuer à assumer son programme d'aide.

On ne peut évidemment manquer de s'interroger sur les mobiles d'une telle rébellion à laquelle le partage du monde en deux camps hostiles, qui était alors en train de s’accomplir, ne laissait pas, dès le départ, beaucoup de chances de succès. Cette fois la rébellion coïncide parfaitement avec les intérêts de la politique soviétique qui se servira de la « question grecque », notamment à l'ONU, en guise de réponse aux attaques menées contre sa présence en Europe Orientale par les puissances du bloc occidental. Sans contester la responsabilité directe du Parti Communiste grec et du bloc soviétique dans la naissance et le développement du conflit, observons que les événements auraient peut-être pris une tournure différente si la Droite, au lieu de témoigner d'un esprit de revanche et d'instituer un climat de persécution larvée de ses adversaires, s'était appliquée à respecter les règles du régime représentatif. Même s'il tient le soulèvement pour une erreur et une faute de gravité exceptionnelle, le commentateur ne peut pour autant oublier que la Grèce de cette époque n'offrait pas aux adversaires du pouvoir, spécialement dans les campagnes, les garanties démocratiques traditionnelles.

Aujourd'hui, plusieurs éléments du Parti Communiste grec ou liés à celui-ci n’hésitent pas à critiquer ouvertement l'action des chefs communistes d'alors. Ainsi Z Zographos dénonce-t-il « les effets négatifs de la politique sectaire et gauchiste de Zachariadis » ${ }^{1}$. Que l'opportunisme khrouchtchévien ait succédé à la rigidité stalinienne, ce changement ne saurait permettre d'annuler rétrospectivement le cours de l'histoire. Or la guerre civile, sans oublier son coût en vies humaines et en ressources matérielles, a compromis de manière durable l'établissement [p. 86] d'une pratique démocratique en Grèce. Actuellement, bien que le temps ait fait son œuvre, les conséquences sur la vie politique et la position internationale du pays n'en sont nullement épuisées.

Sous la législature 1946-1950, le principal souci des dirigeants grecs qui agissent avec l'aide des États-Unis et sous leur étroite supervision sera de détruire la rébellion. Aucun parti ne disposant à la Chambre de la majorité absolue, la formation du gouvernement ne pourra résulter que d'une coalition de partis. Voici la liste des gouvernements qui vont se succéder durant ces quatre années :

In Nouvelle Revue Internationale, octobre 1963 (article pp. 68-84). 


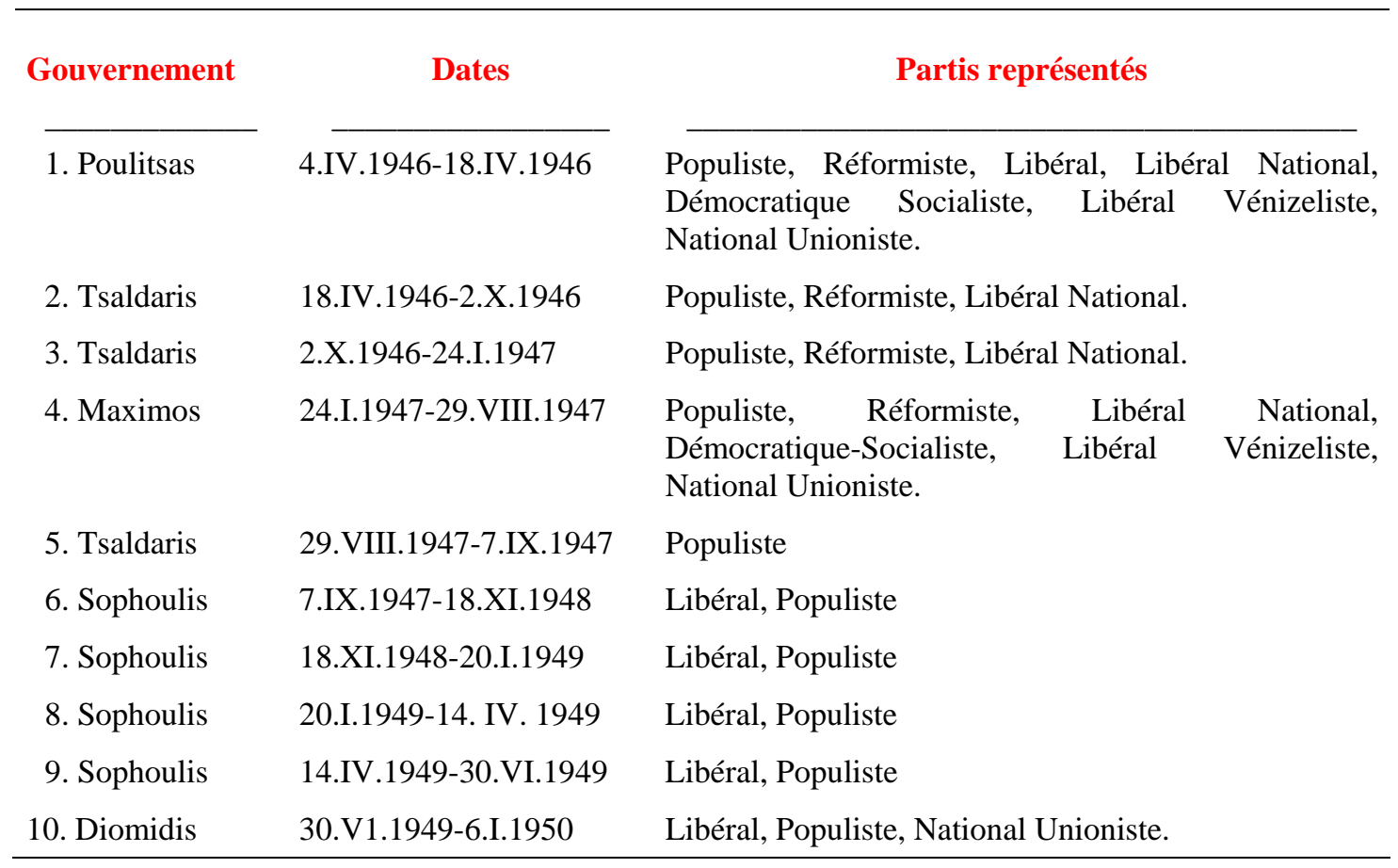

C'est sous les quatre gouvernements Sophoulis (septembre 1947 - juin 1949) que sera accompli l'effort maximum contre la rébellion. Ils constituent une manière d'union nationale dans la mesure où ils rassemblent la Droite et le Centre dans une action commune.

[p. 87] Ce défilé de gouvernements, dont plusieurs se succèdent sans modification dans la majorité parlementaire, a quelque chose de déconcertant. Dès le début, les puissances protectrices insisteront auprès des dirigeants politiques sur la nécessité de donner au Cabinet une assise parlementaire aussi large que possible. Cependant il faut attendre plus d'un an pour que se forme sous la présidence du vieux chef libéral Th. Sophoulis une coalition entre les grands adversaires populistes et libéraux coalition dans laquelle les libéraux assument la charge des ministères traitant de la Défense nationale et du maintien de l'ordre public.

En un sens, cette association - réserve faite de la proposition faite à Georges II lors de rétablissement de la Dictature Métaxas - constitue la première manifestation ouverte d'un affaiblissement du schisme né en 1915 à propos de la conduite à tenir vis-à-vis des belligérants. Il est vrai que l'entente ainsi acquise sous l'effet, ne l'oublions pas, d'une pression américaine croissante, ne survivra pas aux circonstances qui en avait facilité, plus exactement peut-être imposé, la survenance.

En janvier 1950, la Chambre est dissoute et la date des nouvelles élections est fixée au 5 mars. Le gouvernement Diomidis démissionne et un gouvernement de service est constitué sous la présidence de J. Théotokis pour organiser la consultation et assurer la gestion des affaires courantes. 


\section{III. ÉLECTIONS DU 5 MARS 1950}

Retour à la table des matières

En augmentation sensible sur 1946 le nombre des votants s'élève à 1.696.146. Compte tenu de 7.233 bulletins nuls, le chiffre des suffrages exprimés est de 1.688.923. Une fois encore le nombre des inscrits ne fait pas l'objet d'une statistique officielle.

Ces élections s'effectuent selon le même mode de scrutin que les précédentes, la seule transformation notable étant la réduction du nombre des sièges (250 au lieu de 354). On note par contre d'assez importants changements dans les forces en présence et, en particulier, l'apparition de deux forces nouvelles: l'Union Nationale Progressiste du Centre et le Front Démocratique.

La première de ces formations a pour leader le général N. Plastiras. Celui-ci a un long passé de républicanisme. En octobre 1922, alors colonel, il préside le Comité Révolutionnaire qui impose l'abdication au [p. 88] Roi Constantin et qui va gouverner le pays jusqu'aux élections du 16 décembre 1923. En mars 1933, il tente un coup d'État contre le Parti Populiste et, après l'échec de l'opération, il se réfugie en France d'où il reviendra en décembre 1944 pour présider le gouvernement signataire de l'accord de Varkiza. En 1950 enfin, le général Plastiras dont les tendances politiques sont de centre-gauche crée, avec la participation de nombreux résistants de l'EAM, le Parti Libéral Progressiste du Centre qui participe aux élections en collaboration avec le Parti Démocratique Progressiste sous le nom d’Union Nationale Progressiste dénomination qui deviendra par la suite celle du propre parti du général Plastiras.

Bien que par de nombreux aspects le programme du général Plastiras relève du centre-gauche, il nous a paru préférable, vu la nature de sa clientèle ordinaire, de classer son parti dans les formations du Centre (notamment dans l'Annexe I qui récapitule la force parlementaire des diverses tendances). Observons au surplus que les circonstances ne permettront pas au général de mettre véritablement ses idées en œuvre.

La création du Front Démocratique représente le premier effort accompli pour réintroduire la Gauche dans la vie parlementaire. Le Front se compose de plusieurs partis: Union des Démocrates de Gauche de J. Sophianopoulos Parti Socialiste Union de la Démocratie Populaire du professeur Svolos; Parti des Libéraux de Gauche du général Grigoriadis. Il bénéficie aussi du concours de plusieurs personnalités indépendantes de la gauche modérée et du centre gauche. L'objectif de l’opération est de rassembler les éléments de la gauche qui n'ont pas voulu s'associer à la politique aventureuse de guerre civile du parti communiste, celui-ci ayant d'ailleurs été interdit dès 1947 (loi 509/1947).

À l'occasion de cette consultation, les vieux adversaires (Parti Populiste et Parti Libéral) sont toujours aux prises. Cette fois le premier de ceux-ci se présente seul. 
D'autre part, la Droite traditionnelle doit faire face à la concurrence d'une Droite qui se veut plus moderne. Les principaux éléments de celle-ci sont le Parti National Unioniste de P. Canellopoulos et le Nouveau Parti fondé par S. Markézinis qui a abandonné à cet effet le Parti populiste. Quant au Parti Libéral, il tend à refaire son unité par ré-intégration du Parti Libéral National et du Parti Libéral Vénizéliste : toutefois G. Papandréou reste hors du mouvement (le Parti Démocratique Socialiste prenant le nom de Parti de G. Papandréou).

[p. 89] Les élections de 1950 sont disputées par un nombre considérable de partis : 44 en tout dont 25 rassemblés en 9 coalitions et 20 intervenant à titre isolé (l'un d'eux agissant seul ou coalisé selon les circonscriptions). On en trouvera la liste complète dans l'appendice statistique, liste faisant ressortir l'insignifiance totale d'un bon nombre de ces formations (les dix-sept partis qui viennent en queue de liste n'ayant obtenu sur tout le territoire que 2.242 suffrages). En réalité, 10 partis seulement reçoivent des sièges dont 5 intervenant à titre isolé et 5 autres participant à une coalition. Voici le nombre de sièges acquis par ces formations lors des diverses répartitions.

\begin{tabular}{|c|c|c|c|c|}
\hline & $1^{\mathrm{re}}$ & $2^{e}$ & $3^{e}$ & Total \\
\hline 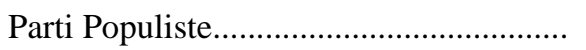 & 35 & 21 & 6 & 62 \\
\hline 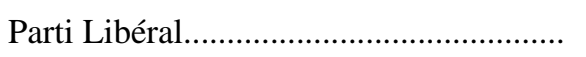 & 30 & 22 & 4 & 56 \\
\hline Union Nationale Progressiste du Centre & 29 & 12 & 4 & 45 \\
\hline Parti de G. Papandréou................................... & 12 & 21 & 2 & 35 \\
\hline 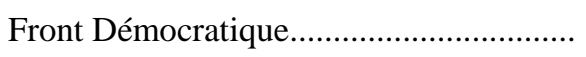 & 11 & 7 & - & 18 \\
\hline Front Politique Indépendant.......................... & 9 & 7 & - & 16 \\
\hline Front de Reconstitution Nationale............ & 3 & 4 & - & 7 \\
\hline 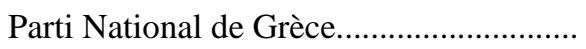 & 4 & 3 & - & 7 \\
\hline Front des Agriculteurs et Travailleurs..... & 1 & 2 & - & 3 \\
\hline \multirow[t]{2}{*}{ 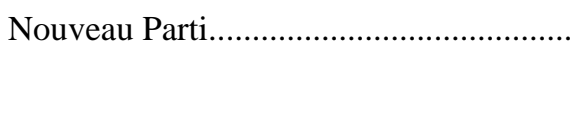 } & 1 & - & - & 1 \\
\hline & 135 & 99 & 16 & 250 \\
\hline
\end{tabular}

L'un des traits distinctifs de cette consultation par rapport à la précédente est l'augmentation sensible du pourcentage des sièges non attribués lors de la première répartition (46\% au lieu d'un peu moins de 10\%). Le mécanisme électoral n'ayant pas subi de modification, la raison de ce changement doit être recherchée dans l'accroissement du nombre des formations ayant pris part à la lutte.

Rapprochons maintenant pour chacune des formations en présence le pourcentage des sièges acquis et des voix obtenues : 
[p. 90]

\begin{tabular}{|c|c|c|c|c|}
\hline & \multicolumn{2}{|c|}{ Pourcentages } & \multicolumn{2}{|c|}{$\begin{array}{l}\text { Différences entre } \\
\text { le \% sièges-voix }\end{array}$} \\
\hline & Sièges & Voix & En + & En - \\
\hline Parti Populiste & 24,8 & 18,80 & 6,00 & - \\
\hline Parti Libéral & 22,4 & 17,24 & 5,16 & - \\
\hline $\begin{array}{l}\text { Union Nationale progressiste } \\
\text { du Centre }\end{array}$ & 18 & 16,44 & 1,56 & - \\
\hline Parti de G. Papandréou & 14 & 10,67 & 3,33 & - \\
\hline Front Démocratique & 7,2 & 9,70 & - & 2,50 \\
\hline Front Politique Indépendant & 6,4 & 8,15 & - & 1,75 \\
\hline $\begin{array}{l}\text { Front de Reconstitution } \\
\text { Nationale }\end{array}$ & 2,8 & 5,27 & - & 2,47 \\
\hline Parti National de Grèce & 2,8 & 3,65 & - & 0,85 \\
\hline $\begin{array}{l}\text { Front des Agriculteurs et } \\
\text { Travailleurs }\end{array}$ & 1,2 & 2,62 & - & 1,42 \\
\hline Nouveau Parti & 0,4 & 2,50 & - & 2,10 \\
\hline \multirow{2}{*}{$\begin{array}{l}\text { Formations non représentées } \\
\text { au Parlement }\end{array}$} & 0,0 & 4,96 & - & 4,96 \\
\hline & 100,0 & 100,00 & 16,05 & 16,05 \\
\hline
\end{tabular}

Les écarts par rapport à une proportionnalité idéale sont certes plus marqués que lors des élections précédentes. Ils demeurent cependant à l'intérieur de chiffres relativement modestes.

En dehors de la rentrée de la Gauche au Parlement, le point saillant de la consultation est la défaite de la Droite traditionnelle (le nombre des sièges du Parti Populiste tombant de 156 à 62). Même si l'on ajoute à ce parti les sièges obtenus par d'autres courants de la Droite (Front politique indépendant, Front de Reconstitution Nationale et Nouveau Parti), le chiffre ainsi obtenu ne dépasse pas 35\% des sièges. La Droite a donc subi un grave échec.

C'est aux partis du Centre que revient la victoire. Pris comme, un ensemble, trois partis (Parti Libéral, Union Nationale Progressiste du Centre, Parti de G. Papandréou) obtiennent 136 sièges, soit environ 55\% du total (chiffres qui s'élèvent à 143 et environ 57\% si l'on tient compte du Parti National de Grèce). Mais il s'agit en réalité de formations distinctes et à plusieurs égards rivales. Ce fractionnement empêche [p. 91] la constitution d'un gouvernement stable et affaiblit considérablement la portée de l'action gouvernementale. Finalement cette législature ne durera que 18 mois pendant lesquels 5 gouvernements se succèdent au pouvoir : 


\begin{tabular}{|c|c|c|}
\hline Gouvernement & Dates & Partis représentés \\
\hline 1. Vénizélos & 23.III.1950-15. IV. 1950 & Libéral, National Unioniste \\
\hline 2. Plastiras & 15.IV.1950-21.VIII.1950 & $\begin{array}{l}\text { Union Nationale, Progressiste du Centre, Parti de G. } \\
\text { Papandréou, Libéral. }\end{array}$ \\
\hline 3. Vénizélos & 21.VIII.1950-13.IX.1950 & Libéral, Parti de G. Papandréou. \\
\hline 4. Vénizélos & 13.IX.1950-3.XI.1950 & Libéral, Populiste, Parti de G. Papandréou. \\
\hline 5. Vénizélos & 3.XI.1950-27.X.1951 & Libéral, Parti de G. Papandréou. \\
\hline
\end{tabular}

Parmi les facteurs de dissension à l'intérieur du Centre, figure le problème de l'amnistie aux hommes de la guerre civile. Le général Plastiras en est partisan dans un but d'apaisement des esprits mais il se heurte sur ce point à l'opposition inflexible de S. Vénizélos et G. Papandréou. Ainsi s'explique également que le général Plastiras n'ait pas pu épurer l'administration des éléments qui s'étaient compromis avec la Dictature et les forces d'occupation - épuration que les gouvernements précédents n'avaient réalisée que de manière très incomplète. À quelques exceptions près (Cafandaris, Plastiras...), il semble bien que l'une des conséquences du conflit avec les communistes ait été de rapprocher la vieille garde libérale de la Couronne sous réserve que celle-ci accepte de jouer son rôle constitutionnel. Et ce facteur pèsera sur les rapports politiques durant la période examinée.

Sous cette courte législature, des changements importants vont se produire dans le système des partis dont voici l'essentiel.

À droite, le fait important est la scission du Parti Populiste qui intervient sur l'impulsion de St. Stéphanopoulos, l'un des dirigeants les plus en vue du parti. Celuici quitte le Parti Populiste avec 27 députés pour fonder le Parti Populiste Social. Puis en novembre 1950 il s'allie avec le Parti National Unioniste de P. Canellopoulos pour fonder le Parti Popu-[p. 92] liste-Unioniste. Ces deux personnalités deviennent conjointement chefs du nouveau parti. Mais l'événement majeur est la démission de l’armée du Maréchal Papagos (31 mai 1951) et sa décision de participer à la bataille électorale. La décision du Maréchal — dans la prise de laquelle il semble bien que S. Markézinis ait joué un rôle important — est rendue publique le 30 juillet 1951, c'està-dire le jour même de l'annonce de la date des nouvelles élections (9 septembre).

Le Maréchal est ainsi amené à fonder le Rassemblement Hellénique auquel adhèrent, dans le courant du mois d'août, le Parti Populiste Unioniste et le Nouveau Parti. Il en va bientôt de même pour la majeure partie des cadres du vieux Parti Populiste (qui connaît ainsi un déclin définitif) et de quelques autres chefs de file de la droite. Le rassemblement constitue dès lors un nouveau mode de regroupement de la droite grecque - le succès de l'expérience permettant à celle-ci d'occuper le pouvoir sans interruption jusqu'aux élections de 1963. 
Au centre E. Tsoudéros, chef du Parti Démocratique Progressiste, quitte l'Union Nationale Progressiste du Centre avec 16 députés (14 juillet 1951). Le général Plastiras gardera désormais cette dernière appellation pour désigner son seul parti.

Des changements se produisent également dans le secteur de la Gauche. Les éléments les plus durs de ce secteur de l'opinion considèrent que le Front Démocratique ne constitue pas un outil adapté aux nécessités de l'heure et ils reprochent à certaines personnalités élues sous cette étiquette de poursuivre, en s'appuyant sur des électeurs de gauche, une politique de compromis, sinon même de compromissions avec les forces de la bourgeoisie. Il semble que la déception ait été particulièrement forte au sein des milieux attachés à l'idéologie communiste milieux qui, par suite de l'interdiction du parti communiste ne possèdent dans le pays même aucun instrument ouvert de combat. Ceux-ci ont le sentiment que plusieurs politiciens du Front n'ont d'autre objectif que de confisquer à leur profit les suffrages laissés sans destination spécifique par l'interdiction du PC. D'où l’idée de regrouper tous les éléments de gauches (communistes compris) dans un parti mieux articulé et plus combattif que le Front Démocratique des élections de 1950.

La première application d'une telle formule est faite à l'occasion des élections communales d'avril 1951 avec la fondation d'un organisme dénommé Rassemblement Démocratique qui remporte un certain succès au scrutin. Le 5 juillet 1951, quelques parlementaires quittent le Front [p. 93] démocratique pour créer un groupe partisan de la nouvelle ligne. Ces efforts aboutissent au mois d'août 1951 à la formation de la Gauche Démocratique Unifiée (EDA) qui se compose des partie et groupes politiques suivants: Rassemblement Démocratique ayant à sa tête G. Spiliopoulos et D. Mariolis ; Parti Socialiste (J. Passalidis); Parti des Libéraux de Gauche (N. Grigoriadis) ; Parti Radical (M. Kyrkos) ; un groupe du Parti des Démocrates de Gauche sous la direction de E. Papachristos et J. Cocorellis.

La Gauche acquiert ainsi une unité qu'elle a conservée jusqu'à présent (sous la seule réserve du départ d'un certain nombre des éléments fondateurs). Cette formation, quoique d'inspiration marxiste, ne constitue pas un parti communiste proprement dit mais les éléments communistes y jouent dès le début un rôle important. Ajoutons qu'à aucun moment les autorités gouvernementales n'ont pris prétexte de l'interdiction du parti communiste pour empêcher l'activité de l'EDA. Il n'y a donc aucune raison de traiter ici l'EDA autrement que comme l'un des membres légalement admis du système grec des partis. 


\section{IV. ÉLECTIONS DU 9 SEPTEMBRE 1951}

\section{Retour à la table des matières}

Le chiffre officiel des inscrits pour cette élection s'élève à 2.224.246 sur lesquels le nombre des votants est de 1.717.246. Compte tenu des 8.108 bulletins nuls, le chiffre des suffrages exprimés est de 1.708.904.

Par rapport aux précédentes élections, on observe une diminution très considérable de l'émiettement partisan : neuf partis seulement, qui interviennent tous à titre individuel, se présentent aux élections. Nous sommes sur la voie du regroupement des forces.

Ces élections se déroulent sous un régime électoral qualifié par les spécialistes grecs de «semi-proportionnel » ou encore de "proportionnelle renforcée ». C'est un système qui s'éloigne de la proportionnalité sans accepter encore le principe majoritaire. Le principe des trois répartitions successives est maintenu mais cette fois l'accès aux deuxième et troisième répartitions est limité à un nombre déterminé de partis : les trois premiers par l'importance des suffrages acquis (sous réserve toutefois qu'ils aient obtenu $17 \%$ des voix : 20\% s'il s'agit d'une coalition). En même temps, la mesure électorale au titre de la première répartition fait l'objet d'une élévation. Dernière particularité de ce mode de scru-[p. 94] tin: la possibilité d'ajouter des sièges au nombre de base, soit 250, en vue de compenser certains déséquilibres de la distribution ordinaire. En fait le total des sièges effectivement attribués sera de 258.

L'objectif de ces modifications - qui, en particulier, inaugurent une politique de pénalisation des coalitions électorales — est de favoriser les grandes formations en vue de promouvoir les conditions d'une meilleure stabilité gouvernementale. Autre mobile de l'opération, qui explique la pression exercée par l'ambassade américaine en faveur de ces ajustements: le souci d'écarter l'EDA de la deuxième répartition (l'obtention par le Front Démocratique en 1950 d'un pourcentage de 9,10 rendant vraisemblable la conquête d'un tel accès sous le régime des élections de 1946 et 1950).

Voici comment se distribuent au cours des diverses répartitions les 258 sièges du nouveau Parlement : 


\begin{tabular}{|c|c|c|c|c|}
\hline & $1^{\text {re }}$ & $2^{e}$ & $\begin{array}{l}\text { Répartitions } \\
\text { complémentaires }\end{array}$ & Total \\
\hline Rassemblement Hellénique & 71 & 39 & 4 & 114 \\
\hline Union Nationale Progressiste du Centre & 40 & 32 & 2 & 74 \\
\hline Parti Libéral & 25 & 31 & 1 & 57 \\
\hline Gauche Démocratique Unifiée & 9 & - & 1 & 10 \\
\hline Parti Populiste & 2 & - & - & 2 \\
\hline \multirow{2}{*}{$\begin{array}{l}\text { Rassemblement des Agriculteurs et } \\
\text { Travailleurs }\end{array}$} & 1 & - & - & 1 \\
\hline & 148 & 102 & 8 & 258 \\
\hline
\end{tabular}

On voit que les trois partis de tête, ayant répondu aux conditions fixées par la loi électorale, participent chacun à la deuxième répartition. Qu'en résulte-t-il au titre du rapport entre les pourcentages de sièges et de voix ?

[p. 95]

\begin{tabular}{|c|c|c|c|c|}
\hline & \multicolumn{2}{|c|}{ Pourcentages } & \multicolumn{2}{|c|}{$\begin{array}{l}\text { Différences entre } \\
\text { le \% sièges-voix }\end{array}$} \\
\hline & Sièges & Voix & En + & En - \\
\hline Rassemblement Hellénique..... & 44,19 & 36,53 & 7,66 & - \\
\hline $\begin{array}{l}\text { Union Nationale Progressiste } \\
\text { du Centre......................... } \\
\text { Parti Libéral }\end{array}$ & $\begin{array}{l}28,69 \\
22,10\end{array}$ & $\begin{array}{l}23,49 \\
19,04\end{array}$ & $\begin{array}{l}5,20 \\
3,06\end{array}$ & - \\
\hline Gauche Démocratique Unifiée & 3,87 & 10,57 & - & 6,70 \\
\hline 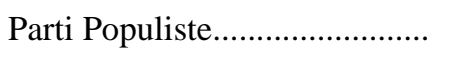 & 0,77 & 6,66 & - & 5,89 \\
\hline $\begin{array}{l}\text { Rassemblement des Agri- } \\
\quad \text { culteurs et Travailleurs........ }\end{array}$ & 0,38 & 1,23 & - & 0,85 \\
\hline $\begin{array}{l}\text { Formations non représentées } \\
\text { au Parlement............................. }\end{array}$ & 0,00 & 2,48 & - & 2,48 \\
\hline & 100,00 & 100,00 & 15,92 & 15,92 \\
\hline
\end{tabular}

Les trois partis de tête sont nettement avantagés, l'EDA et le vieux Parti Populiste recevant sensiblement moins que leur part selon une proportionnelle idéale. Quant au Parti de G. Papandréou, avec 2,10\% de suffrages dans le pays, il disparaît du Parlement (son chef compris). On notera pourtant que le total des écarts relevés sous la nouvelle loi électorale est légèrement inférieur à celui produit par le régime électoral de 1950.

Malgré le «renforcement» effectué, nous ne sommes pas encore très loin, globalement parlant, du mécanisme proportionnaliste. Et si G. Papandréou est totalement éliminé de la Chambre c'est parce que d'une élection à l'autre son 
pourcentage de voix est tombé de 10,67 à 2,10 — la raison, ou l'une des raisons, étant selon, certains avis, que les électeurs du Centre soucieux de "voter utile » auraient concentré leurs suffrages sur les partis de cette tendance les mieux placés pour arriver dans les trois premiers.

Au total, le Rassemblement Hellénique obtient d'emblée un succès considérable qui s'accompagne d'un effondrement du Parti Populiste. Cependant, le Rassemblement ne dispose pas de la majorité absolue qui appartient toujours aux deux formations du Centre (Union Nationale Progressiste du Centre et Parti Libéral). Mais il s'agit d'une majorité très étroite (131 sièges sur 258). Le succès du Rassemblement Hellénique a été facilité par les suffrages des militaires qui, votant dans des bureaux spéciaux, se sont prononcés pour lui à concurrence des trois quarts.

[p. 96] Le Maréchal Papagos se refusant à toute forme de coalition gouvernementale, le cabinet est constitué par le général Plastiras sur la base d'une coalition Union Nationale Progressiste du Centre - Parti Libéral. Ce gouvernement se maintient au pouvoir durant toute la législature dont la durée ne dépassera pas une année. La date de la nouvelle consultation est fixée au 16 novembre 1952 : elle sera tenue sous un gouvernement de service présidé par D. Kioussopoulos. Durant cette législature, le général Plastiras éprouvera de nombreuses difficultés à gouverner en raison de l'étroitesse de sa majorité. Il s'aliénera la Gauche par suite de l'exécution du dirigeant communiste Beloyiannis (30 mars 1952). Il est soumis à une forte pression du Maréchal Papagos ainsi que de l'ambassadeur américain Peurifoy en vue de l'établissement d'un régime de scrutin majoritaire à un tour. Contrairement aux avis de ses partisans, le général Plastiras, privé jusqu'alors de la faculté de réaliser son programme (notamment au titre de l'amnistie dont il estimait la réalisation indispensable), choisit de relever le défi — décision qui allait, durant des années, exercer des conséquences défavorables sur les partis du Centre. La loi électorale est de nouveau modifiée par institution du scrutin majoritaire pur et simple (uninominal ou de liste selon la dimension des circonscriptions dont le nombre est fixé à 99).

\section{V. ÉLECTIONS DU 16 NOVEMBRE 1952}

$\underline{\text { Retour à la table des matières }}$

Le total des électeurs officiellement inscrits s'élève cette fois au chiffre de 2.123.150 sur lesquels 1.600.172 participent au scrutin. Compte tenu de 8.365 bulletins nuls, le nombre des suffrages exprimés est de 1.591.807. Le chiffre des sièges est désormais fixé ne varietur à 800.

Durant la campagne électorale, le Maréchal Papagos fait au pays de nombreuses promesses, dont certaines représentent des points du programme du centre-gauche (ainsi promesse d'un " oubli du passé »). Il y ajoute un autre engagement d'une grande résonnance nationale : la volonté de libérer Chypre de la domination britannique. 
Six formations (dont une coalition de trois partis centristes) briguent les suffrages des électeurs en cette occasion mais deux seulement obtiendront des sièges au Parlement (2 sièges allant toutefois à des listes d'Indépendants). On a la répartition suivante :

[p. 97]

Rassemblement Hellénique Union des trois partis centristes

Listes d'Indépendants
247

51

2

Le Rassemblement Hellénique (sur les listes duquel G. Papandréou figurait en tant que "personnalité ", ce qui lui valut de retrouver un siège) obtient cette fois plus de $80 \%$ des sièges. L'Union des trois partis est une formation centriste qui rassemble l'Union Progressiste du Centre, le Parti Libéral et le Parti Socialiste-Union de la Démocratie Populaire: les deux premières de ces formations obtiennent respectivement 26 et 25 sièges.

Quant aux autres partis concurrents au nombre de quatre : EDA, Parti Populiste, Rassemblement des Agriculteurs et des Travailleurs, Parti Agraire, ils n'obtiennent aucune représentation parlementaire.

C'est là une extraordinaire simplification par rapport aux précédentes législatures mais elle est acquise au prix de très lourdes inégalités de représentation. Il suffit de comparer à cet égard le pourcentage des voix dans le pays et le pourcentage des sièges au Parlement des deux formations représentées.

\begin{tabular}{lcc}
\hline & $\begin{array}{c}\text { Pourcentage } \\
\text { des voix }\end{array}$ & $\begin{array}{c}\text { Pourcentage } \\
\text { des sièges }\end{array}$ \\
\cline { 2 - 3 } Rassemblement Hellénique.......................... & 49,22 & 82,30 \\
Union des trois partis.................................. & 34,22 & 17,2 \\
\hline
\end{tabular}

Le mode de scrutin accepté par le général Plastiras vaut donc une très lourde pénalisation aux formations du Centre. Quant aux quatre autres partis en lice, il faut distinguer entre deux situations. Trois d'entre eux (Parti Populiste, Rassemblement des Travailleurs et des Agriculteurs, Parti agraire) n'obtiennent que des résultats très faibles (1,75\%) : leur élimination du Parlement est donc dans l'ordre des choses. La situation est différente pour l'EDA qui avec 9,55\% des voix (contre 10,57 en 1951) n'obtient aucun siège.

Le Maréchal Papagos prend le pouvoir qu'il occupera jusqu'à sa mort le 4 octobre 1955. L’ascension du Rassemblement Hellénique — expressément voulue et appuyée par les autorités américaines qui durant [p. 98] presque toute la période étudiée vont lier leur politique en Grèce à la permanence de la Droite au pouvoir - a pour notre propos des conséquences fondamentales. Elle marque la fin du recours à la formule de la coalition qui avait caractérisé les 16 gouvernements constitués sous les trois 
premières législatures. En même temps, le Maréchal, qui jouit du prestige d'un héros national, introduit dans la vie politique un style plébiscitaire qui lui survivra (mépris du Parlement et des formations partisanes; subordination des parlementaires à la volonté du chef ; hypertrophie de l'Exécutif).

Parmi les Ministres les plus actifs du Maréchal figure S. Markézinis qui a la charge de la Coordination Économique. Markézinis pratique une politique ouverte (dévaluation de la monnaie, libéralisation des échanges commerciaux) qui lui procure des succès mais lui vaut aussi des ennemis. Nous reviendrons plus tard sur cette politique qui a représenté pour le pays un choix de portée décisive. Alors que certains voyaient en lui un dauphin possible du Maréchal, Markézinis se brouille avec son chef, ce qui le conduit à donner sa démission et, selon un procédé habituel de la vie politique grecque, à sortir du Rassemblement en compagnie de 29 députés pour fonder un nouveau parti : le Parti Progressiste. Cependant la majorité dont disposait Papagos à la Chambre était trop large pour que son gouvernement soit ébranlé par un tel départ.

La santé du Maréchal s'altérant, ce sont les deux vice-présidents du Conseil St. Stéphanopoulos et P. Canellopoulos qui dirigent l'activité gouvernementale, l'affaire de Chypre était alors au centre des préoccupations du pays. Il semble que le Maréchal considérait d'un bon œil que sa succession soit assurée par la première de ces personnalités. Cependant au décès de Papagos, la Couronne, sans attendre l'élection officielle du nouveau chef de la majorité, chargea un politicien de second plan, C. Caramanlis, de constituer le nouveau gouvernement, ce qui est fait le 6 octobre 1955.

Les motifs de cette désignation n'ont pas été complètement éclaircis - certains avançant que Caramanlis fut choisi parce qu'on le savait prêt à se contenter pour Chypre d'une solution « raisonnable », c'est-à-dire en réalité d'une solution acceptable pour les puissances anglo-saxonnes. En tout cas, la conséquence immédiate de cette nomination venue den haut fut que St. Stéphanopoulos, selon la pratique classique, quitta le Rassemblement Hellénique pour redonner vie au Parti Populiste Social.

[p. 99] La principale préoccupation de Caramanlis qui conserve le pouvoir jusqu’à la dissolution de la Chambre (les nouvelles élections intervenant le 19 février 1956 soit moins de 5 mois après le décès du Maréchal) va être d'assurer la perpétuation de la majorité dont la Droite dispose au Parlement. Le Rassemblement Hellénique est dissous en date du 4 janvier 1956 : lui succède l'Union Nationale Radicale (ERE) dont Caramanlis devient le chef. Celui-ci parvient à rallier à la nouvelle formation la presque totalité des cadres du Rassemblement Hellénique (qui, en une très large mesure, étaient formés des anciens cadres du groupe populiste auquel Caramanlis luimême avait appartenu).

Restait à régler le problème de la loi électorale. En mai 1954, le gouvernement du Maréchal Papagos avait fait adopter par le Parlement une loi (loi $n^{\circ} 2.800$ de 1954) assurant le maintien du scrutin majoritaire à un tour avec diverses innovations d'inspiration plébiscitaire (en particulier réduction à 16 du nombre des circonscriptions électorales et limitation à 250 du nombre des sièges parlementaires). Le mobile de cette réforme qui entendait également faciliter le vote des militaires par 
l'instauration de dispositions spéciales était selon ses promoteurs d'inciter tous les partis à se regrouper en deux puissantes formations toutes deux d'inspiration anticommuniste. Or, compte tenu de la disparition du Maréchal, Caramanlis peut craindre que cette loi ne se retourne contre la Droite en raison des dissensions survenues au sein de celle-ci (partis de Stéphanopoulos et Markézinis). Et dès lors, il n'hésite pas à faire voter par le Parlement une nouvelle loi dont l'objectif manifeste est de permettre à l'Union Nationale Radicale de conserver le pouvoir acquis en 1952 par le Rassemblement Hellénique.

Il est impossible d'analyser en quelques mots ce régime dont le dispositif est d'une grande complexité ${ }^{1}$. Disons simplement qu'il institue trois modes de scrutin différents selon la taille des circonscriptions. Voici, limitée à l'essentiel, la méthode électorale ainsi utilisée.

Ce système qui entend limiter la distribution des sièges à deux partis par circonscription distingue à cet effet une liste dite élue et une liste dite suppléante. La liste dite élue est celle qui vient en tête même s'il s'agit d'une majorité simplement relative. Quant à la liste suppléante, c'est celle qui vient en second : toutefois, pour être considérée comme [p. 100] telle et avoir droit aux avantages prévus, il faut que cette liste ait obtenu 15\% des voix dans la circonscription et aussi que le parti dont elle relève ait eu $15 \%$ des suffrages dans tout l'État — ces pourcentages étant portés a 25\% s'il s'agit d'une coalition.

Sur ces bases, les attributions respectives des deux listes varient selon le nombre des sièges attribués à la circonscription :

- Circonscription de 1 à 3 sièges : la liste élue emporte tous les sièges. Dans ce cas c'est donc le principe majoritaire pur qui s'applique.

- Circonscription de 4 à 10 sièges : s'il n’y a pas de liste suppléante au sens de la réglementation, la liste élue a tous les sièges. En cas de présence d'une liste suppléante, celleci obtient les $3 / 10$ du total des sièges sans tenir compte des fractions. Autrement elle dispose d'un siège dans les circonscriptions de 4 à 6 sièges, de 2 dans celles de 7 à 9 , de 3 dans celles de 10. Dans ce cas, le régime majoritaire peut, sous certaines conditions, céder le pas à un régime semi-proportionnel, la liste élue concédant alors une minorité de sièges à la liste suppléante.

- Circonscription de plus de 10 sièges : s'il n'y a pas de liste suppléante, la liste élue prend tout. Au cas où il en existe une, la distribution s'effectue entre la liste élue et la liste suppléante au prorata de leur force électorale respective. Dans cette hypothèse, c'est le scrutin proportionnel qui s'applique mais le bénéfice en est limité aux deux listes arrivant en tête.

La loi était accompagnée d'un redécoupage des circonscriptions conforme aux intérêts locaux de l'ERE - le gouvernement ayant conçu le système de manière à faire prévaloir le principe majoritaire dans les bastions électoraux de la droite et la

1 On trouvera une traduction en langue française de cette loi dans le volume du Ministère de l'Intérieur, Résultats des élections des députés du 19 février 1956, Athènes, 1957, pp. 9-17. 
répartition proportionnelle là où elle se trouve minoritaire. Enfin le système maintenait les dispositions destinées à faciliter le vote de l'armée.

Devant le Parlement, le gouvernement défendit son projet par la nécessité d'assurer la stabilité ministérielle. Il s'agissait, selon lui, d'accorder une certaine représentation aux minorités sans trop s'écarter du régime majoritaire et tout en organisant les conditions d'un isolement de l'EDA. Mais ce raisonnement n'emporta pas la conviction de l'opposition qui dans cette chambre, on l'a vu, se limitait au départ à des éléments du Centre (rejoints il est vrai par quelques hommes de la Droite dont les leaders étaient Stéphanopoulos et Markézinis). On reprocha en particulier au système de tendre à un bipartisme - le parti au pouvoir et l'opposition dite nationale - que la nature même de la Gauche grecque rendait impossible de réaliser. Finalement l'opposition n'ayant pu empêcher le vote de la loi choisit de se coaliser pour en bloquer les résultats.

[p. 101] Deux mots sur les vicissitudes du Parti Libéral au cours de cette législature. Élu sur les listes du Rassemblement Hellénique, G. Papandréou revient pour la première fois après la guerre au Parti Libéral dont il est proclamé chef conjointement avec S. Vénizélos. Ce dernier s'étant démis de sa charge en avril 1954, Papandréou reste le seul leader de cette formation. Mais en avril 1955, Vénizélos, dont la carrière politique ne fut pas dépourvue d'amateurisme, revient sur sa décision d'abandonner la politique et, avec le concours de certains cadres du Parti Libéral fonde un nouveau parti, l'Union Libérale Démocratique. Le Parti Libéral se trouve donc, une nouvelle fois, victime d'une scission due à un conflit de personnalités.

\section{VI. ÉLECTIONS DU 19 FÉVRIER 1956}

$\underline{\text { Retour à la table des matières }}$

En raison de l'introduction du suffrage féminin, le total officiel des inscrits passe à 4.507.907 dont 3.379.445 participent à l'élection. Compte tenu de 15.084 bulletins nuls, le montant des suffrages exprimés s'élève à 3.364.361.

Deux grandes formations s'affrontent : l'Union Nationale Radicale et une coalition de 7 partis qui porte le nom d'Union Démocratique. Il s'agit dune coalition hétérogène et même hétéroclite dont le seul but est de déloger la Droite du pouvoir. En cas de victoire, les membres de la coalition n'envisagent pas de gouverner ensemble mais projettent de dissoudre le Parlement en organisant des élections au système proportionnel. C'est là une position qui s'explique parfaitement si l'on tient compte du caractère du système électoral adopté par les partisans de Caramanlis. Notons que certaines coalitions de cet ordre avaient été constituées lors des élections municipales de 1954, l'entente formée en cette occasion ayant pour fondement unique la critique et le désaveu du gouvernement Papagos.

Les piliers de cette coalition sont des partis du centre mais on y trouve aussi des formations de droite (Parti Populiste) ainsi que la Gauche Démocratique Unifiée. 
C'était la première fois que les partis bourgeois acceptaient de collaborer avec cette formation que beaucoup accusent d'être entièrement dominée par les communistes. Bien que l'opération ait été d'inspiration strictement électorale, la droite ne manqua pas de faire de cette alliance un témoignage du " péril rouge » - l'armée [p. 102] et les corps de sécurité se croyant dès lors autorisés à exercer une pression sur les électeurs au profit de la Droite.

Entrent aussi dans la contestation pour leur propre compte le Parti Progressiste de S. Markézinis et le Parti Populiste Social de St. Stéphanopoulos (ainsi que deux très petits partis : le Parti de la Démocratie Chrétienne et le Parti des Principes de Jean Métaxas). Markézinis engage le combat sur une grande échelle (250 candidats dans 34 circonscriptions). Stéphanopoulos se limite à une seule liste dans son fief personnel : l’Élide.

Voici la distribution des sièges qui résulte du scrutin :

Union Nationale Radicale.

Union Démocratique.

Liste d'Indépendants.

Divers.

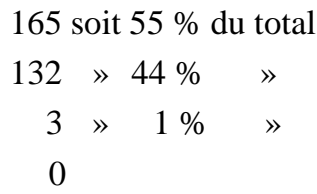

300

En somme le mécanisme électoral fonctionne conformément à l'attente de ses promoteurs. La droite obtient, avec 47,38\% la majorité absolue au Parlement au détriment de l'Union Démocratique qui a pourtant remporté un pourcentage de suffrages supérieur au sien, soit 48,15 (l'écart absolu étant d'environ 25.000 voix). Le Parti Progressiste qui s'était présenté seul reçut 2,22\% des suffrages mais n'obtint pas de sièges. Quant au Parti Populiste Social, son unique liste n'aurait pu être élue que si elle était arrivée en tête dans sa circonscription. Grâce à un redécoupage ad hoc (adjonction à l’Élide de l'arrondissement d'Olympie), St. Stéphanopoulos fut battu, de justesse il est vrai, dans son propre fief.

Voici la répartition des 132 sièges de l'Union Démocratique : Union Libérale Démocratique, 43 ; Parti Libéral, 26 ; Parti Démocratique du Peuple Travailleur, 20 ; Gauche Démocratique Unifiée, 18 ; Union Nationale Progressiste du Centre, 15 ; Parti Agraire - Ouvrier, 7 ; Parti Populiste, 3. À propos de l'Union Progressiste du Centre, mentionnons qu'après le décès du général Plastiras (juillet 1953), le parti subit des pertes, spécialement sur son aile gauche : lors des élections de février 1956 il avait pour chef S. Papapolitis.

Il est incontestable que le mécanisme électoral a favorisé la Droite (qui bénéficia en particulier de $77 \%$ des suffrages militaires). Et sur cette base, il est tentant d'affirmer qu'avec un autre type de régime [p. 103] — un régime mettant franchement en œuvre le principe majoritaire - la Droite aurait été battue par ses rivaux. L'imputation est plausible mais elle n'est pas irréfutable dans la mesure où il n'est pas acquis qu'un régime moins outrageusement partial ait suscité les mêmes regroupements partisans (en particulier l'acceptation de l'EDA dans la coalition) et 
aussi, ne l'oublions pas des réactions électorales identiques chez les citoyens. Contrairement aux expériences de laboratoire, toute variation d'un élément sur la scène politique entraîne des modifications dans les autres. En matière d'analyse sociale, il est impossible de considérer qu'un facteur variant, les autres sont susceptibles de demeurer constants.

N'oublions pas, au surplus, que tant aux élections de 1952 qu'à celles de 1956, la Droite représente, avec le concours de l'appareil d'État il est vrai, près de la moitié de l'électorat (la diminution subie d'une élection à l'autre étant minime). Elle possède au surplus un avantage sur ses adversaires du Centre : celui de l'unité. Lors des élections de 1956, le Centre proprement dit, emporte 28\% des sièges mais ceux-ci sont répartis entre trois formations (Union Libérale Démocratique, Parti Libéral, Union Nationale Progressiste du Centre). La reconquête du pouvoir par le Centre passera par l'unification des forces qui le constituent. Nous n'en sommes pas encore là.

Notons la présence dans la Chambre de 1956 d'un Centre gauche représenté par le Parti Démocratique du Peuple Travailleur et le Parti Agraire-Ouvrier dont l'assise est formée par les coopératives rurales. Cette nuance de l'opinion obtint $9 \%$ des sièges, ce qui ne correspond pas à sa force électorale réelle. Cette poussée est le fruit des marchandages intervenus lors de la création de l'Union Démocratique (garantie d'un certain nombre de sièges dans le cadre de circonscriptions sûres aux petits partis dont les promoteurs de l'Union voulaient obtenir le concours).

Quant à l'EDA dont le système avait pour objectif d'organiser l'isolement, ce parti a réussi pour la première fois (et jusqu'à présent d'ailleurs pour la dernière fois) à établir un front électoral avec les partis du Centre. Il dispose à la Chambre de 6\% des sièges (pourcentage inférieur à sa force réelle dans le pays).

À la suite du succès remporté par l'Union Nationale Radicale, C. Caramanlis garde la direction du gouvernement. Il la conservera jusqu'au début de mars 1958, date à laquelle une crise interne survenue [p. 104] dans son propre parti le conduira à donner sa démission au Roi. Cette crise - sorte de révolution de palais — fut provoquée par la volonté du chef du gouvernement de modifier une fois encore le régime électoral. Deux Ministres (P. Papaligouras et G. Rallis) qui n'étaient pas d'accord avec le projet en cours d'élaboration démissionnèrent le 27 février 1958. Deux jours plus tard, 15 députés de l'Union Radicale, parmi lesquels les deux ministres démissionnaires, déclarèrent retirer leur confiance au gouvernement. Cette défection ramène à 149 voix la force parlementaire de Caramanlis (qui avait déjà perdu le soutien de l'un de ses partisans).

Le gouvernement ne disposait donc plus de la majorité absolue ce qui aurait, s'il s'était maintenu au pouvoir, rendu sa position très fragile. Très habilement, Caramanlis démissionne tout de suite et obtient du Roi la tenue d'une nouvelle consultation qui se tiendra sous un gouvernement de service présidé par C. Georgacopoulos (Président de la Croix-Rouge Hellénique). L'une des tâches de ce gouvernement sera de faire aboutir le projet électoral resté en suspens par suite de la démission du chef de l'ERE. 
Ce projet marquait le retour à un système de « proportionnelle renforcée » avec trois répartitions successives dans le cadre de 55 circonscriptions. L'accès à la deuxième répartition - dont on s'efforçait d'accroître l'ampleur par élévation de la mesure électorale de la première — était limité aux partis ayant obtenu 25\% des suffrages (35\% pour une coalition de deux partis et $40 \%$ pour une coalition de plus de deux). Toutefois il était prévu que deux partis au moins devraient participer à cette répartition même si le quorum n'était pas atteint. La différence de valeur donnée aux quorums selon la nature des formations témoigne d'une hostilité certaine à l'égard des coalitions - hostilité dont nous avons trouvé les premiers éléments dans la législation de 1951.

Ce projet devait faire l'objet de nombreuses attaques au Parlement, plusieurs leaders centristes (en particulier C. Mitsotakis et G. Mavros) ainsi que les représentants de l'EDA déclarant contraire à la tradition constitutionnelle la mission confiée par le Roi au gouvernement de service. Comme l'on pouvait s'y attendre, la rigueur des conditions exigées pour l'accès à la deuxième répartition fut vivement critiquée, certains y voyant le moyen de porter ou de maintenir au pouvoir des gouvernements minoritaires dans le pays.

[p. 105] Il semble que l'objectif de C. Caramanlis en préparant ce projet ait été de mieux asseoir son autorité sur le parti, certains de ses rivaux puisant dans le système majoritaire une autorité susceptible de s’opposer à la sienne. Or les intérêts de C. Caramanlis coïncidaient sur ce point avec ceux des leaders du Parti Libéral (réunifié en mars 1957 sous la direction conjointe de G. Papandréou et S. Vénizélos). Les leaders de ce parti étaient très désireux en effet d'éviter un système électoral impliquant polarisation des forces, c'est-à-dire les obligeant en fait, comme ce fut le cas en 1956, à s'allier avec la Gauche. D'autre part, ils étaient favorables à un système susceptible d'obliger les petits partis du Centre à se rassembler autour du Parti Libéral - la sanction d'un refus étant l'impossibilité pour ces partis de prendre part à la deuxième répartition.

Sur ces bases, un accord fut conclu entre les directions de l'Union Radicale et du Parti Libéral en vue d'assurer le remplacement du système électoral existant par un mode de scrutin du type "proportionnelle renforcée ». Durant le débat, Caramanlis s'était déclaré partisan d'un régime purement majoritaire et Papandréou d'une proportionnelle simple. En réalité chacun des deux leaders était partisan du compromis réalisé mais l'un comme l'autre s’efforçait d'en expliquer la nécessité par l’intransigeance de départ de son partenaire.

C'est en vertu de cet accord, auquel il sera fait de nombreuses allusions lors des débats parlementaires, que C. Georgacopoulos - qui au surplus, se livrant à une manœuvre très critiquée par les personnalités libérales, menaçait la Chambre d'appliquer en cas d'échec le régime hybride de 1956 — put obtenir le vote du projet préparé sous le gouvernement Caramanlis. Il est vrai qu'en pratique le système ne remplira que partiellement les espérances des promoteurs. 


\section{VII. ÉLECTIONS DU 11 MAI 1958}

\section{$\underline{\text { Retour à la table des matières }}$}

Lors de cette consultation, le nombre des électeurs officiellement inscrits est de 5.119.148 — montant sur la légitimité duquel nous avons déjà présenté de très sérieuses réserves. Le chiffre des votants s'élève à 3.863 .982 : déduction faite de 16.197 bulletins blancs le montant des suffrages exprimés est de 3.847.785. Cinq formations (trois partis simples et deux coalitions) sont en présence. Avant de procéder à l'analyse des résultats, il est nécessaire d'exposer brièvement les mobiles et calculs qui expliquent une telle constellation.

[p. 106] L'ERE, parti gouvernemental par excellence de l'époque, présente des candidats dans toutes les circonscriptions. Cependant dans le secteur de la Droite une force s'oppose à elle dans 29 circonscriptions : l'Union du Parti Populiste, coalition de cinq petits partis. Cette coalition rassemble les dissidents de l'ERE qui ont provoqué la crise ministérielle de mars ainsi que les personnalités de la Droite traditionnelle que la nouvelle Droite a bousculées ou écartées de la scène durant son ascension (Stéphanopoulos, Tsaldaris, Tourcovassilis...).

Le Parti Libéral, dont ses leaders estiment qu'il est la seule force susceptible de s'opposer à la Droite, affronte l'ERE dans toutes les circonscriptions. Cependant il n'est pas parvenu à rassembler en son sein les petites formations de Centre gauche et il lui est impossible de se coaliser avec elles en raison des dispositions très rigoureuses prises à l'encontre des coalitions. D'où la présence d'une coalition dite Union Progressiste Agraire Démocratique qui, agissant indépendamment du Parti Libéral, groupe des partis mineurs de centre-gauche ainsi que les progressistes de Markézinis : l'Union présente des candidats dans 54 circonscriptions.

Reste l'EDA. Les partisans de la nouvelle loi électorale n'ont pas caché que les dispositions rigoureuses sur l'accès aux deuxième et troisième répartitions avaient pour objet d'empêcher ce parti d'en bénéficier, qu'il intervienne seul ou agisse en coalition avec d'autres. L'EDA a tenté de créer une coalition avec les petits partis du Centre restés hors du Parti Libéral, un tel groupe pouvant, même exclu des répartitions ultérieures, améliorer la position de ses membres lors de la première répartition. Mais ce projet échoue et finalement l'EDA se présente seule dans les 55 circonscriptions : toutefois elle a réussi à introduire sur ses listes un petit nombre de personnalités centristes isolées (Mercouris, Tsirimocos, Pyromaglou...). 
Les résultats des élections sont les suivants :

Union Nationale Radicale

Gauche Démocratique Unifiée

Parti Libéral

Union Progressiste Agraire Démocratique

Union du Parti Populiste
171 sièges

79 sièges

36 sièges

10 sièges

4 sièges

300 sièges

[p. 107] La victoire revient donc et de fort loin à l'ERE, celle-ci n'ayant que très peu souffert de la concurrence de l'Union du Parti Populiste. Les gains de l'Union se limiteront à quatre sièges dans le Péloponnèse, sièges obtenus grâce aux attaches locales de certains de ses promoteurs. Mais la grosse surprise de cette consultation est que l'EDA arrive en seconde position devant le Parti Libéral avec 24,43\% des suffrages. Deux partis devant participer à la seconde répartition, l'EDA — bien qu'elle n'ait pas tout à fait le quorum requis (25\%) va obtenir une fraction des sièges distribués à ce titre.

Le Parti Libéral est le grand vaincu de la consultation. Il n'obtient que 20,68\% des voix, soit un peu moins du double des suffrages qui vont à l'Union Progressiste Agraire Démocratique (10,62\%). Manifestement les chefs de ce parti en ont surestimé l'attraction électorale, spécialement à l'égard des électeurs sensibles à certains thèmes du Centre Gauche.

Grâce à la deuxième répartition qui porte sur 104 sièges, soit un peu plus du tiers du total, chacune des deux formations bénéficiaires fait un bond en avant d'ampleur sensiblement équivalente (71\%) :

Union Radicale Nationale

Gauche Démocratique Unifiée

\begin{tabular}{|c|c|c|}
\hline $1^{\mathrm{re}}$ & $2^{e}$ & Total \\
\hline 100 & 71 & 171 \\
\hline 46 & 33 & 79 \\
\hline
\end{tabular}

Comparons maintenant les pourcentages de voix et de sièges obtenus par chacune des formations en présence : 


\begin{tabular}{|c|c|c|c|c|}
\hline & \multicolumn{2}{|c|}{ Pourcentages } & \multicolumn{2}{|c|}{$\begin{array}{l}\text { Différences entre } \\
\text { le \% sièges-voix }\end{array}$} \\
\hline & Sièges & Voix & En + & En - \\
\hline Union Nationale Radicale & 57 & 41,17 & 15,83 & - \\
\hline Gauche Démocratique Unifiée & 26,32 & 24,43 & 1,89 & - \\
\hline Parti Libéral & 12 & 20,68 & - & 8,68 \\
\hline $\begin{array}{l}\text { Union Progressiste Agraire } \\
\text { Démocratique }\end{array}$ & 3,34 & 10,62 & - & 7,28 \\
\hline Union du Parti Populiste & 1,34 & 2,94 & - & 1,60 \\
\hline \multirow[t]{2}{*}{ Indépendants et Isolés } & 0,00 & 0,16 & - & 0,16 \\
\hline & 100,00 & 100,00 & 17,72 & 17,72 \\
\hline
\end{tabular}

[p. 108] Ce tableau illustre l'ampleur de l'avantage que vaut à la Droite le nouveau régime électoral De 1956 à 1958, le pourcentage des suffrages obtenu par l'ERE tombe de 47,38 à 41,17; mais le nombre de ses sièges passe de 165 à 171 . Ainsi l'ERE parvient-elle à transformer une majorité relative dans le pays en une majorité absolue au Parlement. Même si le mécanisme électoral n'est pas le seul facteur de l'opération, on ne saurait contester l'aide que parvient à en obtenir le parti gouvernemental.

On s'est naturellement interrogé sur les facteurs du succès remporté par l'EDA à l'encontre du Parti Libéral. Selon une interprétation, beaucoup d'électeurs du Centre, convaincus de la victoire de la Droite, auraient voté pour la Gauche en vue de donner plus d'éclat à leur protestation contre les méthodes de l'Union Radicale (à laquelle, ne l'oublions pas, le Parti Libéral s'était associé pour assurer le vote de la loi électorale). Cette supposition est plausible. N'oublions pas non plus la désunion des politiciens libéraux et la valse des formations partisanes qui en a résulté : un tel spectacle ne pouvait que nuire au prestige de ce courant dans l'esprit des électeurs.

Après les élections, C. Caramanlis assure de nouveau la direction du gouvernement. Il conservera cette charge jusqu'au 29 octobre 1961, date à laquelle la Droite procédera à des élections anticipées - le mobile principal de cette décision étant, selon divers avis, l'espoir de la Droite que les difficultés internationales du moment (notamment création d'une frontière entre les deux Berlins) conduiraient les électeurs grecs à renouveler son mandat.

Durant cette législature, l'ERE, forte de son succès, reste unie autour de Caramanlis ; elle ne subit aucune dissidence. Le Centre en revanche connaît une crise très grave. En novembre 1958, le Parti Libéral se scinde en trois formations. Un Parti Libéral Démocratique se fonde sous la direction de G. Papandréou. D'un autre côté, un certain nombre de députés libéraux vont créer un groupe parlementaire qui prend le nom de Nouveau Mouvement Politique. Quant aux éléments fidèles au Parti Libéral, ils reconnaissent pour chef S. Vénizélos. Cette dispersion est 
particulièrement nuisible au Centre et l'on ne s'étonnera pas que diverses tentatives aient été faites pour y porter remède.

La première est liée à l'intervention du général Grivas qui, auréolé de la gloire acquise à Chypre, choisit en novembre 1960 de descendre dans l'arène politique. S. Vénizélos soutient cette tentative (dont certains [p. 109] dirent même qu'il l'a provoquée) en cédant au général les 15 députés de son parti ${ }^{1}$. Ceux-ci vont former, avec le concours de quelques parlementaires indépendants, le Mouvement de Reconstitution Nationale (nom choisi pour désigner le parti du général). Mais cette tentative comportait plusieurs vices qui devaient la conduire rapidement à l'échec.

En premier lieu, le général Grivas était connu depuis longtemps pour ses opinions d'extrême-droite : relevait de cette tendance le parti qu'au lendemain de la libération il avait formé sur la base de son réseau de résistance. Il lui était dès lors difficile de réunir sous son drapeau des éléments du Centre et surtout du Centre-gauche, dont le concours était indispensable pour créer une formation politique ayant des chances de parvenir au pouvoir. Par ailleurs, la manière même dont ce mouvement essaya de s'implanter — démarches venues d'en haut sans aucun mouvement spontané de la base - fit mauvaise impression et, en plus, heurta les ambitions personnelles des dirigeants des diverses formations politiques du Centre et du Centre-gauche. Enfin, la création même d'un parti purement charismatique ne semblait plus correspondre à l'évolution de la vie politique du pays.

Après dix mois d'efforts menés conjointement pour soulever l'enthousiasme populaire et réunir les forces politiques du Centre, le général Grivas — dont le répertoire idéologique n'est pas très étendu — dut constater son échec sur les deux tableaux. En conséquence, il renonça à poursuivre sa tentative et procéda à la dissolution du Mouvement de Reconstitution Nationale.

Entre temps, le chef du Parti Démocratique Libéral, G. Papandréou, essayait d'obtenir la réunification du Centre, sous sa propre direction. Ses démarches d'abord assez laborieuses — eurent finalement plus de succès. C'est ainsi qu'après des mois de discussion, Papandréou (auquel l'on reprochait à l'époque, en divers milieux, de manquer de fermeté vis-à-vis des initiatives gouvernementales) franchit la première étape en constituant (février 1961) le Centre Démocratique - Union Agraire Libérale, avec le concours du Parti Agraire-Ouvrier et du Nouveau Mouvement Politique. Les pourparlers du leader libéral et des autres dirigeants des formations du centre et centre-gauche se poursui-[p. 110] vent et, au mois d'août de la même année, Elie Tsirimocos, chef de l'Union Démocratique (parti à ne pas confondre avec la coalition antigouvernementale formée sous le même nom lors des élections de 1956) adhère au Centre Démocratique - Union Agraire Libérale. Au mois de septembre, les adhésions se multiplient. Il y a notamment celles du Parti Libéral,

On s'est interrogé sur les mobiles de la démarche de Vénizélos. Certains y voient une nouvelle preuve de son « amateurisme » et de son instabilité. D'autres estiment que cette initiative fut prise d'accord avec la Couronne, en vue de désamorcer politiquement la bombe Grivas. Cette supposition n'est pas invraisemblable mais on ne dispose d'aucune preuve susceptible de l'étayer. 
de l'Union Nationale Progressiste du Centre, du Parti Progressiste OuvrierTechniciens, du Parti Populiste Social et du Parti des Nationalistes. Finalement cette vaste formation prendra le nom d'Union du Centre.

On notera qu'en juin-juillet, les autorités américaines intervinrent dans les négociations pour en faciliter l'aboutissement. Tel semble bien avoir été l'objet, malgré les dénégations officielles, de la visite à Athènes d'un haut personnage du Département d'État McGhee - visite faisant suite à des contacts pris par l'ambassade américaine avec plusieurs des leaders du Centre. Au cours de son séjour, présenté selon l'usage comme d'ordre privé, McGhee tint diverses réunions avec les leaders du parti du Centre. C'était là l'un des premiers signes que les États-Unis n'étaient plus décidés à tenir C. Caramanlis comme le seul garant des intérêts américains en Grèce. Comme nous le verrons plus loin, ce changement, effectué de manière assez prudente, correspondait à l'arrivée d'une nouvelle équipe à la Présidence des États-Unis.

Les deux mots choisis pour désigner la nouvelle formation - union et centre ne correspondaient pas exactement à la réalité. D'abord, il ne s'agit pas d'une « union » au sens courant du terme dans le vocabulaire politique grec, c'est-à-dire d'une alliance occasionnelle. Cette union est en réalité un parti puisque tous les chefs des formations politiques qui la composent ont dissout leur parti et ont adhéré à l'Union du Centre en reconnaissant M. Papandréou comme chef. Ensuite, l’Union englobe des partis d'autre provenance que le centre, puisqu'elle a reçu l'adhésion du Parti Populiste Social et du Parti des Nationalistes qui, historiquement, appartiennent à la droite, ainsi que du Parti Agraire-Ouvrier, formation centre-gauche et de l'Union Démocratique de Tsirimocos, qui s'est allié à diverses reprises avec la Gauche.

Compte tenu de ces réserves, d'ordre secondaire, nous pouvons dire que c'est la première fois, depuis l'époque d'Éleuthère Vénizélos, que toutes les forces politiques du pays, situées entre la Droite et la Gauche se trouvaient réunies, avec la volonté expresse de se constituer en parti autonome. Observons que certains contestent la légitimité du recours à [p. 111] la notion de «centre » pour caractériser la nouvelle formation. Selon ce point de vue, il ne saurait y avoir politiquement d'autre centre que républicain. Ou si l'on préfère, la notion de centre resterait liée dans la politique grecque de cet après-guerre à l'action et à la position du général Plastiras. Et dès lors il ne serait pas légitime de l'employer pour désigner ou couvrir une autre politique. Nous retrouverons le problème.

Les modifications survenues durant cette législature au sein de la Gauche sont certes moins profondes. Signalons en premier lieu: la fondation de l'Union Démocratique sous la conduite de Tsirimocos, par une douzaine de députés élus sous l'étiquette de l'EDA: après avoir subi divers avatars et perdu plusieurs de ses membres, l'Union - comme nous l'avons vu — rejoindra le Centre. Mentionnons également l'activité d'un groupe agrarien dit Nouveau Mouvement Agraire dont la base est formée par de vieux agrariens de gauche venus du parti de J. Sophianopoulos et de quelques uns des politiciens élus sur les listes de l'EDA aux élections de 1958. Un petit nombre de députés agissant avec l'accord du parti, s'affilie à ce mouvement 
qui préfigure ainsi le Parti National Agraire créé à l'occasion de la consultation de 1961.

Notons enfin une initiative tendant à rassembler l'ensemble de l'opposition et qui intervient au moment où se déroulent les difficiles négociations visant à regrouper le Centre : la publication, en date du 23 décembre 1960, d'une proclamation appelant à la formation d'un regroupement centriste véritablement démocratique. Ce manifeste est signé par 16 politiciens ou anciens politiciens appartenant ou ayant appartenu à diverses formations (en particulier Parti Libéral, Nouveau Mouvement Agraire, Union Démocratique).

Dès le début, l'initiative jouit de la sympathie de l'EDA qui l'interprète et la présente comme un effort de rassemblement de tous les éléments progressistes du pays, sans exclusion aucune, contre le gouvernement de la Droite. Le groupe initial dit Comité des Seize — tous d'inspiration centre gauche ou gauche modérée — va se transformer au mois de février 1961 en un Mouvement de Coordination de la Lutte Nationale Démocratique. Entre temps, le comité avait reçu l'adhésion d'autres membres de l'Union Démocratique - ce qui leur valut, ainsi qu'aux signataires initiaux, d'être expulsés de l'Union par E. Tsirimocos alors hostile à toute forme de coopération avec l'EDA. La force parlemen-[p. 112] taire de l'Union Démocratique, ainsi réduite de 7 unités, se limitait dès lors à 5 membres.

Le nouveau Mouvement se défendait de constituer un parti, son but étant seulement d'après les promoteurs de l'opération de rapprocher les groupes existants. En fait, l'objectif de la démarche était d'éviter que le rassemblement des forces antigouvernementales n'aboutit à l'isolement de l'EDA. Il s'agissait d'empêcher que le Centre ne se reconstitue sur la base et avec l'objectif de la lutte contre un double adversaire, la Droite mais aussi la Gauche. On sait déjà que ce Mouvement rencontra un échec total, le Centre se rassemblant en dehors de l'EDA et n'ayant depuis jamais dévié de sa tactique de combat sur deux fronts.

\section{VIII. ÉLECTIONS DU 29 OCTOBRE 1961}

\section{Retour à la table des matières}

Une nouvelle fois le problème de la loi électorale est au centre de la lutte politique, Les principaux points de la dispute sont toujours les mêmes: nonadaptation de la distribution des sièges aux nouvelles réalités démographiques; caractère beaucoup trop rigoureux des conditions limitant l'accès de la seconde répartition; dispositions concernant le vote des militaires ... Le premier de ces arguments est renforcé par le fait que les résultats du recensements de mars 1961 commencent d'être connus : comme on pouvait le prévoir, ils font ressortir que le partage des sièges effectué en 1958 sur la base du recensement de 1940 défavorise considérablement les grandes agglomérations urbaines au profit des régions rurales discordance qui vaut à la Droite le gain d'un certain nombre de sièges. 
Finalement, le régime électoral de proportionnelle renforcée est maintenu, pour cette consultation. Toutefois quelques changements sont apportés au mode de scrutin utilisé pour la précédente consultation, l'inspiration de ceux-ci étant de rapprocher le régime de la proportionnelle ordinaire.

C'est ainsi que l'on revient au système de Hagenbach-Bischoff pour le calcul de la mesure électorale de la première répartition. Les quorums pour la participation à la deuxième répartition font l'objet d'un abaissement sensible (15\% pour un parti isolé, $25 \%$ pour une coalition de deux partis, 30\% pour une coalition de plus de deux). Par ailleurs, dans le cas où deux partis seulement atteignent le quorum nécessaire [p. 113] pour participer à cette répartition, la loi ouvre l'accès de celle-ci à un troisième parti simple. Cette diminution du renforcement paraît susceptible au moins en principe de contribuer à une plus grande ouverture du jeu politique. Quant à la distribution des sièges, elle s'effectue désormais, sauf quelques exceptions, sur la base du recensement de 1951, la population des citoyens de cette époque étant évidemment assez éloignée de celle existant en 1961.

Trois formations sont en présence : l'Union Nationale Radicale qui se présente toujours à titre séparé ; une coalition de l'Union du Centre et du Parti Progressiste ; une coalition dite Front Pandémocratique Agraire de Grèce qui rassemble la Gauche Démocratique Unifiée et le Parti National Agraire — l'objectif de ce parti étant en quelque sorte de chaperonner les personnalités du centre-gauche qui entendent collaborer avec l'EDA.

On sait que le nombre des électeurs inscrits au titre de cette consultation n'a pas été publié par les services officiels. Les partis de l'opposition accuseront par la suite le gouvernement d'avoir truqué la consultation en procédant à un nombre considérable « inscriptions illégitimes (cas des citoyens que l'on autorisera à changer de domicile électoral s'ils sont favorables à la Droite). Nous devons donc nous contenter du chiffre des suffrages exprimés qui s'élève à 4.620.683. Ce chiffre lui-même n'étant pas absolument uniforme selon les publications consultées, nous avons pris celui qui est donné dans le document du Ministère de l'Intérieur ${ }^{1}$. Voici les sièges obtenus par chacune des formations en présence dans le cadre des deux répartitions intervenues:

\footnotetext{
Résultats des élections des députés du 29 octobre 1961, Athènes, 1962, P. 13. Encore faut-il observer que le total donné dans le tableau, soit 4.620.751, ne coïncide pas exactement avec l'addition que le lecteur peut faire des chiffres attribués aux divers partis, soit 4.620.683. C'est ce dernier chiffre que nous avons retenu, bien qu'il diffère de celui présenté par les services du Ministère à la Présidence du Conseil, soit 4.640.366 (brochure sur les élections, p. 19).
} 


\begin{tabular}{|c|c|c|c|}
\hline & $1^{\mathrm{re}}$ & $2^{\mathrm{e}}$ & Total \\
\hline Union Radicale Nationale & 154 & 22 & 176 \\
\hline Coalition Union du Centre-Parti Progressiste & 94 & 6 & 100 \\
\hline \multirow[t]{2}{*}{ Front Pandémocratique Agraire de Grèce } & 24 & - & 24 \\
\hline & 272 & 28 & 300 \\
\hline
\end{tabular}

[p. 114] Notons : immédiatement la petitesse du nombre des sièges renvoyés à la seconde distribution. La coalition, Union, du Centre - Parti Progressiste prend part à cette répartition, son pourcentage dans les voix — 3,64\% — dépassant sensiblement le, quorum de $25 \%$.

Comparons maintenant les pourcentages dans les sièges et dans les voix qu'obtiennent les diverses formations en présence :

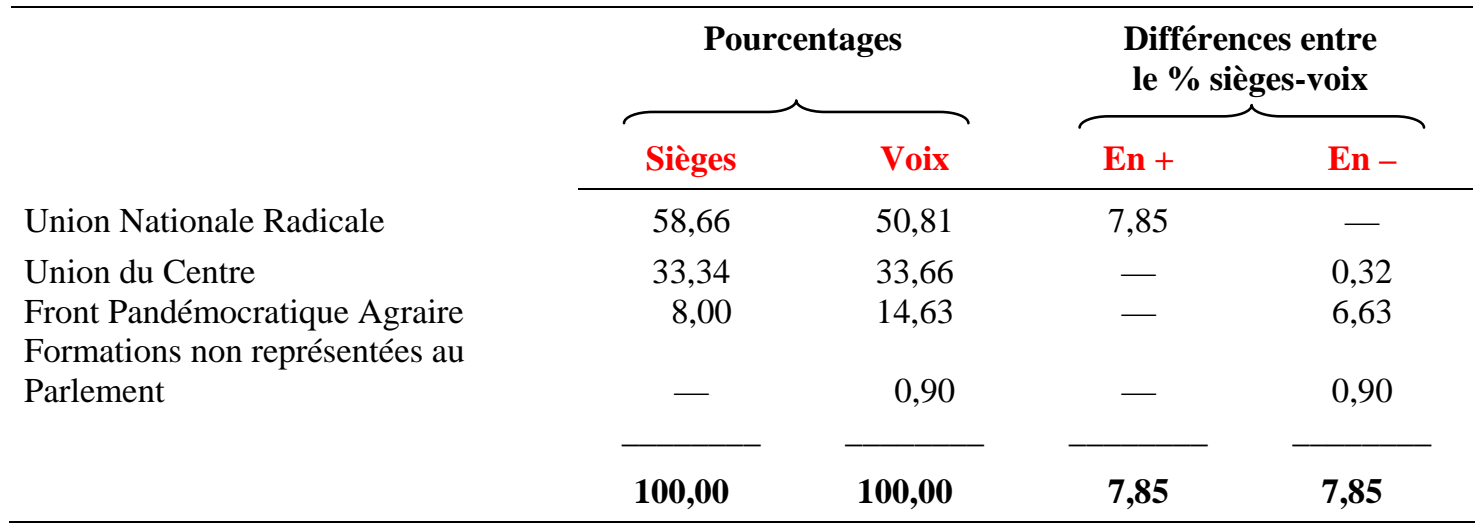

Ce tableau montre que pour l'Union du Centre le système électoral a fonctionné comme une proportionnelle idéale. Il a par contre défavorisé l'EDA qui perd les 2/3 du nombre de sièges conquis en 1958 (mais d'une élection à l'autre le pourcentage des voix mobilisées est tombé de 24,43 à 14,03). Une fois de plus, le parti de C. Caramanlis sort grand vainqueur de la consultation. Le système électoral l'avantage certes mais, cette fois, il a obtenu, de peu il est vrai, la majorité absolue dans le pays. Dès lors - surtout si l'on se réclame d'une inspiration proportionnaliste — il n'est plus possible de parler d'une minorité gouvernant une majorité à l'aide d'un système électoral astucieusement combiné. Du moins n'en saurait-on parler qu'en affirmant et en démontrant que c'est par la fraude au sens le plus large du terme que le pourcentage majoritaire a été acquis.

C'est ce que prétendront immédiatement les partis de l'opposition, aussi bien l'Union du Centre que la Gauche Démocratique Unifiée. Une querelle naît entre ces deux formations sur le point de savoir laquelle des deux a souffert ou le plus souffert de l'offensive de la Droite (l'absence d'analyse sociologique des «transferts » électoraux rendant [p. 115] très difficile d'émettre à ce propos, un jugement ferme). 
Mais l'une et l'autre sont d'accord pour reprocher à L'ERE des manœuvres d'usurpation et de corruption.

Dès le lendemain de la consultation, l'opposition déclare qu'elle ne reconnaîtra pas le gouvernement issu du « coup d'état électoral ». Un gouvernement de service avait été constitué le 20 septembre sous la présidence du général C. Dovas, chef de la Maison militaire du roi. Or le Centre et la Gauche, l'accusent immédiatement d'avoir failli à ses plus élémentaires devoirs d'impartialité et d'équité. Dès la réouverture du Parlement, les partis d'opposition mettront en accusation le gouvernement de service et le réquisitoire tendant à ce que le chef du gouvernement de service fasse l'objet d'un procès judiciaire se poursuivra durant plusieurs semaines au Parlement. En même temps, plusieurs milliers de plaintes sont déposées devant les tribunaux, ce qui, sous un certain angle, transforme la Grèce en une vaste cour de justice.

En un pareil domaine, il n'est jamais opportun, nous l'avons dit, de croire les partis d'opposition sur parole. Cette fois pourtant, la masse de témoignages peu à peu accumulée est impressionnante. L'Union du Centre et l'EDA ont chacune publié un « livre noir » qui, même si l'on fait sa part aux nécessités de la polémique, laisse planer les doutes les plus graves sur la volonté et la capacité du Cabinet Dovas d'accomplir correctement les tâches imparties à un gouvernement de service ${ }^{1}$.

Les accusations les plus graves portent sur la réalisation de fraudes et de manœuvres d'intimidation en des proportions, encore inconnues dans la pratique électorale grecque. G. Papandréou ira jusqu'à affirmer que dans les seules circonscriptions d'Athènes le nombre des inscriptions illégalement acquises atteint le chiffre de 100.000. Les partis d'opposition font état de multiples agressions commises contre leurs membres par des groupes para-militaires d'extrême-droite ainsi que par les Bataillons de sécurité nationale sur l'activité desquels nous reviendrons plus loin. Or, en bien des cas, ces agressions ont été commises avec la complicité passive et même le concours actif, des corps de sécurité (police et gendarmerie). L'armée ellemême, inspirée par un anti-communisme militant, n'a pas hésité à entrer dans la bataille aux côtés de l'ERE dont le chef bénéficie en cette période du soutien de l'État-Major. Selon l'oppo-[p. 116] sition, beaucoup d'officiers se comportèrent en l'occurrence davantage comme des mercenaires au service d'une cause partisane que comme les garants et gardiens de la sécurité nationale. Évoquant le concours apporté par des officiers supérieurs à la réalisation d'inscriptions fictives ou illégales, G. Papandréou, parlant à la tribune du Parlement, ira jusqu'à qualifier de «gang criminel » l'association entre l'État-Major et le parti gouvernemental.

Faisons la part d'une propension des politiciens grecs, surtout quand ils sont dans l'opposition, à hausser le ton et à enfler le réquisitoire. L'adoption d'attitudes de style robespierriste n'est certes pas la meilleure manière d'exprimer un jugement équilibré. Ces précautions prises, il est clair que la consultation de 1961 a emprunté de

1 Le document publié par l'EDA est: Mavri Vivlos, /To Ecloyico Praxicopima Tis 29 Octovriou, Athènes, 1962. Celui de l'Union du Centre intitulé : Mavri Vivlos. Te Chronico tou ecloyicou praxicopimatos tis 29 Octovriou 1961, Athènes, 1962. 
nombreux traits aux élections tenues dans les régimes autoritaires et, aussi, dans les républiques dites de bananes. Certes, de telles pressions et irrégularités s'étaient déjà manifestées lors des consultations précédentes, mais cette fois la densité et la rigueur des interventions sur le comportement des électeurs étaient plus grandes, plus systématiques aussi, que par le passé. Peut-être faut-il en trouver l'explication dans l'ampleur des résultats obtenus par l'EDA en 1958 et la crainte que celle-ci ne fasse encore des progrès.

L’Union Nationale Radicale disposant de la majorité absolue au Parlement, c'est C. Caramanlis qui assume la charge de Premier Ministre. La Grèce continue donc à bénéficier de la stabilité gouvernementale mais il devient rapidement évident que cette permanence ne suffit pas à garantir la stabilité politique.

En fait, le gouvernement se révèle incapable d'empêcher une profonde détérioration de la situation politique. Nous examinerons plus tard de manière détaillée les facteurs et les modalités de cette crise qui conduira finalement au remplacement de la Droite par le Centre dans le gouvernement du pays. Disons simplement ici qu'elle résulta de la violence de l'attaque menée contre Caramanlis par les partis de l'opposition qui refusent d'accepter les résultats de la consultation de 1961 et ne cessent de demander le retour devant le corps électoral.

En dépit des prévisions de plusieurs observateurs qui pronostiquaient son éclatement immédiat après les élections, l'Union du Centre conserve son unité et son leader G. Papandréou mène des attaques de plus en plus dures contre le parti gouvernemental dont il dénonce les agissements «totalitaires». De son côté, la Gauche organise de nombreuses [p. 117] manifestations dans le pays au cours de l'une desquelles G. Lambrakis, député collaborant avec l'EDA, trouve la mort. Immédiatement la Gauche déclare qu'il s'agit d'un assassinat perpétré par une organisation terroriste d'extrême droite avec la complicité de la gendarmerie. Cette mort - et les perspectives de collusion entre des éléments des forces de l'ordre et du parti gouvernemental que l'enquête révèlera — va susciter une énorme émotion dans le pays : il est possible qu'elle constitue le point tournant dans le renversement du rapport des forces qui est alors en train de s'accomplir.

Le 18 mai 1963, C. Caramanlis remet au Roi la démission de son gouvernement. En apparence, il s'agit d'un désaccord entre le monarque et le premier ministre quant à l'opportunité d'un voyage de la famille royale en Angleterre. Mais l'opération a certainement des causes plus profondes sur lesquelles nous essaierons plus loin de faire quelque lumière. Cette démission devait en tout cas aboutir à la sortie de la vie politique de Caramanlis qui avait gouverné le pays de manière ininterrompue pendant plus de 7 ans.

Il est important d'observer l'influence de ces événements sur la position des autorités américaines à l'égard des formations et leaders politiques. Depuis plusieurs années, les États-Unis avaient pris l'habitude de se reposer sur Caramanlis pour la défense de leurs intérêts (militaires, économiques, culturels...) en Grèce et il y a peu de chefs de gouvernement du bloc occidental qui aient été, plus et mieux que lui, dociles aux consignes ou suggestions de la puissance dominante. Déjà la mission 
McGhee était l'indice que les services américains n'entendaient pas rester complètement fermés aux aspirations d'autres groupes partisans. Mais il s'agissait à l'époque moins de prévoir et de préparer le remplacement de la Droite par le Centre que de renforcer celui-ci contre la Gauche ou si l'on préfère, d'organiser une opposition « nationale » dont le poids même réduirait l'EDA à un rôle secondaire.

Ainsi s'explique-t-on qu'au lendemain des élections de 1961, l'Ambassadeur des États-Unis dans son message de Noël ait cru devoir accorder un certificat de bonne conduite démocratique au gouvernement Caramanlis. Pour l'ambassadeur Briggs, cette consultation constituait la preuve tangible de la foi des Grecs dans les idéaux de la liberté individuelle. Vu les circonstances de l'époque, c'était une interférence notable dans la vie politique du pays. Un peu plus tard (fin août 1962), le viceprésident des États-Unis, L.B. Johnson, qui accomplissait un [p. 118] voyage officiel en Grèce décernait au gouvernement de la Droite un brevet d'efficacité et lui promettait la remise d'armes modernes. Il est vrai que ces témoignages de satisfaction s’accompagnaient d'une interruption définitive de l'aide économique.

Il apparaît cependant que sous l’Administration Kennedy, les États-Unis en soit venu progressivement à l'idée de l'opportunité, voire même de la nécessité, d'un remplacement de l'équilibre de la Droite par un cabinet d'inspiration centriste. On peut dès lors se demander si l'invitation faite au général de Gaulle de visiter la Grèce n'avait pas pour objet, dans l'esprit de Caramanlis, de compenser cette diminution de l'intérêt porté à sa personne par les autorités américaines. De toute manière, si, après la démission de Caramanlis, les Américains se sont préoccupés de la sauvegarde de l'ERE, en tant que bastion contre le communisme, il ne semble pas qu'ils aient jugé utile d'étendre cette sollicitude à son leader même. On peut penser que l'incapacité de Caramanlis de mettre un terme à la crise politique née de la consultation de 1961 n'a pas été étrangère à cette attitude.

Pour remplacer Caramanlis, le Roi décide de faire appel à P. Pipinellis, ministre dans le cabinet du premier et, par excellence, homme du « parti royal ». On a dit qu'à l'époque, le Palais caressait l'espoir de constituer une coalition de centre droit par association des éléments modérés de l'Union Radicale et de l'Union du Centre (S. Vénizélos). Quoi qu'il en soit de la réalité de cette supposition, qui paraît tout à fait plausible, Pipinellis forme, en date du 19 juin 1963 un cabinet dont la nature même est ambiguë. On le présente officiellement comme un cabinet de service et il est vrai qu'il était composé de techniciens. Mais ces techniciens sont pour la plupart de hauts fonctionnaires qui doivent leur carrière au précédent gouvernement. L'un d'entre eux toutefois, V. Sakellariou, Vice-président de la Cour de Cassation devait témoigner d'une grande indépendance d'esprit et de caractère dans l'instruction de l'affaire Lambrakis.

Quoi qu'il en soit, le Cabinet Pipinellis à l'instar du Cabinet C. Georgacopoulos se présente devant la Chambre : il en obtient la confiance mais sur la base des seules voix de l'Union Radicale.

Le principal problème que dut affronter le gouvernement Pipinellis, en dehors de la « couverture » du voyage royal à Londres, était celui des nouvelles élections. Les 
partis de l'opposition menaçaient de s'abstenir si la loi électorale n'était pas modifiée et si des garanties ne leur [p. 119] étaient pas assurées quant à un déroulement correct de la consultation. De son côté, la majorité parlementaire réclamait des élections immédiates avec application du système majoritaire, conformément à une disposition qui avait été insérée dans la loi électorale de 1961. Finalement, le gouvernement put obtenir le vote d'une loi qui conservait d'ailleurs pour l'essentiel les dispositions de la précédente. Ce texte, s'il n'obtint pas l'accord explicite de l'opposition, lui apportait toutefois en pratique un certain nombre de concessions (spécialement au titre de l'accès des partis simples aux deuxième et troisième répartitions).

Une fois acquis le vote de la loi électorale, conformément à la demande de l'opposition, un authentique gouvernement de service fut mis en place sous la présidence de S. Mavromichalis le 28 septembre 1963. La date des nouvelles élections fut fixée au 3 novembre 1963. Il semble que la Droite aurait préféré que les élections se tiennent sous le gouvernement Pipinellis. Mais sur ce point, le Roi jugea préférable d'accepter la thèse de l'opposition.

\section{IX. ÉLECTIONS DU 3 NOVEMBRE 1963}

\section{$\underline{\text { Retour à la table des matières }}$}

En accédant au pouvoir, le Premier Ministre Mavromichalis, Président de la Cour de Cassation, se déclara décidé à organiser des élections «impeccables à tous les points de vue ». Parmi les mesures prises à cet effet dès le 10 octobre, mentionnons : éloignement de leur poste du chef de la Gendarmerie et du Chef de la Police; désarmement par échelons des Bataillons de la Sécurité Nationale ; remplacement des préfets par les procureurs durant la campagne électorale; liberté de diffusion du matériel de propagande électorale ... Il est certes douteux que ces mesures aient suffi pour transformer l'esprit de l'appareil gouvernemental mis en place par l'ERE. Par ailleurs, les effets de la pression morale exercée pendant des années sur les électeurs, spécialement dans les campagnes, ne pouvaient disparaître du jour au lendemain (surtout si l'on considère que la Droite ne partait pas nécessairement battue dans ces élections). Cependant les commentateurs s'accordent généralement à reconnaître que ces élections se déroulèrent dans un climat susceptible de faciliter l'expression des préférences des citoyens.

Pour cette élection, comme pour la suivante, la distribution des sièges s'effectue sur la base du recensement de 1961. Toutefois il s'agit non de [p. 120] la population réelle mais de celle figurant sur les registres des municipalités et communes. Rappelons que l'ampleur de l'écart entre ces deux aspects de la population grecque laisse subsister, même dans le cadre d'un recensement très récent, la possibilité d'assez larges inégalités de représentation territoriale.

Quatre formations seulement, toutes des partis simples, sont en présence : l'ERE, le Parti Progressiste, l’Union du Centre et l'EDA. Cette dernière a fait aux partis d'opposition des propositions en vue de rétablissement d'un front uni contre la Droite, 
même si ce front devait se limiter à la période pré-électorale : ces avances ont été totalement rejetées par les intéressés. Par ailleurs, l'EDA renonce à la coalition avec le Parti Agraire National qui ne semble pas avoir procuré les résultats attendus, celuici n'ayant eu que 2 sièges dans la Chambre de 1961. Sans insister sur cet échec, disons que l'EDA elle-même est divisée sur l'opportunité de développer un tel parti : il semble bien que les militants de gauche dans les campagnes, seuls susceptibles de donner une assise solide à un parti agraire, n’aient pas été encouragés à réaliser cette expérience.

Le nombre des inscrits s'élève à 5.662 .965 (2.795.988 hommes et 2.866.977 femmes) - chiffre certainement beaucoup trop élevé. Le chiffre des votants est de 4.708.851, ce qui, déduction faite de 41.675 bulletins blancs ou nuls laisse un montant de 4.667.676 suffrages exprimés.

Voici les résultats obtenus par les quatre partis lors des trois répartitions successives :

\begin{tabular}{lrrrrr}
\hline & $\mathbf{1}^{\text {re }}$ & $2^{\mathrm{e}}$ & $3^{\mathrm{e}}$ & Total \\
\cline { 2 - 5 } Union du Centre & 120 & & 11 & & 138 \\
Union Nationale Radicale & 117 & & 10 & 5 & 132 \\
Gauche Démocratique Unifiée & 25 & & 2 & & 28 \\
Parti Progressiste & 2 & & - & - & 2 \\
\cline { 2 - 2 } & $\mathbf{2 6 4}$ & & $\mathbf{2 3}$ & $\mathbf{1 3}$ & $\mathbf{3 0 0}$ \\
\hline
\end{tabular}

Comparons maintenant les pourcentages de sièges et de voix recueillis par les diverses formations :

[p. 121]

\begin{tabular}{|c|c|c|c|c|}
\hline & \multicolumn{2}{|c|}{ Pourcentages } & \multicolumn{2}{|c|}{$\begin{array}{l}\text { Différences entre } \\
\text { le \% sièges-voix }\end{array}$} \\
\hline & Sièges & Voix & En + & En - \\
\hline Union du Centre & 46 & 42,04 & 3,96 & - \\
\hline Union Nationale Radicale & 44 & 39,37 & 4,63 & - \\
\hline Gauche Démocratique Unifiée & 9,34 & 14,34 & - & 5,00 \\
\hline Parti Progressiste & 0,66 & 3,73 & - & 3,07 \\
\hline \multirow[t]{2}{*}{$\begin{array}{l}\text { Formations non représentées au } \\
\text { Parlement }\end{array}$} & 0,00 & 0,52 & - & 0,52 \\
\hline & 100,00 & 100,00 & 8,59 & 8,59 \\
\hline
\end{tabular}

Bien que d'inspiration proportionnaliste, le système électoral avait donc favorisé les deux formations de tête, celles-ci obtenant ensemble $90 \%$ des sièges pour un peu plus de 80\% des voix. Par rapport à 1961, l’EDA conservait en gros son pourcentage 
de voix et réalisait quelques gains en sièges : toutefois elle était assez nettement défavorisée par le système électoral. Quant au Parti Progressiste qui présentait des candidats dans 51 circonscriptions sur 55, la faiblesse des résultats acquis s'explique si l'on sait que l'influence propre de cette formation se limite aux milieux intellectuels de la jeune Droite et du patronat éclairé.

Observons qu'une fois encore le vote des militaires (auquel s'ajoute, nous le savons, celui des fonctionnaires d'État en service ailleurs qu'au lieu de leur domicile électoral) devait favoriser la Droite comme l'établit le tableau suivant :

\begin{tabular}{lcc}
\hline & \multicolumn{2}{c}{ Pourcentages des partis } \\
\cline { 2 - 3 } & $\begin{array}{c}\text { Dans le vote des } \\
\text { militaires }\end{array}$ & $\begin{array}{c}\text { Dans l'ensemble des } \\
\text { suffrages }\end{array}$ \\
\cline { 2 - 3 } Union Nationale Radicale & 61,47 & 39,37 \\
Union du Centre & 33,74 & 42,04 \\
Parti Progressiste & 2,83 & 14,34 \\
Gauche Démocratique Unifiée & 1,93 & 3,73 \\
Indépendants & 0,03 & 0,52 \\
\cline { 2 - 2 } & $\mathbf{1 0 0 , 0 0}$ & $\mathbf{1 0 0 , 0 0}$ \\
\hline
\end{tabular}

[p. 122] Après la défaite, encore très limitée, que venait de subir son parti, Caramanlis quitta le pays en annonçant son intention d'abandonner la politique. Il fut remplacé à la tête de l'ERE par P. Canellopoulos dans des conditions que nous analyserons plus tard.

Lors de sa seconde réunion le 18 décembre, le nouveau Parlement élut son Président en la personne de $\mathrm{E}$. Tsirimocos, député d'Athènes. Candidat de l'Union du Centre, il obtint 167 voix sur 300, le groupe de l'EDA tout entier lui apportant ses suffrages. Cette élection préfigurait-elle la composition de la majorité parlementaire ? L'EDA se prononçait naturellement en ce sens. Selon elle, l'élection du Président de la Chambre établissait clairement l'existence d'une majorité démocratique dans le nouveau Parlement, le refus de cette solution impliquant discrimination à l'égard d'un parti constitutionnellement légitime et risquant de renforcer les forces de droite hostiles au changement survenu.

Tel ne fut pas cependant le point de vue de l'Union du Centre. Constituée sous la présidence de G. Papandréou, le nouveau gouvernement déclara refuser toute alliance avec la gauche: dès lors, l'ERE ne donnant aucun signe de désagrégation, il ne disposait pas au Parlement de la position stable indispensable à la réalisation d'un programme de longue envergure. G. Papandréou, non sans avoir annoncé la prise de mesures favorables à plusieurs secteurs du corps électoral (paysans, étudiants...), choisit donc de présenter sa démission au Roi le 24 décembre en lui demandant d'organiser une nouvelle consultation. Le Premier Ministre espérait manifestement 
que les électeurs lui donneraient cette fois la majorité absolue. C'était un pari, somme toute, conforme au tempérament de son auteur.

Avant d'accéder à cette demande, le Roi jugea utile de confier à P. Canellopoulos, leader de l'ERE, la mission d'explorer la possibilité de formation d'un gouvernement de coalition ERE - Union du Centre qui disposerait d'une très large majorité parlementaire. Cette démarche royale, qui fut interprétée en divers milieux comme un acte de favoritisme envers la Droite, manqua son but par suite du refus de G. Papandréou de se prêter à l'expérience. Parmi les arguments utilisés par celui-ci pour repousser la suggestion du souverain, mentionnons l'idée qu'une telle collaboration démoraliserait les masses électorales du Centre et le risque que l'EDA, devenue le seul parti d'opposition, ne connaisse un développement rapide.

[p. 123] L'opération ayant échoué, il ne restait plus au Roi qu'à mettre en place un cabinet de service pour organiser les nouvelles élections. La présidence de ce gouvernement fut confiée à J. Paraskévopoulos, Gouverneur adjoint de la Banque Nationale de Grèce et qui avait déjà été vice-président du Cabinet Dovas responsable de la consultation de 1961. Accepté par l'Union du Centre, le nouveau gouvernement de service devait être vivement critiqué par l’EDA.

\section{X. ÉLECTIONS DU 16 FÉVRIER 1964}

Retour à la table des matières

Rien n'est changé au tableau des inscriptions et au système électoral. Le gouvernement de service prend, lui aussi, un certain nombre de mesures susceptibles de favoriser la loyauté de la consultation. Les mêmes forces politiques sont en présence sous la seule réserve que cette fois l'ERE forme une coalition avec le Parti Progressiste.

Le nombre des votants s'élève à 4.626 .990 : déduction faite de 28.151 bulletins blancs au nuls, le chiffre des suffrages exprimés est de 4.598.839.

Voici les résultats obtenus par les trois formations en présence au titre des trois répartitions successives :

\begin{tabular}{lrrrrr}
\hline & $\mathbf{1}^{\text {re }}$ & $2^{\mathrm{e}}$ & $3^{\mathrm{e}}$ & Total \\
\cline { 2 - 3 } Union du Centre & 158 & & 6 & 171 \\
Coalition ERE-Parti Progressiste & 101 & & 2 & & 107 \\
Gauche Démocratique, Unifiée & 22 & & 0 & 0 & 22 \\
\cline { 2 - 3 } \cline { 5 - 6 } & $\mathbf{2 8 1}$ & & $\mathbf{9}$ & $\mathbf{1 0}$ & $\mathbf{3 0 0}$ \\
\hline
\end{tabular}


Comparons une fois encore les pourcentages des sièges et de voix obtenus par les diverses formations en présence :

[p. 124]

\begin{tabular}{|c|c|c|c|c|}
\hline & \multicolumn{2}{|c|}{ Pourcentages } & \multicolumn{2}{|c|}{$\begin{array}{l}\text { Différences entre } \\
\text { le \% sièges-voix }\end{array}$} \\
\hline & Sièges & Voix & En + & En - \\
\hline Union du Centre & 57 & 52,72 & 4,28 & - \\
\hline Coalition ERE-Parti Progressiste & 35,67 & 35,26 & 0,41 & - \\
\hline Gauche Démocratique Unifiée & 7,33 & 11,80 & - & 4,47 \\
\hline $\begin{array}{l}\text { Formations non représentées au } \\
\text { Parlement }\end{array}$ & 0,00 & 0,22 & - & 0,22 \\
\hline & 100,00 & 100,00 & 4,69 & 4,69 \\
\hline
\end{tabular}

G. Papandréou a donc gagné son pari, remportant à la fois, ce qui est plutôt rare dans la vie politique grecque, la majorité absolue des voix dans le pays et celle des sièges au Parlement. La Droite subit une sévère défaite, la coalition ERE-Parti Progressiste n'ayant que 35,26\% des voix (tandis qu'aux précédentes élections le total des voix des deux partis alors séparés était de 43,10\%). L’EDA elle-même est en recul.

À première vue, les pertes de cette dernière s'expliquent par la décision de s'abstenir de présenter des listes dans 24 circonscriptions en vue de faciliter le combat de l'Union du Centre contre l'ERE. Il s'agit des circonscriptions dans lesquelles l'EDA n'a pas de chances d'emporter des sièges mais où, compte tenu du refus du Centre de coopérer avec elle, la présence de candidats de celle-ci aurait pu valoir à l'ERE le gain des sièges en cause. Cette manœuvre électorale décidée par le Comité Central aurait eu pour unique objet selon l'EDA de porter un coup décisif à la Droite : il se serait agi selon les déclarations des leaders de ce parti d'un acte éminemment politique.

Sans entrer dans une controverse à ce propos, observons que cette explication n'a pas été acceptée par tout le monde. D'après certains, la Gauche, sûre de perdre des voix en raison de l'attraction exercée par le Centre, aurait eu l'idée d'accomplir un geste qui lui permette d'attribuer ces pertes à sa seule initiative. En somme, c'est la force du courant suscité par G. Papandréou dans le pays qui aurait poussé l'EDA à cette renonciation. Une autre interprétation a été proposée, il est vrai, par le journal de Droite Niki à la veille des élections : celle d'une collusion formelle entre l'Union du Centre et l'EDA, l'opération ayant fait l'objet d'un véritable accord entre les deux formations dont le journal déclarait [p. 125] avoir la copie. Notons que le Secrétaire de Papandréou ayant traduit Niki en justice, le directeur du journal fut condamné à une peine de prison légère et le journal à un retrait temporaire de l'exonération douanière du papier. 
En réalité, il semble que l'opération ait été l’œuvre de la Direction de l’EDA mais que celle-ci ait été poussée à l'accomplir par la pression d'un certain nombre de militants de base. Ceux-ci auraient voulu que le retrait intervienne dès les élections de novembre 1963 : la Direction de l'EDA s'y étant alors refusée, ses consignes ne furent pas pleinement suivies et le parti subit quelques pertes. Lors des élections de 1964, la Direction de la Gauche choisit elle-même de renverser sa position première à la fois pour faciliter la défaite de la Droite et pour tenir compte du souhait exprimé par divers milieux de la base. Il s'agit probablement d'une décision que l'on ne saurait ramener à un seul mobile. L'Union du Centre en tout cas ne saura aucun gré à l'EDA de sa décision et une fois revenu au pouvoir, avec une majorité parlementaire absolue cette fois, G. Papandréou continuera sa politique de lutte sur deux fronts.

Nous avons ainsi achevé l'étude analytique des neuf consultations électorales organisées depuis la fin de la seconde guerre mondiale. Chemin faisant, nous avons pu observer plusieurs changements dans le déroulement des luttes politiques et la consistance des forces partisanes. Le moment est venu d'en présenter une vue plus systématique. 
[p. 126]

\section{CHAPITRE III}

\section{TRAITS GÉNÉRAUX DE L’ÉVOLUTION}

Retour à la table des matières

L'ACTIVITÉ des partis politiques grecs, telle qu'on peut la saisir à travers les consultations électorales, laisse à première vue l'impression d'une mêlée confuse presqu'entièrement dominée par des rivalités ou des ambitions d'ordre personnel. Le fait que la grande lutte des années 1961-1963 ait porté au premier chef sur la personne de Caramanlis et, en définitive, ait semblé prendre la forme d'un duel Papandréou-Caramanlis ne peut que confirmer une telle impression. Dans cette perspective, qui concorde avec les spéculations actuelles sur la "personnalisation » du pouvoir - spéculations entièrement équivoques d'ailleurs - on en arrive rapidement à la thèse qui explique le déroulement de la vie politique grecque par des oppositions de type individuel entre les principaux candidats au pouvoir.

Cette thèse a des aspects plausibles. Elle présente cependant l'immense défaut de négliger les changements d'ordre général qui soit susceptibles de s'accomplir en liaison avec l'évolution des structures et pratiques sociales.

L'objet de ce chapitre est de déceler les transformations de ce type qui sont survenues dans le système des partis durant l'époque considérée et d'évaluer l'influence du système électoral sur la vie politique. 


\section{EXPOSÉ DES CHANGEMENTS}

$\underline{\text { Retour à la table des matières }}$

Nous allons d'abord nous efforcer de les saisir sous une forme purement statistique; une fois les changements identifiés, nous en montrerons le contenu politique.

[p. 127]

\section{A. ANALYSE STATISTIQUE}

Elle est rendue indispensable par les dimensions mêmes de l’univers considéré (95 partis). En faisant pour le moment abstraction de la signification politique de ces traits, il sera plus facile d'en donner une identification objective.

\section{FRÉQUENCE DES INTERVENTIONS ÉLECTORALES}

Si l'on considère les 95 partis mentionnés dans le lexique comme des entités distinctes, c'est-à-dire sous leur personnalité et leur dénomination d'origine, la fréquence de participation aux élections (de 0 à 9) est la suivante :

$\begin{array}{lrrrrrrrrrr}\text { Nombre de fois } & 0 & 1 & 2 & 3 & 4 & 5 & 6 & 7 & 8 & 9 \\ \text { Chiffre des partis } & 13 & 63 & 9 & 4 & 1 & 2 & 2 & 1 & 0 & 0\end{array}$

Ce tableau met en évidence un très faible degré de continuité dans l'activité partisane, une large majorité des formations entrées dans le combat électoral (72) n'ayant pris part au maximum qu'à 2 consultations électorales. Quant aux 13 formations s'étant abstenues de toute participation, il s'agit de combinaisons précaires ou de groupes de transition qui, constitués entre deux élections, ont rapidement disparu de la scène politique. Manifestement la longévité d'un grand nombre de ces organismes a été brève.

Ces propriétés s'atténuent pourtant si, au lieu de prendre chacun des 95 partis considérés comme une entité isolée, l'on tient compte de divers éléments qui les unissent les uns aux autres et par conséquent réduisent la dispersion du système. Pour illustrer le point, mentionnons que certains partis, apparemment nouveaux, sont en pratique les successeurs d'anciens partis dont ils ne diffèrent que par la dénomination et que d'autres partis résultent du regroupement, plus ou moins stable, de formations existantes.

Après accomplissement des corrections tenant à ces facteurs de continuité, la fréquence de participation s'établit comme suit : 


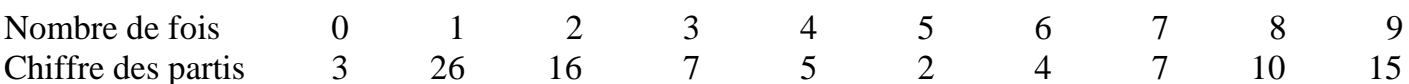

[p. 128] Ce second tableau fait ressortir un degré de continuité sensiblement plus élevé que le précédent. Il donne une vue plus juste que le premier de la période étudiée. Celle-ci pourtant demeure marquée, surtout dans ses débuts, par une pléthore de formations partisanes n'ayant eu, du moins beaucoup d'entre elles, qu'une durée d'existence réduite.

La comparaison de ces deux tableaux traduit le fait qu'en Grèce la complexité du jeu politique traditionnel découle aussi bien de la multiplicité des pièces que de l'instabilité des relations qui s'instituent entre elles. Il suffit d'évoquer à cet égard la figure classique du chef de parti ou de groupe parlementaire qui change de camp en compagnie de ses troupes. De tels transferts ont constitué une pratique courante de la vie politique de ce pays et nous en avons fourni plusieurs exemples dans le chapitre précédent. Il faut noter toutefois que depuis quelques années, la réalisation de semblables manœuvres est en nette régression.

\section{MODALITÉS DES INTERVENTIONS ÉLECTORALES}

Ces modalités ont connu des transformations dont la plus facile à saisir est une réduction sensible du nombre des formations ayant pris part aux élections successives de 1946 à 1964. Voici le détail de cette modification :

\begin{tabular}{lccc||cc}
\hline Élections & $\begin{array}{c}\text { Nombre de } \\
\text { partis } \\
\text { intervenant à } \\
\text { titre individuel } \\
\mathbf{( 1 )}\end{array}$ & $\begin{array}{c}\text { Nombre de } \\
\text { coalition de } \\
\text { partis }\end{array}$ & $\begin{array}{c}\text { Nombre de } \\
\text { partis entrés } \\
\text { dans les } \\
\text { coalitions } \\
\mathbf{( 3 )}\end{array}$ & $\begin{array}{c}\text { Total des partis } \\
\text { intervenant }\end{array}$ & $\begin{array}{c}\text { Total des listes } \\
\text { en présence }\end{array}$ \\
\hline $\mathbf{1 9 4 6}$ & 8 & $\mathbf{( 2 )}$ & $\mathbf{( 1 + 3 )}$ & $\mathbf{( 1 + 2 )}$ \\
$\mathbf{1 9 5 0}$ & 20 & 4 & 19 & 27 & 12 \\
1951 & 9 & - & 25 & 44 & 29 \\
1952 & 5 & 1 & - & 9 & 9 \\
1956 & 4 & 1 & 3 & 8 & 6 \\
1958 & 3 & 2 & 9 & 12 & 5 \\
1961 & 2 & 2 & 4 & 6 & 5 \\
1963 & 4 & - & - & 4 & 4 \\
1964 & 2 & 2 & 2 & 4 & 3 \\
\hline
\end{tabular}

[p. 129] Le changement est particulièrement net pour le nombre des listes en présence dont la diminution s'affirme de manière continue depuis les élections de 1951. Toutefois, pour apprécier correctement la portée de cette transformation, il faut mettre à part les formations à large implantation territoriale, c'est-à-dire celles dont les listes couvrent la très grande majorité des circonscriptions. En voici le nombre pour chacune des élections de la période (le chiffre des circonscriptions figurant à côté du millésime de l'élection) : 


\section{Ampleur de la couverture}

\begin{tabular}{|c|c|c|c|c|c|}
\hline & & Couverture totale & $\begin{array}{l}\mathrm{D}^{\circ} \text { à une ou deux } \\
\text { exceptions près }\end{array}$ & $\begin{array}{l}\text { Plus de } 2 / 3 \text { des } \\
\text { circonscriptions }\end{array}$ & Ensemble \\
\hline 1946 & $(38) \ldots \ldots$. & 1 & 1 & 1 & 3 \\
\hline 1950 & (39)...... & 3 & 2 & 2 & 7 \\
\hline 1951 & $(41) \ldots \ldots$ & 3 & 2 & - & 5 \\
\hline 1952 & $(99) \ldots \ldots$. & 1 & - & 1 & 2 \\
\hline 1956 & $(41) \ldots \ldots$ & 2 & - & 1 & 3 \\
\hline 1958 & (55)...... & 3 & 1 & - & 4 \\
\hline 1961 & $(55) \ldots \ldots$ & 3 & - & - & 3 \\
\hline 1963 & $(55) \ldots \ldots$. & 2 & 1 & 1 & 4 \\
\hline 1964 & $(55) \ldots \ldots$. & 2 & - & - & 2 \\
\hline
\end{tabular}

L'ensemble des formations à large implantation territoriale se décompose en partis et coalitions de partis de manière variable selon les consultations (fluctuations constituant le signe sans équivoque de la plasticité de la structure partisane de la Grèce) :

\begin{tabular}{|c|c|c|c|}
\hline & Partis & Coalitions de partis & Total \\
\hline 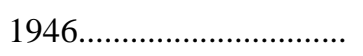 & 1 & 2 & 3 \\
\hline 1950 & 4 & 3 & 7 \\
\hline 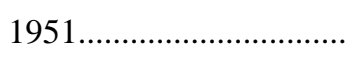 & 5 & - & 5 \\
\hline 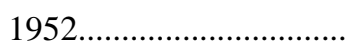 & 1 & 1 & 2 \\
\hline 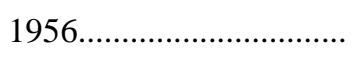 & 2 & 1 & 3 \\
\hline 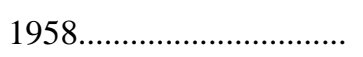 & 3 & 1 & 4 \\
\hline $1961 \ldots \ldots$ & 1 & 2 & 3 \\
\hline $1963 \ldots \ldots \ldots \ldots . .$. & 4 & - & 4 \\
\hline $1964 \ldots \ldots \ldots$ & 1 & 1 & 2 \\
\hline
\end{tabular}

[p. 130] Rapprochons maintenant les indications ainsi obtenues du chiffre des listes en présence au titre de chacune des élections.

\begin{tabular}{|c|c|c|}
\hline & Total des listes & $\begin{array}{c}\text { Nombre des listes à large } \\
\text { implantation }\end{array}$ \\
\hline 1946 & 12 & 3 \\
\hline 1950 & 29 & 7 \\
\hline $1951 \ldots$ & 9 & 5 \\
\hline 1952 & 6 & 2 \\
\hline 1956 & 5 & 3 \\
\hline 1958 & 5 & 4 \\
\hline 1961 & 4 & 3 \\
\hline 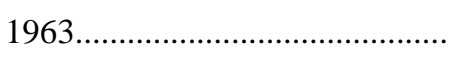 & 4 & 4 \\
\hline 1964 & 3 & 2 \\
\hline
\end{tabular}


Ce dernier tableau montre que les deux séries ont tendance à se rapprocher l'une de l'autre. La coïncidence est totale lors des élections de 1963, les seules listes présentées étant des listes à large implantation territoriale. Quant à la rupture du phénomène en 1964, elle tient à une manœuvre électorale de l'EDA qui réduisit volontairement son implantation (présence dans 31 circonscriptions seulement) en vertu de considérations déjà exposées.

Cette constatation établit que, comme l'on pouvait s'y attendre, la diminution du nombre des listes en présence s'effectue au détriment des petites formations à faible implantation territoriale. Celles-ci sont encore relativement nombreuses aux élections de 1946 et de 1950 ainsi que le fait ressortir le tableau suivant qui donne le chiffre des formations (partis et coalitions) ayant présenté des candidats dans cinq circonscriptions au maximum lors de ces consultations :

\begin{tabular}{ccccccc}
\hline & \multicolumn{4}{c}{ Nombre des formations présentes dans } & \multicolumn{2}{c}{ Total des } \\
\cline { 2 - 7 } & 1circ. & 2 circ. & 3 circ. & 4 circ. & 5 circ. & \\
\cline { 2 - 7 } & 3 & 3 & - & - & 2 & 8 \\
$1946 \ldots \ldots \ldots \ldots . .$. & 9 & 2 & 2 & 1 & - & 14 \\
$1950 \ldots . . . . . . . .$. & 9 & &
\end{tabular}

Dès les élections de 1951 la tendance se renverse et l'on s'achemine [p. 131] vers la disparition rapide des petites formations à implantation locale. Le même sort frappera d'ailleurs ; très vite les formations à implantation moyenne qui ne s'intègrent pas dans un parti ou une coalition plus vaste. Il est tout à fait clair que, durant la période étudiée, la plasticité de la vie politique grecque a finalement joué au profit du regroupement des forces.

L'analyse des candidatures confirme cette évolution. Le nombre des candidats s'établit comme suit pour chacune des élections considérées - la présentation de liste d'indépendants cessant à partir de 1961 :

Nature des Formations

\begin{tabular}{lccccc}
\hline & $\begin{array}{c}\text { Formations à } \\
\text { large } \\
\text { implantation } \\
\text { territoriale }\end{array}$ & $\begin{array}{c}\text { Autres } \\
\text { formations }\end{array}$ & $\begin{array}{c}\text { Listes } \\
\text { d'indépendants }\end{array}$ & $\begin{array}{c}\text { Candidats } \\
\text { isolés }\end{array}$ & Total \\
\cline { 2 - 6 } $1946 \ldots$ & 981 & 325 & 25 & 209 & 1.540 \\
$1950 \ldots$ & 1.640 & 1.006 & 33 & 383 & 3.042 \\
$1951 \ldots$ & 1.480 & 231 & 2 & 168 & 1.881 \\
$1952 \ldots$ & 573 & 206 & 50 & 216 & 1.045 \\
$1956 \ldots$ & 849 & 10 & 24 & 98 & 981 \\
$1958 \ldots$ & 1.192 & 169 & 12 & 110 & 1.483 \\
$1961 \ldots$ & 900 & 2 & - & 93 & 995 \\
$1963 * .$. & & & & & 1.262 \\
$1964 * .$. & & & & & 815 \\
\hline
\end{tabular}

(*) Décomposition non encore fournie par les services officiels. 
Pour l'appréciation numérique des candidatures, le point significatif est celui du nombre de candidats par siège. Il évolue comme suit durant la période considérée :

\begin{tabular}{|c|c|c|c|}
\hline Élections & Sièges & Candidats & $\begin{array}{c}\text { Nombre de candidats } \\
\text { par siège }\end{array}$ \\
\hline 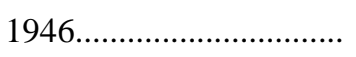 & 354 & 1.540 & 4,3 \\
\hline 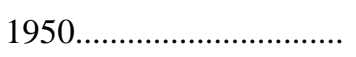 & 250 & 3.042 & 12,2 \\
\hline 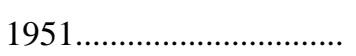 & 258 & 1.881 & 7,3 \\
\hline $1952 \ldots \ldots \ldots \ldots$ & 300 & 1.045 & 3,5 \\
\hline 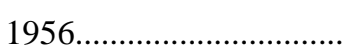 & 300 & 981 & 3,2 \\
\hline 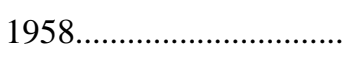 & 300 & 1.483 & 4,9 \\
\hline 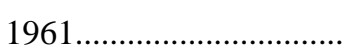 & 300 & 995 & 3,3 \\
\hline 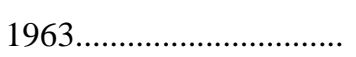 & 300 & 1.262 & 4,2 \\
\hline 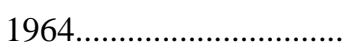 & 300 & 815 & 2,7 \\
\hline
\end{tabular}

[p. 132] Rapprochons enfin le chiffre des candidats du nombre des listes en présence pour chacune des élections de la période étudiée. L'évolution des deux séries est comme suit, le chiffre en apparence aberrant de 1961 s'expliquant par les listes d'indépendants et les candidatures d'isolés :

\begin{tabular}{|c|c|c|c|}
\hline & $\begin{array}{c}\text { Nombre de listes en } \\
\text { présence }\end{array}$ & $\begin{array}{c}\text { Chiffre des candidats } \\
\text { par siège }\end{array}$ & $\begin{array}{l}\text { Dont au titre des } \\
\text { candidats } \\
\text { indépendants et isolés }\end{array}$ \\
\hline 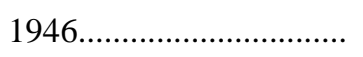 & 12 & 4,3 & 0,8 \\
\hline 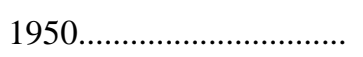 & 29 & 12,2 & 1,7 \\
\hline 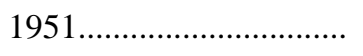 & 9 & 7,3 & 0,7 \\
\hline $1952 \ldots \ldots \ldots \ldots$ & 6 & 3,5 & 1,0 \\
\hline 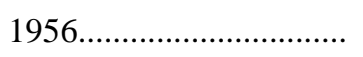 & 5 & 3,2 & 0,4 \\
\hline 1958 & 5 & 4,9 & 0,4 \\
\hline 1961 & 4 & 3,3 & 0,3 \\
\hline $1963 \ldots \ldots \ldots$ & 4 & 4,2 & - \\
\hline $1964 \ldots \ldots \ldots \ldots \ldots \ldots \ldots \ldots \ldots$ & 3 & 2,7 & - \\
\hline
\end{tabular}

À l'exception d'une pointe lors des consultations de 1950 et 1951, le chiffre des candidats par siège n'a connu que des fluctuations limitées (la faiblesse du chiffre de 1964 tenant à la manœuvre déjà indiquée). Dès lors, la chute continue du nombre des listes en présence ne pouvait avoir d'autre effet que de rapprocher les deux séries convergence qui s'affirme nettement à partir de la consultation de 1959.

En définitive, ces observations confirment qu'au cours des dernières années les luttes électorales ont tendu à se dérouler entre un petit nombre de formations qui s'opposent dans chaque circonscription ou, ce qui revient au même, présentent un nombre de candidats égal à celui des sièges à pourvoir. 


\section{[p. 133] 3. RÉSULTATS DES INTERVENTIONS ÉLECTORALES}

Il convient en premier lieu de rapprocher le nombre des partis qui sont intervenus dans le combat électoral (à titre isolé ou comme membre d'une coalition) de celui des partis ayant obtenu une représentation au Parlement. Voici l'évolution des deux séries :

\begin{tabular}{|c|c|c|}
\hline & \multicolumn{2}{|c|}{ Nombre de partis } \\
\hline & présentés aux élections & représentés au Parlement \\
\hline 1946 & 27 & 13 \\
\hline 1950 & 45 & 15 \\
\hline $1951 \ldots$ & 9 & 6 \\
\hline 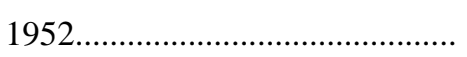 & 8 & 4 \\
\hline 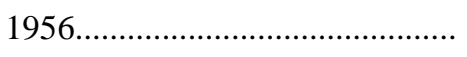 & 11 & 8 \\
\hline 1958...................................... & 12 & 9 \\
\hline $1961 \ldots$ & 6 & 5 \\
\hline 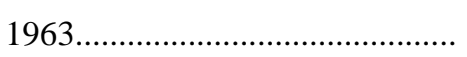 & 4 & 4 \\
\hline
\end{tabular}

Notons qu'aucun candidat se présentant isolément n'a pu obtenir de siège et que les listes d'indépendants n'en ont eu qu'en trois occasions (1946: 2; 1952 : 2 ; 1956 : 3 .

Ces observations confirment au niveau des résultats électoraux les indications recueillies au titre de l'analyse des listes. Cependant, pour évaluer cette concentration des résultats à sa juste mesure, il faut redistribuer les partis ayant accédé au Parlement selon l'importance de la [p. 134] représentation obtenue (en pourcentage du nombre des sièges du Parlement). Tel est l'objet du tableau suivant :

\section{Niveau de la représentation parlementaire}

\begin{tabular}{|c|c|c|c|c|c|}
\hline & $\begin{array}{c}\text { Partis ayant }+ \\
\text { de } 50 \% \text { des } \\
\text { sièges }\end{array}$ & $\begin{array}{l}\text { Partis ayant } \\
\text { de } 30 \text { à } 50 \%\end{array}$ & $\begin{array}{l}\text { Partis ayant } \\
\text { de } 10 \text { à } 30 \%\end{array}$ & $\begin{array}{c}\text { Partis ayant } \\
\text { moins de } 10 \%\end{array}$ & Total \\
\hline $1946 \ldots \ldots \ldots . . . . . . . . . .$. & 0 & 1 & 1 & 11 & 13 \\
\hline 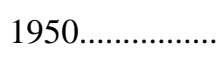 & 0 & 0 & 4 & 11 & 15 \\
\hline 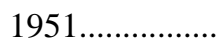 & 0 & 1 & 2 & 3 & 6 \\
\hline 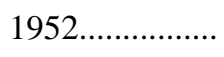 & 1 & 0 & 2 & 1 & 4 \\
\hline 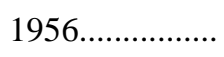 & 1 & 0 & 1 & 6 & 8 \\
\hline 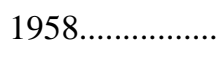 & 1 & 0 & 2 & 6 & 9 \\
\hline 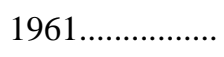 & 1 & 0 & 1 & 3 & 5 \\
\hline 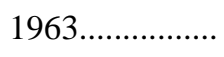 & 0 & 2 & 0 & 2 & 4 \\
\hline 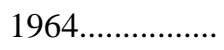 & 1 & 1 & 0 & 2 & 4 \\
\hline
\end{tabular}

Le point essentiel est évidemment la présence au Parlement depuis les élections de 1952 d'un parti bénéficiant de la majorité des sièges. À l'exception d'un bref intervalle (novembre 1963 - février 1964) la situation n'a pas changé depuis lors. Ainsi le 
multipartisme pléthorique des premières années d'après-guerre a-t-il été remplacé par un système de contestation triangulaire.

Observons au surplus que depuis le début de la période, ce sont les formations à large implantation territoriale qui, lors des consultations électorales, ont obtenu l'essentiel et finalement la quasi totalité des voix et des sièges :

\begin{tabular}{|c|c|c|}
\hline & \multicolumn{2}{|c|}{ Résultats obtenus } \\
\hline & en $\%$ des voix & en $\%$ des sièges \\
\hline 1946 & 88,79 & 90,9 \\
\hline 1950 & 80,22 & 91,1 \\
\hline $1951 \ldots \ldots$ & 96,29 & 99,6 \\
\hline 1952 & 83,44 & 99,3 \\
\hline 1956 & 97,75 & 99 \\
\hline 1958 & 96,87 & 98,6 \\
\hline 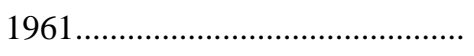 & 99,07 & 100 \\
\hline 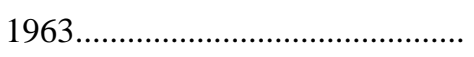 & 99,48 & 100 \\
\hline 1964 & 87,78 & 92,6 \\
\hline
\end{tabular}

[p. 135] Ce tableau montre bien qu'il ne faut pas s'exagérer la portée effective des petites formations dont nous avons recensé un nombre important. Quand une formation obtient quelques dizaines ou quelques centaines de suffrages sur tout le territoire, sa présence signifie davantage une contribution au folklore de la politique qu'un apport sérieux à la contestation partisane.

Le trait essentiel que met en lumière l'analyse statistique est la concentration progressive des forces partisanes. Au point de départ, la situation se caractérise par la présence d'un grand nombre de formations moyennes et petites dont l'audience repose sur le prestige d'un chef ou un réseau d'influences locales (ces deux particularités allant souvent de pair). Les regroupements qui interviennent sont souvent de simples coalitions électorales. À l'arrivée, nous trouvons des partis dits simples possédant une audience sur le plan national et dont chacun se préoccupe d'apporter une solution d'ensemble aux problèmes du pays. Pour les partis se trouvant dans l'opposition, cela signifie la présentation au corps électoral d'une « alternative ».

Le mécanisme de formation de partis liés à une personne continue certes de fonctionner. Le dernier exemple disponible est celui de la création en juillet 1964 d'un groupe dit Nouveau Mouvement Démocratique sous la direction de Ch. Potamianos, général de l'armée de l'air en retraite et ancien aide de camp du Roi Paul. Potamianos fut également Ministre de la Défense Nationale dans le Cabinet de service du général Dovas en octobre 1961. Ce parti, trop récent pour figurer sur notre lexique, se propose, selon son fondateur, de donner une impulsion aux problèmes de la planification dont la méconnaissance compromet le développement économique de la Grèce. Selon une déclaration de son chef — qui ne pêche pas par excès d'originalité 
— le nouveau parti n'a pas été formé pour faire des promesses mais pour trouver les moyens de réaliser les promesses non tenues.

Le mécanisme du parti personnel est donc toujours en place mais on peut se demander si de tels organismes conservent désormais une chance quelconque d'influer réellement sur la bataille politique.

En vue de livrer une telle bataille, les partis sont maintenant tenus de se présenter à l'échelle nationale et, plus particulièrement, de couvrir de leurs candidats l'ensemble du territoire. Ils y parviennent en absor-[p. 136] bant dans leurs rangs les cadres traditionnels de la vie politique qui, auparavant, profitaient de leur influence régionale ou locale pour constituer des formations distinctes.

On peut se demander s'il s'agit là d'une transformation définitive entraînée par des facteurs durables ou d'un changement temporaire dû à des éléments exceptionnels. Nous retrouverons ce problème pour l'étude duquel nous ne disposons pas encore de toutes les données nécessaires.

\section{B. CONTENU POLITIQUE}

Retour à la table des matières

Nous avons voulu présenter en un tableau récapitulatif (Annexe 1) l'évolution de la force parlementaire des divers courants en présence. Nous avons à cet effet distribué sous cinq rubriques — dont la signification réelle sera précisée ultérieurement — les formations ayant obtenu des sièges au Parlement durant la période considérée : Droite, Centre Droit, Centre, Centre-Gauche, Gauche. Nous avons déjà souligné les difficultés d'une telle ventilation et mentionné la convention choisie pour les régler. Nous nous efforcerons par la suite de préciser la signification socio-politique véritable de ces catégories usuelles de la lutte partisane grecque.

La constatation de départ est l'état de désagrégation des principales formations de l'avant-guerre. Cette situation est plus marquée chez les Libéraux que chez les Populistes, les éléments de Droite parvenant plus facilement que ceux du Centre à se coaliser. Parmi les raisons de cette fragmentation, signalons les dommages causés au système des partis grecs par l'interruption de toute vie parlementaire durant près d'une dizaine d'années. Mentionnons aussi l'absence d'hommes politiques capables de faire l'unité autour de leur personne par la possession d'un prestige individuel : dès lors, les épigones, spécialement dans le camp centriste, vont essayer chacun de tenter leur chance séparément.

Autre trait de cette période : la présence, en dehors des partis provenant de la fragmentation des anciens groupements, de multiples organismes d'inspiration diverse. Nous recensons de la sorte, au titre des élections de 1946 et 1950 : cinq partis agraires, huit partis chrétiens trois partis professionnels, quatre partis des travailleurs, quinze partis personnels ... La plupart de ces formations qui n’avaient ni implantation géographique ni organisation administrative, n'obtiendront [p. 137] aucun succès et disparaîtront très rapidement après les premières défaites électorales. 
Cette situation de multipartisme pléthorique — même si en définitive le nombre des partis entrant au Parlement demeure relativement limité — s'accompagne d'une instabilité gouvernementale à laquelle le public, ainsi d'ailleurs que les puissances protectrices, tendront à imputer les maux et désordres dont souffre le pays, notamment dans l'ordre monétaire.

Sur la base de telles prémices, la situation - comme le montre le tableau annexe — va évoluer dans le sens de la simplification et de l'unification des forces partisanes. Ce tableau fait ressortir en effet deux grands mouvements : la disparition progressive mais finalement complète des nuances d'opinion figurant entre la Droite et le Centre d'une part, la Gauche et le Centre de l'autre ; la concentration des forces à l'intérieur de chacune des grandes tendances. Autrement dit, la nuance Centre-Droit et la nuance Centre-Gauche (la première beaucoup plus vite que la seconde) cessent de jouir d'une représentation tandis que chacune des grandes tendances, la Droite beaucoup plus vite que le Centre, va bénéficier d'un mouvement de regroupement qui substituera à plusieurs partis liés par des rapports souples ou en état de rivalité une formation unitaire.

La Droite fera très vite son unité. En réalité, elle présente durant la période étudiée trois incarnations ou plus exactement peut-être trois physionomies successives : la vieille Droite populiste reposant sur des cadres traditionnels dont l'influence relève en une large mesure du clientélisme ; la droite du Maréchal Papagos à laquelle celui-ci donne un certain style plébiscitaire qui tend à réduire les députés à la situation de pions sur un échiquier ; la droite animée et manipulée par C. Caramanlis qui accentue les aspects autoritaires de la précédente expérience et lui adjoint d'importants éléments d'affairisme (l'un des éléments de la multiplication des rapports entre le monde politique et celui des affaires étant le développement des travaux publics qui entraîne des formes spécifiques de trafic d'influence).

Entre ces trois moments de la Droite grecque, il y a des éléments de continuité au sens où les points d'appui de cette tendance dans le pays ne se modifient guère. Mais l'emploi que l'Union Radicale fera de ces concours et de ces fidélités diffère certes considérablement de celui qu'en faisait et qu'aurait voulu en faire le vieux Parti Populiste.

[p. 138] L'élément essentiel pour notre propos est que cette transformation ira de pair avec le regroupement ou si l'on préfère ne lui oppose pas d'obstacle. La droite nouvelle manière absorbera ceux des cadres traditionnels qui acceptent de se soumettre à ses mots d'ordre et à ses techniques de gouvernement. Quant aux cadres qui ne se résignent pas à de telles transformations, l'Union Radicale s'efforcera souvent avec succès de les priver de leurs troupes. Et certains d'entre eux ne parviendront à assurer leur survie politique qu'en acceptant de s'intégrer dans le Centre sous la direction d'un chef qui, lui non plus nous le verrons, n'hésite pas à témoigner d'autorité.

En somme, la Droite s'est transformée et à divers égards on peut parler de transformation qualitative (le point tournant étant la naissance du Rassemblement Hellénique). Mais de 1951 à nos jours, malgré le décès de l'homme autour duquel 
s'était fait le regroupement et malgré les difficultés rencontrées par Caramanlis dans son parti de 1956 à 1958, l'unité de la Droite n'a pas été sérieusement mise en cause. Notre tableau ne laisse place sur ce point à aucune hésitation. Et il est important d'observer que si le pays a connu des mouvements d'extrême- droite, ils ne se sont jamais transformés en partis proprement dits, leur mécanisme d'intervention se situant à l'intérieur ou sur les marges du parti de droite.

La conquête par la Droite de la majorité absolue au Parlement — situation qui durera de 1952 à 1963 — assure la stabilité gouvernementale autour de Papagos d'abord et de Caramanlis ensuite, la Droite faisant de cette propriété un élément essentiel de sa propagande dans le pays et auprès de l'opinion étrangère. Cette stabilité parlementaire trouve son origine immédiate dans la discipline que le chef du parti parvient, à peu d'exceptions près, à faire régner dans son groupe parlementaire. Cette discipline est si forte que le chef (Papagos d'abord, Caramanlis ensuite) en arrive à traiter les députés comme une quantité négligeable ou, si l'on préfère, comme un bataillon à manœuvrer sans qu'il y ait besoin d'expliquer ou de justifier les ordres donnés. De la domination de la vie politique par les groupes parlementaires (ou plus exactement par les chefs de file de ces groupes), on passe à une étroite subordination du groupe de Droite unifié aux directives et volontés du chef du parti. À mesure que les années passent, le groupe parlementaire de l'ERE perd de plus en plus toute influence propre.

[p. 139] En somme, à part quelques brefs intervalles, la Droite a exercé en Grèce une influence politique prépondérante. À bien des égards on peut faire remonter la situation aux élections du 5 mars 1933 qui provoquèrent la défaite d'E. Vénizélos devant les Populistes. Si l'on définit la Droite par le conservatisme social conservatisme plus marqué en Grèce que dans les pays parvenus à un niveau supérieur de modernité — on peut dire que pendant 30 ans (1933-1963), c'est l'inspiration de Droite qui a prévalu. Reste à savoir si le Centre lui-même s'éloigne largement d'un tel conservatisme : nous retrouverons ce problème.

Le phénomène du Centre est plus complexe à interpréter que celui de la Droite. Ce qui surprend est moins son existence que son importance. Pendant très longtemps, le jeu politique grec a été dominé par l'opposition Conservateurs-Libéraux, les seconds constituant par construction même la gauche de la vie politique. C'est là une situation dont on pourrait trouver l'équivalent en de nombreux pays européens et en premier lieu en Angleterre. Mais dans la plupart des cas, les Libéraux ont du céder plus ou moins complètement la place, en tant que l'une des forces politiques de base, à la gauche née de la révolution industrielle. En somme, le mouvement qui les poussait vers le Centre les a en même temps privés d'une large partie de leur importance (parfois de la presque totalité de celle-ci). En Grèce, au contraire, le Centre dispose aujourd'hui de la majorité absolue.

La raison immédiate de cette situation apparaît clairement sur notre tableau : il s'agit de la faiblesse de la Gauche, de cette Gauche que l'on désigne parfois sous l'expression, qui n'est pas sans quelque ambiguïté, de gauche sociale. Réserve faite de l'élection de 1958 qui paraît bien avoir constitué un phénomène exceptionnel, cette 
Gauche nouvelle n'a pas pris en Grèce la place de la vieille opposition à la Droite. Cette particularité, dont nous aurons plus tard à expliquer les facteurs socioéconomiques, est évidemment l'une des clés de l'interprétation de la vie politique de ce pays. Elle seule permet de comprendre que dans une constellation tripartite DroiteCentre-Gauche, le Centre reste fort et soit, aujourd'hui, le plus fort.

Notre tableau montre que l'unification du Centre a été plus lente à se réaliser que celle de la Droite, l'un des échecs les plus marquants à cet égard étant celui subi par le général Plastiras. Le point n'a rien d'étonnant si l'on considère que le Centre, à partir du moment où se crée une gauche sociale, doit nécessairement se battre sur deux fronts [p. 140] ou plus exactement faire face à deux séries de forces centrifuges allant chacune dans une direction opposée. La Droite, au contraire, dès lors qu'elle évite la formation d'une Extrême-Droite ou absorbe en son sein ce qui en tient lieu, n'a qu'une frontière à surveiller, que cette frontière serve de repli ou de base d'attaque.

Valables en toutes situations, ces remarques ont un poids particulier pour la Grèce, les particularités de la vie politique y faisant refluer vers le Centre des éléments qui ne sont pas exactement « centristes » : des hommes de Droite heurtés ou découragés par le style et les méthodes de la Droite de Caramanlis ; des hommes de Gauche ou qui pourraient en être mais qui éprouvent des réticences à collaborer avec un parti qui passe pour être sous la domination des communistes. On a vu que c'est finalement de la très grave défaite subie en 1958 que naîtra l'impulsion unificatrice. La Gauche Démocratique Unifiée dont, sauf pour une brève période, la force parlementaire est demeurée très faible, a pour particularité en effet de comprendre en son sein ce que l'on appelle ailleurs l'Extrême Gauche. Le Parti Communiste Grec étant interdit depuis 1947, les Communistes ne peuvent exercer d'influence sur la vie politique, du moins au titre de l'action ouverte (participation électorale, activité parlementaire...) que par le truchement de la Gauche Démocratique Unifiée. Ce que deviendrait l'EDA dans le cas où l'interdiction contre le communisme serait levée, reste conjectural.

L'existence d'une force de gauche indépendante de toute domination ou orientation communiste augmenterait certes l'âpreté du combat pour l'obtention des suffrages d'inspiration Centre-Gauche. Il est difficile de dire si cette force parviendrait à s'assurer dans le pays le quantum d'appuis et de suffrages nécessaires à l'exercice d'une réelle influence. Notons en tout cas que si, depuis sa fondation en 1951, l'EDA a subi quelques avatars - divers politiciens élus sous son drapeau ayant tendance à s'en éloigner une fois le résultat acquis — son unité n'a jamais été mise en cause.

Ayant désormais analysé le contenu politique de l'évolution, nous sommes en mesure de présenter quelques éléments d’interprétation. 
[p. 141]

\section{INFLUENCE DU SYSTÈME ÉLECTORAL}

$\underline{\text { Retour à la table des matières }}$

Quand il s'agit d'expliquer l'évolution d'un système de partis quelconque, la théorie politique courante nous suggère deux pistes d'investigation sur la portée respective desquelles les spécialistes ne s'accordent pas : l'intervention du mode de scrutin ; l'action du contexte socio-économique. Sans prétendre, bien entendu, qu'il permet de trancher le débat, le cas de la Grèce apporte certains matériaux de valeur à la controverse.

Nous nous concentrerons ici sur les problèmes du système électoral en renvoyant au titre suivant l'analyse des facteurs socio-économiques. C'est donc seulement plus tard que nous serons en mesure de porter un jugement complet sur le sens et la portée de l'évolution observée dans le système des partis de 1946 à 1964.

On peut concevoir que l'influence du système électoral s'effectue par adaptation progressive du système des partis à un régime électoral stable ou qu'elle résulte de manipulations de celui-ci en vue d'obtenir des résultats déterminés. L'exemple de la Grèce relève clairement de la seconde hypothèse. Jusqu'où va en un tel domaine le pouvoir des politiciens?

\section{A. MÉCANISMES D'INTERVENTION}

$\underline{\text { Retour à la table des matières }}$

La plupart des lois électorales grecques de cette période ont été adoptées sur l'impulsion directe de la Droite. Dans certains cas (ainsi 1956) la Droite a profité de sa majorité absolue au Parlement pour imposer le dispositif de son choix. En d'autres situations (1951, 1952), la Droite, bien que minoritaire, a exercé une pression suffisante sur ses adversaires pour que ceux-ci acceptent de jouer son jeu. Il est vrai que dans l'élaboration de ces lois, la Droite a parfois agi de concert avec certains éléments du Centre (1958) ou a tenu compte de quelques revendications des partis de l'opposition (1963). Nous avons également noté que durant les années 1950-1952, l'Ambassade américaine n'a pas craint d'exercer des pressions pour l'adoption de dispositifs favorables à la Droite. En définitive si, pendant cet après-guerre, la loi électorale a été considérée comme une arme du combat politique, c'est pour l'essentiel la Droite qui, avec l'appui de forces constitutionnellement irresponsables, a été en mesure de la manipuler.

[p. 142] En matière politique, il est fréquent que l'on observe une discordance entre les mobiles officiels et les intentions réelles d'une démarche. Cet écart est particulièrement marqué dans l'ordre des manipulations électorales où les déclarations de principe cachent souvent des manœuvres intéressées et parfois sordides 
(découpage des circonscriptions) en vue d'assurer à un groupe déterminé le bénéfice de la conquête ou de la conservation du pouvoir. Il est bien connu que toute argumentation en matière de régime électoral comporte une part de rationalisation. Les promoteurs des régimes électoraux grecs n'ont certes pas failli à une telle pratique. Sans analyser de façon détaillée les débats intervenus en ce domaine débats qui d'ailleurs sont fort proches des entreprises similaires conduites à l'étranger — il ne sera pas inutile d'en signaler quelques aspects.

L'un des arguments les plus souvent utilisés dans ce genre de discussion est le souci d'assurer la stabilité gouvernementale, stabilité qui exige la présence d'une majorité parlementaire solide et compacte. C'est cet argument qui fut mis en avant pour justifier l'instauration du renforcement de la proportionnelle en 1951 et finalement l'institution du scrutin majoritaire à un tour en 1952. On a même vu des partisans de la proportionnelle, ou du moins se donnant pour tels, se rendre à cet argument, c'est-à-dire approuver le régime de proportionnelle renforcée, en soulignant qu'un régime de proportionnelle pure ne saurait être accepté sans danger grave dans un régime politique où le Législatif dispose du pouvoir de renverser l'Exécutif. Est-il indiqué d'admettre, ne serait-ce qu'en raison de telles convergences, que le souci d'assurer la stabilité gouvernementale fut le souci exclusif ou principal des auteurs des lois électorales préparées par la Droite ou sur son impulsion ?

En réalité la modification des règles du jeu électoral par le même parti lors de chaque consultation successive ne peut manquer d'éveiller une profonde suspicion quant aux mobiles réels de telles démarches. La lutte politique étant ce qu'elle est, il paraît légitime d'admettre que, quand la majorité change quelque chose au régime existant, c'est d'abord et peut-être uniquement en vue d'en obtenir des avantages particuliers. Et dès lors, il convient de ne recevoir que sous bénéfice d'inventaire, les critères ou valeurs présentés pour légitimer l'opération. Lors de plusieurs consultations (1956, 1958, 1961), l'ERE justifiera le mode de scrutin imposé à tout ou partie de ses adversaires par les nécessités de la stabilité gouvernementale. Mais il est clair que pour l'ERE cette sta-[p. 143] bilité c'était la perpétuation de son pouvoir. Autrement dit, quand la loi électorale est soumise à modification, le changement ne doit pas être apprécié en lui-même, de manière en quelque sorte académique, mais par rapport au parti qui en prend l'initiative.

Il paraît difficilement contestable que durant son long séjour au pouvoir, la Droite grecque a considéré le système électoral comme l'un des instruments privilégiés du maintien de sa primauté gouvernementale. Ainsi s'explique que lors de chaque consultation, le choix du mode de scrutin ait donné lieu à de larges et souvent très âpres débats politiques.

Autre point significatif du système électoral grec : la préférence donnée aux partis simples sur les coalitions de partis, notamment au titre de l'accès aux deuxième et troisième répartitions. L'argument est qu'une coalition constitue souvent un rassemblement fragile et comme tel susceptible de se défaire au lendemain de la coalition. Dès lors, la coalition ne peut être tenue pour l'instrument d'une majorité 
parlementaire stable et, dans la mesure où l'on tente de promouvoir une telle majorité, il vaut mieux favoriser les partis simples.

Comme le montre bien l'exemple des apparentements en France (spécialement sous la législature 1951-1955), ce mode de raisonnement n'est pas sans valeur. Mais en Grèce les discriminations imposées aux coalitions avaient aussi pour objectif d'empêcher certains regroupements et notamment ceux susceptibles de se constituer autour de l'EDA. Il faut d'ailleurs noter au titre de cette formation que la Droite, suivie en cela par plusieurs politiciens du Centre, n'a jamais fait mystère de son désir de lui rendre la compétition électorale plus difficile et, en tout cas, moins productive. Partant du principe que l'EDA ne constitue pas une force « nationale », les adversaires de ce parti ont généralement témoigné de franchise dans la présentation des mécanismes susceptibles de limiter sa représentation parlementaire.

Au total, la manipulation systématique de la loi électorale peut, sur le terrain de la discussion abstraite, relever de deux inspirations : l'une tendant à produire un effet de réaménagement des structures et pratiques partisanes en vue d'agir finalement sur le fonctionnement de l'appareil gouvernemental ; l'autre visant à favoriser un parti ou un groupe de partis dans la conquête de la représentation parlementaire. D'un côté donc, un essai d'intervention de portée générale et que ses promoteurs déclarent volontiers conforme à l'intérêt général. De l'au-[p. 144] tre, une simple manœuvre égoïste dont le résultat sera le plus souvent de créer ou d'accentuer diverses sortes d'inégalités de représentation. On comprend que les partis qui disposent du pouvoir de modifier le système électoral aient généralement pour habitude de mettre en avant la première de ces deux ambitions. L'expérience établit pourtant que c'est le plus souvent la seconde qui les fait agir.

Notons toutefois qu'en politique, comme dans n'importe quel autre secteur de la vie sociale, les initiateurs d'une mesure ne sont que rarement maîtres de contrôler, sinon même d'entrevoir, la chaîne complète de ses effets. Il est possible que l'adoption d'un régime électoral de favoritisme partisan, conduise, le cas échéant par accumulation ou répétition, le (ou les) groupe victime de l'opération à changer son mode d'organisation ou son plan de bataille. Ainsi une démarche d'inspiration purement électorale sera-t-elle finalement susceptible de provoquer des modifications de portée générale dans le système des partis. Et dans cette perspective, il est parfaitement possible que le parti qui a abusé de sa position de force soit victime de la colère qu'il aura suscitée ou des convoitises qu'il aura provoquées.

Pendant plusieurs années, la Droite grecque a avancé, pour justifier ses manipulations électorales, la nécessité de créer dans le pays les conditions d'un authentique bipartisme - argument qui constitue seulement une autre manière de présenter le thème de la stabilité : d'où en particulier selon elle, la légitimité des privilèges attribués aux formations de tête au titre des deuxième et troisième répartitions. Venant précisément en tête à cette époque grâce à son unité, la Droite s'attribuait ainsi le beau rôle tout en conservant la meilleure part du butin. Mais le jour où le vœu de la Droite s'est réalisé par unification des forces du Centre sous l'égide de l'Union du Centre, la première, loin de se comporter vis-à-vis de la seconde 
selon les règles du bipartisme parlementaire a mené contre elle un combat irrégulier et déloyal. En réalité, la manière dont furent conduites les élections de 1961 annule rétrospectivement la prétention de la Droite de créer en Grèce les conditions d'un régime parlementaire moderne par alternance des deux formations au pouvoir. Néanmoins, la Droite, par ses excès et ses exactions, avait contribué, dans une mesure qui n'est certainement pas négligeable, à créer ce second parti.

En matière de système électoral, il n'y a pas de formule idéale ou parfaite. La recherche d'une telle formule est d'autant plus vaine que [p. 145] l'action d'un système quelconque n'est jamais mécanique et dépend du milieu socio-politique régi. Le principe majoritaire et le principe proportionnel ont chacun leurs avantages, chacun aussi leurs inconvénients. Rien n'interdit dès lors de tenir pour optimal un régime qui fasse une part à chacun de ces deux principes. À une condition élémentaire toutefois : qu'il s'agisse d'une combinaison stable dont les modalités ne soient pas mises en cause à chaque consultation et en fonction des particularités de la situation d'alors. Il n'est pas besoin d'une longue explication pour comprendre que le combat électoral risque de dégénérer en une simple imposture si le parti qui détient les leviers de commande s'en sert pour imposer des règles de son choix aux partis de l'opposition.

En définitive, on doit considérer la stabilité du régime électoral comme un facteur ou un signe d'équité politique dans la mesure où, cette permanence étant acquise, aucune formation ne peut profiter de son passage au pouvoir pour changer les normes et procédés du mode de scrutin. Dès lors, les partis battus dans une précédente consultation se trouvent en mesure de préparer leur revanche sur la base d'un dispositif connu d'avance.

\section{B. EFFETS DE L'INTERVENTION}

$\underline{\text { Retour à la table des matières }}$

Nous partons de l'idée que la Droite a manipulé le régime électoral dans son intérêt propre. Ces démarches ont finalement suscité des réactions dont elle a fait les frais. Il en est résulté en particulier une simplification certaine du jeu partisan dont nous ne pensons pas qu'on puisse lui faire crédit.

\section{EFFETS SUR LES RÉSULTATS ÉLECTORAUX}

La Droite a profité du système électoral de multiples manières, la difficulté étant d'attribuer une valeur d'ensemble à ces manœuvres. Les principales d'entre elles ayant été décrites dans le précédent chapitre, nous nous bornons ici à un simple rappel :

$1 \%$ Retard dans l'adaptation du partage des sièges aux changements démographiques, d'où création de larges inégalités territoriales de repré-[p. 146] sentation. Or, ces inégalités affectent de manières très diverses les formations en présence et l’on peut avancer que la Droite en a été la principale bénéficiaire. 
Soit la consultation de 1958 pour laquelle les sièges furent distribués, on le sait, sur la base du recensement de 1940. Par suite des défectuosités des registres électoraux, il est préférable de raisonner non en vertu des électeurs inscrits mais en fonction des suffrages exprimés. Le point le plus facile à illustrer est la diversité, selon les circonscriptions, du nombre des suffrages exprimés par siège attribué. Le nombre de suffrages exprimés dans l'ensemble du pays étant de 3.847 .785 pour 300 sièges, la valeur moyenne de ce quotient est de 12.826. Elle atteint son point maximum pour Athènes Banlieue: 23.244 et son niveau minimum pour la circonscription de Thesprotie en Épire : 6.862. Observons maintenant le pourcentage de l'ERE dans chacune de ces circonscriptions (son pourcentage moyen national étant de $41,17 \%)$ : il est de $29,21 \%$, soit moins de la moyenne à Athènes Banlieue, et de 57,84\%, soit beaucoup plus dans la circonscription de Thesprotie.

Étendons maintenant cet examen à l'ensemble du territoire. Nous trouvons 31 circonscriptions sur-représentées au sens où le nombre de suffrages exprimés par candidat élu est inférieur à la moyenne nationale, soit 12,826 et, d'après ce même critère, 24 sous-représentées (dont Athènes-Ville, Athènes-Banlieue, SaloniqueVille). Or, dans 22 des 35 circonscriptions sur-représentées, soit dans 63\% de cellesci, l'ERE obtient plus que sa moyenne nationale de suffrages tandis que cette situation ne se produit que dans 11 des 24 circonscriptions sous-représentées, soit $45 \%$ de celles-ci. Dans les sept circonscriptions les plus sous-représentées, l’ERE ne dépasse sa moyenne nationale qu'une fois.

On voit donc que la force électorale de l'ERE est sensiblement plus grande dans les circonscriptions sur-représentées que dans celles sous-représentées. C'est donc cette formation qui a tiré le meilleur parti des inégalités territoriales de représentation.

2\% Conquête d'une part préférentielle dans les suffrages des militaires auxquels sont assimilés, sous cet angle, les fonctionnaires se trouvant en service dans une autre circonscription que celle de leur domaine électoral et choisissant de voter au lieu de service. Nous avons montré, à propos de chaque consultation que la Droite tirait d'importants avantages électoraux des suffrages de cette catégorie, les militaires [p. 147] du contingent ne pouvant éviter de subir la pression d'un corps d'officiers dont le conservatisme est l'un des traits essentiels de la vie politique grecque.

Nous avons vu que les modalités d'émission de ces suffrages ainsi que le procédé d'addition de ceux-ci aux votes des citoyens ordinaires a varié selon les consultations. Dans certaines occasions (ainsi en 1956 et 1961), les suffrages en provenance d'unités militaires ont été ajoutés aux suffrages de la circonscription de stationnement des dites unités - on a pu alors observer que les militaires ont valu à la Droite des sièges qui lui auraient échappé au titre du seul vote des civils. Soit en 1956 le cas de la circonscription de Céphalonie à laquelle trois sièges étaient attachés. Les résultats furent les suivants : 


\begin{tabular}{|c|c|c|c|}
\hline & Vote des civils & Vote des militaires & Total \\
\hline ERE & 12.065 & 1.255 & 13.320 \\
\hline Union Démocratique................... & 12.484 & 490 & 12.974 \\
\hline
\end{tabular}

On voit donc qu'en cette circonscription le vote des militaires stationnés pour la durée de leur service altéra le scrutin au détriment des citoyens de résidence permanente. Toujours pour l'élection de 1956, le vote militaire valut encore à l'ERE deux autres sièges (l'un à Salonique, l'autre dans la circonscription Etolie-AcarnanieEuritanie).

$3 \%$ Attribution d'un pourcentage de sièges supérieur au pourcentage de voix, la différence résultant du mécanisme adopté pour la répartition des sièges. Voici les décalages intervenus au profit de la Droite de 1952 à 1961 :

\begin{tabular}{lllll} 
& $\mathbf{1 9 5 2}$ & $\mathbf{1 9 5 6}$ & $\mathbf{1 9 5 8}$ & $\mathbf{1 9 6 1}$ \\
\cline { 2 - 5 } Pourcentage dans les voix.......................... & 49,22 & 47,38 & 41,17 & 50,81 \\
Pourcentage dans les sièges.................... & 82,30 & 55,00 & 57,00 & 58,66
\end{tabular}

Les élections de 1952 montrent le genre de distorsion qu'est susceptible de créer le scrutin majoritaire à un tour quand la lutte électorale est dominée par des personnalités charismatiques. En 1956, l'ERE a moins de voix que l'Union Démocratique (47,38\% contre [p. 148] 48,15\%) mais elle a plus de sièges (55\% contre 44\%). En 1958, la force parlementaire de l'ERE évolue en sens inverse de sa force dans le pays. Pour 1961, la Droite continue de bénéficier d'un écart notable sièges-voix. Au total, dans les quatre consultations examinées, le mécanisme de distribution des sièges, sous des modalités diverses et avec une ampleur variable il est vrai, a toujours fonctionné au profit de la Droite. Par rapport au pourcentage des voix obtenues dans le pays il lui a permis, tantôt de racheter une défaite ou de compenser un insuccès, tantôt d'amplifier une victoire.

$\mathrm{Au}$ total, il est incontestable que le système électoral pris en un sens large, a facilité et favorisé les entreprises de la Droite. Mais à trop raisonner sur le système électoral et spécialement sur le mécanisme de distribution des sièges, on risque d'oublier un autre élément ou ensemble d'éléments d'une importance pourtant capitale au titre de l'explication des résultats électoraux: les avantages susceptibles de découler de l'occupation du pouvoir elle-même, la prime résultant du pouvoir ou, comme on le dit parfois, la prime au pouvoir.

Cette situation s'observe dans tous les pays, y compris dans ceux les plus respectueux en apparence des exigences de la démocratie représentative. Elle prend de multiples aspects dont la consistance varie selon la structure politicoadministrative. Signalons par exemple, an titre des pays centralisés, l'action dans les collectivités locales des représentants du pouvoir central, tels les préfets en France ou en Italie : on sait l'importance majeure qu'attribuait le parti Radical sous la III $^{\mathrm{e}}$ 
République à ce que le Ministère de l'Intérieur soit occupé par l'un des siens. Autre trait universel cette fois : le maniement du patronage dont le contrôle des ressources publiques permet de multiplier et d'intensifier l'emploi. Or, l'exercice des pratiques qui aboutissent à la formation de la prime au pouvoir est bien loin de se limiter à la campagne électorale stricto sensu: en quelque mesure, la campagne constitue simplement l'époque durant laquelle on recueille ou espère obtenir le résultat d'actions ou de manœuvres entreprises souvent de longue date.

La Droite grecque a occupé le pouvoir sans aucune interruption de 1952 à 1963. Et durant cette période, elle a mis à son service, avec une constance et une rigueur remarquables, l'ensemble des facultés qu'offre le pouvoir — facultés de patronage certes, mais aussi faculté systématique de colonisation de tout l'appareil public et parapublic [p. 149] colonisation impliquant l'élimination ou l'épuration non moins systématique de tous les adversaires du pouvoir établi. Ainsi s'explique qu'au titre de la contestation électorale cet appareil ait en général pris le parti de la Droite, l'intervention embrassant des actes ou démarches incompatibles avec le fonctionnement loyal ou simplement correct du régime représentatif (ainsi rôle de la police dans la distribution des pièces permettant des inscriptions irrégulières sur le registre électoral, dans l'intimidation des électeurs, etc. ...). Comme nous l'avons déjà vu, il ne suffit pas pour comprendre le problème de s'attacher au mécanisme de conversion des voix en sièges, encore faut-il examiner les moyens ayant permis de rassembler les voix. Et il peut arriver que ces moyens - ou si l'on préfère cette utilisation massive et sans scrupule de la prime au pouvoir - vaillent au parti gouvernemental des avantages supérieurs à ceux que lui procure la manipulation du mécanisme électoral lui-même.

Au total, le mode de scrutin n'est pas suffisant pour expliquer la totalité du favoritisme électoral qui a bénéficié à la Droite durant la période considérée. Et c'est seulement après avoir évoqué l'action gouvernementale de celle-ci, spécialement à compter de la formation de l'ERE, que nous évaluerons avec quelque chance d'exactitude les avantages que la Droite a tirés de l'exercice du pouvoir pour la conservation de ce pouvoir.

\section{EFFETS SUR LE SYSTÈME DES PARTIS}

Nous avons déjà indiqué que la concentration des forces partisanes en un petit nombre de formations représente l'un des traits caractéristiques de l'évolution ayant affecté le système des partis durant la période considérée. Il paraît légitime d'avancer que la manipulation du système électoral à son profit par la Droite a constitué l'un des grands mobiles de l'unification de ses adversaires.

Le point est manifeste lors des élections de 1956 où, malgré la répugnance de plusieurs leaders centristes à accepter de telles relations, une coalition se forme entre le Centre et la Gauche. Il est vrai qu'il s'agit d'un front purement électoral et que, par ailleurs, l'entreprise ne sera plus recommencée (les petits partis du Centre-Gauche étant finalement dissuadés de former une coalition avec l'EDA lors de la consultation de 1958). 
[p. 150] L'action du système électoral a été plus forte dans le cas du regroupement centriste. La volonté de mettre fin à la situation hégémonique de la Droite et aux abus de tous ordres en résultant a certainement joué un rôle essentiel parmi les mobiles ou facteurs ayant suscité le rassemblement des partis centristes pour l'exercice d'une action commune. Compte tenu des pénalités infligées par la Droite aux coalitions, la seule manière pour le Centre de se battre avec quelque chance de succès était de constituer une formation unitaire. Cette unité n'était pas susceptible d'assurer à elle seule la victoire du Centre sur la Droite (cas des élections de 1961) mais elle était en définitive la condition nécessaire pour que le premier soit en mesure de se battre à égalité avec la seconde.

De la même manière, on peut considérer que le souci de conserver les avantages allant à une grande formation unitaire a représenté l'un des facteurs du maintien de l'unité au sein de l'ERE. La rupture de cette unité aurait en effet risqué de priver les parlementaires de l'ERE des bénéfices électoraux allant aux membres de la formation de tête. Ayant apprécié les bienfaits du retour à l'unité lors des élections de 1952, la Droite était, par là même, incitée à garder sa cohérence face à un adversaire divisé d'abord et uni ensuite.

Gardons-nous pourtant d'admettre que le système électoral a constitué l'unique facteur du mouvement observé et spécialement de l'autorité exercée par les leaders du parti sur les membres du groupe parlementaire. D'autres éléments que nous étudierons en examinant la structure des partis expliquent la diminution d'intensité des tendances centrifuges. Anticipant sur l'analyse des partis, notons que jusqu'à maintenant cette unification ne s'est pas accompagnée d'un renforcement des structures partisanes. Le mode de scrutin n'a pas exercé grande influence en ce domaine qui reste sous la dépendance de l'évolution sociale toute entière.

Au total, sous quelque angle qu'on en considère les effets, le système électoral, plus exactement la manipulation systématique de celui-ci par le pouvoir établi, tout en ayant joué un rôle important, ne saurait expliquer la totalité des résultats enregistrés et des évolutions observées. Pour expliquer intégralement les phénomènes examinés ou relevés dans [p. 151] ce premier titre, il est nécessaire de faire appel à des éléments tirés ; aussi bien du contexte socio-économique que de l'action gouvernementale ellemême.

Nous sommes ainsi conduits au seuil d'une autre analyse qui va porter sur les origines historico-sociales, les structures d'organisation et d'encadrement, ainsi que les principaux modes d'activité des grandes formations partisanes. Ainsi comprendrons-nous mieux les raisons de la longue domination exercée par la Droite sur la vie politique grecque ainsi que les facteurs de sa récente défaite devant le Centre.

[p. 152, sans texte.] 
[p. 153]

\section{TITRE DEUXIÈME}

\section{état des partis}

Retour à la table des matières

LORS DES DEUX DERNIÈRES CONSULTATIONS électorales (1963 et 1964) quatre partis seulement se sont présentés aux suffrages des électeurs: l'Union Nationale Radicale (ERE), le Parti Progressiste, l'union du Centre (EK), la Gauche Démocratique Unifiée (EDA). Cette simplification était déjà acquise dès les élections de 1961 (si du moins l'on fait abstraction du Parti National Agraire coalisé avec l'EDA en cette circonstance). Nous allons examiner successivement chacune de ces formations qui, prises dans leur ensemble, constituent actuellement le système grec des partis. L'ordre suivi pour l'exposé sera celui de la date de création des partis considérés.

Soulignons d'emblée qu'il s'agit là de formations très différentes les unes des autres. L'Union du Centre, la plus récente, ne dispose encore que d'un embryon de bureaucratie et il ne semble pas que le leader actuel de ce parti, G. Papandréou, éprouve le désir d'en perfectionner l'appareil. On prête toutefois aujourd'hui au leader de l'EK le souci de mettre sur pied une nouvelle organisation de jeunesse du parti qui s'appellerait jeunesse Démocratique Grecque. Le Parti Progressiste, formation de très petite envergure, représente seulement un instrument d'action aux mains d'un homme, S. Markézinis, dont la sortie de la vie politique entraînerait probablement la disparition du parti. Le trait caractéristique de l'Union Nationale Radicale, du moins pendant la présence de C. Caramanlis au poste de Premier Ministre, a été une osmose très poussée, à divers égards un rapprochement presque orga-[p. 154] nique, entre les instances partisanes et les services gouvernementaux. Selon certaines informations, les dirigeants actuels de l'ERE se prépareraient à lancer une vaste campagne idéologique dans le pays. Seule en définitive, l'EDA entre dans la catégorie des partis modernes à structure rigoureuse et à recrutement de masse. 
En somme, malgré certaines apparences, la Grèce n'en est pas encore à l'âge des grandes machines partisanes de style bureaucratique. Aussi sera-t-il utile, avant de passer à l'analyse monographique de mettre en évidence les particularités du contexte qui permettent de comprendre la situation présente. 
[p. 155]

\section{CHAPITRE IV \\ PARTICULARITÉS DU CONTEXTE}

Retour à la table des matières

LE SYSTÈME grec des partis ne saurait être correctement analysé sans examen préalable du milieu social qui leur sert de cadre et dans lequel les formations partisanes puisent leur inspiration comme leurs moyens d'action. Sans négliger le rôle encore considérable des personnalités et sans oublier, quoiqu'elle soit relativement faible dans ce pays, l'influence des grandes querelles idéologiques, c'est seulement en rapprochant le système des partis de la structure sociale que l'activité partisane devient pleinement intelligible. À ce titre, nous consacrerons une première section à l'étude des facteurs d'ordre socio-économique qui donnent à la vie politique grecque sa physionomie caractéristique.

Une autre particularité d'ordre socio-politique cette fois a marqué le monde politique grec durant la période couverte par cet ouvrage : la persistance des séquelles de la guerre civile. Les mesures prises durant le conflit et maintenues en une large mesure après l'achèvement de celui-ci ont non seulement affecté l'état des formations partisanes mais les comportements individuels des citoyens. Il est donc indispensable de rappeler l'essentiel de ce dispositif et d'indiquer sa fréquence d'utilisation.

\section{FACTEURS D'ORDRE SOCIO-ÉCONOMIQUE}

Notre objectif est triple : examiner la répartition actuelle de la population active dans ses rapports avec la stratification sociale; présenter les deux mouvements d'urbanisation et d'émigration qui, sans être nouveaux, affectent considérablement la société grecque d'aujour-[p. 156] d'hui ; souligner les changements que sont susceptibles d'apporter à la pratique politique traditionnelle les procédés gouvernementaux de centralisation économique. 


\section{A. DISTRIBUTION DE LA POPULATION ACTIVE}

$\underline{\text { Retour à la table des matières }}$

Les seuls éléments actuellement disponibles sont ceux fournis par l'étude d'un échantillon réduit (2\%) tiré du recensement de 1961. Les chiffres et proportions mentionnés ici ont donc valeur simplement indicative mais, malgré leur imperfection, ces éléments sont sensiblement meilleurs que les données traditionnelles ${ }^{1}$.

Lors du recensement de 1961, la population active totale de la Grèce a été évaluée à 3.663.100 (dont 2.458.400 hommes et 1.204.700 femmes). En voici, page suivante, la décomposition par branche d'activité économique et statut professionnel (en milliers) :

[p. 157]

\begin{tabular}{|c|c|c|c|c|c|c|}
\hline Secteurs de l'activité économique & Employeurs & $\begin{array}{l}\text { Personnes } \\
\text { travaillant à } \\
\text { leur compte }\end{array}$ & $\begin{array}{c}\text { Aides } \\
\text { familiaux } \\
\text { non } \\
\text { rémunérés }\end{array}$ & $\begin{array}{l}\text { Travailleurs } \\
\text { salariés }\end{array}$ & $\begin{array}{c}\text { Statut } \\
\text { professionnel } \\
\text { non déclaré }\end{array}$ & Total \\
\hline $\begin{array}{l}\text { Agriculture, élevage, forêt, chasse } \\
\text { et pêche... }\end{array}$ & 31,1 & 775,7 & 982,1 & 164,7 & 1,4 & $1.955,0$ \\
\hline Mines, carrières, salines................... & 0,6 & 1,2 & 0,4 & 19,1 & 0,0 & 21,3 \\
\hline Activités manufacturières.................. & 25,3 & 132,1 & 17,1 & 304,7 & 1,8 & 481,0 \\
\hline Bâtiment et Travaux publics........... & 4,0 & 23,6 & 1,8 & 136,9 & 0,6 & 166,9 \\
\hline 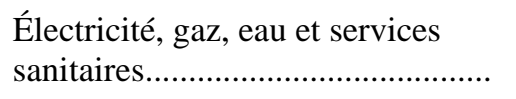 & 0,0 & 0,3 & 0,1 & 20,7 & 0,0 & 21,1 \\
\hline $\begin{array}{l}\text { Commerce, banque, assurance, } \\
\text { transactions immobilières.................... }\end{array}$ & 22,5 & 129,8 & 17,5 & 93,5 & 0,3 & 263,6 \\
\hline 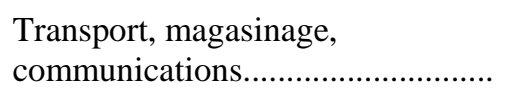 & 4,0 & 36,5 & 1,5 & 116,6 & 0,7 & 159,3 \\
\hline 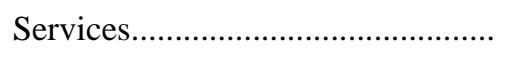 & 11,3 & 80,3 & 9,0 & 340,7 & 1,8 & 443,1 \\
\hline \multirow[t]{2}{*}{ Indéterminé ou non déclaré.............. } & 0,6 & 2,2 & 0,5 & 13,0 & 135,6 & 151,9 \\
\hline & 99,4 & $1.181,7$ & $1.030,0$ & $1.209,9$ & 142,2 & $3.663,2$ \\
\hline
\end{tabular}

[p. 158] En nous plaçant sous le seul angle des conséquences politiques éventuelles de la situation, ce tableau appelle plusieurs commentaires, aussi bien quant à la nature des activités économiques exercées par les Grecs qu'au point de vue de leur statut professionnel (ou rapports de production).

1 Nos tableaux sont extraits du Statistical Yearbook of Greece 1963, pp. 133-150. 


\section{SECTEURS D’OCCUPATION}

Trois traits caractérisent la situation: surabondance paysanne; faiblesse des effectifs industriels ; pléthore des activités de distribution et de services. Il n'est pas difficile de comprendre qu'une telle distribution a d'importantes conséquences politiques.

\section{a) Surabondance paysanne.}

Le point qui saute aux yeux est l'importance de l'agriculture dont, finalement, environ la moitié de la population continue de dépendre. La part de ce secteur dans la population active est certes accrue par la prise en considération des aides familiaux non rémunérés (en particulier les femmes des cultivateurs). Bien que l'inclusion de cette catégorie dans la population active agricole soulève des difficultés et suscite des controverses, il est clair que, sous n'importe quelle présentation statistique, la Grèce reste en 1964 un pays profondément agricole et il est dès lors nécessaire de dire quelques mots des structures agraires de ce pays ${ }^{1}$.

[p. 159] Voici d'abord sans oublier les réserves qu'impose tout dénombrement de ce genre, les dimensions des exploitations grecques en 1961 :

\begin{tabular}{|c|c|c|c|}
\hline $\begin{array}{l}\text { Classes de superficie } \\
\text { en hectares }\end{array}$ & $\begin{array}{l}\text { Nombre d'exploitation } \\
\text { dans chaque classe }\end{array}$ & $\begin{array}{l}\% \text { de chaque classe } \\
\text { dans le total des } \\
\text { exploitations }\end{array}$ & $\begin{array}{l}\% \text { de chaque classe } \\
\text { dans le total de la } \\
\text { surface exploitée }\end{array}$ \\
\hline $0-1$ & 287.106 & 27,7 & 7 \\
\hline $1-5$ & 603.198 & 58,3 & 52 \\
\hline $5-10$ & 114.327 & 11,0 & 24 \\
\hline $10-20$ & 25.912 & 2,5 & 10,5 \\
\hline $20-50$ & 4.200 & 0.5 & 6.5 \\
\hline \multirow[t]{2}{*}{ plus de 50} & 700 & & \\
\hline & 1.035 .443 & 100,0 & 100,0 \\
\hline
\end{tabular}

La Grèce est donc un pays de très petites exploitations agricoles. On a calculé qu'en 1962 la dimension moyenne était, au plan national, de 3,58 hectares. La situation diffère cependant de manière assez sensible selon les régions :

Voir THOMSON (K.), Farm fragmentation in Greece : the problem and its setting. With II village case studies. Athènes, Center of Economic Research, 1963. Voir aussi une étude de D. KITSIKIS sur le niveau d'industrialisation de l'agriculture grecque in Sinchrona Themata, avril-juin 1964, pp. 380-387. 


\begin{tabular}{|c|c|c|c|}
\hline \multicolumn{2}{|c|}{ Régions au-dessus de la moyenne } & \multicolumn{2}{|c|}{ Régions au-dessous de la moyenne } \\
\hline Thessalie......................... & 5,54 & Péloponnèse..................... & 3,25 \\
\hline Thrace............................. & 4,32 & Crète.................................. & 3,02 \\
\hline Grèce centrale et Eubée. & 4,02 & 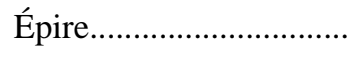 & 2,69 \\
\hline \multirow[t]{3}{*}{ Macédoine........................ } & 3,80 & Îles Égéennes................... & 2,28 \\
\hline & & Dodécanèse....................... & 2,28 \\
\hline & & Îles Ioniennes................... & 1,97 \\
\hline
\end{tabular}

Ce morcellement est en une large mesure le résultat des réformes agraires intervenues à diverses époques de la Grèce moderne, la dernière en date découlant de l'art. 104 de la Constitution de 1952. Désormais la loi fixe à un maximum de 25 hectares la superficie arable pouvant être possédée par une seule personne. Le dispositif de codification de la réforme agraire prévoit toutefois diverses exceptions, no-[p. 160] tamment au profit du propriétaire exploitant personnellement ses terres. Celui-ci peut posséder jusqu'à 50 hectares de terre arable (100 s'il s’agit de prairies).

Le résultat de ces réformes a été de réduire à de très faibles niveaux la catégorie des propriétaires fonciers tirant un revenu des terres dont ils n'assurent pas l'exploitation. On note en Grèce une prépondérance écrasante du faire valoir direct (propriétaire exploitant), le fermage n'occupant qu'une place très réduite. Le point est bien illustré par les chiffres du recensement agricole de 1950.

Pourcentage du total de la surface exploitée

Faire valoir direct. 91,70

Fermage à bail... 5,40

Fermage avec partage de la récolte. 2,10

Autres formes de fermage. 0,80

100,00

Depuis la fin de la seconde guerre mondiale, un effort a été fait pour moderniser l'agriculture grecque, spécialement sous l'angle de la mécanisation. Le nombre des tracteurs est passé de 1.500 en 1940 à 24.000 en 1962. Cependant, si l'on établit la puissance de tracteurs par 100 hectares, la Grèce avec $21 \mathrm{CV}$ se situe très au-dessous de l'Allemagne Occidentale (196), de la Grande-Bretagne (175), de la France (86), de l'Italie (47), mais sensiblement au-dessus du Portugal (7) et de l'Espagne (6).

La modernisation accroît le rendement agricole, mais en même temps elle augmente la pression démographique dans les campagnes (problème du chômage dissimulé). Or, jusqu'à présent, le développement industriel a été bien trop faible pour absorber ce surplus. 


\section{b) Faiblesse des effectifs industriels.}

Nous avons précédemment souligné la lenteur et la médiocrité du développement industriel en Grèce. Le tableau de la population active en 1961 montre bien qu'en dépit de certains progrès, la croissance de l'industrie reste encore fort limitée ${ }^{1}$.

[p. 161] Lors du recensement de 1961, le nombre total des personnes employées dans les activités manufacturières demeurait inférieur à 500.000 dont un peu plus de 300.000 salariés. La différence entre ces deux chiffres est due principalement à la catégorie des personnes travaillant à leur compte, soit 132.000. Cette distribution montre bien l'importance de la place que la toute petite entreprise continue d'occuper dans l'économie grecque.

La petitesse des effectifs ouvriers ressort clairement de la statistique du personnel employé dans les établissements manufacturiers de 10 personnes et plus :

\begin{tabular}{rccc} 
& 1959 & 1960 & 1961 \\
\cline { 2 - 4 } Total pour le pays................................................ & 189.145 & 187.684 & 188.877 \\
dont : pour le Grand-Athènes............................... & 101.790 & 107.251 & 108.410
\end{tabular}

Il s'agit en une très large mesure d'industries légères, principalement destinées à satisfaire les besoins de consommation nationaux. Les trois activités venant en tête au plan national sont pour 1961: les industries textiles (47.454), les industries de l'alimentation (23.569) et les manufactures de tabac (22.288). Ces trois postes représentent 93.311 travailleurs, soit près de la moitié du personnel employé dans cette catégorie d'établissements.

Notons aussi l'importance du Grand-Athènes qui possède près de $60 \%$ des effectifs recensés à ce titre. En 1962, l'agglomération comptait 95 établissements utilisant plus de 200 salariés, les huit premiers en occupant plus de 1.000 (deux manufactures de tabac, une usine d'engrais, les chantiers navals de Niarchos à Scaramanga sur la baie d'Éleusis...). À l'échelle grecque, le Grand-Athènes possède donc les éléments d'une assez large concentration ouvrière.

Le bâtiment est une activité florissante qui occupait en 1961166.000 personnes dont 136.000 salariés. Une part notable de cette branche (le tiers semble-t-il) est affectée à la construction de logements. L'agglomération du Grand-Athènes absorbe plus de la moitié des activités réalisées dans le bâtiment et, pour ce poste encore, compte d'assez importantes concentrations de travailleurs.

1 Pour une vue d'ensemble, se reporter à COUTSOUMARIS (G.), The morphology of Greek industry. A study in industrial development, Athènes, Center of Economic Research, 1963. 


\section{[p. 162] c) Pléthore des activités de distribution et de services.}

Ce trait est caractéristique des économies sous-développées d'inspiration capitaliste. La Grèce est un bon cas d'application de ce schéma général dont le caractère parasitaire est manifeste. Il suffit pour s'en convaincre, d'observer que les seules activités de services occupent à elles seules presque autant de monde (443.000) que l'ensemble des activités manufacturières (481.000). Si, mettant à part l'agriculture, l'on fait le total des activités qui n'ajoutent aucun élément matériel au produit national, le chiffre obtenu s'approche de 900.000, tandis que l'ensemble des mines, des manufactures et de la construction reste inférieur à 700.000.

Le secteur des activités immatérielles occupe un grand nombre de travailleurs salariés, soit environ 550.000. Un peu plus de la moitié de la main-d'œuvre féminine rémunérée en relève. Mais on note également une prolifération des entreprises individuelles ou familiales. Observons par exemple le secteur du commerce dans l'agglomération du Grand-Athènes: les quatre-cinquièmes des entreprises du commerce de détail - et, ce qui est plus surprenant, la moitié de celles du commerce dit de gros - se réduisent à une ou deux personnes actives.

Notons aussi l'ampleur du secteur de professions libérales (avocats, médecins, architectes...). Selon une estimation, leur pourcentage dans la population serait supérieur à 3\%. Une minorité parvient à s'assurer des gains importants et entre dans la bourgeoisie. Mais beaucoup des membres de ces professions végètent ou manquent d'emploi. Ainsi s'explique la répugnance de ceux-ci vis-à-vis de l'ordre bourgeois qui ne leur assure pas une existence décente.

Ces chiffres établissent sans équivoque qu'il existe en Grèce un important gaspillage du facteur humain. Si l'on ajoute au parasitisme tertiaire le chômage dissimulé qui continue d'affecter gravement l'agriculture, il devient manifeste que la Grèce moderne ne tire qu'un bien médiocre parti de son capital le plus précieux.

\section{RAPPORTS DE PRODUCTION}

Revenons au tableau général de la population active. Le trait le plus important sous l'angle du statut professionnel est la faiblesse du nombre des salariés — à peine le tiers de la population active totale. Le nombre des salariés est finalement du même ordre que celui des per-[p. 163] sonnes travaillant à leur compte et dépasse de moins de deux cent mille le chiffre des aides familiaux non rémunérés. Aucune donnée statistique ne saurait illustrer mieux que celle-ci le caractère encore largement primitif de l'économie grecque. Aucune n'a plus d'importance pour expliquer l'état des organisations partisanes de ce pays.

On constate, à la lecture de ce tableau, que la structure sociale de la Grèce d'aujourd'hui comprend un très fort contingent d'éléments se rattachant aux classes dites moyennes: classes moyennes de type ancien (artisans, commerçants, intermédiaires en tous genres...) et, beaucoup moins d'ailleurs, de type moderne (ingénieurs, techniciens de l'industrie...) ; classes moyennes de niveau inférieur, pour reprendre la terminologie anglo-saxonne, dans la mesure où les ressources dont elles 
disposent restent souvent médiocres et parfois aléatoires. Mais ces classes demeurent dans l'ensemble fort attachées à leurs biens propres même si ceux-ci sont tout à fait chétifs, et à leur indépendance, même si celle-ci est en une large mesure fictive. Il arrive que des éléments assez importants de ces classes votent pour des hommes de gauche mais en règle générale ces conduites expriment davantage un état de mécontentement qu'une critique consciente des défauts du système capitaliste. En réalité, ce sont les partis bourgeois qui bénéficient de la plus large fraction des suffrages émis par ces couches moyennes.

La base de ces classes moyennes est certainement constituée de personnes travaillant à leur compte (remarquons que lors du recensement industriel de 1958, près de $81 \%$ des entreprises dénombrées dans l'industrie de transformation étaient des entreprises personnelles). Mais on aurait tort de considérer que leur recrutement ne s'étend pas à la catégorie des travailleurs salariés. Les cadres au sens large du terme se considèrent normalement comme des membres des couches moyennes dont ils forment l'élément moderne. Il en va de même pour une fraction des salariés qui sont loin d'avoir tous une conscience prolétarienne. Bien que les milieux conservateurs tendent parfois à l'exagérer pour des raisons tactiques, la différence entre ouvriers et employés reste considérable, plus peut-être dans les pays économiquement arriérés que dans les économies avancées. Et sous l'angle du potentiel de protestation sociale, l'on ne saurait certes mettre sur le même plan les ouvriers groupés dans les manufactures de banlieue et les travailleurs des activités de service dispersés en milieu urbain.

[p. 164] Reste la masse des paysans. En Grèce, la presque totalité des travailleurs de la terre s'insère dans le cadre de la propriété individuelle. Mais ces propriétaires sont pour le plus grand nombre des gens pauvres. Conformément à une pratique quasi universelle, les revenus individuels des paysans grecs sont inférieurs à ceux obtenus par les autres acteurs de la vie économique. Durant ces dernières années, la production agricole a considérablement augmenté mais pour de nombreuses raisons (pression d'un capitalisme commercial tout puissant, présence d'un trop grand nombre de cultivateurs...), les intéressés n'ont été que très imparfaitement récompensés de cet effort. Selon des estimations officielles, l'écart des revenus individuels entre le secteur agricole et les autres secteurs a eu tendance à s'accroître ${ }^{1}$.

Cette situation explique les nombreuses et parfois graves manifestations des paysans au cours de ces dernières années (tout particulièrement chez les producteurs de tabac et de raisins de Corinthe). Il est arrivé que ces manifestations dégénèrent en émeutes et entraînent des poursuites judiciaires. Cependant, en dehors de ces mouvements de colère et de révolte, la paysannerie demeure, en Grèce comme ailleurs, l'un des plus fermes soutiens de l'ordre bourgeois. Telle est l'une des principales raisons, sinon la cause essentielle, des échecs subis par les promoteurs des partis agraires d'inspiration progressiste.

1 Voir les indications fournies à cet égard dans le volume de l'OCDE : Les faibles revenus dans l'agriculture. Nature des problèmes et recherche de solution, Paris, 1964 (chapitre sur la Grèce, pp. 291-303. 
Quant à la classe qui forme le sommet de la pyramide sociale et dont la puissance repose sur l'acquiescement ou le concours actif des classes moyennes, elle est très réduite en nombre et jusqu'à présent s'est peu intéressé aux problèmes de l'industrie. « Là où il faudrait une bourgeoisie industrielle, on ne trouve en Grèce, écrit Manolis Coracas, qu'un tout petit monde de marchands-commerçants, banquiers et armateurs dont les recettes proviennent d'une part d'affaires louches et de la corruption et d'autre part de l'exploitation des salariés et des consommateurs » ${ }^{1}$.

Ce jugement est sévère et pèche par quelque excès de généralisation. Mais on peut certes accepter l’idée que les milieux dirigeants économiques relèvent bien davantage du capitalisme commercial que du capitalisme industriel. La caractéristique des milieux économiques dominants est une volonté d'enrichissement rapide qui ne recule devant [p. 165] aucun moyen pour parvenir à ses fins. Et ce " compradorisme ", lié à des phénomènes de consommation ostentatoire, tend à se diffuser tout au long de l'échelle sociale. On ne s'étonnera pas dans ces conditions que le capital étranger arrive à occuper les diverses positions-clés de l'économie grecque.

Pour comprendre le niveau de parasitisme économique qui affecte aujourd'hui la société grecque, il faudrait évoquer de nombreux phénomènes relevant de la propriété immobilière et du prêt d'argent. Les statistiques officielles ne permettent pas de s'aventurer dans l'étude de ces pratiques mais le contact avec la vie grecque laisse peu de doutes sur leur ampleur. Il est à peine besoin d'écrire que les bénéficiaires de ces pratiques grossissent les rangs des partisans du système établi.

\section{B. MOUVEMENTS DE LA POPULATION}

\section{$\underline{\text { Retour à la table des matières }}$}

Nous voudrions évoquer rapidement les mouvements d'émigration et d'urbanisation qui caractérisent la situation présente. Ces mouvements ont une importance fondamentale pour l'avenir de la Grèce : cependant, malgré quelques études récentes de qualité, l'information disponible en ce domaine reste très insuffisante.

\section{AMPLEUR DE L'ÉMIGRATION ${ }^{2}$}

Elle est liée au sous-emploi dans les campagnes et au chômage dans les agglomérations urbaines. Ces données sont difficiles à chiffrer avec quelque précision. Le chômage dissimulé atteint sans aucun doute plusieurs centaines de milliers de personnes (600.000 selon les données du recensement de 1961, ce chiffre

In Socialisme (Bruxelles), juillet 1964, p. 492.

Voir KAYSER (B.), « Nouvelles données sur l'émigration grecque », Population, août-septembre 1964, pp. 707-726. On estime à 172.000 drachmes le coût de l'entretien et de la formation jusqu'à 18 ans d'un travailleur manuel. 
adopté par l'OCDE étant certainement un minimum). Quant au chômage proprement dit, l'estimation minimale actuelle est de l'ordre de 200.000 chômeurs complets (certains commentateurs faisant état d'une quantité double).

On a calculé que de 1951 à 1960, l'émigration nette s'est élevée à près de 210.000 individus. La part relative de l'émigration transocéanique qui reste fixée aux environs de 20.000 départs annuels (l'Australie [p. 166] constituant désormais pour les Grecs le premier pays d'accueil d'Outremer) ne cesse de décroître de $75 \%$ en 1963 , elle tombe à $39 \%$ en 1960 et $26 \%$ en 1962 . Ce renversement est dû à un brusque appel venant des pays européens : de la Belgique à partir de 1957 et surtout de l'Allemagne à compter de 1959-1960.

Au titre des années 1961 et 1962, le nombre des « émigrants permanents », c'està-dire des citoyens grecs s'établissant à l'étranger pour plus d'un an s'est respectivement élevé d'après les statistiques officielles à 58.837 et 84.054. Pour comprendre la portée de ce dernier chiffre et le choc qu'il a produit dans l'opinion éclairée, il suffit de dire qu'en 1962 l'excédent démographique naturel s'est élevé à 83.398. Pour l'année 1963 les départs auraient été de la l'ordre de 100.000. On a calculé que sur la base des chiffres 1958-1963, l'émigration absorbe pratiquement toute l'augmentation naturelle de la population. Notons qu'à l'été 1963 les autorités allemandes recensaient 110.000 travailleurs grecs sur leur territoire.

Il faut aller plus loin que l'estimation purement quantitative. Encore que l'on ne dispose à cet égard d'aucune statistique sûre, il est clair que la Grèce perd chaque année depuis longtemps au profit de l'étranger une fraction de ses meilleurs techniciens et spécialistes dans tous les domaines de la pensée et de l'activité humaine. Or les intéressés contractent à l'étranger des habitudes d'existence et y jouissent de conditions de travail qui rendent leur récupération ultérieure à une large échelle problématique ${ }^{1}$.

Si ce mouvement d'émigration devait se poursuivre avec les dimensions quantitatives et qualitatives qu'il a prises au cours des dernières années, ce serait pour la Grèce un facteur irrémédiable de décadence humaine. L'un des aspects les plus préoccupants du phénomène est l'accroissement de la proportion des ouvriers industriels qualifiés parmi les émigrants (45,9\% en 1961 mais 56,2\% en 1962). Par ailleurs, la position internationale du pays au milieu de voisins en pleine expansion démographique ne cesserait de s'affaiblir. Or, et pour les raisons que nous avons dites, la conséquence immédiate de l'émigration est de créer une soupape de sûreté dont les hommes au pouvoir, qu'ils acceptent le phénomène ou s'en inquiètent, ont tiré avantage.

Quelques informations chiffrées viennent d'être fournies pour la première fois, à notre connaissance, sur ce grave problème par C.V. HANOTIS in L'observateur de l'OCDE, août 1964, ppp. 12-15. Selon le titre même de l'étude, il semble que le gouvernement du Centre ait entrepris une expérience de rapatriement volontaire. 


\section{[p. 167] 2. DIMENSIONS DE LA CROISSANCE URBAINE}

Nous avons déjà souligné l'ampleur de l'urbanisation depuis le début de la seconde guerre mondiale. Le phénomène exceptionnel à cet égard est la croissance de l'agglomération athénienne qui renferme aujourd'hui plus de la moitié des citadins de la Grèce entière et plus du cinquième de la population totale du pays ${ }^{1}$.

Athènes constitue, et de fort loin, la région la plus riche de la Grèce. Selon des évaluations du Centre de Recherche Économique, le revenu moyen annuel par tête s'y serait élevé en 1961 à 13.422 drachmes (soit près de 450 dollars U.S.), la moyenne nationale étant seulement de 9.932 (330 \$). D'après les statistiques de la Chambre de Commerce, la part d'Athènes dans la fiscalité serait de $75 \%$ au titre de l'imposition directe et de $65 \%$ à celui de l'imposition indirecte. $\mathrm{Si}$, au cours des dernières années la Grèce a acquis quelques-uns des traits de la société dite de consommation (affluent society) c'est essentiellement dans l'agglomération athénienne qu'on en observe la manifestation.

En dehors d'Athènes, on ne peut citer comme grande ville que Salonique dont la population atteint désormais le niveau de 400.000 habitants. La troisième ville, Patras, n'a qu'un peu plus de 100.000 habitants : c'est d'ailleurs une agglomération plutôt stagnante. Il est remarquable qu'à l'exception de Salonique aucune ville de province ne témoigne d'un dynamisme remarquable.

$\mathrm{Au}$ total, la croissance urbaine concerne essentiellement l'agglomération athénienne ainsi que, mais a un degré moindre, celle de Salonique. Ces deux agglomérations ont d'ailleurs un profil socio-professionnel très voisin. Les grands secteurs d'occupation y sont: l'industrie de transformation (30\% des personnes actives), le bâtiment (9\%), les activités de distribution et de services (plus de 50\%).

Cette écrasante prépondérance des activités dites tertiaires est sans nul doute la conséquence du mouvement qui pousse tant de Grecs à tenter leur chance dans ces vastes agglomérations. Cette venue dans les grandes villes est l'une des branches de l'alternative qui se pose à la population surabondante des campagnes, l'autre branche étant l'émigration. Mais dans la mesure où les postes de travail industriel sont limités, la seule voie ouverte pour gagner sa vie est de prendre l'un de [p. 168] ces petits métiers liés au commerce et aux services. Pour ne citer qu'un exemple, il est fréquent qu'à Athènes plusieurs familles vivent du revenu d'un seul kiosque à journaux.

On peut se demander si le mouvement que nous venons d'évoquer n'est pas en train de transformer certains rapports politiques, en particulier ceux qui se nouent entre l'élu et ses électeurs. Nous avons précédemment examiné les actes de patronage et les relations de clientèle qui constituent l'une des bases essentielles de l'accord intervenant entre les politiciens et les citoyens. De telles pratiques ont certes toujours leur place dans la politique grecque, l'un des éléments les plus fréquents du marché électoral consistant désormais dans l'appui donné par le député ou le candidat-député

Kayser consacre un bon chapitre à Athènes dans son ouvrage déjà plusieurs fois cité, p. 117-130. 
aux électeurs pour l'obtention d'un poste ou d'une occasion de travail. Il est toutefois probable que les phénomènes esquissés sous cette rubrique ont déjà modifié et transformeront davantage à l'avenir les conditions dans lesquelles se posent les rapports politiques.

Le point essentiel à cet égard est la rupture du cadre traditionnel d'existence qu'implique l'urbanisation pour ceux qui s'y soumettent. La conséquence immédiate de l'afflux des Grecs dans les grandes agglomérations est de créer des masses d'électeurs pour lesquels la personnalité des rapports en politique compte beaucoup moins et pour lesquels aussi le patronage traditionnel, s'il conserve un certain rôle, a beaucoup moins de sens ou de portée. Si ces masses, dont la Droite s'est efforcée par divers moyens de limiter le poids électoral, ont toujours besoin d'aides individuelles, il leur faut aussi des mesures collectives, spécialement pour tout ce qui concerne les services sociaux, les problèmes du logement... Les petites formations partisanes sont mal équipées pour s'occuper de tels problèmes et faire aboutir les dispositifs indispensables. De telles fonctions sont en réalité du ressort de formations à large assise parlementaire. Et dès lors on peut admettre que la survenance de transformations dans la nature des problèmes à résoudre a constitué l'un des facteurs d'évolution du système partisan.

Les nouveaux besoins qui se manifestent ainsi, notamment par suite de l'industrialisation et de l'urbanisation ne sauraient être satisfaits par les procédures gouvernementales habituelles. De nouveaux modes d'intervention et de gestion publiques sont dès lors indispensables dont il convient d'examiner les conséquences éventuelles sur les organisations partisanes.

[p. 169]

\section{CENTRALISATION ÉCONOMIQUE ET PRATIQUE POLITIQUE}

$\underline{\text { Retour à la table des matières }}$

Au cours des dernières années, on a pu observer en Grèce une modernisation, lente et partielle d'ailleurs, des techniques de direction économique ainsi que le recours, encore très imparfait, à une politique économique d'inspiration centralisée. La notion de plan étant en vogue, y compris chez les conservateurs qui se piquent de modernité, on n'a pas craint d'utiliser ce mot pour qualifier des dispositifs d'action hâtivement pensés et sans grande cohérence interne. Sans attacher beaucoup de crédit à de tels programmes, souvent destinés à impressionner favorablement les investisseurs et bailleurs de fonds étrangers, il reste que désormais le gouvernement dispose de bien plus de ressources à distribuer que ce n'était le cas autrefois. Les avantages dont sont susceptibles de bénéficier les circonscriptions et les collectivités (barrages, irrigations, routes, hôpitaux écoles...) font de plus en plus l'objet d'une attribution unifiée. Il en va de même à plusieurs égards pour le problème, si important 
dans les campagnes, de la distribution de crédits. Et dès lors, qui contrôle les fils de cette centralisation détient par là-même les leviers du patronage.

La Grèce vivant en régime parlementaire, c'est le parti au pouvoir qui va être mis en possession de ces leviers - situation qu'accentue la médiocrité de la bureaucratie administrative. Il est facile de voir que cette évolution a pour résultat de donner au chef du parti un moyen de pression de grande efficacité sur les parlementaires de son groupe, ceux-ci n'étant en mesure de combler les souhaits de leurs électeurs que dans la mesure où le leader y consent et prend les décisions nécessaires à cet effet. Et il y a là pour les parlementaires une incitation à plus de docilité vis-à-vis du chef et à plus de fidélité vis-à-vis du groupe (l'abandon de celui-ci par le parlementaire étant susceptible de comporter finalement de sérieux désavantages pour la circonscription et les électeurs).

Un tel procédé n’est pas inconnu dans un pays aussi riche que les États-Unis - le Président n'hésitant pas lors de scrutins délicats, spécialement au Sénat, à se gagner les suffrages indispensables par une judicieuse utilisation de la manne fédérale. On peut dès lors imaginer l'importance qu'il est susceptible de prendre dans un pays aussi pauvre que la Grèce.

[p. 170] La situation que nous venons d'esquisser n'est pas familière aux analystes politiques, la gestion centralisée des ressources dans les pays actuellement industrialisés n'étant intervenue qu'une fois ceux-ci arrivés à un niveau élevé de développement économique. Pourtant, même si à ce stade le patronage n'a plus en général la même importance vitale, on observe une tendance des gouvernants à tenir compte de considérations qui s'y rapportent dans l'élaboration et la mise en œuvre des plans. On peut s'attendre à ce qu'une telle propension soit encore plus marquée quand la gestion centralisée est introduite dans un pays où l'administration n'est pas en mesure d'instaurer un contre-poids aux décisions des politiciens. Songeons par exemple à tous les avantages électoraux et autres, qui sont susceptibles de s'attacher à une distribution des licences d'importation.

Dans ces conditions, il est possible que l'allégeance des électeurs tende à s'effectuer au profit du parti ou plus exactement du candidat du parti, l'électeur se rendant compte que l'appartenance au parti gouvernemental est la clé de l'accès aux ressources collectives. Le mouvement aboutirait ainsi à consacrer l'effacement du parlementaire (trait qui, en Grèce comme ailleurs, est la condition élémentaire de la stabilité ministérielle).

Il est admis que C. Caramanlis a utilisé à une très large échelle les facilités que lui ouvrait la réalisation des programmes de mise en valeur du pays et il est permis de penser que cette centralisation du patronage a été l'un des moyens utilisés pour maintenir la discipline du groupe parlementaire de l'Union Radicale. De la même manière, il est possible que la volonté d'avoir accès à ces ressources, dont on tendait systématiquement à les priver, ait conduit ou au moins encouragé les opposants à accepter la discipline d'une formation unitaire.

Certes de tels phénomènes n'expliquent pas tout. Bien qu'elle ait régné sur le patronage pendant de longues années, la Droite a été régulièrement battue aux 
élections du 3 novembre 1963 et du 16 février 1964 dont des observateurs ont dit qu'elles avaient été les plus honnêtes de celles tenues en Grèce durant cet aprèsguerre. D'autres éléments sont donc intervenus dans le renversement de la majorité mais il serait difficile d'admettre pour autant que les évolutions socio-économiques dont l'esquisse a été faite dans cette section soient demeurées sans importance sur le système des partis.

[p. 171] Au total, on se tromperait lourdement en considérant qu'en l'état actuel de la vie politique grecque la centralisation économique gouvernementale a eu pour conséquence de mettre fin au clientélisme. En réalité, la combinaison de gestion centralisée des ressources et de sous-développement économique qui caractérise la Grèce d'aujourd'hui a eu simplement pour effet de provoquer un changement d'échelle des phénomènes anciens. Le clientélisme subsiste sous de multiples formes (distribution des postes de fonctionnaires, octroi de subventions et distribution des commandes, attribution de permis d'émigration et de licences d'importation...). Mais il devient un clientélisme exercé par la haute direction du parti, les députés individuels devant faire le siège des instances supérieures pour en obtenir les ressources nécessaires à leur circonscription et à leurs électeurs.

Ajoutons que dans la mesure où tendent à prévaloir divers aspects du capitalisme moderne, la notion de clientélisme cesse d'être valable pour caractériser les relations entre l'État et les détenteurs du pouvoir économique. Si les hommes du capital monopolisateur reçoivent les avantages et facilités demandées, c'est en vertu d'une faculté globale d'influence qui n'a plus rien à voir avec l'antique promesse de fidélité électorale.

La difficulté d'analyser la vie politique grecque d'aujourd'hui tient au fait qu'elle combine ou cumule des éléments relevant d'anciennes traditions et de facteurs de modernité. Le patronage habituel au profit d'une paysannerie très pauvre et parfois affamée y joue encore un rôle considérable mais en même temps l'oligarchie financière y impose cette osmose des finances publiques et privées qui lui est si favorable. Dans son ensemble, le système des partis est encore de style ancien mais on observe l'apparition dans les structures et pratiques partisanes de quelques secteurs ou points de modernité. Cette somme de contradictions résultant du caractère hétérogène des structures socio-économiques donne au monde partisan grec une allure composite qui, de prime abord, déconcerte l'observateur. On ne saurait en somme l'étudier correctement avec l'angle de vision d'une seule période : plusieurs époques continuent de s'y rencontrer. 
[p. 172]

\section{FACTEURS D'ORDRE SOCIO-POLITIQUE}

$\underline{\text { Retour à la table des matières }}$

Nous voulons surtout insister ici sur les séquelles de la guerre civile qui, à divers égards, continuent d'affecter les contestations partisanes. Le point de départ est l'interdiction du Parti Communiste qui, intervenue en 1947, n'a pas été rapportée depuis lors. Cette interdiction a suscité l'adoption d'un vaste dispositif de lutte contre les activités et menées communistes : or ce dispositif, loin de s'appliquer aux seuls communistes, a été mis en œuvre par la Droite contre tous les partisans ou sympathisants de la Gauche ; la vie politique grecque a pris ainsi des aspects policiers peu favorables à la fibre expression des opinions ou préférences partisanes. Parmi tous les secteurs ou groupes ayant eu à souffrir de ce régime, il convient de mettre à part le mouvement syndical qui a fait l'objet d'une obstruction systématique de la part des pouvoirs publics. Il en résulte que si les travailleurs grecs disposent en quelques domaines de syndicats actifs et dynamiques, il n'y a pas ou pas encore, globalement parlant, de mouvement syndical digne de ce nom.

Ces divers facteurs d'ordre socio-politique ayant profondément marqué les luttes partisanes durant la période examinée en cet ouvrage, nous allons en donner ici une brève présentation.

\section{A. SITUATION DU PARTI COMMUNISTE}

\section{$\underline{\text { Retour à la table des matières }}$}

Jusqu'à la fin de la première guerre mondiale, le monde ouvrier grec, encore très réduit en nombre, avait été dominé par des tendances socialisantes et anarchisantes, cette dispersion n'étant pas favorable à la création d'un organisme de défense unifié. Une modification notable se produit en 1920 quand le parti ouvrier grec, fondé durant l'année 1918, se transforme en parti communiste. Sous l'effet de la victoire remportée par la révolution russe, le mouvement - dont la Fédération Ouvrière de Salonique constitue l'aile marchante - tend à adopter des positions marxistes. La Grèce manquant d'une tradition socialiste par suite de son retard économique, c'est le parti communiste qui va y constituer le premier outil de lutte des travailleurs en tant que tels.

Le parti obtient pour la première fois une représentation parlementaire lors des élections de 1926. Dix députés communistes entrent à la Chambre — dont huit élus en Macédoine et en Thrace, les deux [p. 173] autres l'étant en Thessalie. L'expansion du parti qui se trouve au départ centrée sur les régions du Nord va cependant se 
heurter à des difficultés considérables parmi lesquelles l'adoption de mesures gouvernementales destinées à briser son élan. Au surplus, selon Stavrianos ${ }^{1}$, son développement sera considérablement gêné par la politique qu'adopte le Komintern dans la question des Balkans. Celui-ci se prononce, en particulier, pour l'érection de la Macédoine et de la Thrace en unités politiques autonomes dans le cadre d'une Fédération communiste des Balkans. Un tel programme aboutirait au démembrement de la Grèce. Le Parti Communiste grec qui, malgré quelques déchirements internes, suit la ligne alors imposée par le Komintern, subit de ce fait un grave handicap dans sa propagande auprès des masses.

Les élections de 1928 constituent un gros insuccès pour le parti dont tous les candidats sont battus. Cependant, lors d'élections partielles à Salonique et Mytilène en 1931, les Communistes améliorent leur position électorale — l'un des facteurs de la situation paraissant avoir été le mécontentement des réfugiés à l'égard de la Convention d'Ankara qui comporte abandon des revendications d'indemnisation pour les propriétés abandonnées en Asie Mineure. Aux élections du 26 janvier 1936, le parti rentre à nouveau au Parlement en obtenant 16 sièges de député.

Les forces royaliste et républicaine s'équilibrant approximativement dans cette Chambre, ce sont les communistes qui y détiennent la balance du pouvoir. En exécution d'un accord secret conclu le 19 février entre le Parti et Th. Sophoulis, leader du Parti Libéral, celui-ci est élu Président de la Chambre avec les suffrages communistes. L'opération suscite une grande indignation chez les Monarchistes qui obtiennent que le gouvernement soit formé sur une base non-parlementaire. C'est le cabinet du professeur Démértzis dans lequel le général Métaxas occupe le poste de vice-président et de ministre de la guerre. L'une des raisons alléguées par ce dernier pour justifier l'instauration de la dictature sera la nécessité de lutter contre le danger communiste. Et, de fait, l'interdiction de toute activité communiste sera l'une des normes stipulées par le « Régime du 4 août ».

L'étape suivante est la constitution du Front de Libération Nationale (EAM) qui intervient à Athènes le 27 septembre 1941. L'EAM se compose du Parti Communiste et de plusieurs autres groupes parmi les-[p. 174] quels quatre petits partis socialistes et agraires. Mais ce sont les Communistes qui détiennent le contrôle de l'organisation dont l'infrastructure va reposer au départ sur l'appareil clandestin mis au point par le Parti pendant la dictature de Métaxas. Au départ des Allemands, l'EAM constitue sans nul doute la plus importante formation politique du pays; les Communistes certes ne tiennent qu'une place minoritaire parmi les membres de l'organisation, mais leur rôle dans la direction politique du Front reste prépondérant.

En dépit de sa puissance, l'EAM connaîtra un échec total. Nous avons déjà noté que, selon la nouvelle interprétation communiste de l'histoire, cet insuccès s'expliquerait, en dehors bien entendu de l'intervention anglaise, par la propension des chefs communistes de l'époque, N. Zachariadis en tête, à faire de la coalition ainsi formée un instrument de la lutte des classes et à traiter leurs alliés comme des petits

Op. cit., pp. 614-615. 
bourgeois réformistes. Sans entrer dans une discussion détaillée de cette thèse, observons qu'elle a le grand défaut de dissimuler la responsabilité initiale de la politique soviétique dans le déclenchement de la situation. C'est Staline qui, pour avoir les mains libres ailleurs, accepta que la Grèce soit placée sous le contrôle direct des Britanniques qui ne faisaient pas mystère de leur volonté d'y rétablir l'ordre ancien (dynastie comprise). La conséquence inéluctable de ce marché était de bloquer pour une période indéfinie toute perspective de régénération sociopolitique.

La position de Staline durant les événements de décembre 1944 constitua, par sa correction même à l'égard des entreprises de Churchill, la preuve ouverte de cette collusion. Il est clair que par la suite Staline aurait pu empêcher Zachariadis, malgré les excès de la terreur blanche, de déclencher l'insurrection contre le gouvernement établi : mais on sait que le déroulement de la guerre civile, dont le résultat immédiat devait être le passage de la Grèce sous le contrôle américain, fournit à la politique soviétique d'alors une précieuse argumentation et un solide moyen d'intervention contre les puissances anglo-saxonnes à l'ONU et ailleurs.

Le Parti Communiste a été dissous par la loi 509 du 27 décembre 1947 ainsi que le Front de Libération Nationale (EAM) et le mouvement intitulé La Solidarité Nationale. Ce texte étend en outre la dissolution à tout groupe «travaillant de concert » avec ces formations ainsi qu'à tout organisme «visant directement ou indirectement à la mise en ap-[p.175] plication d'idées ayant pour but le renversement par la violence de la forme d'État et du régime social en vigueur, ou le détachement dune partie du territoire national ».

Le Parti Communiste grec est donc aujourd'hui en exil, ses adeptes sur le territoire national ayant la faculté, comme nous l'avons déjà signalé, de militer dans les rangs de l'EDA. Nous exposerons dans un autre chapitre les mesures prises par le gouvernement en vue d'empêcher et de réprimer d'éventuelles menées clandestines des militants communistes. Après l'échec de l'insurrection, le Parti a subi de graves crises internes qui semblent avoir été surmontées à la suite des changements intervenus dans sa direction au lendemain du $\mathrm{XX}^{\mathrm{e}}$ Congrès du parti soviétique. Le premier secrétaire du Parti communiste grec dont le noyau dirigeant siège à Bucarest est désormais Costas Coliyannis.

Actuellement le Parti épouse entièrement les thèses du parti soviétique à l'égard du parti chinois : « Le Parti Communiste de Grèce, lit-on dans la résolution de la VII ${ }^{\mathrm{e}}$ session du Comité central, a d'emblée condamné la position et les agissements de la direction du Parti Communiste de Chine; il a pris fait et cause pour les thèses marxistes-léninistes des documents de Moscou... " ${ }^{1}$. Conformément au vœu de Khrouchtchev, le parti grec s'est prononcé pour la convocation « dans les délais les plus brefs » d'une conférence des partis communistes et ouvriers en vue de renforcer

On trouvera le texte de cette résolution datée d'avril 1964 in Bulletin d'Information (publié à Prague), $\mathrm{n}^{\circ} 10$, pp. 429-431. Voir aussi le texte de la résolution de la $\mathrm{V}^{\mathrm{e}}$ session plénière du C.C. (octobre 1963) qui contient une condamnation détaillée de la position chinoise. Même bulletin, $\mathrm{n}^{\circ}$ 5, pp. 75-80. 
l'unité du mouvement sur la base des principes du marxisme-léninisme. Le Parti grec tient pour « aventuriste et dogmatique » la ligne d'action préconisée par les dirigeants chinois : il leur reproche aussi de tenter la résurrection du culte de la personnalité.

En matière de politique intérieure, le parti déclare que sa tâche centrale est « d'unir les forces démocratiques du peuple, de combattre pour une démocratisation foncière du pays dans tous les domaines et dans les institutions politiques, économiques et sociales ${ }^{1}{ }^{1}$. Dans l'ordre de la politique étrangère, le parti se prononce en faveur de l'adoption par la Grèce d'une position de neutralité : il recommande la [p. 176] réduction des armements ainsi que la création d'une « zone sans fusées » dans les Balkans et la région de la Méditerranée. Enfin il appuie le droit de Chypre à l'autodétermination.

En conséquence, le Parti déclare rechercher une coopération permanente ou provisoire et accepte de mener une action commune ou tout au moins parallèle avec n'importe quel groupe, parti ou homme politique dès l'instant que cette conjonction d'efforts est susceptible d'amplifier ou d'accélérer la démocratisation de la vie nationale. Telle est la raison d'être du programme proposé par le Parti communiste le 28 février 1964 à l'ensemble des citoyens et aux partis sous le titre de " Programme de lutte pour le rétablissement et l'extension de la démocratie, pour le progrès social et économique du pays ».

L'une des revendications de base du parti est l'abolition de toutes les mesures d'exceptions héritées de la guerre civile. En date du 5 avril 1964, la direction communiste a envoyé une lettre au Gouvernement, au Parlement et aux divers partis politiques en vue d'obtenir le retour à la légalité du Parti. Cette demande n'a pas reçu de suite et actuellement le Parti Communiste reproche au gouvernement de l'Union du Centre de d'avoir pas tenu sa promesse de restaurer complètement la démocratie politique ${ }^{2}$. Il nous faut dès lors examiner le dispositif de lutte anti-communiste mis en place à l'occasion de la guerre civile et presque intégralement maintenu jusqu'à une date récente.

\section{B. DISPOSITIF DE LUTTE ANTI-COMMUNISTE}

$\underline{\text { Retour à la table des matières }}$

L'intitulé de cette rubrique peut être critiqué dans la mesure où le gouvernement de la Droite, spécialement après les élections de 1958, s'est servi de ce dispositif pour frapper ou inquiéter les militants et sympathisants de la gauche toute entière, l'épithète « communiste » étant généreusement utilisée pour qualifier les adversaires politiques du parti au pouvoir. Cependant l'inspiration fondamentale de ces textes étant de lutter contre la diffusion de l'idéologie et de la pratique communistes, il est

1 Extrait du Bulletin d'Information, $\mathrm{n}^{\circ}$ 14, p. 772. Ce texte insiste sur la nécessité d'un changement adéquat du travail idéologique du Parti et de son élévation au niveau nécessaire.

2 Voir à ce propos l'interview donnée par Coliyannis à L'Humanité, nº du 30 juin 1964. 
juste d'accepter ce mobile comme point de départ de l'analyse, quitte par la suite à repérer et à évaluer les extensions que les autorités lui ont attribuées.

[p. 177] Ce dispositif est très complexe et a donné lieu à de vastes controverses juridiques. Il a été formé à la fois de mesures nouvelles et de vieilles lois remises en vigueur pour la circonstance (la plus ancienne étant une loi du 27 février - $1^{\mathrm{er}}$ mars 1871 sur la répression du banditisme). Notre propos n'est pas de présenter un examen détaillé ou une vue complète de ce système mais simplement d'en indiquer les pièces les plus caractéristiques. Nous nous bornerons ici à l'étude des mesures elles-mêmes en réservant pour un autre chapitre le problème des organismes, étatiques et paraétatiques, qui sont intervenus dans leur mise en application.

Beaucoup des mesures que nous allons évoquer constituent des exceptions aux libertés individuelles telles que les définit et les garantit la Constitution Hellénique de 1952. L'adoption de ces lois ayant été justifiée par les nécessités de la guerre civile, on pouvait penser que la fin de celle-ci, annoncée par les autorités militaires dès 1949, aurait entraîné leur abrogation. Or les gouvernements de la Droite s'y sont refusés en avançant la fiction juridique d'une continuation de la guerre civile. C'est seulement en 1962, soit treize ans après l'arrêt effectif des combats, que la cessation du conflit a été officiellement déclarée par le Conseil d’État.

\section{EXPOSÉ DES MESURES D’EXCEPTION}

Mentionnons d'abord le problème des situations résultant directement de la participation à la guerre civile. En premier lieu celle des personnes condamnées pour avoir pris part au conflit (le nombre des détenus à ce titre qui était de 20.291 au $1^{\mathrm{er}}$ décembre 1949 ayant été progressivement réduit à 1.350 au début de 1962 et à un peu moins d'un millier au mois de mai 1963). Il semble que plusieurs prisonniers aient dû leur libération à la signature d'une déclaration de repentir (dilosis métanias) condamnant la révolution communiste et proclamant la loyauté de l'intéressé envers l'État Grec.

Les gouvernements grecs de l'époque contestaient l'existence même de prisonniers politiques en déclarant que les personnes détenues l'étaient pour des crimes et délits de droit commun. Cette position revenait à dire que les détenus purgeaient des peines pour avoir, dans le cadre et à l'occasion de la guerre civile, accompli des infractions de droit commun. Valable pour des cas particuliers que l'on observe dans toutes les insur-[p. 178] rections (le plus banal étant le bris de clôture ou de vitrine pour simple pillage), cette thèse perd sa légitimité quand on l'applique à des actes dont l'intention était d'assurer le triomphe de l'insurrection. Notons que, selon les dénonciateurs de l'action gouvernementale, plusieurs centaines de personnes auraient été condamnées et longtemps détenues pour avoir, durant l'occupation, exécuté des collaborateurs sur ordre de l'EAM et du gouvernement du Caire.

Mentionnons en second lieu, la situation des Grecs ayant quitté le territoire national à l'issue des combats et empêchés depuis lors d'y revenir par le gouvernement. Le chiffre de ces exilés fait l'objet d'évaluations diverses, les uns avançant le nombre de 60.000, d'autres présentant des évaluations plus hautes. On peut tenir pour vraisemblable un chiffre total de 80.000 personnes. Notons à ce 
propos qu'un décret du 7 décembre 1947 avait donné aux autorités la faculté de priver de leur nationalité les personnes menant à l'étranger « une activité antinationale ». En vertu de l'application de ce texte, le gouvernement affirmait que ces exclus n'étaient plus des citoyens grecs.

L'objet ouvertement déclaré du dispositif est de lutter contre les activités et menées communistes sur le territoire. La loi 509 du 27 décembre 1947, déjà mentionnée, prévoit à cet effet des dispositions sévères dont la loi 1975 de 1951 a fait passer la mise en œuvre des tribunaux militaires aux cours d'appel. Cependant une fraction notable des poursuites pour actes relevant de la loi 509 a été effectuée sous le couvert d'accusations d'espionnage avec de ce fait intervention de la loi 375 du 14-18 décembre 1936. Cette loi, qui remonte à la dictature Métaxas, donne compétence aux tribunaux militaires pour toute affaire " espionnage, même si elle concerne des civils et permet « appliquer la peine de mort, même en temps de paix, aux inculpés qui sont reconnus coupables d'une telle infraction (même s'il s'agit seulement d'actes préparatoires).

Il est fort possible, que des actes d'espionnage stricto sensu se soient produits aux frontières et dans les régions, nord du pays au profit des pays communistes voisins. Mais il est également vrai que les autorités ont eu tendance, en plusieurs cas, à interpréter de manière large la notion d'espionnage pour marquer leurs adversaires politiques d'un sceau infâmant. L'un des cas d'application de ces mesures ayant eu le plus de retentissement à l'étranger fut le procès livré à Manolis Glézos en 1959.

Parmi les, dispositions en contradiction ouverte avec les normes constitutionnelles de protection des libertés individuelles, il convient de men-[p. 179] tionner la procédure de déportation des citoyens par voie administrative. Cette institution a permis aux autorités de priver des citoyens de leur liberté par internement au camp d'Agios Eustratios (îlot rocheux situé au nord des Cyclades) sur décision d'une commission administrative statuant d'après des rapports de la police. Officiellement, il s'agissait là d'une mesure administrative préventive censée être de courte durée. Mais en réalité, les autorités disposaient, en vertu du principe de continuation de la guerre civile, d'une faculté de prolonger indéfiniment la détention. La durée de celleci était donc très variable, allant de quelques semaines ou mois à plusieurs années. Les autorités avaient même créé la situation de "déportation sur place » qui permettait de maintenir sous un strict contrôle policier des personnes libérées des camps et renvoyées à leur domicile.

Il est difficile d'évaluer le nombre des citoyens grecs qui ont été soumis à de telles mesures, ce nombre ayant constamment varié par le jeu des arrestations et des mises en liberté successives. Au $1^{\mathrm{er}}$ mars 1962 le nombre des déportés s'élevait à 296 (dont 230 au camp d'Agios Eustratios et 60 sur le lieu de leur domicile). Ce chiffre montre que l'emploi de cette procédure, bien que réduit par rapport aux années ayant suivi la guerre civile, demeurait alors effectif. Cette utilisation restait à l'époque bien assez large pour créer un état permanent d'inquiétude chez les citoyens identifiés par la police comme des opposants au régime. Il est vrai qu'au milieu de 1963, le nombre des déportés était tombé à un chiffre très faible. 
Cependant la pratique ayant affecté le plus grand nombre de Grecs est celle du certificat d'opinions sociales (couramment appelé certificat de civisme) - institution découlant de la loi d'exception 516 du 8 janvier 1948. Au départ, la présentation d'un tel certificat, dont le principe n'a pas encore été aboli, était exigé de tout candidat à un poste de nature publique ou semi-publique (personnes morales de droit public, municipalités et communes, entreprises publiques ou municipales concédées par l'État, sociétés anonymes bancaires, établissements de toute nature subventionnés par l'État...). Il fallait se munir du certificat non seulement pour occuper des fonctions publiques d'autorité ou de gestion supérieure mais encore pour avoir le droit d'accomplir d'humbles métiers (fossoyeur, docker, ouvrier dans les manufactures de tabac ou les entreprises de travaux publics...). De plus l'exigence du certificat avait été progressivement étendue à une série considérable de situations ou d'actes n'ayant [p. 180] aucun rapport avec la sécurité de l'État (inscription à l’Université et attribution de bourses ; délivrance d'un permis de conduite automobile, de chasse, de marchand des quatre saisons...). L'octroi d'un passeport ainsi que celui d'un permis d'émigration était subordonné à l'accomplissement de cette formalité.

Initialement l'objet de ce certificat était d'attester que l'intéressé n’était pas communiste mais, comme on pouvait aisément le prévoir, la police montra beaucoup de promptitude à décerner la qualité de «cryptocommuniste » ou de « communisant ». En fait, sous un tel régime, tout dépendait de l'opinion de la police sur la personne en cause (cette opinion étant pratiquement à la campagne celle du gendarme de chaque village). La personne ayant aux yeux de la police des opinions subversives ou déloyales - ou simplement soupçonnée d'entretenir de telles opinions — faisait l'objet d'un dossier. On ignore le nombre des Grecs soumis à de telles pratiques, certains le fixant à un chiffre excessivement élevé (de l'ordre d'un million et demi). Sans prendre position sur ce point faute de données sûres, observons que ces méthodes de surveillance policière avaient pris une ampleur considérable.

Il existait, il est vrai, une procédure permettant à l’intéressé d'obtenir la fermeture de son dossier à la police — la déclaration de repentir dite couramment procédure de décoloration. L'individu désireux d'être « décoloré », c'est-à-dire de ne plus être tenu pour un rouge pouvait y parvenir en effectuant une déclaration publique de changement d'opinion politique. Celle-ci était inscrite dans les journaux locaux aux frais de l'intéressé. Le remède était en quelque sorte pire que le mal dans la mesure où la procédure de décoloration — sans même insister sur ses aspects fâcheux quant à la dignité individuelle — impliquait en somme pour commencer reconnaissance de culpabilité par le citoyen lui-même.

Il est facile de voir que le système du certificat de civisme donnait aux autorités un moyen de pression considérable sur les citoyens. Une telle pratique ne pouvait manquer de retentir sur tous les secteurs de la participation à la vie politique (y compris la simple lecture des journaux de la Gauche). Au surplus, dans un tel domaine, les textes d'exception ne disent pas tout et il faut songer, sans oublier les simples voies de fait, à tous les ennuis que les autorités sont susceptibles de causer à un citoyen récalcitrant, ainsi à un petit commerçant, par une application pointilleuse des réglementations ordinaires. 
[p. 181] Il serait facile d'allonger cette liste des mesures d'exception au titre par exemple de la réglementation de la presse et de la diffusion des imprimés ou encore de l'épuration des services publics. Sous un régime comme celui qu'a connu la Grèce, il est toujours possible de faire une application partisane ou unilatérale de textes d'apparence objective. Soit la loi 2.500 de 1956 tendant à diminuer les effectifs de la fonction publique : en principe la notion de « fonctionnaire en surnombre » n'est pas politique mais elle le devient dès lors que l'éloignement de tel agent de préférence à tel autre est décidé sur la base d'un dossier d'opinion tenu par la police. Or il est clair que tout a été mis en œuvre pour écarter de l'appareil gouvernemental les fonctionnaires hostiles ou peu favorables au régime.

Les mesures que nous avons mentionnées établissent que sous le gouvernement de la Droite le dispositif de lutte anti-communiste était devenu un système de surveillance et souvent de pénalisation de la Gauche au sens large du terme. La police disposait en pratique des facultés et compétences nécessaires à l'exercice d'une surveillance étendue des opinions politiques des citoyens (la surveillance passant en de nombreuses occasions de l'individu lui-même à sa famille toute entière). Comme nous le verrons plus tard, l'existence de ce régime avait été portée à la connaissance de divers milieux étrangers et une forte pression internationale s'exerçait en faveur de son abolition.

Cette pression semble bien avoir été l'une des causes de la révision effectuée en juillet 1962 dans le cadre du décret législatif n 4234. Mais la caractéristique de ce texte adopté sous le gouvernement de Caramanlis est de maintenir, avec quelques modifications dans l'agencement du dispositif, une large partie du système de surveillance et de répression. Ce texte conserve l'institution de la déportation administrative et du certificat de civisme. S'il prétend abolir les dispositions d'exception sur la privation de la nationalité hellénique, il maintient la déchéance de nationalité des exilés : quand ceux-ci rentrent en fraude, ils sont passibles d'une peine de prison après l'exécution de laquelle on procède à leur expulsion. Le décret renonce aussi aux mesures de confiscation des biens adoptés contre les participants à la guerre civile et il organise même dans son article 5 la récupération des biens confisqués dans la mesure où ceux-ci n'ont pas encore été attribués. Mais en réalité, la procédure instituée à cet effet soumet cette restitution au bon vouloir des autorités gouvernementales, le dépôt de la demande de restitution [p. 182] étant subordonné à une déclaration des services compétents sur l'état des biens en cause. Enfin, l'article 6 du décret maintient l'interdiction du PC et des autres organisations dissoutes. Il punit « tous les actes visant à les porter au pouvoir de même que la publicité donnée à leurs slogans ou décisions dans le dessein évident de les appuyer et de les renforcer ».

La présence d'un tel dispositif conduit nécessairement à discuter la nature du régime politique sous lequel vivait la Grèce depuis la fin de l'insurrection armée et spécialement depuis les élections de 1958 qui, par suite des carences du Parti Libéral, virent l’EDA devenir au Parlement le premier parti d'opposition. 


\section{NATURE DU RÉGIME}

Parlant à Paris, le 26 mai 1962, devant une assemblée de juristes, Ilias Iliou avocat au barreau d'Athènes et l'un des leaders de l'EDA — soulignait l'existence en Grèce à côté de la constitution démocratique de 1952 d'une constitution parallèle ou para-constitution qui l'emportait finalement sur la première. Il déclarait que la Grèce n’en était pas arrivée au fascisme de type classique mais offrait « le spectacle original d'une "démocratie" dominée par l'esprit du fascisme qui admet les institutions abolissant en pratique toutes les garanties constitutionnelles des droits de l'homme et du citoyen ${ }^{1}{ }^{1}$. Il affirmait que ce dispositif permettait à la police de persécuter à sa guise les militants de la Gauche, ceux-ci étant, d'après les policiers, surveillés et poursuivis non au titre du parti légal qu'est l'EDA mais à celui de l'appareil illégal et clandestin du Parti Communiste.

De telles accusations constituaient alors l'un des éléments de base de l'argumentation présentée par l'EDA tant à destination intérieure qu'extérieure : ce parti ne cessait d'affirmer que l'ERE engageait la Grèce sur la voie de la fascisation ouverte. Or, à Partir d'une certaine date - et il semble bien que les élections de 1961 furent à cet égard un point tournant — on vit de nombreuses personnalités centristes émettre, quoiqu'avec un vocabulaire différent, des points de vue analogues. À [p. 183] l'été de 1963, divers leaders de l'Union du Centre, dont certains tels St. Stephanopoulos d'inspiration politique modérée, caractérisaient la situation comme celle d'un État de police. Ces accusations convergentes exprimaient-elles correctement la réalité ?

Notons d'emblée la réserve initiale d'Iliou : la Grèce n'était pas un pays fasciste de type classique. Un point suffirait à l'établir : le fait que l'opposition, y compris celle de Gauche, ait pu continuer à s'exprimer et à lutter publiquement et ouvertement. Certes l'opposition rencontrait de graves difficultés et courait des risques sérieux dans l'accomplissement de sa tâche. Le système comportait une dose considérable d'ingérences policières dans la vie des individus - le danger de mesures arbitraires étant normalement à son point maximum pour les militants et sympathisants de base. Tout ceci admis, dont nous n'entendons pas sous-estimer la profonde gravité, le gouvernement, même s'il s'appliquait par plusieurs de ses organes à détruire systématiquement certains éléments de l'opposition, acceptait ou tolérait la présence et l'activité d'adversaires décidés à le renverser. Et finalement ceux-ci réussiront dans leur entreprise après avoir obtenu la réalisation d'une consultation électorale correcte. Ce n'est pas là, évidemment, le schéma habituel de la dictature fasciste.

Cela étant, les remarques d'Ilion concernant l'existence d'une constitution parallèle paraissent justifiées par l'existence des pratiques d'alors. Il est clair que, sous couleur de lutte contre le communisme, les gouvernements au pouvoir depuis la fin de la guerre avaient maintenu et parfois renforcé un système de persécutions, vexations et brimades policières. L'un des traits de ce système était de punir des opinions

1 In Réunion de juristes d'Europe Occidentale pour la restauration des libertés publiques en Grèce, Paris, 26 mai 1962. Éditions de l'Association Internationale des Juristes Démocrates, p. 9. 
politiques par des sanctions socio-économiques. On commet probablement quelque excès terminologique en définissant le certificat de civisme comme une guerre économique menée par les autorités à l'encontre des adversaires politiques du gouvernement. Le fait demeure cependant que dans un pays où les postes de travail restent si difficiles à obtenir, l'opinion de la police sur une personne pouvait valoir à celle-ci privation d'un emploi.

Ajoutons que sous un régime de cet ordre, ce sont les hommes les moins scrupuleux, ceux qui n'hésitent pas à se renier, qui se tirent le mieux d'affaire. C'est ainsi que des citoyens dépourvus de ressources matérielles propres ont été jugés trop dangereux pour occuper des postes tout à fait modestes et ont été ainsi privés de la possibilité de gagner [p. 184] leur vie. À l'inverse, des personnages plus importants, autrefois sympathisants affichés du mouvement communiste, ont pu occuper, moyennant quelque reniement, des situations proches du pouvoir.

Il est douteux que dans l'état présent des structures socio-économiques de la Grèce et aussi dans la situation actuelle du communisme international, les dirigeants de l'ERE aient effectivement pu croire à l'imminence ou simplement à la présence d'un péril communiste dans le pays. Mais l'anti-communisme est un pavillon commode pour couvrir toutes sortes de marchandises : en particulier la volonté d'empêcher la croissance d'un authentique syndicalisme des travailleurs dont l'activité serait susceptible d'améliorer le statut moral et matériel de la classe ouvrière. De plus, la référence à un péril communiste a représenté, durant toute une période, un argument électoral puissant en raison des mauvais souvenirs laissés par la guerre civile. Enfin la dénonciation d'un tel péril et l'affirmation de la volonté de lutter contre lui ont constitué pendant de nombreuses années un excellent argument, probablement le meilleur de tous, pour obtenir l'appui américain — un appui ayant normalement pour objet le maintien des tares du système capitaliste et de l'économie de marche, qui, bien plus que l'or de Moscou, forment le meilleur élément de la propagande communiste.

On ne saurait d'ailleurs comprendre entièrement la position du citoyen grec à l'égard des forces de police, spécialement dans les campagnes, sans prendre en considération la pauvreté et le sous-développement économique du pays. Observons par exemple le cas de l'Italie dont les services de l'ordre ont gardé plusieurs des prérogatives acquises au temps de Mussolini : chacun sait qu'il ne fait pas bon s'y trouver sans influence sociale et sans possession de biens matériels devant les représentants de la loi. Dans cette perspective, il semble bien que le sousdéveloppement économique avec son cortège de conséquences sociales, constitue par lui-même un terrain défavorable à la sauvegarde des prérogatives de l'individu, l'une des conséquences habituelles de la misère étant de susciter la crainte de celui qui détient une parcelle de l'autorité.

Quiconque a vu un gendarme grec se pavaner sous les arbres d'un village ou à la terrasse du café local comprendra sans peine la portée de cette observation. En d'autres termes, si l'action anti-communiste du gouvernement a considérablement aggravé la situation des individus modestes devant la police, elle ne porte pas la 
responsabilité intégrale [p. 185] d'une situation qui ne saurait disparaître sans la réalisation préalable de plusieurs conditions (dont l'élargissement et l'amélioration du système éducatif).

\section{FAIBLESSE DU MOUVEMENT SYNDICAL}

\section{$\underline{\text { Retour à la table des matières }}$}

Cette faiblesse a une double origine : l'étroitesse de la base proprement ouvrière du pays qui résulte directement de la modicité de la croissance industrielle; l'intervention du gouvernement dans l'organisation syndicale en vue de s'assurer la loyauté politique et la docilité sociale du mouvement. Durant toute la période étudiée, le syndicalisme grec est demeuré sous le contrôle de la police (présence d'une section consacrée aux syndicats dans les services de la Sécurité Publique).

L'organisme central officiel est la Confédération Générale du Travail de Grèce dont le financement repose sur un système de cotisation obligatoire. Elle fait partie de la Confédération Internationale des Syndicats Libres (CISL) et participe désormais en qualité de membre associé aux activités du Secrétariat Syndical Européen qui est l'organe du rassemblement des syndicats du Marché Commun : la CGT grecque est représentée dans le Secrétariat Européen par son secrétaire général Photis Macris.

Notons immédiatement que la Gauche refuse de tenir la CGT dans son état actuel pour représentative du mouvement ouvrier grec. Selon elle, la direction de la Confédération est assumée par des hommes ne devant leur existence qu'à l'appui des autorités publiques et à la bonne volonté patronale. Dès lors ces leaders, dont beaucoup se laissent financièrement corrompre, n'ont d'autre préoccupation que d'obtenir le respect des directives du pouvoir et de seconder la police dans sa lutte contre le communisme. Photis Macris lui-même n'hésite pas à se présenter publiquement comme un défenseur de la civilisation occidentale contre les hordes du panslavisme.

Le tableau ainsi brossé de la CGT par la Gauche risque de paraître exagérément noir. Pourtant, sur la base d'une analyse attentive de la réalité syndicale grecque, on peut admettre qu'il correspond grosso modo à la situation. La caution donnée par la CISL à l'organisme officiel grec montre bien que la première fait passer l'anticommunisme avant toute autre considération.

La situation actuelle remonte à la décision, prise en 1946 par le gouvernement Tsaldaris, de destituer en bloc le bureau élu lors du premier congrès d'après-guerre et de le remplacer par une équipe d'hommes [p. 186] dévoués aux autorités. Depuis lors, la CGT est demeurée sous le contrôle de politiciens imposés d'en haut et soustraits à tout contrôle de la base syndicale. Parmi les moyens utilisés à cet effet, mentionnons l'absence totale de proportionnalité entre le chiffre des effectifs et le montant des voix disponibles lors des élections syndicales. Aucun syndicat ne peut avoir plus de 7 voix, tout syndicat doit en avoir au moins une : ainsi, pour prendre un exemple réel, un 
syndicat de 3.500 membres disposait-il de 7 voix au titre de l'élection des dirigeants confédéraux tandis que 3.100 travailleurs répartis en une poussière de petits syndicats bénéficiaient en tout d'une centaine de suffrages.

Autre technique de consolidation du pouvoir des dirigeants: l'expulsion des syndicats ne témoignant pas du loyalisme politique exigé des citoyens. Pour appartenir à la CGT, les organisations syndicales devaient désavouer le mouvement communiste et se prononcer en faveur de ce que les dirigeants de la CGT appelaient par antiphrase le syndicalisme libre. C'était en somme une sorte de certificat de civisme collectif. Sur cette base un grand nombre de syndicats (près de 250 semble-til) ont été écartés de la Confédération Générale.

En vue de porter remède à la situation, les milieux de gauche ont créé le Mouvement syndical Démocratique dont la direction est assumée par D. Stratis (ancien sénateur de Vénizélos et ancien secrétaire général de la CGT). Ce mouvement n'est pas une organisation syndicale à proprement parler mais un groupement d'inspiration progressiste qui entend œuvrer à la démocratisation de la vie syndicale et au renforcement de la lutte ouvrière dans les organismes existants. L'un des moyens employés à cet effet est la formation de cadres capables d'appuyer et d'amplifier l'activité des militants de base. L'une des principales revendications du Mouvement, la plus importante et significative en réalité, est l'assainissement de la situation de la CGT : il demande à cet effet la tenue d'élections libres et honnêtes dans tous les syndicats et, sur cette base, la désignation d'une nouvelle direction confédérale. C'est en fait toute l'orientation future du mouvement syndical que cette revendication met en jeu.

Beaucoup des syndicats exclus de la CGT — qu'ils en aient été expressément radiés ou qu'ils n'aient pas été acceptés au départ par celle-ci — participent aux travaux du Mouvement Syndical Démocratique. Il existe au surplus entre les syndicats - initialement désignés comme les 115 syndicats coopérants (mais on en comptait 243 en février 1964) un certain mode de collaboration au titre de questions d'ordre professionnel [p. 187] ou de problèmes de politique générale. Parmi leurs revendications figurent bien entendu la réintégration sans condition d'ordre politique dans le cadre du mouvement ouvrier ainsi que la cessation de toutes les interférences de l'Administration dans la vie syndicale. Depuis l'arrivée au pouvoir du gouvernement du Centre, ces syndicats ont un accès direct aux autorités publiques (en particulier Ministère du Travail).

En dépit de la situation que nous venons d'évoquer, on a observé au cours de ces dernières années le déclenchement de nombreux mouvements de grève en des secteurs très divers de l'activité sociale (travailleurs du bâtiment, employés de banque, personnel des transports, membres de l'enseignement public...). Le gouvernement s'est efforcé d'endiguer le mouvement en utilisant plusieurs lois dont certaines remontant à la dictature Métaxas : ainsi la loi 1984 de 1939 qui permet aux autorités de procéder à la réquisition du personnel en grève (disposition qui fut utilisée vis-àvis du personnel de la Société des Transports Électriques, de celui de la Société des Télécommunications, des postiers, des cheminots, du personnel des transports 
aériens, des instituteurs ainsi que, par les soins du Cabinet Papandréou, du personnel de l'Entreprise Publique d'Électricité...). Le gouvernement a aussi employé la loi 3239 de 1955 qui impose la cessation de la grève dès que le conflit entre patrons et ouvriers est porté sur intervention du Ministre du Travail devant un tribunal d'arbitrage (dispositif utilisé notamment lors d'une grève des employés de banque). Signalons enfin la survenance de nombreux heurts entre grévistes et forces de police (le dernier en date étant celui arrivé le 22 juillet 1964 à la fabrique textile Caréla de Laurium dans laquelle s'étaient enfermés 1.200 grévistes pour protester contre le renvoi des membres du comité de grève).

Malgré les forces à leur disposition, les autorités n'ont réussi qu'imparfaitement à bloquer le mouvement revendicatif lancé le plus souvent sans l'accord et parfois contre la volonté expresse de la CGT. Les grévistes ont en plusieurs cas, obtenu des avantages appréciables et amélioré leur situation mais, par suite de l'inorganisation du mouvement syndical, ces actions n’ont généralement qu'une portée fragmentaire. À l'exception de quelques branches privilégiées (ainsi bâtiment), le pouvoir d'achat des ouvriers, qui sont privés de la faculté de négocier de véritables contrats collectifs, demeure limité. Cette situation est plus favorable à la multiplication de grèves d'inspiration anarchique qu'à la conduite d'une action syndicale cohérente et de longue haleine.

[p. 188] La situation comporte d'ailleurs un vice fondamental tenant au fait que le gouvernement attribue à l'arrivée du capital étranger une importance primordiale au titre de l'industrialisation du pays. Or la faiblesse des salaires grecs constitue, spécialement dans le cadre du Marché Commun, l'un des facteurs essentiels d'attraction de ce capital. Cependant elle est en même temps l'un des éléments qui poussent les travailleurs à émigrer. Dans ces conditions, la volonté de sauvegarder le potentiel ouvrier du pays et d'y attirer le capital étranger semble bien relever en quelque mesure de la quadrature du cercle.

Le gouvernement de l'Union du Centre vient de faire passer, en date du 26 août 1964, une loi tendant à assurer la réorganisation et la démocratisation du mouvement syndical. Un projet avait été déposé à cet effet le 21 juillet 1964 par le Ministre du Travail. Or ce projet, sitôt connu, suscita une très vive émotion dans les cadres dirigeants de la CGT ainsi que dans les milieux du syndicalisme international avec lesquels ces cadres sont liés. Dès le 21 juillet, la CISL dépêchait une mission en Grèce, sous la conduite de W. Schevenels - mission ayant en principe pour tâche d'enquêter sur la situation syndicale du pays mais ayant en réalité pour tâche d'intervenir auprès du gouvernement à propos du projet soumis au Parlement. En date du 22 août, le secrétaire général de la CISL lui-même envoyait un télégramme au Premier Ministre pour l'informer des « préoccupations » de son organisme au sujet de la législation syndicale en préparation ${ }^{1}$. De quoi s'agissait-il ?

Il suffit pour comprendre les mobiles de ces préoccupations, de lire l'article 5 du projet déposé par le gouvernement. Celui-ci tendait en définitive à proportionner la

Bulletin hebdomadaire de la CISL, 27 août 1964, p. 1. 
représentation des divers syndicats dans les organes de la CGT à l'importance réelle de leurs effectifs. Le projet garantissait qu'une telle proportionnalité interviendrait pour les élections à tous les niveaux de l'organisation syndicale. C'était supprimer d'un seul coup l'arsenal de pratiques et de combinaisons grâce auxquelles l'actuelle direction parvenait, d'un congrès à l'autre, à conserver son pouvoir. À partir de là, on pouvait envisager qu'à plus ou moins brève échéance la CGT grecque réorganisée choisisse une nouvelle orientation qui l'éloigne de la CISL.

Sur ce point capital et sur quelques autres de moindre importance, la loi définitive marque un retrait par rapport au texte initial. C'est ainsi [p. 189] que le nouvel article 5 déclare qu'aucun syndicat, quelle que soit l'ampleur de ses effectifs, ne pourra disposer d'une force de vote supérieure au dixième du total des voix existantes. L'intervention étrangère n'a donc pas été inutile au titre des intérêts défendus par la CISL mais elle n'a que partiellement reçu satisfaction. En particulier, la CISL n'a pu obtenir que le $15^{\mathrm{e}}$ Congrès de la CGT, prévu pour le mois de septembre avec les normes habituelles de représentation, ait effectivement lieu.

Cette intervention de la CISL dans la politique grecque, en vue de sauver Ph. Macris et son équipe, est absolument exemplaire et il est important pour notre propos d'observer que le Ministre du Travail C. Bacatselos s'est cru obligé de donner des explications à cet organisme. Comme s'il s'agissait d'une autorité devant laquelle il fut politiquement responsable, le Ministre a tenu à assurer la CISL de la portée démocratique réelle de la nouvelle législation syndicale ${ }^{1}$. Il est vrai que de semblables ingérences n'ont rien d'exceptionnel, I. Brown lui-même étant intervenu à plusieurs reprises dans le passé au profit de l'actuelle direction de la CGT.

Pour en terminer avec le système de pression international, mentionnons la récente intervention du Comité exécutif de l'organisation CISL des syndicats du Marché Commun. Cet organisme vient d'indiquer, dans une résolution publique de son Comité Exécutif, qu'il cesserait d'accepter en son sein la Confédération Générale des Travailleurs de Grèce si le gouvernement grec continuait d'intervenir dans la vie syndicale et si la Confédération n'avait pas à sa tête des dirigeants librement choisis par les syndiqués. On se demande, dans ces conditions, les motifs qui ont pu conduire cet organisme à accepter durant des années, à titre de membre associé, l'équipe de $\mathrm{Ph}$. Macris. Nous voudrions être sûrs que l'Organisation de la CISL pour le Marché Commun n'a pas simplement propension à tenir pour indésirables les efforts, d'ailleurs très partiels, entrepris en vue d'éliminer de la CGT les agents du gouvernement et du patronat que le gouvernement Caramanlis y avait placés.

Les démarches de la CISL montrent en tout cas que l'analyse des impérialismes contemporains reste incomplète si l'on ne prend pas en considération l'activité des organisations internationales privées qui travaillent en liaison avec les grandes puissances ou dans leur sillage. Il est à peine [p. 190] besoin de mentionner ici, tellement la connaissance de ce point est du domaine public, les rapports de tous ordres qui existent entre la politique des États-Unis et l'activité de la CISL.

Bulletin hebdomadaire de la CISL, 10 septembre 1964. 
Notons pour terminer qu'un jugement du Tribunal de Première Instance d'Athènes en date du 15 décembre 1964 a démis de ses fonctions l'administration en exercice de la CGT. Elle a été remplacée par une administration provisoire qui, forte de 31 membres, gérera l'organisme jusqu'à la réunion du Congrès Panhellénique.

En définitive, le mouvement syndical a considérablement souffert de la constitution parallèle et des séquelles de la guerre civile. Sous prétexte de lutter contre le communisme, il s'agissait en fait pour les hommes au pouvoir d'empêcher ou d'entraver la concentration des forces ouvrières, l'objet de ce dispositif étant d'ordre politique aussi bien qu'économique. S'agissant de la période examinée en cet ouvrage, on peut dire que le gouvernement est assez largement parvenu à ses fins. Pour l'avenir, c'est une autre histoire.

\section{POSITION DE LA PRESSE}

$\underline{\text { Retour à la table des matières }}$

Selon un catalogue publié par le Ministère à la Présidence du Conseil, le nombre des organes de presse publiés en Grèce durant l'année 1963 s'établit comme suit :

\begin{tabular}{lccc}
\hline & Journaux quotidiens & $\begin{array}{c}\text { Journaux non } \\
\text { quotidiens }\end{array}$ & Revues \\
\cline { 2 - 4 } Région d'Athènes & 33 & 441 & 437 \\
Reste de la Grèce & 63 & 340 & 88 \\
\cline { 2 - 3 } & $\mathbf{9 6}$ & $\mathbf{7 8 1}$ & $\mathbf{5 2 5}$ \\
\hline
\end{tabular}

Les principaux journaux quotidiens du pays sont ceux publiés à Athènes : leur diffusion s'étend en moyenne à l'ensemble du territoire. Il existe aussi quelques quotidiens importants à Salonique. Quant aux quotidiens publiés dans les autres villes de province, leur diffusion est très restreinte.

[p. 191] Voici la classification des principaux journaux quotidiens d'Athènes selon l'orientation politique suivie (cette liste tenant compte à la fois de l'importance du tirage et de la signification partisane de l'organe en cause). 


\begin{tabular}{lll}
\hline & \multicolumn{1}{c}{ Tournaux du matin } & \multicolumn{1}{c}{ Journaux du soir } \\
\hline Droite & Cathirnerini & Messimvrini \\
& Acropolis & Apogevmatini \\
& Imera & Vradini \\
& Ethnicos Kirix & \\
Empros & \\
& Niki & Estia \\
& & Ta Nea \\
Parti Progressiste & Vima & Athinaiki \\
Centre & Elefteria & Ethnos \\
& & Democratiki Allayi \\
Gauche & Avghi & \\
\hline
\end{tabular}

Tous ces journaux appartiennent à des propriétaires privés à l'exclusion de ceux de la Gauche qui sont la propriété collective du parti. À l'exception de ces derniers, ils disposent tous de leur imprimerie, l'équipement de ce secteur ayant été fortement modernisé au cours des dernières années.

Dans le secteur de la Droite, le principal groupe de presse est celui d'Hélène Vlachou. Il publie deux quotidiens (Cathimerini et Messimvrini), un hebdomadaire illustré (Icones) un digest (Eklogi) et une collection d'ouvrages (Éditions Galaxias). Le groupe a soutenu en son temps le gouvernement Caramanlis mais sa ligne est plutôt celle d'une Droite modérée ou d'un conservatisme indépendant (les adversaires du groupe disant qu'il s'efforce d'avoir un pied dans chacun des deux camps). Témoignent d'un esprit plus agressif, qui va jusqu'à l'adoption de positions d'extrêmedroite, des journaux comme Acropolis et Apogevmatini édités par un groupe qui publie aussi un hebdomadaire de variété : Proto. Actuellement le bastion des partisans du retour de Caramanlis est constitué par les journaux d'Athanassiadis: Imera et Vradini. Ce groupe publie aussi le quotidien économique Naftemboriki. Le quotidien Niki (propriétaire Livanos) constitue le point d'appui de P. Canellopoulos.

Le principal groupe dans le secteur du Centre est celui de Lambrakis. Il publie deux quotidiens (Vima et Ta Nea), un hebdomadaire [p. 192] sportif (Omada), un hebdomadaire magazine (Tachydromos), une hebdomadaire économique (Economicos Tachydromos), un mensuel littéraire (Epoches). Lors de l'arrivée sur la scène politique du Maréchal Papagos, le groupe avait pris un tournant en faveur du Rassemblement Hellénique mais il est revenu ensuite sur des positions centristes.

Durant la phase de rapprochement du groupe Lambrakis avec la Droite, le seul quotidien matinal du Centre a été Elefteria qui appartient à Panos Cocas. Sous le gouvernement Caramanlis il a constamment défendu les Libéraux et servi de tremplin à un homme comme Mitsotakis. Actuellement, le journal prend des positions critiques à l'égard du Cabinet Papandréou et en particulier de Garoufalias. En somme Vima et 
Elefteria ne soutiennent pas exactement les mêmes milieux politiques bien qu'ils se réclament tous deux du label centriste.

Au titre des quotidiens publiés à Salonique, nous mentionnerons Makédonia (matin) et Thessaloniki (soir) qui, appartenant à un même propriétaire (Veclidis), sont de nuance centre-droit. Le journal du matin Hellinikos Vorras relève d'une droite très militante. Pour Patras, nous signalerons Néologos (libéral) et Péloponnissos (droite).

Pour le tirage, les informations disponibles varient considérablement selon la source, les journaux ayant tendance à gonfler fortement les chiffres de leur diffusion en vue d'attirer les annonceurs. Mais on peut admettre que ces évaluations même gonflées restent en dessous du nombre réel des lecteurs. Normalement les journaux sont lus par plusieurs personnes, spécialement à la campagne où il arrive que la lecture se fasse au café à haute voix. Dans la ville d'Athènes, certains kiosques des boulevards ont l'habitude d'afficher les journaux à leur devanture, ce qui permet au public des promeneurs de lire gratuitement la première page de ceux-ci. Il y a même des dépositaires qui acceptent de " prêter » les journaux durant un moment en vue d'attirer la clientèle pour les autres produits en vente.

Selon des informations officielles ${ }^{1}$, la diffusion totale des quotidiens politiques d'Athènes (nombre d'exemplaires vendus) aurait évolué comme suit de 1961 à 1962 :

\begin{tabular}{|c|c|c|}
\hline & 1961 & 1962 \\
\hline 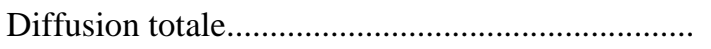 & 130.856.286 & 143.160 .860 \\
\hline dont : vendus dans le Grand Athènes................. & 82.504 .383 & 91.328 .918 \\
\hline Ce qui laisse pour le reste du pays............................. & 48.351 .903 & 51.831 .942 \\
\hline
\end{tabular}

[p. 193] Toujours d'après la même source, la diffusion totale des journaux (quotidiens et non quotidiens) publiés à Salonique et dans le reste du pays aurait été en 1961 de 41.190.448. Pour 1962, nous n'avons que le chiffre de Salonique 17.385.511.

Les estimations que nous venons de mentionner doivent être prises sous toutes réserves. Selon certains spécialistes du problème, les chiffres fondés sur les déclarations de l'Union des propriétaires des journaux quotidiens d'Athènes seraient très grossièrement exagérés. Alors que l'Union revendique pour 1963 une vente totale de 169.173.004 journaux, d'autres ramènent ce chiffre à 86.240.000. N'ayant pas le moyen d'effectuer une quelconque vérification, nous nous bornons à signaler ces écarts et préférons dès lors ne pas mentionner les chiffres relatifs aux tirages individuels qui font l'objet d'estimations fortement divergentes.

Au titre de la liberté de la presse, on doit noter que le gouvernement dispose d'un important arsenal de mesures répressives (remontant à la dictature Métaxas, à la guerre civile et au gouvernement Papagos) — dispositif qui, tout en ne faisant l'objet que d'une application limitée, n'en a pas moins été gênant pour la liberté de la presse

Statistical Yearbook of Greece 1963. 
en laissant planer sur elle une épée de Damoclès. Au surplus, ce sont les publications de la gauche qui ont fait l'objet du traitement le plus rigoureux (notamment au titre de l'article 6 de la loi 4234 déjà cité) ${ }^{1}$. La plupart des procès intentés aux journaux se sont terminés par des non-lieux.

On doit également compter avec la faculté dont dispose le gouvernement en Grèce comme ailleurs d'exercer un certain nombre de pressions économiques sur la presse (en particulier au titre de la distribution des ordres de publicité émanant des services publics et entreprises publiques). Signalons à ce propos une sanction originale et pouvant être très grave qu'adopta en 1953 le Parlement dans le cadre d'un dispositif tendant à renforcer la répression des délits de presse : le retrait de l'exonération des droits de douane sur le papier journal, retrait susceptible d'aller d'une période de deux mois à un an. Comme cas d'application, mentionnons le retrait infligé en décembre 1962 pour 4 mois au journal du Centre Athinaiki - retraite accompagnée de l'envoi en prison pour six mois du propriétaire du journal — pour avoir affirmé que la Reine Frédérika laissait sa mère dans un complet dénuement. Enfin, [p. 194] n'oublions pas l'octroi par le gouvernement d'un appui financier direct qui a pris des formes diverses au cours de la période étudiée en cet ouvrage (prêts remboursables, subventions occultes sur fonds secrets...).

Dans l'ensemble, la presse grecque est très politisée, ou, si l'on préfère, avant tout politique, les secteurs conservateurs et modérés de l'opinion disposant d'un nombre d'organes bien plus grand que les milieux de gauche qui éprouvent des difficultés matérielles à faire vivre leur presse. Ce n'est pas là d'ailleurs, chacun le sait, une situation propre à la Grèce.

Selon M. Marceau, c'est la «presse démocratique de Centre-gauche » qui aurait été la plus visée et la plus importunée par les gouvernements de Droite. Cahiers de l'institut International de la Presse, novembre 1964, p. 7. 
[p. 195]

\section{CHAPITRE V \\ GAUCHE DÉMOCRATIQUE UNIFIÉE (EDA)}

Retour à la table des matières

NOUS AVONS déjà analysé les étapes du retour de la Gauche sur la scène politique au lendemain de la guerre civile. Celles-ci ont été au nombre de trois; participation aux élections du 5 mars 1950 sous la forme d'une coalition de partis dite Front Démocratique ; intervention lors des élections municipales d'avril 1951 d'un organisme dénommé Rassemblement Démocratique qui, jugeant la politique du Front trop modérée et trop opportuniste, s'efforce de réunir autour de lui les partisans d'une action plus rigoureuse; fondation de l'EDA en août 1951, soit à la veille de la consultation électorale du 9 septembre, avec le mot d'ordre Paix-DémocratieAmnistie.

L'EDA se présente donc au départ comme un regroupement de formations partisanes et de personnalités. C'est déjà bien plus qu'une simple coalition électorale, ce n'est pas encore un parti organiquement unitaire. Il suffit pour s'en convaincre d'observer que les statuts de l'époque prévoient que le nouvel organisme sera dirigé par un comité formé de deux représentants de chacun des partis associés. On peut, en gros, considérer l'opération comme un effort de reconstitution de l'EAM.

Il est facile de comprendre les difficultés de mise en œuvre d'une telle formule au titre de la conduite et de la gestion permanente d'une formation partisane. Aussi bien une lutte va-t-elle s'engager au sein du parti entre les tenants du système initial et les partisans d'une direction plus homogène. Le combat tournant à l'avantage des seconds, on assistera au départ plus ou moins volontaire de plusieurs des promoteurs de l'expérience et des fondateurs de l'organisme. Cette élimination facilitera, sans nul doute, la tâche de ceux qui souhaitent donner au parti une organisation plus stricte.

[p. 196] Cette mutation entreprise dès 1955 sera consacrée par les nouveaux statuts qu'adopte la Première Conférence Panhellénique (15-17 juillet 1956) et que 
ratifiera un peu plus tard le premier Congrès du Parti (28 novembre - 2 décembre 1959). Depuis lors, l'organisation de celui-ci n’a pas subi de modification.

\section{STRUCTURE ET DIRECTION}

$\underline{\text { Retour à la table des matières }}$

Nous allons étudier successivement le mode, d'organisation de l'EDA puis la composition socio-professionnelle de ses organes centraux. Nous achèverons cette présentation en mentionnant les noms et qualités de ses principaux leaders.

\section{A. MODE D'ORGANISATION}

L'EDA est le seul parti grec qui mette effectivement en pratique l'organisation prévue par ses statuts. Celle-ci épouse le cadre départemental, les villes de plus de 100.000 habitants bénéficiant toutefois d'une organisation propre. Les organismes établis au niveau de chacun des départements et centres urbains importants sont divisés en un certain nombre de sections qui se composent elles-mêmes des éléments d'organisation contenus dans leur circonscription.

Ces éléments ou cellules sont formés sur la base soit du voisinage géographique, soit du lieu de travail ou de l'activité professionnelle. La formation d'une cellule exige la présence d'au moins 3 membres de l'EDA. Chaque cellule est dirigée par un comité de 3 à 7 membres. Toutefois, si l'élément en cause a peu de membres, on se contente d'un secrétaire.

L'organe suprême de l'EDA est le Congrès du Parti dont les statuts prévoient la réunion ordinaire tous les trois ans. Participent au Congrès avec droit de vote les délégués des organisations des départements et villes importantes d'une part, le groupe parlementaire de l'autre. Le Congrès arrête la ligne du parti et élit le Comité directeur qui porte la responsabilité de la marche du Parti entre deux sessions du Congrès. Le Comité dont le nombre des membres (réguliers et suppléants) est arrêté par le Congrès, se réunit au moins tous les six mois (en pratique tous les 4 mois sans compter les réunions extraordinaires). Il élit lui-[p. 197] même son président qui est simultanément Président du parti. De plus, le Comité désigne le Comité Exécutif dont il détermine le nombre des membres.

Le Comité Exécutif est choisi parmi les membres du Comité Directeur et c'est le Président de ce dernier qui en est également le président : il assume, sous le contrôle du Comité Directeur, la charge du fonctionnement courant du parti. Le Comité Exécutif est aidé dans sa tâche par un certain nombre de commissions dont il arrête le nombre et, fixe l'objet. Il existe des Commissions pour l'organisation du parti, les syndicats, les classes moyennes, les femmes, les coopératives, etc. Le Comité 
Exécutif se réunit en principe toutes les semaines sans compter les réunions extraordinaires.

Quant au Comité de Supervision dont les membres doivent être pris hors du Comité Directeur, il est élu par le Congrès. Il a compétence pour instruire les affaires dans un certain nombre de domaines délicats (en particulier les questions de discipline et de gestion financière).

Les statuts prévoient deux autres organes susceptibles d'entrer en action si le besoin s'en fait sentir. En premier lieu, la Conférence Panhellénique qui peut être appelée à siéger entre deux Congrès pour préciser la ligne du parti dans le cadre des directives arrêtées par le précédent Congrès. Moins nombreuse que le Congrès, la Conférence Panhellénique est convoquée par le Comité Directeur sur proposition du Comité Exécutif. En pratique, les sessions de la Conférence Panhellénique sont séparées par un intervalle de 6 mois à un an. Notons la récente convocation (25-28 juillet 1964) de la Première Conférence Panhellénique d'Organisation.

Le second de ces organes est le Conseil National. Ce dernier, de caractère purement consultatif, peut être réuni entre les Congrès du Parti ou les Conférences Panhelléniques pour l'étude des problèmes posés par la mise en application de la politique du Parti.

Le système prévu au titre de la prise des décisions s'inspire des principes du centralisme démocratique. Que ce soit dans les réunions des éléments de base, dans les assemblées des sections ou dans toute autre réunion de l'EDA, les adhérents bénéficient de la liberté de discussion : ils se trouvent habilités à donner leur avis sur les questions qui leur sont soumises par les organes de direction et à présenter de leur propre initiative d'autres thèmes de débat. L'ordre du jour du Congrès du Parti est établi par le Comité Directeur, celui des sessions de la [p. 198] Conférence Panhellénique par le Comité Exécutif. Cependant, une fois la discussion terminée, les décisions arrêtées par les instances compétentes sont obligatoires pour tous ceux qu'elles concernent. Mentionnons également que tous les organes de direction du parti sont élus par vote secret.

Dans un système de cet ordre, chaque organe porte la responsabilité de son activité devant l'organe dont il tient son pouvoir, tout pouvoir trouvant finalement son origine dans le Congrès qui est l'émanation de la base. Mais chacun sait que dans les formations hiérarchisées de cette manière, les circuits réels de l'autorité n'obéissent pas nécessairement aux normes statutaires. D'où l'existence dans le mécanisme de prise des décisions d'un degré de centralisation plus important que celui prévu par la Charte du parti.

Un point renforce cette tendance à la centralisation: la faculté ouverte en plusieurs cas à l'organe supérieur d'intervenir dans la gestion de l'organe inférieur. Mentionnons par exemple la faculté attribuée au Comité de Direction de se faire représenter dans n'importe quelle conférence ou réunion des divers organes de l'EDA. Soulignons aussi la disposition des statuts prévoyant qu'exceptionnellement le Comité Exécutif peut désigner ou remplacer les membres des organes de direction de toutes les organisations de l'EDA, sous condition toutefois de l'approbation du Comité 
Directeur du Parti. Dernier exemple : l'expulsion d'un membre relève de l'élément d'organisation auquel il appartient mais cette décision doit être ratifiée par l'organe situé au-dessus dans la hiérarchie.

\section{B. COMPOSITION SOCIO-PROFESSIONNELLE DES ORGANES CENTRAUX}

Retour à la table des matières

Voici, tout d'abord, selon des documents officiels publiés par le parti ${ }^{1}$, la composition professionnelle de ces organes, telle que déterminée à l'issue du Second Congrès (8-15 décembre 1962), les chiffres entre parenthèses concernant les membres suppléants : [p. 199]

\begin{tabular}{|c|c|c|c|}
\hline Professions & $\begin{array}{c}\text { Comité } \\
\text { Directeur }\end{array}$ & $\begin{array}{l}\text { Comité } \\
\text { Exécutif }\end{array}$ & $\begin{array}{l}\text { Comité de } \\
\text { Supervision }\end{array}$ \\
\hline 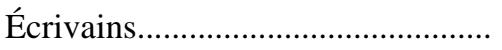 & $1(2)$ & - & - \\
\hline 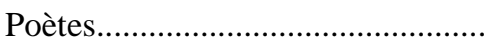 & $1(1)$ & - & - \\
\hline Professeurs d'Université..................... & 4 & 2 & - \\
\hline 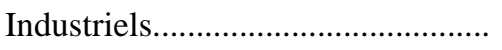 & - & - & 1 \\
\hline 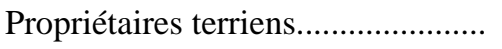 & 1 & - & - \\
\hline 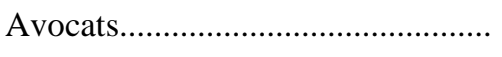 & $11(8)$ & $2(1)$ & - \\
\hline 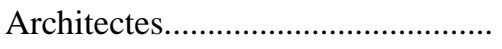 & 1 & - & - \\
\hline 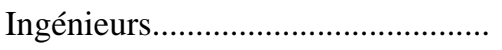 & $1(1)$ & - & - \\
\hline Ingénieurs agronomes...................... & 2 & - & - \\
\hline 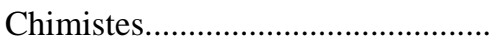 & 1 & - & - \\
\hline 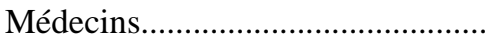 & $2(2)$ & - & 1 \\
\hline 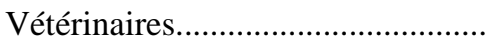 & - & - & $-(1)$ \\
\hline 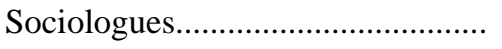 & 1 & - & - \\
\hline 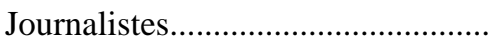 & $8(4)$ & $5(2)$ & - \\
\hline 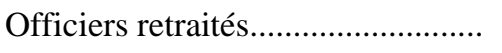 & 3 & 1 & 1 \\
\hline Professeurs dans le secondaire........ & 1 & - & - \\
\hline 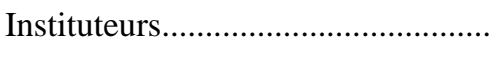 & $4(2)$ & - & - \\
\hline 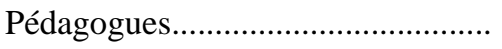 & $1(1)$ & - & - \\
\hline 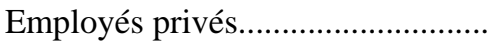 & $13(7)$ & $1(2)$ & $2(1)$ \\
\hline 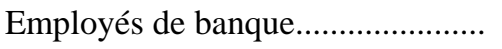 & 2 & 1 & - \\
\hline Employés des PTT............................. & 1 & - & - \\
\hline 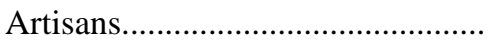 & $3(1)$ & - & $-(1)$ \\
\hline 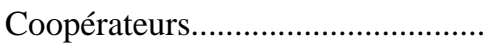 & 2 & - & - \\
\hline 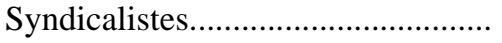 & $9(2)$ & $2(2)$ & - \\
\hline
\end{tabular}

1 To B. Panelladico synedrio tis EDA, epissima Kimena, Éditions de la Gauche Démocratique Unifiée, Athènes 1963. 


\begin{tabular}{|c|c|c|c|}
\hline 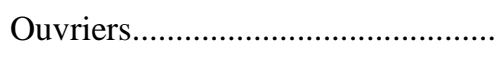 & $7(10)$ & $-(1)$ & 5 \\
\hline 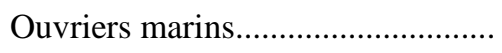 & 1 & & - \\
\hline 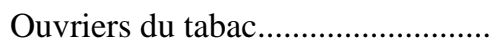 & $-(1)$ & - & - \\
\hline 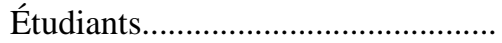 & $1(1)$ & - & - \\
\hline 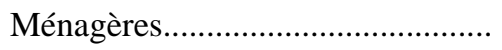 & $1(2)$ & - & - \\
\hline Total................ & $85(45)$ & $14(8)$ & $10(3)$ \\
\hline
\end{tabular}

[p. 200] Il est possible de regrouper les diverses professions figurant sur le précédent tableau en quelques grandes rubriques susceptibles de mieux mettre en évidence les catégories socio-professionnelles parmi lesquelles sont recrutées les membres des organes centraux. Nous proposons à cet effet la distribution suivante :

\begin{tabular}{|c|c|c|c|}
\hline & $\begin{array}{c}\text { Comité } \\
\text { Directeur }\end{array}$ & $\begin{array}{l}\text { Comité } \\
\text { Exécutif }\end{array}$ & $\begin{array}{l}\text { Comité de } \\
\text { Supervision }\end{array}$ \\
\hline 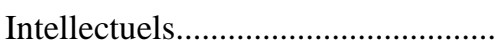 & $6(3)$ & 2 & - \\
\hline Professions libérales............................... & $27(15)$ & $7(3)$ & $1(1)$ \\
\hline Fonctionnaires et retraités.................. & $9(2)$ & 1 & 1 \\
\hline Employés de commerce..................... & $15(7)$ & $2(2)$ & $2(1)$ \\
\hline 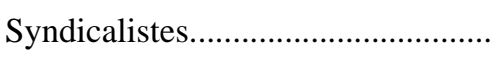 & $9(2)$ & $2(2)$ & - \\
\hline 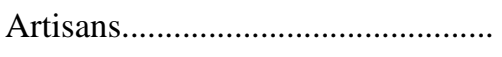 & $3(1)$ & - & $-(1)$ \\
\hline 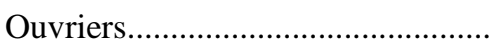 & $8(11)$ & $-(1)$ & 5 \\
\hline 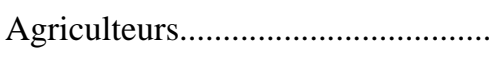 & 2 & - & - \\
\hline 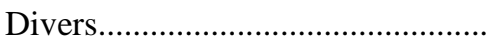 & $6(4)$ & - & 1 \\
\hline 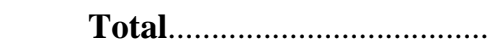 & $85(45)$ & $14(8)$ & $10(3)$ \\
\hline
\end{tabular}

Enfin, il est intéressant d'observer la part respective des hommes et des femmes dans les organes centraux. La distribution par sexe s'établit comme suit :

\begin{tabular}{|c|c|c|c|}
\hline & $\begin{array}{c}\text { Comité } \\
\text { Directeur }\end{array}$ & $\begin{array}{l}\text { Comité } \\
\text { Exécutif }\end{array}$ & $\begin{array}{l}\text { Comité de } \\
\text { Supervision }\end{array}$ \\
\hline Hommes.............................. & 76 (39) & $13(8)$ & $9(2)$ \\
\hline 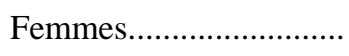 & $9(6)$ & 1 & $1(1)$ \\
\hline
\end{tabular}

Parmi les traits qui ressortent le plus clairement de cette documentation, observons l'importance considérable dans la gestion centrale du parti des personnalités exerçant des professions libérales ou des métiers de type intellectuel. 
Leur place est prépondérante au sein du Comité Exécutif. Par contre, ce sont des ouvriers qui figurent en majorité dans le Comité de supervision.

[p. 201]

\section{PRINCIPAUX LEADERS DU PARTI}

\section{$\underline{\text { Retour à la table des matières }}$}

La présidence de l'EDA est assurée par J. Passalidis que l'on peut tenir pour une figure historique. Né en 1885, il fut élu en 1918 député social-démocrate (menchevik) au Parlement de la Géorgie alors indépendante de la Russie. Dès 1923 cependant, il était élu député de Salonique au Parlement grec (circonscription qu'après la seconde guerre mondiale il obtiendra de représenter aux élections de 1951, 1956, 1958, 1961, 1963 et 1964). Il fut le fondateur du Parti socialiste grec, l'une des formations ayant donné leur adhésion à l'EAM. En 1945, Passalidis est membre du Comité Central de cet organisme.

Le leader du groupe parlementaire de l'EDA est Ilias Iliou, député de Mytilène (Lesbos) : avocat au barreau d'Athènes, il est l'un des ténors du parti. Au titre des parlementaires influents on doit citer : S. Iliopoulos député d'Athènes, B. Ephremidis député de Salonique, A. Brillakis député du Pirée-Ville et L. Kyrkos député d'Athènes-Banlieue. Les deux premiers comptent parmi les ténors du parti tandis que Brillakis et Kyrkos passent pour être les « durs » de l'EDA. Faisons une place à part à $\mathrm{N}$. Kitsikis député d'Athènes. Ancien Doyen de l'École Polytechnique et ancien sénateur de Vénizélos, Kitsikis, qui provient de la grande bourgeoisie, jouit d'un haut prestige intellectuel fondé sur de vastes connaissances techniques et économiques.

Parmi les personnalités de l'EDA n'occupant pas de siège parlementaire, il faut citer avant tout $M$. Glézos tenu par la Gauche pour un héros de la Résistance Nationale et inculpé d'espionnage dans des conditions déjà mentionnées. Glézos fut élu député d'Athènes en 1961 alors qu'il purgeait une peine de prison mais son élection fut cassée. Libéré le 12 décembre 1962, il ne peut briguer de mandat parlementaire en raison de l'indignité nationale dont sa condamnation pour espionnage l'a frappé.

Toujours dans cette catégorie, mentionnons aussi V. Néphéloudis, leader syndicaliste de la Gauche. Néphéloudis qui subit une déportation sous le gouvernement de la Droite avait été élu en 1936 sur les listes du Front Patriotique (Communiste). L'EDA vient de lui procurer un siège à Athènes par démission du titulaire.

Nous signalerons enfin parmi les personnalités de la vieille garde républicaine qui collaborent aujourd'hui avec l'EDA le cas de D. Stratis dont il a déjà été question à propos du Mouvement Syndical Démocratique. 
[p. 202]

\section{IDÉOLOGIE ET PROGRAMME}

$\underline{\text { Retour à la table des matières }}$

Nous allons tout d'abord exposer le programme de base de l'EDA et dirons ensuite quelques mots des positions les plus récentes du parti dans l'ordre des affaires intérieures et extérieures.

\section{A. PROGRAMME DE BASE}

Le document essentiel à cet égard est le texte adopté par la Première Conférence Panhellénique de l'EDA en juillet 1956. Il s'intitule : Pour un Changement National Démocratique - expression ayant en langue grecque les mêmes initiales que le parti (EDA) ${ }^{1}$. Ce document, qui sous l'angle de l'analyse de la situation est d'inspiration marxiste, prévoit néanmoins une ligne de conduite politique de contenu assez modéré et d'inspiration très souple.

Le premier chapitre de ce programme entend dégager les caractéristiques générales de la situation. Il déclare que la Grèce est devenue par suite de l'application de la Doctrine Truman une tête de pont des Américains contre les pays socialistes ainsi que contre ceux du Proche-Orient. Il souligne que depuis la fin de la guerre la dépendance de l'économie à l'égard du capital monopoliste étranger a considérablement augmenté, l'économie grecque étant tenue d'absorber en priorité les produits de l'agriculture et de l'industrie américaine. Le programme insiste sur l'exploitation et la misère du peuple. Enfin, il dénonce l'aspect antidémocratique et non-constitutionnel des méthodes de gouvernement (en particulier dans l'ordre des libertés individuelles).

Le deuxième chapitre constitue un catalogue des principes que l'EDA propose en vue de porter remède à la situation. Ces principes concernant trois domaines :

- Politique étrangère : rétablissement et sauvegarde de l'indépendance nationale ; politique de paix et d'amitié avec tous les peuples. Parmi les dispositions proposées à cet effet, mentionnons : refus d'installation de bases atomiques; prohibition de l'emploi du territoire national comme base d'activités agressives à l'encontre des pays socialistes, retrait de la Grèce du camp agressif de l'OTAN ;

- Politique intérieure: restauration et élargissement de la démocratie, ce changement impliquant en particulier l'abolition de toutes les [p. 203] mesures

Une version en langue anglaise de ce document a été publiée en 1961 par les soins de l'EDA sous le titre The program of EDA. For a national democratic change. 
policières restrictives des libertés individuelles, la libération de tous les détenus politiques, l'abrogation de l'interdiction du parti communiste. En matière électorale, le parti se prononce pour un partage équitable des sièges entre les diverses circonscriptions et pour l'adoption d'un mécanisme de représentation proportionnelle simple ;

- Politique économique : l'objectif du gouvernement en ce domaine doit être la réalisation d'un libre développement économique du pays et l'élévation du standard de vie et du niveau culturel du peuple. Le programme souligne en premier lieu la nécessité impérative de créer une industrie lourde et d'étendre les industries légères l'accomplissement d'un tel projet impliquant la nationalisation de certains secteurs de l'activité économique. Le parti affirme également l'urgence de libérer les paysans des exactions commises à leur détriment par le capital monopoliste. Il se prononce pour une expansion et un perfectionnement de la sécurité sociale. Le programme prévoit aussi des mesures au profit des diverses catégories sociales (y compris de la «bourgeoisie nationale » qui doit être préservée de l'action des monopoles). Il déclare que l'accès à l'enseignement supérieur doit être garanti à tous les jeunes Grecs qui ont les capacités nécessaires à cet effet. Le dernier paragraphe préconise l'amélioration de la condition financière du bas clergé.

L'ultime chapitre, très bref d'ailleurs, indique que la réalisation de ce programme de changement est liée à la constitution d'un « front patriotique ». L'EDA, dont toutes les démarches restent marquées par l'expérience de l'EAM, déclare à ce propos rechercher avec insistance une coopération avec les partis du centre et avec les « éléments patriotiques » de la droite : en vue de réaliser cet objectif, elle se tient prête à une collaboration portant sur un programme minimal qui tiendrait compte des impératifs nationaux les plus urgents.

En définitive, sans renoncer à l'établissement du socialisme, la voie du changement national démocratique préconise simplement une transformation progressive de la société grecque dans le sens d'une plus grande efficacité économique et d'une plus grande justice sociale. Ce document s'achève sur le souhait de voir les Grecs « libres, bien nourris, joyeux et civilisés » et sur l'ambition que la Grèce occupe parmi les nations une place digne de ses grandes traditions.

[p. 204] On peut illustrer l'esprit de ce programme en citant des déclarations faites à l'époque par le président de l'EDA J. Passalidis. Parlant devant la Première Conférence Panhellénique, il n'hésite pas à admettre la nécessité d'un élargissement prudent des relations avec la droite. Selon lui, il existe dans la partie nationale de la droite des hommes qui se préoccupent sincèrement du bien du pays. Il faudrait éviter que ces hommes continuent à suivre la fraction de la Droite qui se place à la remorque des intérêts étrangers ${ }^{1}$.

Quelques mois plus tard, lors d'une session du Conseil National ( $1^{\text {er }}$ décembre 1956), le Président souligne que le problème posé au peuple grec par l'EDA n'est pas

Avghi, nº du 17 juillet 1956, p. 2. 
celui d'une transformation socialiste mais d'un changement d'orientation qui soit d'inspiration nationale, anti-impérialiste et démocratique. Il s'agit avant tout de lever la contradiction qui ne cesse de s'aggraver entre la nation d'un côté, l'impérialisme étranger et l'oligarchie qui lui est subordonnée de l'autre. Le contenu du programme de changement est dicté par cette nécessité ${ }^{1}$.

Si l'on va au fond de cette analyse, il est clair que pour l'EDA la contradiction entre l'intérêt national et l'impérialisme étranger prédomine actuellement sur la contradiction entre les groupes sociaux eux-mêmes. Plus exactement, cette deuxième contradiction n'est retenue que dans la mesure où elle consolide la première (oligarchie au service de l'étranger). La tactique à utiliser consiste donc à s'appuyer sur toutes les forces nationales en vue de mettre fin à l'emprise de l'étranger sur la vie du pays. La référence à la catégorie, si parfaitement nébuleuse d'ailleurs, de la « bourgeoisie nationale » n'a pas d'autre raison d'être.

L'adoption d'une telle tactique ne signifie certes pas que l'on renonce à régler les contradictions sociales elles-mêmes: elle consiste à admettre que cette tâche ne pourra être menée à bien sans que l’hypothèque étrangère ait été levée. La voie de la transformation socialiste passe par l'indépendance nationale.

Tel est le programme de base de l'EDA. C'est un document de portée tout à fait générale qui esquisse des orientations plus qu'il ne propose des solutions concrètes. Voyons maintenant les applications qui ont été faites de cette doctrine durant les années récentes.

[p. 205]

\section{B. PRISES DE POSITION RÉCENTES}

\section{$\underline{\text { Retour à la table des matières }}$}

Partons du deuxième Congrès de l'EDA qui se tient en décembre $1962^{2}$. La résolution politique adoptée en cette occasion met au premier plan la lutte pour la paix. Elle souligne que le combat du peuple grec pour la sauvegarde de la démocratie prend la dimension d'un mouvement de résistance nationale. Elle insiste sur la nécessité de réaliser l'unité des forces démocratiques. Paix, démocratie, unité : ce texte reprend en somme les mots d'ordre qui sont ceux de l'EDA depuis sa formation.

Ce Congrès se tient quelques semaines à peine après l'affrontement qui a mis aux prises les États-Unis et l'U.R.S.S. sur la question de Cuba. Le rapport introductif

Avghi, $\mathrm{n}^{\circ}$ du 4 décembre 1956, p. 1.

Selon les chiffres fournis par l’EDA ce Congrès a rassemblé 354 délégués (278 hommes. 33 femmes, 43 jeunes). En termes de condition sociale, les délégués se distribuent comme suit : 146 ouvriers et employés; 51 paysans; 99 intellectuels et savants; 41 membres des professions libérales ; 13 étudiants ; 4 anciens militaires de carrière. Sur le total des délégués rassemblés, Athènes et Le Pirée comptent pour 180. 
présenté au Congrès déclare qu'en ces circonstances, la politique soviétique a sauvé la paix. Il y a dans le monde un front pacifique qui s'oppose à un front belliqueux. Bien que les risques d'un conflit n'aient pas totalement disparu, la guerre ne saurait désormais être tenue pour une catastrophe inévitable. Dans cette perspective, le rôle de la politique grecque doit être de contribuer au renforcement de la cause de la paix par la disparition des causes de conflit qui pourraient affecter la région des Balkans.

Sur ces bases, l'EDA se prononce pour la création de «zones sans fusées » en divers points d'Europe et notamment dans les pays balkaniques. Elle déclare s'opposer à tout équipement nucléaire des unités grecques par l'armée américaine. Les querelles avec les pays voisins et notamment la Bulgarie lui semblent désormais totalement dépassées: il faut profiter des dispositions pacifiques de ceux-ci pour régler les difficultés en suspens et parvenir à des arrangements définitifs. L'EDA qui reproche au gouvernement de cette époque d'entretenir l'inquiétude sur les intentions de la Bulgarie approuve l'activité du Comité qui s'est donné pour rôle de promouvoir une plus grande compréhension que par le passé entre les peuples des Balkans.

Quand le deuxième Congrès de l'EDA se réunit, l'accord d'association de la Grèce au Marché Commun officiellement signé le 9 juillet 1961 vient juste d'entrer en application. Le point de vue du parti à [p. 206] l'égard de ce dispositif est celui d'une totale opposition. L'EDA se flatte d'avoir été le premier groupement du pays à lever l'étendard de la révolte contre cette politique et elle affirme que la Nation ne reconnaît pas l'accord signé en son nom par le gouvernement de la Droite ${ }^{1}$.

Pour l'EDA, l'association avec la CEE risque d'entraîner l'abolition complète de l'État grec et de l'indépendance nationale. Parmi les dangers immédiats que l'on en peut redouter figurent la poursuite de l'émigration à une large échelle, la stagnation des salaires, l'abaissement des prix agricoles et l'accentuation de la pénétration du capital étranger. L'entrée de la Grèce dans le Marché Commun aboutit en fait à placer celle-ci dans l'espace politico-économique vital de la République Fédérale : ainsi l'Allemagne obtiendra-t-elle par de semblables combinaisons ce qu'elle n'a pas réussi précédemment à gagner par les armes.

L'EDA ne cesse en effet d'insister sur les dangers d'une renaissance du militarisme allemand pour l'Europe toute entière et pour la Grèce en particulier. Elle dénonce la place tenue par d'anciens nazis dans la conduite et la mise en exécution de la politique étrangère du gouvernement de Bonn. À cet égard, le Parti tient pour juste et loyal le projet soviétique d'un traité de paix entre les deux Allemagnes auquel seraient associées toutes les puissances ayant lutté contre l'hitlérisme.

On sait qu'au cours des derniers mois la question de Chypre est redevenue d'une brûlante actualité. À cet égard, la position de l'EDA se résume en quelques propositions : octroi de l'Île d'une totale indépendance ; abolition définitive du traité de Zurich et des divers instruments que l'ont mis en ouvre ; rejet absolu du dispositif

1 Voir à cet égard l'ouvrage publié par Ilias Iliou, I alithia ya fin Kini agora, Athènes, 1962. Consulter également l'ouvrage publié sous la direction de KITSIKIS I Thiella tis Kinis Agoras, Athènes, 1962. 
d'intervention de l'OTAN pour la solution du problème. Si une solution correcte ne peut être obtenue sur place, c'est devant l'ONU que la question chypriote doit être portée.

Depuis le début de la crise, l’EDA dénonce les pressions exercées sur le Gouvernement grec pour le contraindre à accepter une solution favorable aux intérêts des puissances anglo-saxonnes. Le Parti estime par contre que l'URSS défend la cause de Chypre d'une manière désintéressée : selon lui, l'accord signé le 30 septembre 1964 entre l'Union [p. 207] Soviétique et Chypre constitue l'événement le plus important dans les derniers développements de l'affaire chypriote ${ }^{1}$.

Au titre de la politique générale grecque, nous mentionnerons encore une prise de position de l'EDA : la résolution votée le 12 mai 1964 par le Comité Directeur à l'issue de sa $6^{\mathrm{e}}$ session. Le Comité, qui reproche au gouvernement de l'Union du Centre de mener une politique de compromis, déclare considérer la démocratisation du pays comme l'exigence et le besoin les plus immédiats du peuple. Ce mouvement doit s'affirmer dans les six secteurs suivants : démocratisation de la vie publique, ce qui implique notamment la suppression de toutes les mesures d'exception et le retour a la légalité du Parti Communiste, démocratisation de la machine étatique et des municipalités; démocratisation du syndicalisme; démocratisation de la vie économique, ce qui suppose l'annulation des conventions léonines passées avec le capital monopoliste étranger, la réduction des dépenses militaires, l'amélioration du niveau de vie des travailleurs des villes et des campagnes, l'octroi de crédits aux paysans pauvres et aux artisans ; démocratisation de l'enseignement et de la culture ; démocratisation de la politique extérieure par l'adoption d'une politique d'indépendance nationale et la suppression des ingérences impérialistes dans les affaires du pays ${ }^{2}$.

Ces propositions ne s'écartent finalement en aucune manière de la lettre et de l'esprit du programme de Changement Démocratique National adopté par l'EDA en 1956. S'il relève d'une inspiration de gauche, le programme actuellement avancé par l'EDA n'a rien dans son contenu qui soit spécifiquement socialiste. L'attitude de modération et de souplesse inscrite en filigrane dans le document de base est intégralement maintenue.

L'adoption d'une telle position implique que dans la conjoncture présente l'EDA ne croit pas aux chances et spécialement aux chances électorales d'un programme qui préconiserait de profondes réformes dans l'agencement des rapports de production. Les mesures suggérées signifieraient tout au plus si elles étaient intégralement mises en œuvre le franchissement de quelques étapes initiales dans cette direction. Dans l'optique de l'EDA, cette manière d'envisager les choses doit probablement sa légitimité au fait qu'elle tient compte du rapport actuel des [p. 208] forces tel que le détermine l'état des structures socio-professionnelles du pays. On peut toutefois se demander si certaines des mesures proposées ne sont pas susceptibles d'aggraver les

Bulletin Hebdomadaire de l'EDA, n² 207, 3 octobre 1964.

D'après le Bulletin Hebdomadaire, nº 187, 16 mai 1964. 
maux qu'il s'agirait de guérir (ainsi l'octroi à la paysannerie pauvre, sans que la productivité agricole soit susceptible d'en être améliorée, d'une fraction des faibles ressources financières dont dispose le pays). Le piège de la position réformiste a toujours a été la proposition ou l'adoption de mesures immédiates en contradiction avec les objectifs de portée lointaine — contradiction généralement résolue, comme l'établit le cas de la social-démocratie, par l'abandon de ces objectifs.

\section{STRATÉGIE ET TACTIQUE}

$\underline{\text { Retour à la table des matières }}$

Selon les termes de l'article premier de ses statuts, l'EDA est un parti qui travaille dans les cadres de la légitimité démocratique constitutionnelle et du parlementarisme. C'est là une position de principe à laquelle le parti ne cesse de se référer.

L'attitude adoptée par le parti lors du décès du roi Paul survenu le 6 mars 1964 constitue en particulier un témoignage de ce souci de jouer le jeu constitutionnel. Bien que l'EDA ait toujours été systématiquement exclue des consultations et entretiens du Souverain avec les dirigeants des partis, le Président Passalidis a envoyé au nouveau roi et à la reine-mère le jour du décès de Paul une dépêche de condoléances. Les funérailles du souverain ont été suivies par une délégation du Comité Exécutif de l’EDA (composé de MM. Kitsikis, Brillakis, Iliopoulos, Theodorakis ainsi que du député collaborant avec l’EDA S. Mercouris) ${ }^{1}$.

Nous allons examiner les divers aspects revêtus par l'activité de l’EDA, ce qui nous conduira à poser la question des ressources financières de l'organisme.

[p. 209]

\section{A. ACTION PARLEMENTAIRE}

Retour à la table des matières

Nous prendrons comme base d'étude la législature comprise entre les élections du 11 mai 1958 et celles du 29 octobre 1961. Cette législature présente pour notre propos un intérêt exceptionnel dans la mesure où l'EDA est numériquement le premier parti de l'opposition.

\footnotetext{
D'après le Bulletin Hebdomadaire de l'EDA, $\mathrm{n}^{\circ}$ 178, 14 mars 1964. S. Mercouris, père de Mélina Mercouri, appartient à une vieille famille monarchiste et lui-même était autrefois d'affiliation Populiste. Il est député collaborant avec l'EDA depuis les élections de 1961 et il assume la présidence d'un Comité destiné à promouvoir la compréhension et des rapports pacifiques entre les pays balkaniques.
} 
Voici un tableau faisant ressortir les divers genres d'intervention du groupe parlementaire de l'EDA durant cette période ${ }^{1}$ :

\begin{tabular}{|c|c|c|c|c|c|}
\hline & \multicolumn{5}{|c|}{ Genre d'intervention } \\
\hline & Pétitions & $\begin{array}{c}\text { Questions } \\
\text { parle- } \\
\text { mentaires }\end{array}$ & $\begin{array}{c}\text { Demande } \\
\text { de } \\
\text { documents }\end{array}$ & $\begin{array}{c}\text { Inter- } \\
\text { pellations }\end{array}$ & $\begin{array}{c}\text { Démarches } \\
\text { diverses }\end{array}$ \\
\hline Questions agricoles................. & 231 & 499 & 17 & 42 & 58 \\
\hline Ouvriers, employés, retraités & 322 & 424 & 23 & 28 & 29 \\
\hline Fonctionnaires........................... & 57 & 58 & 1 & - & 1 \\
\hline Artisans et classes moyennes & 58 & 65 & 6 & 1 & 1 \\
\hline Actes antidémocratiques des & \multirow{3}{*}{333} & \multirow{3}{*}{227} & \multirow{3}{*}{13} & \multirow{3}{*}{41} & \multirow{3}{*}{151} \\
\hline 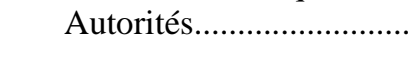 & & & & & \\
\hline Problèmes d'Athènes et du & & & & & \\
\hline Pirée......................................... & 35 & 72 & - & 1 & 7 \\
\hline Fonction publique.................... & 26 & 136 & 15 & 6 & 3 \\
\hline 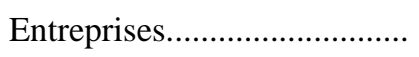 & 35 & 208 & 22 & 22 & 8 \\
\hline 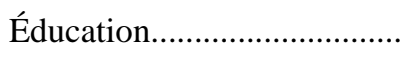 & 43 & 284 & 3 & 18 & 14 \\
\hline Prévoyance sociale.................. & 95 & 304 & 15 & 17 & 8 \\
\hline Économie, Finances................ & 36 & 56 & 12 & 14 & 3 \\
\hline Affaires intérieures................. & 39 & 178 & 39 & 29 & 5 \\
\hline Affaires extérieures................ & 129 & 50 & 9 & 12 & 1 \\
\hline Travaux Publics.......................... & 36 & 385 & 4 & 12 & 34 \\
\hline Communications........................ & 32 & 137 & 8 & 4 & 5 \\
\hline 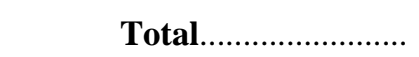 & 1.507 & 3.083 & 187 & 247 & 328 \\
\hline
\end{tabular}

[p. 210] Le Bureau du groupe parlementaire déclare, par ailleurs, avoir durant cette période, reçu 5.533 lettres et envoyé 5.317 réponses, s'adressant en tout à 246.620 personnes physiques ou morales. Toujours durant cette législature, le groupe parlementaire déposa plusieurs projets de loi (dont nous donnons la liste dans l'annexe II du présent ouvrage pour la période 1956-1961) et entreprit de dévoiler 17 « scandales du parti gouvernemental ».

Nous constatons donc une activité parlementaire intense, qui vise d'une part à harceler le gouvernement, et de l'autre à mettre en évidence, à la tribune de la Chambre, le programme et les revendications de la gauche.

1 Données extraites d'une brochure publiée par le parti sous le titre 1956-1961. I Kinovouleftiki drassis tis EDA. 


\section{B. ACTIVITE EXTRA-PARLEMENTAIRE}

$\underline{\text { Retour à la table des matières }}$

Cette lutte parlementaire est accompagnée et soutenue par une lutte extraparlementaire, qui emploie tous les moyens susceptibles de mobiliser les masses populaires. Elles s'adaptent étroitement aux circonstances et tient compte de toutes les occasions qui se présentent (ainsi exaspération des cultivateurs de tabac par suite de la mévente de leur produit).

Voici quelques exemples d'action directe tirés d'un document publié par l'EDA en septembre 1962 au titre de la préparation de son second Congrès. Il s'agit de mouvements et de manifestations que le parti se félicite d'avoir organisés, encadrés ou soutenus (moralement ou matériellement) dans plusieurs secteurs des relations sociales :

Classe ouvrière: Grève avec manifestations sur la voie publique des ouvriers du bâtiment, en 1960. Grève de 9 jours des ouvriers-boulangers, au printemps 1962. Grève des ouvriers des usines d'engrais en été 1962.

Classe paysanne: Manifestations revendicatives à Carditsa en 1961 et à Iraklion (Crète) en 1961 et 1962 (cette fois avec prise d'assaut et saccage de la préfecture). Mobilisation des producteurs de tabacs en Macédoine et à Agrinion. Manifestations des agriculteurs à Xiromeri qui ont fait un mort et des blessés, etc. ...

Classe artisanale : Mobilisation du secteur de l'habillement contre l'association de la Grèce au Marché Commun.

Professions libérales : Grève des médecins de l'institut d'Assurance Sociale (IKA) des musiciens du système national de radiodiffusion (EIR), des juristes, etc. ...

Fonctionnaires : Grève des instituteurs.

[p. 211] Jeunesse : Grève de longue durée des élèves des écoles du soir et grève des étudiants avec manifestations sur la voie publique.

Manifestations et meetings pour le désarmement, la libération de Manolis Glézos, le retour à la légalité du PC grec, la paix, etc. ...

Notons que dans toutes ces actions, les revendications sociales sont associées avec des revendications politiques telles que : «le rétablissement de la démocratie », la « liberté syndicale », le « départ du gouvernement illégal de Caramanlis », etc. ...

Au titre de la lutte pour la paix, l’EDA a organisé ces dernières années une marche dite Marche de Marathon. Cette manifestation, qui s’inspire du modèle britannique, emprunte la route d'une quarantaine de kilomètres joignant le tombeau des soldats morts à la bataille de Marathon à la ville d'Athènes. En fait la première marche prévue pour le 21 avril 1963 fut interdite par le gouvernement de l'ERE : elle se traduisit par des heurts avec la police qui entraînèrent plusieurs centaines d'arrestations. La seconde marche effectuée en date du 17 mai 1964 s'est par contre 
déroulée dans le calme ; selon l’EDA, cette manifestation, véritable « apothéose de la paix » aurait constitué un événement de grande importance dans l'évolution politique du pays. L'un des domaines dans lesquels l'EDA a livré ses plus vifs combats est celui, pour reprendre ses propres expressions, de la liquidation des conséquences de la guerre civile. Selon elle, la seule manière d'effacer les traces de ce passé dramatique dans un sens conforme à la volonté du peuple est la proclamation d'une amnistie générale permettant la libération des hommes encore détenus à ce titre longtemps après l'achèvement des combats et donnant à ceux, bien plus nombreux d'ailleurs, qui restent en exil la possibilité de rentrer dans le pays.

Ce combat est lié, chez l'EDA, à l'exaltation de la Résistance Nationale telle que, pour elle, la représente l'EAM. Le parti établit ainsi dans ses déclarations publiques un rapport direct entre la guerre des partisans sous l'occupation et l'insurrection déclenchée dans les années d'après-guerre. Dès lors, les détenus politiques condamnés pour participation à la guerre civile ne sont rien d'autres que les combattants de la résistance - eux-mêmes continuateurs des héroïques traditions de $1821^{1}$. Cette interprétation des événements se heurte au fait que [p. 212] bon nombre des membres de l'ELAS durant l'occupation allemande ne se retrouvaient plus dans les rangs de l'armée d'insurrection de 1946 à 1949. Mais il faut admettre que de nombreux adversaires de l'EDA procèdent à la même assimilation (la simple appartenance à l'EAM durant la guerre mondiale ayant, en de nombreux cas, constitué le seul mobile de l'ouverture d'un dossier par la police).

Un témoignage récent de cette situation nous est fourni par les commentaires qu'a suscités la décision de l'EDA d'organiser en date du 27 septembre 1964 une manifestation en l'honneur du $23^{\mathrm{e}}$ anniversaire de la création de l'EAM. Cette décision a fait l'objet de sévères critiques de la part du Premier Ministre qui l'a jugée incompatible avec la politique de l'apaisement dont l'EDA préconise par ailleurs la réalisation. G. Papandréou a déclaré que l'on se livre à une falsification de l'histoire en voulant faire de l'EAM une figure légendaire du destin national. Selon lui, si l'EAM a eu sous l'occupation quelques pages de résistance nationale, elle a eu durant la même époque beaucoup de pages de crime national. Après le départ des Allemands, l'EAM n'a fait que susciter des désastres nationaux.

Sans entrer ici dans l'analyse de cette controverse qui porte sur des événements extérieurs à notre ouvrage, observons qu'en Grèce, et contrairement à ce qui s'est passé dans les autres pays occupés par l'Allemagne, la valeur morale de la Résistance, du moins de l'organisme qui en a assumé la plus large part, reste l'objet de grandes controverses politiques. Aujourd'hui encore le sentiment prévaut en divers secteurs de l'opinion bourgeoise que la véritable libération d'Athènes est intervenue le 7 janvier 1945, c'est-à-dire le jour où les forces sous direction britannique parvinrent à annihiler dans cette ville les troupes de l'ELAS qui continuaient d'ailleurs à tenir une large partie du pays. Il y a là certainement un facteur que l'on ne saurait négliger pour la compréhension des clivages partisans actuels.

1 Selon une expression du Bulletin Hebdomadaire de 1'EDA, n 18, 23 mars 1961 dont nous n'avons pu consulter que la version en langue anglaise (weekly Press Bulletin). 
Au titre de l'histoire très récente, l'acte ayant suscité le plus d'émotion dans le pays fut, nous l'avons déjà mentionné, l'assassinat, au cours d'une manifestation de la Gauche à Salonique, de G. Lambrakis, professeur agrégé de médecine à l'Université d'Athènes et député collaborant avec l'EDA pour la circonscription du Pirée et des Îles. Lambrakis était très populaire en raison des victoires (course et saut) qu'il avait remportées aux Jeux Balkaniques avant la guerre.

[p. 213] L’EDA a tout de suite présenté cette mort comme le résultat d'un crime opéré sur la base d'un plan prémédité. Selon cette interprétation, Lambrakis aurait été exécuté comme Grimao venait de l'être en Espagne ${ }^{1}$. Depuis lors, l'EDA a combattu avec beaucoup d'énergie pour un éclaircissement total des circonstances de cette tragédie dont la survenance a probablement pesé sur le destin politique de C. Caramanlis. Aujourd'hui l'EDA accuse le gouvernement de l'Union du Centre de ne pas rechercher avec assez d'énergie les instigateurs de ce meurtre et même de témoigner à cet égard d'une sorte de «tolérance protectrice » ${ }^{2}$.

Signalons, pour en terminer avec cette rubrique, que la lutte pour l'amnistie des détenus politiques et contre la législation d'exception a pris assez rapidement une dimension internationale. Parmi les organismes qui, en liaison avec l'EDA se sont particulièrement occupés de ces pratiques mentionnons la Fédération Internationale des Droits de l'Homme et la Fédération Internationale des Résistants. Mais le groupement dont les interventions ont été à ce propos les plus nombreuses et les plus vigoureuses est l'Association Internationale des juristes Démocrates dont le siège est à Bruxelles et qui ne fait pas mystère de ses sympathies progressistes (l'URSS, les pays communistes de l'Est Européen et la Chine Populaire comptant parmi les 50 pays où elle possède des groupes) ${ }^{3}$.

Parmi les démarches effectuées par l'Association des juristes, mentionnons : envoi en Grèce au début de l'année 1955 d'une délégation composée de deux juristes français ayant pour mission d'enquêter sur les violations des libertés démocratiques ; envoi d'observateurs au procès de M. Glézos et formation d'une commission chargée d'examiner la validité des accusations d'espionnage faites à celui-ci; envoi de nouvelles missions d'enquête en 1961 ; organisation à Paris, le 26 mai 1962, d'une réunion de 70 juristes appartenant à des pays d'Europe Occidentale et création d'une commission chargée de l'application des déci-[p. 214] sions de la réunion; organisation à Paris les 23 et 24 mars 1963 d'une conférence européenne sur l'amnistie. Signalons enfin la constitution d'un Comité International Permanent pour l'Amnistie en Grèce.

Bulletin Hebdomadaire de l'EDA, n 132, 23 mai 1963.

Bulletin Hebdomadaire de l'EDA, n 139, 29 mai 1964.

Il existe à Genève une Commission Internationale de juristes qui, en particulier, publie un Bulletin consacré aux violations de la légalité à travers le monde (20 numéros parus en date de septembre 1964). On trouvera dans le $n^{\circ} 10$ (janvier 1960) une critique sévère de la loi 375 , faite à propos du procès Glézos. La Commission a fait établir divers rapports sur la situation grecque, notamment par un journaliste suisse A. Gaspard, mais elle n'a pas effectué de démarche publique pour obtenir le redressement de la situation. 
L'Association Internationale des juristes Démocrates ne disposant pas de grands moyens de pression et d'intervention auprès du Maréchal Papagos et de C. Caramanlis, ces démarches n'ont eu au départ qu'une influence très limitée. Cependant les déclarations de l'Association jointes aux dénonciations et protestations des leaders de l'EDA sont finalement parvenues à susciter en plusieurs pays un courant défavorable aux pratiques des gouvernants grecs en ce domaine. Il est à peine besoin d'écrire que les partisans des gouvernements de l'époque virent dans ces démarches autant d'ingérences inadmissibles dans les affaires intérieures du pays. En réalité, la volonté d'influer sur le comportement des autorités helléniques était incontestable et dès lors ces démarches relèvent des mécanismes de la pression internationale dont nous avons déjà vu d'autres cas d'application.

Parmi les témoignages de cette mobilisation de l'opinion internationale, on peut citer l'organisation à Florence les 15 et 16 décembre 1962, sous les auspices de six revues et hebdomadaires d'Italie d'une conférence sur le régime politique grec. Mais c'est en Grande-Bretagne où existe une forte colonie grecque que les manifestations devaient être les plus graves et les plus significatives. Dès le 13 février 1961, C. Caramanlis, en déplacement à Londres, était accueilli à sa descente d'avion par un groupe réclamant l'amnistie. La même mésaventure devait arriver à la Reine Frédérika lors d'un voyage dans la capitale britannique en avril 1963. Cependant la campagne devait atteindre son point culminant lors de la visite officielle à Londres des souverains grecs du 9 au 11 juillet 1963. Plusieurs organisations britanniques (dont le Comité des 100) s'associèrent ouvertement à la protestation des citoyens grecs et autres manifestants (parmi lesquels la femme anglaise d'un leader syndicaliste T. Ambatiélos détenu depuis la fin de la guerre civile occupait une place de premier rang). Si le Parti Travailliste ne s'associa pas en tant que tel à la campagne, un groupe de parlementaires de ce parti y joua un rôle actif.

Sans que l'on puisse attribuer à l'EDA la responsabilité totale de ces démarches et manifestations, il est clair qu'elle a contribué à leur déclenchement. Or, comme nous le verrons plus tard, cette activité eut un double résultat : d'une part, elle conduisit les autorités à prendre [p. 215] un certain nombre de mesures favorables aux personnes et aux causes ainsi défendues; d'autre part, elle exerça, en liaison avec l'affaire Lambrakis, une influence sur la séquence d'événements qui devait conduire au renversement de la Droite par le Centre.

\section{APPAREIL DE COMMUNICATION}

$\underline{\text { Retour à la table des matières }}$

L'un des thèmes essentiels de l'EDA est que sous le gouvernement Caramanlis, la Grèce ne jouissait que d'une façade démocratique, le régime en étant au stade de la fascisation progressive. C'était, selon elle, particulièrement vrai pour la presse, la liberté de celle-ci étant simplement mythique. 
L'EDA publie actuellement deux journaux quotidiens, l'un du matin, intitulé Avghi, l'autre du soir ayant pour titre Dimocratiki Allagi et qui est beaucoup plus récent. Le parti se plaint que la circulation de sa presse soit entravée de multiples manières, ces obstacles étant bien plus forts en province qu'à Athènes même. Selon les porte-parole de l'EDA, la lecture de l'Avghi serait pratiquement interdite dans les villages, le simple fait de l'acheter étant susceptible de valoir des démêlés avec la police et, en tout cas, l'ouverture d'un dossier. De nombreux procès (une vingtaine) ont été livrés à l'Avghi par le gouvernement et son directeur fut arrêté en date du 6 mars 1963 pour avoir publié un communiqué du Parti Communiste légalement interdit. L'EDA souligne toutefois que la presse elle-même bénéficie d'une tolérance faisant entièrement défaut à la Radio qui demeure sous le contrôle exclusif du gouvernement. Il est difficile d'évaluer la propension de la police à abandonner sous le gouvernement du Centre les habitudes acquises sous celui de la Droite.

Depuis l'été 1963 l'EDA assure la publication d'une revue mensuelle Elliniki Aristéra. L'objectif de cette revue est de contribuer à l'approfondissement théorique des problèmes qui se posent aux dirigeants et militants du parti aussi bien sous l'angle des difficultés immédiates que des perspectives de long terme. L'essentiel de la revue est rédigé par les membres de l'EDA. Cependant on note la présence occasionnelle de divers collaborateurs étrangers (ainsi au titre des Français S. Deschizeaux, G. Garaudy, M. Thorez).

En dehors de la presse quotidienne et de sa revue mensuelle, l'EDA assure la publication d'un Bulletin Hebdomadaire d'information en an-[p. 216] glais et en français qui est destiné à l'information des milieux étrangers s'intéressant au parti. Elle édite également selon les besoins et les circonstances divers documents d'intérêt politique. Enfin, l'EDA s'intéresse à la publication d'un certain nombre d'œuvres étrangères (en particulier classiques du marxisme) ${ }^{1}$.

On ne saurait considérer que les moyens ainsi décrits représentent la totalité du système de communication à la disposition de l'EDA. Le parti met naturellement en œuvre, à l'instar de toutes les formations qui disposent d'une organisation hiérarchisée, la technique des communications par l'intermédiaire des personnes à sa disposition (ainsi diffusion de consignes ou de mots d'ordres aux organismes locaux par le truchement des parlementaires ou d'envoyés spéciaux). L’EDA bénéficie d'un réseau de permanences couvrant tout le territoire et grâce auquel il lui est possible de toucher de manière directe de vastes ensembles de population. Le nombre de celles-ci s'élève à 242 (dont 50 pour Athènes, 9 pour le Pirée et 20 pour Salonique). Il est vrai que le financement d'un tel appareil impose des charges, cette remarque nous conduisant à poser le problème des finances de l’EDA.

Mentionnons également deux revues proches des préoccupations du parti mais indépendantes de lui : l'une consacrée aux problèmes de la défense de la paix, Les chemins de la Paix, la seconde traitant de questions artistiques et intitulée Revue d'Art, Revue mensuelle des Lettres et des Arts. 


\section{SITUATION FINANCIÈRE}

$\underline{\text { Retour à la table des matières }}$

l'EDA, comme d'ailleurs tous les partis grecs et la plupart des partis dans le monde, ne publiant pas ses comptes, on en est réduit sur ce point à de simples conjectures. Les estimations établies par ses adversaires tendent généralement à maximer les dépenses faites par l'organisme et à minorer les concours qu'il reçoit de ses membres : il en résulte apparemment un gros déficit dont on déclare ou suggère qu'il est couvert et ne peut-être couvert que par des subventions de l'étranger. Or il n'est pas difficile, sous chacun des angles considérés, d'apporter à ces vues de très sérieuses rectifications de principe.

Un parti comme l'EDA est certainement tenu d'engager des dépenses relativement importantes (rémunération des journalistes, du personnel administratif permanent, loyer des bureaux charges de matériel et d'équipement, communications postales et téléphoniques, frais de déplacement des membres, impression des journaux et documents, propa-[p. 217] gande...). On commet toutefois de sérieuses erreurs en estimant que le parti doit régler ces opérations aux tarifs en vigueur sur le marché. En fait, il est fréquent que celui-ci s'en tire à meilleur compte: c'est vrai pour le personnel qui se contente normalement de conditions inférieures à celles accordées dans les autres secteurs d'activité mais la même situation existe pour divers postes du budget (cas du fournisseur ou de l'imprimeur sympathisant qui accorde des rabais).

Au surplus, il ne faut pas oublier les services que le parti obtient gratuitement de ses militants - concours qui, en de nombreux cas, s'étend à l'octroi gracieux de facilités matérielles (ainsi hébergement d'un militant en déplacement) et sont l'expression d'une étroite solidarité entre les membres. Qu'on tienne ces appuis pour des minorations de dépenses ou pour des recettes supplémentaires, le fait est qu'en les négligeant, ou s'expose à commettre des fautes d'interprétation quant au système de financement des partis de gauche.

Au titre des recettes, les statuts prévoient les cotisations et souscriptions des membres ainsi que les dons de ceux-ci et des amis du parti. Compte tenu de la faiblesse du revenu moyen par tête d'habitant en Grèce, il ne semble pas que les ressources obtenues à ce titre puissent être très considérables - surtout si l'on note que le nombre des adhérents proprement dits ne semble pas être élevé. Cependant, on doit admettre que généralement les partis de gauche parviennent à obtenir de leurs adhérents et sympathisants des concours bien supérieurs à ceux dont les autres partis bénéficient en ce domaine (organisation périodique de quêtes ou de souscriptions pour des objectifs divers). De tels concours, c'est l'évidence, ont pour les premiers une importance qu'ils n'ont jamais eue pour les seconds.

Dans la mesure où l'on impute à l'EDA des dépenses supérieures à ses recettes, il faut bien mentionner une source susceptible de combler le déficit. Or ce parti exclu par sa nature même des distributions gouvernementales et patronales n'est guère en 
mesure - pour les raisons que nous avons dites - d'obtenir des contributions syndicales importantes. Dès lors, il est tentant d'avancer que la couverture du déficit est assurée par un financement d'origine extérieure et plus précisément de provenance communiste. Beaucoup d'adversaires de l'EDA tiennent pour une certitude que la charge de ses dépenses - notamment au titre de la propagande électorale - est partiellement assurée par l’URSS et les pays de l'Est.

[p. 218] Trop de partis en de nombreux pays ont bénéficié de subsides accordés par des services gouvernementaux et des organismes privés étrangers pour que l'hypothèse d'un tel mode de financement au profit de l'EDA fasse l'objet d'une négation de principe. Observons toutefois que durant cet après-guerre les États-Unis se sont montrés en ce domaine bien plus larges que l’Union Soviétique: il est douteux qu'aucun organisme russe ait jamais disposé du pouvoir et des ressources de la CIA. Le comportement effectif des dirigeants communistes paraît en cette matière assez éloigné de celui que leur prête la propagande anti-communiste. Certes l'URSS paraît avoir aidé certains partis (ainsi le Parti Communiste Italien) en les faisant participer à divers circuits d'échanges commerciaux. On ne saurait dire pour autant qu'à notre époque l'« or de Moscou » ait constitué l'une des grandes bases financières des partis communistes européens. En tout cas, aucune preuve de tels transferts, disons de transferts à une échelle importante, n'a jamais pu être apportée.

On ne voit pas les raisons qui auraient pu conduire les pays communistes à attribuer un traitement préférentiel à l'EDA. Il est certes possible que des sommes aient été collectées à l'étranger pour la couverture des frais du procès de dirigeants ou militants communistes, mais l'envoi de tels subsides, pour l'octroi desquels il existe des organismes spécialisés, ne saurait être confondu avec l'attribution de disponibilités financières au titre des activités courantes de l'EDA. Dans un domaine voisin, notons que des organismes comme la Fédération Internationale des Droits de l'Homme ou l'Association Internationale des juristes Démocrates ont aidé les porteparole de l'EDA à couvrir leurs frais de voyages au titre des réunions internationales contre le dispositif d'exception.

En définitive, il est bien peu probable que l'EDA ait les moyens que lui prêtent les spécialistes de la soviétologie ou, ce qui revient au même, qu'elle effectue toutes les dépenses qu'on lui impute. Il est plus vraisemblable que ce parti comme tant d'autres formations de gauche éprouve des difficultés financières permanentes et doit en une large mesure son rythme d'activité aux concours de tous ordres, en argent ou en services, qu'il parvient à obtenir de ses fidèles. C'est en tout cas une hypothèse de travail qui vaut bien la précédente. Mais a-t-on une idée juste des dimensions atteintes par le groupe des fidèles ? 
[p. 219]

\section{DIMENSIONS DU PARTI}

$\underline{\text { Retour à la table des matières }}$

Il n'existe aucune information sur le nombre des adhérents de l'EDA. Selon les dirigeants, le recrutement serait freiné par les risques qui s'attachent à l'adhésion (danger de passer sous surveillance policière ou de perdre son emploi...). En revanche, le parti disposerait d'un grand nombre de sympathisants qu'il lui est possible de réunir au titre de certaines manifestations. Mais il n'existe pas d'autre mode d'estimation numérique que les statistiques électorales.

Nous voudrions présenter d'abord quelques considérations générales sur l'implantation de l'EDA puis dire quelques mots des élections municipales de juillet 1964 dont l'interprétation a suscité des controverses.

\section{A. IMPLANTATION TERRITORIALE}

$\underline{\text { Retour à la table des matières }}$

Depuis sa création, l'EDA a obtenu les résultats suivants :

\begin{tabular}{|c|c|c|c|c|}
\hline \multirow[b]{2}{*}{ Élections } & \multirow[b]{2}{*}{ Nombre de voix } & \multirow[b]{2}{*}{ Sièges } & \multicolumn{2}{|c|}{ Pourcentage } \\
\hline & & & Voix & Sièges \\
\hline 1951......................... & 180.640 & 10 & 10,57 & 3,9 \\
\hline $1952 \ldots \ldots$ & 152.011 & 0 & 9,55 & 0 \\
\hline $1956 \ldots$ & - & 18 & - & 6 \\
\hline 1958........................ & 939.902 & 79 & 24,42 & 26,3 \\
\hline 1961....................... & 675.959 & 24 & 14,62 & 8 \\
\hline 1963.................... & 669.267 & 28 & 14,34 & 9,3 \\
\hline 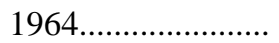 & 540.687 & 22 & 12 & 7,3 \\
\hline
\end{tabular}

Il est impossible de donner un chiffre de suffrages pour les élections de 1956, l'EDA ayant fait partie d'un cartel électoral aux résultats indissociables. En 1961, l'EDA est intervenue en association avec le Parti National Agraire : mais, compte tenu de la faiblesse de ce dernier, il est légitime d'attribuer à la formation dominante la totalité des voix remportées par la coalition. Pour toutes les autres élections, l'EDA s'est présentée sous son propre pavillon. Observons cependant que les résultats de 1964 ne sauraient être tenus pour entièrement représentatifs [p. 220] de la force de l'EDA, celle-ci ayant décidé de se retirer d'un certain nombre de circonscriptions dites « arides » parce qu'elle n'y avait jamais obtenu de sièges - en vue d'améliorer la position de l'Union du Centre. En réalité, l'EDA a également subi quelques pertes au profit du Centre même dans les circonscriptions où elle présentait des candidats. 
Si l'on fait abstraction des élections de 1958 dont les résultats furent probablement dus au jeu de nombreux facteurs qui ne devaient pas se reproduire par la suite, la force électorale de l'EDA est passée en une dizaine d'années d'environ 10\% des suffrages à un peu moins de $14 \%$. Cette augmentation constitue certes un progrès sensible, mais l'accroissement est encore trop limité pour permettre à l'EDA de jouer un rôle décisif sur la scène parlementaire.

Nous présentons dans un appendice cartographique les résultats obtenus par chacune des formations en présence lors des trois consultations de 1961, 1963 et 1964. La consultation des cartes relatives à l'EDA permet de dégager facilement les zones de force du parti qui ne subissent pas de modification d'une élection à l'autre. Ce sont les circonscriptions du Pirée-banlieue et d'Athènes-banlieue, la circonscription de la ville de Salonique, les circonscriptions insulaires de Lesbos, Leucade et Samos-Icaria. L'EDA dispose également de bonnes positions dans la circonscription d'Athènes-Ville, dans plusieurs villes de Thessalie et de Macédoine Centrale (Larissa et Volos: présence d'industries et tradition de luttes paysannes) ainsi que dans le département de Cavalla (ouvriers du tabac).

La force de l'EDA dans les grandes agglomérations s'explique par le niveau relativement élevé de concentration ouvrière qui est déjà réalisé. En moyenne c'est dans les villes que ce parti obtient les meilleurs résultats (son pourcentage dans les votes ruraux n'atteignant en règle générale que moins de la moitié de celui obtenu dans les votes urbains). En dehors de la couche des ouvriers industriels qui constitue son meilleur soutien, le parti trouve également des appuis assez importants dans certains secteurs des classes moyennes.

[p. 221]

\section{B. LES ÉLECTIONS MUNICIPALES DE JUILLET 1964}

$\underline{\text { Retour à la table des matières }}$

Nous avons vu que lors des élections de 1964, l'EDA, que ses dirigeants l'aient expressément souhaité ou qu'ils se soient résignés à l'inévitable, a subi certaines pertes au profit de l'Union du Centre. Le mouvement inverse s'est réalisé, à une échelle sensiblement plus forte d'ailleurs, lors des élections municipales du 5 juillet 1964. Bien qu'aucune analyse approfondie de cette consultation n'ait encore été effectuée au moment où nous écrivons ces lignes, on s'accorde à admettre que tant la Droite que l'Union du Centre ont subi des pertes en cette occasion. Des commentateurs en ont déduit que ce scrutin exprimait la déception causée aux électeurs grecs par la politique de compromis de l'Union du Centre et spécialement par sa tactique de lutte sur deux fronts. Cette interprétation n'est pas invraisemblable mais il s'en faut de beaucoup qu'on puisse l'accueillir sans réserve.

En règle générale, il est toujours aléatoire de comparer des élections municipales à une consultation nationale : on ne saurait en effet tenir pour nécessairement acquis, 
même quand l'intervalle séparant les deux séries d'opérations est assez bref, que les électeurs se prononcent de la même manière. Dans le cas qui nous occupe ici, le gouvernement de l'Union du Centre avait expressément déclaré qu'il n'attachait aucun caractère politique à ces élections : en conséquence, les partisans du Centre avaient été laissés libres de voter selon leurs sympathies locales. À l'appui de sa position, le gouvernement manifestait le souhait que les élections municipales demeurent dans un cadre administratif. Mais il est possible que cette attitude ait en réalité traduit le souci du gouvernement de ne pas engager son prestige et son crédit sur un plan où l'Union du Centre, par suite de la faiblesse de son organisation locale, se trouve mal placée pour remporter la victoire. Quoi qu'il en soit, il ne suffit pas de déclarer une consultation quelconque dépolitisée pour ôter toute portée politique aux résultats enregistrés.

Fidèle à sa tactique de regroupement des forces, l'EDA a patronné partout où elle l'a pu des listes dites de collaboration démocratique - les personnalités inscrites sur ces listes aux côtés des membres de l'EDA étant en bien des cas des indépendants ou même des partisans du Centre qui jouissaient d'une position avantageuse sur le plan local. Beaucoup de ces listes ont remporté un net succès en dépassant le pourcentage de 40\% qui assure l'élection automatique du candidat-maire [p. 222] inscrit sur la liste bénéficiaire. Cependant l'opération n’a pas réussi à Athènes où le candidat maire de l'EDA, N. Kitsikis, n'a réussi à obtenir que 30\% des voix (ce qui constituait d'ailleurs une nette avance par rapport aux résultats de février) : l'élection du maire relevant dans ce cas des conseillers municipaux, c'est finalement le candidat de la Droite G. Plytas qui l'a emporté.

En définitive, ces élections municipales sont un bon témoignage de l'aptitude de l'EDA à se battre efficacement sur le plan local (ne serait-ce qu'en raison de la valeur de son organisation). Il serait hasardeux d'en déduire que ces résultats expriment une modification durable dans l'orientation politique du pays et le rapport des forces.

\section{V. ÉVALUATION D'ENSEMBLE}

$\underline{\text { Retour à la table des matières }}$

Dans le contexte politique grec, il est difficile de présenter une évaluation correcte ou, plus modestement, plausible de l'EDA sans prendre en considération ses rapports avec le communisme. Deux grandes thèses s'affrontent, à cet égard que l'on peut grossièrement résumer comme suit. Pour les uns, l'EDA représenterait seulement le couvert sous lequel et à l'abri duquel se déroulent l'activité et la propagande communiste. Selon ce courant qui englobe la Droite mais aussi de nombreux partisans du Centre, l'EDA n’est pas en réalité la Gauche mais l'Extrême-Gauche, le parti communiste grec n'ayant pas besoin de ce fait de se livrer à des démarches clandestines pour mener son combat. D'autres, sans nier que les communistes jouent un rôle important dans cette formation, déclarent que l'EDA constitue une formation de défense républicaine ouverte à tous les démocrates et dont le but est de poursuivre 
l’œuvre entreprise par l'EAM au temps de la résistance nationale contre l'occupation ennemie.

Un tel débat, même s'il s'inspire uniquement du souci de clarifier la situation, ne sauraient manquer de provoquer un réel malaise. Deux raisons au moins, également fortes d'ailleurs, sont susceptibles de nous dissuader d'entrer dans une telle discussion.

Le premier de ces motifs est en quelque sorte d'ordre technique à moins de faire état de catégories qui, tout en ayant un certain fondement positif, ouvrent la porte à tous les abus partisans (celles de «communisant» ou de «sympathisant communiste » par exemple), il [p. 223] n'y a d'autre moyen légitime d'identifier les communistes que de considérer les membres et les électeurs d'un parti se donnant pour tel. Or, en Grèce, le parti communiste est hors la loi. Et dès lors, pour évaluer le niveau d'implantation du communisme dans les organes de l'EDA, nous ne pourrions raisonner qu'en fonction de gens qui seraient communistes si le parti était autorisé à fonctionner. Il n'est pas besoin de souligner le danger d'un tel mode d'argumentation.

La seconde difficulté est d'ordre moral. Il est incontestable que durant ces dernières années les militants et électeurs de l'EDA - et spécialement les personnes d'humble condition sociale — ont fait l'objet de persécutions et de vexations policières sous le motif ou le prétexte d'affiliations et de sympathies communistes. En vue d'éviter que l'enquête scientifique ne risque d'être mêlée à l'investigation policière ou confondue avec celle-ci, il peut sembler préférable de suspendre toute appréciation en ce domaine jusqu'à ce que les citoyens grecs aient recouvré la faculté de se déclarer communistes sans courir de ce fait le danger d'être privés de leur liberté.

Il existe toutefois un moyen de surmonter de telles difficultés : la limitation du raisonnement aux conduites ouvertement assumées par les intéressés et aux attitudes que l'on peut déduire des prises de position publiques. Le procédé paraîtra sans nul doute bien naïf aux techniciens de la Kremlinologie : pourtant, sans donner toutes les clés de l'interprétation, il permet d'utiles mises au point.

L'élément de base d'une telle explication est qu'il existe dans la Grèce d'aujourd'hui des communistes, c'est-à-dire des citoyens qui, en cas de retour du parti communiste à la légalité, le choisiraient de préférence à tout autre pour lui donner leur adhésion ou lui apporter régulièrement leur voix. Le parti ne s'étant plus présenté aux élections depuis 1936 - date à laquelle il obtint environ 6\% des suffrages — il est impossible de pronostiquer l'ampleur de son électorat éventuel. Il serait certes facile d'avancer un pourcentage quelconque mais la démarche n'aurait pas de signification, le niveau susceptible d'être atteint par les suffrages communistes dépendant, surtout au titre des électeurs incomplètement convaincus, du climat politico-économique dans lequel serait réalisée la consultation.

L'EDA, c'est un point reconnu par elle, accepte dans ses rangs les partisans de l'idéologie communiste et les personnes sympathisant avec celle-ci. Il est également admis que des hommes de convictions commu-[p. 224] nistes ont le droit d'accéder aux organes de direction du parti à tous les niveaux, y compris au plan des organes centraux. D'un autre côté, l'EDA, encore qu'il n'y ait pas sur ce point unanimité dans 
ses rangs, n'a jamais dissimulé une préférence pour la méthode d'analyse et le mode d'argumentation marxistes. Ainsi offre-t-elle aux communistes grecs la possibilité de militer dans un parti ou au profit d'un parti dont l'inspiration est à plusieurs égards proche de la leur. Enfin l'EDA, nous l'avons vu, a toujours mis et met plus que jamais au premier plan de ses revendications la suppression des mesures frappant le parti communiste en général et les communistes à titre individuel : dès le début, elle a fait de ce retour du communisme à la légalité l'un des articles essentiels de son programme.

Ainsi s'expliquent, sans doute, la sympathie et le crédit dont jouit l'EDA auprès des milieux communistes étrangers et dans les organes du mouvement communiste international, en particulier La Nouvelle Revue Internationale. On pouvait lire dans ce périodique au lendemain des élections du 3 novembre 1963, que «le Parti Communiste qui soutient l'EDA a lui aussi consacré toutes ses forces à la victoire du peuple ${ }^{1}$. Les commentaires assez dithyrambiques qui furent consacrés à ces mêmes élections par l'hebdomadaire Italien Rinascita ${ }^{2}$ étaient révélateurs eux aussi d'une grande estime pour le travail de l'EDA. Même en cette phase de coexistence pacifique, les organes communistes sont généralement avares de tels éloges vis-à-vis des partis avec lesquels ils n'ont pas d'affinités particulières. Il suffit cependant de lire ces documents pour s'apercevoir qu'ils n'effectuent jamais la moindre assimilation entre le Parti Communiste grec et la Gauche Démocratique Unifiée.

Ces considérations permettent de comprendre qu'il existe entre le mouvement communiste et l'EDA un réseau de sympathies mutuelles — sympathies qu'augmente presque nécessairement la propension de tant de milieux gouvernementaux et privés à confondre ces deux éléments dans le même ostracisme (rappel de la contestation politique du rôle de l'EAM durant la guerre étrangère). Mais nos remarques aident aussi à expliquer les convergences indiscutables que l'on observe dans l'ordre de l'idéologie entre l'EDA et le Parti Communiste : il n'est que de [p. 225] comparer à cet égard la résolution du PC d'avril 1964 et celle de l'EDA de mai de la même année qui l'une et l'autre, nous l'avons déjà signalé, mettent au premier plan de la lutte politique l'exigence d'une démocratisation foncière du pays. Encore convient-il d'observer que l'adoption d'une telle position est entièrement conforme aux objectifs déclarés dans les statuts de l'EDA tandis que pour un parti proprement communiste, tel le PC grec, elle représente une sorte de mise en veilleuse de l'objectif officiel qui est la transformation totale des rapports sociaux.

Abordons maintenant le domaine de la politique étrangère. L'EDA critique vigoureusement l'impérialisme américain et dénonce le danger pour la Grèce d'une nouvelle expansion économico-militaire de l'Allemagne — une expansion réalisée sous la conduite d'hommes déjà actifs au temps du national-socialisme. Ce sont là certes des positions habituellement adoptées par les communistes, mais aujourd'hui

$\mathrm{N}^{\circ}$ de janvier 1964, p. 158.

$\mathrm{N}^{\circ}$ du 9 novembre 1963. Notons que le Président de l'EDA a adressé un télégramme de félicitations au Parti Communiste italien à l'occasion des récentes élections locales (novembre 1964) Bulletin Hebdomadaire, $\mathrm{n}^{\circ}$ 216, p. 5. 
bien des Européens qui n'ont aucune attache avec un quelconque parti communiste, s'élèvent contre la prétention des États-Unis de régenter l’Europe et s'inquiètent, pour employer un terme modéré, des conséquences du réarmement allemand. Le soutien donné par l'EDA aux thèses et démarches de la diplomatie soviétique est certes plus troublant. Cet appui, qui paraît s'étendre à la querelle sino-soviétique, tend à prendre forme d'alignement inconditionnel : pour ne citer qu'un exemple, il paraît bien difficile d'admettre avec l'EDA que dans l'affaire chypriote les décisions de l'URSS soient totalement désintéressées.

En raison de la cession de la Grèce faite jadis par Staline à Churchill, on aurait pu concevoir que les milieux de gauche de ce pays - un pays qui a toujours souffert d'être un objet dans les querelles internationales — soient tentés par le neutralisme. Mais ceux-ci rétorqueront peut-être que ce serait là une position fort peu réaliste face à la totale adhésion donnée par les autorités gouvernementales au bloc atlantique. Dans cette perspective, le recours à l'URSS serait de l'ordre du contre-poids. Pourtant, si un tel jugement convient pour qualifier les démarches de l'ethnarque Macarios, il semble bien que les positions officielles de l'EDA en politique étrangère expriment une réelle confiance dans la valeur des thèses et la rectitude des actes de la diplomatie soviétique. En ce domaine, l'EDA ne paraît pas disposer du libre jugement vis-à-vis des divers blocs que s'attribuait en Italie le parti socialiste nennien à l'époque où, détaché du pacte d'action commune avec les communistes, il ne s'était pas encore lié à la Démocratie Chrétienne.

[p. 226] En définitive, l'EDA n'est pas comme l'affirment ses adversaires, la simple couverture ou le simple substitut du parti communiste grec mais une formation de la gauche militante qui situe son action dans le cadre du régime parlementaire et au sein de laquelle s'exerce une influence communiste - influence variable selon les époques, les secteurs en cause, les hommes en présence. La diversité d'origine idéologique de ses dirigeants actuels explique les discussions qui s'établissent dans le parti quant à la sélection des tactiques optimales. C'est, par exemple, un fait que des divergences se sont manifestées sur l'opportunité d'encourager l'expansion d'un mouvement agraire en invitant les militants de l'EDA dans les campagnes à s'associer à cet effort. On sait également que le choix des positions à l'égard de l'Union du Centre, notamment dans l'ordre électoral, ne s'est pas effectué sans débat, les uns préconisant de tout mettre en œuvre pour assurer le succès du Centre contre la Droite tandis que les autres s'affirmaient partisans d'un dispositif d'action sauvegardant an maximum la situation de l'EDA.

Peut-être le point le plus intéressant de ce débat est-il de conjecturer ce que deviendrait l'EDA si le Parti Communiste grec était autorisé à rentrer dans la légalité. On peut penser que, au moins dans un premier temps, le PC et l'EDA se présenteraient aux électeurs sous forme d'une coalition. Mais ces agencements tactiques laisseraient subsister le problème de fond qui est de connaître ou du moins d'estimer les chances d'une formation se situant entre les Communistes d'une part, les éléments proprement centristes de l'autre. C'est du point de vue de l'avenir politique grec une question d'une importance capitale. 
Actuellement l'EDA, en tant que force de gauche est grossie d'une importante contribution communiste. En sens inverse, il est possible et on peut même tenir pour très probable que cette présence communiste éloigne d'elle ou décourage de collaborer avec elle des éléments d'inspiration " gauche modérée » ou centre-gauche. La puissance éventuelle d'un parti de gauche séparé de la masse communiste est évidemment fonction de l'ampleur d'un tel courant. Or il est bien difficile d'en donner une vue réaliste ou simplement sensée.

Il est bien connu que la Grèce n'a jamais disposé d'un parti socialiste de masse. Le socialisme y est resté l'apanage d'un certain nombre d'intellectuels et de cadres syndicalistes, les divers partis formés par ces éléments restant de dimensions modestes. On peut voir dans cette situation une conséquence du caractère tardif de l'industrialisation de la [p. 227] Grèce. Dans les pays d'Europe Occidentale, la formation de la classe ouvrière a précédé la Révolution d'Octobre, tandis qu'en Grèce c'est plutôt l'inverse qui a eu lieu. Une telle particularité ne pouvait que jouer au profit du mouvement communiste.

Il existe à l'heure actuelle un certain nombre de groupes se réclamant de l'idéologie socialiste mais ces formations, dont la ligne politique n'est pas toujours dépourvue d'équivoque, ne disposent que dune influence extrêmement réduite. Ainsi présence à Athènes d'une Ligue ou Club socialiste qui, évitant de prendre part aux luttes électorales, se donne pour mission de faire pénétrer les conceptions du socialisme dans les partis existants. On connaît aussi des groupements servant de point de rassemblement à des courants tout à fait marginaux de la politique grecque (ainsi des éléments d'inspiration trotskiste ou même nassérienne). Il suffit, pour n'avoir aucune illusion sur le poids réel de ces formations, d'observer qu'aux élections de 1951 l'une d'elle, le Parti Socialiste - Archives du Marxisme qui se présentait dans deux circonscription n'obtint en tout que 53 voix ${ }^{1}$.

Dans le contexte politique grec, un parti de gauche non communiste ne saurait avoir d'autre base sérieuse que le vieux centre gauche d'allégeance républicaine celui du général Plastiras. En son état actuel, la constellation partisane n'est pas favorable à l'émergence et à la consolidation d'un tel courant comme force politique autonome. Mais ce courant existe et à divers égards, la modernisation de l'activité économique pourrait contribuer à le renforcer. Nous retrouverons le problème dans le dernier chapitre de cette seconde partie ${ }^{2}$.

1 Signalons que parmi les problèmes que poserait l'Union de Chypre avec la Grèce figure le cas du Parti Progressiste des Travailleurs de Chypre (AKEL). Ce parti entre aux côtés du PC grec dans la catégorie dite des partis communistes et ouvriers, c'est-à-dire dans le mouvement communiste proprement dit. Sur les positions actuelles de l'AKEL, voir les deux brèves études publiées dans la Nouvelle Revue Internationale, mars 1963, pp. 97-107. Voir aussi la résolution du Comité Central du Parti en date du 7 juin 1964 in Bulletin d'Information (Prague), pp. 1075-1083.

2 L'évolution de l'attitude soviétique dans la question chypriote à la suite de la visite à Ankara de la délégation Pogdorny semble avoir placé le PC grec et l'EDA dans une situation difficile. Il est clair qu'en cette affaire l'U.R.S.S., dont peut-être le gouvernement grec avait eu tendance à surestimer les bonnes dispositions à l'égard de l'Enosis agit selon son intérêt propre. À l'inverse des États-Unis 
[p. 228]

\section{CHAPITRE VI}

\section{PARTI PROGRESSISTE}

$\underline{\text { Retour à la table des matières }}$

CE PARTI s'appelle en grec Proodefticon Comma. L'emploi pour désigner ce parti en langue française de l'expression « Parti Progressiste » — expression d'ailleurs utilisée dans les documents officiels de statistique électorale — est donc terminologiquement acceptable. Mais si l'on tient compte du sens attribué au mot " progressiste » dans la pratique politique française ${ }^{1}$, l'expression risque d'induire en erreur : tout en se réclamant de quelque modernisme, le Parti Progressiste est, spécialement en politique intérieure, un parti conservateur. Il est certes bien différent du vieux parti progressiste formé en 1928 par Cafandaris, homme d'un républicanisme irréductible, lors de sa rupture avec E. Vénizélos.

Cette formation est étroitement liée à l'action de S. Markézinis, avocat au barreau d'Athènes depuis 1931 et conseiller juridique du roi Georges II de 1936 à 1946. Membre du Parti Populiste et élu député aux élections du 31 mars 1946 au titre de la coalition des Nationalistes, Markézinis devait ensuite exercer, du 19 novembre 1952 au 3 avril 1954 les fonctions de Ministre de la Coordination Économique dans le Cabinet du Maréchal Papagos. Le Parti Progressiste a été créé en février 1955 sans doute pour faciliter le retour au pouvoir de Markézinis (précédemment fondateur du Nouveau Parti qu'il avait dissout lors de son entrée dans le Rassemblement Hellénique dont il fut l'un des plus ardents promoteurs).

Le Parti Progressiste est essentiellement un parti de cadres. Au cours [p. 229] des dernières années toutefois, il a été doté d'un bureau d'organisation qui s'est efforcé

et de la Grande-Bretagne qui ont toujours fait de même, elle a au moins l'excuse de ne pas être l'alliée de la Grèce.

1 ROBERTT donne comme définition du terme : «Qui est partisan du progrès sur le plan politique social et économique, qui tend à la modification de la société vers un idéal, par des réformes ou des moyens violents ». Comme néologisme, le mot a pris le sens suivant : "Qui est partisan d'une politique d'extrême gauche proche de celle des communistes ». 
d'assurer au parti une certaine implantation locale. Le parti s'est également préoccupé de fonder des organismes particuliers destinés à la jeunesse et aux femmes.

Le programme du Parti Progressiste reflète en pratique les idées de S. Markézinis. Celui-ci, qui a des liens avec le grand capital grec — spécialement le capital commercial - a fondé sa réputation sur les mesures de libéralisation du commerce et d'encouragement de l'initiative privée qu'il mit en œuvre lors de son passage au pouvoir. Les gouvernements qui se sont succédé depuis lors n'ont rien ajouté d'essentiel à cette politique dont l'inspiration continue de régir l'économie grecque.

Les mesures économiques et sociales préconisées par le Parti Progressiste répondent dans l'ensemble à un libéralisme d'inspiration ouverte. Cependant celui-ci tend désormais à se prononcer en faveur d'une programmation publique en quelques secteurs particuliers (par exemple dans celui de l'enseignement supérieur).

Conservateur dans les affaires économiques et sociales, le parti de S. Markézinis, qui a effectué un voyage à Moscou, répond toutefois mieux à son nom au titre des relations extérieures de la Grèce. C'est ainsi qu'il s'est prononcé pour la création d'une zone balkanique dénucléarisée, pour la normalisation des rapports de la Grèce avec les pays voisins du monde communiste (Bulgarie et Roumanie en particulier), pour le développement des échanges commerciaux avec les pays du bloc communiste ... Les positions assumées de ce chef par le Parti Progressiste sont favorablement jugées par les dirigeants de l'EDA.

Notons toutefois qu'actuellement Markézinis suit au titre de la question chypriote une ligne politique résolument pro-atlantique : critiquant avec vigueur la position de Mgr. Macarios, il préconise une solution du problème par entente directe avec la Turquie. Son idée paraît être qu'il faudrait assurer aux Turcs quelque compensation mais la nature et l'ampleur éventuelles de celle-ci restent dans le vague.

En matière électorale, le Parti Progressiste a utilisé une tactique essentiellement changeante et l'on peut avancer qu'il a eu recours, généralement avec un succès très relatif, à toutes les formules concevables :

— En 1956 il s'est présenté seul, constituant alors l'un des rares partis à être resté en dehors de l'Union Démocratique. Il a récolté $2,22 \%$ des voix sans obtenir de siège au Parlement.

[p. 230] - En 1958, le Parti Progressiste a pris des contacts avec l'EDA en vue de réaliser une coalition électorale avec celle-ci. Cette tentative a finalement échoué et le parti s'est présenté dans le cadre d'une coalition dite Union Progressiste Agraire Démocratique qui a remporté en tout $10,62 \%$ des suffrages et 10 sièges parlementaires : deux de ceux-ci sont revenus au parti de Markézinis.

- En 1961, le Parti Progressiste a fait alliance avec l'Union du Centre et il a conquis seize sièges. Au lendemain de la consultation, il s'est d'ailleurs séparé de ses associés quant au choix de la tactique politique optimale. Partisan de la Monarchie, mais d'une Monarchie qui reste au-dessus des querelles partisanes, S. Markézinis était d'avis que l'opposition constituée par le Centre joue le rôle d'une « opposition de Sa 
Majesté ». Au contraire, le leader de l'Union du Centre, G. Papandréou, se fondant sur les irrégularités commises lors de la consultation, réclamait au Souverain la prise d'initiatives tendant à favoriser le retour à la légalité parlementaire.

- En 1963, le Parti Progressiste s'est présenté seul : bien qu'ayant fait acte de candidature dans 51 circonscriptions sur 55, ce parti n'a eu que 3,73\% et deux sièges au Parlement.

— En 1964, enfin, il est entré dans une coalition de Droite avec l'Union Radicale Nationale et a conquis 7 sièges au Parlement.

Nous donnons dans l'appendice géographique une carte des résultats électoraux du parti en 1963. Ces derniers sont uniformément faibles, les deux seules zones de force relative du parti étant la circonscription des Cyclades, pays d'origine de son chef et celle de Rhodope en Thrace (ou le Parti présente un candidat appartenant à la minorité turque et qui recueille les suffrages de celle-ci).

$\mathrm{Au}$ vu de ces fluctuations, on pourrait évidemment s'interroger sur la position réelle du parti en matière politique. Selon les occasions, on le trouve entre la Gauche et le Centre ou entre le Centre et la Droite. Il semble bien que cette seconde position corresponde mieux que la précédente aux conceptions et tendances de S. Markézinis dont les préférences semblent aller à un conservatisme d'inspiration moderne. Les fluctuations dans les tactiques électorales du parti illustrent les difficultés qu'éprouve désormais une formation liée à un homme — un homme doué d'une vive intelligence et d'une grande ambition - à se faire une place en tant que telle sur la scène politique grecque.

[p. 231] Au titre de notre travail, disons que de la combinaison S. Markézinis Parti Progressiste, c'est le premier élément qui a le plus d'importance. Markézinis qui est seulement dans sa cinquante sixième année constitue certainement une personnalité de réserve, mieux peut-être, un outsider. Comme autres parlementaires du Parti Progressiste, nous désirons mentionner Th. Capsalis, député d'Acarnanie, connu pour sa compétence économique et allié à la famille Papastratos ainsi que $\mathrm{P}$. Lycourézos, député de Messinie et membre du barreau. 
[p. 232]

\section{CHAPITRE VII}

\section{UNION NATIONALE RADICALE (ERE)}

$\underline{\text { Retour à la table des matières }}$

L'ERE a été fondé en janvier 1956 par C. Caramanlis dans des circonstances que nous avons déjà mentionnées. On peut y voir le troisième mode d'organisation de la Droite grecque à l'époque contemporaine, les deux premiers ayant été le Parti Populiste et le Rassemblement Hellénique.

Deux traits compliquent l'analyse de l'ERE. Le premier tient au fait que la Charte de cet organisme est pratiquement restée lettre-morte. Bien que l'ERE possède sur le papier une structure administrative complète, il semble que durant la plus large part de la période étudiée (soit de 1956 presque jusqu'à la fin de 1963), l'Union ait été dirigée, sans aucun partage de responsabilité par son leader C. Caramanlis. D'un autre côté, durant cette période, le travail de l'ERE n'est pas loin de se confondre avec l'activité gouvernementale. Plus exactement peut-être, celle-ci est systématiquement utilisée en vue de consolider la domination exercée par l'ERE sur l'activité politique nationale. En réalité, au cours de cette époque, il est pratiquement impossible de considérer les démarches du pouvoir et celles du Parti comme deux séries ayant chacune une réalité distincte.

L'ERE ayant détenu les leviers de commande officiels sans interruption de sa création jusqu'à la veille des élections du 3 novembre 1963, c'est donc essentiellement comme parti gouvernemental que nous aurons à l'étudier. Nous essaierons pourtant, bien que le recul fasse presque entièrement défaut, de dire quelques mots de son comportement récent en tant que parti d'opposition. 
[p. 233]

\section{STRUCTURE ET DIRECTION}

$\underline{\text { Retour à la table des matières }}$

Les statuts du parti tels qu'adoptés en 1956 - il s'agit de « statuts provisoires » mais qui semblent depuis être demeurés dans leur état initial — établissent un système d'organisation complet. Cependant, qu'il s'agisse de la direction centrale du parti ou de sa structure organique, les normes statutaires ne semblent avoir été mises en application que de manière très partielle.

\section{A. DIRECTION CENTRALE DU PARTI}

$\underline{\text { Retour à la table des matières }}$

Les statuts du parti prévoient à cet effet neuf organes : il semble que la plupart (exactement 6) n'aient pas été appelés à fonctionner durant la période considérée. Ces organes sont :

\section{ASSEMBLÉE GÉNÉRALE}

Aux termes des statuts, l'Assemblée qui se réunit tous les deux ans constitue l'organe souverain du parti. Elle adopte, complète et modifie les statuts, trace la ligne idéologique et politique du parti.

L'Assemblée se compose du chef du parti, des membres du Conseil général, des députés du parti, des candidats aux dernières élections ayant précédé l’Assemblée générale, des divers directeurs du Secrétariat général, des membres des commissions d'étude du parti, du Conseil Suprême de discipline, ainsi que des délégués des organisations locales du parti.

Le nombre de ces derniers est fixé par le Conseil général et il est proportionnel, pour une moitié, au nombre d'électeurs de chaque circonscription et pour l'autre moitié, au nombre de voix du parti, par circonscription, lors des dernières élections.

Participent également à l'Assemblée générale, des délégués du mouvement de jeunesse du parti. Leur nombre qui doit demeurer inférieur au vingtième du nombre total des délégués à l'Assemblée générale est fixé par le Conseil général.

Il ressort de ce mode de constitution que l'Assemblée générale a un caractère nettement élitaire. Il s'agit plutôt d'une assemblée de [p. 234] notables que d'un organe représentatif de la base militante du parti, Le Conseil général, c'est-à-dire un organe exécutif de la direction du parti, a compétence pour arrêter le nombre des membres qui n'appartiennent pas à l'une ou l'autre des catégories participant d'office aux débats de l’Assemblée. S'agissant des délégués de la base, leur nombre est fixé 
indépendamment du chiffre des adhérents qui sont pourtant ou, devraient être l'un des éléments essentiels de la force du parti au niveau de l'organisation locale.

En somme, par sa conception même, l’Assemblée générale du parti qui devrait en être l'organe le plus représentatif, voit sa représentativité fortement compromise. En pratique, cette question de représentativité ne s'est jamais posée, puisque dans les huit années d'existence de l'Union Nationale Radicale, la direction n'a jamais convoqué d’Assemblée générale.

\section{CHEF DU PARTI}

D'après les statuts de l'ERE, le Chef du parti dirige la lutte idéologique et politique du parti ; il est son porte-parole, et le représente vis-à-vis de l'extérieur. Placé à la tête du groupe parlementaire, il dirige, supervise et contrôle tous les organes du parti.

Au titre de cet organe, les statuts comportent deux lacunes importantes :

- Absence de toute disposition quant au mode d'élection ou de réélection du Chef du parti. En pratique, lors de la création du parti, ses fondateurs, c'est-à-dire la majorité des parlementaires du Rassemblement Hellénique se sont réunis autour de C. Caramanlis qui, déjà choisi par le Souverain comme Premier Ministre, demeure à la tête de l'ERE jusqu'à sa démission, en décembre 1963. Lors de son départ, C. Caramanlis choisit comme successeur P. Canellopoulos. Ce choix fut approuvé par le groupe parlementaire du parti, dans une séance du 10 décembre 1963. En réalité donc, la désignation du chef du parti a été effectuée d'en haut, le groupe parlementaire se bornant dans les deux cas à ratifier une décision prise en dehors de lui.

- Imprécision des normes fixant le contenu des pouvoirs du Chef du parti et la répartition des responsabilités entre celui-ci et les autres organes du parti. La question revient à rechercher le principe du par-[p. 235] tage des pouvoirs entre l'Assemblée générale, le Chef du parti et le Groupe parlementaire, puisque les autres organes du parti sont, selon les statuts « dirigés, supervisés et contrôlés » par le Chef.

En pratique, la question de cette distribution ne s'est jamais posée à l'égard de l'Assemblée générale, celle-ci n'ayant pas été réunie depuis la création de l'ERE. Nous examinerons un peu plus loin les rapports entre le Chef et le groupe parlementaire. Disons immédiatement que, dans l'ensemble et contrairement aux habitudes politiques courantes du pays, le premier avait fini par dominer complètement le second. 


\section{AUTRES ORGANES CENTRAUX DE DIRECTION}

Ils sont au nombre de cinq :

- Conseil Général. Il est composé de dix membres élus par l'Assemblée générale. Il a à sa tête le Chef du parti et il est habilité à définir la ligne du parti, dans le cadre des directives de l'Assemblée. Il doit se réunir une fois par mois.

- Comité Exécutif. Il est constitué du Chef du parti, du secrétaire général et de trois membres du Conseil Général. Il est responsable de la direction et de l'organisation du parti; il suit l'évolution politique et organise les campagnes électorales.

- Comités d'études. Ils sont chargés de préparer le programme du parti ; ils constituent un organe consultatif pour les ministres dans le cas où le parti occupe le pouvoir. Les Comités sont nommés par le Comité Exécutif et divisés en sections spécialisées.

- Comité des Finances. Formé de cinq à sept membres nommés par le Comité Exécutif, il prépare le budget du parti, surveille l'encaissement des cotisations et contresigne les dépenses extra-budgétaires (à l'exception des dépenses élevées pour lesquelles la signature du Chef du Parti est exigée).

- Conseil Supérieur de Discipline. Il est composé de neuf membres élus par l'Assemblée générale. Il est habilité à statuer sur les questions disciplinaires, de manière définitive pour les membres du parti et, en première instance, pour les cadres qui ont la faculté de recourir devant le Conseil Général.

À notre connaissance, les cinq organes mentionnés sous cette rubrique n'ont encore pratiquement jamais fonctionné.

[p. 236]

\section{SÉCRÉTARIAT GÉNÉRAL}

C'est l'organe à l'aide duquel et par le canal duquel le Comité Exécutif assume la direction du parti ; il a la responsabilité de l'organisation du parti, de la propagande et de la préparation de la campagne électorale. Il se charge de la récolte des cotisations et des paiements.

Les compétences du Secrétariat Général sont subdivisées de la manière suivante : Secrétariat général ; Direction d’organisation ; Direction de propagande ; Direction du Bureau politique ; Direction des études ; Direction de la jeunesse.

Le secrétaire général est élu par le Conseil général et les chefs des diverses Directions, par le Comité Exécutif. 
L'activité de certaines directions du Secrétariat général de l'ERE a été considérablement facilitée par le fait que l'Union Nationale Radicale a conservé le pouvoir presque jusqu'au moment où s'arrête cette étude. Cette situation lui a valu des avantages considérables, en particulier pour ses rapports avec le public. C'est ainsi que, du point de vue de la propagande, les services gouvernementaux chargés de présenter et de magnifier l'œuvre gouvernementale, n'omettaient jamais de mentionner dans les communiqués et articles de presse, à la radio, dans leurs multiples publications, que toutes les réalisations accomplies étaient dues à l'activité du parti qui se trouvait au pouvoir, aux efforts de son leader et de ses collaborateurs chargés de fonctions ministérielles.

D'autre part, les nombreux déplacements du Président du Conseil et de ses ministres à travers le pays, à l'occasion de manifestations officielles constituaient un aspect important de la propagande partisane et cela sans le moindre effort financier ou administratif du parti lui-même. Notons à ce propos que C. Caramanlis assista à la pose de la première pierre, (qui fut souvent d'ailleurs aussi la dernière) de 300 « travaux » à travers la Grèce, avant les élections de 1961.

Observons aussi que le bureau politique de la Présidence du Conseil et les services équivalents des divers ministères avaient pour charge de s'occuper de la clientèle électorale du Premier Ministre et des membres du Cabinet. Un tel appui allégeait considérablement le travail de la direction du Secrétariat général chargée en principe de cette mission. Par ailleurs, un grand nombre de fonctionnaires étaient « détachés » de leurs fonctions administratives officielles pour en occuper d'autres, [p. 237] de nature officieuse, dans le secrétariat politique privé de certains ministres et même de certains députés du parti au pouvoir.

Il est difficile, de ce fait, d'évaluer de façon exacte l'importance et la valeur réelle du Secrétariat général de l'ERE. Nous pouvons cependant avancer, sans crainte de commettre une erreur grave, qu'en dehors des périodes pré-électorales, la majeure partie du travail incombant normalement au Secrétariat général du parti, était effectuée par les services publics mis à cet effet à la disposition du Président du Conseil et des ministres.

Au total, les pratiques de Caramanlis et de son équipe correspondaient aux démarches habituelles et aux règles établies du patronage dans la politique grecque. Cependant l'ERE, durant l'époque où elle assuma la charge du gouvernement, procèdera à un perfectionnement et à une rationalisation de l'expérience traditionnelle. En d'autres termes, le levier qu'offre le pouvoir à ses détenteurs fit l'objet d'une exploitation systématique.

\section{GROUPE PARLEMENTAIRE}

Font partie du groupe parlementaire de l'ERE : les députés ayant été élus sous son drapeau et ayant déclaré à la Chambre leur appartenance à ce parti. Le Chef de l'ERE est à la tête du groupe parlementaire. Aux termes des statuts, le groupe se réunit régulièrement tous les mois. Les députés de l’ERE sont chargés de l'organisation du 
parti dans leur circonscription et de la surveillance des organisations locales. Il est d'autre part prévu un Secrétariat du groupe parlementaire.

L'étude des rapports entre le Chef et le groupe parlementaire de l'ERE révèle une pratique récente : l'omnipotence du Chef sur le groupe parlementaire (E. Vénizélos lui-même ayant utilisé des procédés plus souples pour asseoir son autorité sur les membres de son groupe). Dans la vie politique grecque de l'immédiat après-guerre, ce sont les noyaux parlementaires qui ont fait et défait la plupart des partis politiques. Rien de tel n'est survenu à l'Union Radicale, l'examen de la période 1956-1964 montrant au contraire une subordination croissante du groupe parlementaire au Chef du parti. On note en particulier que le groupe parlementaire se réunit de moins en moins et que, quand il le fait, c'est pour entériner des décisions prises par la direction du parti et non pour élaborer la politique de ce dernier.

[p. 238] Cet autoritarisme qui dérivait de l'expérience du Rassemblement Hellénique provoqua certes plusieurs réactions défavorables au cours des premières années d'existence de l'ERE — période durant laquelle Caramanlis n'était pas encore parvenu à imposer son autorité. C'est ainsi que le parti enregistre diverses démissions : celles des députés Eftaxias et Caroussos, le 15 novembre 1956, pour cause de désaccord avec le gouvernement sur sa politique chypriote ; celle du viceprésident du Conseil Apostolidis, le 17 juillet 1957 ; celles surtout des ministres Papaligouras et Rallis, le 27 février à propos de la loi électorale. Rappelons aussi que cette démission fut suivie du retrait de la confiance au gouvernement par 15 députés de la Droite (parmi lesquels $P$. Canellopoulos alors très sévère à l'égard de Caramanlis) le $1^{\mathrm{er}}$ mars 1958, rébellion qui entraîne la démission du Premier Ministre. Expliquant publiquement les motifs de sa démission, Papaligouras déclara entre autres que le Conseil des ministres avait pratiquement cessé de fonctionner, toutes les décisions étant dictées par C. Caramanlis aux ministres intéressés.

Cependant, une fois assurée la consolidation gouvernementale de l'ERE à la suite des élections de 1958 et 1961, les mutineries cessent et les éléments récalcitrants que nous venons de mentionner retrouvent leur place dans le groupe. Dès lors, on n’observe plus que quelques cas isolés d'insubordination, comme celui du ministre de la Prévoyance sociale du dernier gouvernement Caramanlis, A. Stratos se plaignant que le Président du Conseil ait refusé de le recevoir pendant huit mois. Citons aussi le cas de Christos Grammatidis qui quitta le parti après les élections de 1963 pour désaccord politique avec Caramanlis (désaccord manifeste depuis 1961).

Tous ces cas de conflit entre le Chef du parti et les députés ou ministres de l'ERE n'ont jamais fait l'objet d'un examen sur le fond de la part du groupe parlementaire. Quand ce dernier était convoqué pour une affaire de ce genre, il s'agissait toujours simplement de voter l'expulsion des mutins.

Au temps de Papagos, la discipline des députés de la Droite au sein du Parlement était devenue légendaire, comme en témoigne le mot de " compagnie » qui leur était couramment appliqué. Cette propension à l'obéissance continuera de s'affirmer sous l'ERE. La discipline parlementaire était alors si forte que les propositions gouvernementales, y compris celles risquant d'être impopulaires auprès des électeurs, 
réunissaient, pratiquement toujours, l'unanimité des députés de l’ERE. Tel fut [p. 239] le cas du rejet d'un projet de pension pour les paysans, que l'opposition avait déposé en janvier 1960. C. Caramanlis ayant fait de son rejet une question de discipline, le projet fut repoussé à mains levées par les députés de l'ERE.

Au total, sur les neuf organismes prévus par les statuts provisoires de L'ERE, trois seulement ont effectivement fonctionné durant la période considérée : le chef du parti, le groupe parlementaire et le secrétariat général (les deux premiers étant en principe des centres de décision, le troisième un instrument d'exécution). Encore faut-il noter que le Chef, profitant des habitudes prises sous Papagos, a dominé le groupe parlementaire jusqu'à lui enlever toute faculté d'action autonome, tandis qu'une large fraction des tâches revenant au secrétariat général était assumée par les services gouvernementaux eux-mêmes.

On voit donc que le système officiel d'organisation du parti a constitué une simple façade derrière laquelle s'exerçait le pouvoir d'un homme qui n'hésitait pas à mettre les ressources de la machine gouvernementale au service de sa propre personne et des membres de son parti.

\section{B. STRUCTURE ORGANIQUE DU PARTI}

Retour à la table des matières

Selon les statuts, la gestion du parti fait l'objet d'une décentralisation qui épouse les circonscriptions administratives officielles. Or, sous cet angle également, il n'y a pas coïncidence entre les normes statutaires et les réalisations pratiques.

Les statuts prévoient la création des « centres politiques » de l'ERE dans toutes les circonscriptions électorales qui, grosso modo, coïncident avec les départements. Il est d'autre part précisé que ces « centres politiques » devront progressivement créer des «commissions » provinciales, communales, locales et de quartier. Le mode de direction de ces «centres politiques » est identique, pour ce qui est des organes prévus, à la direction centrale du parti. À ce niveau également, nous remarquons le caractère élitaire de l' « assemblée du centre politique ».

Quant aux relations entre la direction centrale et la direction des «centres politiques », il est décidé que : « l'Assemblée du centre politique fixe les moyens et les méthodes de l'activité idéologique et politique [p. 240] dans la circonscription considérée sur la base des directives de l'organisation centrale " et que " la procédure de convocation de l'assemblée et son fonctionnement font l'objet d'un règlement spécial, approuvé par l’Assemblée générale du parti ». Nous remarquons donc une certaine main-mise de la direction centrale sur les organisations locales.

Examinons maintenant le degré d'application de ce système. Selon les renseignements dont nous disposons, il semble que ce soit seulement dans un petit 
nombre de centres importants (essentiellement dans les grandes villes), que l'on ait tenté de mettre en œuvre ces dispositions. Dans le reste du pays, et au niveau des circonscriptions électorales, l'organisation partisane est aux mains des députés du parti et d'un certain nombre d'autres politiciens qui rassemblent autour du noyau de leur parti personnel une certaine quantité de sympathisants. Ainsi plusieurs formes de relations traditionnelles (clientèle) gardent-elles le pas sur les normes d'organisation nouvelle. C'est en divers cas, à travers l'allégeance à des personnes que se fait l'adhésion à l'ETRE ou le vote en sa faveur.

De ce fait, l'organisation locale de l'ERE varie considérablement d'un endroit à l'autre, non seulement quant au nombre d'adhérents, mais aussi quant au type de rapports. Cette diversité résulte souvent de facteurs individuels, tels que le dynamisme et la qualité des moyens dont disposent les politiciens du parti d'une circonscription donnée, ou encore l'accession d'un député de la région à un poste de ministre, ce qui lui permet d'obtenir des avantages particuliers pour la circonscription.

Malgré leur caractère fragmentaire, ces remarques montrent que l'ERE était encore bien loin, au moment de son éviction du gouvernement, d'avoir organisé un appareil politique décentralisé de façon uniforme et démocratique.

Pour en terminer avec ces problèmes, notons que les statuts prévoient également la création d'une organisation de jeunes. En réalité, c'est la direction de la jeunesse du Secrétariat général qui a la haute main sur l’organisation de jeunesse du parti. À notre connaissance, il existe des sections de jeunesse de l'ERE à Athènes et à Salonique. Jusqu'à maintenant, leur activité principale a consisté à animer les réunions électorales du parti et à noyauter les comités de Faculté des deux Universités.

Il existe par ailleurs une autre organisation de jeunesse, l'Organisation Estudiantine Nationale Sociale (EKOF) qui, sans être officiellement un organe de l'ERE proprement dit, s'inspire nettement de la politique du parti dans ses activités.

[p. 24l] Signalons enfin que les statuts de l'ERE prévoient la création d'un club féminin. Selon nos informations, cette disposition est pratiquement restée lettre morte.

Au total, aussi bien pour la direction centrale que pour la structure organique, la plus grande partie des organes prévus par les statuts n’a pas fonctionné effectivement. Par ailleurs, sous la rubrique « dispositions transitoires », l'article 36 conférait tous les pouvoirs au Chef du parti «jusqu'à la mise sur pied de l'organisation du parti ». Le maintien de ce "provisoire », qui dure depuis 8 ans et demi, a eu pour conséquence d'affermir la position du Chef du parti qui, en fait, était devenu au temps de Caramanlis, l'unique organe de direction et de décision de l'ERE. Il est en tout cas certain qu'aujourd'hui encore aucun groupe représentatif de la base n'intervient, même dans un but consultatif, lors de la prise des décisions concernant le parti. En d'autres termes, on n'a encore jamais tenté d'introduire quelque élément de démocratie dans le fonctionnement de l'ERE. 
On doit toutefois se demander si le Chef du parti, lors de la prise d'une décision, est à lui seul le «moteur » et l'« élément d'élaboration » de la décision. Il ne semble pas que cette hypothèse soit plausible. Si l'on tient compte que, durant ses 8 ans et demi d'existence, l'ERE est demeurée 7 ans et demi au pouvoir, il serait absurde de prétendre qu'un seul homme ait pu concevoir, élaborer et prendre toutes les décisions concernant la direction du parti et, par voie de conséquence, en une large mesure la direction du gouvernement. Caramanlis passait certes pour un homme capable de décider vite et de manière nette mais il ne pouvait se faire lui-même un jugement sur tous les problèmes qui lui étaient soumis.

Il faudrait donc rechercher, dans le cadre d'une étude exhaustive du système gouvernemental grec les organes ou personnes qui, intervenant à la place des organismes officiellement prévus, secondaient ou suppléaient officieusement le Chef de l'ERE dans sa tâche. En ce qui concerne « l'élément moteur » des décisions, nous pouvons dire que, dans une très large mesure, celles-ci étaient provoquées par des éléments extérieurs au parti et au gouvernement, sans oublier la simple nécessité de faire face à des situations données. Cette dépendance à l'égard des circonstances [p. 242] et difficultés quotidiennes est le signe d'une carence grave dans le choix d'objectifs durables, que ce soit dans le cadre du parti ou dans le cadre du gouvernement (infra).

Pour ce qui est de "l'élément d'élaboration », la documentation dont nous disposons nous permet d'en distinguer trois séries : un «brain trust », officiel ou officieux ; un petit nombre de politiciens dévoués à la personne du Chef du parti ; un certain nombre de parlementaires de l'ERE en position de chefs de file. Ces trois catégories de personnes étaient, selon le cas qui se présentait, consultées conjointement ou séparément.

Il faut examiner maintenant les raisons qui ont conduit les intéressés, et spécialement les parlementaires, à accepter cette prépondérance du chef dans la conduite des affaires du parti.

\section{SITUATION PERSONNELLE DU CHEF DU PARTI}

\section{$\underline{\text { Retour à la table des matières }}$}

Les partis grecs actuels sont si récents qu'il est pratiquement impossible de tirer de leurs démarches des enseignements généraux. Nous ne pouvons raisonner que sur des cas particuliers sans avoir la moindre certitude que les conduites du passé se répètent dans l'avenir. Sous cette réserve, nous allons examiner le cas de C. Caramanlis et de son successeur P. Canellopoulos. Nous dirons ensuite quelques mots d'autres personnalités influentes au sein de l'ERE. 


\section{LE CAS DE C. CARAMANLIS}

On pourrait être tenté de rechercher la source de l'indiscutable autorité dont a bénéficié C. Caramanlis au sein de l'ERE dans la possession et la manipulation des leviers de commande d'un solide appareil partisan. Or, nous venons de voir que, contrairement à des notions qui ont circulé à l'étranger, l'ERE n'a nullement acquis une telle structure durant la période considérée. Il n'y a, de ce point de vue, aucune ressemblance entre cette formation et l'EDA qui dispose d'une authentique structure administrative allant jusqu'au niveau local. Il faut chercher ailleurs la raison de cette influence et nos observations à cet égard ne peuvent qu'avoir un caractère provisoire. L'observation attentive de la vie politique grecque [p. 243] durant cette période permet toutefois de formuler des hypothèses assez significatives.

La première hypothèse qui vient à l'esprit à cet égard - une hypothèse qu'au cours des dernières années la science politique a utilisée ad nauseam - est celle du charisme (ce que la langue française traduit par l'expression, assez faible d'ailleurs, de rayonnement ou magnétisme personnel et que des auteurs américains, plus proches de l'idée wébérienne, désignent comme the touch of grace). Peut-on expliquer l'ascension de C. Caramanlis par des qualités de cet ordre?

Il ne semble pas y avoir lieu de retenir un tel élément. En effet, quand il prend le pouvoir en 1955, Caramanlis, Ministre des Travaux dans le gouvernement Papagos du Rassemblement Hellénique, est certes un ministre qui passe pour avoir réussi dans son domaine. Sans entrer dans un exposé détaillé de son activité de l'époque, observons toutefois qu'elle ne bénéficie pas d'une approbation unanime. On a pu reprocher à Caramanlis de faire passer le souci de son propre prestige avant celui du service de la collectivité en donnant volontiers priorité à des travaux rentables sur le plan des « relations publiques » (ainsi percement ou aménagement de voierie dans la ville d'Athènes). On lui fait aussi grief d'avoir couvert ou suscité de graves fautes techniques sans témoigner d'exigences suffisantes dans le domaine des prix de revient. En tout cas, cet homme encore jeune (il est né le 23 février 1907), fait figure, même dans son propre parti, de technicien et d'homme politique de deuxième plan. Son nom est inconnu des masses, et c'est avec une surprise certaine que l'on apprend sa désignation à la tête du gouvernement. Il est vrai que Caramanlis devait s'efforcer d'annuler ce handicap en utilisant toutes les ressources de la propagande officielle.

En effet, au cours des huit années durant lesquelles il est demeuré au pouvoir comme premier ministre, la radio étatique, la presse gouvernementale et sympathisante, les services gouvernementaux en Grèce et à l'étranger ont déployé de grands efforts pour créer, devant l'opinion publique - nationale et internationale l'image d'un chef jeune, dynamique, créateur, loyal, défenseur des «valeurs occidentales », self made man issu du peuple. C'est là un aspect de cet essai de conditionnement de la conscience qui constitue désormais une véritable industrie et qui fait l'objet d'une utilisation croissante, aux frais du contribuable, de la part des autorités publiques. 
[p. 244] On aura une juste idée du contenu et du style de telles campagnes en lisant quelques extraits d'une biographie de Caramanlis publiée et éditée en plusieurs langues par la Présidence du Conseil en mai 1959.

«Constantin Caramanlis est de souche paysanne. Son père était maître d'école et l'un des importants cultivateurs de tabac de la région. Il est l'aîné de quatre frères et trois sœurs. Son père étant mort laissant des enfants en bas âge, Constantin, alors âgé de 19 ans, suivant la coutume des familles grecques, se chargea de la famille et de l'éducation de ses frères et sœurs. Son père s'était toujours efforcé de dissuader le jeune Constantin de suivre une carrière politique, alléguant que celui-ci était d'un caractère trop droit et honnête pour avoir du succès comme politicien ».

« Il a débuté dans la carrière politique jeune encore, à l'âge de 28 ans ».

« En 1946, il accéda pour la première fois au Conseil des ministres ... Il se distingua à tous ces postes par l'assiduité, l'initiative créatrice, l'efficacité administrative et un zèle infatigable dans la réalisation des tâches qui lui étaient confiées. »

« Durant cette période particulièrement fructueuse de sa carrière politique, ses qualités d'homme d'État, et particulièrement son énergie exceptionnelle, sa sûreté de détermination, son esprit de méthode et d'initiative splendide dans les travaux de progrès furent éprouvées et universellement reconnues. Il acquit ainsi l'appréciation profonde et l'estime du peuple grec. »

« En homme jeune, possédant une grande expérience et doué d'une indomptable force de volonté et de décision, il n'hésite pas. Animé par le vif désir de réorganiser les forces politiques du pays afin de manier efficacement ses problèmes, il fonde l'Union Nationale Radicale. »

« M. C. Caramanlis n'hésite pas à présenter un programme pro-occidental et à affronter audacieusement l'opinion publique. Malgré sa position contre le courant émotionnel existant et grâce à son prestige personnel, il sortit vainqueur. »

« Il n'est pas exagéré de dire que dans une proportion de plus des trois quarts, l'œuvre de reconstruction effectuée depuis la libération de la Grèce (octobre 1944) a été instaurée, poursuivie et parachevée par M. Caramanlis. »

«Constantin Caramanlis a mené jusqu'ici avec un grand succès sa tâche gigantesque, grâce à une conduite alliant une assiduité indéfectible, ne connaissant aucun répit même un seul jour de fête, à une sévérité inaliénable envers ses collègues et collaborateurs, imposée non tant pas ses ordres que par son exemple personnel. Tempérant dans sa vie privée, simple et modeste en public, son caractère et ses manières sont exemplaires. En outre, il a fait montre, au poste de Premier Ministre, de sagesse politique, de perspicacité dans le jugement et d'habileté à saisir les situations de façon prompte et précise. Il a ainsi réussi, en dépit de la réaction, à acquérir la situation du leader politique le plus puissant de Grèce. »

[p. 245] Rien ne manque à un tel tableau mais, comme l'indique la sagesse populaire, qui dit trop ne dit rien. Encore que des éléments de ce portrait aient été acceptés en divers milieux étrangers, il est douteux que de semblables campagnes aient influencé considérablement l'opinion des élites grecques et spécialement les membres du parti.

Aucune de ces explications ne met en lumière la véritable source du pouvoir de Caramanlis qui est d'avoir été choisi par le Roi pour diriger la Droite, c'est-à-dire le 
groupe politique qui dans la Nation et au Parlement, constitue l'assise de la Couronne. Des adversaires de Caramanlis le dépeignent comme un simple employé du Palais appelé par le Souverain à remplir un poste de confiance et brutalement limogé dès le moment où son comportement paraît susceptible de compromettre la Couronne devant le pays. Le jugement est sévère dans la forme mais nous pensons qu'il exprime avec assez d'exactitude l'esprit des rapports noués entre le Roi et son Premier Ministre. De toute manière, et selon un mécanisme qui deviendra clair quand nous aurons exposé le rôle des forces extra-parlementaires dans la vie politique grecque, la désignation royale vaut à Caramanlis l'appui des forces armées — un appui qui conduira les militaires jusqu'à l'intimidation et à la falsification électorale au profit de la droite.

Les raisons ayant motivé l'octroi initial de la confiance royale restent conjecturales. Beaucoup disent que Caramanlis fut appelé parce qu'il était prêt et même parce qu'il s'était expressément engagé à accepter un règlement de la question chypriote conforme aux intérêts britanniques et aux préoccupations américaines. L'acceptation par l'ERE des accords de Zurich semble valider cette hypothèse mais on connaît les réserves qu'appelle le mode de raisonnement consistant à trouver les mobiles d'une conduite passée dans le déroulement ultérieur du cours des choses.

Une autre hypothèse est que Caramanlis fut choisi parce qu'on le jugeait, par sa dureté et sa rigueur apparente, plus capable que ses rivaux d'inspirer confiance aux Américains au titre de la lutte contre le communisme. Nous sommes alors au temps de Foster Dulles et l'Amérique aime que les pays recevant l'aide économico-militaire témoignent d'énergie dans la sauvegarde des valeurs occidentales (cette défense impliquant en dehors de la croisade idéologique, l'octroi d'un traitement préférentiel aux banquiers et marchands américains). Par ses fonctions ministérielles, Caramanlis était en contact avec les services des États-[p. 246] Unis en Grèce et il n'est pas impossible qu'il soit parvenu à se faire reconnaître par ceux-ci comme persona non grata avant même d'avoir été remarqué par le Palais.

Dans la situation de dépendance où se trouvait alors la Grèce vis-à-vis des ÉtatsUnis, il était en tout cas inconcevable que le Roi nomme un Premier Ministre qui ne leur aurait pas inspiré pleinement confiance. Caramanlis, qui n’aurait pas été désigné s'il n'avait joui au départ de cette confiance, devait par la suite la mériter entièrement et, en fait, l'appui américain ne lui fit pas défaut pendant plusieurs armées. Pour que cette préférence diminue, il faudra attendre les changements provoqués par l'arrivée au pouvoir de J.F. Kennedy dans les modalités d'exercice de l'impérialisme américain.

Caramanlis étant assuré de la faveur royale et bénéficiant de l'aide de la puissance protectrice, il était dès lors facile à la propagande caramanlique de faire passer le Premier Ministre pour l'homme de la situation. C'est ainsi que Caramanlis sera présenté comme le meilleur garant et même comme l'unique garant de situations chères aux catégories dirigeantes et aux couches privilégiées du pays, sans oublier les nombreux éléments des classes moyennes qui pensent et agissent dans leur sillage : la sauvegarde du pays des dangers de l'infiltration et de la subversion communistes (peur sans aucun fondement raisonnable du «troisième round » que le PC grec se 
préparerait à lancer contre la bourgeoisie); le maintien de l'appui des alliés et spécialement des Américains qui, sous couleur d'assurer la protection de la nation contre l'invasion étrangère garantissent en fait la permanence des structures sociales existantes ; la possession de la confiance de l'étranger (banquiers, groupes industriels, touristes, etc.) dont on attend les devises nécessaires pour enrichir les bénéficiaires de l'ordre existant et faire manger le peuple ...

En gros, la propagande caramanlique consistait à affirmer que sans Caramanlis la sauvegarde de telles valeurs serait irrémédiablement compromise. La ficelle était certes un peu grosse dans la mesure où bien d'autres politiciens grecs, y compris les leaders du Centre auraient pu garantir à la bourgeoisie grecque et devaient effectivement lui garantir par la suite les mêmes avantages. Mais le fait reste que durant une période Caramanlis parvint à se faire prendre pour l'homme indispensable à la défense des intérêts de la Droite et ceci explique, au moins pour partie, que les parlementaires de l'ERE aient, à quelques exceptions [p. 247] près, témoigné de docilité vis-à-vis du leader mis en place par le Roi avec le consentement actif de l’Amérique.

Ces manœuvres, pour significatives qu'elles soient, n'expliquent pas tout. Il faut également insister sur l'importance des leviers d'intervention et des instruments d'influence que valait au Premier Ministre la domination de l'appareil gouvernemental, domination d'autant plus forte que le parti lui-même n'avait ni structure ni volonté propres et que la haute bureaucratie grecque est bien trop faible et dépendante pour avoir simplement le désir de s'opposer aux politiciens. En de telles circonstances n'importe quel leader se serait trouvé en mesure d'influer sur le comportement de ses troupes. Dans le cas qui nous occupe, les facultés d'action habituellement ouvertes au chef de parti devenu Premier Ministre devaient être amplifiées et alourdies par la rigueur avec laquelle fut effectuée la colonisation de l'appareil gouvernemental et la centralisation du patronage aux mains de Caramanlis. Ainsi comprend-on que les parlementaires de l'ERE, soucieux de jouir pour euxmêmes et pour leur circonscription d'une fraction de ces avantages aient marqué leur acquiescement à la politique du Chef plutôt que d'entreprendre une lutte contre lui, lutte nécessairement hasardeuse par suite des appuis dont il jouissait.

Il convient d'évoquer également le problème électoral. La force de la Droite lui venait pour partie de constituer depuis 1951 un bloc solide face à la fragmentation du courant centriste. On peut admettre que le souci de conserver cette situation privilégiée était de nature à détourner les députés de l'ERE de constituer des dissidences. Et dès lors, ils étaient voués à se plier à l'autorité du Chef du Parti.

Ceci étant acquis, il reste à expliquer la démission du poste de Premier Ministre présenté au Roi par C. Caramanlis en date du 11 juin 1963. Le jour où cette démission intervient, l'ERE dispose au Parlement de 176 sièges sur 300. Caramanlis a donc une majorité confortable et une majorité qu'il tient bien en mains. Dès lors, pourquoi ce départ qui ressemble si complètement à une fuite et qui en est peut-être une ?

Il ne semble pas en tout cas que la raison invoquée - un désaccord sur l'opportunité du voyage du couple royal à Londres — soit la bonne. Comme nous 
l'avons vu, il est difficile de croire que le Chef de l'État ait pu entrer en conflit avec le chef de la majorité parlementaire à propos d'une affaire malgré tout secondaire. D'autre part, à condition toutefois de raisonner dans le cadre du système constitutionnel établi, [p. 248] on peut penser qu'il aurait été relativement facile au Président du Conseil, compte tenu de la majorité absolue qu'il avait à la Chambre, de dissuader le Chef de l'État d'effectuer un voyage protocolaire, si le différend s'était strictement limité à ce problème.

Si l'on veut aller plus au fond de la question, il faut se souvenir que la période de 18 mois ayant précédé la chute du gouvernement Caramanlis fut une phase de «lutte irréductible » (selon les termes mêmes de G. Papandréou) pour le renversement du gouvernement de la Droite et le retour devant le corps électoral. Nous analyserons plus tard les modalités de cette lutte. Le point à retenir est que ce combat devait créer dans le pays une sévère crise politique dans laquelle l'Union du Centre n’hésita pas à impliquer la Monarchie. Or C. Caramanlis se révéla tout à fait incapable de dominer cette crise que l'assassinat du député Lambrakis devait porter à son point culminant. Cette crise était encore aggravée par les défauts et les insuffisances de la situation économique beaucoup moins brillante, surtout dans une perspective de long terme, que ne l'affirmaient les propagandistes gouvernementaux et que n'étaient portés à le croire divers milieux étrangers.

À partir de cette situation, plusieurs hypothèses sont possibles quant au comportement des principaux intéressés. On peut penser que C. Caramanlis a provoqué la crise pour contraindre le Roi à dissoudre le Parlement et pour engager à nouveau la bataille électorale - une bataille qui, si l'on en juge, a posteriori il est vrai, d'après l'étroitesse de la victoire du Centre le 3 novembre 1963, était loin d'être perdue d'avance. Mais il n'est pas interdit d'envisager que Caramanlis, effrayé du tumulte créé par l'opposition et soucieux de ne pas aggraver l'exaspération de celle-ci (ne serait-ce que pour éviter des représailles ultérieures) ait en réalité décidé de partir en choisissant un "point de chute" en quelque sorte extérieur au contenu de la bataille en cours. La mollesse et, disons-le, le défaitisme apparent dont l'ancien chef du gouvernement devait faire preuve après la première victoire du Centre (élections du 3 novembre) donnent certes du relief à cette hypothèse.

On peut, il est vrai, faire d'autres conjectures dont le propre est d'attribuer l'initiative à la Monarchie. Celle-ci ne pouvait manquer de s'inquiéter de la vague montante des critiques qui lui étaient adressées en de nombreux secteurs de l'opinion nationale mais aussi étrangère. On comprend que le Souverain - auquel le Centre ne pardonnait pas l'appui initial apporté à Caramanlis — ait tenté de rétablir la situation [p. 249] en éliminant Caramanlis, soit pour organiser purement et simplement une nouvelle consultation, soit pour amorcer certains regroupements partisans (création d'une sorte de rassemblement de Centre droit réunissant autour de S. Vénizélos par exemple les éléments modérés de l'Union radicale et de l'Union du Centre).

Sur cette base, nous retrouvons l'opinion voulant que le Souverain ait renvoyé son Premier Ministre comme un patron licencie un subordonné qui a failli dans l'accomplissement de sa tâche. Le Roi était d'autant mieux placé pour réaliser 
l'opération qu'il pouvait compter, et non le Premier Ministre, sur l'appui des forces armées. L’État-Major, loyal à Caramanlis tant qu'il était l'homme du Palais, lui retirait son concours quand changeaient les préférences royales: il fut en tout cas ostensiblement consulté par le Souverain la veille de la démission du Premier Ministre, les journaux rendant compte de l'événement. Au surplus, la nouvelle politique américaine n'était pas défavorable à l'arrivée d'un gouvernement moins ouvertement réactionnaire.

En définitive, Caramanlis tombait sous le coup des forces qui avaient assuré son ascension. Et sa chute était due au fait qu'il n'était plus maître des éléments sur lesquels il avait assis son pouvoir. L'ERE avait sous sa conduite commis tant d'abus que le "temps du mépris » était venu. Mais les forces extraparlementaires et les milieux étrangers ne voulaient pas faire les frais de ce mépris. Dans une telle conjoncture, il n'y a d'autre tactique à appliquer que celle du bouc émissaire ou encore du changement des hommes pour conserver la substance des choses. En définitive, la thèse attribuant à l'initiative royale le départ de Caramanlis nous semble la meilleure - une initiative dans le choix de laquelle la reine Frédérika au courant de la maladie de son époux (cancer) aurait, d'après beaucoup d'avis, joué un rôle important.

Dès le 18 juin 1963 en tout cas, Caramanlis quittait la Grèce en plaçant à la tête de l'ERE un Comité de direction formé de trois membres. Il devait y revenir le 28 septembre pour faire campagne en vue des élections du 3 novembre. Cependant, peu de temps après ces élections, il prit subitement la décision d'abandonner la direction de son parti ainsi que la vie politique et de repartir pour l'étranger. Le 9 décembre, il quittait Athènes à destination de Paris, sans même avertir au préalable ses plus proches collaborateurs et après avoir réservé des places dans l'avion sous un nom d'emprunt (M. Triantaphilidés). Deux heures avant le départ de l'avion, en route pour l'aéroport, il [p. 250] remit à P. Canellopoulos, son oncle par alliance et également son premier lieutenant dans l'ERE, une lettre par laquelle il le désignait comme son successeur.

Ce départ ne saurait s'expliquer par des raisons objectives. L'ERE, après les élections de novembre 1963, demeurait le deuxième parti de la Chambre, avec seulement 6 sièges de moins que le parti vainqueur. Battue, elle était encore un solide instrument de combat - instrument d'autant plus solide que le Palais paraissait fort désireux de ne pas venir à la solution d'un gouvernement purement centriste.

Selon certains, C. Caramanlis aurait cédé à des pressions de membres de l'ERE qui lui imputaient la défaite du parti. D'autres ont dans ce départ une simple démarche tactique devant permettre à l'intéressé, une fois apaisé le tumulte de la crise ouverte par les élections de 1961, de revenir à la vie publique éventuellement dans le rôle de sauveur. D'autres enfin attribuent ce départ à des éléments émotionnels.

Nous ne saurions rien affirmer de certain sur la base des données actuellement disponibles. Mais l'hypothèse d'une faiblesse individuelle ne nous paraît pas la moins vraisemblable de ces conjectures. Nous n'aurons pas en tout cas la cruauté d'insister sur la différence entre cette conduite et le portrait tracé du chef de l'ERE au temps de sa plus grande splendeur par la propagande officielle. 
Ainsi, après avoir repris le pouvoir dans le parti au directoire de trois personnes qui l'avaient exercé du 18 juin au 28 septembre, C. Caramanlis abandonna ses fonctions au bout de quarante jours à P. Canellopoulos. Nous en arrivons ainsi au choix du second leader de l'ERE.

\section{LE CAS DE P. CANELLOPOULOS}

Canellopoulos, député de Patras, est un homme fort différent de Caramanlis. Un peu plus âgé que son ancien chef (il est né le 13 décembre 1902), il est réputé pour sa probité et son intégrité morale. Il jouit d'un prestige intellectuel certain, ayant occupé autrefois des postes universitaires et ayant écrit de nombreux ouvrages littéraires. Il est entré dès 1935 dans la politique en fondant son propre parti, le Parti National Unioniste qui était d'inspiration républicaine non véni-[p. 251] zéliste. Assigné à résidence sous la dictature Métaxas, il est l'un des politiciens grecs à avoir rejoint le Proche-Orient. Après la Libération Canellopoulos fait complètement volte-face sur la question du régime en se prononçant ouvertement pour la Monarchie dont il n'a cessé depuis d'être un ferme soutien. Au total, Canellopoulos est tenu pour un homme attaché aux valeurs démocratiques et l'on a déjà vu qu'en 1958 il s'était provisoirement séparé de Caramanlis dont il n'admettait pas la propension à manipuler le système électoral.

Il est encore trop tôt pour présenter des observations fermes sur la position au sein du parti du nouveau leader qui, en somme, a été accepté par le groupe parlementaire après avoir été choisi par l'ancien leader. On peut cependant relever quelques faits intéressants :

1\% L'élection de P. Canellopoulos s'est faite, en quelque sorte, dans une atmosphère de contrainte psychologique. D'une part, le caractère inattendu du départ de Caramanlis n'a pas permis de réagir aux divers courants qui avaient commencé de se cristalliser à l'intérieur de l'ERE durant la période allant de juin à septembre 1963. D'autre part, l'imminence des élections de février 1964 obligeait le parti à se donner une apparence d'unité aux yeux des électeurs. Cependant, G. Cassimatis, ancien libéral converti à l'ERE, présenta une proposition tendant à la création d'un directoire en vue d'éviter d'élection d'un chef de parti.

$2 \%$ Le principal atout de Canellopoulos en cette conjoncture a été de constituer à plusieurs égards un commun dénominateur. Sa modération et son intégrité de caractère, son ancienneté dans la hiérarchie politique grecque et le fait qu'il ait été auparavant chef de parti et premier ministre, tous ces traits rendaient sa candidature acceptable ou du moins supportable pour les divers «chefs de file » de l'ERE. D'ailleurs, lors de la réunion du groupe parlementaire où l'on procéda à l'élection de Canellopoulos, les discours prononcés par ces « chefs de file » laissèrent l'impression qu'il s’agissait seulement de la désignation d'un Chef de transition due au besoin d'unité du parti.

$3 \%$ Dès juin 1963, un certain nombre de courants ont commencé à se dessiner au sein de l'ERE. Les principaux seraient groupés autour de MM. Rodopoulos, ancien 
président de la Chambre, Pipinelis, ancien premier ministre, Cassimatis, Averof, Papaligouras, anciens ministres.

[p. 252] À en croire d'ailleurs des informations journalistiques, un mouvement pour le retour de $\mathrm{M}$. Caramanlis (KEK) aurait été récemment créé sans que ses membres aient encore pu être identifiés. Dans le climat politique grec d'aujourd'hui, une telle entreprise n'aurait pratiquement pas de chance de succès.

Ces facteurs sont-ils susceptibles de provoquer une révolution de palais qui entraînerait des remaniements dans la direction de l'ERE ? Tel ne semble plus être le cas pour l'immédiat bien que s'affirme la tendance à considérer P. Canellopoulos comme un leader de transition. La large majorité que l'Union du Centre a obtenue aux élections de février 1964 peut, pour le moment, garantir une période de stabilité qui s'étende même aux adversaires politiques de l'Union.

Notons seulement que le Groupe Parlementaire de l'ERE ne fonctionne plus comme à l'époque de Caramanlis. Canellopoulos, dont l'autorité sur les parlementaires de la Droite n'est nullement comparable à celle de Caramanlis, doit tenir compte des courants qui s'y manifestent avant de prendre des positions publiques. Au départ, les durs du parti lui ont reproché de témoigner de mollesse à l'égard du Centre et de son leader Papandréou. Depuis lors, le leader de la Droite, bien plus porté que son prédécesseur à jouer le jeu parlementaire, a sensiblement durci ses positions.

\section{PARLEMENTAIRES INFLUENTS DE LA DROITE}

\section{$\underline{\text { Retour à la table des matières }}$}

L'ERE comportant des éléments très divers, depuis les survivants de vieilles couches traditionnalistes jusqu'aux parlementaires affairistes de l'époque caramanlique, il n'est pas facile d'établir une liste entièrement significative et tout dénombrement de ce type peut prêter à contestation. Voici cependant le nom de quelques députés que l'on peut tenir pour représentatifs de la situation analysée :

On trouve encore dans l'ERE des députés appartenant aux familles des six fusillés de 1922 — c'est-à-dire des ministres exécutés à la suite du désastre d'Asie Mineure exécution dont nous avons déjà mentionné le choc profond et durable qu'elle suscita dans une partie de l'opinion. Ce sont actuellement : $\mathrm{S}$. Théotokis, député de Corfou où il possède une propriété foncière et qui est en relations avec la famille royale ; A. Stratos, député d'Acarnanie qui dispose d'une forte situation [p. 253] locale et sait témoigner de souplesse dans l'action politique ; A. Protopapadakis, député de Naxos où il jouit d'une position bien assise et enfin P. Canellopoulos (neveu de Gounaris, l'un des fusillés) dont nous avons déjà décrit la carrière).

L'ERE comprend aussi des membres ayant participé à la dictature Métaxas : ainsi l'officier en retraite, C. Maniadakis, député de Corinthe et aujourd'hui d'Athènes, 
Ministre de l'Intérieur de Métaxas ; Maniadakis qui, aux dernières élections, a été élu au titre de la liste de l'ERE pour Athènes-Ville est l'un des durs du parti. Signalons aussi le cas de G. Rallis, député d’Athènes : c'est le fils de J. Rallis, nommé Premier Ministre en 1943 sous l'occupation, fondateur des milices et qui devait mourir en prison au lendemain de la Libération. La famille Rallis dispose d'une bonne position locale à Athènes et d'une propriété foncière en Attique.

Nous mentionnerons enfin six personnalités ayant joué un rôle à des titres divers au cours des dernières années : $P$. Pipinelis, diplomate de carrière, député d'Athènes depuis 1963, homme de la Cour qui a une influence certaine dans les coulisses ; P. Papaligouras, député de Corinthe qui manifeste beaucoup d'ambition et a l'appui du monde des affaires ; C. Rodopoulos, député de Larissa qui, ayant présidé la Chambre pendant 10 ans - fonction à laquelle il sut donner du relief — connaît tous les dessous de la politique grecque et tient beaucoup de fils dans ses mains ; E. Averof, député de Janina, qui dispose d'une forte situation locale en Épire et possède des relations d'affaires ; L. Eftaxias, député de Lamia et qui passe pour avoir une fortune immobilière considérable à Athènes ; T. Macris, député de Florina, lieutenant de Caramanlis au Ministère de l'Intérieur qui, très attaqué par l'opposition au titre de diverses affaires, est aujourd'hui en perte de vitesse.

La majorité de ces hommes dispose de fortunes, d'origine plus ou moins ancienne, il est vrai. Beaucoup jouissent de solides positions locales, en province et dans la capitale.

[p. 254]

\section{IDÉOLOGIE ET PROGRAMME}

$\underline{\text { Retour à la table des matières }}$

L'ERE ayant été, dès sa création à 1963, le parti gouvernemental, le plus simple pour illustrer le point considéré est d'exposer les grandes lignes de la déclaration d'investiture des gouvernements Caramanlis de 1958 à 1961. Nous utilisons aussi pour l'établissement de ce tableau le programme présenté par l'ERE lors de la campagne pour les élections de février 1964.

Au titre de la politique étrangère, le fondement de la politique de l'ERE a toujours été la fidélité envers le « pacte défensif de l'alliance atlantique ». Tout en se déclarant favorable à un désarmement général contrôlé, le parti a combattu l'idée de la création de zones dénucléarisées.

À l'égard des relations entre la Grèce et les pays du bloc oriental, l'ERE manifestait le désir d'en effectuer la normalisation mais rejetait sur ces pays et sur leur manque de compréhension à l'égard de la Grèce l'échec d'un tel projet. Ainsi s'expliquait, selon le parti, l'impossibilité d'arriver à un règlement du contentieux existant avec la Bulgarie et l'Albanie (la Grèce était toujours juridiquement en état de belligérance avec cette dernière). 
Les dirigeants de l'ERE se sont toujours déclarés favorables à l'amélioration des rapports avec la Yougoslavie et la Turquie, ainsi qu'à la continuation de la traditionnelle politique d'amitié avec les pays arabes — politique assez inconsistante d'ailleurs et n'ayant pas produit de résultats très substantiels (retard mis à signer avec l’Égypte un accord commercial).

Sur le plan militaire, l'ERE préconisait d'effectuer les dépenses nécessaires à la sécurité du pays, ces dépenses ne devant toutefois pas être augmentées. En vue de diminuer la charge résultant de cette politique, l'ERE demandait le maintien de l'aide militaire étrangère et la création d'une caisse de soutien des pays de l'OTAN (caisse alimentée par les pays les plus riches de la coalition au bénéfice des plus démunis).

Dans le domaine économique, voici les têtes de chapitre du programme de l'ERE qui, ne l'oublions pas, a été celui du gouvernement grec durant plus de 7 ans : stabilité monétaire ; augmentation des investissements dans le domaine de l'infrastructure; reconversion de l'activité agricole en vue d'augmenter la quantité de produits expor[p. 255] tables ; octroi d'un soutien au développement industriel et à la modernisation des structures existantes, l'un des objectifs étant ici aussi de promouvoir l'exportation; maintien du niveau d'imposition fiscale en vue de faire face à l'accroissement des investissements ; stabilisation des salaires dans le secteur public ; octroi d'une priorité absolue dans le domaine du crédit aux branches d'activités agricoles et industrielles axées sur l'exportation; continuation des efforts tendant à assurer la venue de capitaux étrangers en Grèce.

Sous l'angle social, le programme de l'ERE portait sur l'augmentation de l'emploi, l'organisation de la sécurité sociale, une rationalisation de la gestion des crédits consacrés au domaine social. Dans le secteur de l'éducation enfin, l'ERE préconisait, d'une part l'extension des facilités offertes en matière d'instruction technique et professionnelle, d'autre part le rattrapage, à l'aide et dans le cadre d'un plan pluriannuel, des retards existant au titre des divers ordres de l'enseignement.

Les dirigeants de l'ERE se recommandent volontiers de l'économie de marché. Ils insistent sur les avantages de la liberté d'entreprise et de la concurrence. En réalité, le système en vigueur consistait à mettre au compte de l'État une part aussi large que possible des dépenses de tous ordres nécessités par le développement et à laisser à des personnes privées la totalité des profits réalisés sur ces bases. Encore qu'un tel système ait toujours caractérisé la croissance capitaliste, la Grèce offre un exemple accompli de l'enrichissement particulier par le truchement de contributions publiques. On peut définir ce système en peu de mots en disant qu'il repose sur des circuits qui vont de l'État dispensateur d'avantages de tous ordres (attribution de privilèges fiscaux, octroi de subventions, distribution de crédits... sans oublier le combat contre les revendications ouvrières) aux propriétaires et chefs d'entreprises bénéficiaires de tous les profits obtenus.

Nous aurons l'occasion de faire un peu plus loin le bilan des efforts accomplis et des résultats obtenus par les quatre gouvernements Caramanlis dans ces divers domaines, spécialement dans l'ordre économique. Disons cependant que la caractéristique d'un tel programme est, spécialement pour les problèmes de la 
croissance industrielle, sa profonde médiocrité intellectuelle et sa totale inadaptation à la situation de la Grèce contemporaine. Sous réserve de quelques efforts de planification, d'ailleurs plus apparents que réels, les dirigeants de l'ERE ne se sont pas suffisamment souciés d'établir un inventaire systématique [p. 256] des problèmes à résoudre, de dresser un état complet des options en présence et d'effectuer des choix cohérents en fonction des perspectives à moyen et long termes.

Au surplus, l'ERE a été liée en plusieurs domaines par les exigences américaines, les États-Unis s'opposant à l'extension des cultures susceptibles de les gêner sur le plan international (tabac, huile d'olive, raisins secs...). D'où l'implantation de nouvelles monocultures (agrumes) ne répondant pas toujours, vu l'état des marchés, aux intérêts grecs.

Le programme retenu par l'ERE, au gouvernement d'abord et dans l'opposition ensuite, donne sur plusieurs points l'impression d'un catalogue de mesures établi «à la petite semaine » et dans un esprit de facilité. Un tel programme pouvait certes valoir à la Grèce certaines réussites superficielles, mais il n'apportait aucune réponse de fond aux retards techniques dont souffre le pays.

Pour achever de caractériser l'idéologie de l'ERE, nous mentionnerons le dépôt, en date du 21 février 1963, et sous la signature de tous les membres du Cabinet, d'une motion tendant à la révision de la Constitution. Ce projet qui n'eut pas de suite, en raison du départ de Caramanlis et de la défaite électorale de l'ERE, contenait vingt deux points qui mettaient en cause, parfois de manière profonde, le fonctionnement habituel des institutions. Il ne sera pas inutile d'esquisser en quelques mots, d'après l'exposé des motifs, l'inspiration principale de ce document. Tout en donnant une interprétation libre et non une traduction littérale, nous nous efforcerons de rendre fidèlement l'esprit de ce projet.

Le Cabinet Caramanlis partait en somme de l'idée que le franchissement rapide des étapes allant du sous-développement au développement normal constitue dans un régime politique démocratique une sorte de tour de force. La démocratie peut fonctionner aisément dans les pays très développés et par ailleurs les régimes nondémocratiques sont susceptibles d'obtenir une croissance rapide. Toutes les difficultés viennent de la volonté de combiner le respect de la démocratie et le souci d'une croissance accélérée. Parmi les inconvénients d'une telle combinaison, on peut mentionner la propension des divers groupes sociaux à exiger l'octroi d'avantages immédiats qui ne sont pas compatibles avec les nécessités de la situation.

[p. 257] De portée universelle, ces difficultés sont encore aggravées dans le cas de la Grèce par plusieurs facteurs. D'abord, la présence d'une grave menace communiste dans l'ordre interne, la preuve de ce danger se trouvant dans les diverses tentatives déjà effectuées par les communistes pour se saisir du pouvoir par la force. En second lieu, le fait que la Grèce est située, aux frontières du bloc de l'Est et se trouve soumise à un danger d'invasion. Enfin la psychologie du peuple grec et son manque de culture politique qui le conduisent à abuser des facultés ouvertes aux citoyens par la 
démocratie. Celle-ci suppose pour fonctionner correctement un sens de la mesure qui fait défaut au pays.

Ainsi s'explique qu'en bien des occasions le régime parlementaire grec fonctionne comme un frein à la croissance économique. Ce régime ouvre la porte à toutes les forces démagogiques dont l'action est de plus en plus pernicieuse. Sous couleur de préoccupation sociale, on aboutit à des abus de droits qui sont la négation, de la vraie démocratie. La Grèce tend ainsi à vivre sous une démocratie de minorités organisées ou de clans dans laquelle les groupes les mieux organisés ou les plus bruyants finissent par l'emporter sur tous les autres.

Il ne saurait y avoir d'autre remède de fond à une telle situation que le réajustement des normes constitutionnelles aux exigences politiques et sociales de l'heure. Un tel réajustement est à la fois impératif et urgent. Sans entrer dans le détail des mesures proposées, on peut dire que l'ensemble de celles-ci était d'inspiration nettement autoritaire. Qu'il s'agisse du régime de la fonction publique, de la réglementation de la presse, de l'activité des partis, des méthodes de travail parlementaire et des facultés de légiférer ouvertes à l’Exécutif, de l'organisation judiciaire ... toutes ces mesures tendaient finalement à restreindre les droits des citoyens et les compétences de leurs représentants directs.

On peut se demander si en présentant un tel projet l'ERE ne suivait pas tout simplement le chemin habituel des formations, qui, sentant leur audience s'affaiblir dans le pays, tentent de compenser leurs pertes d'autorité ou de prestige, par un renforcement, des prérogatives légales à leur disposition. Ce projet suscita en tout cas de très vives oppositions au sein de l'opposition qui le dénonça, comme une attaque contre la souveraineté du peuple et les libertés politiques. L'EDA parla à ce propos de « révision d'esprit hitlérien », mais l'Union du Centre, quoique plus modérée dans les termes, ne fut pas moins ardente dans son atta-[p. 258] que du projet. Tenant pour illégal le Parlement élu en 1961, le Centre déclarait que le seul problème à soumettre au peuple n'était pas l'opportunité d'une révision constitutionnelle mais l'appréciation du précédent coup d'État électoral. En somme, le projet ainsi combattu par l'opposition ne pouvait manquer d'aggraver la crise politique qui en ce début de 1963 avait déjà atteint un niveau élevé. 


\section{STRATÉGIE ET TACTIQUE}

Retour à la table des matières

Le trait fondamental de la situation est que l'ERE, parti gouvernemental dès sa formation, a tout mis en œuvre pour conserver le bénéfice de cette situation. Tout parti au pouvoir tend à agir ainsi en quelque mesure. Mais l'Union Nationale Radicale a utilisé les avantages résultant de l'occupation des centres gouvernementaux avec une rigueur exceptionnelle et un appétit quasiment insatiable. Il en est résulté une très grave crise politique qui a finalement abouti au départ de C. Caramanlis et à la défaite de son parti ${ }^{1}$.

\section{A. PRATIQUES DE L'ERE}

$\underline{\text { Retour à la table des matières }}$

Dès le début de la deuxième partie de cet ouvrage, nous avons signalé l'osmose réalisée par l'ERE entre le parti et l'État, osmose jouant dans le sens d'une emprise des chefs du parti sur l'appareil étatique. L'Union Radicale utilisant à fond le système des dépouilles a profité de son long séjour au pouvoir pour épurer cet appareil, non seulement [p. 259] de tous les éléments liés à la Gauche mais aussi de ceux témoignant de velléités d'opposition vis-à-vis du régime caramanlique. Valable pour l'administration publique proprement dite ainsi que pour les forces de l'ordre (armée, police, gendarmerie), l’observation couvre aussi le secteur des exploitations publiques et semi-publiques (Banques d'État et Crédit agricole, chemins de fer, électricité, télécommunications...). Cette situation a procuré à l'ERE trois séries d'avantages.

Le premier, que nous avons déjà mentionné, est celui du patronage — patronage facilité par le fait que grâce aux aides venues de l'étranger, Caramanlis disposait de

1 Nous entendons laisser hors du débat le problème de l'honnêteté personnelle de l'ancien Premier Ministre que ses partisans ont toujours dépeint comme un homme d'une intégrité exceptionnelle. De très graves accusations ont été portées contre lui par l'EDA et plusieurs groupes du Centre - en particulier celle pratiquement classique d'avoir de l'argent en Suisse - mais, comme c'est presque toujours le cas, en de pareils domaines, il s'agit d'imputations sans preuves positives. Notons seulement que le 16 juin 1964, l'un des leaders de l'EDA, S. Eliopoulos, a formellement accusé à la Tribune du Parlement C. Caramanlis d'avoir acheté, au nom des membres de sa famille et de quelques-uns de ses amis, plusieurs grands terrains, des villas, des blocs d'appartements... Selon l'orateur, Caramanlis se serait rendu coupable de bien d'autres spéculations. L'EDA a demandé la formation d'une Commission d'enquête qui a été refusée par le Premier Ministre — celui-ci étant en faveur d'un système général de contrôle dont nous parlerons plus loin. N'ayant pas eu la faculté de consulter le dossier en question, nous croyons opportun de suspendre jusqu'à plus ample information la présentation d'un avis formel en cette matière. Mentionnons aussi le reproche fait à la Banque Nationale de Grèce d'avoir consenti au frère de Caramanlis un crédit disproportionné à la garantie offerte. 
ressources relativement importantes. Cet accroissement de la manne a permis de faire du Trésor Public un instrument d'enrichissement des clientèles, les clientèles des politiciens individuels tendant à se fondre, par suite de la centralisation du patronage, en une vaste clientèle du parti gouvernemental et de son chef. À une échelle plus modeste, n'oublions pas les multiples facultés d'influence qu'a values au gouvernement la distribution aux paysans de crédits agricoles et même de subsides en espèces (les uns et les autres nécessaires aux intéressés pour faire face aux besoins quotidiens).

Mentionnons aussi, dans un domaine différent, l'appui matériel apporté sous des formes diverses aux organes de la presse, plusieurs de ceux-ci étant souvent dans l'incapacité de couvrir les charges de l'exploitation avec leurs propres ressources. Le souci de conserver un tel appui (en particulier la réception des fonds au titre de la publicité des entreprises publiques) n'est probablement pas étranger à la docilité de nombreux quotidiens à l'égard des directives ou suggestions gouvernementales. Parmi les autres faveurs accordées aux quotidiens gouvernementaux, mentionnons la diffusion de certains d'entre eux parmi les ouvriers grecs en Allemagne (Hellénicos Vorras), le coût de l'opération étant supporté par les finances publiques. On ne saurait non plus méconnaître les avantages tirés de la distribution des fonds secrets. Si l'on en croit les premières enquêtes faites à ce sujet par l'Union du Centre, il semble bien que le montant des sommes attribuées à ce titre aient pris en plusieurs Ministères des proportions anormales.

La deuxième série de facilités ouvertes à l'ERE par l'occupation de l'appareil gouvernemental est relative au financement des activités partisanes. Les statuts de l'ERE ne comportent pas de mention spéciale quant au mode de financement du parti. Ils se bornent à traiter de manière indirecte des cotisations des membres et de la gestion de la [p. 260] fortune du parti. Encore que toute information fasse entièrement défaut en ce domaine, une chose est certaine : l'ERE a dû disposer de sommes importantes, aussi bien pour ses campagnes électorales que pour ses frais de propagande générale. Elle en a obtenu une partie en obligeant ses candidats à couvrir sur leurs propres ressources et, en tout cas, par leurs propres moyens, une fraction aussi large que possible des frais entraînés par les campagnes électorales.

L'occupation du pouvoir par l'ERE pendant près de 8 ans lui a au surplus facilité le rassemblement des ressources financières indispensables. D'une part, l'utilisation systématique de la machine étatique pour les tâches de secrétariat lui a valu de nombreuses ressources en services et a dès lors sensiblement réduit l'ampleur des sommes nécessaires. D'autre part, l’ERE a bénéficié, sans aucun doute, de donations et de souscriptions considérables. C'est là le mode de financement de tous les partis grecs, mais l'ERE avait de ce point de vue deux avantages particuliers : la possession dans sa clientèle électorale des groupes les plus aisés du pays; l'occupation des centres publics de décision, ce qui lui permettait de donner de substantielles contreparties à ses commanditaires.

La troisième série d'avantages a consisté dans l'utilisation directe d'un certain nombre d'organes et de services étatiques contre les activités de l'opposition. C'est 
ainsi qu'au temps du gouvernement de l'ERE, les corps de sécurité, sous prétexte de lutte contre le communisme, avaient été pratiquement transformés en une sorte de garde prétorienne du parti gouvernemental. De tous les dangers que comportait une telle situation, le moins grave n'était certes pas le sentiment d'impunité qui s'emparait de nombreux membres de la police et les poussait à se conduire de manière brutale et grossière, sinon même illégale, vis-à-vis des citoyens. L'octroi à de simples exécutants d'une autorité pratiquement incontrôlée ne peut manquer d'engendrer l'oppression.

L'armée elle-même n'a pas échappé à ce mouvement. Mentionnons à ce propos l'action des Bataillons de Sécurité Nationale (TEA) — bataillons paramilitaires organisés au niveau des villages par des officiers spécialement entraînés à la propagande anti-communiste. Ces officiers ne manquaient pas également de vanter l’œuvre accomplie par le parti au pouvoir. Les bataillons de sécurité réalisaient en somme un travail d'encadrement et de surveillance propre à renforcer l'obéissance au gouvernement.

[p. 261] Signalons aussi l'activité des services d'information et d'espionnage, en particulier celle de l'Agence Centrale de Renseignements (KYP) dont on trouve les agents sur tout le territoire. Ces services ainsi que divers éléments de l'Armée et des corps de sécurité étaient en rapports avec plusieurs des groupements d'extrême-droite sur l'activité desquels nous reviendrons si l'on en croit les déclarations que fit à l'époque G. Papandréou, un certain nombre de ces groupes qui tendaient à prendre le statut d'organe para-étatique, auraient vu le jour dans les bureaux mêmes du Premier Ministre et, à la suite d'enquêtes récentes, on peut admettre en tout cas que ces organisations ont reçu des appuis financiers en provenance de fonds secrets.

On aurait tort de faire de ces organisations l'unique instrument de base de la puissance de l'ERE dans le pays. Il est fréquent par ailleurs que les polices secrètes manquent de l'efficacité qu'on leur prête volontiers, ne serait-ce que parce qu'elles se gênent mutuellement. Pourtant, au vu des abus et excès de tous ordres de la campagne électorale de 1961, il n'est pas possible de passer sous silence l'activité de ces groupes comme facteur de dégradation du climat démocratique - dégradation qui, nous l'avons vu, s'accentua au lendemain de la consultation électorale de 1958.

Il est vrai que l'abus des avantages ainsi évoqués va susciter une grave crise politique et entraîner un combat de plus en plus violent contre la Droite. Il nous faut maintenant exposer brièvement les modalités de cette lutte. 


\section{B. LA DROITE FACE À L'OFFENSIVE DE L'OPPOSITION}

Retour à la table des matières

L'origine de cette lutte remonte aux élections du 29 octobre 1961, à l'occasion desquelles l'ERE fut accusée d'avoir commis un coup d'État électoral. Il s'ensuivit une réaction profonde de la part de l'opposition, l'EDA certes mais aussi désormais l'Union du Centre. Dans ce combat, l'opposition n'hésita pas à employer tous les moyens qui lui étaient accessibles :

$1 \%$ Lutte sociale, avec pour principaux acteurs les paysans, les ouvriers du bâtiment, les étudiants, le corps enseignant. De nombreux heurts avec la police firent quelques morts et des dizaines de blessés. Mention spéciale doit être faite des démêlés du gouvernement avec les [p. 262] étudiants de l'Université d'Athènes : contre toutes les traditions, la police envahit les locaux de l’Université dont le Cabinet décréta la fermeture pour un mois (avril-mai 1962).

Au même moment, un procès est livré au mouvement de jeunesse de l'Union du Centre qui avait dénoncé les abus électoraux de 1961 : le mouvement est d'ailleurs acquitté. Signalons aussi la campagne des étudiants et lycéens - campagne lancée initialement sans liaison avec les partis d'opposition — pour que l'État consacre à l'éducation $15 \%$ du budget.

$2 \%$ Campagnes de presse contre le gouvernement et dénonciation de fautes ou carences de celui-ci à la tribune du Parlement. C'est ainsi que le gouvernement fut accusé avec beaucoup de violence et de brutalité de s'être laissé circonvenir par ses alliés lors de la signature des accords de Zurich qui signifiaient, au moins pour l'immédiat, la fin de tout espoir d'Union de Chypre avec la Grèce ; d'avoir créé, ou laissé se créer, des organisations paramilitaires ; de porter la responsabilité d'énormes scandales financiers dans l'ordre de certains travaux publics (Mont-Parnasse, Place Omonia, etc. ...) ; d'avoir livré le pays au capital étranger par la signature de conventions de type colonial telles que celles conclues avec Tom Papas-Esso, Péchiney, etc. ... ; d'avoir favorisé le grand capital grec aux dépens de l'intérêt public, comme lors des affaires des chantiers navals de Scaramangas et de la raffinerie d'Aspropirgos (Niarchos), de la Banque Commerciale (Andréadis), de l'Olympie Airways (Onassis), etc. ... ; d'avoir utilisé la milice (TEA) pour brimer l'opposition dans les campagnes; de compter parmi les ministres certaines personnes ayant collaboré avec l'ennemi pendant l'occupation (affaire Merten, affaire très importante, sur laquelle nous reviendrons); de puiser dans les fonds secrets de l'État pour l'accomplissement de buts, partisans ; d'avoir corrompu et noyauté l'administration publique, l'armée, etc. ... Nous avons déjà rencontré plusieurs de ces accusations et en examinerons quelques autres de manière détaillée en de prochains chapitres. 
$3 \%$ Dépôt de motions de censure successives au Parlement qui, sans permettre à l'opposition de renverser le gouvernement, lui donnaient la faculté de revenir sur ces accusations et, de la sorte, d'en saisir à nouveau la presse. Mentionnons par exemple la production de photostats de notes par lesquelles le Président de la Chambre, ainsi que divers [p. 263] Ministres demandaient au Directeur compétent du Ministère des Finances d'accorder un traitement fiscal de faveur au profit d'industriels amis du parti.

4\% Pression sur le Palais ; le chef de la majorité de l’opposition, G. Papandréou, déclarait tenir le Roi Paul pour responsable du «maintien illégal au pouvoir de C. Caramanlis » et avait rompu toute relation avec le Palais (y compris au titre des relations protocolaires et lors de manifestations officielles ou fêtes nationales). C'est ainsi que le 19 mars 1963, Papandréou écrivit au Roi pour l'informer de sa volonté de ne pas prendre part à la célébration du Centenaire de la Monarchie. En cette conjoncture d'ailleurs, un autre leader du Centre, S. Vénizélos, montrera bien plus de souplesse à l'égard de la Couronne. Au surplus, l'Union du Centre, tout en critiquant la Monarchie, déclarait attendre du Souverain une initiative pour sortir le pays de l'impasse politique.

5\% Mobilisation de l'opinion internationale — surtout du fait de l'EDA — avec la campagne pour la libération des prisonniers politiques (affaire de Glézos et d'Ambatiélos, marche de la paix à Marathon, etc. ...).

C'est dans ce climat déjà très tendu que survient l'affaire Lambrakis. L'émotion dans le pays, nous l'avons dit, est considérable. Peu après intervient la démission de Caramanlis : si l'on replace ce départ dans un tel contexte, l'idée devient plausible qu'il fut le résultat dune initiative du souverain tendant à dissocier la Couronne de la vague de boue que l'opposition faisait déferler chaque jour sur l'ERE et son leader.

Une fois Caramanlis hors du pouvoir, il semble que le Palais ait songé à former un gouvernement d'orientation centre-droit ayant pour base les éléments modérés de l'ERE et les députés de l'Union du Centre. Mais pour que ce gouvernement dispose d'une majorité suffisante, il fallait détacher de l'Union Radicale une cinquantaine de parlementaires. Peu de personnalités étaient capables de réaliser cette opération délicate à laquelle d'ailleurs, selon des informations qui paraissent sûres, les services américains devaient opposer leur veto. Ceux-ci n'étaient plus décidés à se battre pour assurer la conservation du pouvoir à Caramanlis, mais il leur répugnait que l'ERE, qui avait fait ses preuves dans la lutte contre le communisme, connaisse la désagrégation. Ainsi s'explique la mauvaise humeur dont témoignaient à l'égard des Américains durant [p. 264] l'été 1963 ceux des leaders du Centre qui n'auraient pas été défavorables à une opération Centre-Droit.

Après l'échec de ce projet - le Palais ayant paru songer successivement à $\mathrm{P}$. Canellopoulos et S. Markézinis pour le réaliser — le Souverain semble se rallier à l'idée d'un gouvernement de service mais il compose celui-ci d'une manière qui lui donne une couleur politique. C'est le cabinet Pipinelis que la Gauche présentera immédiatement comme un ersatz du gouvernement de l'ERE. Ce jugement n'est pas sans fondement. Pipinelis, alors âgé de 64 ans, passe pour être l'un de hommes qui ont facilité l'arrivée de Caramanlis au pouvoir. De tendances particulièrement 
conservatrices et très favorable au pouvoir royal, il a été battu aux élections de 1958 et 1961 (les forces de l'ordre lui ayant pourtant donné leur concours lors de cette dernière consultation). Cependant Caramanlis le prend comme Ministre nonparlementaire du Commerce dans le Cabinet qu'il forme après les élections de 1961. Lors de sa présentation au Parlement, Pipinelis qui reste en rapports étroits avec des hommes de la Cour (Choidas, Conseiller politique du Roi, Potamianos...) n'obtient que les voix de l'ERE.

La situation grecque est alors particulièrement trouble. Markézinis qui, dans la Chambre élue en 1961, a choisi de jouer le rôle d'une Opposition de Sa Majesté, est très déçu de n'avoir pas été retenu par le Souverain pour constituer le Cabinet. Une partie de l'opposition redoute que le Cabinet Pipinelis n'effectue, avec le concours de l'armée et de la police, la réédition de la consultation de 1961. En d'autres milieux, on déclare craindre le déclenchement d'un coup d'État militaire. Finalement, ces alarmes se révèleront vaines et il sera possible d'organiser le 3 novembre 1963, dans des conditions déjà analysées, la consultation qui aboutira à transférer le pouvoir à l’Union du Centre.

Le passage d'un parti à l'autre a donc pu se réaliser, mais au lieu de s'accomplir de manière ordonnée et dans un climat de clarté démocratique, ce changement prendra place à travers une atmosphère de peur, de suspicion, de complot. Rien ne saurait mieux illustrer le fait que, durant son long séjour au gouvernement, la Droite n'est pas parvenue, mais l'a-t-elle cherché, à instaurer un régime d'inspiration véritablement parlementaire.

[p. 265]

\section{DIMENSIONS DU PARTI}

$\underline{\text { Retour à la table des matières }}$

S'agissant de l'ERE, nous ne pouvons faire état, comme d'ailleurs pour tous les autres partis grecs que des résultats électoraux. La structure de ce parti, fondée au plan local sur des comités politiques et non sur des sections composées d'adhérents, rend d'une part très difficile la distinction entre adhérents et sympathisants, d'autre part presque impossible l'évaluation, même approximative, de leur nombre. Sociologiquement, la caractéristique de l'ERE sous Caramanlis était de mobiliser les couches traditionnellement conservatrices du pays à l'aide d'un réseau d'hommes ou d'un ensemble de groupes dont les tendances ne concordaient guère avec celles du parlementarisme habituel (hommes d'affaires enrichis ou s'enrichissant grâce aux spéculations du régime, officiers anti-communistes procédant à la mobilisation du vote paysan...). Nous ne sommes pas en mesure d'indiquer les changements que la nouvelle direction est désireuse ou capable d'apporter à ces pratiques. Voici les résultats électoraux du parti depuis sa création : 


\begin{tabular}{|c|c|c|c|c|}
\hline \multirow{2}{*}{ Élections } & \multicolumn{2}{|c|}{ Nombre } & \multicolumn{2}{|c|}{ Pourcentage } \\
\hline & Voix & Sièges & Voix & Sièges \\
\hline 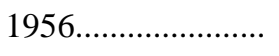 & 1.594 .112 & 165 & 47,38 & 55 \\
\hline $1958 \ldots \ldots \ldots \ldots \ldots$ & 1.583 .885 & 171 & 41,16 & 57 \\
\hline $1961 \ldots \ldots$ & 2.347 .541 & 176 & 50,80 & 58,6 \\
\hline 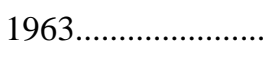 & 1.837.377 & 132 & 39,37 & 44 \\
\hline 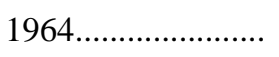 & $(1.576 .550)$ & 105 & 35,00 & 34 \\
\hline
\end{tabular}

Ces résultats ont été obtenus par l'ERE seule, à l'exception toutefois de ceux acquis aux élections de 1964 pour lesquelles l'Union Radicale a formé une coalition avec le Parti progressiste. Or les résultats acquis en cette occasion sont, en chiffres absolus, un peu inférieurs à ceux obtenus aux élections de 1956, c'est-à-dire au lendemain de la fondation du parti. Mais, par suite de l'augmentation du nombre des électeurs ayant voté, la diminution en pourcentage des voix est beaucoup plus sensible. En fait, l’ERE a connu une défaite politique importante.

[p. 266] On peut se demander laquelle des deux consultations de 1963 ou 1964 traduit le mieux la force électorale actuelle de l'ERE. Selon une conception, les chiffres de 1963 seraient plus représentatifs que ceux de 1964 de la puissance de l'ERE, la volonté de donner toute sa chance à une majorité centriste ayant pu, lors de la seconde consultation, pousser des électeurs de droite à attribuer leurs suffrages à l'Union du Centre. D'autres estiment, au contraire, que les élections de 1963, bien que tenues dans un climat de liberté, auraient encore été influencées par les séquelles des pressions et des intimidations anciennes : beaucoup d'électeurs, spécialement dans les campagnes, ne savaient pas en 1963 que l'on pouvait sans risque social cesser de voter pour l'ERE. Les résultats de 1963 ayant prouvé que l'ERE était susceptible d'être battue, ces électeurs auraient retrouvé en 1964 leur libre arbitre et, en conséquence, abandonné la Droite.

Du point de vue théorique, l'une et l'autre de ces positions sont soutenables mais, faute de sondages d'opinion publique et d'études de sociologie électorale, il n'est pas possible de dire lequel de ces deux mouvements a joué ou, les deux étant probablement intervenus, lequel des deux a eu l'influence la plus forte.

La consultation des trois cartes relatives à l'ERE dans l'appendice cartographique montre clairement l'effritement des positions de ce parti d'une élection à l'autre. L'ERE qui, en 1961, détenait la majorité absolue dans 31 circonscriptions sur 55 a beaucoup perdu de sa force en 1964. Il faut pourtant noter que, dans la grande majorité des départements elle est demeurée au-dessus de $30 \%$.

L'ERE bénéficie d'un certain nombre de fiefs électoraux dans le pays. Ce sont en particulier : les circonscriptions d'Arcadie, de Corinthe, de Laconie et de Messénie dans le Péloponnèse ; la circonscription insulaire des Cyclades ; les circonscriptions de Chalcidique, Castoria et Florina en Macédoine ; la circonscription d'Arta en Epire. 
Les circonscriptions d'Athènes-Ville et du Pirée-Ville lui donnent des pourcentages relativement importants et stables.

En termes de motivation électorale, la prédominance de l'ERE dans le Péloponnèse (spécialement au Sud-Est) ainsi que dans les Cyclades s'explique en une large mesure par des raisons historiques, ces régions faisant partie de la «Vieille Grèce » qui a toujours montré une propension à voter pour la Droite. Le point nouveau dans la sociologie électorale de la Droite sous l'ERE est la conquête d'importantes positions [p. 267] dans la Grèce du Nord jadis fief solide des Libéraux (supra, action des réfugiés). Mentionnons en particulier le poids d'Averof dans l'Épire et celui de Rodopoulos dans la Thessalie. Cette transformation s'explique peut-être par l'origine macédonienne de Caramanlis, mais elle a découlé en une large mesure de l'implantation dans ces régions d'un large dispositif militaire (propension conservatrice du corps des officiers).

Au total, les trois cartes relatives à l'ERE confirment bien que la Droite Grecque, dont ce parti constitue l'un des modes d'organisation successifs, dispose dans le pays d'une puissante base sociale. Cette constatation ne doit certes pas conduire à oublier et sous-estimer les fraudes et jongleries électorales dont l'Union Nationale Radicale s'est en diverses occasions rendue coupable pour conserver le pouvoir. On ne peut non plus ignorer la pesante pression psychologique exercée par l'ERE sur les électeurs grecs avec le concours des forces de l'ordre - pression culminant avec le slogan électoral que quiconque ne votait pas pour l'ERE n'était pas grec. Cependant tous ces artifices et toutes ces manipulations n'auraient eu qu'une faible portée si le parti n'avait disposé de points d'appui sur le terrain. En Grèce, il existe une forte Droite qui a été dilatée certes, mais non créée par les interventions caramanliques.

Cette droite est pour partie d'origine historique. Elle correspond, de manière d'ailleurs classique, à une structure socio-professionnelle encore peu marquée par la révolution industrielle. Le maintien à la terre d'une large population paysanne est le garant de sa permanence et de sa solidité en plusieurs régions du pays. À plus long terme pourtant, ses chances dépendent de la capacité qu'elle montrera d'absorber les couches nouvelles issues de la modernisation économique. Sans entrer à fond dans la discussion, nous devons examiner en terminant si les politiques suivies et les résultats acquis par l'ERE durant son long séjour au gouvernement sont de nature à séduire ces couches. 
[p. 268]

\section{V. ÉVALUATION D'ENSEMBLE}

Retour à la table des matières

L'un des arguments essentiels de la propagande de l'ERE était que ce parti assurait à la Grèce la stabilité gouvernementale. Il. suffit de considérer le nombre des gouvernements successifs entre 1946 et 1952 pour comprendre la valeur d'une telle situation auprès de larges secteurs du public et aussi des gouvernements alliés (spécialement du gouvernement américain). Mais ces louanges contrastaient avec les attaques de plus en plus vives de l'opposition qui tendaient à voir dans cette stabilité le résultat de méthodes autoritaires ou de tendances fascisantes du gouvernement au pouvoir. En d'autres termes, - et la contradiction s'accusa sans cesse davantage à partir de 1960 - la stabilité de l'Exécutif avait pour contrepartie une absence de sécurité politique. D'apparence solide, le gouvernement était miné par une crise profonde dont on a pu craindre un moment que le régime parlementaire ne fit les frais.

Nous avons déjà analysé en détails les étapes et les mécanismes de cette crise. L'ERE se flattait d'assurer au pays le bénéfice d'un régime démocratique et, lors de l'essai de lancement d'une procédure de révision en février 1963, ses porte-parole allaient jusqu'à dire et écrire que les partis et les citoyens tendaient à abuser des privilèges démocratiques. Pourtant, l'ingérence du corps de sécurité dans le jeu politique et la vie des citoyens étaient bien trop denses et graves pour qu'il soit légitime de présenter la Grèce de cette époque comme une démocratie. Si l'expression "démocratie policière » ne contenait pas une contradiction dans les termes, c'est probablement celle qui conviendrait le mieux pour caractériser plusieurs époques du gouvernement de la droite depuis 1946. Cette expression implique en effet que les libertés de base ne sont pas supprimées et que l'on peut se servir de certaines d'entre elles (tribune du Parlement par exemple) mais elle signifie qu'en raison de leur omniprésence et parfois de leur omnipotence, les corps de sécurité finissent par annuler une large partie de ces libertés.

Un autre aspect de cette crise est l'atmosphère générale de corruption qui régnait en Grèce sous le régime de l'ERE. Ce n'était certes pas là une nouveauté mais le poids des habitudes anciennes était aggravé, si l'on peut ainsi dire, par la multiplication des occasions et des tentations. L'époque caramanlique est marquée par une croissance économi-[p. 269] que qui repose notamment sur l'accomplissement de grands travaux publics et le développement de la construction immobilière. Chacun sait que de telles situations sont particulièrement favorables à la réalisation de combinaisons de tous ordres entre les autorités politico-administratives et les milieux d'affaires. De cette pénétration du secteur gouvernemental par l'affairisme - un affairisme assez souvent louche et de bas étage - la France du second Empire et, bien plus près de nous, l'Italie du miracle offrent des exemples bien connus. La Grèce 
n'a pas manqué à la tradition et l'on ne saurait dire que les dirigeants de l'ERE aient pris, ou envisagé de prendre, des mesures quelconques pour endiguer le courant corrupteur.

La politique étrangère de l'ERE n'était certes pas de nature à rehausser le tableau sauf aux yeux de milieux si apeurés par la menace du «troisième round » communiste qu'ils en sont prêts à accepter inconditionnellement toutes les servitudes de l'atlantisme — terme que nous utilisons ici pour désigner le mécanisme d'instauration par l'Amérique d'un protectorat de fait sur ses alliés. Durant la période étudiée, la Grèce a fidèlement accompli ses obligations de membre de l'OTAN consacrant aux activités de défense une large part de ses ressources budgétaires. Or cette docilité ne lui a valu aucune contre-partie quant au règlement de ses problèmes spécifiques. Il suffit d'évoquer à ce propos la capitulation imposée à la politique grecque dans la question chypriote.

Les défenseurs de la politique caramanlique en ce domaine indiquent que le sacrifice accompli par les Grecs était justifié par la nécessité de conserver à tout prix le maintien de l'aide et de la protection américaines. Certains ajoutent même que la signature des accords de Zurich et de Londres (février 1959) a constitué une étape utile, voire indispensable, sur la route de l'Enosis. Jusqu’à présent, il ne semble pas que la création d'une République indépendante de Chypre — avec attribution à la minorité turque de facultés gouvernementales étendues et sans aucun rapport avec son importance propre - ait beaucoup contribué à rapprocher l'union de l'île avec la Grèce. En réalité, Caramanlis ne pouvait s'opposer en la circonstance à la pression des États-Unis soucieux de donner satisfaction à la Turquie, tenue pour le bastion oriental de l'OTAN.

Ce n'est certes pas l'ERE qui porte la responsabilité initiale de la main-mise américaine sur la politique grecque, celle-ci datant de la [p. 270] proclamation de la Doctrine Truman et ayant trouvé son facteur de consolidation dans le déroulement de la guerre civile. Toutefois, le parti n'a rien fait pour atténuer cette dépendance qui, en certaines occasions, est allée jusqu'à la servilité. Rappelons que Caramanlis fut le seul chef de gouvernement du bloc occidental à féliciter publiquement le président Kennedy après l'équipée de la baie des Cochons. Notons aussi l'adoption, sur la pression des autorités américaines, de mesures tendant à imposer aux armateurs grecs le respect du blocus de Cuba et ceci à un moment où la crise de l'armement maritime avait pour conséquence l'augmentation du nombre des marins grecs au chômage.

Reste le domaine économique auquel nous consacrerons un développement spécial dans la suite de ce livre. Pour résumer ici la situation en peu de mots, il suffira de dire que des résultats ont certainement été acquis dans l'ordre de la croissance mais qu'ils l'ont été d'une manière qui aggrave sensiblement la dépendance du pays vis-àvis de l'étranger et spécialement du grand capitalisme international. En raison des influences qui pèsent sur elle et des intérêts dont elle assume la protection, on ne pouvait certes attendre de l'ERE l'instauration de cette planification rigoureuse sans laquelle la Grèce n'a pas beaucoup de chances de survivre comme une nation indépendante dans le monde de demain. 
L'un des traits de la politique de l'ERE sur lequel nous donnerons plus tard de longues explications a été de favoriser l'entrée des capitaux étrangers au titre de l'industrialisation du pays. Or, même si l'on fait abstraction des concessions démesurées consenties par les autorités gouvernementales aux groupes monopolistes étrangers, cette politique a pour résultat de faire dépendre le développement national de centres de décisions extérieurs au pays et dont la maximation du profit reste la seule loi. On ne saurait certes concevoir de méthode plus dangereuse et plus imparfaite pour assurer la croissance nationale. C'est se résoudre à appliquer en cette seconde moitié du $\mathrm{XX}^{\mathrm{e}}$ siècle la méthode ayant eu cours avant la première guerre mondiale, notamment en Amérique Latine, avec les résultats que l'on sait.

Parmi les résultats de la politique économique de l'ERE - qui fut en définitive la simple continuation de la politique de Markézinis - mentionnons la survenance des tous premiers éléments d'une société de consommation dans un pays encore désespérément pauvre. Les couches aisées ainsi qu'une partie des classes moyennes ont pu ainsi acquérir, [p. 271] spécialement dans l'agglomération athénienne, des habitudes de consommation incompatibles avec les exigences d'un développement social c'est-à-dire d'un développement dont les fruits aillent en priorité aux masses des déshérités. Une misère indicible continue de régner dans les villages de montagne, mais désormais il devient presque impossible, si dense y est la circulation automobile, de garer une voiture dans le centre d'Athènes.

Une telle politique hypothèque l'avenir et peut-être le compromet de manière irréversible mais elle étend la clientèle des partis bourgeois. De tous les reproches que l'on peut faire à ceux-ci dans les pays pauvres, c'est certainement le plus grave. 
[p. 272]

\section{CHAPITRE VIII}

\section{UNION DU CENTRE (EK)}

Retour à la table des matières

L’UNION a été fondée en septembre 1961 dans des circonstances que nous avons déjà relatées. Elle se rattache à la tradition du parti Libéral fondé par E. Vénizélos avec l'ambition d'assurer un fonctionnement effectif du régime parlementaire et dont nous avons retracé les nombreuses vicissitudes depuis 1946.

Au point de départ, l'EK se présente comme une coalition hétéroclite de personnalités dont les tendances politiques vont de la droite à la gauche, du conservatisme traditionnel à des positions gauchisantes. Il s'agit en somme d'un concours de personnalités ou notabilités locales dont certaines viennent au Centre parce qu'elles ne trouvent pas de place, du moins pas de place leur convenant, dans la Droite. Cependant, rappelons-le, ce sont des individus et non des partis qui deviennent membres du nouvel organisme dont l'objectif essentiel est de chasser la Droite du pouvoir. Compte tenu de la diversité des opinions et des styles qui se manifestent au sein du parti, beaucoup pronostiquent sa désagrégation sitôt le but initial rempli. Or, ces prédictions ne se sont pas réalisées et jusqu'à présent les tensions internes ont pu être surmontées. Cette situation résulte en quelque mesure de l'ascendant pris par G. Papandréou sur ses troupes et aussi du fait que l'ERE ne s'étant pas désagrégée dans l'opposition, la dislocation du Centre donnerait à celle-ci une excellente chance de retourner au pouvoir.

L'Union offre actuellement le spectacle d'un parti occupant le pouvoir sans que son organisation interne, tant au niveau central que local, ait été encore mise en place. Bien qu'elle ait disposé, lors des consultations de 1963 et 1964 d'un large électorat, cette formation ne constitue pas un parti de masse à structure bureaucratisée. Réserve faite de l'autorité [p. 273] que G. Papandréou est parvenu à établir sur les membres du groupe parlementaire, l'EK reste proche des structures partisanes traditionnelles.

En principe, les promoteurs de l'Union ont prévu ou envisagé la mise en place d'un dispositif plus rigoureux d'administration et d'encadrement. L'exemple de l'ERE 
qui, plus de huit ans après sa fondation en est demeurée à la phrase des «statuts provisoires ", montre bien que le monde politique grec reste encore en une large mesure étranger à l'esprit et aux techniques des larges bureaucraties partisanes.

\section{STRUCTURE ET DIRECTION}

$\underline{\text { Retour à la table des matières }}$

Les statuts de l'Union du Centre ont été élaborés par son Chef G. Papandréou et approuvés par le groupe parlementaire du parti le 27 septembre 1962, soit donc une année après la création officielle de celui-ci. Il s'agit dès lors d'un système d'organisation venu d'en haut.

\section{A. DIRECTION CENTRALE DU PARTI}

Elle se compose de quatre organes principaux : le Chef, le Congrès, le Groupe Parlementaire et le Conseil de Discipline. De ces organes, deux seulement ont été mis en fonction jusqu'à présent; le Chef et le Groupe Parlementaire. Encore faut-il observer que c'est le premier qui, avec toutefois moins de rigueur que Caramanlis pour l'ERE, s'est saisi de la réalité du pouvoir.

\section{CHEF DU PARTI}

Les statuts disposent que le parti est placé sous le commandement du Chef, qui le représente, dirige ses travaux à l'intérieur et à l'extérieur du Parlement, en est le porteparole officiel. Le Chef a également compétence pour superviser et contrôler tous les organes du parti. Si la place de Chef devient vacante, de quelque manière que ce soit, les statuts attribuent au Congrès du Parti convoqué à cet effet l'élection d'un nouveau titulaire.

Nous avons vu précédemment que, lors de la création de l'Union du Centre, G. Papandréou avait été placé à la tête du parti par le consen-[p. 274] tement de tous les dirigeants des formations ayant constitué l'EK. Il y a donc eu à l'origine cooptation du chef parmi les dirigeants du Centre, pour la plupart des parlementaires, sans aucune intervention de la base du parti. Certes la personne de G. Papandréou était largement approuvée par l'électorat du Centre, mais cette approbation ne s'est pas exprimée par un acte concret, telle que la décision d'un congrès ou d'une assemblée de cadres non parlementaires.

Nous observons donc, comme nous l'avons fait pour l'ERE, que la création du parti aussi bien que l'élection de son Chef ont été l'affaire des parlementaires 
composant la nouvelle formation. En ce qui concerne l'Union du Centre toutefois, une concession est faite aux procédures démocratiques puisqu'en cas de vacance du poste, ce doit être le Congrès du parti, donc un organe relativement représentatif de la base qui procède à l'élection du nouveau chef. Reste à savoir, quand le cas se présentera, si le parti aura conservé sa forme actuelle et si la clause en question sera respectée.

Voyons maintenant le rôle attribué au Chef dans la direction du parti. En application des dispositions transitoires des statuts, il est précisé que, jusqu'à la convocation du Congrès, le Groupe Parlementaire détient les attributions de celui-ci. Il est également prévu que jusqu'à ce que l'organisation complète de la base ait été mise en place et que des élections régulières aient été tenues, les comités des organisations régionales et locales sont désignés par le Chef ou par des organes régionaux avec son autorisation.

Dès lors, à l'heure actuelle, le Congrès n'ayant pas encore été convoqué et l'organisation de la base n'étant pas achevée, le Chef du Parti partage tous les pouvoirs avec le Groupe Parlementaire. Le problème que nous retrouverons un peu plus loin est donc celui des rapports entre ces deux organes.

\section{CONGRÈS DU PARTI}

Le Congrès est l'organe souverain du Parti. Il prend les décisions générales au titre du programme politique et de l'organisation du parti.

Il est composé du Groupe Parlementaire du Parti, des anciens premiers ministres, ministres et députés, membres du Parti, des candidats aux dernières élections législatives, d'un nombre de représentants des organisations départementales du Parti égal à la moitié du nombre des [p. 275] députés élus dans la même circonscription et enfin de 75 représentants des organisations de jeunesse et de femmes ainsi que des organisations professionnelles du Parti.

L'ordre du jour du Congrès est établi par le Groupe Parlementaire du Parti trente jours avant le début de la session. Le Congrès élit un Comité Exécutif composé de dix membres, dont le but est la préparation et l'exécution des décisions du Groupe Parlementaire. Il désigne également un Comité d'Organisation de dix membres pour la supervision de l'organisation du parti. Les propositions de ces deux Comités ont un caractère consultatif. Le Chef du parti préside les deux Comités. Les ex-premiers ministres du parti participent de droit à ces deux Comités.

Trois ans après la création du parti, le Congrès n'a pas encore été convoqué, mais l'on peut déjà tirer de l'examen de sa forme statutaire quelques indications relatives au type d'organisation adopté :

- maintien du caractère élitaire du parti. En effet, les représentants de la base sont noyés dans la masse des notables qui participent d'office au Congrès ; 
- conservation de la prépondérance parlementaire. Compte tenu de l'attribution d'un caractère purement consultatif au Comité directeur et au Comité d'organisation, les seuls organes de décision entre les sessions du Congrès sont le Chef du parti et le Groupe Parlementaire. La base ne peut donc intervenir dans les décisions du parti qu'une fois tous les deux ans, lors du Congrès ou alors, mais de façon négative, en désavouant les personnes qui lui sont proposées, lors des élections législatives, tous les quatre ans.

En définitive, l'attribution à la gestion du parti d'un caractère démocratique point sur lequel les dirigeants de l'Union du Centre, si volontiers critiques des méthodes de l'ERE, ont tant insisté — semble compromise par la Charte même de l'organisme. Au surplus, les dispositions démocratiques, déjà limitées sur le papier, sont demeurées lettre-morte par absence de convocation du Congrès.

\section{GROUPE PARLEMENTAIRE}

Il se compose des députés élus sous le drapeau de l'Union du Centre, ainsi que de ceux qui y ont adhéré. Le groupe est chargé d'appliquer [p. 276] les décisions du Congrès ; il a la responsabilité du travail législatif et du contrôle parlementaire, dans le cadre des directives du Congrès.

Le Groupe Parlementaire, qui est placé sous le commandement du Chef du parti, a la faculté de constituer des commissions d'études pour l'analyse des questions politiques et des problèmes du parti. Il est prévu que des personnalités extraparlementaires peuvent participer à ces commissions.

Mentionnons enfin que le Groupe Parlementaire est statutairement compétent pour procéder à l'expulsion d'un de ses membres.

Dans l'esprit des statuts de l'Union du Centre, le Groupe Parlementaire devait exercer la direction du parti conjointement avec le Chef, une limitation mutuelle des pouvoirs intervenant de cette façon. Or, nous allons voir que cet équilibre dans la direction du parti a été récemment rompu et que le Chef a affirmé sa supériorité sur le Groupe.

Reste à savoir si cet état de choses est définitif ou si, par une mise en œuvre démocratique de l'organisation du parti, l'équilibre Chef - Groupe Parlementaire sera rétabli ou encore remplacé par un autre système de direction.

\section{CONSEIL DE DISCIPLINE}

Élu par le Groupe Parlementaire, le Conseil a pour rôle de prendre des mesures disciplinaires en première instance contre les cadres du parti et, en deuxième instance, contre les adhérents du parti. Les mesures disciplinaires concernant les premiers ne sont définitives que par décision du Groupe Parlementaire statuant sur proposition du Conseil de discipline. 
Ce Conseil n'a jamais été constitué. Les mesures d'expulsion déjà prises contre les députés du parti l'ont été par le Chef sans que le Groupe Parlementaire ait été convoqué, même pour entériner la décision et sans qu'un quelconque organisme disciplinaire ait été constitué pour l'étude du dossier.

Il ressort de tout ceci que la direction centrale du parti relève statutairement du Chef et du Groupe Parlementaire. Or, en l'état actuel des choses, le Chef du parti est en mesure d'imposer ses vues au parti et ainsi les pouvoirs du Groupe Parlementaire sont de facto considérablement réduits.

[p. 277] Relevons un dernier point : les statuts ne prévoient pas la création d'un secrétariat général ou autre organe administratif. L'Union a bénéficié du secrétariat du Club des Libéraux dont elle a hérité après la dissolution du Parti Libéral (l'une des missions du Club étant d'assurer la conservation des archives d'E. Vénizélos).

Parallèlement, G. Papandréou disposait d'un bureau politique personnel. Selon les renseignements dont nous disposons, tel était le cas d'ailleurs pour presque tous les politiciens importants de l'EK.

\section{B. STRUCTURE ORGANIQUE DU PARTI}

Retour à la table des matières

Les statuts prévoient la constitution d'organisations du parti dans chaque département, chaque province et chaque commune. Il est également précisé que chacune de ces organisations doit créer des groupements de jeunes, de femmes, ainsi que des organisations professionnelles du parti.

Les détails d'application des présents statuts, et spécialement de l'organisation du parti, doivent être précisés dans un règlement intérieur soumis à l'approbation du Groupe Parlementaire. L'organisation de jeunesse sera aménagée par un règlement spécial.

Aux termes de ce schéma, l'Union du Centre entend donc se doter d'une structure à deux dimensions. La première de type vertical tend à assurer l'implantation géographique du parti dans toutes les circonscriptions administratives, la commune constituant le secteur de base. La seconde, d'inspiration horizontale, vise à donner au parti une implantation dans les différentes professions.

Bien que les dirigeants du parti annoncent périodiquement la création d'un grand nombre de sections locales, il ne semble pas que l'organisation verticale soit déjà achevée. Quant à la structure horizontale, il n'apparaît pas que de grands efforts aient été faits pour l'aménager.

Au total, il est douteux que la nouvelle organisation ait supplanté les structures anciennes fondées sur l'attachement à des personnes. L'Union continue de reposer en 
plusieurs cas sur des partis personnels d'implantation locale qui constitue le noyau de ses militants et de sa clientèle électorale. Ces partis appartiennent encore davantage aux personnalités ayant constitué l'Union qu'à celle-ci. Il reste à savoir si une consolidation de l'Union n'aboutirait pas finalement à un transfert de loyauté des unités locales à l'organisation centrale.

p. 278]

\section{SITUATION PERSONNELLE DU CHEF DU PARTI}

$\underline{\text { Retour à la table des matières }}$

Nous avons noté à plusieurs reprises que le leader de l'Union du Centre, G. Papandréou était parvenu à établir son autorité sur le Groupe Parlementaire. Ce processus s'est effectué en deux étapes : la première allant de la création de l'Union du Centre (septembre 1961) jusqu'aux élections du 3 novembre 1963, et la seconde de ces élections à nos jours.

\section{LE PARTI DANS L'OPPOSITION}

Durant la première période, on a observé des conflits qui ont provoqué des «grincements» plus ou moins sérieux entre le Chef du Parti et le Groupe Parlementaire. Ces conflits étaient principalement dus à deux raisons: le fractionnement des tendances au sein du parti, les tensions qui en résultaient étant accrues par le jeu des ambitions personnelles.

On comprend aisément le premier de ces motifs en observant que l'Union du Centre a été constituée par un grand nombre de petits partis dont les tendances n'étaient pas identiques. Cette diversité idéologique a eu pour conséquence la survenance d'un certain nombre de conflits sur les positions optimales à prendre par le parti en diverses circonstances. Quand une position était arrêtée, le Chef du Parti devait faire face aux mécontents qui l'accusaient, tantôt de faire une politique de Gauche et tantôt une politique de Droite. Il semble qu'en cette matière les tensions les plus vives soient survenues entre le Chef et le courant de Gauche.

Le second des motifs de conflit — c'est-à-dire le jeu des ambitions personnelles - s'explique par le fait que l'Union du Centre étant constituée depuis très peu de temps, plusieurs des chefs des anciens partis fondus dans celle-ci voyaient d'un mauvais œil le renforcement des pouvoirs du leader et entendaient que leur point de vue soit respecté en toute circonstance.

Les discordes les plus sérieuses ayant surgi durant cette phase sont celles qui opposèrent G. Papandréou à S. Vénizélos. Il s'agissait certes d'un conflit sur la tactique optimale mais aggravé par un choc de personnalités. 
[p. 279] S. Vénizélos, en effet, était la seule personnalité de l’EK pouvant, dans les circonstances de l'époque, disputer à G. Papandréou la direction du Parti, avec des chances sérieuses de réussite. En relations avec le Palais, il disposait de l'appui d'un grand nombre de députés du Centre ; son assise électorale était relativement large et il avait été le Chef du Parti Libéral (pendant longtemps la plus importante formation du Centre). Or, le point de vue tactique de $S$. Vénizélos pour la bataille politique contre l'Union Nationale Radicale était différent de celui de G. Papandréou. Pour renverser l'ERE, il fallait, selon le premier, proposer aux éléments modérés de ce parti une alliance gouvernementale avec les éléments modérés de l'Union du Centre — alliance susceptible de se transformer en formule gouvernementale.

Sans que ceci fut expressément dit, l'opération projetée avait pour fondement le désir de résoudre la crise politique par mise à l'écart des deux leaders dressés l'un contre l'autre, C. Caramanlis et G. Papandréou. C'était une formule de compromis modéré d'inspiration Centre-Droit que le Roi Paul s'efforça vainement de réaliser au lendemain de la démission de Caramanlis.

Comme l'on s'en doute, ce point de vue était combattu par G. Papandréou et ses partisans à l'intérieur de l'EK ainsi que par l'aile gauche du Parti. Lorsque S. Vénizélos fit une dernière tentative pour imposer ses vues, en accordant sa voix au gouvernement Pipinelis, G. Papandréou déclara alors l'expulser du parti. Il s'en suivit un grand tumulte au sein de l'EK qui mena celle-ci au bord de l'éclatement. Après de multiples efforts de médiation, les deux leaders se réconcilièrent afin de sauvegarder l'unité du parti.

Nous voyons donc que durant cette période, il y a eu des conflits entre le Chef du Parti et certaines personnalités ou certaines tendances de Groupe Parlementaire. Le Chef du Parti a maintenu sa position et a réussi, dans une certaine mesure, a imposer ses vues, mais sans faire finalement acte d'autorité. Il a dû tenir largement compte des diverses tendances du parti et ménager les susceptibilités personnelles. Nous pouvons donc avancer qu'il y a eu un équilibre entre Chef de Parti et Groupe Parlementaire, les deux organes dirigeant conjointement l'Union du Centre. Cet équilibre a résulté, d'une part de la souplesse du Chef et d'autre part du fait que les divergences opposant des éléments du Groupe Parlementaire au Chef étaient simplement des conflits de [p. 280] personne ou de tactique : or l'opinion publique n'aurait pas compris que des disputes de cet ordre soient poussées jusqu'à la rupture. La crainte d'un jugement défavorable de l'opinion était donc une incitation au compromis.

\section{LE PARTI AU POUVOIR}

Cet équilibre a été rompu en faveur du Chef du Parti, au cours de la seconde période qui va de novembre 1963 à nos jours, Le point de départ de ce changement est le gain des élections du 3 novembre 1963 par l'Union du Centre. Plusieurs raisons ont contribué à ce nouvel état de choses : 
- La victoire électorale remportée par l’Union et, à laquelle peu de gens croyaient, même au sein de l'EK, renverse la situation politique du pays, puisque pour la première fois depuis plusieurs années, la Droite quitte le pouvoir en cédant celui-ci à une formation de création très récente.

- Cette victoire est en même temps la consécration de la politique personnelle de G. Papandréou qui avait cru à la possibilité d'un revirement du corps électoral et avait œuvré dans ce sens en repoussant toute tentative de compromis avec l'ERE. C'est la réussite totale de la « lutte irréductible » qui, au sein du Parti, a pour conséquences de mettre dans une position d'infériorité l'aile modérée qui doutait de la possibilité d'un tel succès. Cette victoire renforce les sentiments d'admiration et de fidélité de ceux qui avaient soutenu Papandréou durant ce combat.

- L'arrivée au gouvernement de l'Union du Centre, après sa victoire aux élections de 1963 consolide la position de G. Papandréou en tant que Chef, puisqu'il se voit immédiatement chargé de former le nouveau Cabinet. Dès lors, il dispose de moyens d'actions bien plus efficaces qu'auparavant envers son Groupe Parlementaire.

- En accédant au gouvernement, G. Papandréou a besoin, pour accomplir sa tâche, de bénéficier du soutien étroit de son Groupe Parlementaire. Il doit donc s'efforcer de le rendre plus homogène par une neutralisation des extrêmes. Cette évolution s'est faite en deux temps, [p. 281] l'un ayant amené la subordination au Chef de l'aile droite du Parti, le second ayant impliqué un affrontement avec l'aile gauche (les deux séries de démarches étant combinées avec un « noyautage » du Parti par des personnalités fidèles à G. Papandréou).

Le départ de la première opération a été donné, nous l'avons déjà vu, par la réussite de la « lutte irréductible » de G. Papandréou qui affaiblit la position de l'aile modérée. La mort de S. Vénizélos, survenue peu de temps après, le 7 février 1964, prive ce secteur de son élément de tête et crée, incontestablement, un grand vide dans les rangs du Centre. Chef populaire et manœuvrier, Vénizélos avait incarné ce courant pendant de longues années en tant que Chef du Parti Libéral. Cependant, son ambition personnelle, qui n'était pas sans justification, et un certain amateurisme dans sa ligne politique n'aurait pu manquer, à plus ou moins long terme, de nuire à l'unité de l'EK, comme ils avaient nui précédemment à l'unité du Parti Libéral. En tout cas, si la disparition du leader Libéral prive l'EK d'un de ses chefs et d'un spécialiste incontesté des questions internationales, on peut admettre qu'elle est de nature à améliorer sa cohésion. En même temps, elle supprime un rival dangereux de G. Papandréou et permet à celui-ci de se subordonner plus facilement l'aile droite du Parti.

Quant au conflit avec l'aile gauche, il est intervenu après les élections du 16 février 1964. Lors de la formation du nouveau gouvernement Papandréou, les chefs de file de l'aile gauche, E. Tsirimocos et S. Papapolitis n'obtiennent pas les postes qu'ils convoitaient : la Présidence de la Chambre pour le premier et le Ministère du Commerce pour le second (poste que celui-ci avait déjà occupé sous Plastiras). Refusant les fonctions qui leur sont offertes, ils vont se dresser contre le Premier Ministre. Au moment de l'élection du Président de la Chambre on note 33 défections 
parmi les membres de l'EK et dès lors le candidat de celle-ci, Athanassiadis-Novas, ne sera élu qu'au second tour. Sur les 33 rebelles, 30 déposent des bulletins contenant le mot "Démocratie », un refuse de voter, les deux derniers donnent leur suffrage à d'autres personnalités du Centre. La réponse de G. Papandréou est brutale : les deux personnalités qu'il tient pour responsables du «complot » sont radiées du parti, leur acte étant considéré comme une insubordination à l'égard des consignes de celui-ci. Malgré les protestations de Tsirimocos et Papapolitis qui se livrent à des affirmations de fidélité et demandent que [p. 282] le Groupe Parlementaire soit convoqué pour trancher la question, G. Papandréou ne cède pas.

Cette décision a produit une profonde impression dans les milieux politiques grecs. Certains y ont vu la survenance dans la majorité d'une première fissure aux conséquences imprévisibles. En quelques milieux, l'élimination de ces personnalités d'inspiration Centre-Gauche a été interprétée comme le souci de rassurer la bourgeoisie, de plaire à la Cour, de donner un gage aux Américains. De toute manière, la conséquence immédiate de la radiation a été de briser l'élan des dissidents.

Dans une déclaration publique, E. Tsirimocos a reproché au Premier Ministre de parler comme si l'EK était son fief et la Démocratie sa propriété indiscutée. Il a dit que si de nouvelles élections avaient lieu, le front démocratique du peuple n'accepterait certainement pas d'élire une majorité d'esclaves acceptant d'être gouvernés dictatorialement par n'importe quel Premier Ministre.

L'Union du Centre disposant au départ de 171 sièges sur 300, l'aile gauche du parti pourrait, avec une trentaine de voix, provoquer le renversement du gouvernement. Mais pour l'instant, les récalcitrants en sont demeurés au stade des protestations purement verbales. Il semble que, depuis, une réconciliation soit intervenue et l'on annonce périodiquement que des personnalités de ce courant vont entrer dans le Cabinet (opération effectuée au début de 1965).

Parallèlement à ces deux opérations, G. Papandréou, en dressant les listes de candidats pour les élections du 16 février 1964, s'était efforcé d'y inclure le plus grand nombre possible de personnalités fidèles, beaucoup de celles-ci étant élues par suite de la grande victoire du Centre lors de cette consultation.

En l'état actuel des choses, c'est le chef qui détient les leviers de commande : les pouvoirs du Groupe Parlementaire ont été mis en veilleuse, celui-ci n'ayant même pas été convoqué pour prendre à son tour la décision d'expulsion de deux de ses membres, alors que statutairement cet acte relevait de sa compétence.

\section{PERSONNALITÉ DE G. PAPANDRÉOU}

Né le 13 février 1888, Papandréou, lorsqu'il devient Premier Ministre en qualité de leader de l'Union du Centre a derrière lui une très longue carrière politique. Directeur du Cabinet politique d'E. Vénizélos en [p. 283] 1916, on le trouve Ministre de l'Intérieur dans le Cabinet révolutionnaire de S. Gonatas de janvier à octobre 1923. De janvier 1930 à mai 1932, il est Ministre de l'Éducation Nationale de Vénizélos — 
époque durant laquelle il accomplira un très important travail pour la rénovation du système d'enseignement. Après l'abandon par Vénizélos de la politique, Papandréou fonde en 1935 son propre parti, le Parti Démocratique (qui deviendra plus tard le Parti Démocratique Socialiste). Arrêté par les Italiens sous l'occupation, il finit par se rendre au Moyen-Orient en avril 1944 : il y devient pour la première fois Président du gouvernement - un gouvernement composé seulement de deux hommes dans lequel il détient le portefeuille des Affaires Étrangères, de la justice, des Finances, de l'Armée et de l'Aviation. Il revient en Grèce comme Premier Ministre du gouvernement d'Unité Nationale constitué, avec participation de l'EAM, au lendemain de la Conférence du Liban (mai 1944). C'est en cette qualité que Papandréou doit faire face à l'insurrection de décembre 1944 : il démissionne le 3 janvier 1945 pour céder la place à un gouvernement Plastiras qui signera l'accord de Varkiza. Les différentes étapes de sa carrière depuis cette date ont été retracées dans les précédents chapitres.

Durant la première partie de sa carrière, Papandréou, qui agit dans le sillage d'E. Vénizélos, manifeste des sentiments ouvertement républicains. La guerre cependant le rapprochera de la Monarchie, l'opposition à la Couronne tendant alors à se concentrer, sans oublier bien entendu les communistes, chez des hommes de la vieille garde libérale comme Cafandaris et Plastiras. Il n'apparaît pas que Papandréou se soit publiquement rétracté lors du référendum sur le régime. Il semble dès lors qu’il soit resté marqué, aux yeux du Palais, par son attitude initiale ce qui explique peut-être les efforts entrepris par le Roi Paul au lendemain de la démission de Caramanlis et également après celle de Papandréou lui-même en décembre 1963 pour constituer un gouvernement dans lequel l'Union du Centre et donc Papandréou seraient partiellement neutralisés par la présence d'une fraction de la Droite.

Nous avons précédemment relevé l'adulation, proche par quelques côtés du culte de la personnalité, dont C. Caramanlis faisait l'objet dans les publications gouvernementales officielles. Rien de semblable certes n'est encore survenu à l'égard de G. Papandréou. Pourtant quelques signes de telles pratiques se manifestent comme le montre la publication dans un magazine privé d'un profil de G. Papandréou dont nous croyons [p. 284] utile de citer quelques extraits - citation faite dans la langue où ce texte nous est parvenu afin de lui garder toute sa saveur ${ }^{1}$ :

"It is no easy task to present a profile of George Papandreou ... For fifty years, he has lived intensively... Throughout this period he has been discussed, condemned, lauded, and the constant butt of the caricaturist and satirists. The nicknames with which he has been dubbed by the public are legion; and, in an age when other political figures are ignored, he is idolized by an immense electorate which has succumbed to the power of his oratory and his indisputable personal charm.”

"The private life of the author of a Political Themes has not always been one of serenity. The man who once charmed and married Kyveli, the leading Greek actress, and still

\footnotetext{
Pictures from Greece, juillet 1964, pp, 9-11.
} 
maintains - with a tinge of narcissism, say his opponents - his confidence in his own fascination, was bound to derive inspiration and courage from his own unquenched passions."

"He is accused of ambivalence in the unchartered regions of Greek politics ... At the same time he is accused of unwarranted ... adherence to theoretical patterns which often complicate rather than clarify the situation in hand ... It has been said that George Papandreou first creates a term, and then a situation to fit the term.”

"He has also been described as a "pendulum" ... The swing of the pendulum is also the beat of the metronome, and it is this beat which helps to maintain a basic rhythm — even in the most turbulent cadenzas."

"His voice remains unchanged, but his vocabulary is constantly being enriched... He moves with the times, and each particular attitude he elects merges easily with its predecessor. However divergent, his attitudes blend one with the other like the colours of a well-designed mosaic.”

"The practical side of things does not escape George Papandreou. What he has missed is the connection between persons and situations which would have given his a longer tenure as prime minister.”

Ce texte est certainement plus astucieux que le lourd éloge de Caramanlis précédemment cité mais, en définitive, on doit dire qu'il est peut-être aussi mystifiant. Il n'est pas raisonnable, même sur le mode ironique, d'attribuer au charme personnel du leader de l'Union du Centre un tel rôle dans le renversement du rapport des forces et l'éviction du pouvoir de l'Union Radicale Nationale. Si tel était le cas, il faudrait bien donner raison aux dirigeants de l'ERE qui justifiaient la nécessité d'un renforcement de l'autorité gouvernementale par la médiocrité de la culture politique des citoyens grecs. Le succès de Papandréou lui vint d'avoir représenté en un moment décisif l'ensemble des groupes qui sou-[p. 285] haitaient un changement et des forces qui allaient le rendre possible. Au surplus, il n'est pas du tout certain que l'histoire ratifie le jugement bienveillant porté sur les tendances pendulaires de l'ancien partisan de Vénizélos dont il faut toutefois dire que l'honnêteté personnelle n'a jamais été mise en cause.

Nous n'aurions certes pas insisté sur un tel document si, destiné à l'étranger, il ne risquait d'y avoir pour effet de renforcer l'image stéréotypée de la politique grecque - c'est-à-dire finalement d'une activité pas très sérieuse — qui a cours habituellement hors de Grèce. Or, nous le voyons une fois de plus, ce sont les Grecs qui concourent à la persistance de telles mystifications. 


\section{PARLEMENTAIRES INFLUENTS DU CENTRE}

Retour à la table des matières

Étant donné la grande hétérogénéité du Centre, il est encore plus difficile que pour la Droite d'en établir une liste qui soit véritablement représentative. L'établissement d'une telle liste nous paraît néanmoins indispensable ne serait-ce que pour illustrer la diversité des hommes qui composent cette formation. Nous insisterons principalement sur six d'entre eux :

- C. Mavros, député d'Athènes : venu du barreau, cet ancien ministre occupe aujourd'hui le poste de Gouverneur de la Banque Nationale de Grèce — poste comportant des fonctions très importantes et n'impliquant aucunement la renonciation de l'intéressé à une carrière proprement politique. Homme fortuné (gendre d'armateur), Mavros est réputé pour sa compétence économique.

- C. Mitsotakis, député de Crète : ayant exercé une activité de résistant (hors de l'EAM) et l'un des hommes en vue du Parti Libéral, il passe désormais pour l'un des hommes forts du Centre.

— E. Tsirimocos, député d’Athènes : avocat et ancien journaliste, résistant de l'EAM qu'il représenta aux côtés du professeur Svolos dans le cabinet Papandréou, il est en relation avec l'intelligentsia social-démocrate dont il épouse et représente les convictions. La Droite et divers milieux étrangers lui reprochent de constituer une sorte de pont entre l'EK et l'EDA.

- S. Costopoulos, député de Calamata : banquier de profession et ayant de ce fait d'importantes relations d'affaires, cet homme d'une [p. 286] grande souplesse et d'une particulière habileté était très fidèle à $S$. Vénizélos.

— St. Stéphanopoulos, député de l'Élide : avocat et économiste, il représente au sein de l'EK la Droite traditionnelle, du moins la partie de celle-ci qui n'avait pu s'accommoder de l'ascension de Caramanlis. Il dispose en Élide d'une solide implantation locale.

— J. Zigdis, député du Dodécanèse et ancien ministre de Plastiras d'une grande compétence économique, cet homme dont chacun connaît l'absolue intégrité pourrait être qualifié d'économiste technocrate.

Il faut désormais ajouter à cette liste qui comprend probablement le successeur éventuel de G. Papandréou le fils de celui-ci. A. Papandréou, député de Patras : économiste de formation américaine, il est rentré en Grèce après un long séjour aux États-Unis durant lequel il remplit les fonctions de professeur à l'Université de Californie. On le dit de tendance kennedyiste et on peut admettre que le défunt Président des États-Unis voyait d'un très bon œil sa présence dans les milieux dirigeants grecs. D'aucuns en faisaient déjà le "dauphin » mais il est douteux qu'un processus de succession de type familial se soit accompli sans soulever de vives 
contestations (en particulier de la part d'hommes comme Mavros et Mitsotakis qui peuvent légitimement entretenir l'espoir de succéder à Papandréou). Au surplus, A. Papandréou a démissionné de ses fonctions ministérielles (Ministre adjoint de la Coordination dans des conditions qui ont fait l'objet d'appréciations divergentes (15 novembre 1964). Et il est possible que l'événement lui ferme les portes de la grande carrière politique.

Il nous paraît intéressant de mentionner le cas de J. Toumbas qui est un excellent représentant du groupe des officiers qui tentèrent en 1935 d'effectuer un coup d'État républicain (supra). Ayant perdu en cette occasion ses galons d'officier, il fut rappelé au service lors de la guerre avec l'Italie et affecté à la défense des côtes (Salonique). Il participa aux opérations qui permirent de soustraire aux Allemands la plus large part de la flotte grecque. Mis à la retraite par le gouvernement de la Droite alors qu'il occupait le second poste de la Marine (Chef de la flotte), il se présenta avec succès comme candidat du Parti Libéral aux élections de 1956 dans les rangs de l'Union Démocratique. Après la victoire de l'Union du Centre, Papandréou le destinait, semble-t-il, au poste de Ministre de la Défense Nationale mais ce fut en définitive [p 287] P. Garoufalias dont les sentiments conservateurs et l'atlantisme inconditionnel sont bien connus qui fut choisi pour assumer cette responsabilité. Toumbas fut alors placé au Ministère de l'Intérieur.

Nous voudrions mentionner encore trois autres personnalités du Centre qui se situent à un étage inférieur à celui occupé par les précédents : S. Papapolitis, député du Pirée qui, avocat de formation, hérita du parti de Plastiras à la mort de celui-ci et possède des relations dans les affaires ; A. Baltadzis, député de Thrace, soutenu par les agrariens à tendances affairistes de la Confédération des Coopératives agricoles ; A. Canellopoulos, député de l'Élide qui, venu de la Gauche, a réalisé, une fois ses convictions initiales abandonnées, une carrière rapide. 


\section{PROGRAMME ET IDÉOLOGIE}

$\underline{\text { Retour à la table des matières }}$

Le programme et l'idéologie de l'Union du Centre, de sa formation à nos jours, peut se résumer en deux phrases : « l'établissement de la démocratie politique » dans le pays ; « application de la démocratie politique, sociale et économique ».

\section{A. RÉTABLISSEMENT DE LA DÉMOCRATIE POLITIQUE}

Par rétablissement de la démocratie politique, l'Union du Centre entendait d'abord le départ de C. Caramanlis du pouvoir car, d'après elle, celui-ci avait violé l'ordre constitutionnel en subordonnant l'administration publique, l'année et tous les services étatiques à son parti et en empêchant la libre expression de la volonté populaire par la « fraude » et la "violence ». L'application de la démocratie politique, sociale et économique devait constituer la base de la politique de l'EK une fois celle-ci au pouvoir.

Dès lors, durant la période 1961-1963, phase durant laquelle l'EK se trouve dans l'opposition, elle réclame le rétablissement de la démocratie ce qui, d'après ses porteparole, implique «un État honnête, un système électoral honnête, des élections honnêtes ». Voici le contenu donné par l'Union à ce «triptyque » qui forme la base idéologique de la « lutte irréductible » :

— «État honnête » c'est-à-dire avant tout départ de l'ERE du pouvoir ; mise en place d'un gouvernement de service jouissant de la con-[p. 288] fiance de tous les partis pour procéder à des élections ; " décaramanlisation » des services préalablement aux élections; (remplacement des préfets par les procureurs de première instance, révocation des Chefs de l'armée et des corps de sécurité en place, remplacement d'un certain nombre de hauts fonctionnaires et d'agents de la radiodiffusion d'État).

— « Système électoral honnête » : ce peut être indifféremment la proportionnelle simple ou le système majoritaire, mais en aucun cas l'un des systèmes bâtards, coupés sur mesure par le parti au pouvoir. Cependant, l'Union du Centre penchait plutôt pour un régime de proportionnelle simple, un mode de scrutin de ce type permettant de dresser un bilan exact des forces politiques du pays et empêchant la polarisation politique.

— «Élections honnêtes », c'est-à-dire élections libres sans intervention en faveur de l'ERE de la milice (TEA) ou des forces de sécurité ainsi que sans le recours à la 
fraude matérielle (suppression des doubles inscriptions électorales) et psychologique (abolition de la « terreur » dans les campagnes).

Ce programme de " rétablissement de la démocratie » devait être appliqué en une assez large mesure au niveau électoral par le gouvernement de service qui présida aux élections du 3 novembre 1963 dont on a vu qu'elles s'effectuèrent dans un climat de liberté.

À l'issue de ces élections, G. Papandréou, Chef de l'Union du Centre, accéda au pouvoir pour une période de 52 jours. N'ayant pas la majorité absolue à la Chambre et refusant le soutien qui lui offrait l'EDA, il démissionna dans des conditions déjà relatées pour procéder à de nouvelles élections qui assurèrent cette fois à l'EK la majorité absolue tant en voix dans le pays qu'en sièges au Parlement.

\section{B. MISE EN EUVRE DE LA FORMULE DÉMOCRATIQUE}

$\underline{\text { Retour à la table des matières }}$

Voyons maintenant quel est le programme de ce gouvernement pour « l'application de la démocratie politique, sociale et économique ». Nous utiliserons pour cet examen les engagements pris devant les électeurs ainsi que les déclarations faites par le Président du Conseil sur le programme gouvernemental, devant la Chambre, le 20 mars 1964.

[p. 289]

\section{CRÉATION DE L'ÉTAT DE DROIT}

C'est le premier article de ce programme qui tend à assurer l'épanouissement de la démocratie politique. Il s'agit en somme, sous un titre qui est d'inspiration clairement vénizéliste (le Vénizélos des années 1910) d'assurer le perfectionnement de l'appareil étatique par une action sur ses éléments constitutifs :

- Administration : rétablissement moral et matériel ; reclassement de la fonction publique par fixation d'une nouvelle échelle de traitements (un tiers de l'augmentation annuelle du budget étant consacré aux augmentations des traitements du secteur public, outre les accroissements normaux); création d'une école d'administration dont, par la suite, seuls les élèves auront accès aux services publics ; réduction du poids de la bureaucratie par élimination de divers conseils; accentuation de la compétence et de la responsabilité des services publics par attribution aux hauts fonctionnaires d'une responsabilité solidaire avec les ministres; décentralisation administrative.

- Justice : doublement des traitements de base du corps judiciaire et suppression de tous les autres émoluments que recevaient les membres de ce corps au titre de leur 
participation à diverses commissions ; achèvement de la construction des palais de justice et des prisons au cours du mandat de quatre ans donné à l'Assemblée.

- Abolition des mesures d'exception: libération de tous les «prisonniers politiques» qui ont purgé une peine de 15 ans; abolition de la déportation administrative ; jugement des délits d'espionnage non plus par les tribunaux militaires mais par les Cours d'Appel ; limitation de l'exigence des certificats de civisme aux seuls cas d'entrée dans les services publics et dans les corps de sécurité.

- Forces armées : éloignement de la politique et amélioration de leur situation matérielle, des dispositions analogues étant prises pour les corps de sécurité dont la situation matérielle sera améliorée.

- Éducation: renaissance nationale par une rénovation de l'éducation; enseignement gratuit aux trois échelons de l'instruction ; extension de l'enseignement obligatoire de six à neuf ans d'études; augmentation des subventions de l'État pour les bourses ; réorganisation du système d'éducation ; amélioration de la situation du Corps enseignant.

[p. 290] — Église : collaboration harmonieuse entre l’Église et l’État ; relèvement du niveau matériel et spirituel du clergé.

\section{POLITIQUE ÉCONOMIQUE}

Elle se réalisera dans le cadre d'une planification du développement économique. Le Centre de Recherche Économique, jusque là institution privée fonctionnant avec le concours de l'Université de Berkeley (Californie) et de la Fondation Ford, sera placé sous le contrôle du Ministère de la Coordination Économique et soumettra au gouvernement des programmes à long terme et des programmes annuels de développement. Une priorité absolue sera donnée aux investissements visant à élever le niveau spirituel et culturel du peuple. Dans le domaine économique, l'État se chargera de l'infrastructure et des secteurs où l'économie privée ne peut faire face aux problèmes posés. Au titre des grandes branches de l'activité, voici les mesures envisagées :

- Agriculture : augmentation des investissements dans le secteur primaire pour une mise en valeur rapide de toutes les ressources agricoles du pays ; réorganisation des cultures et spécialisation par branches pour aboutir à une qualité supérieure ; compression du prix de revient par suppression des intermédiaires inutiles; organisation des transports ; création par le gouvernement de centres d'emballage et de sélection, de marchés régionaux et de chaînes frigorifiques ; soutien des prix quand cela s'avère nécessaire.

- Industrie: création prioritaire d'industries agricoles; préparation de l'infrastructure nécessaire pour permettre à l'initiative privée de se développer ; établissement de zones industrielles qui constitueront les pôles d'attraction de la croissance régionale ; appel aux capitaux étrangers sur une large échelle à condition que leurs détenteurs tiennent compte des intérêts de l'économie nationale. 
- Tourisme : développement du tourisme d'après un plan d'ensemble permettant la mise en valeur de toutes les régions.

- Domaine social : juste répartition du revenu national entre les différentes classes ; équitable rétribution du travail et plein emploi ; rédaction d'un code unifié de législation du travail ; établissement d'un syndicalisme libre et démocratique; système d'arbitrage des conflits ouvriers; réorganisation et développement de l'assurance so-[p. 291] ciale; vaste programme pour l'habitation ouvrière et populaire; réorganisation du système de soins médico-pharmaceutiques et d'hospitalisation.

- Réforme fiscale : diminution du coefficient de l'imposition de 10 à $15 \%$ sur tout le barème ; élévation de 3.600 à 9.000 drachmes du revenu présumé non imposable que les propriétaires obtiennent en habitant leur propre maison ; imposition séparée des revenus du travail de l'épouse ; publication des listes de contribuables, ainsi que de données précises sur le revenu déclaré ; réorganisation des services du fisc et simplification de la législation fiscale.

\section{POLITIQUE EXTÉRIEURE}

Politique d'alliance avec l'Occident et recherche de l'amitié avec l'Orient; politique de bon voisinage avec les pays limitrophes ; application au problème de Chypre des principes contemporains de liberté et de justice.

Enfin, au titre de la politique militaire, le gouvernement prévoit une réduction des dépenses qui, s'effectuant par une réorganisation des forces armées, ne porte pas atteinte à la sécurité du pays.

Tel est le programme présenté au Parlement par G. Papandréou et que l'on doit tenir dès lors comme celui de l'Union du Centre. Ce programme, d'inspiration très modérée, constitue à divers égards un catalogue assez extensif de promesses aux diverses catégories sociales — engagements dont tous ne sont pas exempts de tendances démagogiques. On peut à ce propos s'interroger sur la capacité des finances publiques grecques à faire face à l'intégralité des engagements pris.

Si l'on juge d'après les principes, le programme, spécialement dans l'ordre économique, a plus de cohérence que celui des gouvernements de l'ERE. Ceux-ci avaient pris l'habitude de présenter sous le pavillon de la planification des textes dénués de base solide aussi bien sous l'angle des besoins à satisfaire que des possibilités existantes (ainsi le premier plan de développement 1960-1964 et les perspectives décennales 1962-1971). Au surplus, l'effort de coordination entre les diverses pièces du dispositif demeurait tout à fait insuffisant, sinon [p. 292] même inexistant (technique que l'on peut qualifier de planification-fiction). 
L'actuel gouvernement manifeste l'intention de mettre en œuvre des procédés de calcul plus rigoureux et notamment d'établir un système de priorités au titre des investissements publics. Mais le meilleur des plans ne saurait remplir son office si les gouvernants n'ont pas les moyens d'en assurer l'exécution. Et de ce point de vue, les références faites à l'initiative privée et aux capitaux étrangers n'incitent pas, c'est le moins que l'on puisse écrire, à beaucoup d'optimisme.

Dans un pays économiquement aussi retardé que la Grèce d'aujourd'hui, il ne saurait y avoir d'autre base à une croissance équilibrée qu'une expansion de l'économie publique et un développement de l'épargne nationale. Le capitalisme étranger n'a jamais été et ne peut être qu'un facteur d'exploitation de l'économie du pays. Quant à l'initiative privée, il n'est pour en apercevoir les limites et les tares que d'examiner les désordres permanents et catastrophes périodiques qu'ont subis les pays aujourd'hui développés pour avoir abandonné leur croissance aux impulsions anarchiques de la rentabilité capitaliste. Si la Grèce en reste à de tels procédés, on peut s'attendre à ce que l'écart (quantitatif et qualitatif) entre son économie et celle des pays européens s'approfondisse.

Finalement, on peut se demander si la différence entre l'action gouvernementale de l'ERE et celle de l'Union du Centre a chance d'être aussi grande que le prétendent les leaders de celle-ci. La planification, surtout si elle reste indicative, n'est certes pas le procédé magique qui garantirait le développement national en dispensant de l'indispensable pesée sur les structures socio-économiques. Sans préjuger à l'avance les résultats d'une expérience qui en est à ses débuts, c'est là un problème que nous ne pouvions nous dispenser de soulever. Il revient à se demander où va l'Union du Centre. 
[p. 293]

\section{STRATÉGIE ET TACTIQUE}

$\underline{\text { Retour à la table des matières }}$

Le Centre a toujours manifesté par la voix de son leader la volonté de se battre sur deux fronts, c'est-à-dire contre la Droite représentée par l'ERE et contre la Gauche incarnée par L’EDA. Adoptée au temps où le parti était dans l'opposition, cette attitude a été conservée depuis que l'EK occupe le pouvoir. Une telle position n'est jamais confortable dans la mesure où elle conduit les intéressés à éviter soigneusement toute action susceptible de faire pencher la balance dans un sens ou dans l'autre. On peut au surplus se demander si l'attitude centriste est réellement transférable au plan du gouvernement et si l'exercice du pouvoir ne pousse pas nécessairement les hommes responsables des décisions à s'engager dans une direction déterminée.

Nous avons déjà évoqué à quelques reprises les modalités de la lutte engagée par l'EK pour renverser la Droite et signalé que le choix de la tactique optimale suscita des divergences au sein des milieux dirigeants du parti. Papandréou en tenait pour la lutte irréductible sur tous les plans, y compris à la tribune du Parlement, dans le but d'en arriver au renvoi de l'ERE par le corps électoral. C'est en définitive cette conception qui l'emporta à la fois sur celle des adeptes de l'« opposition de Sa Majesté » (Markézinis) et celle des partisans de la démission en bloc de tous les députés de l'EK en signe de protestation contre la fraude et la violence dont l'opposition avait été la victime.

En un premier temps, la bataille se déroule devant le Parlement mais cette forme d'attaque ne produit pas les résultats escomptés puisque Caramanlis refuse de démissionner et que le Roi ne manifeste aucune intention d'imposer ce départ. Ayant pris la décision de cesser toute relation avec le Chef de l'État jusqu'à ce qu'il ait pris l'initiative de rétablir l'ordre constitutionnel par des élections libres, l'EK va entreprendre une vaste campagne de masse dans le pays - campagne inhabituelle même en période pré-électorale. Durant l'année 1962, les dirigeants et députés du parti, ainsi qu'un grand nombre de politiciens parcourent le pays dans tous les sens en organisant des meetings et des manifestations sur la voie publique. L'Union du Centre suscite ainsi des mobilisations de masse dont on peut avancer qu'elles ont joué un rôle dans la chute de Caramanlis.

Or, durant cette phase, Papandréou, entendant que l'Union combatte [p. 294] seule, repousse les propositions d'entente et de coopération qui lui sont faites par l'EDA. Celle-ci, qui tend à s'attribuer l'initiative et la responsabilité de la mobilisation intervenue, estime que la tactique de la lutte sur deux fronts ne peut qu'augmenter les chances de la Droite de conserver le pouvoir. Papandréou reste sourd à ces arguments et comme nous l'avons vu, c'est sous son seul drapeau que l'Union livrera les deux 
batailles électorales qui lui vaudront la victoire. Caractéristique fut à ce propos la volonté de Papandréou de venir une seconde fois devant le peuple plutôt que de conclure avec l'EDA le pacte qui lui aurait valu la majorité absolue au Parlement.

Ayant obtenu cette majorité par ses seules forces, l'Union ne peut que persévérer dans sa tactique de lutte sur deux fronts. Cette position lui vaudra des critiques en provenance de ses deux adversaires, chacun de ceux-ci l'accusant de ne faire une politique centriste qu'en apparence et de rompre sans cesse l'équilibre au profit de l'autre. C'est ainsi que l'EDA reproche à l'EK de faire systématiquement le jeu de la Droite tandis que les éléments conservateurs dénoncent les complaisances de Papandréou à l'égard de l'extrême Gauche. Il nous paraît utile de faire un bilan rapide de ces critiques.

\section{A. POSITION DE L'UNION VIS-À-VIS DE LA DROITE}

\section{$\underline{\text { Retour à la table des matières }}$}

Les critiques de l'EDA, déjà très vives lors du refus de Papandréou de constituer un Cabinet avec l'appui de la Gauche au lendemain des élections du 3 novembre, 1963, vont s'aggraver lors de la formation du gouvernement qui suit la consultation de février 1964. L’ÉDA reproche au leader de l'EK d'avoir systématiquement orienté son Cabinet vers la Droite en vue de donner satisfaction à la Cour, aux dirigeants économiques privés et aux milieux étrangers. Significative lui paraît à cet égard la désignation comme Ministre de la Défense Nationale de P. Garoufalias qui, sous la législature de 1961, s'est séparé de l'opposition en participant aux activités du Parlement. L'EDA voit également un signe de cette orientation vers la Droite dans la décision prise par Papandréou, après de longues hésitations semble-t-il d'écarter de la Présidence de la Chambre E. Tsirimocos (qui avait occupé ce poste après les élections de novembre 1963).

Par la suite, l'EDA reprendra ces accusations en de multiples circonstances. Tout en reconnaissant que le nouveau gouvernement a des as-[p. 295] pects positifs, notamment sous l'angle de la protection des libertés individuelles, elle lui fera grief de ne tenir qu'incomplètement ses promesses dans le souci de ménager les forces parlementaires et extra-parlementaires de la Droite. Ainsi en va-t-il selon la Gauche dans l'ordre de la restauration des libertés politiques, de la découverte et de la punition des scandales commis par les politiciens de l'ERE, de la révision des contrats léonins passés avec les groupes capitalistes étrangers ... Sur ces points et sur plusieurs autres, l'action gouvernementale de l'EK se caractérise d'après les leaders de l'EDA, par des hésitations et des demi-mesures.

Parmi les affaires ayant valu à Papandréou de violentes critiques de la part de plusieurs milieux du Centre (notamment Eléftéria) et de la Gauche figure le remplacement du Chef de l'État-Major de l'Armée, Sakellariou, mis à la retraite le 17 avril, par le lieutenant-général Gennimatas. Selon l'EDA, ce dernier a pris une part active au coup d'état électoral de 1961 en tant que commandant de la division de la 
Macédoine centrale (circonscriptions de Kilkis et de Pella). Dès lors, sa désignation signifie que les mécanismes occultes de direction de la vie nationale sont toujours d'actualité. Le Premier Ministre répondra que, tout en connaissant les accusations portées contre le général, il juge sa nomination conforme à l'intérêt du pays.

Il serait facile d'allonger la liste de telles accusations : ainsi le reproche fait au gouvernement d'attribuer dans le nouveau budget une beaucoup trop grande part des ressources du pays aux dépenses militaires et de sacrifier ainsi le développement économique du pays au « Moloch de la guerre et de l'OTAN ».

Parmi les mesures du gouvernement qui sont en contradiction avec ces reproches, on peut mentionner la dissolution des organisations para-étatiques d'extrême-Droite intervenue le 15 juillet 1964. Les groupements dissous, au nombre de 11, peuvent être subdivisés en deux catégories :

- Organisations para-étatiques dont le statut et la personnalité juridique avaient été légalement reconnus : Croisade Nationale Panhellénique ; Corps des jeunes gens porteurs d'espoir ainsi que son annexe Organisation de jeunesse Nationale; Résistance Nationale de la Grèce ; Organisation Anticommuniste Nationale ; Ligue des combattants et des victimes de la Résistance nationale de la Grèce du Nord ; Ligue des [p. 296] combattants nationalistes de l'ELAS; Organisation Nationale « Phalange Bleue »; Croisade anticommuniste de la Grèce.

-Organisations para-étatiques n'ayant pas demandé la reconnaissance de leur statut et de leur personnalité juridique et qui donc agissaient dans la clandestinité : l'Épingle ; les Garants du Roi ; Solidarité Sociale Nationale.

Depuis longtemps, le Centre et la Gauche réclamaient la dissolution de ces organismes accusés de conspirer en vue de l'établissement d'une dictature et d'entretenir dans le pays un climat de violences (effectivement le Chef de la Ligue des combattants et des victimes de la Grèce du Nord a été mis en détention préventive au titre du meurtre de G. Lambrakis). Au temps de l'ERE, l'opposition accusait le gouvernement de protéger ces organismes et d'en utiliser les services, sinon même d'en inspirer l'activité. Les enquêtes effectuées depuis le changement de majorité ont mis en évidence un accroissement notable après 1958 des fonds secrets distribués par divers Ministères (Ministre de l'Intérieur, Ministère de la Grèce du Nord, Direction de la Gendarmerie et surtout Ministère à la Présidence du Conseil et Ministère des Affaires étrangères), le mobile donné pour cette augmentation étant la recrudescence d'activité du parti communiste illégal. Il est probable que certaines des associations aujourd'hui dissoutes ont bénéficié de telles largesses.

Le Ministre de l'Intérieur du Gouvernement Papandréou, J. Toumbas, a accusé ces organisations d'avoir établi une organisation et une discipline militaire parmi leurs membres, de s'être saisies illégalement de responsabilités étatiques, de mettre la violence au service de leurs objectifs. Il a signalé que plusieurs de ces associations avaient à leur tête des personnes frappées d'indignité notamment pour actes de collaboration durant l'occupation. Enfin il a déclaré que ces groupements étaient étroitement liés aux services de la police avec laquelle ils correspondaient sur un pied d'égalité et que leurs activités étaient financées à l'aide de fonds publics. Notons que 
le Ministre n'a pas inclu sur la liste l'EKOF organisation activiste des étudiants de Droite et d'Extrême-Droite dont la dissolution est réclamée par l’Union des Étudiants Grecs.

Il n’est jamais facile d'apprécier le poids exact de tels organismes dans la vie politique et d'évaluer le danger qu'ils font réellement courir [p. 297] à l'ordre constitutionnel. Dans le cas grec, il n'est pas contestable que ces groupes ont eu des rapports avec les services de la police et qu'ils ont été utilisés pour la mise au pas des adversaires du gouvernement de l'ERE. On peut également lier ces groupes à la survenance de manifestations d'inspiration ouvertement fasciste ${ }^{1}$. Tout en reconnaissant la validité de ces démarches pour la défense de l'ordre démocratique, la Gauche estime que l'action gouvernementale est insuffisante en cette matière, notamment au titre de l'épuration de la police. Elle lui fait grief en particulier de ne pas avoir dissous le «FBI grec », c'est-à-dire l'Agence Centrale de Renseignements (KYP).

Les critiques émises par la Gauche contre le gouvernement Papandréou se retrouvent dans la presse communiste internationale : «Les masses démocratiques, écrit par exemple D. Parcalidis, s'inquiètent de l'orientation que cela peut cacher. Et les premiers actes du Chef du gouvernement justifient cette inquiétude ${ }^{2}{ }^{2}$. Il est vrai qu'au même moment, d'autres accusent le gouvernement de faire le jeu des communistes.

\section{B. POSITION DE L'UNION DU CENTRE VIS À-VIS DE LA GAUCHE}

Retour à la table des matières

La Droite et certains milieux du Centre tendent généralement à voir dans l'EDA une simple couverture du parti communiste illégal et dès lors leur principal grief à l'égard de Papandréou est qu'il favorise l'expansion du communisme grec en adoptant vis-à-vis de l'EDA une attitude bien trop tolérante. On lui reproche également de marquer trop de bienveillance à l'égard des revendications de la trentaine de députés d'orientation Centre-Gauche ou d'inspiration socialisante auxquels il doit sa majorité. Ces reproches ne sont certainement pas étrangers au mouvement de défiance qui s'est manifesté à l'égard de la monnaie nationale depuis la défaite de l'ERE et notamment dans l'intervalle entre les deux élections de novembre 1963 et de février 1964 (tendance irrésis-[p. 298] tible des Grecs, y compris de ceux à ressources limitées à

1 Ainsi, dans la nuit du 3 juillet 1964, l'envahissement du Parlement par environ deux cents jeunes qui sont parvenus à faire irruption jusque dans la salle des séances où les députés discutaient de l'affaire chypriote. Selon les porte-parole de la Gauche, cette manifestation d'apparence spontanée aurait été en fait préméditée et organisée par les éléments des services de sécurité mécontents du nouveau cours de l'évolution.

2 In Nouvelle Revue internationale, avril 1964, p. 88. 
acheter des livres-or dès que la moindre incertitude se manifeste à l'horizon monétaire).

Les allégations présentées à ce titre correspondent davantage, en général, à des procès d'intention qu'à l'exposé de faits précis. Ainsi en va-t-il quand on accuse l'aile gauche de l'Union du Centre de constituer ait sein de ce parti un élément de sape et de désagrégation de l'adhésion grecque à l'Alliance Atlantique. Parfois ces reproches portent sur des questions précises : par exemple l'effort du gouvernement de réaliser une certaine démocratisation de la vie syndicale par adoption d'un mécanisme de représentation professionnelle pour les élections à tous les organes syndicaux. Les conservateurs soulignent qu'un tel système est susceptible de faire passer le contrôle de la CGT aux mains d'éléments d'extrême Gauche. Citons encore un aspect de ce procès : l'insuffisance des efforts accomplis par le gouvernement grec pour obtenir un règlement de la question chypriote qui soit de nature à ne pas menacer la cohésion du flanc oriental de l'OTAN et permette d'éloigner de l'Île l'influence soviétique.

Papandréou répond à ces critiques en rappelant le combat qu'il mena jadis contre le communisme et en disant sa foi dans les procédures démocratiques pour arrêter l'expansion de celui-ci. Selon lui, c'est la satisfaction des justes revendications des travailleurs et non la mise en œuvre de mesures policières, comme le faisait l'ERE, qui peut seule arrêter le glissement vers le communisme. En même temps, le gouvernement manifeste le souci de conserver une fraction du dispositif d'exception : en particulier il s'oppose au retour dans la légalité du Parti Communiste et à la rentrée en Grèce des communistes exilés. Peut-être faut-il voir dans le souci d'échapper à des accusations de "gauchisme » la raison de très dures prises de position du leader de l'Union du Centre à l'égard des forces de Gauche (rappel de son attaque récente contre l'EAM).

Les quelques remarques que nous venons de présenter sous cette rubrique n'avaient d'autre mobile que de souligner les difficultés intrinsèques de l'Union du Centre. Celle-ci a pris les dimensions électorales que nous allons voir parce qu'elle a reçu les voix d'électeurs de Droite inquiets ou fatigués de divers aspects de l'expérience cara-[p. 299] manlique. Mais il est plus facile de totaliser des mécontentements et des refus que de fonder sur de telles bases une action gouvernementale.

Plus exactement, la seule manière d'éviter les crises internes dont disposent les formations centristes tiraillées sur leurs deux ailes est de s'en tenir à un prudent immobilisme (position dont la Démocratie Chrétienne italienne a été pendant de nombreuses années un excellent exemple). Mais l'Union du Centre s'est au contraire engagée à intervenir avec vigueur sur tous les plans de la vie nationale et il faut convenir que la situation actuelle de la Grèce légitime une telle ambition. Or, dans la pratique, il est peu fréquent que l'on parvienne à définir des solutions moyennes. Tout dynamisme gouvernemental risque de faire pencher la balance dans un sens plutôt que dans l'autre - le souci de neutraliser ce risque pouvant conduire à multiplier la 
distribution des avantages de manière que chacune des parties en présence ait le sentiment de tirer bénéfice du soutien accordé aux hommes politiques en cause. Mais la limite de tels stratagèmes est dans la nature des choses ou, si l'on veut, dans la nécessité d'augmenter les ressources disponibles avant d'en étendre la distribution.

Une fois atteint le plafond de telles largesses, il faut en arriver aux arbitrages qui risquent d'engendrer autant de déceptions et de colères : c'est alors qu'il est de plus en plus difficile au Centre de rester tel. Et, dans cette perspective, l'un ou l'autre des opposants au Centre - en vérité ce peut être les deux à la fois — sont susceptibles de retrouver leur chance et de rendre les coups qui leur ont été portés.

On peut, il est vrai, prendre la question de plus haut en essayant d'analyser la nature propre du Centre et sa position réelle sur l'échiquier politique. La revendication par le Centre d'une sorte d'équidistance à l'égard de la Droite et de la Gauche n'a de légitimité et, partant, de chance finale de succès qui si le Centre diffère effectivement par le contenu de sa clientèle et l'esprit de son idéologie des deux autres courants considérés. Dès le moment où il serait acquis qu'en pratique le Centre est bien plus proche de l'une que de l'autre de ces deux tendances, la revendication d'équidistance ne correspondrait plus qu'à une habileté tactique ou à une simple utopie. Pour la Grèce, c'est une question à laquelle il ne sera possible de répondre qu'après avoir examiné et évalué la manière dont les attitudes politiques effectives se distribuent entre les partis : l'esquisse de ce tableau de répartition sera faite au chapitre suivant.

[p. 300]

\section{DIMENSIONS DU PARTI}

Retour à la table des matières

Comme pour les partis déjà analysés, nous ne sommes en mesure de faire état que de résultats électoraux. Rappelons que l'EK a livré trois batailles électorales: la première en coalition avec le Parti Progressiste (1961), les deux autres $(1963,1964)$ sous son seul drapeau. Les résultats ont été les suivants :

\begin{tabular}{|c|c|c|c|c|}
\hline \multirow{2}{*}{ Élections } & \multicolumn{2}{|c|}{ Nombre } & \multicolumn{2}{|c|}{ Pourcentage } \\
\hline & Voix & Sièges & Voix & Sièges \\
\hline 1961....................... & $(1.555 .442)$ & (100) & 33,66 & 33,3 \\
\hline 1963.......................... & 1.962 .019 & 138 & 42,04 & 44,0 \\
\hline 1964.......................... & 2.424 .447 & 171 & 52,72 & 57,6 \\
\hline
\end{tabular}

La consultation de la carte de 1961 montre que l'EK dispose d'une très solide position dans les quatre circonscriptions de Crète, cette situation s'expliquant par le fait que l'Île est le pays de naissance d'E. Vénizélos, fondateur du Parti Libéral dont l'Union du Centre est le successeur. L'Union est également très bien implantée en Élide, fief électoral de S. Stéphanopoulos et dans l'archipel du Dodécanèse (J. Zigdis). On observe également que, dès 1961, l’Union a pris pied sur l'ensemble du 
territoire, son pourcentage des résultats ne tombant nulle part au-dessous de 10,9\%. Par ailleurs, en dehors des circonscriptions déjà citées, elle obtient de 30 à $50 \%$ des suffrages dans trois des quatre circonscriptions de l'agglomération athénienne (Le Pirée-Banlieue formant l'exception), cinq circonscriptions du Péloponnèse, quelques circonscriptions de Thessalie, les circonscriptions de la Thrace.

De 1961 à 1964, l'EK a considérablement progressé sur le plan électoral (ses résultats de 1964 ne tombant jamais au-dessous de 30,9). Elle dispose de la majorité absolue en Crète ainsi qu'en Élide et dans le Dodécanèse mais cette fois elle a également acquis une telle majorité dans le Péloponnèse du Nord, en Grèce Continentale (Attique, Béotie, Étolie-Acarnanie, Phtiotide, Phocide), en Thessalie et dans certains départements de l'Épire et de la Macédoine. Cependant l'EK n’obtient cette [p. 301] majorité ni dans l'agglomération athénienne, ni dans la circonscription de Salonique-Ville. On sait au surplus qu'à l'époque contemporaine le Centre a cédé à la Droite une partie des positions jadis occupées par les Libéraux en Grèce du Nord.

\section{V. ÉVALUATION D'ENSEMBLE}

\section{$\underline{\text { Retour à la table des matières }}$}

Comme force d'opposition, l'Union du Centre a atteint son objectif essentiel qui était de battre l'ERE sur le terrain électoral en un combat loyal. Les mises en garde adressées à la Monarchie par les leaders et parfois aussi la presse du Centre ont certainement compté parmi les facteurs ayant conduit le Palais à un relâchement du favoritisme témoigné jusqu'alors au profit de la Droite. Avec le recul du temps, il est possible que l'on tienne pour le principal succès de l'EK en ce domaine le fait d'avoir conduit les forces extra-parlementaires (armée et corps de sécurité) à ne plus s'immiscer directement dans la consultation. Ainsi l'EK a-t-elle contribué à réduire l'écart qui séparait la lettre des institutions de leur fonctionnement pratique.

Au titre de la formation d'un grand parti de style démocratique, l'expérience de l'EK se solde jusqu'à présent par un échec. Le parti constitue toujours comme dans les premiers temps de sa formation un groupe manipulé d'en haut sans que la base ait la faculté d'exprimer son sentiment sur la politique à suivre. Après le succès électoral c'est l'opposition à Papandréou, spécialement celle représentée par E. Tsirimocos, qui a revendiqué la mise en œuvre d'une gestion démocratique. Le Premier Ministre qui aime les manifestations de reconnaissance spontanée en provenance de la base ${ }^{1}$ ne semble pas pressé pour autant de donner suite au souci de démocratisation du parti qui aboutirait certainement à réduire la liberté de manœuvre dont il dispose.

\footnotetext{
Nous avons été témoins de l'une d'elles : la montée à Castri, commune distante d'une quinzaine de kilomètres d'Athènes et lieu de résidence du Premier Ministre, d'une forte délégation motorisée des chauffeurs de taxi-pirate - délégation venant remercier le Chef du Gouvernement de leur avoir procuré les permis nécessaires à la régularisation de cette situation. Il est à peine besoin d'écrire que c'était un spectacle bruyant et coloré.
} 
Le leader de l'EK n'a certes pas brisé, en tout cas pas encore, le pouvoir et la position des autres politiciens de son parti comme Caramanlis l'avait fait pour ceux de l'ERE. Peut-être ne cherche-t-il pas à réaliser un tel abaissement ou peut-être le temps lui a-t-il manqué pour [p. 302] obtenir déjà un tel résultat. Beaucoup en tout cas doutent qu'il y parvienne jamais : d'où les bruits qui circulent périodiquement sur l'éventualité d'une désagrégation du Cabinet, voire de l’EK toute entière.

Venons-en maintenant à l'EK comme instrument de gouvernement. Dans l'impossibilité de porter un jugement motivé sur une expérience dont la durée n'est encore que de quelques mois, nous nous limiterons à poser quelques jalons.

Au titre de la restauration des libertés politiques, des mesures d'apaisement ont été prises par le gouvernement: ainsi libération de quelques centaines de prisonniers politiques encore détenus à l'exception toutefois de 125 (parmi lesquels 8 femmes) condamnés pour délit d'espionnage en vertu de la loi d'exception 375. Les certificats de civisme sont demandés avec moins de virulence quoique, semble-t-il, les services d'exécution ne mettent pas tous une égale bonne volonté à appliquer les directives gouvernementales ${ }^{1}$. Le climat est certainement changé depuis l'arrivée au pouvoir de Papandréou ainsi qu'en témoigne la dissolution déjà évoquée des organisations d'Extrême-Droite ou, sur un autre plan, le projet de délivrer désormais des passeports valables pour plus d'une année et pour plusieurs voyages. Mais le Premier Ministre n'a nullement accédé à toutes les demandes présentées par la Gauche : c'est ainsi qu'il a déclaré s'opposer au retour massif des exilés (quelques-uns toutefois ayant été autorisés discrètement à rentrer dans le pays à titre individuel). De même, le gouvernement n'a pas permis aux enfants vivants à l'étranger de visiter durant l'été les parents qu'ils ont en Grèce.

Jusqu’à une époque récente le gouvernement s'en était tenu en ce domaine à des mesures particulières sans mettre en cause l'ensemble du dispositif d'exception. D'où des situations peu compatibles avec le [p. 303] rétablissement de l'ordre démocratique. Ainsi, en juillet 1964, lors de la mise au concours d'une chaire de science politique à l'École des Sciences Politiques d'Athènes (École dite Pandios) le certificat de civisme figurait-il ouvertement sur la liste des pièces à remettre par les candidats pour leur inscription. Un projet a été déposé pour normaliser la situation mais il n'a pas encore été voté, les tractations sur son contenu étant toujours en cours (décembre 1964): l'EDA lui reproche de maintenir en vigueur une fraction du dispositif existant. Il en va ainsi de la loi 509 qui interdit le Parti Communiste et punit toute activité se rattachant à l'expansion de l'idéologie communiste. Le texte conserve le principe du certificat de civisme quoiqu'il en limite l'emploi aux candidats à la fonction publique et à un certain nombre d'autres activités (en particulier, sur la demande des armateurs, aux inscrits maritimes).

Le nouveau régime a entrepris de réaliser une «décaramanlisation » de l'administration et des services parapublics, ainsi qu'un rajeunissement de la bureaucratie (mise à la retraite d'office des fonctionnaires ayant plus de 35 ans de 
service). Le Cabinet Papandréou éprouve d'ailleurs des difficultés à trouver pour occuper les postes ainsi rendus disponibles des hommes ayant les compétences techniques nécessaires et ne s'étant pas (ou pas trop) "mouillés » avec l'ERE. Dans l'ensemble, cette politique a été menée de manière plus rigoureuse pour les services de l'Administration de même que pour les organes des forces de l'ordre. Très prudent en ce qui concerne l'armée, le nouveau gouvernement a toutefois marqué un peu plus d'audace vis-à-vis de la Gendarmerie.

Signalons aussi la tentative faite par la nouvelle équipe pour purger la vie politique grecque du vice de la corruption. Durant la phase de « lutte irréductible » les dirigeants du Centre, et spécialement G. Papandréou, avaient accusé les membres dirigeants de l'ERE d'une grande malhonnêteté dans la gestion des affaires publiques. Dès son arrivée au pouvoir, le nouveau gouvernement a décidé de soumettre cette gestion à des enquêtes approfondies. Il vient d'aller plus loin en faisant voter une loi datée du 17 août 1964 qui, concernant la protection de l'honneur du monde politique, tend en réalité à assurer de manière permanente la moralisation de la vie publique grecque - loi dont le gouvernement s'est servi pour repousser la demande d'enquête spéciale sur Caramanlis et sa famille présentée par la Gauche.

Ce dispositif se situe dans la tradition de lois d'inspiration analogue prises par diverses cités de la Grèce antique (notamment Athènes et [p. 304] Corinthe). La disposition fondamentale de ce texte est que les citoyens grecs ayant occupé les postes gouvernementaux les plus élevés durant les 18 dernières années devront établir que leur fortune actuelle et celle de leurs proches ne trouve pas son origine dans un abus de l'autorité ou un trafic des fonctions dont ils furent investis. À en croire G. Papandréou, les politiciens grecs auraient l'habitude de s'appauvrir durant l'accomplissement de leurs devoirs publics : l'objectif de la loi est donc de découvrir et de punir le petit nombre d'hommes ayant fait exception à cette norme.

La caractéristique de ce système est d'être mis en œuvre non sur dénonciation individuelle mais de manière automatique pour plusieurs catégories de personnes : premiers ministres, ministres, chefs de parti, représentants parlementaires de parti, secrétaires d'État (ainsi que leurs épouses et enfants mineurs). Ces personnes doivent effectuer une déclaration de fortune dans les quatre vingt dix jours suivants la mise en vigueur de la loi. Ces déclarations sont en principe soumises à publicité.

Pour l'avenir, les titulaires des postes couverts par la loi (celle-ci s'étendant désormais à tous les députés et aux fonctionnaires de grade 1) devront faire une déclaration chaque année (ainsi qu'une dernière fois trois ans après avoir abandonné le poste).

Sans entrer dans la discussion approfondie de ce texte, observons qu'il tend à sous-estimer les facultés de dissimulation qu'ouvrent la fortune mobilière et l'intervention des banques étrangères, les établissements suisses offrant à cet égard des facilités et des garanties sans rivales. Seuls les naïfs ou les maladroits risquent d'être confondus par de telles vérifications dont on peut redouter au surplus qu'elles soient plus exigeantes pour les adversaires du gouvernement en place que pour ses amis. En définitive, ce texte, comme diverses autres démarches de l'actuel Premier 
Ministre, se caractérise par une sorte d'honnêteté démagogique dont il n'y a pas lieu d'attendre beaucoup de résultats pratiques.

En matière de politique étrangère, la réalisation la plus notable du nouveau gouvernement a été la signature, en date du 9 juillet 1964, d’une série de douze accords gréco-bulgares (économiques, commerciaux, techniques) qui mettent fin à l'état de tension qui régnait entre les deux pays depuis la seconde guerre mondiale. Lors d'une visite à Sofia du Ministre des Affaires Étrangères S. Costopoulos (24-29 septembre 1964), il a été déclaré aux termes du communiqué final que « les [p. 305] parties utiliseront uniquement des moyens pacifiques pour le règlement de toutes les questions bi-latérales et que toutes prétentions territoriales étant exclues pour toujours, la coopération entre eux représente une base solide pour la sauvegarde de la paix dans les Balkans et dans le monde ».

Un effort de normalisation des rapports a également été entrepris avec la Yougoslavie. En mars 1962, le gouvernement yougoslave avait accusé la Grèce de se livrer à la persécution de la minorité slave en Macédoine. À la suite de cette déclaration, le gouvernement grec avait suspendu de son propre chef l'accord sur le trafic frontalier signe en 1959 avec la Yougoslavie. Tout en admettant la présence en Macédoine de quelques 40.000 " grecs parlant un dialecte slave » le gouvernement grec refuse de considérer qu'il existe de ce fait un problème de minorité ethnique et tient l'intérêt porté à ces Grecs par les autorités yougoslaves pour l'indice d'un rêve irrédentiste. Les négociations ouvertes en fin septembre entre les deux pays pour effacer les traces de la déclaration yougoslave (notamment remise en vigueur de l'accord de 1959) ont abouti à un accord (novembre 1964). Notons que jusqu'à présent le gouvernement grec n'a accompli aucune démarche pour normaliser les relations gréco-albanaises, la Grèce étant toujours en état de belligérance avec l'Albanie.

Cependant, durant cette période, c'est le problème de Chypre qui, une fois de plus a été au premier plan de l'actualité et des préoccupations du gouvernement grec. Celui-ci, ainsi d'ailleurs que le Palais, est soumis à une intense pression américaine dont le but est de désolidariser la Grèce de Mgr Macarios et d'amener la première à adopter le projet de partage élaboré par l'ancien secrétaire d’État américain Dean Acheson. La caractéristique des propositions de ce dernier qui, ayant été mis en place par le seul Président Américain, intervint en pratique sous le couvert de l'ONU, est de faire fi de l'appui que la communauté chypriote grecque donne à son chef.

Il est impossible, sur la seule base des informations courantes, d'évaluer la conduite du gouvernement grec en la matière. En apparence, le comportement de celui-ci semble marqué de fluctuations et de vacillations. Mais peut-être l'utilisation de tactiques dilatoires ou changeantes est-elle la seule solution dont les pays faibles disposent face à un grand État qui tente de leur imposer, avec un minimum d'égards diplomati-[p. 306] ques, une solution conforme à ses préoccupations. Une fois de plus, en tout cas, le peuple grec éprouve le caractère unilatéral de l'atlantisme ${ }^{1}$.

1 Voir à ce propos les déclarations faites par A. Papandréou à l'envoyé du journal Le Monde, $\mathrm{n}^{\circ}$ du 45 octobre 1964. Celles-ci ayant, par leur franchise, suscité des protestations en Grèce, Papandréou 
Dans l'ordre des affaires intérieures, le gouvernement a immédiatement consenti un effort important au titre de l'éducation — effort dont le coût pour 1964 est estimé à 500 millions de drachmes (soit environ 16 millions et demi de dollars US). Parmi les points socialement importants de ce programme, signalons l'octroi de la gratuité des études pour l'enseignement supérieur et la distribution de repas aux enfants des écoles primaires.

L'un des principaux traits de la politique suivie en ce domaine est la gratuité complète de l'enseignement du cycle primaire au supérieur inclus.

Citons aussi l'action entreprise pour centraliser sous une administration unique les diverses branches de la politique économique et de faire du Ministère de la Coordination avec le concours du Centre de Programmation et de Recherche Économique (centre désormais intégré dans l'appareil gouvernemental) l’État-Major chargé de dresser les plans du développement économique. C'est là certainement un élément positif pour l'amélioration de l'économie nationale. Le gouvernement a aussi marqué l'intention d'améliorer la condition sociale des travailleurs: toutefois, par suite des charges qu'entraîne pour la Grèce — comme d'ailleurs pour la Turquie — le conflit de Chypre (présence dans l'Île de troupes au-delà de la limite autorisée par les accords de Zurich) il leur a demandé de suspendre toute nouvelle revendication jusqu'à la solution du problème.

En définitive, l'équipe de l'Union du Centre a certainement fait preuve de dynamisme et de bon sens à l'égard de plusieurs problèmes d'intérêt vital pour le pays (relations de bon voisinage avec les pays contigus; perfectionnement du système d'éducation ; coordination du développement économique...). Cependant cet effort, si intéressant soit-il, ne touche guère aux questions de fond de la structure sociale et de la position internationale du pays. Mais l'Union du Centre et plus généralement le système grec des partis sont-ils correctement équipés pour envisager et mettre en œuvre de telles réformes?

a, selon la formule consacrée, déclaré que sa pensée avait été mal présentée. Selon la Gauche, c'est la résistance d’A. Papandréou aux interventions et pressions des États-Unis qui constituerait la raison, ou l'une des principales raisons, de sa chute.

Notons que le point de vue de l'EDA en cette affaire n'est pas partagé par tous les milieux de Gauche, une part de ceux-ci (tendance représentée notamment par l'hebdomadaire Eléftéros) estimant que malgré ses démêlés avec les services officiels américains, A. Papandréou reste l'un des hommes des États-Unis en Grèce. 
[p. 307]

\section{CHAPITRE IX}

\section{ESQUISSE D'UN BILAN}

$\underline{\text { Retour à la table des matières }}$

QUICONQUE examine de l'extérieur les résultats des dernières élections grecques est susceptible de les interpréter comme une preuve décisive de la modernisation politique du pays. Par rapport à l'immédiat après-guerre, l'indice le plus sûr de changement est la réduction à deux des grands adversaires en présence, l'un cédant finalement à l'autre la majorité absolue qu'il détenait au Parlement depuis plus de sept ans. En considérant les avantages qui sont généralement attribués au système bipartisan, on peut être tenté « admettre que la Grèce dispose désormais de l'instrument gouvernemental indispensable à son développement économique et social.

Un tel jugement, qui mise sur l'adoption par la Grèce d'un bipartisme de style britannique, reste empreint d'optimisme et on peut, à divers égards le tenir pour fallacieux. Certes la structure partisane a subi des modifications, mais il n'est pas du tout sûr que le contenu des rapports politiques ait évolué aussi complètement et aussi rapidement que l'apparence. On peut au surplus se demander si les deux grands partis qui, s'opposent aujourd'hui ne sont pas la simple reconstitution des deux formations qui ont alternativement gouverné la Grèce depuis la première guerre mondiale et ont échoué à la moderniser. L'évolution observée durant ces dernières années ne seraitelle pas, au moins en une large mesure, la remise en l'état des vieux clivages partisans?

N'oublions pas, au surplus, l'existence d'une Gauche qui, même si son rôle est finalement plus étendu et plus diversifié, offre néanmoins aux communistes une faculté d'influencer de l'intérieur la vie politique et le travail parlementaire. Cette Gauche, elle-même unifiée depuis 1951, ne [p. 308] dispose pas ou pas encore des forces parlementaires et extraparlementaires qui lui permettraient de bloquer ou même d'entraver de manière décisive le jeu bipartisan ainsi évoqué. Cependant, sa 
capacité d'intervention est déjà trop grande pour qu'elle ne constitue pas un élément irréductible du système partisan.

Certains avancent, il est vrai, qu'il suffirait probablement de l'adoption d'un système électoral majoritaire pour réduire, au moins sur le plan parlementaire, les obstacles que l'EDA peut apporter à la confrontation Droite-Centre. Or, soulignentils, le scrutin majoritaire, sous la seule réserve que ses promoteurs s'y rallient, non pas à titre tactique pour une seule consultation mais de manière durable, a tout autant de légitimité que le système proportionnel. L'observation ne manque pas de valeur. Mais lorsque dans un pays coexistent des courants irréductibles ou difficilement réductibles les uns et les autres, ce mode de scrutin est susceptible de provoquer l'étouffement parlementaire des minorités sans pour autant en provoquer la disparition dans le pays. On s'oriente ainsi vers un régime dont la légitimité peut être contestée dans la mesure où il comporte de graves inégalités de représentation. Au surplus, beaucoup de Grecs, surtout dans les rangs du Centre, redoutent que l'instauration d'un tel régime n'entraîne une excessive polarisation des forces. La représentation proportionnelle leur paraît le système le mieux approprié pour réduire les tensions et affrontements qui caractérisent la vie politique grecque.

Notre idée est que, réserve faite de quelques éléments de modernité, le système des partis grecs tant dans son mode d'organisation que dans l'inspiration de ses clivages relève davantage des systèmes traditionnels du XIX ${ }^{\mathrm{e}}$ siècle que des systèmes bureaucratisés de notre temps. Après avoir caractérisé les traits de ce système, il faudra donc examiner ses chances de modernisation.

\section{TRAITS CARACTÉRISTIQUES DU SYSTÈME DES PARTIS}

$\underline{\text { Retour à la table des matières }}$

Durant les quatre ou cinq dernières années, la contestation partisane, spécialement au niveau électoral, a mis aux prises quelques grandes formations susceptibles de couvrir tout le territoire. La lutte se concentre désormais autour de quelques sigles et en apparence nous avons un régime très voisin de celui que l'on peut observer dans des pays comme [p. 309] la Grande-Bretagne, la Belgique ou l'Allemagne Fédérale. Mais une telle comparaison appelle immédiatement des réserves. 


\section{A. PERMANENCE DES STRUCTURES TRADITIONNELLES}

\section{$\underline{\text { Retour à la table des matières }}$}

La consolidation définitive des traits qui semblent se dégager de l'expérience de ces dernières années est en effet subordonnée à la présence de partis dont la solidité et la cohésion ne dépendent pas, c'est-à-dire ne dépendent plus, des qualités des leaders placés à leur tête. Un tel objectif ne saurait être atteint sans l'existence, au sein du parti, d'un appareil qui soit à la disposition du leader désigné par les instances compétentes. C'est un appareil de cet ordre, dans lequel, ne nous y trompons pas, doit figurer quelque élément d'organisation bureaucratique, qui peut seul transformer un parti lié à une personne ou un parti-coalition de personnalités en un instrument permanent de conquête et, en cas de victoire électorale, d'occupation du pouvoir. Or, nous l'avons vu, qu'il s'agisse de l'ERE ou de l'EK, un tel appareil n'existe encore pour l'essentiel que sur le papier.

Certes, divers facteurs (en particulier les mécanismes de la loi électorale, la conviction de l'impossibilité d'accéder au pouvoir et d'y demeurer sans l'acceptation d'une certaine discipline, la centralisation du patronage en raison du passage à une gestion centralisée des ressources publiques...) ont réduit le rôle des personnalités locales dans chacun des deux partis et contribué à l'affermissement de la position du leader. Mais il n'est pas possible d'avancer que ce rôle a été supprimé. Pour de nombreux électeurs grecs, spécialement dans les campagnes - et le monde rural représente encore globalement la moitié de la population grecque — le vote en faveur de l'un des partis passe encore à travers l'allégeance à un parti personnel ou un ancien parti personnel. Le signe le plus clair de cette situation est la difficulté d'appliquer aux partis grecs la notion d'adhérent - telle qu'elle s'est peu à peu dégagée en Europe Occidentale au début de ce siècle de la pratique des partis socialistes.

Les partis grecs, à la seule exception de l'EDA, restent encore des partis ou groupes parlementaires de type traditionnel. Leur implantation administrative propre dans les circonscriptions reste légère. Cette situation ne les empêche pas de présenter des candidats se réclamant de leur sigle dans toutes les circonscriptions et à ce propos il est intéressant d'observer que l'EK, comme d'ailleurs précédemment l'ERE, ont [p. 310] pu réaliser cette performance quelques semaines à peine après la date de leur création formelle.

Cette particularité s'explique aisément si l'on considère qu'il suffit, pour affronter les élections sur une base extensive, de disposer d'un large réseau de relations. Un tel réseau, dans lequel agissent encore des relations de famille et des rapports de clientèle, permet des mobilisations électorales mais ne suffit certes pas pour accomplir le travail d'encadrement et d'éducation que les partis d'esprit moderne s'efforcent de réaliser entre deux campagnes électorales. Or, ce travail, les grandes 
formations helléniques ne l'accomplissent que de manière très restreinte et il n'est pas certain que les dirigeants actuels pensent ou souhaitent qu'il doive être accompli.

Dès lors, le commentateur ne saurait tenir pour définitivement acquis les résultats du récent mouvement de centralisation partisane. En considérant le passé, tout ce que l'on peut écrire est que la Droite, soumise à un leader autoritaire - jouissant de puissants appuis extra-parlementaires - est parvenue à maintenir son unité et que les partis centristes ont compris que leur seule chance de renverser le courant les éloignant du pouvoir était de s'unir eux-mêmes. La désagrégation de l'un ou l'autre des deux blocs ôterait au survivant l'incitation à rester uni ou, tout au moins, en rendrait l'urgence moins pressante. Le fait est que si la propension à l'unité venait à faire défaut au sein de l'un ou l'autre des groupes parlementaires — et aujourd'hui bien des mécontentements s’affirment autour de G. Papandréou, bien des réticences se manifestent à son endroit — il n'y aurait pas d'appareil partisan pour y substituer le désir de survie qui caractérise les éléments bureaucratiques. En définitive, il faut bien constater que beaucoup de choses dépendent encore du leader placé à la tête du gouvernement ou de l'opposition ainsi que des luttes susceptibles de se dérouler pour sa succession.

Observons toutefois que l'opinion tend à marquer quelque sévérité ou défiance à l'égard des manœuvres de scission ou de fragmentation partisanes fondées sur des ambitions ou animosités personnelles. Cette tendance s'est manifestée à propos de la querelle G. Papandréou - S. Vénizélos dont nous avons précédemment parlé. Il s'agit certes d'un mouvement récent et encore fragile. Si cette tendance se confirmait et s'approfondissait, il en résulterait la formation de courants au sein des grands partis plutôt que la désagrégation périodique de [p. 311] ceux-ci. Un frein serait mis aux démarches centrifuges dont nous avons vu tant de cas d'application.

Nous ne pouvons encore prévoir le destin d'un tel mouvement. Il est seulement possible de dire qu'aujourd'hui tous les grands partis grecs se caractérisent par une pluralité de courants. C'est vrai pour l'ERE, le départ de Caramanlis ayant ouvert la voie à des discussions et oppositions au sein du Groupe Parlementaire, c'est vrai pour l'EK dans lequel la politique du Cabinet fait l'objet de discussions, c'est vrai aussi pour l'EDA dont les décisions sont souvent le fruit de compromis.

En définitive, les éléments de consolidation risquent d'être affectés de fragilité par suite de l'absence de solides organisations partisanes. Le point est dès lors de déterminer les obstacles qui s'opposent à la construction de tels appareils. La plupart des commentateurs ne se posent guère un tel problème ou plutôt n'hésitent pas sur la réponse à y faire qui, d'après eux, est l'indiscipline naturelle des Grecs, leur versatilité, leur légèreté même. Il est fréquent que sur cette lancée l'on se réfère à une sorte de personnalité méditerranéenne qui, depuis l'Antiquité, se signalerait par l'incapacité de mener toute forme d'action politique cohérente. Observons pourtant au passage que les Italiens, eux-mêmes méditerranéens et, selon les mêmes sources ou des sources analogues, spécifiquement indisciplinés, disposent aujourd'hui d'appareils partisans dont la survie ne dépend pas de destins individuels. 
En dehors des commodités qu'elles offrent, les explications folkloriques dispensent, nous l'avons dit, d'aller au fond des choses, c'est-à-dire, au titre de notre analyse, de considérer la structure sociale dont, d'une manière ou d'une autre, les partis sont l'expression, au niveau de la réalité politique. N'oublions pas que, dans les pays d'Europe Occidentale, c'est généralement dans le secteur socialiste et en liaison avec la formation d'une vaste classe ouvrière qu'a pris naissance le mouvement de bureaucratisation des partis. Sans doute, aucun des partis de ces pays, y compris les partis communistes, n'est un modèle d'homogénéité sociale et tous ont un recrutement diversifié (certains, notamment les partis démochrétiens tirant même leur originalité du refus de principe d'une telle homogénéité: formule dite en Italie de l'Interclassisme). Mais nous savons bien que chacun de ces partis a un centre de gravité quant à l'origine sociale de ses membres et de ses électeurs.

Le point reste vrai même si l'on tient compte du développement considérable des classes moyennes qui bouleverse une partie des données [p. 312] acquises. Les partis britanniques - conservateur et travailliste — se disputent chacun une fraction des électeurs qui, selon les circonstances et l'état de la conjoncture politique peut pencher alternativement d'un côté ou de l'autre. Ce trait est important au sens où il suscite inévitablement un rapprochement des programmes mais il existe de part et d'autre une fraction irrévocablement fidèle à son parti parce qu'elle y voit, et ceci à juste titre, l'instrument de défense d'une certaine conception de la vie sociale et donc des intérêts attachés au maintien de cette conception.

En règle générale, on peut se demander s'il existe une chance de bâtir un appareil partisan au sens européen du terme (cette précision tendant à écarter de la discussion les machines américaines qui sont des instruments d'une toute autre nature) sans un enracinement de cet appareil dans un électorat d'une nature sociale particulière. En dehors de divergences irréductibles dans cette base sociale, on peut concevoir d'un parti à l'autre des différences sur le mode d'agencement des institutions (monarchie république) mais non sur l'organisation de la société elle-même.

Or, la Grèce n'a pas connu ou n'a connu que fragmentairement les transformations techniques et les redistributions professionnelles qui ont provoqué ailleurs le passage des luttes idéologiques du $\mathrm{XIX}^{\mathrm{e}}$, siècle aux oppositions sociales du $\mathrm{XX}^{\mathrm{e}}$ siècle (ces transformations ayant fini par susciter aujourd'hui, peut-être de manière provisoire, un certain apaisement des oppositions sociales). Pour parler concrètement, le pays n'a pas connu les changements qui, en Belgique et Grande-Bretagne, ont amené face au parti conservateur la naissance d'un puissant parti d'inspiration socialiste qui, selon le mode de scrutin, devait rejeter dans une position secondaire (Belgique) ou quasi nulle (Grande-Bretagne) le vieux Parti Libéral. Et cette circonstance qui détermine l'état structurel des partis retentit aussi sur les clivages qui les séparent. 


\section{B. MAINTIEN DES CLIVAGES ANCIENS}

Retour à la table des matières

Les deux grands partis grecs d'aujourd'hui ont finalement — si l'on raisonne en termes d'organisation sociale — des programmes assez voisins l'un de l'autre. Actuellement celui mis en œuvre ou, au moins, proposé par C. Papandréou est d'esprit plus progressiste que celui effectivement appliqué par C. Caramanlis. Mais, pas plus l'un que l'autre, ils ne mettent en cause l'état des structures et des rapports socioéconomi-[p. 313] ques. Le propre de ces programmes est en somme de s'adresser à chacune des couches professionnelles et de faire à chacune des promesses, aucune de ces couches ne constituant à priori un objectif hors de la portée de l'un ou l'autre des deux adversaires en présence.

On dira que cette analyse méconnaît le fait que ces partis disposent chacun de bastions dans des zones déterminées du pays (ainsi liaisons entre la Droite et de nombreux milieux ruraux). On mentionnera aussi peut-être le sentiment d'identification à un parti à travers l'allégeance à une personne - étant d'ailleurs entendu que ces attitudes concernent autant les petits partis d'assiette locale que les grandes formations. Ces faits sont réels mais il s'agit en réalité de la persistance en notre siècle de modes de rapport ayant leur origine dans des phénomènes d'un temps antérieur - un temps ne connaissant pas encore les transformations sociales suscitées par le progrès technique. Quand un paysan vote pour un notable, fut-ce sur la base du patronage, ce choix est exactement le contraire de celui que dicterait la conscience d'une appartenance sociale particulière. Et dès lors, ce qu'un notable a pu obtenir pourquoi un autre notable devrait-il s'estimer privé de la perspective de l'obtenir à son tour?

L'Union Radicale et l'Union du Centre restent en définitive des partis de l'ordre bourgeois dont les divergences, pour réelles qu'elles soient ou aient été, ne sont pas — surtout après liquidation du féodalisme agraire — de nature fondamentale. Cette caractéristique commune les voue l'un et l'autre à demeurer des partis de cadres plutôt que des partis de masses. La situation ne serait susceptible de se modifier que si le développement de l'industrialisation valait à l'EDA une puissante base ouvrière qui, pour la plus large part, se refuserait au soutien des partis bourgeois et dont la nature même provoquerait une différenciation sociale dans les clientèles partisanes. La structure sociale grecque, nous l'avons vu, n'en est certes pas là et dès lors il n'y a pas incitation à la formation du côté bourgeois d'un appareil partisan enraciné dans les couches favorables à l'ordre existant.

La situation politique grecque s'éclaire considérablement si, en choisissant pour base du raisonnement le domaine essentiel de la défense de l'ordre social existant, l'on observe que le système partisan est entièrement dominé et, pour la plus large part, occupé par deux grandes variétés de conservatisme que l'on pourrait qualifier de conservatisme traditionnel et de conservatisme libéral. Ces deux expressions, bien 
mieux que les [p. 314] termes de Droite et de Centre, nous paraissent traduire les clivages existants.

Le conservatisme traditionnel, qui se situe dans la ligne du vieux parti populiste, met l'attachement à la Monarchie au centre des valeurs défendues. Moins fermé aujourd'hui qu'hier à l'idée du mouvement et à la conception d'un projet réformiste, il tient néanmoins à la stabilité des rapports sociaux et au maintien des institutions juridiques sur lesquelles repose cette stabilité. Le conservatisme libéral représente la ligne vénizéliste qui n'avait certes rien d'antidynastique : il admet ou si l'on préfère ne met pas en question l'institution monarchique sous réserve toutefois, ce qui fut rarement le cas dans la Grèce contemporaine, que le Monarque accepte le jeu constitutionnel et ne témoigne pas de favoritisme à l'égard des traditionnalistes.

Le conservatisme libéral est certainement plus ouvert, selon l'expression connue, aux vents du changement ne serait-ce qu'en raison de la nature de sa clientèle liée aux progrès de l'urbanisation et à l'ascension des classes moyennes. Ce courant accorde plus d'importance que le conservatisme traditionnel aux problèmes de l'éducation, de la justice fiscale, de l'amélioration du sort des travailleurs industriels. Mais, fondamentalement, il reste attaché au régime de la propriété privée et à toutes les forces socio-politiques qui en découlent.

On peut dès lors s'interroger sur les facteurs qui ont donné une telle violence à l'affrontement Droite - Centre au cours des dernières années. Peut-être la manière correcte de poser le problème est-elle de se demander si l'évolution aurait pris le même cours au cas où le Palais n'aurait pas imposé Caramanlis comme leader de la Droite et où ce poste serait allé à St. Stéphanopoulos. Notre sentiment est que, durant une période, C. Caramanlis s'est servi de la Droite traditionnelle en la pervertissant d'une double manière: d'une part en lui donnant une coloration essentiellement affairiste, d'autre part en lui conférant un caractère nettement fascisant (liaison avec la frange fasciste et à quelques égards nazie dont les organisations para-étatiques aujourd'hui dissoutes étaient l'émanation). Ce développement de l'affairisme et de la fascisation de l'appareil gouvernemental sur la base d'une structure électorale traditionnaliste constitue la marque propre de l'expérience Caramanlis.

Cette expérience pourrait bien n'avoir été qu'une parenthèse si du moins l'Union du Centre entreprenait avec assez d'énergie la purification des rapports économiques entre les groupes d'affaires et le pouvoir ainsi [p. 315] que l'épuration des services publics (corps de sécurité compris). Sans excuser pour autant l'orientation caramanlique, on peut penser que quelques-uns de ses aspects les plus fâcheux ceux que l'ERE justifiait par la nécessité de la lutte contre le communisme — étaient en rapport direct avec le travail des agents américains en Grèce (en particulier ceux de la CIA). En d'autres tenues, ces abus représentaient au moins partiellement le fruit ou la conséquence d'ingérences étrangères dont nous essaierons plus tard de donner une vue systématique.

En somme, la situation présente des deux grandes formations grecques, si on la débarrasse, au moins idéalement, de l'apport spécifique du caramanlisme, ressemble par plusieurs traits à celle des pays d'Europe Occidentale avant la grande expansion 
industrielle. Cependant, la confrontation entre ces deux variétés de conservatisme n'exprime pas la totalité de la vie politique grecque. Il faut aussi compter avec l'existence d'une Gauche qui, comme nous l'avons vu, sans perturber entièrement le jeu analysé, en altère certaines modalités. Une large partie des conservateurs grecs et les Libéraux eux-mêmes n'échappent pas entièrement à cette propension assimilent automatiquement au communisme tous les hommes portés d'une manière ou d'une autre à mettre en cause les institutions et pratiques de l'ordre établi. La réalité est certes plus complexe.

L'aspect ancien de la gauche, lié à la philosophie libérale du XIX ${ }^{\mathrm{e}}$ siècle, c'est le républicanisme, le remplacement de la Monarchie par la République. Cette gauche, qui s'attache à la question du régime politique sans mettre en cause ou en ne contestant que faiblement les principes de l'ordre capitaliste, a tenu un grand rôle dans l'entre-deux guerres. Liée à un certain souci de justice sociale ou de défense des faibles (en particulier dans l'ordre de l'amélioration de l'enseignement public, du perfectionnement des rapports de travail, de la consolidation de la petite propriété agricole, de l'octroi d'une aide aux réfugiés...) cette gauche s'est pratiquement confondue durant une période avec le vénizélisme.

Nous avons vu que la guerre et l'insurrection communiste ont eu pour résultat de rapprocher de la Monarchie, ce rapprochement étant plus ou moins étroit selon les cas, bien des hommes d'opinions précédemment républicaines, des hommes aussi divers que P. Canellopoulos et G. Papandréou. On peut admettre qu'il en est allé de même pour la plupart des républicains de tendances socialement conservatrices. Autrement dit, la peur du communisme a renforcé la cause de la Monarchie [p. 316] tenue à juste titre, par suite de l'attachement actuel de l'Armée à la Couronne, comme le pilier de l'ordre établi.

Désormais, les républicains favorables à l'ordre existant ne paraissent plus constituer un secteur autonome et spécifique du monde politique grec. Ralliés à l'un des deux partis conservateurs, le conservateur libéral surtout, ils acceptent jusqu'à nouvel avis l'institution monarchique, même s’ils n'éprouvent aucune admiration pour le principe dynastique et aucune vénération pour le titulaire actuel de la Couronne. Rappelons qu'au moment où le Palais témoignait ouvertement de favoritisme à l'égard de l'ERE, Papandréou lui-même, tout en reprochant cette attitude à la Monarchie, déclarait compter sur elle pour rétablir une situation correcte.

La gauche se compose donc désormais des hommes favorables à des transformations dans l'ordre socio-économique existant, c'est-à-dire dont les convictions se rattachent, quoiqu'à des degrés divers, au socialisme. Étant donné qu'en Grèce la Monarchie représente le symbole et le garant de l'ordre établi, il serait difficile d'entretenir de telles convictions sans avoir en même temps une préférence pour le régime républicain. En d'autres termes, la gauche se caractérise aujourd'hui par deux dimensions: une option en faveur du régime républicain que les circonstances actuelles transforment en une simple aspiration sans grande chance de réalisation immédiate ou même prochaine; une propension à recommander ou 
revendiquer le changement social qui s'affirme désormais même chez ses plus ardents partisans, sous une forme particulièrement modérée.

Au niveau des principes toutefois, on peut répartir la gauche en deux grandes catégories : d'une part les adeptes du socialisme proprement dit, c'est-à-dire ceux qui ont la volonté, même s'il s'agit là d'un projet de longue haleine, de transformer complètement l'ordre social ; d'autre part ceux qui sont simplement d'orientation socialisante ou réformiste. Les communistes relèvent, bien entendu, de la première de ces tendances dont pourtant il ne serait pas juste de prétendre qu'ils ont l'exclusivité. C'est évidemment la première de ces tendances qui donne à l'EDA, sa base la plus solide, celle qui pour l'essentiel lui reste fidèle dans les diverses circonstances de la lutte politique. Mais où va la seconde tendance?

Le trait caractéristique du système des partis grecs est qu'il n'y existe pas (ou plus) de formation susceptible de rassembler, de manière auto-[p. 317] nome, les hommes qui, sans être partisan d'une collectivisation totale de style marxiste, sont néanmoins désireux d'apporter diverses modifications au régime social existant (ainsi renforcement de la zone de l'exploitation publique) ou de lutter contre diverses pratiques des gouvernements au pouvoir, Centre compris (ainsi colonisation de la Grèce par le capitalisme étranger). On dira peut-être que, sur la base de son programme actuel, l'EDA offre à ce courant un point de fixation acceptable. Mais aux yeux d'une partie de l'opinion de gauche, l'EDA reste marquée par ses contacts avec les communistes - des contacts assez étroits pour donner au communisme une place importante et éventuellement primordiale dans la direction de l'organisme. En définitive, la politique du parti est marquée de quelque ambiguïté. Il n'est pas facile de déterminer la part du communisme dans la formation des décisions de l'EDA ou, si l'on préfère, d'apprécier le poids des relations entre Athènes et Bucarest. Au surplus, cette formation, sans jamais cesser de placer ses démarches sous le signe de l'unité des forces démocratiques, n'a pas toujours un style d'action propre à faciliter l'établissement de tels contacts.

Si l'on en croit divers commentateurs, le courant de la gauche réformiste ou socialisante représenterait, idéologiquement, le seul Centre authentique de la politique grecque, cette situation lui venant de son refus du conservatisme (y compris le conservatisme libéral) et du socialisme tel que représenté par l'EDA. Pourtant, cette nuance de l'opinion qui, constituée d'un mélange d'aspirations républicaines et socialisantes, pourrait jouer un rôle de ferment, est conduite à se diviser faute d'une formation qui lui soit propre. Une fraction collabore avec l'EDA dans laquelle elle ne peut probablement exercer qu'un rôle mineur. L'autre aujourd'hui plus nombreuse que la première, constitue l'aile gauche de l'EK. Or cette aile gauche ne semble avoir qu'une influence réduite sur l'orientation politique du gouvernement G. Papandréou qui travaille finalement, malgré le procès d'intention que lui livre la Droite la plus intransigeante, à une consolidation du capitalisme et de son appareil politique de soutien (Monarchie comprise).

Les raisons d'une telle situation sont nombreuses. On peut mentionner la pénalisation infligée aux petites formations par les lois électorales de proportionnelle 
renforcée. Par ailleurs, on comprend que les leaders de cette tendance aient jugé opportun d'entrer dans une formation qui, même d'inspiration socialement conservatrice, se proposait de chasser du pouvoir la Droite affairiste et fascisante de Caramanlis. [p. 318] Le souci de n'être pas trop éloignés de la distribution des avantages du pouvoir a pu jouer dans le même sens. Mais la raison de fond est que, pour les raisons que nous avons dites, ce courant ne dispose pas d'une base sociale étendue. Et, comme tous les groupes dont la superstructure intellectuelle ne s'appuie que sur une base sociale insuffisante, ce secteur est voué à la fragmentation.

La conséquence de cet état de choses est que cette gauche - ce centre-gauche préfèrent dire certains - ne tient qu'une place limitée dans la politique grecque. Certains des hommes qui la constituent sont de bons drapeaux sur une liste électorale et à ce titre leur concours est recherché en période électorale. Mais la campagne terminée, ce sont les forces habituelles qui tendent à prendre le dessus. La principale influence qui puisse altérer la prépondérance de ces forces est la pression des groupes sociaux (paysans, travailleurs industriels, artisans...) mobilisables sur la base du mécontentement. Et à cet égard c'est l'EDA qui est la mieux placée pour encourager et encadrer de tels mouvements.

En définitive, sous des apparences de modernité, les deux grands adversaires demeurent des partis d'inspiration ancienne même s'il leur arrive d'utiliser de temps à autre des techniques de liaison et de communication modernes. Il est douteux que leurs dirigeants, du moins la plupart d'entre eux, aient pleinement assimilé les exigences de la révolution industrielle et les clivages susceptibles d'en résulter. Cette situation est aisément compréhensible si l'on admet qu'il existe inévitablement un certain parallélisme entre les structures partisanes d'une part, le tissu des rapports socio-économiques qui leur sert de fondement d'autre part. Il est dès lors naturel que les chances de modernisation de l'appareil politique soient en relations étroites avec le développement économique.

\section{DÉVELOPPEMENT ÉCONOMIQUE ET MODERNISATION POLITIQUE}

$\underline{\text { Retour à la table des matières }}$

Sans entrer dans une discussion approfondie de ce parallélisme, nous voudrions signaler que le problème a une signification bien différente selon que les structures partisanes constituent l'élément moteur des transformations socio-économiques ou un élément induit de celles-ci. En évoquant des notions fort générales, nous n'avons d'autre ambition que [p. 319] d'évaluer les chances d'introduction et de consolidation dans la vie politique grecque de la formule du parti de masse bureaucratisé.

Dans un certain nombre de situations, qui sont allées en se multipliant au cours des dernières années, on a assisté à la création de structures politiques tendant expressément à la destruction des structures socio-économiques existantes et à leur remplacement par des modes nouveaux de relations. Le procédé a été utilisé pour 
lutter aussi bien contre des clivages sociaux que contre des clivages ethniques. À notre époque, l'appareil politique transformateur est généralement un parti unique ou, au moins hégémonique.

En moyenne, la mise en œuvre de cet appareil repose initialement sur l'action d'une minorité qui s'est, d'une manière ou d'une autre, assuré les leviers de commande, cette minorité étant ensuite tenue d'obtenir le plus vite possible l'appui populaire utile au démarrage de l'expérience et finalement indispensable à sa consolidation. En des situations de cet ordre, l'ampleur et la rapidité des changements socio-économiques dépendent de la capacité d'autorité et plus généralement d'influence que la nouvelle structure partisane parvient à s'assurer.

Dans les pays capitalistes, la modification des structures socio-économiques a été le résultat du progrès technique soit que les vieilles structures tombent d'elles-mêmes sous la poussée des perfectionnements technologiques, soit que les gouvernants euxmêmes mus par le souci d'un rendement maximal en provoquent l'adaptation ou l'élimination. Disons en gros que la classe capitaliste, soucieuse de modernité dans l'ordre des institutions économiques, s'est efforcée de freiner autant que possible les changements sociaux ou du moins les conséquences de ceux-ci sur la distribution du pouvoir. Mais, ainsi que le montre bien la naissance et l'expansion des partis socialistes comme des syndicats ouvriers (le lien entre ces deux séries de groupements variant selon les pays), les transformations sociales parviennent finalement à se frayer un chemin jusqu'au niveau de la représentation politique.

Le système des partis bourgeois (fondé en principe sur d'autres clivages que ceux nés des rapports de production) s'est donc trouvé en présence de forces neuves constituées sur la base d'un enracinement social spécifique, l'un des résultats du mouvement étant d'enlever aux partis traditionnels le droit de parler et d'agir comme s'ils étaient représentatifs de l'ensemble de la population. Comme le montre bien la lenteur du processus d'introduction des socialistes dans les conseils gou-[p. 320] vernementaux, les bénéficiaires de la situation ont tenté de restreindre et, en tout cas, de freiner les conséquences de transformations socio-économiques sur le fonctionnement du système partisan. Mais il est clair qu'une certaine adaptation ne pouvait manquer de s'accomplir.

Cette adaptation s'est faite de manière bien différente selon les cas. Les partis conservateurs ont d'abord nié l'existence de classes sociales aux intérêts divergents. Puis ils ont contre-attaqué en faisant appel aux classes moyennes, ce qui revenait en apparence à se placer sur le même terrain de lutte que les partis de gauche. En divers pays, les conservateurs ont été en mesure de construire de solides appareils partisans dont la puissance tient à une conjonction entre la grande bourgeoisie et de nombreux éléments des classes moyennes - le propre du capitalisme à un stade relativement avancé de son fonctionnement étant de multiplier et de diversifier les couches intermédiaires.

Retenons de toute manière que l'une des conséquences essentielles du développement capitaliste est de créer les bases d'une distribution sociale des hommes à l'intérieur du système partisan, les conditions étant désormais réunies pour la 
formation de vastes appareils ayant chacun une consistance particulière. La question reste d'ailleurs ouverte de savoir si, à un stade ultérieur, le capitalisme ne crée pas les éléments d'un adoucissement des clivages sociaux et des oppositions partisanes qui en résultent.

Le type d'évolution socio-économique de la Grèce relève certes du modèle évolutif et dérivé, mais, comme beaucoup d'autres, le gouvernement de ce pays souhaite tout à la fois accélérer et contrôler le processus de transformation. C'est dire que l'inspiration de base du modèle purement volontariste ne lui est pas tout à fait étrangère. Cependant, le gouvernement partant de l'hypothèse d'un respect initial des structures socio-économiques, la liberté de manœuvre, comme aussi la capacité d'intervention dont il dispose, sont limitées.

Nous nous trouvons ainsi devant un cercle vicieux. Des partis plus solides et relativement sûrs de leur durée seraient utiles et parfois nécessaires pour accélérer les changements indispensables mais l'acquisition de cette solidité et de cette durée est en quelque sorte liée à la réalisation de ces changements. En pratique, il n'est aucun cercle que l'on ne parvienne à desserrer un peu à condition de faire preuve d'une volonté suffisante. Cependant les résultats qui sont acquis de la sorte exigent beaucoup d'efforts et prennent plus de temps qu'on ne le souhaiterait.

[p. 321] Si ce raisonnement a quelque validité, la modernisation du système des partis en Grèce ne saurait résulter que d'un ajustement progressif, et presque nécessairement lent, aux transformations socio-économiques que le gouvernement tente de promouvoir aujourd'hui à un rythme plus vif que par le passé. Le courage ou le prestige d'un homme est susceptible de combler, durant une période, quelques unes des lacunes ou insuffisances de base. Mais, dans la mesure où l'on ne peut se livrer à une destruction frontale des vieilles structures de la vie sociale, il n'est pas possible d'éviter qu'elles n'affectent le déroulement du jeu politique. Là est probablement le plus grave des obstacles à la modernisation du système partisan et de l'activité nationale, ces deux aspects ne pouvant être que très faiblement dissociés dans le cadre d'un régime d'inspiration parlementaire.

On ne saurait émettre qu'un pronostic réservé quant aux conséquences probables ou possibles d'une modernisation économique de la Grèce sur la distribution et la puissance respective des forces partisanes. La première inconnue est l'ampleur de la croissance industrielle que la Grèce parviendra à réaliser dans les 15 à 20 prochaines années. La seconde, presque aussi importante, est la nature des industries ainsi créées (lourde ou légère, grande consommatrice de main-d’œuvre ou automatisée). Enfin, on doit compter avec la transformation éventuelle des forces politiques (ainsi le communisme) par rapport auxquelles se détermineront dans l'avenir les grands clivages partisans. Dès lors, les considérations que l'on va esquisser sur ces problèmes - considérations qui s’inspirent nécessairement de l'analyse des expériences passées — s'apparentent, en une large mesure, à de véritables spéculations. 
En apparence, l'industrialisation affaiblit la Droite en la privant de manière irréversible d'une large fraction de son électorat rural. Et pourtant, l'exemple actuel des pays d'Europe Occidentale établit, avec toute la clarté désirable, que la Droite ne disparaît pas pour autant du fait de ces modifications. C'est que le développement économique fait surgir de nouvelles couches moyennes et moyennes supérieures qui, jointes aux couches moyennes traditionnelles - dont la persistance est bien plus grande qu'on ne l'avait prévu - constituent la base solide du conservatisme contemporain (démocratie chrétienne allemande comme aussi [p. 322] parti conservateur britannique). Encore faut-il, pour attirer ou retenir ces couches, que la Droite se plie en quelque mesure à l'évolution des esprits, c'est-à-dire qu'elle passe d'une conception rigide à une conception souple et parfois élastique du capitalisme. Autrement dit, les changements nés de l'industrialisation conduisent la Droite à s'approprier les thèmes et projets du conservatisme libéral — propension d'autant plus marquée que celle-ci dispose de leaders plus avisés et prévoyants.

La croissance industrielle ne peut manquer de renforcer la Gauche même si celleci par la suite n'utilise pas ou utilise mal la puissance qu'elle tient de l'adhésion des masses. Il est probable qu'en Grèce l'expansion du groupe des travailleurs industriels ou, si l'on préfère, la conversion des paysans en ouvriers d'usine profitera pour une très large part à ce secteur de l'univers partisan (l'orientation prise par le mouvement syndical devant jouer à cet égard un rôle capital). Bien entendu, le destin final de l'EDA dépend aussi bien de l'attitude des dirigeants grecs à l'égard du communisme que de l'évolution intrinsèque de celui-ci. Cependant, même si le parti communiste continue à faire pendant longtemps l'objet d'une interdiction légale, l'on ne saurait empêcher, le contexte politico-social de la Grèce étant ce qu'il est, que grandisse au fur et à mesure des progrès de l'industrialisation le nombre des travailleurs attirés par la perspective d'un changement profond dans les rapports de production.

Si l'on en juge par l'expérience des autres pays, c'est le courant actuellement qualifié de Centre qui paraît en danger de faire les frais de l'évolution. À vrai dire la persistance de ce courant en Grèce à une échelle massive — courant qui constitue une version du conservatisme traditionnel modérément éclairée et ouverte aux exigences du temps — ne s'explique que par le retard considérable du pays dans l'ordre de la croissance industrielle : quant à sa prépondérance actuelle, elle serait difficilement compréhensible si l'on n'avait en mémoire la crise politique suscitée par le comportement de l'ERE à l'époque de Caramanlis.

La reconversion de la Droite traditionnaliste en un parti conservateur d'inspiration moderne comme aussi l'expansion prévisible du courant d'inspiration socialiste risquent d'enfermer le Centre actuel dans un espace de plus en plus étroit et de réduire le poids qu'il exerce en tant que formation centriste sur la vie politique. Si la Droite ne parvenait pas à faire sa reconversion, il est possible que ce soit le Centre actuel qui parvienne à former le noyau du futur groupe conservateur : mais [p. 323] alors la survivance de ce courant serait liée à la perte de sa qualité médiane actuelle.

Le Centre a toutefois une chance de subsister comme tel, c'est-à-dire avec une vocation centriste, en raison du poids que l'idéologie communiste ou celle d'un 
socialisme rigoureux paraît susceptible d'exercer sur le prolétariat grec. On peut admettre, sur la base de l'observation sociologique, que de nombreux éléments des classes moyennes qui se joignent aux travailleurs industriels dans les partis d'inspiration travailliste ou social-démocrate éprouvent des réticences ou des répugnances à le faire dans le cas de formations communistes ou marquées par l'influence communiste. Certes, la persistance de cette attitude dépend de l'évolution du monde communiste mais chacun sait qu'en politique les représentations collectives, une fois formées, mettent beaucoup de temps à se transformer. Et dès lors, même si dans la période à venir le communisme continue de perdre de son dynamisme et de son mordant, il reste possible que beaucoup continuent à s'en défier.

Un tel facteur pourrait, dans une structure socio-professionnelle évoluant vers un niveau de salarisation plus élevé, faciliter la constitution de ce parti socialiste modéré qui, à proprement parler, n'existe pas dans la pratique politique grecque d'aujourd'hui. La modernisation économique aboutirait ainsi à donner des troupes à ce CentreGauche qui, actuellement n'en possède pas assez pour influencer de manière décisive la gestion des affaires nationales. En d'autres termes, dans l'hypothèse encore lointaine d'une large industrialisation du pays, la meilleure chance du Centre de survivre comme tel serait de transformer le conservatisme libéral qui l'anime en une idéologie d'inspiration travailliste ou social-démocrate : en somme, il se maintiendrait en devenant ou redevenant un authentique Centre-Gauche.

On dira peut-être que les prédictions politiques n'ont d'autre raison d'être que d'exprimer ou de laisser deviner les préférences de leurs auteurs. Pour ne pas tromper le lecteur, nous lui dirons qu'effectivement la faiblesse du Centre-Gauche nous paraît l'imperfection la plus grave du système des partis grecs, le défaut qui le déséquilibre complètement. Mais cette lacune - dont la constatation est pour nous exempte de tout jugement de valeur sur l'idéologie en cause - résulte en une large mesure de la nature des choses, c'est-à-dire du contenu des structures socio-économiques tel que l'a façonné l'évolution enregistrée jusqu'à présent.

[p. 324] Cependant, si la Grèce parvient à se moderniser économiquement de manière assez large et cohérente, il est possible que notre hypothèse prenne corps. Il est vrai que, comme nous le verrons dans la troisième partie, la politique économique adoptée ou acceptée par les gouvernements grecs depuis la fin de la seconde guerre mondiale a valu au pays les apparences plus que la substance de la modernisation. 
[p. 325]

\section{TITRE TROISIÈME}

\section{partis et groupes dirigeants}

\section{$\underline{\text { Retour à la table des matières }}$}

NOUS ALLONS ÉTUDIER désormais les forces qui, en dehors des partis, sont susceptibles d'influer sur l'orientation de la politique et le contenu de l'action gouvernementale. L'objectif de cette analyse est de mettre en évidence les groupes qui dirigent effectivement la Grèce moderne et d'évaluer la marge d'autonomie dont les partis disposent à l'égard de ceux-ci.

La structure des groupes dirigeants, c'est-à-dire en somme la structure ultime de pouvoir du pays considéré, varie sensiblement d'une expérience nationale à l'autre. L'une des principales difficultés de la recherche est d'identifier au départ, sur la base de la seule observation sociologique, les forces susceptibles d'assumer un tel rôle. Il est à peine besoin d'écrire que ces groupes relèvent du phénomène oligarchique.

Si l'on s'attache à la période 1946-1964, trois séries d'éléments ont exercé une influence dominante sur la vie politique grecque : les forces extra-parlementaires de la vie publique (Couronne et Armée); les groupes d'affaires nationaux (capitalisme financier et industriel) ; les puissances étrangères, spécialement les États-Unis qui sont intervenus de manière constante aussi bien sur le plan politique que dans l'ordre économique. Encore que de telles fluctuations soient difficiles à déceler, il est possible que le poids respectif de ces groupes ait connu quelques variations durant la période considérée mais leur présence ne s'est jamais démentie.

Cette identification n'est pas exhaustive dans la mesure où elle néglige d'autres groupes qui, à quelques égards, sont capables de conditionner [p. 326] les démarches des autorités politiques officielles : ainsi l'Église, la bureaucratie administrative, le mouvement syndical et le monde paysan. Dans d'autres pays, de tels éléments se trouvent en mesure de jouer un rôle important et parfois décisif. Pour des raisons déjà 
partiellement exposées, il n'en va pas de même en Grèce et ces groupes ne détiennent finalement qu'une influence politique mineure.

La Grèce étant presque totalement dépourvue d'enseignement et de recherche sociologiques, il n'existe aucune documentation d'inspiration universitaire sur un grand nombre des problèmes qui seront évoqués dans cette troisième partie. Une telle situation, déjà fâcheuse en soi, le serait encore bien davantage si elle devait conduire, faute de disposer de l'appareil usuel de références bibliographiques, à passer sous silence les éléments-clés de la vie politique grecque. Tout en admettant que notre recherche a un caractère simplement exploratoire, nous pensons indispensable d'en consigner ici les résultats, ne serait-ce qu'en vue d'inciter les chercheurs grecs à entreprendre progressivement l'analyse approfondie de ces questions. 
[p. 327]

\section{CHAPITRE X \\ LES FORCES EXTRA-PARLEMENTAIRES DE LA VIE PUBLIQUE}

Retour à la table des matières

NOUS ALLONS EXAMINER dans ce chapitre la place de la Monarchie et le rôle des Forces Armées. Tout en faisant, pour commencer, l'étude séparée de chacune de ces catégories dirigeantes, il convient de dire d'emblée que le trait caractéristique de la période considérée a été leur étroite conjonction en vue d'assurer la sauvegarde des relations et pratiques conservatrices. À l'issue de ces développements nous dirons quelques mots sur la situation de l'Église.

Le lecteur sera peut-être tenté d'aborder ce chapitre en pensant, pour prendre l'exemple de pays voisins de la France, à ce qu'il sait de l'expérience belge et hollandaise. En réalité, aucune des normes gouvernant de telles situations n'a la moindre valeur quand il s'agit d'analyser l'action de la Couronne et de l'Armée grecques depuis la fin de la seconde guerre mondiale.

\section{PLACE DE LA MONARCHIE}

En termes de symbole et de garant de l'unité nationale, les services rendus à la Grèce par la Dynastie des Glücksburg ne sont pas très impressionnants. Il est possible que certains liens d'ordre affectif entre la Couronne et le peuple se soient formés sous Georges I, spécialement au temps des victoires balkaniques, préparées et réalisées par E. Vénizélos. Mais, dès 1915, l'attitude anti-constitutionnelle du monarque devait créer un schisme aboutissant à la scission de l'unité. Entre les deux [p. 328] guerres, la question du régime passera au premier plan des luttes partisanes, le pays se divisant sur la valeur de l'institution monarchique. Et si Georges II remonte finalement sur le trône, ce sera pour compromettre la Monarchie avec la dictature Métaxas. 
La Constitution hellénique, telle qu'en vigueur depuis le $1^{\mathrm{er}}$ janvier 1952, dispose dans son art. 21 que « la forme de l’État Hellénique est la Démocratie Royale » et que « tous les pouvoirs émanent de la Nation ». En conséquence de ce principe, l'art. 29 précise que « la personne du Roi est irresponsable et inviolable » et l'art. 30 stipule qu'« aucun acte du Roi n'a de force et ne peut être exécuté s'il n'est contresigné par le Ministre compétent, qui par sa seule signature en assume la responsabilité ». Le dessein de la Constitution est donc sans équivoque : il relève du vieil adage que le Roi règne et ne gouverne pas. Autrement dit, la Constitution hellénique exclut formellement que le Roi ait une politique personnelle sur les affaires de l’État.

Il est douteux que l'on puisse sérieusement soutenir que, durant la période analysée en cet ouvrage, la Monarchie s'en soit strictement tenue à ces stipulations. En réalité, le seul point en discussion est de déterminer l'ampleur de la liberté de manœuvre que la Couronne s'est réservée et l'orientation qu'elle a donnée à ses ingérences dans la vie politique du pays. En fait, l'intervention du Souverain constituait une pratique si bien établie que, durant la phase de «lutte irréductible » contre l'ERE, G. Papandréou lui-même, aujourd'hui défenseur de l'institution monarchique, demandera ouvertement au Roi Paul d'agir pour écarter de la scène le « gouvernement illégal » de Caramanlis.

En essayant de déterminer cette marge de manœuvre, il faut se garder de mettre l'accent sur certaines activités mondaines de la Cour, plus proches certes de l'opérette que de la politique pure : ainsi les croisières organisées en Méditerranée en vue de rassembler, notamment à des fins matrimoniales, les survivants de vieilles monarchies européennes emportées par la vague républicaine. C'était là divertissement de princes sans grande portée politique.

De telles festivités risquaient parfois en définitive de valoir des charges supplémentaires au peuple grec : ainsi le paiement d'une dot de 300.000 dollars US à la princesse Sophie à l'occasion de son mariage avec l'un des prétendants au trône d'Espagne. Lors de cette union, à l'occasion de laquelle la princesse dut se convertir au catholicisme - ce qui heurta le sentiment nationaliste de bien des Grecs — on vit [p. 329] s'instituer des pratiques difficilement compatibles avec une conception moderne des rapports sociaux : obligation faite aux pensionnaires des orphelinats de travailler au trousseau de la princesse; pression effectuée sur les habitants des quartiers pauvres d'Athènes pour qu'ils contribuent à l'achat de cadeaux ... En somme le pays devait solder les frais d'une politique dynastique de style antique et finalement assez aléatoire. Mais pour révélatrices qu'elles fussent de certaines mœurs, de telles démarches — qui semblent avoir été abandonnées lors du récent mariage du roi Constantin — n'en avaient pas moins une importance mineure.

Négligeant désormais ces bagatelles d'ancien régime, nous voudrions essayer de déterminer les traits du comportement de la Monarchie en Grèce et les chances d'avenir de l'institution monarchique dans ce pays. Nous nous en tiendrons pour l'instant à l'aspect purement national du problème, l'examen des relations extérieures de la Monarchie grecque (notamment par le jeu des rapports de famille avec des dynasties étrangères) étant renvoyé à un chapitre ultérieur. 


\section{A. TRAITS DU COMPORTEMENT DE LA MONARCHIE EN GRÈCE}

$\underline{\text { Retour à la table des matières }}$

Il nous paraît possible de résumer l'essentiel du problème en un petit nombre de propositions.

\section{FACTEURS DU RETOUR DU ROI}

Au lendemain de la seconde guerre mondiale, c'est dans une très large mesure à la politique britannique que Georges II dut de retrouver son trône. Si durant la période qui suivit le départ des Allemands les forces américaines avaient été aux leviers de commande en Grèce, on peut légitimement douter que le problème du régime ait été résolu de la sorte. Inventés par la Grande-Bretagne en 1863 comme maison régnante de Grèce, les Glücksburg étaient ainsi remis en selle par la même puissance.

Ces considérations ne sont certes pas incompatibles avec les résultats du plébiscite du $1^{\text {er }}$ septembre 1946 par lequel un peu plus de 1.100.000 électeurs (pour une population totale dépassant les 7 millions) se prononcèrent en faveur du retour du roi. Mais ce plébiscite, tenu dans une atmosphère de pression et d'intimidation («terreur blanche " et sur la [p. 330] base de registres électoraux particulièrement approximatifs, ne compte pas parmi les consultations auxquelles le commentateur pourrait être tenté d'attribuer une réelle authenticité. Les jeux étaient faits avant que le peuple soit appelé à se prononcer. Et il est peu contestable que l'insurrection manquée de décembre 1944 pesa sur les résultats.

Encore qu'aucune étude systématique de cette opération n'ait été faite, les renseignements disponibles montrent que de nombreux électeurs se prononcèrent pour le retour du Roi non parce que ce retour leur semblait en lui-même désirable mais en raison des dangers de la situation internationale et des menaces qui pesaient alors sur la Grèce. Pour parler plus clairement, le retour du Roi, conforme au vœu de la puissance protectrice de l'époque, leur semblait susceptible de valoir à la Grèce une sauvegarde internationale contre l'expansion du communisme.

C'était là pour la dynastie une carte qu'elle exploitera à fond en s'identifiant dans les années suivantes à la lutte contre le soulèvement armé communiste. En se mettant ouvertement à la tête du combat, le Roi deviendra en quelque sorte le garant de la présence de la Grèce dans le camp occidental : et dès lors, les Américains eux-mêmes oublieront leurs réserves et réticences initiales pour se ranger, à la suite des Britanniques, dans le camp des soutiens de la Monarchie.

Au total, le ralliement à la Couronne, aussi bien sur le plan national qu'international, a trouvé pour une bonne part son origine non dans un attachement raisonné à l'égard de la formule monarchique ou une vénération affective vis-à-vis des Souverains mais dans la position de soutien de l'ordre social établi qu'adopta la 
dynastie dès son retour en Grèce. Au total, après l'intervention britannique qui sauva initialement la Monarchie, la grande chance de celle-ci a été d'apparaître comme un rempart contre le danger communiste.

\section{RELATIONS DE LA COURONNE AVEC LA DROITE}

Comme nous l'avons vu dans le chapitre préliminaire, la dynastie régnante n'est jamais parvenue à jouir en Grèce d'une totale sécurité ou stabilité. Déjà latente sous Georges I, la menace d'un renvoi allait se préciser et s'accentuer à partir du moment où, durant la première guerre mondiale, le Souverain s'efforça d'assurer le triomphe de sa propre poli-[p. 331] tique. La conclusion donnée au désastre d'Asie Mineure, sans oublier la fusillade des six ministres fidèles au Roi, devait établir que de telles craintes ne manquaient pas de fondement.

Ainsi s'explique que le Souverain ait tendu à s'appuyer sur les groupes de politiciens et d'électeurs dévoués à sa cause et à sa personne. À partir de 1915, l'activité du Parti Populiste fut principalement d'organiser et de consolider ce rassemblement. On comprend également que la Monarchie ait toujours montré de la méfiance à l'égard du Parti Libéral dont le Chef, E. Vénizélos portait à ses yeux la responsabilité directe, sinon de la chute même de l'institution monarchique, du moins des événements l'ayant provoquée. Dans cette perspective qui exprime correctement la situation jusqu'au déclenchement de la seconde guerre mondiale, le Roi apparaissait comme le Chef réel des monarchistes, c'est-à-dire des conservateurs traditionnels contre les conservateurs libéraux plus ou moins favorables aux thèses de l'anti-dynastisme.

La seconde guerre mondiale et les événements qui y firent suite devaient provoquer un certain reclassement des opinions sur ce problème. C'est un fait que plusieurs des leaders républicains partis au Moyen-Orient sous l'occupation (en particulier S. Vénizélos, P. Canellopoulos et C. Papandréou) y effectuèrent finalement un rapprochement avec la Monarchie non sans avoir au préalable joué un rôle assez trouble dans les mutineries de 1943-1944. Cependant, lorsque se posa le problème du régime d'après-guerre, rares furent les hommes politiques à repousser l'idée que le retour du Roi soit soumis a un plébiscite (mentionnons parmi ceux-ci C. Tsaldaris). Cette conjoncture - jointe au fait que certains libéraux de la vieille Garde, tels Th. Sophoulis prirent ouvertement position contre le retour du Roi lors du plébiscite - ne pouvait manquer de consolider la méfiance de la dynastie à l'égard de tous les politiciens dont la conduite à son égard n'avait pas été celle d'une fidélité inconditionnelle.

Cette situation explique la préférence donnée par le Roi aux hommes de la Droite la plus conservatrice durant cet après-guerre et, en particulier, à C. Caramanlis qui, ayant été tiré de l'ombre par le Monarque, se trouvait en quelque sorte voué à lui apporter son plus ferme soutien. Cette même situation rend compte des efforts entrepris par le Souverain pour éviter que le pouvoir ne passe entièrement dans les mains de l'Union du Centre - celle-ci ayant, aux yeux des monarchistes intransigeants, le défaut de comprendre des hommes de Centre Gauche et comme tels 
[p. 332] d'une allégeance monarchique tiède ou douteuse. Nous avons rencontré ces efforts en deux occasions : au lendemain du renvoi de Caramanlis quand le Roi Paul essaya de donner vie, sous la conduite d'une personnalité fidèle à l'institution monarchique (S. Vénizélos, P. Canellopoulos, S. Markézinis...) à une combinaison gouvernementale de Centre-Droit ; après les élections de novembre 1963 quand l'EK n'ayant pas obtenu la majorité absolue, le Roi s'efforça de promouvoir une formule de gouvernement ERE-EK.

Ce "favoritisme », pour reprendre un terme de l'opposition - qui de surcroît excluait l'EDA de tous les contacts et projets politiques du Roi - reposait sur une vue démodée de la situation. En effet, la plupart des leaders et des journaux du Centre ne se trouvaient plus d'humeur à mettre en cause le principe même de la monarchie. Sous-estimant la force et peut-être la sincérité de ce ralliement, la Couronne en venait à prendre des positions — ainsi l'organisation des élections douteuses de 1961 par l'un de ses hommes - susceptibles de rejeter certains des leaders du Centre vers l'opposition anti-dynastique : et, après tout, il eut été bien compréhensible que G. Papandréou en vint à menacer la Couronne au lieu de déclarer qu'il lui faisait confiance pour rétablir la situation.

Au surplus, il est possible que le Roi ait surestimé la fidélité de certains secteurs de la Droite. Les milieux nationalistes s'étaient plaints une première fois de l'opposition faite à la personne du Maréchal Papagos par les milieux traditionnalistes de la Cour (cette hostilité relative émanant davantage de la Reine que du Roi). Le même mécontentement devait se manifester au lendemain du renvoi de Caramanlis et des efforts assez maladroits du Souverain pour provoquer la scission de l'ERE impliquée par son projet de regroupement Centre-Droit.

Ajoutons cependant que le calcul monarchique était fondé dans la mesure où l'on pouvait penser que le Centre, tout en acceptant le principe de la Monarchie, s'efforcerait de mettre fin à divers abus que la Droite avait laissé s'accumuler et durer sans aucune protestation (en particulier les ingérences de la Reine Frederika dans la vie politique du pays).

Si l'on peut utiliser un mot pour qualifier le comportement royal c'est en définitive celui d'amateurisme. Compte tenu de la position des leaders du Centre, le Roi Paul avait les moyens, en cessant de favoriser la Droite, de consolider l'institution monarchique sans pour autant avoir à sacrifier quoi que ce soit sur le front de la défense de l'ordre [p. 333] social établi. Or, au lieu d'utiliser son influence dans ce sens, le Roi allait laisser se développer une très grave crise politique dont la prolongation et l'accentuation auraient fini par mettre en danger les valeurs mêmes qu'il se proposait de défendre et dont il était le garant.

La position assumée par le Souverain aurait eu quelque cohérence s'il avait tenu pour valables les insinuations faisant de G. Papandréou le fourrier du communisme en Grèce. Mais, F. Dulles disparu, les Américains eux-mêmes en venaient progressivement à l'idée que les leaders du Centre pourraient bien constituer des interlocuteurs valables. Au surplus, même si le défunt Roi ne brillait pas par une largeur de vues exceptionnelle, il était trop proche de la vie politique grecque pour 
croire les conservateurs libéraux du Centre capables de mettre l'ordre social en danger.

Certains commentateurs ont tenté d'expliquer le comportement du Roi Paul par le sentiment profond qu'il aurait eu de sa légitimité et de sa capacité de donner à la politique grecque une orientation correcte. Il est vrai certes que, mis à part Georges I, la dynastie n'a que rarement montré un souci particulier de respecter l'ordre constitutionnel. Ce trait permet de bien comprendre la propension du souverain à défendre les prérogatives monarchiques sur des bases incompatibles avec les idéaux d'une société en voie de modernisation : il ne suffit pas pour rendre compte des erreurs de manœuvres commises par le Roi dans la défense de ses privilèges.

\section{ACTIVITÉS SOCIALES DU PALAIS}

D'autres personnes proposent une explication plus simple du comportement rigidement conservateur du Souverain défunt en soulignant l'influence qu'aurait exercée sur lui son épouse Frederika. Les particularités de l'institution monarchique ont donné au peuple grec une reine de descendance allemande (Frederika est la petitefille de Guillaume II) au lendemain d'une guerre durant laquelle l'Allemagne avait infligé au pays des désastres majeurs. Or, loin de mener une existence effacée, la Reine devait intervenir presque ouvertement dans le jeu des institutions et la conduite de la politique gouvernementale. Il n'est possible de juger celle-ci que d'après ses démarches publiques : sur cette base, on serre de très près la réalité en définissant son comportement comme autoritaire et arrogant.

[p. 334] L'histoire éclaircira ou n'éclaircira pas le genre d'influence politique que la Reine a pu avoir sur son époux et la part qu'elle a prise dans les décisions de celuici. Bien plus nombreux en tout cas ont été et sont ceux qui l'accusent d'ingérences abusives dans la vie du pays que ceux tentant de la laver de telles imputations. Il est significatif que des partisans déclarés de l'institution monarchique reprochent à la Reine-mère de la déconsidérer par ses prétentions et ses activités intempestives. Admettons que cette convergence de critiques, assez impressionnante en elle-même, constitue, sinon une preuve absolue, du moins une sérieuse présomption de la validité des comportements contestés ou déplorés. On peut trouver une autre présomption de telles ingérences dans les efforts actuellement entrepris sans beaucoup de subtilité ni de fermeté d'ailleurs par G. Papandréou en vue de mettre la Reine-mère hors d'état d'exercer une influence sur les nouveaux souverains.

On est sur un terrain plus solide en observant certaines activités officielles de la Reine, c'est-à-dire officiellement admises, dont l'objectif ou le résultat était de créer des secteurs d'activité royale échappant au contrôle de la représentation populaire. On doit mentionner à cet égard le Fonds de leurs Majestés, plus couramment appelé par les Grecs «Fonds de la Reine » qui est la plus caractéristique et la plus significative de ces usurpations de souveraineté. L'origine de cette institution, qui remonte à 1947 et qui juridiquement a le statut d'une organisation non gouvernementale, est un ensemble d'activités charitables menées par la Couronne au lendemain de la guerre 
civile avec le produit de quêtes ou de dons volontaires : pour faciliter cette tâche, il avait été admis que durant une période, ce fonds pourrait être alimenté par des ressources de caractère fiscal mais l'autorisation de percevoir de telles taxes n'était envisagée, à l'origine, que pour une durée limitée. Or le Fonds a continué de fonctionner et de se développer, représentant en somme une sorte de sécurité sociale à direction exclusivement monarchique et agissant parallèlement au système officiel de l'État.

Parmi les activités du Fonds, on mentionnera : organisation de colonies au profit d'enfants déshérités auxquels on donne une instruction technique (environ 3.000 actuellement) ; établissement de centres pour la jeunesse rurale (offrant en particulier des facilités d'entraînement aux nouvelles techniques agricoles); création d'unités mobiles qui participent à la reconstruction de villages dévastés; gestion de centres urbains qui ouvrent aux enfants des villes des possibilités sportives et récréatives ; [p 335] participation au programme de suppression des taudis; encouragement à l'artisanat ... Ce sont là des tâches que, pour la plupart, l’État assume de son côté.

Le mécanisme de la combinaison est simple. L'État collecte pour le bénéfice du Fonds plusieurs ressources ayant le caractère d'une fiscalité indirecte (taxes sur les places de cinéma, les voitures neuves, les cigarettes...). Or ces ressources indiscutablement publiques, le Fonds les emploie à sa guise sans être soumis à aucun contrôle d'opportunité. On estime à environ 300 millions de drachmes (soit 10 millions de dollars US) les sommes ainsi soustraites au budget grec, le Fonds utilisant pour exécuter ses objectifs quelques milliers de personnes dont beaucoup à titre bénévole.

Ce système a suscité depuis longtemps de vives protestations, en particulier de la part des exploitants de salles de cinéma d'Athènes et du Pirée. Ceux-ci se sont plaints que sur la base d'une mesure prise pour six mois en 1948, les billets de cinéma soient toujours frappés d'une surtaxe de $20 \%$ au profit des œuvres de la Reine. Il est assez révélateurs des mœurs politiques grecques que, pour mettre un terme à cette protestation, l'on ait autorisé les dits exploitants à effectuer un prélèvement supplémentaire en vue d'alimenter leur propre caisse de retraite.

La gestion du Fonds vaut à la Monarchie de se constituer, aux frais du contribuable grec, une double clientèle : celle des personnes utilisées moyennant rémunération dans les divers secteurs d'activité de l'institution; celle des bénéficiaires des largesses de l'organisme à travers le pays. En somme, le Fonds de la Reine, c'est en un sens le compartiment «publicité » ou « relations publiques » de la Couronne, celle-ci se déchargeant du coût de l'opération sur le citoyen. Ajoutons que le choix des bénéficiaires est loin d'être indemne de considérations partisanes (ainsi envoi de paquets contenant des pièces vestimentaires aux membres des Bataillons de Sécurité Nationale). Mentionnons enfin, dans le cadre du Fonds ou en marge de celuici, des pratiques telles que la réalisation de quêtes pour la dotation de jeunes filles, l'envoi de chemises de flanelle aux soldats ...

Le Fonds de la Reine constitue au sens propre de l'expression un État dans l'État. L'institution était entièrement acceptée par le gouvernement Caramanlis qui, au temps 
où il jouissait de la faveur de la Couronne, avait l'habitude de ne pas contrarier les désirs de celle-ci (c'est également lui qui fit voter, contre le vœu de l'EK et de l'EDA, [p. 336] l'octroi d'une dot à la princesse Sophie). Caramanlis laissa donc le Fonds se développer, le contrôle de l'État sur l'institution se limitant à une vérification des balances comptables. On prête au gouvernement de l'Union du Centre l'intention de « nationaliser » le Fonds — projet qui, s'il était réalisé, serait très significatif de la différence de conduite à l'égard de la Monarchie des conservateurs traditionnalistes et des conservateurs libéraux. Notons toutefois que les leaders du Centre déclarent avoir pour seul objectif de replacer la Couronne dans la haute position que lui confère la Constitution.

\section{LE CLAN ROYAL}

Le Fonds de la Reine est le chaînon qui nous permet de passer de la notion constitutionnelle de Roi à celle, qui est de pur fait, de Cour ou de Palais. Tous les souverains ont autour d'eux un certain nombre de serviteurs et, presque inévitablement, un certain nombre de courtisans. Quand ce noyau se prolonge ou s'amplifie en un réseau d'hommes occupant des positions de prestige ou d'influence en divers secteurs de la vie sociale et quand ce réseau apporte au Roi son soutien pour la conduite d'une politique propre - politique que le réseau tend lui-même à influencer ou à déterminer — alors on peut parler, sous la réserve terminologique déjà faite, d'un parti de la Cour ou clan royal.

Le parti de la Cour ou clan royal - que l'on désigne parfois génériquement comme le Palais - ne doit pas être confondu avec le (ou les) parti se vouant à la défense de la cause monarchique devant les électeurs. Il arrive que certains éléments dirigeants ou influents du second figurent dans le premier mais il s'agit là de phénomènes de nature différente. Actuellement d'ailleurs, les démarches de la Couronne lui ont certainement aliéné la sympathie d'une fraction des milieux de la Droite nationaliste. De même, le parti royal doit être distingué des forces capables de servir d'appui à l'institution monarchique, ainsi en Grèce l'établissement militaire : il est préférable de ne pas mélanger le groupe de soutien et le centre susceptible d'en inspirer ou d'en orienter l'intervention.

En fait, ce que nous appelons ici parti de la Cour se compose d'un nombre restreint de personnes qui, occupant des postes ou détenant des positions d'importance, constituent les hommes de confiance du Roi et qui, comme tels, sont susceptibles de remplir à son profit des mis-[p. 337] sions multiples : donner au Souverain des informations ou des conseils en dehors des canaux officiels ; accomplir pour son compte ou sur ses instructions des missions délicates ; établir les liaisons ou mobiliser les appuis nécessaires à l'exécution de la politique royale. En bref, l'ensemble de ces démarches, d'inspiration nettement élitaire, relève davantage de la notion de clan que de parti au sens ordinaire du mot dans la pratique politique.

Le clan royal ainsi défini se composant de personnalités choisies sur la base de rapports personnels, il est dès lors pratiquement impossible d'en décrire le contenu de 
façon exhaustive ou simplement extensive. Au surplus, l'octroi (ou le retrait) de la confiance par le Souverain mettant en jeu des facteurs purement individuels, il est très difficile de se livrer de l'extérieur à la moindre évaluation de la distribution de l'influence au sein du groupe. Enfin, les frontières d'un tel groupement sont essentiellement fluides du fait que, en quelque mesure, le réseau des relations dont dispose chaque participant direct peut être rattaché au phénomène. Ce sont d'ailleurs les mêmes difficultés qui rendent si difficile de délimiter avec quelque précision les entourages qui se constituent autour de certains hommes politiques. Ces questions n'ayant jamais fait l'objet d'études sociologiques, nous devons nous borner à tracer ici un schéma abstrait qu'il ne serait probablement pas impossible de remplir, au moins partiellement, à l'aide de recherches monographiques.

Si l'on va du centre vers la périphérie, le premier élément de cette combinaison est formé par les hommes qui jouent officiellement le rôle de conseiller politique du Roi ou participent aux activités de ses différentes maisons (en particulier la Maison Militaire). Le réseau comprend aussi un certain nombre d'hommes politiques influents susceptibles d'occuper selon l'état de la conjoncture politique des fonctions d'ordre ministériel. Il comporte également des personnages de rang très élevé dans les étatsmajors militaires et la bureaucratie civile. Mais le réseau s'étend au-delà du cercle gouvernemental proprement dit: c'est ainsi que normalement le Roi dispose d'hommes à lui à la tête de banques ou d'entreprises publiques et entretient des relations, directement ou par personnes interposées, avec les milieux d'affaires les plus puissants (S. Niarchos en particulier). Enfin, le réseau se prolonge dans les milieux étrangers, que ce soit par le canal de relations familiales du Souverain, le truchement d'ambassadeurs ou le jeu de rapports purement officieux.

L'étude attentive de la composition des gouvernements de service [p. 338] serait certainement de nature à ouvrir bien des perspectives utiles sur la composition du parti royal. Nous avons vu que le principe de tels cabinets est de faire appel à des personnes de grande ou de bonne notoriété dans des secteurs variés de l'administration publique, de la magistrature, des professions libérales ... On peut penser que le Roi, responsable du choix des membres de ces gouvernements, y appelle de préférence des hommes sur lesquels il peut compter dans les périodes souvent délicates et parfois dramatiques qui précèdent la tenue d'une consultation générale. Rappelons à ce propos que les membres des cabinets de service n’ont aucune responsabilité à l'égard de l'institution parlementaire.

En une très large mesure, l'action du clan royal relève de la politique fermée ou confidentielle (closed politics). Elle entre dans cette catégorie de démarches que les théoriciens ne parviennent à saisir ou à identifier qu'avec les plus extrêmes difficultés et qu'ils sont dès lors portés à ignorer, voire parfois à contester. La complexité de la recherche est bien entendu accrue par le soin avec lequel les intéressés s'efforcent de brouiller les pistes (si bien qu'en de nombreux cas le fait qu'un contact ou une conversation fasse l'objet d'un démenti officiel constitue en réalité une sérieuse présomption que l'opération considérée a eu effectivement lieu). À condition de tenir compte des risques du procédé, il est parfois possible de remonter des conduites effectives aux consignes et suggestions qui les ont inspirées. Par exemple, sur la base 
des résultats observés, il paraît légitime d'admettre que le Roi a donné des instructions bien différentes aux personnalités ayant présidé les cabinets de service lors des élections de 1961 d'une part, de 1963 et 1964 de l'autre.

Sans la possession d'un tel réseau, le Souverain serait en tout cas dans l'impossibilité d'avoir une politique personnelle et, a fortiori, de tenter de la mettre en exécution. Telle est sans doute la raison pour laquelle les hommes du Centre qui s'efforcent actuellement de ramener la Monarchie grecque à son rôle constitutionnel insistent sur la nécessité de réduire les pouvoirs de la Cour ou du Palais sur la vie politique.

\section{B. CHANCES D’AVENIR DE LA MONARCHIE}

$\underline{\text { Retour à la table des matières }}$

Il existe en Grèce des partisans inconditionnels de l'institution monarchique dont la pensée, quand elle s'exprime en termes de philosophie politique, constitue désormais un simple archaïsme ${ }^{1}$. Cette [p. 339] préférence s'accompagne généralement d'un conservatisme intégral en matière sociale et dès lors les adeptes, de ce courant sont portés à admettre, voire à soutenir, toute activité du Monarque et du Palais dès lors que l'objectif en est de consolider les privilèges existants. Il est peu probable que la modernisation économique accroisse ce courant et il est douteux que ce groupe de fidèles offre à la monarchie une base assez large pour assurer sa sauvegarde et sa survie.

On trouve, il est vrai, un autre courant qui se rattache au monarchisme constitutionnel. Partant de l'idée que la Grèce doit nécessairement avoir un Chef de l'État, les tenants de cette position estiment que la Monarchie est susceptible de la lui fournir dans des conditions relativement satisfaisantes, Le principal avantage de la Couronne est, selon eux, de soustraire la désignation du Chef de l'État aux vicissitudes et aux incertitudes de la lutte partisane : compte tenu des pratiques politiques grecques, la proclamation de la République aurait presque nécessairement pour effet de créer une période de flottement et il n'est pas certain que l'on parvienne ensuite à stabiliser la situation. Les partisans de ce courant invoquent volontiers à l'appui de leur thèse les mauvais souvenirs laissés par l'expérience républicaine de l'entre-deux guerres.

Mais ce courant n'accepte la Monarchie que dans la mesure où, renonçant à ses habitudes anciennes, la dynastie acceptera de s'en tenir à son rôle constitutionnel et donc renoncera à s'ingérer dans la conduite des affaires du pays. Beaucoup de ces monarchistes de raison estiment que la Monarchie grecque est nécessairement vouée à la disparition si elle tente de maintenir la situation de ces dernières années c'est-à-

1 Voir à cet égard l'ouvrage de P. PIPINELLIS, homme de cour par excellence ; To Stemma ke to plession fon dimocraticon thesmon, Athènes, 1960. 
dire si elle s'efforce de conserver le contrôle des luttes politiques. Ils affirment que le pays ne tolèrerait pas très longtemps, une famille royale qui aurait pour pratique de s'identifier à l'un des adversaires en présence. Autrement dit, la Monarchie grecque n'a d'avenir que si elle parvient à se situer et à demeurer hors du système partisan.

Les chances d'une telle reconversion seraient, à en croire plusieurs avis, relativement bonnes. Comme ce fut déjà plusieurs fois le cas, la Grèce a un souverain jeune (24 ans) qui est ainsi beaucoup moins marqué que ses prédécesseurs par le souvenir des luttes anciennes. On estime dès lors, en divers milieux, qu'il lui serait assez facile d'accepter le rôle d'un monarque constitutionnel et, en particulier, de considérer le Premier Ministre comme son principal conseiller politique : ces milieux [p. 340] s’accordent généralement à reconnaître que la première condition de succès d'un tel projet est un éloignement total et définitif de la Reine-mère des affaires de la Couronne (opération difficilement réalisable selon plusieurs avis si la reine Frederika n'accepte pas de se retirer dans un domaine de sa famille en Autriche).

En dehors des attitudes partisanes de la Couronne les critiques de l'institution monarchique invoquent, il est vrai, un autre argument : celui de la lourdeur de la charge financière qu'elle impose au pays. Si l'on en croit une récente déclaration du Ministre des Finances que l'on doit tenir pour une estimation minimale, le total des dépenses supportées à ce titre par le Trésor Public serait de 19.500.000 drachmes (soit 650.000 dollars US). Compte tenu de la pauvreté de la Grèce, c'est là une somme qui est tout de même considérable et il est probable que la mise en œuvre d'un programme royal d'austérité permettrait d'en économiser une fraction appréciable.

En réalité, si l'on admet que de larges secteurs du peuple grec témoignent aujourd'hui d'une assez grande indifférence à l'égard de la question du régime - ce qui revient à dire qu'il n'existe pas un mouvement de fond en faveur de la République - l'exigence de neutralité politique de la Couronne que posent les monarchistes constitutionnels semble bien, en première analyse, représenter l'attitude la plus progressiste que l'on puisse adopter en la matière. Certes le républicain de conviction ne saurait admettre le jugement assez banal selon lequel les Grecs seraient incapables de vivre en République : mais tant que la question d'un changement de régime sera incapable de passionner les masses, le citoyen à tendances républicaines - ce qui est peut-être le cas d'une certain nombre de députés appartenant à l'aile gauche de l'Union du Centre - ne saurait manquer de tenir le retour du monarque à son rôle constitutionnel pour un élément ou une étape utile. Telle est d'ailleurs la position de l'EDA dont les programmes officiels évitent de revendiquer l'établissement de la République.

Toute la question est de savoir si la reconversion de la Monarchie que s'efforce de promouvoir actuellement le Premier Ministre relève du domaine des possibilités. La longueur du délai qui fut nécessaire pour écarter de la Maison militaire du Roi, le général Dovas, chef du gouvernement qui présida à la consultation d'octobre 1961, illustre les difficultés de l'entreprise. Il faut considérer, en dehors de la personne du Monarque, le jeu des forces qui l'entourent et qui comptent sur lui pour assurer leur [p. 341] sauvegarde. Nous avons noté que pour beaucoup de Grecs, la Monarchie 
constitue avant tout non le symbole de l'unité nationale mais le garant de l'ordre social établi. On peut penser que, dans le cas ou le corps électoral effectuerait une poussée vers la Gauche - impliquant par exemple des actes de nationalisation à l'encontre du capital national et étranger - l'une des solutions pouvant être choisies par ces milieux sera de peser de toutes leurs forces sur la Monarchie pour qu'elle tente de s'opposer à de tels programmes. Et on ne prend pas un grand risque d'erreur en avançant que dans une conjoncture de cet ordre, bien des monarchistes constitutionnels d'aujourd'hui accepteraient ou même revendiqueraient une intervention plus active du Souverain dans les affaires du pays.

Ces observations nous semblent en définitive plus importantes et plus significatives que les spéculations relatives au tempérament du Roi lui-même. En étudiant les perspectives d'un retour durable de la Couronne aux principes de l'ordre constitutionnel - Georges I ayant été le seul monarque de la dynastie à accepter effectivement ces principes - les monarchistes constitutionnels raisonnent comme si la structure sociale actuelle ne devait connaître aucun danger. Si tel devait être le cas, l'hypothèse d'une reconversion monarchique prendrait certes de la vraisemblance. Dans le cas inverse, l'expérience politique grecque étant ce qu'elle est — et l'on connaît la lenteur avec laquelle évoluent les attitudes - il est douteux que la Monarchie ait le désir ou simplement la faculté de s'abstraire des conséquences de la lutte sociale.

Face à une poussée socio-politique de grande ampleur dans le sens d'une démocratisation de la vie nationale, les couches privilégiées pourraient envisager deux voies d'issue. La première consisterait à sacrifier la Monarchie aux aspirations populaires si l'état d'esprit des masses donnait à penser qu'une telle revendication désamorcerait, au moins pour un temps, le projet de réforme de l'ordre social. La seconde au contraire, plus vraisemblable au départ, reviendrait comme nous l'avons dit à se servir de la Couronne comme d'un instrument de protection et à obtenir d'elle les démarches ou mesures propres à briser ou à canaliser l'élan des groupes protestataires. On peut estimer que l'un des éléments-clés de ce choix serait la position des forces armées à l'égard de l'institution monarchique et de l'ordre social établi. Nous ne pouvons donc répondre complètement à la question posée qu'après avoir étudié le rôle de ces forces dans la vie politique grecque.

[p. 342]

\section{RÔLE DE L'ARMÉE}

Retour à la table des matières

En quelque mesure, l'intervention des militaires dans la vie politique grecque remonte au tout début de l'histoire nationale: mécontentement des troupes révolutionnaires licenciées par Othon qui leur préfère des contingents bavarois. Écartés de l'armée, les survivants des combats de la Libération feront peser sur le 
pouvoir des menaces larvées de résistance et de rébellion (ainsi que divers risques de brigandage). Ce milieu participe à la révolte qui contraint le Roi, en 1843, à accorder une constitution à ses sujets. Plus tard, Georges I crée un malaise certain au sein du corps des officiers en encourageant le favoritisme dans la distribution des commandements et des charges des État-Major au profit de ses fils et des enfants des grandes familles.

Par ailleurs, nous avons montré dans le chapitre préliminaire que depuis la formation de la Ligue militaire, l'armée grecque ou des fractions de cette armée avaient contracté l'habitude d'intervenir activement dans la vie politique du pays. À cette époque, le corps des officiers contient des éléments progressistes qui entrent en lutte contre l'institution monarchique, celle-ci leur paraissant responsable de la situation peu brillante de la Grèce au $\mathrm{XX}^{\mathrm{e}}$ siècle. Durant cette période, l'armée ne peut donc être tenue pour un instrument de défense du régime politique établi, la République devant, après la Monarchie, faire les frais de cette propension du soldat à l'action politique.

En apparence, la situation a subi de profondes modifications depuis la fin de la seconde guerre mondiale. La dernière équipée militaire remonte à 1951 : elle trouva son origine dans le mécontentement provoqué chez certains officiers par la démission de l'armée du Maréchal Papagos. Ceux-ci prirent possession d'un émetteur de radio en vue de soulever le peuple en faveur du Maréchal. La petite histoire raconte que Papagos dès que prévenu de l'affaire, se rendit en personne à la station saisie par les comploteurs auxquels il intima l'ordre de rentrer chez eux, ce qu'ils firent apparemment sans discuter. À l'exclusion de cet incident minuscule, l'armée grecque s'est gardée de toute opération mettant en cause l'ordre établi, ordre dont elle apparaît comme le plus ferme gardien.

Tel est en effet le trait majeur de la situation : l'attachement général du corps des officiers à la Couronne et leur propension à défendre le [p. 343] régime social contre toute atteinte. L'armée grecque, étroitement tenue en mains par les Américains dans le cadre de l'OTAN, est ainsi devenue une force profondément conservatrice, le facteurclé de la situation étant la série des épurations réalisées en diverses circonstances (en 1933-35, au Moyen-Orient pendant la guerre, à l'occasion du soulèvement communiste) pour écarter de l'armée de carrière tout officier suspecté de sympathies républicaines ou libérales. En somme, le régime a entendu se protéger en formant une armée qui soit à son image et, dès lors, la loyauté des militaires à l'égard de l'ordre établi s'explique par le fait qu'au moins pour le présent ce régime correspond à leurs vœux.

Gardons-nous d'en conclure que cette fidélité a été de nature passive. Bien au contraire, l'armée est intervenue de multiples manières à rencontre des ennemis du régime ou des citoyens présumés tels. Autrement dit, l'armée a jugé que son devoir n'était pas seulement de constituer l'ultime rempart de l'ordre public mais d'agir quotidiennement pour réduire les adversaires éventuels du système existant. On peut voir dans ces interventions - dont on n'a pas besoin de souligner qu'elles sont en contradiction ouverte avec le régime parlementaire — un témoignage sans équivoque 
de la fidélité de l'armée au système monarchique et à la structure sociale qui lui sert de point d'appui. Mais on doit aussi y voir l'indice d'une propension des militaires à juger eux-mêmes de ce qui est bon pour le pays : et dès lors on est conduit à s'interroger sur l'ampleur et la qualité de la marge de manœuvre que l'Armée accepte de concéder au pouvoir civil dans la conduite des affaires nationales.

\section{A. EXPOSÉ DES INTERVENTIONS}

$\underline{\text { Retour à la table des matières }}$

Le trait dominant du comportement militaire en Grèce est un anticommunisme que l'on peut qualifier sans exagération de fanatique ou, ce qui revient au même, une complète allégeance à l'OTAN. Le corps des officiers, aujourd'hui encore, partage dans son ensemble l'idée que le monde est divisé en deux camps rivaux et que la mission des forces armées est d'interdire à tout élément du monde communiste de franchir la ligne de séparation entre les deux univers. Cette volonté, qui répond parfaitement au souhait des états-majors de l'OTAN, implique la surveillance et la défense des frontières mais, selon un processus classique, elle comprend aussi la lutte contre l'ennemi intérieur.

[p. 344] On sait que les militaires ont une conception particulièrement extensive de la pénétration et de la subversion communistes. Ils tendent volontiers à y assimiler tout essai d'indépendance intellectuelle à l'égard des dogmes traditionnels et toute forme d'action gouvernementale qui implique un dialogue avec des éléments de Gauche. On apprendra donc sans surprise qu'au moment de sa démobilisation, le général Vélios, commandant de la $1^{\text {re }}$ Armée, ait adressé à ses troupes un ordre du jour où l'actuel Premier Ministre — accusé de collaborer avec les communistes était présenté comme le Kerensky de la Grèce (allégation qui a valu au dit officier d'être déféré en justice par G. Papandréou).

Tout récemment (octobre 1964), les services gouvernementaux ont découvert l'existence d'un plan de campagne d'inspiration analogue menée par six officiers appartenant à l'État-Major de la Défense Nationale dans le cadre des activités d'une revue de soviétologie - le terme couvrant ici, comme en bien d'autres cas, une activité de propagande anti-communiste. Pour le directeur de cette revue - qui était parvenu à se faire engager par l'État-Major de l'armée comme membre du bureau des relations avec le public — l'occupation du pouvoir par G. Papandréou ne saurait avoir d'autre résultat que de faire glisser le pays vers la gauche (glissement susceptible de diminuer la capacité de l'armée elle-même de lutter contre le communisme). L'affaire serait certes banale si les officiers mis en cause n'avaient commandé à la dite revue 1000 exemplaires du numéro contenant cette attaque en vue de distribution aux unités militaires. Livrés le 29 septembre, les exemplaires furent emballés à destination des unités mais le gouvernement prévenu à temps par des officiers fidèles put en effectuer la saisie. Des poursuites ont été engagées contre les officiers responsables de l’opération. 
Nous avons mentionné ce fait avec quelques détails parce qu'il est révélateur de l'état d'esprit qui règne dans certaines hautes sphères des forces armées. Les accusations lancées contre le Premier Ministre sont d'autant plus surprenantes qu'il a choisi comme Ministre de la Défense Nationale en la personne de P. Garoufalias un homme appartenant aux milieux d'affaires (bière Fix) et connu pour ses opinions très conservatrices ainsi que pour ses rapports avec le Palais. Or, de telles prises de position ne constituent nullement un cas isolé dans l'armée grecque.

Le rôle politique de l'armée commence par un effort d'endoctrinement systématique des soldats du contingent. Il se traduit en particulier [p. 345] par une censure très vigilante de leurs lectures (censure qui, selon une circulaire confidentielle de l'État-Major dont le texte fut révélé devant le Parlement s'étend même à des œuvres de Renan et de Victor-Hugo). Les forces armées disposent de leur propre système de radiodiffusion dont jusqu'à une date récente, les programmes échappaient à tout contrôle gouvernemental. Or ceux-ci ont toujours eu un caractère nettement politique et même franchement partisan. Attaqué sur ce point devant le Parlement par des leaders de l'EDA, P. Garoufalias affirma n'avoir jamais écouté le poste militaire mais déclara aussi que désormais la partie politique des émissions de celui-ci était la même que celle du système national de radiodiffusion.

Cette propension des États-Majors militaires à un engagement au profit des partis et groupes de Droite explique le concours militant apporté par l'armée aux candidats du Rassemblement Hellénique et de l'Union Nationale Radicale. Nous avons suffisamment insisté sur ce point dans la première partie de l'ouvrage pour n'avoir pas à y revenir ici. Électoralement parlant, l'Armée n'a pas craint, spécialement lors des élections de 1961, d'apporter ouvertement son soutien à Caramanlis, moins probablement par sympathie à sa personne que par fidélité à la croisade anticommuniste dont il se proclamait le champion. On aura une juste idée du climat politique de l'époque en sachant qu'au lendemain de la consultation des officiers supérieurs allaient jusqu'à souligner la contribution de l'armée aux résultats obtenus.

L'anti-communisme de l'armée trouve son plein épanouissement dans l'attachement à la cause royale et à la personne du Souverain, celui-ci étant tenu par les milieux conservateurs du pays et par les gouvernements alliés pour le garant du maintien de la Grèce dans le camp occidental. Comme indice de l'étroitesse de cette union, on peut mentionner l'essai entrepris sous le gouvernement Papandréou de donner à l'armée grecque le titre d'armée royale (septembre 1964) : notons que le décret stipulant cette désignation fut immédiatement révoqué non sans avoir suscité de très vives protestations en de nombreux secteurs de l'opinion. L'expression choqua dans la mesure où elle avait un authentique parfum d'ancien régime : quant au fond pourtant, elle avait le mérite de mettre en évidence l'existence de relations privilégiées entre la Couronne et l'Armée. Notons d'ailleurs que l'adjectif « royal » qualifie la marine, l'aviation et la gendarmerie.

Selon des informations de presse qui ne furent pas démenties, le [p. 346] défunt Roi Paul dit un jour aux officiers du $3^{\mathrm{e}}$ Corps : en garnison à Salonique que lui et eux avaient été unis par Dieu, qu'il leur appartenait et qu'ils lui appartenaient. De toute 
manière cette phrase correspond à ce qu'ont été les rapports entre le Souverain et les États-Majors militaires, à diverses périodes de l'histoire grecque. Un Roi comme Constantin au temps de sa lutte contre E. Vénizélos ne l'aurait certainement pas désavoué et il est permis de croire que sur ce point le fils n’était pas sans avoir subi l'empreinte du père.

En définitive, jusqu'à la défaite de l'ERE, l'Armée a eu propension à combattre sous le couvert de l'anti-communisme l'opposition toute entière (y compris l'activité de G. Papandréou). Aujourd'hui nous avons vu, l'idée persiste en divers milieux des forces armées que le gouvernement de l'Union du Centre constitue une menace pour le destin national. On peut dès lors s’interroger légitimement sur la marge de manœuvre que l'armée est susceptible de laisser au pouvoir civil.

\section{B. MARGE DE MANGUVRE DU POUVOIR CIVIL}

\section{$\underline{\text { Retour à la table des matières }}$}

Les commentateurs qui s'attachent à caractériser le rôle politique de l'armée grecque se réfèrent assez souvent à une société secrète qui existerait au sein de celleci : le Lien Sacré des Officiers Grecs (IDEA). Cette société, dont l'existence a été formellement dénoncée par le Premier Ministre en date du 23 avril 1964, aurait été créée dès octobre 1944 par des officiers de tendances fascistes et anti-communistes. Mais c'est seulement en mai 1947 que son activité aurait effectivement commencé, ses démarches devant s'aggraver et se multiplier sous les gouvernements Papagos et Caramanlis.

L'objectif final de l’IDEA consisterait dans l'établissement d'un régime dictatorial soutenu par les forces armées : en attendant la réalisation de ce plan, l'organisme qui procèderait par noyautage de tous les secteurs de commandement et n'hésiterait pas à utiliser la violence, au moins à titre de menace, pour parvenir à ses fins - se donnerait pour objectif d'assurer le contrôle ou la régulation de la vie politique toute entière. Le tableau, on le voit, est assez noir. Il est vrai que, sommé par le leader de l'ERE d'apporter des preuves de l'existence de l'organisme et de ses activités sous le gouvernement de Caramanlis, le Premier Ministre se borna à faire état d'un sentiment commun quant à la présence de l'IDEA.

[p. 347] Si l'on en croit un autre son de cloche, l'IDEA aurait bien eu au départ les objectifs qu'on lui prête aujourd'hui mais assez vite elle se serait transformée, tout en gardant des éléments de la phraséologie initiale, en un organisme tendant à favoriser la carrière de ses membres. En somme, l'IDEA ne serait plus que l'une de ces mafias ou sociétés d'aide mutuelle que les anciens élèves de certaines grandes écoles excellent à former pour s'assurer l'exclusivité de divers postes avantageux.

Chacune de ces deux interprétations ne manque pas de vraisemblance, la seconde s'appuyant sur l'appétit d'avantages matériels que manifeste le Corps des officiers. On peut citer, il est vrai, à l'appui de la première, des textes qui signés de personnes se disant membres de la société, exposent des plans de conquête du pouvoir d'inspiration 
ouvertement fasciste. Mais l'expérience de cas similaires montre qu'il peut s'agir en réalité de documents n'engageant pas beaucoup plus que la responsabilité de leur auteur. Qu'il y ait eu au sein de l'armée une clique se faisant appeler IDEA, qu'elle ait rassemblé des officiers hostiles à l'ordre démocratique, que ceux-ci aient dressé des plans de conspiration et se soient mutuellement soutenus dans le déroulement de leur carrière, rien de tout cela n'est invraisemblable ni même extraordinaire. Le seul point important est de savoir si l'IDEA a effectivement disposé du pouvoir qu'on lui prête. Avouons notre incapacité à trancher la discussion.

Au surplus, point n'est besoin à l'Armée de s'organiser en société secrète pour exercer une influence sur la vie politique, spécialement dans un pays où elle entretient avec le souverain les rapports que nous avons mentionnés. Il suffit pour s'en convaincre de réfléchir à la supériorité que possède l'établissement militaire sur les partis comme centre d'organisation et d'encadrement. Quand l'Armée est décidée à intervenir dans la politique et qu'elle possède le minimum d'unité politique indispensable à cet effet, il faudrait pour lui tenir tête des partis susceptibles de mobiliser les masses et de jeter leur poids dans la bataille. Les deux plus grands partis grecs, l'ERE comme l'EK, seraient certes bien incapables de réaliser, sauf de manière tout à fait épisodique, un tel rassemblement. Dès lors, par sa seule structure de société hiérarchisée, partiellement fermée et éventuellement fanatisable, l'Armée peut constituer un instrument d'intervention pratiquement sans rival. Et ce déséquilibre, sous l'angle de l'organisation entre la société militaire et civile [p. 348] déséquilibre si caractéristique de la vie politique grecque — nous paraît plus important que la formation d'une clique ou d'une quelconque camorra au sein des forces armées.

On peut admettre qu'aujourd'hui en Grèce l'Armée constitue un instrument de préservation de l'ordre social existant et qu'elle se dresserait contre tout groupe tendant à en réaliser la rupture ou la désagrégation. Nous retrouvons ici le problème de déterminer le point à partir duquel l'Armée estimerait la menace suffisante pour lancer ouvertement ses forces dans le combat, éventuellement à titre préventif. Il n'y a aucun doute que le dispositif jouerait, et certainement très vite, dans le cas d'un danger ou soulèvement communiste mais dans la situation politique d'aujourd'hui l'hypothèse d'un tel mouvement est dépourvue d'actualité.

La seule perspective digne d'être prise en considération, quoique sa réalisation semble peu probable pour l'immédiat, est celle de la position que prendrait l'armée à l'égard d'un gouvernement ayant reçu mandat du corps électoral de réaliser certains points d'un programme d'inspiration progressiste (ainsi retour du parti communiste à la légalité, adoption d'un plan graduel de désarmement des forces armées, mise en œuvre d'une politique d'éloignement de l’OTAN...). Sans vouloir jouer au prophète, disons qu'un tel programme aurait bien des chances de susciter l'opposition irréductible de l'établissement militaire. Sur cette base, il est légitime d'avancer que le principal rôle politique de l'armée, bien plus important certes que la participation à des manipulations électorales, est de constituer un frein, sinon un obstacle absolu, à toute politique d'inspiration progressiste. 
Nous avons vu plus haut que pour plusieurs éléments de l'armée l'actuel gouvernement Papandréou apporte au pays un risque de glissement vers la Gauche ou, si l'on préfère, un amoindrissement de la capacité de résistance nationale à l'entreprise communiste. Ces attitudes ne sont certes pas sans rapport avec les rumeurs qui ont circulé à diverses reprises de la préparation d'un coup d'État perpétré par les militaires avec le concours d'éléments de l'Extrême-Droite. À quiconque prend en considération le caractère profondément conservateur de l'équipe gouvernementale actuelle - propension qui n'est sans doute pas étrangère à l'extrême mollesse avec laquelle a été réalisée l'épuration des forces armées - de telles rumeurs risquent d'apparaître comme de purs produits de l'imagination. Mais la bourgeoisie grecque est si rigi-[p. 349] dement conservatrice et si farouchement égoïste qu'elle est capable d'interpréter comme une marche vers le communisme un simple programme d'amélioration du sort des petits et des pauvres.

On ne s'étonnera donc pas que des gens conspirent contre le gouvernement Papandréou, l'éventualité que des membres des services de sécurité participent à de telles machinations étant somme toute probable. Il est toutefois fort douteux que la Droite - qui n'a aucune raison de désespérer de son avenir électoral - accepte de se lancer dans une telle aventure. Et l'on ne voit pas par ailleurs les raisons qui pourraient pousser la Couronne, à peine sortie de la grave crise des années 1960, à souhaiter ou simplement à tolérer une telle opération qui, victorieuse ou non, ne pourrait en définitive que précipiter sa chute. Au surplus, aucune opération de cet ordre ne serait concevable si l'OTAN, c'est-à-dire les États-Unis, ne donnait le «feu vert ».

En considérant l'expérience étrangère, une autre question il est vrai peut être posée : celle que l'armée s'éloigne ou se détache un jour des groupes socio-politiques qu'elle a la charge de protéger. Cette hypothèse correspondrait à la répétition, en style du $X X X^{\mathrm{e}}$ siècle, de la vieille expérience de la Ligue Militaire et il n'est pas difficile, au moins en principe, d'imaginer le facteur susceptible de déclencher un tel mouvement : une humiliation nationale, impliquant reculade de l'armée dans l'affaire chypriote. Une telle opération, si elle devait être tentée n'aurait certainement pas pour objet de remplacer les politiciens de l'EK par ceux de l'ERE mais bien plutôt d'écarter de la gestion des affaires nationales l'ensemble des politiciens. En somme, lasse de défendre l'ordre des autres, l'armée pourrait tenter d'imposer au pays sa propre conception de l'ordre.

Plusieurs estiment peu vraisemblable qu'une telle opération s'accomplisse. Si l'on en croit des déclarations publiques faites par des officiers supérieurs, il n'est pas certain que l'armée, dans son ensemble, place l'union de Chypre avec la Grèce audessus du maintien des liens avec l'OTAN. Comme nous l'avons déjà dit, le corps des officiers tend à considérer que le communisme continue de représenter le principal péril pour la Grèce (le général Loumakis l’ayant expressément déclaré au lendemain de la signature des accords gréco-bulgares). Et dans cette perspective, l'armée grecque ne peut qu'approuver les efforts accomplis pour que la question chypriote n'écarte pas la Turquie de l'Alliance Occidentale : les déclarations faites à Die Welt au lendemain 
du bom-[p. 350] bardement turc de Chypre par l'officier grec du grade le plus élevé à l'État-Major de Smyrne ne laissent pas beaucoup de place au doute en ce domaine.

En définitive, l'armée est aujourd'hui la garante de l'ordre social et il est probable qu'elle interviendrait très vite, en accord avec l'OTAN, si cet ordre lui semblait réellement menacé. On peut aussi avancer que les forces militaires grecques, pas plus que les États-Majors atlantiques, ne pècheraient par sous-évaluation dans le calcul des périls susceptibles de compromettre cet ordre. Le point important toutefois reste que les partisans de tels changements ne sont pas encore très nombreux en Grèce et n'ont pas beaucoup de chances d'accéder au pouvoir dans un proche avenir. Les forces armées risquent donc de demeurer l'arme aux pieds dans leur tâche de surveillance des démarches de l'appareil partisan.

L'étude du rôle de l'armée, montre en tout cas que les efforts entrepris pour ramener la Couronne au respect de son rôle constitutionnel n'ont quelque chance d'aboutir que si les forces armées effectuent elles-mêmes une reconversion d'esprit démocratique, c'est-à-dire prennent l'habitude de ne plus s'immiscer dans les choix du corps électoral et l'activité des gouvernements qui en émanent. L'armée ayant été dressée depuis plusieurs décennies à tenir pour normales de telles ingérences, la transformation ne saurait s'effectuer en un jour. En réalité, la démocratisation de la vie politique - dont la réduction à leur rôle officiel des forces extra-parlementaires est une étape ou un aspect - constitue une œuvre de bien plus longue haleine que divers leaders ou organes du Centre ne tendent à le laisser supposer.

\section{SITUATION DE L'ÉGLISE}

Retour à la table des matières

La Constitution hellénique de 1952 débute par l'invocation suivante « Au nom de la Trinité sainte, consubstantielle et indivisible ». Les deux premiers articles de ce document sont placés sous une rubrique intitulée «De la religion ». L'art. premier énonce que « la religion dominante en Grèce est celle de l'Église Orthodoxe Orientale du Christ... ». L'art. 2 rend un son quasi théologique, l'al. 2. précisant que " le texte des Saintes Écritures est tenu pour inaltérable ; il est absolument interdit de le rendre en une autre forme de langage quelconque sans l'approbation préalable de l'Église autocéphale de Grèce et de la [p. 351] Grande Église du Christ à Constantinople ». Faut-il déduire de ces prémices inusuelles que la Grèce moderne est un État théocratique?

Ce serait une déduction bien excessive. L'art. premier, après avoir donné à la religion orthodoxe le statut de religion dominante — et en fait la presque totalité de la population grecque relève de cette confession - précise que « toute autre religion connue est libre et (que) les pratiques de son culte s'exercent sans entraves sous la protection des lois » [situation qui s'applique aux très faibles minorités religieuses du pays : minorité musulmane de Thrace, minorités catholiques des Cyclades (Santorin) 
et des îles Ioniennes]. Le même article, il est vrai, interdit « le prosélytisme et toute autre intervention contre la religion dominante ».

Il existe certes un effort de prosélytisme catholique (spécialement par le truchement du rite uniate). Mais en l'état actuel des choses, et vu l'extrême répugnance des Grecs à changer de religion, le respect de la disposition interdisant le prosélytisme ne paraît certes guère susceptible de causer à l'État de souci majeur. Notons toutefois que si l'Église Orthodoxe est finalement plutôt libérale à l'égard des minorités confessionnelles, elle reste assez intolérante à l'égard des Grecs qui ne relèvent pas d'une autre confession — un Grec extérieur à son Église ou excommunié par elle ne pouvant en particulier se marier (absence de mariage civil). Il est vrai que de telles situations sont extrêmement rares, tous les Grecs nés dans l'Orthodoxie acceptant la discipline confessionnelle. Il faut à cet égard souligner qu'en règle générale, les membres de la Gauche eux-mêmes se conduisent en bons chrétiens.

D'un autre côté, conformément à une vieille tradition de césaro-papisme, l’Église orthodoxe n'intervient pratiquement pas dans la vie politique courante et les contestations partisanes. Et cette soumission de l'Église au pouvoir civil a pour contre-partie le fait que personne ne met en cause sa présence et son activité. L'idée d'un combat laïque contre les forces confessionnelles est totalement étrangère à la mentalité politique grecque. Au lendemain de la seconde guerre mondiale, l'État a décidé de prendre à sa charge les traitements du clergé et nous avons vu qu'en ce domaine le programme de l'EDA elle-même se borne à recommander une hausse de la rémunération attribuée au bas-clergé.

Celui-ci qui, on le sait, vit en état de mariage, se trouve généralement dans une situation matérielle précaire. Cette position contraste avec celle du Haut-clergé qui, lui, n'est pas autorisé à contracter ma-[p. 352] riage. Ce dernier, grâce à la fortune de l'Église qui reste encore confortable, vit souvent dans une relative aisance et dispose parfois de quelque luxe. Les gouvernements n'ignorent pas que l'administration des biens d'Église a des défauts et qu'elle ne répond pas entièrement aux principes de charité et de renoncement qui devraient la guider. Cependant, ils tolèrent ces anomalies dans la crainte des répercussions qu'un conflit avec le Clergé pourrait avoir sur l'opinion.

En définitive, l'Église grecque n'intervient guère dans les affaires de l’État. Il arrive certes qu'elle témoigne de quelques réticences à l'égard d'actes du domaine civil. Ainsi en est-il allé lors du récent mariage du Roi Constantin, le seul monarque régnant de l'orthodoxie mondiale, avec une princesse de confession luthérienne. Il semble que plusieurs personnalités de l’Église orthodoxe auraient souhaité que celleci soit baptisée préalablement au mariage selon le rite de la religion de son futur époux. De son côté, le président de l'Union Panhellénique orthodoxe a déploré qu'en cette occasion, la famille royale se montre, spécialement quant au choix de la date de la cérémonie, " étrangère et irrespectueuse envers la religion du pays ». Cependant le Saint-Synode n'a pas insisté sur ces divers points et il a seulement été indiqué que le Roi assumerait, après le mariage, la mission de catéchiser son épouse. 
L'absence de querelles entre l'État et l'Église, ainsi que la propension de chacun des partenaires à éviter tout conflit ouvert avec l'autre, s'explique probablement par l'attitude des Grecs à l'égard de leur Église. Ceux-ci ne sont certes pas dupes des défauts du clergé orthodoxe dont les mœurs sont bien loin d'être irréprochables. Mais ces critiques n'atteignent pas, semble-t-il, l'attachement des Grecs vis-à-vis de l'Église - cet attachement existant en réalité même chez ceux qui affirment, plus ou moins ouvertement, quelque scepticisme à l'égard des manifestations du culte.

La raison de ce sentiment est que l'Église grecque fait partie de la tradition nationaliste du pays. Pendant les longs siècles de l'occupation turque, l'Église orthodoxe a certainement constitué le principal des facteurs qui ont permis aux Grecs de maintenir leur identité nationale — les Turcs, observons-le, n'ayant entrepris, pour des raisons diverses, aucun effort en vue de convertir leurs sujets à l'Islam. Et lorsque vint le temps de l'insurrection, nombreux furent les membres du Clergé parmi ceux qui levèrent l'étendard de la révolte. Pour un peuple dont la libé-[p. 353] ration a été si lente - et il y aurait sous cet angle un intéressant parallèle à tracer avec la situation du catholicisme en Pologne - ce sont là des souvenirs dont l'effacement ne saurait être que très lent.

L'exemple de Chypre où le Chef religieux, l'Ethnarque Macarios se trouve à la tête du combat de libération nationale, permet de comprendre l'origine de la confiance que dans les jours d'épreuve les Grecs ont été amenés à accorder à leurs dirigeants spirituels. Sous l'occupation turque, le Chef religieux, en occupant la première place de la hiérarchie sociale, ne cédait pas à un souci de puissance temporelle : il devait en fait assumer une telle position en tant que garant, aux yeux des autorités ottomanes, du comportement de ses fidèles.

Mentionnons un dernier point : l'attachement de l'Église orthodoxe grecque, qui se tient pour l'héritière de l'Église de Byzance, à sa propre indépendance vis-à-vis des autres Églises de l'orthodoxie et a fortiori vis-à-vis de l'Église catholique romaine. L'Église grecque se tient pour dépositaire du patrimoine de l'hellénisme en matière confessionnelle. Les Patriarcats d'Alexandrie et de Jérusalem sont encore aux mains d'un personnel hellénique, seul celui d'Antioche allant à un Arabe. Or, sur ce terrain, la tradition grecque se heurte aux démarches de l'Église romaine qui oppose aux Orthodoxes plusieurs groupes confessionnels (clergé maronite, clergé latin, clergé uniate).

Ainsi s'explique les réticences de l'Église grecque à l'égard du Concile. Tout en finissant par admettre qu'il peut y avoir quelque utilité pour l'Orthodoxie à engager des contacts avec Rome, à condition qu'ils se déroulent sur un pied de stricte égalité, l'Église grecque (qui ne semble pas avoir été très heureuse de la rencontre en Palestine entre le Pape et le Patriarche de Constantinople) n'a pas donné suite à l'invitation de participer aux travaux de Vatican II. Cette réserve contraste avec l'accueil cordial fait au Concile par d'autres Églises orthodoxes, celle de Russie en particulier — la chaleur de cette dernière à l'égard de Rome paraissant aujourd'hui en diminution. 
L'Église grecque a finalement accepté de prendre part à la dernière conférence Pan-orthodoxe de Rhodes (novembre 1964): elle y a préconisé d'attendre, pour engager des négociations avec Rome, que celle-ci ait défini sa position à l'égard de l'orthodoxie. C'est là, objectera-t-on, pure affaire de théologie et de spiritualité. Pourtant, dans le monde contemporain, l'effort œcuménique comporte des résonances politiques. Il est bien connu que le Patriarcat de Constantinople subit une forte [p. 354] influence américaine, ne serait-ce qu'en raison du fait qu'il tire l'essentiel de ses ressources des communautés orthodoxes d'Amérique du Nord - ressources dont le flot serait tari par l'érection de ces communautés en Église autocéphale. Or, il est très probable qu'à l'époque actuelle, cette influence s'est exercée dans le sens d'un rapprochement entre le Patriarche et le Vatican.

L'Église grecque, par la position dont elle dispose dans le pays, échappe en une large mesure à des pressions de cet ordre. Elle est donc dans les rapports entre l'Orthodoxie et l'Église Catholique un élément frein. Et il est possible qu'une fois encore la position prise par l'Église autocéphale de Grèce convienne au sentiment national Grec ${ }^{1}$.

Le lecteur qui souhaiterait examiner les problèmes et positions de l'orthodoxie pourra consulter, au titre d'une première initiation, les ouvrages suivants : CLÉMENT (O.), L'Église Orthodoxe, Paris, 1961 (Que sais-je ?, n 949) ; MEYENDORFF (J.), L'Église Orthodoxe hier et aujourd'hui, Paris, 1960 ; WARE (T.), The Orthodox Church, Penguin Books, 1963; BOULKAKOFF (S.), L'orthodoxie, Paris, 1958 (réimpression d'un ouvrage publié en 1932) ; SERAPHIM (Métropolite), L'Église Orthodoxe. Les dogmes, la liturgie, la vie spirituelle, Paris, 1952. 
[p. 355]

\section{CHAPITRE XI \\ LES GROUPES D'AFFAIRES NATIONAUX}

Retour à la table des matières

LE SUJET DE CE CHAPITRE est simplement d'identifier les éléments ou secteurs du monde des affaires qui ont la faculté de peser sur la politique gouvernementale. Après avoir brièvement recensé les diverses catégories de forces économiques, nous essaierons de préciser la nature et les dimensions de leur influence.

Nous nous en tiendrons pour le moment aux groupes d'affaires nationaux, renvoyant au chapitre suivant l'étude du capital étranger. Cette séparation présente divers inconvénients dont l'un est de minimiser ou de dissimuler les relations susceptibles d'intervenir entre capitalistes de l'intérieur et de l'extérieur. Un point, particulier à la Grèce, aggrave d'ailleurs la complexité du problème : la difficulté de classer les capitalistes nationaux-étrangers (peut-être serait-il plus exact de dire: étrangers-nationaux), c'est-à-dire les hommes, tels S. Niarchos, dont le centre de puissance et de fortune se situe hors du pays mais qui interviennent également dans l'économie nationale. La division adoptée possède toutefois, sous l'angle de l'analyse politique, une justification solide — le fait que le capital étranger — et il s'agit essentiellement d'un capital monopoliste - dispose, tant par ses dimensions que par l'appui reçu des puissances gouvernementales extérieures, d'une capacité d'influence spécifique. Dès lors, sans nous interdire d'esquisser dès maintenant certains rapports économiques entre milieux grecs et milieux étrangers, c'est seulement dans le chapitre suivant que nous en donnerons une vue générale. 
[p. 356]

\section{PRÉSENTATION DES GROUPES}

Nous mentionnerons successivement le secteur des banques, de l'industrie et de la navigation. Le secteur bancaire, fortement affecté par le désastre monétaire de l'hyperinflation, témoigne aujourd'hui d'une assez vigoureuse expansion. L'industrie, malgré plusieurs bulletins de victoire fort prématurés, reste le point faible de l'économie grecque. Le compartiment de la marine marchande a toujours été l'un des atouts de la Grèce, atouts très rares en vérité, sur le plan économique : il en va toujours ainsi sous réserve de la propension des armateurs helléniques à installer le centre de leurs affaires à l'étranger et à utiliser des pavillons de complaisance.

\section{A. SECTEUR BANCAIRE}

Retour à la table des matières

Les principaux éléments en sont: la Banque de Grèce; les banques commerciales ; divers organes d'investissement; divers établissements spécialisés. Après avoir dit quelques mots sur chacun de ces éléments de l'appareil bancaire, nous présenterons quelques remarques générales sur le capitalisme financier grec. Pour faciliter la compréhension des chiffres cités, rappelons que l'équivalence du change est en chiffres ronds de 30 drachmes pour 1 dollar US.

\section{BANQUE DE GRÈCE}

La Banque de Grèce a été créée en 1928 avec le privilège d'émission (jusqu'alors détenu par la Banque Nationale de Grèce). C'est une société dont les actions sont entre les mains de personnes privées et d'organismes de droit public. L'État désigne le Gouverneur et les deux Gouverneurs-adjoints de la Banque ; il reçoit le profit net de l'établissement après répartition du dividende dont le maximum est fixé à $8 \%$. Pour l'année 1962 la part allant au Trésor Public a été de 84,4 millions de drachmes sur un total de 103 millions de bénéfice.

La Banque de Grèce surveille l'ensemble du marché de l'argent dans le cadre des directives du Comité Monétaire (qui est composé de cinq Ministres et du Gouverneur de la Banque). Elle remplit les fonctions de banquier du gouvernement et agit sur le marché comme banque des [p. 357] banques. Elle contrôle les transactions en monnaies étrangères et gère, les ressources en devises du pays. Enfin, la Banque joue 
le rôle de conseiller économique du gouvernement pour tout ce qui concerne la monnaie et le crédit.

La Banque a pour Gouverneur Xénophon Zolotas qui exerce également les fonctions de professeur d'économie politique. Son idée de base est que la stabilité monétaire commande la réalisation d'un taux satisfaisant de développement dans la longue période. À court terme, il est possible de dissocier les deux objectifs et d'obtenir un taux élevé de développement au détriment de la valeur de la monnaie. Mais, à plus long terme et dans le cadre d'une économie de marché, l'accroissement du revenu et la stabilité de la monnaie sont des éléments inséparables. Dans cette perspective, les tâches fondamentales du secteur bancaire sont de sauvegarder la valeur de la drachme et d'encourager la création d'industries internationalement compétitives.

La philosophie économique de la Banque de Grèce est clairement exprimée dans les rapports annuels à l’Assemblée générale des actionnaires. La règle essentielle en est l'exaltation de l'initiative privée : c'est d'elle que doit venir l'impulsion principale pour la modernisation et l'augmentation de la production. Il est donc nécessaire d'éliminer de la vie des affaires les interventions paralysantes des services administratifs et de simplifier les procédures relatives à la création de nouvelles entreprises ou à la fusion d'anciennes. Toutefois, on attend de l'État qu'il intervienne pour mettre en place l'infrastructure nécessaire au développement industriel et pour stimuler fortement, par la concession d'avantages appropriés, l'expansion des investissements productifs. Il est facile de comprendre qu'une telle formule aboutit à favoriser et à amplifier la formation des profits privés à l'aide des ressources de la collectivité.

La Banque de Grèce tient pour un impératif la venue du capital étranger. Elle porte un jugement favorable sur l'association de la Grèce au Marché Commun. À ce propos, le rapport pour l'année 1960 présente comme un objectif réalisable l'obtention par la Grèce en une vingtaine d'années de standards de consommation semblables à ceux des pays d'Europe Occidentale. C'est là une prédiction audacieuse.

\section{[p. 358] 2. BANQUES COMMERCIALES}

Il en existe neuf mais les trois plus grandes (Banque Nationale de Grèce, Banque Commerciale, Banque Ionienne et Populaire, les deux dernières faisant partie du même groupe) effectuent 95\% des transactions de toutes les catégories. Nous nous limiterons donc à celles-ci en nous bornant à signaler le cas de la Banque de Crédit Commercial (I.F. Costopoulos Ltd) dont l'un des actionnaires, S. Costopoulos, est aujourd'hui Ministre des Affaires Étrangères. Sans entrer dans des détails techniques, notons que les banques commerciales grecques qui renforcent aujourd'hui leurs liens avec le capital financier international ont un champ d'action très large, effectuant des opérations (crédits à court terme, prêts à long terme, prises de participations...) qui en d'autres pays relèvent de catégories différentes d'établissements. 


\section{a) Banque Nationale de Grèce.}

Juridiquement constituée le 30 mars 1841, la Banque obtenait en janvier 1842 le privilège d'émettre des billets de banque, cette faculté étant transférée à la Banque de Grèce en 1928. De banque d'émission, la Banque Nationale de Grèce est donc devenue simple banque commerciale.

Tout au long de son histoire, la Banque a procédé à la constitution ou participé à la formation d'autres banques : en 1899, Banque de Crète ; en 1904, Banque d'Orient (en coopération avec la Banque Nationale d'Allemagne); en 1905, Banque Populaire ; en 1913, Banque d'Athènes (en coopération avec la Banque de l'Union Parisienne); en 1927, Banque Nationale de Crédit Foncier de Grèce ; en 1929, Banque Agricole de Grèce (à la demande du Gouvernement) ; toujours en 1929, Hellenic Bank Trust $\mathrm{C}^{\circ}$ (New-York). La Banque Nationale a d'ailleurs absorbé plusieurs des banques ainsi créées au cours de son développement : Banque de Crète (1919) et Banque d'Orient (1932). La dernière en date de ces opérations de concentration a été la fusion avec la Banque d'Athènes en février 1953. Signalons également que la Banque Nationale a des rapports particuliers avec la Hambro's Bank de Londres (fondation avec celle-ci en 1928 de la Hellenic Corporation Ltd destinée à intervenir dans le domaine des investissements étrangers en Grèce).

[p. 359] Au 31 décembre 1963, la Banque disposait d'un montant de dépôts égal à 19,1 milliards de drachmes (dont 8,5 à titre de dépôts d'épargne). La majeure partie des fonds disponibles pour les opérations de crédit sont avancés à court terme mais la Banque effectue aussi des prêts à long terme pour l'extension et la modernisation d'installations. Enfin, la Banque participe à la création de nouvelles entreprises en coopération, le cas échéant, avec des firmes étrangères. Mentionnons à ce propos la création en 1960 de la Compagnie de prospection pétrolière Aitolian (en collaboration avec la British Petroleum) et en 1961 de la Société pour l'Industrie Chimique de la Grèce du Nord (en collaboration avec Saint-Gobain et la Société Hellénique des Produits Chimiques et Engrais). La Banque a également pris part en 1960 à la création de l'Organisation de Développement Industriel.

Le trait majeur de l'activité de la Banque est, selon ses propres déclarations, l'établissement d'étroites liaisons avec l'industrie. La Banque affirme qu'il n’y a guère d'entreprise industrielle de quelque importance dans le pays qui n'ait été encouragée et activement soutenue par elle. En dehors du financement des besoins courants de crédit et de la création d'entreprises, la Banque apporte à l'industrie des conseils techniques et financiers (préparation d'études sur les structures de diverses industries en liaison avec un institut de l'École Polytechnique de Zurich). En somme, nous avons là, dans les limites d'intervention effective de la Banque, un processus typique de développement industriel suscité et contrôlé par le capitalisme financier.

La Banque est une société dont les actions sont dans les mains de personnes privées, de compagnies d'assurances, d'institutions culturelles et charitables. Sans en être propriétaire, l'État y joue un rôle déterminant par le truchement des personnes morales de droit public qui en sont actionnaires. Elle a actuellement pour Gouverneur 
— celui-ci étant élu par l'assemblée des actionnaires - G. Mavros, personnalité très influente du Centre (supra). Mavros, qui était Ministre dans le Cabinet Papandréou, a remplacé à ce poste, en date du 25 mai 1964, D. Helmis qui appartenait à la Droite. Le gouverneur-adjoint est J. Paraskévopoulos qui a été Ministre dans divers gouvernements de service et a présidé le Cabinet constitué pour la consultation de février 1964. Paraskévopoulos est couramment tenu pour un homme du clan royal.

La présence au sommet de la Banque Nationale de J. Paraskévopoulos aide à comprendre le mécanisme des liaisons entre la Cour et le monde [p. 360] des affaires. L'existence de ces liens a été rendue manifeste par la réelle importance qu’a donnée la Banque à la célébration du centième anniversaire de la dynastie intervenu en une période de grave tension entre le Palais et l’Union du Centre. Une réunion spéciale du Conseil d'Administration a été organisée à cet effet le 10 mars 1963 avec participation de la famille royale au grand complet. Plusieurs personnalités officielles participaient également à la réunion parmi lesquelles : Sa Béatitude Chrysostome, Métropolite d’Athènes ; le Premier Ministre ; le Président de la Chambre ; le Gouverneur de la Banque de Grèce ...

Notons, sans insister, que dans une adresse établie à cette occasion, la Banque déclarait que la Couronne a toujours été le symbole vers lequel le peuple s'est tourné avec foi et espérance à la fois dans les jours de triomphe national et dans ceux de malheur et d'infortune ${ }^{1}$. C'est évidemment prendre de belles libertés avec l'histoire.

\section{b) Banque Commerciale.}

Présidée par Stratis C. Andréadis (qui assume également la Présidence de la Banque Ionienne et Populaire), la Banque Commerciale se livre aux mêmes sortes d'activité que la Banque Nationale de Grèce. La Banque Commerciale, qui a été créée en 1907, disposait au 31 décembre 1963 d'un montant de dépôts égal à 6 milliards de drachmes (dont 3,1 au titre des dépôts d'épargne). C'est donc un organisme beaucoup moins puissant que la Banque Nationale : le total du bilan de celle-ci atteint en effet 35,6 milliards contre seulement 14,1 pour la Banque Commerciale.

La Banque Commerciale participe elle aussi à la création d'entreprises industrielles et dispose d'un portefeuille de valeurs ${ }^{2}$. En dehors de la Banque Ionienne et Populaire, les principaux actifs de la banque en ce domaine (par ordre d'importance de la valeur inscrite au bilan) se trouvent dans les affaires suivantes: Industrie Hellénique d'Engrais Phosphoriques ; Chantiers navals L'Éleusis ; Chemins de fer électriques helléniques; Pirelli Grèce S.A. ; Industrie Hellénique de Jus et Conserves avec le concours de la firme britannique Schweppes, etc. ... La Banque dispose également de participations dans plusieurs compagnies d'assurances. Notons enfin qu'elle a également pris part à la fondation de l'Organisation de Développement Industriel. Nous retrouvons donc pour [p. 361] la Banque Commerciale le type de

Texte dans la revue de la Banque, Greece Today, mars 1963, p. 20.

Dont le détail est fourni dans le Rapport du Conseil d'Administration pour 1963. 
liaisons entre capitalisme financier et développement industriel déjà observé pour la Banque Nationale.

Le Comité monétaire a récemment autorisé l'installation à Athènes d'une succursale de la First National City Bank de New-York. C'est la première fois qu'une banque étrangère obtient le droit de s'implanter en Grèce pour y effectuer des opérations de banque courantes. Selon les informations disponibles, le Comité aurait mis certaines conditions à l'opération en vue de limiter les dommages pouvant être causés aux banques commerciales grecques par la concurrence américaine. Cependant, l'octroi de cette permission a suscité de vives protestations de la part des banques intéressées, en particulier de la Banque Nationale de Grèce ${ }^{1}$.

\section{ORGANISMES D'INVESTISSEMENT}

Nous mentionnerons d'abord l'Organisation pour le Financement du Développement Économique fondée en 1954 en tant que personne morale de droit privé et qui fonctionne sous le contrôle du Ministère de la Coordination. Initialement, le capital de l'Organisme était constitué par les créances relatives aux prêts consentis entre 1948 et 1954, soit par la Commission Centrale d'Emprunts, soit par la Mission Américaine de Secours à la Grèce. Depuis lors, l'Organisation est parvenue par divers moyens à augmenter ses ressources propres dont le total était de l'ordre de 3,5 milliards de drachmes au 31 décembre 1962. Elle a également pu augmenter ses disponibilités par des emprunts faits à des institutions étrangères.

L'Organisation, dans le Conseil de laquelle figurent des représentants du Ministère de la Coordination, de la Banque de Grèce, de la Banque Nationale de Grèce, de la Banque Nationale de Crédit Foncier, a pour principal rôle d'attribuer des prêts à des entreprises d'une importance particulière pour le développement économique (ainsi expansion de diverses branches industrielles et du tourisme). L'Organisation s'est également in-[p. 362] téressée à la mise en chantier de nombreuses installations et au lancement de diverses entreprises.

Signalons en second lieu, l'Organisation de Développement Industriel constituée en février 1960 sous forme de société anonyme. L'objet de cette institution était d'entreprendre la promotion de projets industriels sous l'égide l'État, d'assurer la réalisation des études préalables dans l'ordre financier et technique, de prendre des participations dans le capital des entreprises dont elle avait contribué à assurer l'établissement. L'Organisation avait l'État pour principal actionnaire (45\% du capital) mais, comme nous l'avons vu, la Banque Nationale de Grèce et la Banque Commerciale détenaient une part du capital.

1 Voir Greece Today, novembre 1963, p. 84. Sur les conditions de l'opération, voir la revue de la Banque Commerciale Economic Bulletin, octobre-décembre 1963, pp. 28-30. 
Au 31 décembre 1962, l'Organisation avait déjà investi 402 millions de drachmes (dont 120 effectivement versés) dans le capital de 8 entreprises, sa part dans le capital allant de 3\% (Marbre Grec de Paros) à 100\% (Tanneries Helléniques, Constructions métalliques de Grèce, Marbre de Grèce...). Notons une participation de $12 \%$ dans le capital d'Aluminium de Grèce (société sur laquelle nous reviendrons au chapitre suivant). De plus, l'Organisation avait pris la décision d'investir des fonds dans plusieurs autres compagnies en cours d'établissement.

Le gouvernement de l'Union du Centre a entrepris de remplacer ces deux organismes — ainsi que l'Organisation de Crédit pour le Tourisme — par une banque unique de développement industriel qui sera un établissement public appartenant entièrement à l'État. Une déclaration du Ministre de la Coordination, G. Mavros, en date du 22 février, éclaire les mobiles de cette décision : selon le Ministre, il aurait existé des liens étroits entre certains des membres du Conseil de l'Organisation de Développement Industriel et quelques uns des grands monopoles étrangers s'intéressant à la Grèce. Ainsi les firmes Krupp et Péchiney étaient-elles, en fait, représentées dans le conseil de cet organisme.

L'objectif de cette réforme est de rassembler sous une direction unique les initiatives dispersées prises durant cet après-guerre pour remédier à la pénurie de capital. Le nouvel établissement, dont le Gouverneur, les vice-gouverneurs et les membres du Conseil seront désignés par décret royal (le premier gouverneur de l'établissement étant N. Porphyroyennis), aura pour rôle de promouvoir la croissance de l'industrie nationale - modernisation, fusion ou création d'entreprises — par une politique d'ouverture de crédits et de prise de participations. On espère que cet organisme sera en mesure d'attirer des capitaux étrangers.

[p. 363] Au cours des dernières années, chacune des deux plus grandes banques commerciales a tenu à fonder sa propre banque d'investissement en coopération avec plusieurs maisons étrangères. La première de ces banques a été créée en 1962 par la Banque Commerciale avec le concours de la Bank of America, de la Dresdner Bank, du Comptoir National d'Escompte et de la Société Générale, de l’Union Européenne Industrielle et Financière, de la Banca Nazionale del Lavoro, de Samuel Montague and $\mathrm{C}^{\circ}$ et de la Commercial Bank of the Near East (avec laquelle la Banque Commerciale a des liens ordinaires d'association). La Banque d'investissement de la Banque Nationale de Grèce a été créée en 1963 avec le concours de la Chase International Investment Corporation, de la Manufacturers Hanover International Banking, de la Deutsche Bank, de la Banque Lambert et de Cofinindus, du Crédit Lyonnais et de la Banque Nationale pour le Commerce et l'Industrie, de la Mediobanca ainsi que d'un groupe de maisons anglaises sous la direction de la Hambro's Bank (celle-ci étant une vieille relation d'affaire de la Banque Nationale).

Il est beaucoup trop tôt pour se prononcer sur la valeur de ces initiatives qui regroupent, deux par deux, les quatre grands établissements de crédit français. Le point est de savoir jusqu'à quel point ces nombreuses banques étrangères accepteront et seront en mesure de mobiliser au profit de l'économie grecque les ressources financières de leur marché respectif. Évoquant ce mouvement dans son dernier 
rapport, l'OCDE s'est demandé s'il n'aurait pas été préférable de fonder un seul organisme disposant de moyens et de possibilités d'action plus vastes. Cette réserve ne manque pas de pertinence.

\section{4. ÉTABLISSEMENTS SPÉCIALISÉS}

Il en existe un petit nombre parmi lesquels nous mentionnerons en premier lieu la Banque Agricole fondée en 1929 par l'État (avec l'aide de la Banque Nationale de Grèce) en vue de procurer aux paysans, dans des conditions adéquates, des crédits et une aide technique. La Banque a pour gouverneur Tassis Vgénopoulos ancien député de Patras. La distribution des crédits s'effectue dans le cadre de programmes approuvés par le Comité Monétaire : il s'agit aussi bien de facilités à court terme que de prêts à moyen et long terme dont le taux, quoique ayant fait l'objet de deux réductions, reste élevé. Le montant des crédits ainsi [p. 364] répartis a considérablement augmenté au cours des dix dernières années. Notons que le gouvernement Papandréou au nommé au poste de Gouverneur adjoint de la Banque A. Papalassis qui exerçait précédemment les fonctions de professeur d'économie politique à l'Université de Californie.

Signalons aussi l'existence d'une Banque Nationale de Crédit Foncier constituée en 1928 comme société commerciale. La principale activité de la Banque consiste dans l'octroi de prêts à long terme sur hypothèque pour faciliter la construction d'habitations privées. Mentionnons enfin le cas de deux institutions étatiques, la Caisse d’Épargne Postale et la Caisse des Dépôts et Consignations qui prêtent une fraction de leurs ressources aux collectivités locales et à d'autres organisations publiques.

\section{OBSERVATIONS GÉNÉRALES}

Nous avons relativement insisté sur le secteur bancaire car la pénurie de capitaux a longtemps représenté et constitue encore - spécialement au titre des investissements publics — une sérieuse entrave à la modernisation économique du pays (la situation étant aggravée par la propension de nombreux détenteurs de capitaux à les utiliser sous la forme de placements d'un rendement quasi-immédiat, constructions immobilières notamment, ou d'opérations de pur négoce). Cette conjoncture vaut, il est à peine besoin de l'écrire, une influence particulière aux banquiers et autres personnes associées au maniement de l'argent.

Dans ce domaine, d'assez sérieux progrès - laissant d'ailleurs subsister diverses lacunes — ont été réalisés depuis l'année 1953 qui marque le début du retour à la stabilité monétaire. Ces progrès ont été de deux ordres. Le premier concerne le perfectionnement de l'appareil bancaire qui a été modernisé, étendu et quelque peu diversifié. L’État s'est associé de diverses manières à cet effort (notamment par l'octroi de conditions fiscales avantageuses dans le domaine des fusions). La seconde

série d'améliorations porte sur la reconstitution de la capacité d'épargne nationale : le 
retour à la confiance dans la valeur de la drachme a eu pour conséquence un gonflement important des dépôts d'épargne dans la réception desquels la Banque Nationale de Grèce détient une place privilégiée ainsi qu'une certaine renaissance du marché financier sur [p. 365] lequel divers emprunts ont pu être placés (notamment au bénéfice de l'Entreprise Publique d'Électricité) ${ }^{1}$.

Certes ces résultats, encore partiels eu égard aux besoins, ont dû être, surtout au départ, chèrement payés : c'est ainsi qu'en 1956, pour attirer dans les banques les capitaux séduits par la thésaurisation de l'or et les placements immobiliers, on a accordé un taux d'intérêt de 10\% aux dépôts d'épargne (celui-ci ayant été réduit par la suite à 4,50\%). Mais, compte tenu des souvenirs laissés aux Grecs par l'hyperinflation, il était probablement difficile, dans le cadre d'une économie de marché, d'agir de manière différente. Le même raisonnement permet de comprendre que l'on ait cru devoir accorder des conditions très avantageuses aux souscripteurs des emprunts de l'Entreprise d'Électricité (7\% d'intérêt et indexation sur le cours officiel du dollar US).

L'évolution que nous venons de résumer a eu, sous l'angle de la distribution du crédit aux entreprises, une triple conséquence : augmentation, beaucoup plus rapide que celle du revenu national, de la somme des facilités et prêts accordés aux entreprises; accroissement de la part des crédits nourris par les banques sur leur propre trésorerie sans recours à la Banque Centrale; diminution progressive et d'ailleurs plutôt lente des tarifs exigés des emprunteurs. Soulignons en revanche que l'État a largement utilisé le financement monétaire pour l'exécution des programmes de travaux publics et l'octroi d'avances aux entreprises publiques. Cette pratique est l'une des causes de la vive expansion des disponibilités monétaires observée au cours de cette période (15 à 16 par an depuis 1955).

Deux mots enfin du secteur des assurances dont les liens avec le marché des capitaux sont bien connus. Dès 1891 la Banque Nationale de Grèce fondait la Compagnie Ethniki. De son côté, la Banque Commerciale a des participations dans trois entreprises de ce secteur (Phoenix, Ethniki, Ioniki), Il existe en tout sur le marché grec une quarantaine de compagnies d'assurances dont plusieurs de faibles dimensions (c'est ainsi que les dix dernières ne représentent que $5 \%$ du chiffre d'affaires de la branche). Parmi les personnalités les plus en vue de ce secteur, nous mentionnerons G. Plytas, candidat victorieux de la Droite au poste de maire d'Athènes contre $N$. Kitsikis lors des dernières élections.

1 Sur ces problèmes voir WESTEBBE (R.M.), Saving and investment in Greece, Athènes, 1964 (Centre de Recherche Économique). 
[p. 366]

\section{B. SECTEUR INDUSTRIEL}

\section{$\underline{\text { Retour à la table des matières }}$}

Il est nécessaire de commencer par quelques indications générales sur l'industrie grecque dont nous avons précédemment souligné la faiblesse en étudiant la répartition socio-professionnelle. Nous mentionnerons ensuite, sans tenter d'établir une énumération exhaustive, quelques-unes des personnalités les plus influentes dont, de toute manière, le nombre n'est pas très élevé.

\section{RYTHME DE LA CROISSANCE INDUSTRIELLE}

Si l'on en croit des estimations de la Banque Nationale de Grèce ${ }^{1}$, le taux de croissance de l'industrie (celle-ci étant prise en un sens large : construction, services d'utilité publique...) aurait atteint une moyenne annuelle de 9,6\% de 1952 à 1962. Quant à celui de l'activité manufacturière ou de transformation, il se serait fixé à $8,4 \%$. Ces taux sont de primes abords assez impressionnants mais ils perdent quelque peu de leur éclat si l'on considère qu'après dix ans de troubles profonds et de destructions étendues, l'économie industrielle grecque partait d'un niveau très bas. Dans une telle conjoncture, il est relativement facile, si l'on dispose de ressources financières et humaines adéquates, d'obtenir un démarrage rapide.

Un point confirme cette impression : la quasi stagnation de la part de l'activité industrielle de transformation dans le produit national brut de 1952 à 1962. La part totale de l'industrie (incluant la construction immobilière, les travaux publics...) passe bien de 21,4 à 26,6\% mais celle de l'industrie proprement manufacturière ne s'élève que faiblement (17,9\% en 1962 contre 16,4\% en 1952). Ce n'est certes pas un échec complet mais on aurait tort d'y voir, à l'instar de quelques commentateurs optimistes, le signe d'une pleine réussite.

[p. 367] Cette impression se maintient si l'on observe l'évolution de la part de chacune des branches d'activité dans le total de l'industrie de transformation durant la même période :

\footnotetext{
Chiffres présentés dans la revue de la Banque Quarterly Review, n 13-14, p. 9.
} 


\begin{tabular}{|c|c|c|c|c|}
\hline & \multirow[b]{2}{*}{1952} & \multirow[b]{2}{*}{1962} & \multicolumn{2}{|c|}{ Différences 1962/1952 } \\
\hline & & & $\overparen{\text { En }+}$ & $\overline{\text { En }-}^{-}$ \\
\hline Alimentation, boissons et tabac & 20,0 & 21,3 & 1,3 & - \\
\hline Textiles et habillement..................... & 36,0 & 25,7 & - & 10,3 \\
\hline Bois, liège et ameublement........... & 7,0 & 7,1 & 0,1 & - \\
\hline Papier et travaux d'imprimerie.... & 6,6 & 4,8 & - & 1,8 \\
\hline Produits chimiques............................ & 10,7 & 13,0 & 2,3 & - \\
\hline Pierre, argile et glace......................... & 4,2 & 5,2 & 1,0 & 一 \\
\hline Industrie des métaux de base....... & 1,4 & 2,1 & 0,7 & - \\
\hline $\begin{array}{l}\text { Constructions mécaniques et } \\
\text { Équipement électrique....................... }\end{array}$ & 9,8 & 12,7 & 2,9 & - \\
\hline Équipement de transport................ & 1,3 & 5,2 & 3,9 & - \\
\hline \multirow[t]{2}{*}{ 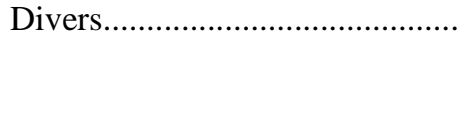 } & 3,0 & 2,9 & - & 0,1 \\
\hline & 100,0 & 100,0 & 12,2 & 12,2 \\
\hline
\end{tabular}

La modification la plus sensible est la chute du secteur textile-habillement (10,3). Sont par contre en hausse assez marquée : l'équipement de transport $(+3,9)$, la construction mécanique et électrique $(+2,9)$ et les produits chimiques $(+2,3)$. On peut donc noter une certaine diversification (mécanique, chimique, électrique) mais pour l'essentiel, l'industrie grecque demeure une industrie de biens de consommation immédiate. L'industrie lourde débute à peine : c'est seulement le 27 juin 1963 qu'a pu être inauguré, en présence du Roi, le premier haut-fourneau grec (installation appartenant à la firme Halyvourghiki qui l'a édifié avec le concours de la Banque Nationale de Grèce).

Au surplus, le recensement statistique ne donne pas à lui seul une vue complète du problème. Il faut prendre également en considération la qualité de l'implantation et la valeur de la gestion industrielle. Sous cet angle, les résultats acquis ne sont pas uniformes. Dans certains cas, des progrès substantiels ont été accomplis au titre de la productivité, [p. 368] ce qui tendrait à expliquer que le niveau de la production ait augmenté plus vite que la dimension de l'emploi ou si l'on préfère que l'accroissement absolu de l'activité industrielle n'ait eu qu'une influence limitée sur la réduction du chômage et du sous-emploi. En de nombreux autres cas cependant, le développement industriel ne répond guère aux impératifs du rendement économique : en l'absence d'un plan tendant à assurer l'utilisation optimale des ressources, le développement de ce secteur a été caractérisé par une pléthore de très petites unités qu’on a souvent bien du mal à séparer du simple artisanat ou de l'activité de service. Ces unités, dépourvues de bases solides et hors d'état de produire des articles de qualité, sont souvent d'une grande fragilité. Leur prolifération constitue certes un obstacle à l'élévation de la productivité. 
En définitive, comme le note l'OCDE dans son rapport sur la Grèce pour 1963, les progrès de l'industrialisation sont demeurés insuffisants compte tenu des besoins de la demande et des réserves de main-d'œuvre. On pourrait être tenté, il est vrai, de tempérer la rigueur de ce jugement en considérant les grands complexes en voie d'installation avec l'aide et sous la direction prépondérantes du capital étranger. Les autorités grecques, c'est un fait, ont jusqu'à présent placé de fortes mises sur la réalisation de projets spectaculaires — projets choisis davantage sur l'impulsion du grand capital étranger en quête d'une maximation du profit que d'après les exigences d'une croissance harmonieuse. L'exécution de ces projets entraînera sans nul doute une élévation de l'indice de la production industrielle : il est peu probable qu'elle contribue à la création d'emplois productifs de manière proportionnelle aux ressources utilisées.

\section{PERSONNALITÉS INFLUENTES DE CE SECTEUR}

Nous mettrons à part le cas des armateurs étrangers-nationaux que l'on pourrait qualifier de «Grecs conditionnels » dans la mesure où ils ne s'intéressent à l'économie de leur pays qu'une fois bien placés pour en tirer des profits supplémentaires. Tel est le cas de S. Niarchos qui avait de nombreux liens avec Caramanlis et entretient des rapports suivis avec le monde de la Cour. Niarchos a fondé en 1958 les Chantiers navals de Skaramanga qui occupent environ 3.600 salariés (c'est la seule firme de cet ordre qui existe en Grèce) et il s'est occupé aussi du raffinage du pétrole (la raffinerie d'Aspropyrgos — la seule de son genre [p. 369] jusqu'à l'apparition du projet Esso-Papas, appartenant à l'État mais ayant été louée à un groupe privé). Niarchos a joué un grand rôle sur lequel nous reviendrons dans la négociation du contrat Péchiney.

Mentionnons aussi le cas d'A. Onassis qui passe pour avoir été en mauvais termes avec Caramanlis (celui-ci lui reprochant de financer les partis du Centre). Onassis dont on sait qu'il détient la majorité du capital de la Société des Bains de Mer de Monaco — s'est limité en Grèce à l'exploitation du transport aérien (Compagnie dite Olympic Airways qui détient le monopole des lignes intérieures et a plusieurs liaisons long courrier avec l'étranger). Onassis a d'ailleurs obtenu pour la réalisation de ce projet des facilités particulièrement considérables. Il a également reçu la concession de deux paquebots construits en Italie au titre des réparations et qui ont été utilisés pour des croisières.

Comme élément représentatif de la catégorie industrielle, nous mentionnerons Th. Athanassiadis-Bodossakis qui vint s'établir en Grèce au lendemain du Traité de Lausanne après avoir joué un rôle important dans l'économie turque. Les affaires dont il s'est occupé sont nombreuses et variées (fabrique de poudres ; Société Hellénique des produits chimiques et engrais; exploitations minières; commerce de vins et spiritueux...). Bodossakis qui a eu en 1958 de graves difficultés avec Caramanlis est actuellement en rapports avec Saint-Gobain au titre des engrais (liaison avec la Banque Nationale de Grèce supra) et il entretient des relations étroites avec Krupp au titre des exploitations minières (gisements de ferronickel de Larymna). Nous 
signalerons aussi le cas de Ch. Catsambas qui a été président de l’Union des Industriels Grecs de 1945 à 1952. Catsambas détient une place considérable dans l'industrie du coton (affaire Piraïki-Patraiki dont certains établissements ont déjà atteint un excellent niveau technique) mais il a aussi d'autres intérêts, notamment dans l'exploitation minière (chrome) et la fabrication du ciment.

Au titre du secteur métallurgie - travail des métaux, deux noms s'imposent : celui des frères Angelopoulos qui possèdent 60\% de la firme Halyvourghiki et celui de Papanicolaou qui exploite l'entreprise Ellenilka Chalivourgia. Dans le cadre de l'activité manufacturière, nous mentionnerons - S. Malcotsis (industrie de moteurs Diesel — représentation générale en Grèce de la General Motors) ; G. Ladopoulos (industrie du papier) ; G. Dracos (fabrique d'appareils électro-ménagers — présidence de l'Union des Industriels Grecs). Il semble d'ailleurs que [p. 370] la plus large part de l'entreprise Dracos ait été achetée par des firmes américaines.

L'industrie du ciment a connu un développement important par suite de l'expansion de la construction immobilière. Deux firmes dominent le marché : les ciments Titan (qui possèdent à Éleusis la plus moderne et la plus importante des fabriques grecques de ciment) et les ciments Heraklis. La première est dirigée par L. Canellopoulos qui a donné son soutien à Caramanlis, la seconde par A. Tsatsos (qui a été président de l'Organisation du Développement industriel durant ses premières années de fonctionnement). Notons que les Tsatsos sont une famille à cheval sur la vie économique et politique (sa présence s'étant affirmée dans l'ERE comme dans l'EK). Pour le secteur des travaux publics et de la construction des routes, on mentionnera les noms de Trézos et E. Averof.

En ce qui concerne l'industrie du tabac, on citera le nom de la famille Papastratos qui dispose au Pirée d'une manufacture employant 2.800 travailleurs. La firme rivale est la manufacture Caranis qui emploie dans la même ville environ 4.000 salariés. Pour les boissons (bières, jus de fruits, eaux gazeuses...) mentionnons la famille Fix (dans laquelle est entré l'actuel Ministre de la Défense Nationale P. Garoufalias). Indiquons aussi le cas de la famille Sourambas qui détient des facultés monopolistiques dans le domaine de la pasteurisation du lait (famille dans laquelle est entré, par mariage, J. Boutos sous-ministre de la Coordination au temps de Caramanlis).

Plusieurs hommes d'affaires importants s'occupent à la fois d'entreprises industrielles et commerciales (spécialement au titre de l'import-export). Signalons par exemple le cas de l'armateur G. Chandris qui, en dehors de ses intérêts dans le transport maritime, s'occupe de brasserie (la bière A rivale de la bière Fix), intervient dans l'industrie des jus de fruits, assume la représentation en Grèce du groupe britannique d'automobiles Rootes et importe des machines allemandes. Mentionnons aussi : S. Fostiropoulos (représentation de la firme Mercédès — industrie de transformation des produits agricoles et exportation de raisins secs) ainsi que D. Scalistiris (représentation de l'huile Valvoline, président et principal actionnaire de la société anonyme des bauxites d'Éleusis). Au titre de la bauxite, le groupe le plus 
important est celui du Parnasse (famille Héliopoulos) qui s’occupe également d'importer dans le pays des machines et véhicules soviétiques.

[p. 371] Parmi les grandes firmes d'import-export, nous signalerons les StasSinopoulos père et fils (importation de bois ainsi que d'articles hygiéniques et sanitaires, exportation de denrées agricoles), G. Frangistas (importation de bois exportation de fruits frais et de raisins secs) et la firme Bunge (commerce de tabac et de nourriture pour les animaux) fondée par C. Rodopoulos, président de la Chambre sous les gouvernements de la Droite.

Bien qu'elle ne soit nullement exhaustive, la liste ainsi établie nous semble représentative des personnalités grecques du monde industriel. Dans l'ensemble, il s'agit encore d'une industrie familiale dont les propriétaires assument effectivement la gestion. Ce sont en somme les firmes étrangères, avec lesquelles les affaires grecques ont des liens les plus nombreux, qui vont introduire à une échelle importante, les méthodes du capitalisme des managers.

\section{SECTEUR PUBLIC INDUSTRIEL}

Il se compose essentiellement de quatre firmes: l'Entreprise Publique d'Électricité ; la Compagnie Sucrière Hellénique (toute le sucre produit en Grèce) ; la Raffinerie de Pétrole d'Aspropyrgos; la Société des Engrais Azotés (capacité annuelle de l'usine de Ptolemaïs 300.000 tonnes). On peut en rapprocher : la Société des Chemins de Fer grecs; l'Organisme National des Télécommunications; l'Organisme National du Tourisme (qui exploite la plus importante chaîne d'hôtels du Pays) l'Organisme du Port du Pirée.

L'Entreprise Publique d'Électricité assure la totalité de la production du pays et détient, par une filiale, la propriété d'importants gisements de lignite (infra). Au cours des dernières années, elle a entrepris avec l'aide de capitaux étrangers et dans le cadre de plans dressés par des experts étrangers (rôle de l'Ebasco), un vaste programme de développement de la capacité de production électrique et d'électrification du pays (en particulier trois grands barrages sur la rivière Acheloos: Kremasta, Kastraki et Tapoliana). L'entreprise va également procéder, à l'aide d'un crédit allemand, à l'établissement d'une grande centrale thermique à Megalopolis (Péloponnèse central). Selon le programme de la société, la production d'électricité grecque devrait atteindre en 1970 le niveau de 10 milliards de kWh (niveau actuel de l'ordre de 3,7).

[p. 372] Quant au raffinage du pétrole, la décision de construire une usine appartenant à l'État avait été prise par les cabinets du Centre avant l'accès au pouvoir du Rassemblement Hellénique. Le mobile de cette décision était de réserver à l'État grec la possibilité de choisir ses fournisseurs de pétrole — faculté qui aurait été inévitablement annulée si la raffinerie avait appartenu en propre aux trusts internationaux. C'est sous le gouvernement de la Droite que devait être édifiée la raffinerie, l'opération étant effectuée aux frais de l'État grec par les soins de la société américaine Hydro-carbon Research. Notons que le coût final de la construction s'éleva à 24 millions de \$ (au lieu de 10 millions prévus dans le devis initial). 


\section{SECTEUR DE LA NAVIGATION}

$\underline{\text { Retour à la table des matières }}$

C'est l'un des secteurs d'activité privilégiés de la Grèce, l'un de ceux dans lequel les Grecs ont toujours fait preuve d'excellence. Le monde entier connaît le nom des armateurs étrangers-nationaux qui ont effectué une carrière éblouissante depuis la fin de la seconde guerre mondiale (S. Niarchos, A. Onassis, S. Livanos...).

Soit le cas de Niarchos dont la famille exploitait des moulins. Âgé aujourd'hui de 55 ans, sa fortune et sa puissance datent du lendemain de la seconde guerre mondiale. Construite à partir de contrats de transport avec des compagnies pétrolières, la flotte de Niarchos est actuellement de l'ordre de 2 millions de tonnes et sa valeur a été récemment estimée à 260 millions de dollars. Selon des informations émanant de journaux sérieux (New-York Times, Monde...), Niarchos serait désireux de vendre la totalité de sa flotte, la détermination des mobiles d'une telle décision relevant de la pure conjecture. On sait que l'armateur s'est aménagé un domaine princier dans la petite île de Spetsopoula où il offre des séjours somptueux à diverses personnalités.

Il va sans dire que la corporation des armateurs grecs ne se limite nullement à ces premiers rôles dont l'ascension foudroyante est assez récente. Parmi les familles d'armateurs de longue date, nous mentionnerons les noms de Goulandris, Nomicos, Typaldos, Vérnicos ...

Pays de marins, la Grèce a eu pendant de longues années le peu enviable privilège d'être désertée par la plus large partie des bateaux appartenant à des Grecs à travers le monde. Le phénomène des pavillons de complaisance délivrés par des États qui profitent de l'absence d'or-[p. 373] ganisation de la société internationale est trop connu pour qu'il soit nécessaire de l'exposer ici. On sait qu'au lendemain de la guerre, les États-Unis ont appuyé le transfert d'une partie de leur flotte sous l'un des pavillons Panlibhonco (Panama, Liberia, Honduras, Costa-Rica), l'un des mobiles de l'opération étant d'affronter la concurrence européenne dans de meilleures conditions. Disons aussi que de tous les États intéressés, seul le Costa-Rica tint compte de la pression syndicale en retirant les licences de battre pavillon costaricain dont bénéficiaient les navires étrangers.

Les armateurs grecs ont justifié le recours à ces pavillons - que les défenseurs du système appellent " pavillons de nécessité » — par l'impossibilité où les aurait mis la législation fiscale et sociale de la Grèce d'affronter avec quelque chance de succès la concurrence internationale. La Banque Commerciale ne craint pas de faire peser la responsabilité de l'opération sur les tendances égoïstes (selfish tendencies) des gouvernements grecs ${ }^{1}$. Sans entrer dans la controverse, observons qu'il n'y a pas

Economic Bulletin, janvier-mars 1962, p. 27. 
d'État si les ressortissants de celui-ci sont en mesure de braver sa législation et de marchander les conditions de leur allégeance.

Au cours des dernières années toutefois, un rapatriement massif de ces navires est intervenu comme le montre l'évolution de la flotte sous pavillon grec de 1952 à 1962 :

\begin{tabular}{|c|c|c|}
\hline & 1952 & 1962 \\
\hline 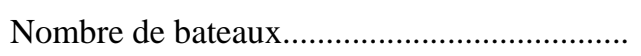 & 489 & 1.232 \\
\hline Tonnages (en milliers GRT) ................................ & 1.270 & 6.774 \\
\hline
\end{tabular}

La Grèce est ainsi passée du 14 au $6^{\mathrm{e}}$ rang dans l'ordre des flottes marchandes. Cependant, on a calculé que si la totalité des bateaux appartenant à des Grecs était mis sous pavillon grec, la flotte marchande hellénique ne serait dépassée que par celle des États-Unis et du Royaume Uni.

Deux facteurs expliquent ce mouvement : la survenance de quelques difficultés dans l'emploi des pavillons de complaisance (notamment du fait de l'action syndicale internationale contre les pavillons bon marché) ; la concession par le gouvernement grec aux armateurs d'avantages substantiels et de facilités exceptionnelles. Ce dernier a dû payer un prix élevé pour que ses ressortissants acceptent de battre pavillon grec.

[p. 374] Si, en termes d'autorité politique, l'opération n'a pas été des plus honorables, elle a du point de vue économique, présenté le grand avantage de contribuer à l'équilibre de la balance des paiements. De 1953 à 1963, les recettes entrant dans la balance sont passées de moins de 23 millions de dollars US à plus de 125. Encore faut-il noter que par suite de la tendance de nombreuses compagnies à conserver leur siège hors de Grèce, les revenus que la Grèce tire de sa marine marchande sont relativement faibles par rapport à ceux de la plupart des autres pays maritimes. Selon l'OCDE qui raisonne pour l'année 1962, ces recettes seraient en Grèce de l'ordre de 20 dollars par tonne de navire et par an (contre 50 à 80 pour la Grande-Bretagne, l'Italie et la Norvège ${ }^{1}$ ). Il est d'ailleurs possible que d'autres facteurs que le lieu du siège social, ainsi l'état des navires, aient une part de responsabilité dans cette infériorité.

Au mois de juillet 1964, la flotte grecque comprenait 1.377 bateaux représentant un peu plus de 7 millions de tonnes. On estime que la croissance de cette flotte serait plus rapide si un fort courant ne continuait de se manifester en faveur des pavillons de complaisance (tout particulièrement le pavillon Liberia). La raison invoquée par les armateurs est la difficulté de faire face aux obligations concernant la nationalité du personnel navigant par suite de la pénurie relative de certaines catégories (officiers, ingénieurs...). Mais le transfert a également eu pour cause le léger retard mis par le gouvernement à prolonger comme les armateurs le voulaient la période d'exemption

Rapport 1962, p. 16. 
fiscale qui couvrait seulement au départ les sept premières années du navire à compter du lancement.

\section{INFLUENCE DES GROUPES}

$\underline{\text { Retour à la table des matières }}$

Les groupes d'affaires sollicitent ou exigent des gouvernements diverses garanties et avantages que l'on peut rassembler sous deux rubriques : sécurité politique et sociale; sécurité économique et financière. Durant la période couverte par cet ouvrage, les chefs d'entreprise grecs ont obtenu sous tous ces angles de très larges satisfactions, Après en avoir fait l'examen, nous nous prononcerons sur le sens des rapports ainsi noués entre le monde politique et le monde des affaires.

[p. 375]

\section{A. SÉCURITE POLITIQUE ET SOCIALE}

$\underline{\text { Retour à la table des matières }}$

Il s'agit avant tout de l'aptitude du pouvoir à imposer le respect de l'ordre établi. Ce souci conduit les affaires à subventionner les partis conservateurs et les a poussées, en des cas où l'institution parlementaire ne semblait plus garantir l'ordre bourgeois, à se faire les bailleurs de fonds des mouvements fascistes. La propension des milieux d'affaires à préférer la légalité bourgeoise au pouvoir dictatorial dépend de leur évaluation des forces adverses mais aussi de leur degré de culture politique : ainsi les patrons français savent-ils bien mieux que les patrons italiens que l'arrivée des socialistes au pouvoir n'est nullement mortelle pour l'économie de profit. Il semble que, pour l'instant, les groupes d'affaires grecs aient une vue particulièrement extensive et fort peu réaliste des dangers de subversion sociale.

Le point s'est vérifié à propos des armateurs faisant naviguer leurs bateaux sous des pavillons de complaisance. Aux raisons matérielles immédiates de cette position s'ajoutait certainement la crainte de troubles politiques susceptibles d'aboutir à des confiscations révolutionnaires. C'est dès 1953 que le gouvernement offrit aux intéressés des conditions juridiques et fiscales avantageuses. Pourtant le mouvement de retour en masse ne commença vraiment qu'en 1958 (l'augmentation du tonnage sous pavillon grec qui, de 1953 à 1958 avait été de 700.000 tonnes dépassant les 4 millions durant les trois années 1959, 1960 et 1961). Manifestement, c'est seulement à partir de 1958 que les armateurs, la pression du syndicalisme international aidant, jugèrent la situation politique suffisamment stabilisée pour risquer l'opération à une large échelle.

Si pour les affaires la notion de stabilité politique couvre avant tout le respect intégral de la propriété privée, elle s'applique également au maintien des avantages 
précédemment consentis et à l'octroi des nouvelles facilités qui pourraient se révéler nécessaires. Autre point particulièrement important : l'attitude des autorités à l'égard des revendications des travailleurs et leur propension à briser, par la force si nécessaire, l'action collective ouvrière. La présence du mouvement syndical est désormais partie intégrante de l'univers patronal dans les pays économiquement les plus avancés. Ce n'est certes pas le cas pour les pays comme la Grèce où l'expérience des rapports collectifs du travail est embryonnaire. Dans ces pays, le souci de sécurité po-[p. 376] litique comporte un désir de tranquillité sociale, c'est-à-dire de neutralisation par le pouvoir de la force ouvrière.

Nous savons que la solution adoptée sur ce plan par la Droite grecque depuis 1946 a consisté à placer à la tête du mouvement syndical des hommes dociles aux consignes gouvernementales et dévoués aux intérêts patronaux — des hommes qui en bien des cas n'hésitaient pas à collaborer avec la police en lui dénonçant les militants syndicaux soupçonnés de sympathies communistes. Le gouvernement de l'Union du Centre a entrepris, nous l'avons dit, d'assurer la démocratisation du mouvement syndical mais si l'on en croit le comité des syndicats exclus de la CGT, le Ministre du Travail manœuvrerait de manière à couvrir la plupart des dirigeants mis en place sous le gouvernement Caramanlis.

Sans porter un jugement qui serait prématuré sur la politique du Cabinet Papandréou en ce domaine, observons que, compte tenu de ses options fondamentales (en particulier appel massif au capital étranger), il lui est bien difficile de susciter ou de tolérer un syndicalisme autonome à l'égard des autorités et vigoureux dans la défense de ses revendications. Selon une récente déclaration du Ministre-adjoint de la Coordination, le taux d'accroissement des salaires sous le gouvernement de l'ERE n'aurait été en moyenne que la moitié du taux d'augmentation de la productivité. Une modification de la situation est certes souhaitable et, à divers égards, inévitable. Mais, compte tenu de ses options initiales, l'actuel Cabinet est également obligé de ralentir la hausse des salaires.

Il ne serait certes pas difficile de multiplier les indices de la position sociale privilégiée attribuée aux couches supérieures par les autorités gouvernementales. Nous mentionnerons seulement la composition des ressources fiscales : durant l'année 1963 la part des impôts directs dans le total des ressources ordinaires de l'État n'a été que de 16,9\% (18,4\% en 1962). Si l'on considère les seules ressources fiscales, la part de l'imposition directe n'a été que de 19\% (21\% en 1963). Cette situation s'explique en partie par le manque de progressivité du système fiscal grec.

Il existe aussi une importante évasion fiscale dont la conséquence est d'augmenter la part des dépenses publiques mise à la charge des milieux à revenus modestes. Une observation faite par le Directeur Général des Impôts au Ministère des Finances devant le quatrième [p. 377] Congrès des Chambres de Commerce Grecques (mai 1962) établit clairement l'inefficacité et l'absence totale d'équité du système fiscal : ce haut fonctionnaire a indiqué que 21.000 Grecs seulement déclarent un revenu annuel supérieur à 100.000 drachmes (environ 3.300 \$) alors que le nombre des possesseurs d'une voiture privée atteignait déjà alors le chiffre de 45.000 . 
Par sa coloration anti-communiste et anti-syndicale, la politique de Caramanlis ne pouvait manquer de plaire aux groupes d'affaires. Toutefois certains des dirigeants économiques, nous l'avons vu, s'étaient brouillés avec le Premier Ministre et quelques-uns soutenaient le parti de S. Markézinis. On ne saurait dire que jusqu'à présent le gouvernement Papandréou a suffisamment changé la politique de son prédécesseur pour mériter l'hostilité ou simplement l'antipathie de ces milieux.

\section{B. SÉCURITÉ ÉCONOMIQUE ET FINANCIÈRE}

\section{$\underline{\text { Retour à la table des matières }}$}

Les manuels classiques d'économie politique évitent en général de souligner que la formation du profit privé dépend en une large mesure de l'aide de la puissance publique. La Grèce est de ce point de vue un cas exemplaire et nous allons évoquer les principaux aspects de la contribution que la collectivité apporte à l'enrichissement d'un petit nombre de ses membres.

\section{1. ÉTABLISSEMENT DE L'INFRASTRUCTURE}

C'est un fait connu de longue date que l'entreprise privée ne prend à sa charge que les coûts directs de son exploitation en laissant à la collectivité la charge d'acquitter les dépenses générales d'agencement du territoire (ainsi réseau routier) et de régler les coûts sociaux de l'activité entreprise (ainsi pollution de l'air ou des cours d'eau). Cette propension habituelle des firmes est encore plus forte dans le cas des opérations dites de décentralisation économique : il est désormais fréquent que les autorités, pour attirer les industriels en certaines régions, prennent à leur charge, sans parler encore de la concession de bien d'autres faveurs, une part notable des dépenses de premier établissement. Il arrive que l'action de l'État en ce domaine vaille à [p. 378] des particuliers des bénéfices entièrement parasitaires (plus-values foncières découlant de la construction d'une route ou du percement d'une avenue).

Depuis les années 1950 les gouvernements grecs se sont efforcés de perfectionner l'infrastructure du pays qui était d'ailleurs très insuffisante. Des sommes toujours croissantes ont été affectées aux investissements publics, les dépenses effectuées à ce titre ayant plus que doublé de 1958 à 1963. Le programme de ces investissements a été conçu de manière à favoriser le développement de l'agriculture (bonification de terres), de l'industrie (électrification, communications...) du tourisme. On est actuellement en train d'établir des zones industrielles destinées à accueillir les manufactures dans les villes de Salonique, Volos, Cavalla, Patras et Héraclion.

Pour l'avenir toutefois, le gouvernement a prévu un ralentissement du rythme d'accroissement de ces investissements (qui représentaient plus du tiers de l'investissement total du pays). On estime qu'il revient désormais au secteur privé de prendre en quelque mesure le relais de l'action gouvernementale. 
Les investissements publics dont la réalisation a été facilitée par les ressources obtenues de l'étranger procurent à l'économie privée une double série d'avantages. D'une part, ils lui permettent de se déployer notamment par la création de nouvelles unités de production ou l'agrandissement des anciennes : compte tenu de la nature de notre système économique, l'investissement public est probablement la condition nécessaire de la croissance industrielle mais dès lors, quand on fait le bilan de l'économie de marché, il ne faut pas oublier que l'État en est le promoteur initial sans que les bénéficiaires ultérieurs de l'opération aient à en acquitter le coût.

La seconde série d'avantages est l'ensemble des bénéfices obtenus par les firmes chargées d'exécuter les programmes de travaux publics pour le compte de l’État. On sait que, spécialement dans les pays où ne s'exerce pas le contrôle d'une solide bureaucratie administrative, la conclusion de tels marchés est normalement génératrice de profits substantiels : il ne semble pas, c'est le moins que l'on puisse écrire, que le gouvernement Caramanlis ait pris des dispositions pour renverser cette norme.

Un trait de la situation, mais que la Grèce ne détient pas en propre, est qu'en de nombreux cas (en particulier pour la construction de bar-[p. 379] rages) l'on a enregistré de substantiels dépassements de devis. Nous avons déjà noté le phénomène à propos de la raffinerie de pétrole d'Aspropyrgos mais on le rencontre aussi dans la construction de l'usine étatique d'engrais azotés. On estime aujourd'hui que le coût final de l'édification de cet établissement atteindra presque le double du devis initial. Il est vrai que la conclusion de ce contrat s'est effectuée dans des conditions discutables (le gouvernement Caramanlis ayant renoncé, sur les conseils de ses experts danois, à mettre en concurrence les deux groupes qui avaient fait des offres de service et ayant préféré leur demander un projet commun).

Parmi les causes de ces dépassements, qui sont souvent l'œuvre de firmes étrangères de travaux publics, figure en dehors d'erreurs techniques, l'insuffisance du contrôle exercé par l'État sur le cahier des charges et sur le déroulement des opérations. Celui-ci, faute de disposer d'un personnel technique qualifié s'adresse souvent à des cabinets d'experts étrangers pour la vérification des devis et le contrôle des travaux. L'expérience a établi que l'intervention de ces cabinets, bien que très coûteuse, est loin de toujours apporter à l'État Grec la sécurité qu'il en attend.

\section{PROTECTION DOUANIÈRE}

Durant la période étudiée, les industriels grecs ont bénéficié en moyenne d'une protection considérable à l'égard de la concurrence étrangère. L'adoption en 1960 du nouveau tarif a sensiblement renforcé cette protection, un autre avantage accordé aux industriels étant l'abaissement des droits sur les matières premières importées et sur les biens d'équipement. Des lois spéciales, applicables dans de nombreux cas, ont même accordé une franchise complète de droits pour l'achat de l'équipement étranger.

Cette politique de protection de l'industrie nationale semble toutefois avoir reçu un coup sérieux avec la décision prise sous le gouvernement de l'ERE d'associer la 
Grèce au Marché Commun. Nous reviendrons plus tard sur les mobiles de cette décision qui suscita de très sérieuses réserves de la part du Centre et une opposition totale de celle de l'EDA. Sous l'angle qui nous intéresse ici, l'accord prévoit une démobilisation tarifaire progressive qui, de part et d'autre, doit être complète à l'expiration d'une période de douze ans. Toutefois, pour un certain nombre de produits [p. 380] représentant environ le tiers des importations de la Grèce en provenance de la $\mathrm{CEE}$, la période transitoire est portée à vingt-deux ans. On peut dire en simplifiant les choses que la période de vingt-deux ans correspond aux industries existantes, celle de douze aux industries nouvelles.

Deux dispositions ont été prévues à l'avantage de la Grèce : la première tendant à la faire bénéficier des mesures de réduction que les Six se sont déjà accordées et de celles qu'ils s'accorderont dès qu'elles auront été prises, y compris en cas d'accélération (ce qui va créer un décalage sensible entre les avantages douaniers accordés par les Six à la Grèce et ceux attribués par celle-ci aux premiers); la seconde ayant pour objet de permettre à la Grèce, durant la période de douze années, d'instituer une protection spéciale au titre des industries naissantes.

L'accord d'association a en réalité pour objet d'assurer une véritable intégration entre le Marché Commun et la Grèce. Selon la Commission, il est apparu aux diverses parties intéressées que seule une telle intégration permettrait «par les avantages qu'elle procure comme par les disciplines qu'elle impose, de faire sortir la Grèce de l'état de sous-développement dans lequel elle se trouve par rapport aux Six » : mais, bien entendu, la réalisation même progressive de ce processus impose à la Grèce « de s'adapter à des conditions entièrement nouvelles ${ }^{1}{ }^{1}$. Un tel jugement ne semble pas dépourvu d'optimisme et, pour en apprécier la validité, on ne doit pas oublier le poids fondamental du capital monopoliste dans le Marché Commun. Il apparaît pour le moins fort douteux que l'économie nationale grecque bénéficie de tous les avantages annoncés par les autorités de Bruxelles.

Soit le cas des industries existantes : on peut admettre qu'une période de vingtdeux ans donne assez de temps pour réaliser l'indispensable modernisation. Mais, n'oublions pas que la protection ira s'amenuisant tout au long de la période et que la productivité industrielle dans les Six pays progresse à un rythme rapide. Quant aux industries nouvelles, le système sous-entend qu'elles seront immédiatement constituées à une dimension et avec des moyens leur permettant d'affronter relativement vite la concurrence des firmes des six pays. Or, il semble bien que seul le capital étranger est capable d'obtenir de tels résultats. [p. 381] En d'autres termes — et il est peu vraisemblable que les négociateurs grecs de l'accord d'association n'aient pas aperçu le point — la seule manière d'exécuter ce contrat, sans qu'il en résulte une désorganisation et en plusieurs secteurs une destruction de l'économie industrielle grecque - est un recours croissant au capitalisme étranger.

Ainsi s'explique l'opposition faite à ce projet par l'Union des Industriels Grecs l'accord étant toutefois bien accueilli par tous les groupes d'affaires déjà liés ou en

Quatrième Rapport Général sur l'activité de la Communauté, Bruxelles, juillet 1961, pp. 206-207. 
voie de liaison avec le capital étranger. Les opposants, au Parlement et dans le pays, n'ont eu aucune peine à établir que la Grèce abordait cette redoutable aventure dans un état de totale impréparation.

L'accord signé le 9 juillet 1961 à Athènes, est entré en vigueur le $1^{\mathrm{er}}$ novembre 1962, une première brèche intervenant de ce fait dans le dispositif protectionniste. Le fonctionnement de la convention ayant valu des déboires à la Grèce (notamment dans l'ordre des produits agricoles), l'Union des Industriels Grecs a demandé la suspension de la démobilisation douanière et de la seconde réduction de $10 \%$ devant intervenir en 1964 pour les produits soumis à démobilisation tarifaire en douze ans. Le gouvernement de l'Union du Centre a refusé de prendre cette demande en considération et s'est déclaré en faveur de la continuation de la mise en œuvre des dispositions du Traité.

\section{RÉGIME FISCAL DE FAVEUR}

Les entreprises ont bénéficié d'avantages fiscaux de toutes sortes et en constante augmentation. Pour apprécier l'ampleur de ces concessions, il suffit d'observer que de 1958 à 1961 la part dans les impôts sur le revenu des recettes provenant du revenu des entreprises industrielles et commerciales est tombée de 55,9 à 48,9\% - celle des salaires et émoluments passant de 19 à 24,9\% durant la même période ${ }^{1}$.

Parmi les privilèges accordés, mentionnons ceux qui concernent les taux d'amortissement. D'après les lois en vigueur, les provisions constituées par les entreprises pour couvrir la dépréciation de leurs actifs peuvent, dans certains cas, atteindre jusqu'à 10\% par an pour les bâtiments industriels et 20 à 25\% pour les machines et biens d'équi-[p. 382] pement. Ces pourcentages sont doublés pour les entreprises s'installant en province. En cette matière d'ailleurs, le régime grec par les multiples exceptions privilégiées qu'il institue est d'une particulière complexité.

Autre source d'avantages déjà mentionnée : la possibilité ouverte en de nombreux cas d'importer en franchise les équipements nécessaires à la modernisation. Une loi de 1961 a attribué des exemptions particulièrement importantes aux entreprises nouvelles qui investissent plus de trois millions de dollars - ces exemptions concernant non seulement les biens d'équipement proprement dits mais encore tout ce qui est nécessaire à l'exécution de l'investissement (matériel de construction, appareils de recherche, grues, moyens de transport...).

Bien d'autres privilèges fiscaux sont concédés à l'industrie, parmi lesquels, sans ambition d'établir une liste exhaustive, nous citerons: exemptions ou réductions concernant les droits d'enregistrement en cas de fusion d'entreprises et de création de sociétés anonymes ; constitution de réserves ou provisions en franchise d'impôts en vue d'assurer la modernisation de l'entreprise ou de couvrir des pertes futures éventuelles; déduction du revenu brut imposable des entreprises de 2 à $4 \%$ des

Chiffres extraits du dernier rapport de l’OCDE sur la Grèce, Paris, août 1964, p. 24. 
recettes brutes tirées de l'exportation des produits de la firme ; réduction de l'impôt sur le chiffre d'affaires pour les entreprises installées en province, la réduction étant encore amplifiée pour celles qui s'établissent dans les Îles, etc.

Il est peu contestable qu'un tel système heurte profondément l'équité sociale. Ce grief est d'autant plus sérieux que cette fiscalité de faveur qui avait pour objectif d'accélérer la modernisation par utilisation sur place des bénéfices réalisés ne semble avoir atteint qu'imparfaitement son but.

\section{FACILITÉS DE CRÉDIT}

On aura une idée de leur importance en considérant que selon certaines estimations près de $70 \%$ de l'actif des entreprises a été constitué à l'aide de fonds empruntés ${ }^{1}$. Compte tenu de la faiblesse du marché des capitaux, c'est le secteur bancaire qui, avec l'aide de la Banque de Grèce, a assumé la charge principale de ce financement (grande importance à cet égard des banques commerciales).

[p. 383] On sait que les banques assurent aux entreprises, non seulement des crédits à court terme mais encore des prêts à long terme. En vue de consolider la propension de ces établissements à s'intéresser au financement des investissements productifs, les autorités monétaires ont décidé en 1958 de bloquer pour la réserver à cet usage $15 \%$ de la contrepartie des dépôts bancaires. Des facilités exceptionnelles ont été attribuées en 1962 au profit des entreprises qui fusionnent, se modernisent ou exportent une fraction déterminée de leur production.

Au départ, les conditions du crédit étaient assez lourdes (ainsi 12\% pour les prêts à long terme à l'industrie). Ces tarifs ont été abaissés au fur et à mesure de l'expansion des disponibilités bancaires, des conditions particulières étant consenties aux entreprises dont les autorités jugent l'activité importante au titre du développement économique et de l'équilibre de la balance des paiements.

Le gouvernement de l'Union du Centre a manifesté l'intention de revoir l'ensemble de la politique de crédit aux entreprises. Les premières mesures de réorganisation du marché de l'argent et des concours bancaires ont été annoncées en septembre 1964. Sans entrer dans une analyse détaillée de ce dispositif qui tend à renforcer la responsabilité propre des banques commerciales, disons qu'il continue d'assurer l'octroi de facilités considérables aux unités de production industrielle.

Pour limitées et rapides qu'elles soient, les observations que nous venons de présenter suffisent à établir l'étroitesse des rapports entre les autorités publiques et les

In Rapport de l'OCDE sur la Grèce pour 1963, p. 27. 
entrepreneurs privés. Les premières dans toute la mesure de leurs moyens, n'ont cessé de mettre à la disposition des seconds les ressources et facilités nécessaires ou utiles au développement industriel. Il n'est pas dès lors excessif d'avancer que c'est la collectivité toute entière qui, d'une manière ou une autre, a assumé une large partie de la charge de l'industrialisation.

On pourrait être tenté d'expliquer l'ensemble de ces concessions par l'exercice d'une pression directe des intéressés sur les centres publics de décision. Il est certes probable qu'en bien des cas les choses se sont passées de la sorte. On ne saurait pourtant exclure qu'en d'autres occasions l'initiative de la décision soit venue des autorités [p. 384] désireuses d'obtenir des résultats déterminés ou de mettre en œuvre diverses parties de ce programme. Certains principes de base étant acceptés (ainsi réalisation du développement par le canal de l'entreprise privée) les autorités n'avaient en vérité pas grande marge de manœuvre. Autrement dit, si les groupes d'affaires ont bénéficié de tant d'avantages, le facteur essentiel de la situation a été la conformité de ces privilèges avec la pente du système.

Le cas de l'association au Marché Commun rentre facilement, en dépit des apparences, dans ce schéma explicatif. C'est un fait que la pente du système adopté par les autorités grecques depuis 1953 - choix de l'économie de marché d'inspiration libérale pour assurer la croissance - conduit inévitablement à un renforcement des liens avec les économies étrangères, l'intervention de celles-ci étant nécessaire aussi bien pour absorber la main-d'œuvre excédentaire que pour fournir les capitaux d'investissement. Il est également probable que les États-Unis ont poussé à l'adoption de cette solution, la Grèce leur apportant des facilités supplémentaires de pénétration dans le Marché Commun. Mais le poids du facteur étranger dans la vie économique étant sans cesse plus massif, des contradictions sont susceptibles de surgir entre les groupes d'affaires de l'intérieur et ceux de l'extérieur. Si l'on raisonne en termes de profit privé et non certes d'intérêt national, ces contradictions peuvent être levées ou, au moins, atténuées soit par la concession aux groupes grecs d'une plus grande somme d'avantages publics soit par la participation de ces groupes aux activités entreprises par les firmes étrangères.

Que le poids final de l'industrialisation retombe sur la collectivité, c'est là un point que toutes les spéculations sur le rôle dit créateur ou moteur de l'initiative privée ne parviennent plus à dissimuler. En échange de ces prestations, la collectivité a ou, plus exactement, devrait avoir un double droit: celui de s'assurer que les décisions d'investissement correspondent à l'avantage collectif et ne sont pas dictées par le souci de " faire de l'argent » de manière aussi rapide que possible ; celui de participer de toutes les manières concevables (par exemple baisse des prix) aux résultats de l'opération ou, si l'on préfère, d'éviter que les sacrifices publics n'aient pour premier résultat d'assurer l'enrichissement de quelques-uns.

Telle qu'agencée jusqu'à présent, la croissance grecque ne répond à aucun de ces deux impératifs. Ce sont les groupes d'affaires qui pren-[p. 385] nent ou inspirent les décisions qui commandent l'avenir du pays. En même temps, des fortunes privées se 
bâtissent ou se développent sur la base de sacrifices de tous ordres demandés au peuple au titre de l'industrialisation.

Au surplus, il arrive que les groupes capitalistes parviennent à rejeter sur les finances publiques le poids de leurs erreurs de gestion. Mentionnons à ce propos le cas de l'exploitation des lignites de Ptolemaïs auxquels s'est intéressé le capital allemand. En 1955, le contrôle du bassin était passé à la Société des produits chimiques et engrais dont l'animateur Bodossakis a de nombreux rapports, nous l'avons dit, avec le capital monopoliste allemand (Krupp en particulier). Deux usines ont été construites et équipées avec du matériel acheté à Krupp : l'une de demi-coke, l'autre de briquettes destinées aux hauts-fourneaux de Larymna et impropres à un usage différent. Actuellement, l'exploitation de ces deux usines est arrêtée et certains estiment qu'elles sont devenues inutilisables dans leur forme actuelle. Cependant, la Société des produits chimiques a été sauvée de la faillite par l'intervention de l'Entreprise Publique d’Électricité qui lui a racheté comptant les actions de Ptolemaïs. L'utilisation de ces minerais s'effectue dès lors de manière peu avantageuse, car sans aucun enrichissement, dans les centrales thermiques construites à Ptolemaïs par l'Entreprise Publique d'Électricité.

\section{PROBLÈMES DE L'AGRICULTURE}

\section{$\underline{\text { Retour à la table des matières }}$}

Il nous paraît nécessaire de les évoquer en vue de donner un tableau complet de l'action économique menée par les partis au pouvoir. Ayant pour seul objet d'éclairer un secteur particulier des activités gouvernementales, notre analyse sera limitée à un simple schéma.

Voyons d'abord les résultats finaux. Si l'on part des années 1952-1953, les gains acquis en quelques secteurs ont été importants et parfois spectaculaires. Ainsi pour le coton (désormais l'une des principales exportations agricoles du pays), le blé (dont la récolte couvre les besoins nationaux depuis 1958 et comporte un fort excédent au titre de la campagne 1964), les agrumes (dont la production a représenté en 1960-62 le sextuple de l'avant-guerre) et la betterave à sucre (dont la culture, nouvelle en Grèce, permet déjà de produire une partie du sucre consommé dans le pays). Cependant le tabac, [p. 386] culture traditionnelle, n'a rien perdu de son importance (cette culture occupant un exploitant sur dix et représentant le tiers des exportations nationales). Autres grands secteurs de l'agriculture grecque : l'oléiculture, la production de raisins secs, celle des fruits frais dont le marché a tendance à s'élargir. Par contre, la situation est nettement déficiente au titre de l'élevage, les formes modernes de cette spéculation ne tenant encore qu'une place limitée dans l'économie agricole.

Les accroissements de production ainsi acquis sont d'autant plus significatifs que durant la période considérée la superficie mise en culture n'a augmenté que de 6\%. 
Les augmentations sont donc pour la plus large part le résultat de l'élévation de la productivité. Celle-ci résulte de plusieurs facteurs : élargissement des surfaces irriguées en de nombreuses régions du pays ; développement de l'emploi des engrais que doit élargir encore la création de deux nouvelles usines : Engrais Azotés (État) et Phosphoriques (groupes Andréadis); extension du recours à la mécanisation... Cependant, bien qu'améliorées par rapport à l'avant-guerre, les conditions techniques de l'agriculture grecque sont encore en retard par rapport aux pays d'Europe Occidentale. Rappelons aussi le morcellement bien trop considérable des exploitations paysannes et la présence dans les campagnes d'un large chômage dissimulé. Évoquons enfin les difficultés causées aux gouvernements grecs par les directives américaines (supra).

Dans l'ensemble, la production agricole a fait l'objet d'un dirigisme étroit. Le cas est particulièrement net pour le tabac dont l'État contrôle entièrement le marché (fixation annuelle par région et par village des autorisations de culture). Mais il va de même pour bien d'autres produits, l'objectif des démarches gouvernementales étant de promouvoir dans toute la mesure du possible l'ajustement de l'offre à la demande. Connaissant les difficultés de tous ordres qu'implique en agriculture le contrôle de l'offre, on ne saurait s'étonner des imperfections du dispositif institué à cet effet. Ajoutons qu'en certains secteurs (ainsi celui du riz) la politique suivie a manqué de netteté.

En Grèce, comme ailleurs, le problème est de trouver des débouchés extérieurs pour les produits excédentaires. La question est particulièrement complexe pour les articles dont le marché est déjà bien pourvu. Or tel est pratiquement le cas pour toutes les exportations agricoles de la Grèce. Au titre du tabac, celle-ci s'est heurtée aux producteurs américains qui s'efforcent systématiquement d'obtenir une [p. 387] part aussi large que possible de la riche clientèle d'Europe Occidentale (Allemagne de Bonn en particulier).

Il semble que la Grèce ait la possibilité de trouver des débouchés importants en Union Soviétique et en divers pays d'Europe Orientale. Cependant, jusqu'à une époque récente, le commerce avec ces pays avait été entravé par des facteurs politiques (pressions américaines tendant à limiter les échanges Est-Ouest). Le nouvel accord de 5 ans signé avec la Russie en date du 13 octobre 1964 constitue à cet égard l'amorce d'une nouvelle politique: il prévoit en particulier une expansion des exportations grecques de tabac, fruits frais, fruits secs... Des résultats encore meilleurs pourraient être obtenus si une forte pression ne s'exerçait sur les autorités grecques pour qu'elles limitent leurs achats de pétrole et de machines soviétiques. Un accord de même inspiration a été signé avec la Pologne.

Il reste encore beaucoup à faire au titre des industries agricoles et alimentaires. En dépit d'efforts récents (notamment dans le domaine des jus de fruits), la Grèce ne dispose pas de l'outillage moderne indispensable à la transformation des produits agricoles. Le gouvernement actuel a manifesté l'intention de développer ce secteur. Il serait certes souhaitable que les autorités empêchent les grands trusts internationaux (genre Nestlé ou Unilever) de s'approprier le marché grec et de l'exploiter à leur 
guise. On sait que ces trusts, ainsi que les grosses firmes américaines (type Libby) sont en train de coloniser successivement tous les marchés européens (France comprise). Il est fatal qu'ils insèrent la Grèce dans leur plan d'expansion et il serait bien extraordinaire que ce pays parvienne à échapper à de tels efforts.

Pas plus que leurs homologues des autres pays, les agriculteurs grecs ne jouissent de la « parité » avec les travailleurs des villes. L'État intervient sur plusieurs marchés en vue de soutenir le revenu des paysans intéressés. Il procède soit en établissant des prix-plancher (raisins secs) soit en donnant sa garantie pour l'achat de quantités déterminées à des prix fixés (tabac, huile d'olive). Dans le cas du blé, l'État s'est servi du prix pour orienter la production. Mais en ce domaine la politique suivie a connu des fluctuations d'une année à l'autre et les autorités ont reculé devant les mesures susceptibles d'éviter une surproduction.

Le gouvernement actuel se préoccupe de l'établissement d'un plan quinquennal pour le développement de l'agriculture. L'un des articles [p. 388] de ce programme serait l'extension du secteur élevage par fixation à l'avance de prix minima.

De plus, le gouvernement a apporté des avantages aux cultivateurs dans le domaine des assurances sociales agricoles (suppression des Cotisations paysannes) et de l'aménagement des dettes.

Dans les pays où l'économie fonctionne selon le système du marché, l'agriculture est normalement en proie aux combinaisons affairistes du capital monopoliste. Cette pression sur les revenus paysans se manifeste à la fois en amont (vente des produits nécessaires à l'exploitation : engrais, combustibles, machines agricoles...) et en aval (cession des produits de la terre aux négociants et, de plus en plus aussi, aux industriels de l'alimentation). En raison de sa faiblesse intrinsèque et des imperfections de l'organisation professionnelle agricole, le paysan grec subit cette pression avec une intensité particulière. Dans l'ordre des engrais, la Banque Agricole paraît s'être préoccupée davantage de l'intérêt des producteurs que de celui des utilisateurs. En plusieurs cas (notamment dans le domaine du tabac) le gouvernement de l'ERE a laissé les marchands exploiter les paysans à une grande échelle (d'où les manifestations massives de ceux-ci). On peut craindre que l'un des résultats de l'association au Marché Commun ne soit d'aggraver encore le poids du capital monopolistique dans les campagnes.

Les milieux de gauche (en particulier le Parti National Agraire) reprochent à la Confédération Panhellénique des Coopératives Agricoles (PASEGES) et à l'Union des coopératives de cultivateurs de tabac de ne pas avoir défendu, comme ils avaient mission de le faire, les intérêts de leurs membres. Ils mettent en cause l'activité de la société anonyme SEKE constituée en 1947 sur l'impulsion de la Paseges (avec le soutien du Service étatique de Commercialisation des produits agricoles et de l'Union des coopératives) en vue de contribuer à la régularisation du marché du tabac. La société, qui achète $10 \%$ du tabac d'exportation, était tenue par l'article 30 de ses statuts de redistribuer aux producteurs de tabac, en sus du prix payé, une fraction substantielle de ses bénéfices : mais, invoquant la nécessité de renforcer son capital, elle a été dispensée depuis 1950 de l'application de cette clause. La Société, qui 
dispose d'abondantes réserves, a fondé une dizaine de sociétés commerciales spécialisées dans l'importation du matériel et de divers produits acquis dans les pays communistes en vertu d'ac-[p. 389] cords bilatéraux. Il lui est ainsi possible de jouer directement ou indirectement sur les deux tableaux de l'importation et de l'exportation.

Le Conseil d'Administration de la SEKE a été présidé de 1947 à 1951 par A. Baltadzis qui est intervenu dans la politique par le truchement de divers partis agraires (voir les numéros 5 et 11 du lexique des partis grecs). En 1961 Baltadzis a intégré son parti dans l'Union du Centre et il est devenu Ministre de l'Agriculture du Cabinet Papandréou. La direction générale de la SEKE est assurée par son gendre V. Alantzis.

L'État détient un important moyen de pression à l'égard des coopératives du fait qu'il est maître de la distribution des crédits nécessaires au financement de leurs opérations commerciales. Celles-ci sont incitées de la sorte à témoigner de docilité à l'égard des directives gouvernementales et ne se trouvent donc pas bien placées pour défendre les revendications paysannes. 
[p. 390]

\section{CHAPITRE XII \\ LES PUISSANCES ÉTRANGÈRES}

$\underline{\text { Retour à la table des matières }}$

NOUS AVONS déjà signalé, tout au long des précédents chapitres, de multiples cas d'intervention des puissances étrangères dans la vie nationale. Le moment est venu de proposer un tableau systématique de ce facteur. Nous étudierons successivement à ce titre les efforts d'orientation politique de l'État grec par des gouvernements étrangers et les essais de mainmise du capitalisme international sur l'économie du pays - mainmise déjà considérable et dont l'expansion mènerait à une véritable colonisation de l'économie nationale.

L'étude que nous entreprenons ici constitue, en dehors de sa portée immédiate pour l'examen de la vie politique grecque, une contribution à l'analyse de l’impérialisme dans le monde contemporain, l'impérialisme étant défini ici comme l'ensemble des efforts entrepris et des résultats obtenus par un État ou ses ressortissants en vue de conditionner ou d'influer sous l'un quelconque de ses aspects la vie d'un pays étranger. À ce propos nous voudrions rappeler quelques principes généraux d'interprétation qui s'appliquent correctement à l'exemple grec.

La première de ces remarques est pour dire que la distinction entre domination politique et mainmise économique n'a bien souvent, au titre de l'explication du système capitaliste, d'autre fondement ou valeur que de faciliter l'exposé des phénomènes.

Il arrive certes dans la pratique des choses que les deux mouvements aient une certaine autonomie l'un par rapport à l'autre. Cependant, dans la moyenne des cas, ils sont étroitement liés et se fortifient réciproquement. La domination politique facilite la conquête économique mais la seconde tend normalement à consolider la pre[p. 391] mière. Disons que la domination politique trace le cadre dans lequel s'inscrit la conquête économique et que les bénéficiaires de celle-ci visent ensuite, ne serait-ce que pour sauvegarder leurs actifs, à placer ou à maintenir sous leur influence les gouvernants du pays subordonné. 
La conséquence immédiate de cette jonction est qu'on commettrait une erreur en établissant une séparation entre l'action des gouvernements étrangers et les démarches des firmes privées qui en relèvent juridiquement. Ici encore on peut constater des décalages plus ou moins nombreux selon les époques (ainsi cas d'un gouvernement refusant d'endosser les revendications de l'un de ses ressortissants vis-à-vis d'un autre gouvernement) mais, en règle générale, les affaires capitalistes sont soutenues ou défendues par les gouvernants dont elles relèvent dans leurs efforts de pénétration sur les marchés étrangers.

Cette association d'intérêts politico-économiques, conforme à la logique du capitalisme a d'autant plus de chances de se manifester que l'appareil gouvernemental du pays où s'installe le capital étranger s'occupe plus activement du développement industriel. Dès le moment où cet appareil centralise les facilités et avantages destinés aux affaires, on peut s'attendre à ce que les États étrangers agissent directement sur lui en vue de ménager à leurs ressortissants le meilleur climat possible et la situation la plus favorable.

Encore qu'elle soit d'une importance considérable et, à divers égards, primordiale, cette promotion par les gouvernements étrangers des intérêts des firmes capitalistes n'exprime pas la totalité des efforts que déploient les premiers pour asseoir et élargir leur influence dans le pays considéré. La remarque a surtout pour objet de mettre en évidence la portée de la pénétration culturelle qui s'affirme aujourd'hui selon les règles d'une parfaite stratégie. Les États présentent volontiers ce compartiment de leurs démarches sous un pavillon altruiste : l'effort pour disséminer à l'étranger une langue ou une culture serait en somme "désintéressé ». Il est clair que cette qualification n'exprime pas la réalité des motifs qui inspirent de telles actions. L'expansion culturelle favorise par de multiples moyens l'exercice d'une influence politique et la conquête de débouchés économiques. Et, dans cette perspective, peu importe que la mission culturelle soit assumée par des services gouvernementaux ou des groupements privés (notamment Fondations américaines).

[p. 392] On doit également noter que divers organismes de statut international, qu'ils soient de composition gouvernementale ou non gouvernementale, se trouvent en réalité aux mains ou sous l'influence prépondérante d'un État déterminé qui parvient de la sorte à les utiliser comme instruments de sa politique. Le cas de l'OTAN, en tant que moyen du leadership américain sur les pays du bloc atlantique n'exige aucune explication particulière. Au titre des organisations non gouvernementales, nous signalerons le cas de la Confédération Internationale des Syndicats Libres dont, en tant de domaines, les démarches sont strictement parallèles à celles de la diplomatie américaine et qui n'a jamais élevé la moindre protestation contre la mainmise du capital monopoliste américain sur un nombre déjà impressionnant d'entreprises européennes.

L'impérialisme, tel que nous le concevons en ce chapitre, implique une différence de puissance, à la fois quantitativement et qualitativement, entre les éléments considérés. La démarche d'inspiration impérialiste découle en premier lieu des efforts, consciemment accomplis, d'utilisation de ce décalage par l'élément qui en bénéficie : 
en ce sens l'impérialisme s'établit par une exploitation systématique des autres. Mais la démarche s'exerce aussi du seul fait de la disproportion des forces: entre des partenaires ou interlocuteurs aux moyens considérablement inégaux le fort, même si telle n'est pas son intention expresse, tend nécessairement à peser sur le faible. Si l'on veut effectuer une étude significative de l'impérialisme, il est nécessaire de prendre en considération ces deux processus, celui qui vient de la volonté mais aussi celui qui sort de la nécessité. Au titre de l'expérience grecque, il semble préférable de partir du mode intentionnel mais il ne faudra pas oublier pour autant les effets de la disproportion de puissance.

Notre dernière remarque a pour objet de souligner qu'en bien des cas l'établissement d'une influence étrangère trouve son origine dans un concours de volontés, celle de l'État puissant mais aussi celle de l'État faible (l'État, c'est-à-dire naturellement les représentants des groupes sociaux qui détiennent le contrôle de l'appareil gouvernemental.). Il est fréquent que par la suite l'élément supérieur aille plus loin que l'élément inférieur ne l'envisageait lors du déclenchement du processus : ainsi le second concluant une alliance militaire avec le premier peut-il n'avoir pas prévu, initialement, que celui-ci tenterait [p. 393] d'en faire un instrument de domination économique — l'Alliance atlantique comme mode de constitution d'un espace privilégié pour les firmes américaines. Mais l'on ne saurait s'exonérer de la responsabilité d'une chaîne d'événements quand on a soi-même contribué à en forger le premier maillon.

\section{EFFORTS D'ORIENTATION POLITIQUE}

Retour à la table des matières

Nous avons déjà exposé l'état de dépendance de l'État grec, depuis sa fondation jusqu'à la seconde guerre mondiale, à l'égard des puissances étrangères et singulièrement de la Grande-Bretagne. Durant cette longue phase de l'histoire grecque, E. Vénizélos fut probablement le seul des hommes politiques helléniques à traiter sur un certain pied d'égalité avec les représentants des grands États. Encore, nous l'avons vu, était-il fort attentif à ne pas mettre en cause la prépondérance britannique.

Le destin de la Grèce en cet après-guerre a été initialement déterminé par le partage d'influence dans les Balkans intervenu entre Churchill et Staline. Il est très probable que la Grèce serait, elle aussi, devenue une démocratie populaire si les armées soviétiques avaient eu la latitude de se déployer sur son sol. Par la suite, le déclenchement de l'insurrection devait avoir pour effet de consolider l'appartenance de la Grèce au bloc occidental.

La lutte contre l'expansion communiste est donc le premier des facteurs ayant conduit les divers gouvernements d'après la Libération à solliciter l'appui militaire et le concours matériel des puissances étrangères alliées. Une fois la guerre civile 
achevée, c'est la crainte d'une invasion soviétique qui a conduit les gouvernements grecs à souhaiter la prolongation de cet état. Toutefois, la volonté de défendre l'intégrité territoriale s'est ajoutée, sans l'effacer, au souci de protéger l'ordre social existant. Pour les partisans grecs de l'atlantisme, ce sont là à vrai dire les deux faces d'un même combat: il s'agit d'empêcher que le communisme battu sur le plan intérieur obtienne sa revanche par le truchement d'une intervention armée étrangère.

Un second facteur a poussé les gouvernements grecs vers les puissances étrangères : la nécessité d'obtenir une aide en vue d'assurer la survie du pays d'abord, sa reconstruction ensuite. Déjà très pauvre, [p. 394] la Grèce a été ravagée sans avoir commis aucune provocation par les troupes des pays de l'Axe (Allemagne, Italie, Bulgarie). Or les réparations qu'elle a pu obtenir au titre des pertes suscitées par l'invasion et l'occupation ennemies sont demeurées à un niveau extrêmement bas. La Grèce dont même en temps normal la vie économique dépend si étroitement de l'étranger n'avait donc, à moins de modifier complètement son système socioéconomique, d'autre ressource que de solliciter l'assistance maximale de ses alliés : ce n'étaient pas là évidemment des démarches susceptibles de consolider son indépendance.

Au début de la période examinée, c'est la Grande-Bretagne qui détient l'influence principale sur la Grèce. Assez vite toutefois, les États-Unis vont se substituer à elle et leurs interventions éclipseront celles de tous les autres pays. Certains de ceux-ci toutefois continuent de détenir ou sont en train de récupérer des positions appréciables.

\section{A. ACTION DE LA GRANDE-BRETAGNE}

$\underline{\text { Retour à la table des matières }}$

Par tradition, la Grande-Bretagne a toujours assumé le rôle de puissance protectrice de la Grèce, cette situation ouvrant au Cabinet britannique la faculté de donner son avis au gouvernement grec sur les problèmes politiques du pays et valant au capital britannique d'occuper une situation privilégiée dans la vie économique de la nation. À l'exclusion des incartades de Constantin au temps de la première guerre mondiale, la dynastie des Glücksburg a constitué l'un des instruments de cette influence. La famille royale grecque a divers liens de parenté avec la famille royale britannique dans le cadre de la descendance de la Reine Victoria. Rappelons également que le défunt roi Paul était le cousin germain du duc d’Édimbourg. Même s'ils ont perdu beaucoup de leur importance ancienne, ces liens dynastiques ne sont pas totalement dépourvus de portée dans les relations entre États. On peut admettre par exemple que dans l'affaire de Chypre la monarchie grecque n'a pas été indifférente aux préoccupations et aux intérêts britanniques.

On s'explique ainsi que, durant la seconde guerre mondiale, la Grande-Bretagne se soit efforcée de faire admettre par ses alliés que la Grèce constituait une «affaire britannique ». Ce point de vue est exactement celui d'E. Tsoudéros qui devient 
Premier Ministre le 21 avril 1941 et, ayant suivi le Roi dans son exil, conservera ce poste [p. 395] pendant trois ans. Tsoudéros, d'allégeance vénizéliste, était proche de l'ambassade britannique d'Athènes avec laquelle il passait pour entretenir des contacts suivis. Toute sa politique de guerre sera fondée sur l'idée qu'une fois la paix revenue, la Grande-Bretagne est vouée à tenir, comme par le passé, un rôle prépondérant en Grèce. Au début de 1943, quand le gouvernement Tsoudéros commence à éprouver des doutes sur les bonnes dispositions des Trois Grands alliés vis-à-vis de la Grèce, c'est au Foreign Office qu'il s'adresse pour obtenir des assurances. G. Papandréou, qui succède à Tsoudéros le 26 avril 1944 — après que S. Vénizélos ait échoué dans la tâche de former un Cabinet — maintient la même politique et reçoit des promesses de soutien de W. Churchill.

Nous avons déjà souligné le rôle décisif joué par les forces britanniques ou sous pavillon britannique dans l'écrasement final des troupes de l'EAM en décembre 1944 - janvier 1945. Lors de la Conférence de Yalta, on parlera peu de la Grèce, Staline déclarant toutefois qu'il n'a pas l'intention de critiquer l'action menée par les Britanniques à Athènes ni d'intervenir dans les affaires grecques. Cette attitude se modifiera par la suite mais elle n'en a pas moins, pour la compréhension des événements de l'époque, une importance considérable. Elle établit que l'URSS comme aussi les États-Unis à cette époque tiennent la Grèce pour une région appartenant, politiquement et militairement, à la sphère d'influence britannique. Et, lors de la conférence de Postdam, Staline se plaindra que les Anglo-saxons critiquent ses démarches en Bulgarie et en Roumanie alors qu'il s'est, lui, bien gardé de se mêler des affaires grecques.

Durant les deux premières années d'après la Libération, la Grande-Bretagne va effectivement jouer un rôle fondamental dans le gouvernement de la Grèce sans que le remplacement des Conservateurs par les Travaillistes en juillet 1945 change quoi que ce soit à la situation. L'intervention s'effectuera par le truchement d'un certain nombre de missions (en particulier missions au titre de la police et de la gendarmerie dont l'objet est d'organiser et d'entraîner les forces de sécurité). Encore faut-il noter que, toutes les fois où une décision implique des dépenses, les fonctionnaires britanniques en Grèce doivent en référer à la Trésorerie. Lors de son voyage à Londres en juillet 1946, le Premier Ministre Tsaldaris demandera, avec quelque insistance, au Foreign Office que l'Ambassadeur britannique à Athènes [p. 396] ou le Chef de la Mission de Police soit autorisé à traiter sur place des problèmes relatifs aux armes, à l'équipement, aux rations alimentaires, aux uniformes...

Il y a aussi une Mission Économique qui fait pression sur le gouvernement grec pour qu'il abaisse les prix et élève les impôts. La Mission, qui recommande l'adoption du système budgétaire britannique, considère que la Grèce doit assurer son relèvement économique et financier à l'aide de ses propres moyens. L'un de ses principaux soucis est d'obtenir que la trésorerie grecque règle sur ses très maigres réserves de change la plus large part possible des fournitures envoyées de GrandeBretagne. Ainsi s'affirme l'un des traits habituels de l'impérialisme britannique: l'avarice à l'égard des pays dominés. La Grande-Bretagne avait certes ses propres difficultés à l'époque mais elle disposait tout de même d'assez larges actifs à travers le 
monde pour se montrer moins rigoureuse à l'égard d'un pays sur lequel elle exerçait un contrôle politique total.

Durant cette période, les gouvernements successifs du pays - qui abandonnent à des éléments étrangers le contrôle ou la supervision de secteurs fondamentaux de la vie nationale (ainsi surveillance des ressources de change) - ne cesseront de fonder des espoirs sur la Grande-Bretagne au titre du relèvement économique comme aussi de la défense des revendications grecques dans les conférences de la Paix. Lors de son voyage à Londres, Tsaldaris demandera même au gouvernement britannique de faire préparer par ses propres experts un plan de relèvement et de reconstruction du pays. La Mission Militaire britannique aura toute latitude pour réorganiser les forces armées du pays. Cependant le secours financier demeure faible et, dès l'été 1946, le gouvernement britannique fait connaître son intention d'arrêter dans un bref délai l'aide en nature fournie à l'armée grecque. Quant aux diverses revendications territoriales de la Grèce vis-à-vis de l'Albanie et de la Bulgarie, on sait que la politique hellénique connut alors une faillite totale. En définitive, la confiance placée par les hommes politiques grecs dans la politique britannique se soldait, spécialement dans l'ordre international, par une complète débâcle.

Durant les derniers mois de 1946 la Grande-Bretagne confirme son incapacité de maintenir l'aide consentie jusqu'alors à la Grèce. Le résultat de cette décision sera de faire passer cette dernière dans la sphère d'influence américaine. Il est possible qu'en dehors de ses motivations finan-[p. 397] cières cette attitude ait été commandée en quelque mesure par le lancement et l'intensification des actions communistes de guérilla. Or, sans en tirer une justification de la position communiste, on doit observer que l'obstination de la Grande-Bretagne à restaurer intégralement l'ordre ancien (monarchie comprise) n'était certainement pas étrangère au conflit qui déchirait le pays depuis deux ans. Ainsi les Britanniques esquivaient-ils, au moment du plus grand danger les responsabilités d'une situation qu'ils avaient contribué à créer.

L'égoïsme national est une composante habituelle de la démarche impérialiste mais cette propension a particulièrement affecté les rapports entre la Grande-Bretagne et la Grèce. Nous en avons fourni plusieurs exemples dans le chapitre préliminaire mais de nos jours, l'affaire de Chypre en donne une illustration saisissante. Sous la domination britannique, l'Île a connu un colonialisme de type classique et absolument rien n'a été fait pour assurer son développement. Pourtant, il y a plus grave: la reconnaissance officielle par la diplomatie britannique à la Turquie d'un droit à s'occuper de Chypre. Cette reconnaissance est intervenue lorsqu'en 1955, pour éviter un tête-à-tête avec la Grèce qui n'aurait pu porter que sur l'Enosis, la GrandeBretagne réunit en une conférence à Londres (29 août- ${ }^{\mathrm{er}}$ septembre) les gouvernements grec et turc. Rien, sauf la volonté de jouer la carte turque contre la revendication grecque, ne pouvait justifier une telle décision puisque, par le Traité de Lausanne, la Turquie avait renoncé à tous ses droits sur l'Île au profit de la GrandeBretagne. Celle-ci était donc fondée, l'eut-elle voulu, à laisser s'accomplir l'union de l'Île avec la Grèce que souhaitait la très grande majorité des Chypriotes. 
Une fois introduite dans la place, la diplomatie turque avec son habileté et sa ténacité coutumières n'allait plus en sortir - l'effet immédiat étant de dresser l'une contre l'autre deux communautés qui jusqu'alors avaient vécu en paix. Mais la Grande-Bretagne conservait ses bases et, une fois arrivé le danger d'une guerre grécoturque, les Britanniques laisseraient supporter aux États-Unis la charge des efforts de conciliation.

Ces considérations expliquent que le poids politique du parti ou clan britannique en Grèce ait nettement baissé depuis la fin de la seconde guerre mondiale — ce déclin affectant la position relative des firmes de Grande-Bretagne dans la vie économique. Certes, ce pays lutte pour assurer le maintien de son influence notamment dans l'ordre culturel (rôle du British Council) mais il est loin de bénéficier des mêmes atouts [p. 398] qu'autrefois et il a largement perdu, au profit des États-Unis, sa vocation à conseiller politiquement le gouvernement grec. Cependant, la Grande-Bretagne dispose encore de points d'appui en divers milieux de la Cour (rôle des liens dynastiques), en quelques secteurs du monde partisan (notamment dans le Parti Progressiste), en certains compartiments de la vie des affaires (en particulier banquiers, armateurs et négociants traditionnellement liés à la Cité de Londres)... C'est encore assez pour faire figure, ce n'est plus suffisant pour régenter la politique du pays.

\section{B. ACTION DES ÉTATS-UNIS}

$\underline{\text { Retour à la table des matières }}$

En considérant la place tenue par les États-Unis depuis 1947 dans la vie politique et économique de la Grèce - directement ou par le truchement de l'OTAN, c'est presque la même chose — on a peine à se représenter qu'ils aient au départ montré si peu d'empressement à s'occuper de ce pays et à lui accorder leur protection. On a déjà dit que les autorités américaines n'éprouvaient guère de sympathie pour la restauration monarchique voulue par Churchill. Durant l'année 1945, la Droite grecque fait grief au Département d'État de ne pas adopter d'emblée la thèse faisant de l'EAM une simple cinquième colonne au service de l'Union Soviétique. Le renversement qui intervient assez vite est un cas typique d'établissement de rapports inégaux par le consentement des deux parties en présence.

\section{RAPPEL HISTORIQUE}

Durant la guerre, le gouvernement en exil, tout en fondant principalement sa politique sur l'appui britannique, avait tenté d'intéresser les États-Unis à ses revendications et d'en obtenir une aide. La seconde de ces requêtes aboutit à la signature en date du 10 juillet 1942 d'un accord de prêt-bail qui devait procurer à la Grèce 81,5 millions de dollars de fournitures (notamment un chasseur de sous-marins pour la marine hellénique). D'autre part, la Grèce bénéficiera après la Libération 
d'une aide de l'UNRRA qui vient pour l'essentiel de la contribution américaine (aide arrêtée en date du $1^{\mathrm{er}}$ avril 1947). Mais les gouvernants grecs de l'époque veulent davantage. D'une part, ils se préoccupent d'obtenir le soutien américain au titre de leurs revendications territoriales et de leurs demandes de réparations : en ce domaine l'échec des [p. 399] démarches grecques sera quasi total. D'autre part, ils souhaitent obtenir une large assistance financière en vue de remettre en marche et de développer l'économie : sur ce plan les réactions américaines ne seront pas entièrement négatives mais elles seront marquées, initialement, de prudence et même de réserve. Les Américains ne cacheront pas que la dégradation monétaire comme aussi l'instabilité gouvernementale constituent autant d'obstacles à l'octroi d'un concours.

Cependant, l'attrait qu'éprouvent les hommes politiques grecs pour Washington grandit à mesure que les événements établissent la faiblesse de l'appui britannique. Dès le mois de juillet 1946, une mission dirigée par S. Vénizélos se rend à Washington pour exposer aux autorités américaines les données du problème grec. L'un des objectifs de la Mission est d'inviter celles-ci à envoyer des experts en Grèce pour y étudier la situation économique et y évaluer les besoins de la reconstruction. En cette occasion les États-Unis ne font aucune promesse concrète d'assistance mais ils n'excluent pas la possibilité qu'elle soit accordée par la suite.

Un peu plus tard, en décembre 1946, le Premier Ministre lui-même (Tsaldaris) effectue une visite de quatre jours à Washington sur invitation du gouvernement américain. Les demandes qu'il présente concernent à la fois l'octroi d'un crédit à court terme pour la satisfaction de besoins urgents et l'intervention de firmes américaines pour l'exécution de projets au titre de la reconstruction. En même temps, le Premier Ministre sollicite l'octroi d'une aide pour l'équipement et le renforcement des troupes grecques en lutte avec les éléments communistes. Le communiqué final de la rencontre témoigne de l'intérêt que les États-Unis portent désormais à la Grèce, et en fait, le 13 janvier 1947 une mission américaine dirigée par Paul Porter s'envole à destination d'Athènes. Cette fois, les hommes politiques grecs sont, au moins sur le terrain de l'assistance, parvenus à leurs fins.

Il va de soi que la nouvelle attitude de Washington est le résultat direct de la rupture du front des alliés et de la division de l'Europe en deux blocs rigidement opposés qui est en train de s'accomplir. On a eu plusieurs indices de cet intérêt pour les affaires grecques depuis le milieu de 1945 : annonce en date du 20 août 1945 que les États-Unis participeront à la commission de contrôle des élections ; arrivée dans le port du Pirée, en date du 6 décembre 1945, du croiseur américain Providence dont le commandant recevra à bord le Régent et dînera ensuite [p. 400] avec le Ministre des Affaires Étrangères ; arrivée en date du 10 avril 1946 du cuirassé Missouri venant de Constantinople et dont le séjour dans les eaux grecques sera entouré d'une solennité particulière ; suggestion faite le 14 octobre 1946 par l'attaché militaire américain d'inviter officiellement la mission d'experts dont le gouvernement grec souhaitait tant la venue ...

Un facteur va précipiter l'évolution: l'annonce faite par les Britanniques aux Américains en date du 20 février 1947 que la Trésorerie s'oppose à toute continuation 
de l'aide à la Grèce. Le 12 mars, le Président des États-Unis prononce devant les deux chambres du Congrès le discours posant les bases de la "doctrine Truman ». Cette démarche qui s'inscrit dans le cadre d'une stratégie globale de lutte contre le communisme aboutit pour la Grèce à remplacer le débile suzerain qu'était la GrandeBretagne par le puissant protecteur que sont les États-Unis. Quelles sont les conséquences de cette situation?

\section{TRAITS DE L'INTERVENTION AMÉRICAINE}

Il y aurait un intéressant parallèle à tracer entre le comportement des envoyés américains à l'étranger et celui des représentants britanniques. En considérant seulement l'expérience grecque, on s'aperçoit que dans certains cas, la différence s'établissait au niveau, pourtant élémentaire de l'habillement : tout Athènes savait par exemple que le Roi Paul ne prisait guère les écarts du défunt ambassadeur Peurifoy en matière d'étiquette vestimentaire. D'autre part, et c'est plus important, les Américains savent beaucoup moins bien que les Britanniques se contraindre à la démarche confidentielle ou à l'intervention indirecte: il est arrivé plusieurs fois à des ambassadeurs des États-Unis d'exprimer publiquement des jugements susceptibles de choquer profondément l'opinion grecque, le traditionnel démenti ultérieur ayant généralement pour effet de confirmer l'authenticité du propos tenu et d'accroître l'irritation des citoyens helléniques.

Cependant les différences de fond sont aussi accusées et naturellement plus significatives pour notre propos. La première tient à l'ampleur des moyens financiers

et matériels mis en œuvre. La Grèce a reçu des États-Unis une aide économique et militaire (dont nous donnerons plus loin le détail) sans aucune commune mesure avec ce qu'elle avait obtenu ou aurait pu obtenir de la Grande-Bretagne ou de tout autre pays euro-[p. 401] péen. D'un impérialisme à l'autre il y a un décalage qualitatif, la Grande-Bretagne n'ayant jamais témoigné d'une telle propension même quand elle était le pays le plus riche du monde. Sans doute cette aide n'allait pas sans contrepartie même sur le seul plan économique et nul ne saurait sérieusement affirmer, à commencer par les Américains eux-mêmes, qu'elle n'aurait pas pu faire l'objet d'une utilisation plus judicieuse. Cependant, le fait demeure que les Américains ont assorti le contrôle exercé de décaissements relativement élevés. Il est vrai que cette aide a pris fin en 1962 et que depuis lors les États-Unis, réserve faite d'une tendance à introduire les Allemands dans le circuit, ne manifestent nulle intention de relâcher leur pression politique générale sur la Grèce.

L'octroi de ce concours a entraîné durant la période considérée une surveillance étroite, encore que pas nécessairement efficace, des activités gouvernementales grecques par les multiples services ou missions que les Américains établissent sans compter dans les pays soumis à leur influence. Cette supervision s'est d'abord exercée avec beaucoup de vigilance à propos des opérations militaires contre les troupes de guérilla communistes. Fournissant les moyens militaires indispensables aux forces gouvernementales, les autorités américaines n'ont pas ménagé les conseils pour en assurer l'utilisation optimale. Par la suite, les liens entre officiers grecs et américains 
sont demeurés étroits tant du fait de l'aide militaire que des contacts noués dans le cadre de l'OTAN (en particulier à l'État-Major de Smyrne). Comme dans les autres pays de l'OTAN, les forces américaines stationnées en Grèce bénéficient de droits d'exterritorialité (l'opinion circulant d'ailleurs que par le jeu de conventions secrètes les États-Unis jouiraient dans ce pays de facilités plus grandes qu'ailleurs).

Les Américains sont également intervenus, notamment par des liaisons directes avec le Ministre de la Coordination, dans l'établissement des programmes économiques du gouvernement et la préparation des projets de travaux publics. Ils se sont prononcés en faveur du développement prioritaire de certaines cultures et ont fortement encouragé les tendances favorables à l'expansion du tourisme. En dehors de toute autre considération, un pays aussi pauvre que la Grèce ne pouvait se permettre, à moins d'envisager un changement total de sa politique, d'ignorer les conseils ou suggestions d'un pays susceptible de lui apporter des ressources substantielles en dollars.

[p. 402] Chemin faisant, nous avons rencontré de nombreuses interventions américaines dans le domaine des luttes partisanes. C'est ainsi que les Américains ont fortement soutenu le Maréchal Papagos dans sa lutte pour la conquête du pouvoir. À cette époque, les journaux américains se faisaient l'écho des dissensions entre l'Ambassadeur Peurifoy et certains milieux de la Cour (la reine Frederika) qui passaient pour être hostiles au Maréchal. Plus tard le soutien des États-Unis ira à l'Union Nationale Radicale dont le leader C. Caramanlis semble, au moins pendant les premières années de son activité gouvernementale, avoir inspiré une grande confiance aux services américains.

La pierre de touche de ces préférences est simple : il s'agit de l'aptitude du groupe ou de la personne en cause à assurer, avec le maximum d'efficacité et dans le respect des intérêts matériels américains, la protection du pays contre le danger communiste - protection devant résulter selon l'opinion américaine d'une part de l'amélioration de la situation économique et de l'élévation du niveau de vie des travailleurs, d'autre part de l'entretien d'une puissante armée et de la lutte sans relâche contre les agents internes de la subversion.

Bien entendu, la valeur respective attribuée à chacun des éléments de ce dispositif a varié selon les époques et aussi selon les personnalités en présence. Par ailleurs l'Administration du Président Kennedy a fait preuve dans la lutte contre le communisme de dispositions plus subtiles que celle du général Eisenhower, étant toutefois entendu que les modifications survenues au niveau du gouvernement central ne se répercutent souvent qu'avec lenteur sur les agents exerçant leurs fonctions à l'étranger. Sous toutes ces réserves, il nous semble que le critère choisi pour caractériser et particulariser les démarches américaines en Grèce durant la période considérée exprime correctement la réalité des comportements.

Un tel souci devait nécessairement amener les Américains à se préoccuper, comme les Britanniques l'avaient fait au temps de leur puissance, du fonctionnement des services de sécurité. On peut envisager à ce propos des rapports de différentes sortes, l'une étant la fourniture aux services chargés de la lutte anti-communiste d'une 
sorte d'assistance technique en vue d'améliorer leur efficacité (ainsi fourniture d'un matériel perfectionné : télé-objectifs, dispositifs d'écoute, magnétophones d'écoute à distance, voitures à équipements spéciaux...). Une telle assistance n'avait certes rien de contraire à l'esprit des rapports gréco-américains de [p. 403] l'époque et l'on peut penser que les intéressés n'ont pas manqué d’y avoir recours avec l'acquiescement des autorités gouvernementales grecques.

Mais il existe une autre forme de pénétration qui s'exerce en marge des structures et pratiques officielles: la conquête par les services compétents de la puissance étrangère d'un droit de regard sur le contenu de l'activité des corps de sécurité nationaux et d'une faculté d'orientation de leur activité. L'opération peut s'effectuer de multiples manières, dont l'établissement de liaisons directes entre responsables policiers des deux pays, sans que ces liens soient nécessairement portés à la connaissance de l'un ou l'autre (parfois de l'un et de l'autre) des gouvernements en cause. On peut aussi concevoir que le service policier étranger procède par l'installation d'agents secrets dans les organes de l'État dont il s'agit de contrôler le fonctionnement. Il faudrait de bien longs développements pour exposer en détails les procédés multiples utilisés dans ce genre d'intervention. De toute manière, l'effet de ces dispositifs quel qu'en soit l'agencement est de créer dans le pays un potentiel de surveillance policière qui échappe à l'emprise gouvernementale.

À plusieurs reprises les journaux de l'opposition ont dénoncé la présence dans les services de la sûreté générale d'hommes à la solde d'organismes américains. Ce sont là des allégations qu'il est généralement impossible de prouver dans le cadre des enquêtes administratives habituelles, circonstance qui ne suffit pas d'ailleurs pour établir leur fausseté ou leur caractère imaginaire.

On en dira autant des enquêtes publiées par des journalistes de Gauche sur les rapports entre la CIA américaine et l'Agence Centrale de Renseignements grecque (KYP), organisme dont S. Vénizélos lui-même déclarait devant le Parlement que les tentacules s'étendaient sur toute la Grèce (l'un de ses procédés de travail étant l'enregistrement des conversations téléphoniques des hommes n'appartenant pas à la faction gouvernementale). Selon ces enquêtes, les rapports entre la CIA américaine et l'Agence grecque seraient des relations de patron à exécutant, la subordination de l'Agence à l'organisme américain tenant au fait qu'elle en reçoit des armes, des instruments d'investigation et des fonds. La surveillance pour le compte des services américains des Grecs soupçonnés de sympathies à l'égard de la Gauche s'exercerait ainsi non seulement dans le pays même mais encore dans les communautés grecques de l'étranger (à Chypre, au sein des milieux gréco-américains des États-[p. 404] Unis). Sans entrer dans le détail de telles enquêtes, disons que l'un des reproches adressés à la CIA est de faire à Chypre une propagande anti-grecque (dans certains cas avec l'aide de l'Agence Hellénique).

Les dénonciations de cette sorte ne font pas l'objet de preuves au sens propre du mot. Rien de ce que nous savons sur le fonctionnement de la CIA — et grâce à la publication récente de divers livres américains sur cet organisme, nous en savons déjà assez long sur sa structure et ses activités — n'autorise à qualifier d'emblée ces 
imputations d'invraisemblables. Au surplus, les services secrets américains ne sont pas les seuls à travailler en Grèce (rôle traditionnel des services britanniques et depuis quelques temps rentrée des services allemands). Le seul point important pour nous est d'apprécier la portée politique éventuelle de telles manœuvres.

Sur la base de multiples erreurs commises tout au long de l'histoire par de tels services, il est en première analyse assez tentant d'adopter l'opinion qui fait de cette activité une "grande farce ». Mais ce serait probablement une vue assez courte du problème. Au surplus, ces services, dont il faut se garder de faire le moteur de l'histoire, ne se contentent plus de surveiller ou d'espionner : il est fréquent qu'ils interviennent directement dans le combat politique par exemple en noyautant des groupes existants ou en organisant des associations parallèles. Il est probable que la suppression radicale de ces pratiques aurait permis, en Grèce comme ailleurs, d'éviter des troubles, d'améliorer la sécurité des citoyens et de sauvegarder des vies humaines.

Admettons que les États-Unis ont bien d'autres moyens d'influer sur l'opinion publique grecque que d'utiliser les techniques des services secrets sans oublier bien entendu le fait que l'OTAN a la haute main sur le dispositif militaire grec. L'un de ces moyens, dont il a probablement été abusé depuis une dizaine d'années est le déplacement des unités de la $6^{\mathrm{e}}$ flotte qui se trouve toujours là où il est nécessaire de matérialiser le fouet de la puissance américaine. Mais il y a des instruments de pénétration bien plus efficaces et dont peu de citoyens songent à mettre en cause la légitimité : ainsi l'exceptionnelle diffusion en Grèce des films américains qui, à peu d'exceptions près, donnent une vue favorable et passablement optimiste de l'american way of life. Si l'on raisonne sur la base du nombre des billets vendus, le cinéma américain vient largement en tête avec plus de $40 \%$ des billets (près de $44 \%$ au titre du dernier exercice connu) : ce cinéma dépasse nettement le cinéma grec et laisse [p. 405] fort peu de place aux films des autres pays européens (le pourcentage du cinéma soviétique étant de l'ordre, de 1\%).

Sans verser dans le paradoxe, nous hésiterions beaucoup à admettre que cette pratique cinématographique ne fait pas davantage et même bien davantage que l'ensemble des démarches des services secrets pour assurer le développement de l'influence américaine en Grèce.

\section{CLAN AMÉRICAIN}

Le clan ou parti américain se compose des hommes qui, par inclination idéologique ou par intérêt matériel, sont prêts en toutes occasions à justifier les positions américaines et à aider les représentants des États-Unis dans l'accomplissement de leurs desseins en Grèce. Dans la mesure où le sort de la Grèce leur paraît étroitement lié à celui des États-Unis, ces hommes trouvent parfaitement légitime que les seconds exercent une influence sur la vie politique de leur pays. En somme, le clan américain reproduit exactement à l'égard de l'Amérique le genre de conduite adopté par les tenants de la prépondérance britannique vis-à-vis des autorités de Sa Majesté. De plus, les Américains possèdent à l'égard de la Grèce un atout 
important: la présence aux États-Unis d'un fort contingent de population de descendance hellénique — contingent capable d'influer, ne serait-ce que par l'octroi d'une aide, les familles ou parentés demeurées au pays.

Comme le parti royal, il s'agit d'un phénomène essentiellement élitaire : le parti américain ne se confond pas plus avec l'ensemble des américanophiles que le clan de la Couronne ne doit être assimilé à la totalité des monarchistes. L'utilisation de la notion de parti américain n'a de sens que si l'on se borne à y faire entrer les hommes répondant à une double condition : témoigner d'un attachement durable aux ÉtatsUnis ; détenir une position d'influence, d'autorité ou de prestige. C'est seulement si ces deux exigences sont satisfaites que ces hommes se trouvent en mesure de rendre les services que l'Amérique attend d'eux et dont le premier est de consolider la position américaine soit dans un centre de décision quelconque, soit auprès de tel ou tel secteur de l'opinion.

La Grèce n'a aucun monopole de ce genre de rassemblement socio-politique dont il existe par exemple un spécimen tout à fait au point en France. Cependant la pratique grecque offre une difficulté particulière qui est l'ana-[p. 406] lyse des liaisons entre le clan royal et le clan américain. Les deux partis ne sont pas composés en principe, du moins pas nécessairement, des mêmes membres, encore qu'ils puissent en avoir certains en commun. Dans cette seconde éventualité, le point intéressant est de savoir laquelle des deux allégeances l'emporterait en cas de conflit ou de contradiction.

La question était plus simple au titre du clan britannique en raison de l'étroitesse des liens de la Monarchie grecque, durant la plus grande partie de son histoire, avec la Grande-Bretagne. Certains commentateurs estiment qu'au cours des dernières années la dynastie, attentive aux modifications dans le rapport des forces, aurait tendu à se détacher quelque peu de l'ancien protecteur pour s'appuyer davantage sur le nouveau conquérant. Mais, compte tenu de l'anti-monarchisme foncier des Américains, il est douteux que ceux-ci considèrent la Couronne autrement que comme un instrument provisoirement utile, plus ou moins utile d'ailleurs, dans la lutte contre le communisme. Il est très probable que si les Grecs souhaitaient vivre en République, les Américains, à condition qu'il s'agisse d'une république bourgeoise ouverte au big business d'Outre-Atlantique, n'y mettraient aucun obstacle. Et dès lors, en dépit d'une évolution récente, les clans américain et royal, malgré les affiliations qu'ils partagent, ont probablement plus d'autonomie réciproque que n'en avaient, au temps où l'influence de la Grande-Bretagne prédominait, le clan britannique et le clan royal.

La communauté d'appartenance est probablement assez poussée chez les étatsmajors militaires qui, jusqu'à présent du moins, ont été foncièrement promonarchistes mais sont très liés avec leurs collègues américains, notamment dans le cadre des organismes de l'OTAN (supra). Cette communauté est vraisemblablement moins accusée dans le secteur des dirigeants d'entreprise : il est douteux en effet que l'influence américaine ne soit pas exclusive ou prépondérante chez les financiers ou industriels grecs qui viennent au parti des États-Unis sur la base de liens privilégiés avec des groupes d'affaires de ce pays. 
Pour élargir leur influence, les Américains, sans avoir le monopole de telles pratiques, se servent de l'octroi de facilités d'études dans leurs universités. Ce n'est certes pas un procédé dont ils ont l'exclusivité, mais, grâce à l'ampleur de leurs ressources, ils sont en mesure de lui donner une bien plus large extension que les autres pays. Voici d'après des documents de l'Ambassade américaine le nombre des bourses attribuées à des Grecs au seul titre du programme Fulbright de 1950 à [p. 407] 1963 (une partie de ces bourses étant supportée par les universités ellesmêmes) :

- Au niveau undergraduate: 294. Durée moyenne du séjour: 4 ans. Frais supportés pour chaque bénéficiaire : environ 3.000 \$ par an plus les frais de voyage.

— Au niveau graduate : 386. Durée moyenne du séjour : 3 ans avec le même cout annuel (plus les frais de voyage) que la catégorie précédente.

- Au niveau research scholar: 66. Durée moyenne du séjour: 7 mois. Attribution d'une bourse d'environ 3.500 \$ plus les frais de voyage.

Autre moyen de stimuler l'intérêt pour les États-Unis chez les élites étrangères (foreign leaders) : l'octroi d'une allocation permettant d'entreprendre la visite de ce pays de manière optimale. Au titre des quatre années 1959-1962, cinquante-sept allocations ont été attribuées à des leaders grecs que l'on peut répartir dans les catégories socio-professionnelles suivantes: hauts fonctionnaires, 17 ; nomarques (l'équivalent des préfets français), 14 parlementaires, 7 ; maires, 3 ; journalistes, 5 ; professions libérales, 4 écrivains, 4 ; activités liées aux affaires, 3.

Les facilités ainsi mentionnées ne représentent qu'une partie de celles accordées par la totalité des institutions américaines (groupes privés, en particulier Fondations, inclus). On aurait certes tort d'admettre que tout bénéficiaire de ces facilités devient ipso facto adepte du clan américain : les mécanismes de formation des allégeances politiques ne sont pas aussi simples. Toutefois, il est vraisemblable que ces procédés, pris dans leur ensemble, aident les services américains à consolider et à élargir l'influence des États-Unis.

Les hommes du clan américain sont susceptibles de rencontrer des difficultés sérieuses quand les démarches ou positions de la diplomatie des États-Unis sont en contradiction avec des conceptions ou revendications grecques, disposant d'une très large audience dans l'opinion. Tel a été et tel est toujours le cas pour l'affaire chypriote. Dès le moment où l'on reconnaissait à la Turquie le droit de s'occuper officiellement du problème, il devenait impossible de trouver une solution capable de satisfaire les deux parties en présence. La signature des accords de Zurich a probablement représenté l'un des plus grands services rendus par Caramanlis à la diplomatie américaine (la Cour ayant probablement agi dans le même sens que celleci, notamment auprès de Macarios). Mais, [p. 408] dans la meilleure des hypothèses pour la Grèce, ces accords aboutissaient à différer l'Enosis et impliquaient donc pour elle une capitulation provisoire. Au surplus il suffisait de lire la Constitution issue de ces accords pour comprendre que, loin de constituer un instrument de pacification des 
rapports entre ces deux communautés, elle ne pouvait qu'alourdir les contradictions et antagonismes.

Depuis la dénonciation de ces accords par Macarios, les Américains se sont efforcés de trouver une solution qui contente la Grèce tout en satisfaisant la Turquie. En réalité ils n'ont pas voulu choisir, le seul résultat d'une manœuvre de cet ordre, conduite au surplus avec beaucoup de maladresses et nombre de déclarations publiques intempestives, étant de leur aliéner des sympathies dans l'un et l'autre camp. Il serait significatif que la Grande-Bretagne parvienne à faire oublier aux intéressés, et ce au détriment des États-Unis, qu'elle porte l'entière responsabilité de la tragédie chypriote.

\section{ACTION D'AUTRES PAYS}

$\underline{\text { Retour à la table des matières }}$

Nous mentionnerons d'abord l'Allemagne Fédérale qui, durant ces dernières années, a effectué un retour assez massif en plusieurs domaines de la vie nationale. Touristes, hommes d'affaires, ingénieurs de travaux publics, éléments des services secrets, tels ont été durant cet après-guerre les divers éléments de la pénétration allemande. L'influence allemande, contrairement à l'influence britannique, suit actuellement une ligne ascendante, les Américains eux-mêmes paraissant souhaiter que les Allemands se substituent à eux dans certains compartiments de l'aide apportée à la Grèce notamment dans l'ordre militaire.

La Gauche dénonce dans ce retour la mise en œuvre d'un plan néo-hitlérien de revanche sur la Grèce et elle s'élève contre l'octroi éventuel à l'armée allemande de bases ou de terrains de manœuvre sur le territoire national. Selon elle, la Grèce risque d'être utilisée systématiquement par l'Allemagne avec le consentement américain comme une tête de pont pour la conquête de positions dominantes dans tout le Moyen-Orient. En somme, l'Allemagne regagnerait dans la paix et grâce au concours américain les avantages qu'elle avait perdus du fait de la victoire alliée.

De prime abord, les accusations de l'EDA peuvent sembler excessives. Avant de les critiquer toutefois, observons que le processus dénoncé au titre de la Grèce correspond exactement à celui qui est en train de se [p. 409] réaliser dans le cadre de l'Europe toute entière. L'impérialisme allemand avec ses traits de toujours est de nouveau en marche. Au surplus, l'argumentation de l'EDA serait plus facile à contester si le service diplomatique allemand en Grèce et dans le Moyen-Orient comportait, notamment au niveau des ambassadeurs, moins de membres ayant appartenu au parti national-socialiste.

À propos des rapports gréco-allemands, on doit mentionner à nouveau l'affaire Merten, ancien haut fonctionnaire nazi en Grèce du Nord sous l'occupation, qui, ayant eu l'imprudence ou l'audace de revenir sur territoire hellénique au titre d'un voyage d'agrément, y fut arrêté comme criminel de guerre, jugé par une Cour martiale et 
condamné à 20 ans de détention. Dès l'arrestation de Merten, qui occupait des fonctions importantes au Ministère de la justice, les autorités de Bonn intervinrent activement pour stopper l'activité de la justice grecque et obtenir du gouvernement grec le renvoi en Allemagne de l'accusé. Une fois le jugement acquis, Caramanlis présenta au Parlement un texte donnant satisfaction aux revendications allemandes : cependant, vu les réactions de l'opinion, le dispositif finalement adopté (Décret-loi 4016 de 1959) se limitait à transférer pour l'avenir la compétence hellénique en matière de crimes de guerre allemands au gouvernement de Bonn en excluant les cas déjà jugés, c'est-à-dire essentiellement l'affaire Merten. Un peu plus tard toutefois, Caramanlis revint à la charge et obtint l'acceptation du décret-loi 4122 de 1960 qui permit effectivement de renvoyer Merten dans la République Fédérale.

On sait que celui-ci devant être, selon l'accord gréco-allemand, jugé par les tribunaux allemands allégua pour sa défense que durant l'occupation Caramanlis et Macris (dont la femme était alors secrétaire de Merten) aurait livré des juifs aux forces allemandes de Salonique. L'affaire divulguée par le Spiegel fit grand bruit quoique les déclarations de Merten soient restées inconsistantes, spécialement à l'égard de Caramanlis qui, durant la guerre, vivait à Athènes. Les intéressés portèrent plainte devant des tribunaux grecs et non allemands comme les en défiait Merten. Finalement, le gouvernement allemand parvint à amortir l'affaire, l'ambassadeur grec à Bonn ayant par la suite fait des déclarations assez critiques quant aux contacts noués à cet effet entre services allemands et grecs.

L'affaire eut, sans nul doute, un profond retentissement dans l'opinion grecque et contribua à discréditer le gouvernement de la Droite. [p. 410] Celui-ci aurait été mieux placé s'il avait résisté aux pressions des autorités de Bonn tendant à le dessaisir de sa compétence en matière de crimes de guerre. Mais il était évidemment difficile au gouvernement de réclamer que justice soit faite à cet égard et en même temps d'accepter une participation sans cesse croissante des monopoles allemands à la vie économique du pays.

La France exerce encore en Grèce, malgré la nette préférence des jeunes générations pour la langue anglaise, une influence culturelle appréciable. Au surplus, le capital français a été relativement actif dans ce pays. Mais les facultés d'investissement économique dont elle dispose demeurent très inférieures à celles que sont capables de mettre en œuvre les grands monopoles allemands et américains. Dans l'ordre militaire, tout essai de coopération directe avec l'armée grecque se heurterait au fait que celle-ci est entièrement équipée de matériel des États-Unis et se trouve sous la supervision étroite des états-majors américains.

Dans ces conditions, la France ne peut guère espérer tenir un rôle de premier plan. Le voyage accompli en Grèce par le général de Gaulle, du 16 au 19 mai 1963, lui a valu certes un grand succès personnel tant auprès des foules que devant le Parlement. Mais les dirigeants grecs n'ont pas dissimulé qu'en comparaison de la collaboration gréco-américaine la coopération franco-hellénique ne constitue, malgré son utilité intrinsèque, qu'un élément relativement secondaire de la position internationale grecque. 


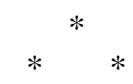

Les développements qui précèdent n'ont pas fait mention d'un clan ou parti prosoviétique. En réalité, si l'on prend la notion de clan dans le sens d'un réseau de personnalités occupant des points stratégiques ou des positions importantes dans l'activité nationale, il est douteux que son application au cas soviétique ait quelque intérêt ou même quelque plausibilité. Sans reprendre ici la discussion sur la nature des allégeances politiques de l'EDA, observons que ce parti n'a jamais fait mystère de ses sympathies et de ses préférences pour les conceptions soutenues et les positions prises par la diplomatie de l'URSS. Celle-ci dispose donc d'un appui pour la présentation et la défense de ses thèses et par ailleurs elle s'efforce d'obtenir les sympathies d'un certain nombre d'hommes importants ou influents par la mise en œuvre d'une politique d'in-[p. 411] vitations à un séjour en URSS (les autres pays communistes agissant de manière analogue). Mais le combat politique étant ce qu'il est en Grèce, il paraît peu vraisemblable que des hommes partageant les thèses soviétiques soient actuellement en mesure de détenir les situations qui donnent sa véritable portée à l'existence d'un clan étranger ou pro-étranger.

\section{ESSAIS DE MAINMISE ÉCONOMIQUE}

\section{$\underline{\text { Retour à la table des matières }}$}

Vu l'ampleur de la pénétration déjà réalisée, on commet peut-être un euphémisme en utilisant le terme " essai ». Tout en employant une terminologie modérée, nous n'avons aucun doute sur le fait que la Grèce est actuellement en proie à une tentative de colonisation économique mais les résultats acquis notamment au titre des investissements directs sont encore trop faibles pour qu'on puisse la dire achevée. Les deux modalités principales de ce processus sont l'octroi d'une assistance économique à l'État Grec par des États étrangers ; la réalisation d'investissements directs par des groupes d'affaires étrangers dans la vie économique nationale. En apparence, seule la seconde modalité paraît susceptible d'engendrer la colonisation économique mais l'expérience générale, spécialement celle des pays pauvres et économiquement en retard, montre que l'assistance prépare et consolide la pénétration du capital privé.

\section{A. ASSISTANCE ÉCONOMIQUE}

Nous examinerons successivement celle procurée par les États-Unis, l'ensemble des autres pays étrangers et les organisations internationales. Nous procèderons ensuite à quelques remarques générales sur la portée et les conséquences de cette assistance. 
Cette assistance comprend une aide à fonds perdus et des prêts remboursables. Pour le moment, nous allons étudier cette assistance sur la base des engagements pris à l'égard du gouvernement grec par les États qui l'accordent. Nous renvoyons à un autre paragraphe l'étude des dettes assumées par le premier du fait de cette aide au 31 décembre 1963.

[p. 412]

\section{ASSISTANCE FOURNIE PAR LES ÉTATS-UNIS}

Les évaluations de cette aide variant d'une source à l'autre et les statistiques officielles ne brillant pas par l'exactitude, nous avons demandé aux services financiers de l'Ambassade des États-Unis de nous communiquer leurs propres estimations. Les chiffres présentés dans ce paragraphe sont tirés des documents de travail qui nous ont été fournis par ces services.

De la Libération au 30 juin 1964, le total de l'assistance accordée par les ÉtatsUnis s'est élevé à 3.984 millions de dollars (montant approximativement égal au produit national brut de la Grèce durant l'année 1963). Ce total comporte à concurrence de 1.740 millions de dollars une aide militaire sous la forme d'équipements et d'articles d'usage courant. Il reste donc une aide civile de 2.244 millions de dollars (dont 18 au titre de la coopération technique). Cette aide civile (assistance technique comptée à part) peut être répartie chronologiquement en quatre périodes :

$1^{\circ}$ Octobre 1944-mars 1947

Essentiellement, part américaine dans les distributions

faites par l'UNRRA

$2^{\circ}$ Avril 1947-mars 1948

Phase de l'aide intérimaire 157

$3^{\circ}$ Avril 1948-juin 1953

Attributions au titre du plan Marshall 1.095

$4^{\circ}$ juin 1953-juin 1964

Phase de limitation de l'aide en Europe à la Grèce et à la Turquie

On voit que c'est durant la phase du plan Marshall que la Grèce a obtenu l'aide maximale (son pourcentage par tête d'habitant dans les fonds distribués ayant été plus haut que celui des autres pays euro-[p. 413] péens). Par nature d’\%ide, le total de l'assistance civile se décompose comme suit : 


\begin{tabular}{|c|c|c|}
\hline & Valeur absolue & Pourcentage du total \\
\hline 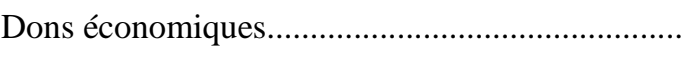 & 1.823 & 81,2 \\
\hline 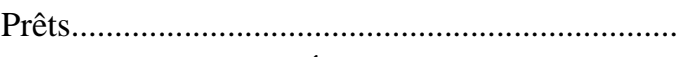 & 297 & 13,2 \\
\hline \multirow[t]{2}{*}{ Fonds utilisés par les États-Unis en Grèce............. } & 124 & 5,6 \\
\hline & 2.244 & 100,0 \\
\hline
\end{tabular}

Une partie des avances ainsi accordées représente des prêts faits par l'Agency for International Development (ADI) pour l'expansion de la capacité électrique. Au titre des emprunts consentis à la Grèce par les États-Unis, on doit noter qu'une large portion, environ 180 millions de dollars, est remboursable en monnaie grecque, ce qui a limité et limitera au titre de la partie non encore remboursée la pression de cette dette sur les ressources de change. Par ailleurs, au 31 décembre 1963, il restait encore à utiliser un certain montant sur les crédits ouverts (principalement 45 millions accordés par l'ADI).

La détermination de l'emploi fait de ces ressources par les autorités grecques soulève des problèmes complexes et ne peut donner lieu à des évaluations parfaitement tranchées. Les services financiers de l'Ambassade des États-Unis avancent pour leur part les estimations suivantes :

\begin{tabular}{|c|c|c|}
\hline & Valeur absolue & Pourcentage du total \\
\hline 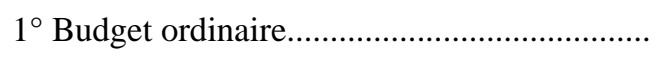 & 1.136 & 50,6 \\
\hline 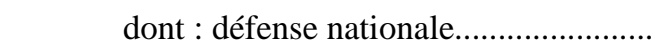 & (404) & (18) \\
\hline 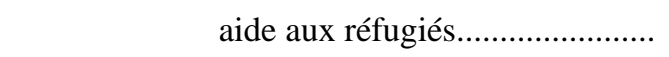 & $(130)$ & $(5,8)$ \\
\hline découverts budgétaires................. & $(602)$ & $(26,8)$ \\
\hline 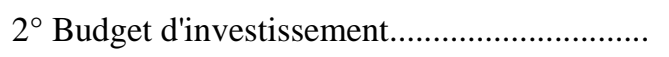 & 794 & 35,4 \\
\hline $3^{\circ}$ Financement de la Banque Agricole.............. & 57 & 2,5 \\
\hline \multirow[t]{2}{*}{$4^{\circ}$ Attribution de surplus agricoles américains } & 133 & 5,9 \\
\hline & 2.120 & 94,4 \\
\hline \multirow[t]{2}{*}{$5^{\circ}$ Dépenses américaines en Grèce....................... } & 124 & 5,6 \\
\hline & 2.244 & 100,0 \\
\hline
\end{tabular}

[p. 414] On peut en définitive reclasser comme suit l'aide totale de 3.984 millions de dollars que les services américains déclarent avoir été attribuée par les États-Unis d'octobre 1944 à juin 1964 : 


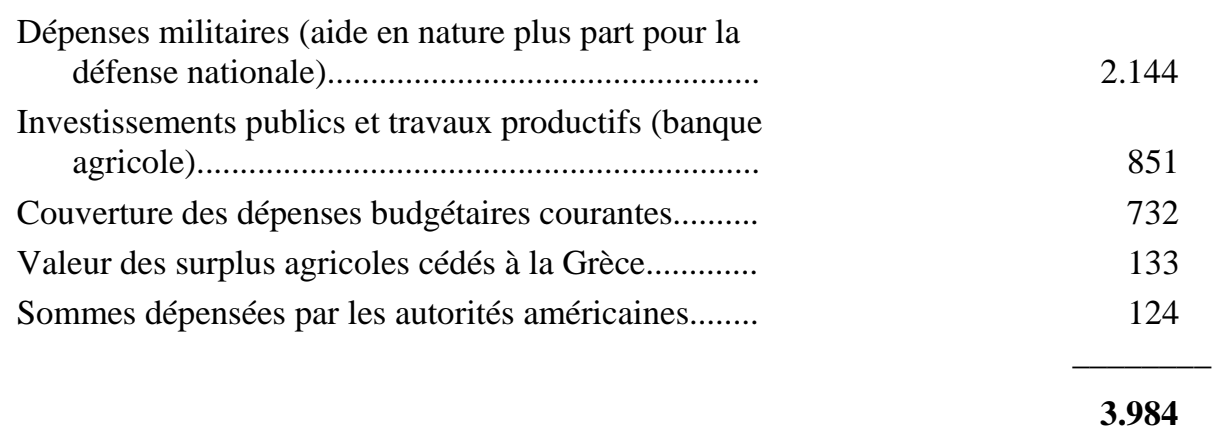

Nous avons déjà signalé que l'aide attribuée en monnaie depuis juin 1953 au titre du soutien de la défense nationale et de l'économie a pris fin au 30 juin 1962, le principe étant posé que le gouvernement américain se bornerait désormais à l'octroi éventuel de prêts répondant à des conditions déterminées et avec des garanties définies ainsi le prêt de 38,5 millions de dollars accordé en novembre 1964 pour l'importation de produits agricoles en 1965-1966 (produits fourragers pour l'élevage, huile de soja,...).

N'oublions pas que l'effet économique d'une aide de ce type est double: augmenter les ressources monétaires à la disposition du gouvernement ; accroître les réserves de change du pays (du moins pour la partie de l'aide qui ne se ramène pas à une livraison de produits).

Pour être complet, mentionnons enfin les crédits accordés par les firmes américaines à des entreprises du secteur public: deux prêts de la Manufacturers Hanover Trust de New-York (l'un de 6 millions à l'Entreprise Publique d'Électricité, l'autre de 8 à l'Organisation pour le financement du développement économique) ; un crédit de 1 million ouvert par la Socony Mobil Oil à la Raffinerie étatique de pétrole.

\section{ASSISTANCE FOURNIE PAR LES AUTRES PAYS}

D'octobre 1944 à fin 1963, le total des concours attribués à la Grèce par ces puissances s'élève à la somme de 558,2 millions de dollars. Il en faut immédiatement déduire un chiffre de 146,4 millions représentant les réparations et restitutions reçues par l'État grec. On ne saurait décemment introduire dans le cadre de l'assistance le remboursement d'un [p. 415] dommage causé. Observons d'ailleurs pour apprécier la valeur de ce dédommagement que le total des revendications présentées par la Grèce à la conférence de la Paix était de l'ordre de 13 milliards de dollars sur la base de la valeur 1938 du dollar. Déduction faite de ce poste, le montant de l'assistance est de 411,8 millions de dollars.

Pour mieux apprécier la portée réelle de cette assistance durant la période considérée, il est préférable de mettre à part l'aide accordée par la Grande-Bretagne durant la période 1944-46. Elle s'élève en tout à 220,3 millions de dollars : une aide 
militaire de 152 ; une attribution gratuite de fournitures civiles de 28 ; un prêt de 40,3 pour assurer la stabilisation de la drachme (prêt entièrement remboursé).

Nous restons donc avec un total de 191,5 millions de dollars, chiffre représentant les engagements en faveur de la Grèce. Ils se décomposent comme suit :

\begin{tabular}{|c|c|c|c|}
\hline Pays & Aide & Prêts & Total \\
\hline 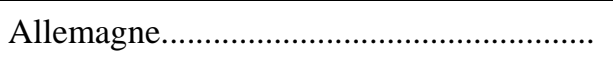 & 12 & 128,7 & 140,7 \\
\hline 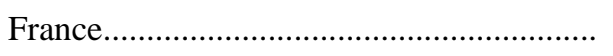 & - & 31,1 & 31,1 \\
\hline 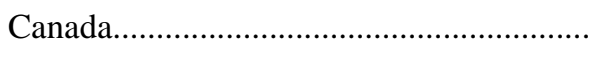 & 7,2 & 2 & 9,2 \\
\hline 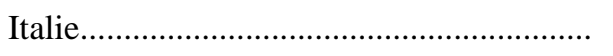 & 2,4 & 6 & 8,4 \\
\hline 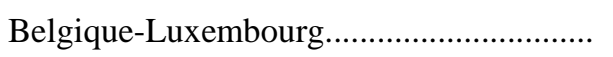 & 1,1 & - & 1,1 \\
\hline \multirow[t]{2}{*}{ 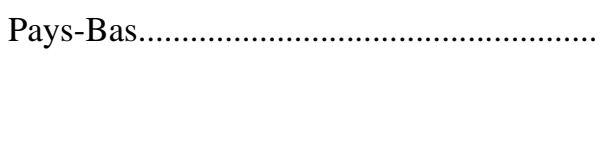 } & 1 & - & 1 \\
\hline & 23,7 & 167,8 & 191,5 \\
\hline
\end{tabular}

L'aide représente à concurrence de 12,5 millions un appui pour la défense attribué en 1963 dans le cadre de l'OTAN par cinq pays (Allemagne, Belgique-Luxembourg, Canada, Italie, Pays-Bas). Une partie des prêts (France : 25 millions, Italie : 6...) représente des avances faites au titre du Consortium d'aide à la Grèce. Ce Consortium — dont il existe un homologue pour la Turquie — a pour but de pallier les difficultés subies par la Grèce du fait de la suppression de l'aide américaine.

Les prêts allemands ont été ouverts pour les objets suivants : aide au budget grec, 50 millions ; centrale thermo-électrique de Mégalopolis 50 (non encore entamé au 31 décembre 1963) ; fabrique d’engrais de l'État, 14,9 (crédits privés) ; raffinerie étatique de pétrole, 10,6 (crédits privés) fabrique de sucre de Larissa, 3,2.

[p. 416] Notre tableau s'arrête à fin décembre 1963. Comme nous l'avons dit, il représente les engagements pris par les États fournisseurs de l'aide et non les utilisations faites par le pays bénéficiaire. Au titre des prêts, une partie n'a pas encore été utilisée et une fraction de celle déjà prélevée a été remboursée. Depuis, certains des pays qui y figurent ont attribué de nouvelles facilités financières à la Grèce mais le total de cette assistance reste néanmoins fort limité.

\section{ASSISTANCE FOURNIE PAR DES INSTITUTIONS INTERNATIONALES}

Cette assistance a été jusqu'au 31 décembre 1963 de l’ordre de 250 millions de dollars dont il faut immédiatement déduire la part non américaine de l'UNRRA, soit 104 millions.

En dehors d'une aide de 3,8 millions de dollars attribuée de 1959 à 1963 par l'organisme des Nations Unies pour les réfugiés et d'une vingtaine de millions de 
crédits ouverts durant la même période dans le cadre de l'OECE — OCDE (dont 16 allant à la Banque de Grèce), la seule opération d'envergure réalisée durant la période a été l'octroi à la Grèce de la possibilité " obtenir des prêts de la Communauté Économique Européenne jusqu'à un montant de 125 millions de dollars. Ce crédit ouvert à l'occasion de l'association de la Grèce au Marché Commun pourra être utilisé au cours des cinq années suivant l'entrée en vigueur de l'accord et conformément aux règles habituelles de la Banque Européenne d'Investissement. Celle-ci a déjà approuvé le financement partiel, soit pour 23 millions de dollars, de quatre projets routiers et d'un projet dans le domaine de l'énergie.

Ici encore nous raisonnons en termes d'engagement des fournisseurs de l'aide et non de dettes en cours du pays bénéficiaire — une large partie du crédit de l'OECE a déjà été remboursée tandis que le crédit du Marché Commun n'avait pas encore été entamé au 31 décembre 1963.

\section{OBSERVATIONS GÉNÉRALES}

Les estimations que l'on vient de présenter établissent sans équivoque que durant la période considérée l'assistance économique à la Grèce est demeurée une affaire entre le gouvernement américain et le gouvernement grec. Réserve faite des interventions allemandes qui démarrent vraiment à compter de 1959-1960, ce tête-àtête n'a été que faiblement [417] altéré par la propension des autres gouvernements à accorder, de temps à autres, une modeste contribution à l'entreprise. L'arrêt de l'aide américaine risque, il est vrai, de modifier sérieusement l'équilibre acquis, le gouvernement allemand semblant aujourd'hui le plus désireux et d'ailleurs aussi le plus capable d'assumer un rôle important.

La masse globale d'assistance apportée par les États Unis est de prime abord impressionnante. Pourtant, sans en contester l'ampleur, il est nécessaire d'apporter à cette observation immédiate de sérieuses nuances. Celles-ci portent principalement sur tout ce qui concerne l'aide en nature spécialement au titre militaire. Vu l'immense quantité de matériel et de fournitures dont regorge l'armée américaine, l'accélération du progrès technique ayant pour résultat de déclasser, éventuellement de manière secondaire ou limitée, des engins en parfait état de marche — ce n'était probablement pas un gros sacrifice que d'équiper une armée de dimensions modestes comme l'est en définitive la force armée grecque. L'aide en monnaie impose certes à celui qui l'attribue des charges plus considérables. Mais dans le cas grec, elle a eu pour les Américains une contre-partie immédiate en facilitant aux autorités grecques le financement du large déficit commercial de leur pays à l'égard des États-Unis. En voici les dimensions pour les trois dernières années connues (en million de drachmes) : 


\begin{tabular}{|c|c|c|c|}
\hline & 1960 & 1961 & 1962 \\
\hline Importations en provenance des États-Unis & $2.844,86$ & $2.431,22$ & $2.016,54$ \\
\hline \multirow[t]{2}{*}{ Exportations à destination des États-Unis } & 818,11 & 970,90 & 575,55 \\
\hline & $2.026,75$ & $1.460,32$ & $1.440,99$ \\
\hline
\end{tabular}

Selon un processus pratiquement classique, l'octroi d'une aide financière, même non strictement liée, facilite le commerce d'exportation de celui qui l'octroie et donc réduit la pression de l'opération sur les réserves de change.

Du point de vue de la Grèce, le jugement à porter sur une telle assistance est certes plus complexe. Du moment où ce pays était dans l'impossibilité d'obtenir réparation des dommages subis - ses agresseurs, par un tour de passe-passe dont l'histoire offre peu d'exemples aussi [p. 418] crus, étant rapidement devenus les alliés de leurs vainqueurs - la solution d'une assistance étrangère était difficilement évitable. Au surplus, compte tenu des options politico-sociales des gouvernants de l'époque, il n'y avait guère d'autre solution que de solliciter une aide massive des États-Unis.

Il est à peine besoin de souligner les risques majeurs d'assujettissement qu'une telle relation portait nécessairement en elle. On imagine sans peine le degré de dépendance d'une armée à l'égard de la puissance alliée qui l'équipe entièrement et exclusivement de son propre matériel : la nécessité d'obtenir par la suite munitions et pièces de rechange allant avec les engins livrés suffirait à lier étroitement la première à la seconde. Encore que moins éclatant, le cas des surplus agricoles ne doit pas être passé sous silence. On connaît l'acharnement avec lequel les Américains s'efforcent d'en assurer le placement. Il est probable que ces livraisons ont restreint la liberté de manœuvre de la politique agricole grecque (obligation de ne pas exporter des produits semblables à ceux qui font l'objet de l'aide).

Mais il y a un risque plus général : celui que le bénéficiaire de l'aide perde toute faculté d'avoir une position de quelque autonomie à l'égard de celui qui la lui attribue. Quand l'assistance prend des dimensions massives, spécialement si elle provient d'une seule source, le pays court le risque que son gouvernement soit en réalité le vassal d'un suzerain étranger. Et en dehors d'un alignement complet du pays assisté sur les positions du pays distributeur dans l'ordre de la politique étrangère, le second tend normalement à demander ou exiger du premier un traitement préférentiel pour ses ressortissants y compris naturellement les groupes d'affaires. Sur cette base, la colonisation économique est potentiellement incluse dans l'assistance financière.

Les inconvénients que nous venons de mentionner seraient probablement réduits par une diversification réelle des sources d'assistance. Mais il est un danger que cette pratique ne suffirait pas à neutraliser : celui que le pays assisté ne s'habitue à vivre audessus de ses possibilités propres. Cette propension est particulièrement redoutable pour les pays qui en sont toujours aux premiers stades du développement. Le plus grand péril est que les couches privilégiées ne profitent de l'aide pour contracter des 
habitudes de consommations supérieures aux disponibilités nationales et sur lesquelles il est par la suite très difficile, sinon pratiquement impossible, de revenir.

[p. 419] Le propre de l'assistance, spécialement sous la forme d'une aide gratuite, est que le pays distributeur se lasse nécessairement un jour de l'octroyer. Et, dès lors, les dirigeants nationaux responsables sont tenus de trouver des solutions de remplacement afin de conserver les rythmes acquis sans toucher pour autant aux habitudes de facilité adoptées. Or il n’y a pas beaucoup de solutions de cet ordre.

La première est de remplacer l'octroi de l'aide gratuite par la souscription d'un emprunt. L'opération procure les mêmes avantages immédiats que la précédente tant pour l'accroissement des moyens monétaires que pour l'augmentation des ressources de change. Mais elle amplifie l'endettement extérieur avec son cortège de conséquences habituelles. La seconde est de charger des capitalistes étrangers d'assurer eux-mêmes l'exploitation des richesses nationales : si l'opération n'accroît pas les moyens monétaires à la disposition du gouvernement, elle le libère de certaines obligations de financement et contribue à l'élargissement du stock national de devises. Mais chacun connaît les défauts d'une telle formule sur lesquels nous reviendrons d'ailleurs un peu plus tard.

Aujourd'hui le gouvernement grec s'adresse, de manière presque frénétique, à toutes les institutions publiques ou privées susceptibles de lui ouvrir les crédits nécessaires au maintien de l'expansion et également à la continuation des habitudes de vie contractées par les couches privilégiées. Chaque prêt consenti, même si les conditions en sont sévères, fait l'objet d'un bulletin de victoire. Pourtant le gouvernement serait bien inspiré, en négociant de telles opérations, de penser à celles qu'il faudra réaliser plus tard pour tenir les engagements pris aujourd'hui. De la même manière, les autorités accueillent désormais de façon large tous les groupes étrangers susceptibles ou désireux d'investir des fonds dans l'industrie nationale. C'est au fond un second aspect du même engrenage mais ses conséquences sont encore plus lourdes pour l'avenir de l'économie nationale.

\section{B. INVESTISSEMENTS DIRECTS}

Retour à la table des matières

Le problème de la participation du capital étranger à l'exploitation directe des ressources nationales se pose en pratique depuis la formation de l'État Grec. Jusqu'à la seconde guerre mondiale, le marché grec est dominé par le capital britannique qui agit notamment par l'intermédiaire de la Banque Nationale de Grèce (rappel de la fondation en 1928 de la [p. 420] Hellenic Corporation Ltd avec la Hambro's Bank et Erlangers). Les principaux secteurs d'application de ce capital sont: l'exploitation minière (avec exportation des produits vers les pays d'Europe Occidentale); les services dits d'utilité publique (transports, distribution d'eau et d'électricité) ; les travaux publics ; les assurances ; la marine commerciale ; l'exportation du tabac (dont les trois quarts se réalisaient par l'intermédiaire de capitalistes étrangers) ... C’est 
l'application à la Grèce du schéma classique d'utilisation des pays pauvres par les pays riches : il en résulte une certaine expansion de la vie économique nationale mais les efforts d'industrialisation proprement dite restent très limités.

Selon des estimations publiées par le Ministère de la Coordination en 1947, le total des capitaux étrangers entrés en Grèce de la fondation du Royaume à 1938 se serait élevé, emprunts publics non compris, à 850 millions de francs or (dont 310 pour la seule période de 1922-1938). Toujours d'après la même source, le montant des capitaux de placement dans ce total aurait été de 610 millions (soit 410 investis dans des affaires et 200 prêtés à des personnes physiques ou morales). Le prélèvement annuel total effectué par le capital étranger (dette publique incluse) sur les ressources du pays aurait atteint en 1938 la somme de 130 millions de francs or.

Bien entendu, ces chiffres qui sont censés couvrir toute l'histoire de la Grèce depuis son érection en État indépendant ne sauraient être acceptés qu'avec diverses réserves : ils montrent toutefois l'importance qu'a revêtue ce problème pour le pays durant les premières phases de formation de l'économie nationale.

Au lendemain de la seconde guerre mondiale, le problème immédiat que doivent affronter les autorités est celui d'assurer la survivance du pays. Il s'agit alors d'obtenir l'appui des États alliés sous forme d'assistance et, non d'aménager l'entrée des capitaux privés étrangers sur la base de la rentabilité. Assez tôt cependant, les autorités helléniques vont se poser la question et créer les instruments juridiques propres à faciliter les investissements directs. Pourtant, il faut attendre la fin de la décennie 1950-1960 pour que le système commence à fonctionner à une certaine échelle : aujourd'hui, l'entrée des capitaux étrangers en Grèce se trouve placée, au centre des programmes de développement économique.

\section{RÉGIME JURIDIQUE}

Les capitaux étrangers que leurs détenteurs investissent en Grèce y bénéficient d'une double série d'avantages : d'une part, de garanties et de privilèges qui leur sont attribués en propre sur la base de la provenance ; d'autre part, des faveurs et facilités consenties aux capitaux d'investissement d'origine nationale. Ayant déjà évoqué la seconde série d'avantages dans le précédent chapitre, c'est uniquement de la première que nous nous occuperons ici.

Voulant assurer aux capitalistes étrangers une protection solennelle, les autorités grecques en ont introduit le principe dans la Constitution de 1952. L'art. 162 de ce texte dispose qu'«une loi unique réglera la protection des capitaux importés de l'étranger pour être investis dans le pays ». Selon l'interprétation officielle, il faut entendre "loi unique » dans le sens de loi qui après avoir été adoptée ne peut plus être modifiée. Autrement dit, après avoir réglé le statut des capitaux étrangers, le législateur n'a plus, constitutionnellement, le droit d'y toucher. Ce dispositif unique a été voté dès 1953: il s'agit du décret-loi 2687 du 31 octobre 1953 sur les investissements et la protection des capitaux étrangers. Sans entrer dans une analyse détaillée de ce texte qui nous intéresse ici principalement sous l'angle des 
investissements directs (participation dans le capital) nous devons en souligner les principaux aspects ${ }^{1}$.

La loi définit comme capital étranger tout capital importé dans le pays sous une forme quelconque (devises, machines et matériels, brevets, procédés techniques, marques commerciales...). Le dispositif prévu est applicable sous la condition qu'il soit placé dans des investissements productifs, c'est-à-dire dans des investissements tendant au développement et au progrès économique du pays (qu'il s'agisse d'une prise de participation dans le capital ou de l'octroi d'un prêt). Dans son art. 13 la loi assimile au capital étranger les navires jaugeant plus de 1500 tonnes qui seront immatriculés sous pavillon hellénique à compter de son entrée en vigueur (disposition qui entraîne de nombreux privilèges pour les armateurs). Enfin le dispositif peut également couvrir certains dépôts en devises effectués de l'étranger dans les banques grecques.

[p. 422] Le capitaliste étranger désireux d'investir dans le pays est tenu d'en soumettre la demande au Ministère de la Coordination Économique qui confie l'examen de cette requête à une commission consultative. En cas d'agrément, l'autorisation est donnée selon l'importance de l'investissement par décret royal ou simple arrêté. De toute manière, l'autorisation une fois fournie est réputée irrévocable quant aux conditions fixées pour l'opération : ces conditions ne sauraient plus dès lors être modifiées qu'avec l'accord du bénéficiaire.

Le décret-loi 2687 couvre en particulier les domaines suivants qui sont d'un intérêt primordial pour les détenteurs de capitaux étrangers :

— rapatriement du capital investi : il est garanti au bout d'une année révolue d'activité dans une limite annuelle de $10 \%$ du montant importé ;

- transfert à l'étranger des bénéfices et intérêts : il est autorisé dans une limite annuelle de $12 \%$ du capital importé pour les bénéfices et de $10 \%$ pour les intérêts ;

- concession de facilités fiscales : le décret-loi pose le principe de l'octroi de faveurs fiscales, ces avantages devant aller de préférence aux activités qui permettent d'économiser d'importants montants de devises étrangères ou contribuent au développement des exportations.

— statut du personnel étranger : les entreprises fondées ou aidées par des capitaux étrangers ont la possibilité dans certaines conditions d'engager pour les hautspostes du personnel non grec qui peut être rémunéré en devises transférables à l'étranger.

Depuis 1953 les autorités grecques ont adopté plusieurs textes qui tendent uniformément à améliorer les conditions faites au capital étranger. Mentionnons en

1 Chacune des deux plus grandes banques commerciales a publié un guide exposant les garanties et avantages offerts au capital étranger : Banque Nationale de Grèce, Investing in Greece, $2^{\mathrm{e}}$ édition, Athènes, 1964 ; Banque Commerciale de Grèce, Investment Guide to Greece, Athènes, 1963 
particulier plusieurs dispositions de la loi 4171 de 1961 qui énonce des mesures propres à stimuler le développement économique du pays. Les entreprises dans lesquelles sont investis des capitaux étrangers pour un montant supérieur à 3 millions de dollars jouissent d'avantages particuliers. Le trait caractéristique de ce texte est d'écarter d'un trait de plume l'application du droit commun dès que celui-ci pourrait être défavorable ou insuffisamment favorable aux intérêts de groupes capitalistes étrangers. Quels ont été les résultats d'une telle mansuétude ?

[p. 423]

\section{AMPLEUR DES OPÉRATIONS EFFECTUÉES}

Depuis l'entrée en vigueur de la loi 2687 jusqu'au 31 décembre 1963, 605 demandes représentant un total de 628 millions de dollars ont été présentées au Ministère de la Coordination. Les autorités grecques en ont approuvé 341 dont le montant total est de l'ordre de 400 millions. Quelques-unes des initiatives autorisées ont été abandonnées par les intéressés mais, selon les informations officielles, la plupart des projets approuvés par les autorités seraient en voie d'exécution. Toutefois les sommes effectivement entrées à ce titre dans le pays ne s'élevaient encore à la fin de 1963 qu'à 110 millions de dollars. Voici la décomposition annuelle des résultats enregistrés (en millions de dollars) au titre du décret-loi 2687 :

\begin{tabular}{|c|c|c|}
\hline & Autorisations d'importation & Montant des entrées effectives \\
\hline $1954 \ldots \ldots \ldots \ldots \ldots \ldots \ldots \ldots \ldots \ldots$ & 1,1 & - \\
\hline 1955................................. & 2,9 & 3 \\
\hline $1956 \ldots \ldots \ldots \ldots \ldots \ldots \ldots \ldots \ldots$ & 19,7 & 1,9 \\
\hline $1957 \ldots \ldots \ldots \ldots \ldots$ & 4,7 & 6,7 \\
\hline 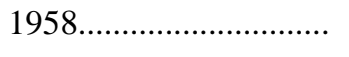 & 6,3 & 8,2 \\
\hline 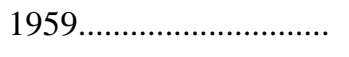 & 21,2 & 8,3 \\
\hline $1960 \ldots \ldots \ldots \ldots \ldots \ldots \ldots \ldots \ldots$ & 74,3 & 11,7 \\
\hline 1961............................... & 30,8 & 13,5 \\
\hline 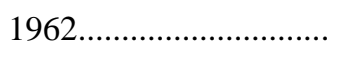 & 185,5 & 16,8 \\
\hline 1963............................ & 52 & 40 \\
\hline Total cumulé & 398,5 & 110,1 \\
\hline
\end{tabular}

Encore qu'en augmentation constante le montant des entrées ne se développe que très lentement. Au titre des autorisations, on doit distinguer deux périodes entre lesquelles la ligne de séparation s'établit approximativement autour de l'année 1960. Durant la première phase, les autorités tendent à appliquer la loi de manière assez restrictive, les refus portant sur près de la moitié des demandes. Il semble que l'un des mobiles de cette réserve ait été de ne pas contracter d'engagements comportant des risques tenus pour excessifs par rapport à la contribution éventuelle de ces projets au développement économique. À partir de 1960, l'attitude devient beaucoup plus 
libérale (peut-être en raison de l'amélioration de la [p. 424] qualité des projets et aussi de la cessation de l'aide américaine) et le pourcentage des refus tombe à $20 \%$. L'objet des négociations porte notamment sur l'étendue des concessions fiscales ainsi que sur l'ampleur des sauvegardes données contre l'apparition des concurrents éventuels. Compte tenu de la place prise dans le total de 400 millions par les très gros projets, on s'aperçoit que les autorisations demandées portent en réalité sur des projets de dimensions relativement modestes (encore qu'assez appréciables à l'échelle industrielle grecque).

Les autorisations d'importation concernent principalement l'industrie de transformation (300 millions de dollars environ). Viennent ensuite l'activité minière avec 40 et le secteur des chantiers navals avec 34. Le tourisme ne compte que pour 12 millions, le surplus, soit une douzaine de millions se répartissant entre diverses branches (entreprises agricoles, pêche en eau profonde...). Disons enfin que depuis le début de 1964, le rythme des demandes et des autorisations ne paraît pas se ralentir le chiffre des autorisations en 1964 devant être notablement relevé par la forte augmentation du contrat Esso-Papas.

La part spécifiquement américaine dans le total à fin 1963 concerne une quarantaine de projets représentant 165 millions d'autorisation, soit 40\% du total et seulement 20 millions soit 18,5\% environ dans les entrées effectives. Sur ces chiffres, le contrat Esso-Papas compte à lui seul respectivement pour 111 et 7 millions : il s'agit d'un grand complexe industriel (seconde raffinerie de pétrole, sidérurgie, matières plastiques...) qui doit être édifié dans la région de Salonique. Parmi les autres projets américains importants, en dehors de la participation de Reynolds Metal au contrat Péchiney citons : une usine d'assemblage de véhicules Chrysler, plusieurs fabriques de produits chimiques (dont une usine de polystylène au Laurion pour le compte de la Dow Chemical Company) et de produits pharmaceutiques, une usine de pâte à papier, une autre de jus de fruits ... Parmi les projets les plus récents (non compris dans le récapitulatif ci-dessus) mentionnons ceux de la firme Ethyl Corporation (affiliée au groupe Dupont de Nemours) tendant à la construction à Salonique, en liaison avec le complexe Papas d'une fabrique de produits chimiques anti-choc d'un coût de 11 millions de dollars de l'American Ciment Co relatif à l'établissement d'une usine de ciment à Patras (en coopération avec les ciments Titan)

Ces projets ne représentent pas la totalité des investissements américains, plusieurs firmes des États-Unis opérant en Grèce hors du cadre de [p. 425] la loi 2.687 - en particulier les organismes distributeurs de pétrole et les organisations de vente de diverses firmes (IBM, Singer sewing machines...). De plus certains travaux publics sont actuellement effectués par des firmes américaines.

Dans une note en date du 24 avril 1964, l'Ambassade des États-Unis soulignait que la Grèce suscite aujourd'hui un assez grand intérêt dans les cercles d'affaires américains, l'un des motifs de cette attitude étant que ce pays, sans oublier ses avantages propres (faible coût du travail, fiscalité raisonnable...) peut ouvrir aux firmes américaines une porte de derrière (back door) utile dans le Marché Commun. 
Notons qu'en novembre 1964 une mission de cinq hommes d'affaires américains sous la direction d'un fonctionnaire d'un Département du Commerce, a visité la Grèce en vue d'un élargissement des relations commerciales et financières de celle-ci avec les États-Unis. Selon des déclarations faites à la presse, la Mission était porteuse de 348 propositions d'affaires.

Il est donc possible qu'au cours des prochaines années le rôle des firmes américaines dans la croissance industrielle de la Grèce aille s'amplifiant. Le même pronostic est valable pour les entreprises de l'Allemagne de l'Ouest et spécialement les grands monopoles dont la place dans l'économie grecque n'a cessé de s'élargir au cours des dernières années. Les Allemands ont toujours joué un grand rôle dans le commerce extérieur de la Grèce et il leur a fallu peu de temps après la guerre pour reconquérir leur position. En 1962, les importations grecques en provenance d'Allemagne se sont élevées à 3.986 millions de drachmes (contre 2.511 pour la Grande-Bretagne et 2.016 pour les États-Unis).

Dans le cadre des garanties fournies par le gouvernement de Bonn, les grands complexes allemands (Krupp, AEG, Glockner, Rheinhausein...) ont joué un rôle considérable dans l'exécution du programme grec de travaux publics. C'est ainsi que Krupp a procédé à l'étude et à la fourniture de toute une série de matériels spécialisés pour la réalisation de certains de ces travaux. Ces opérations ont favorisé et facilité l'élargissement de la pénétration industrielle allemande. Le plus grand effort entrepris à cet égard a été celui de Krupp qui est intéressé à plusieurs exploitations minières. Citons aussi les noms de Siemens pour le matériel téléphonique et d'Osram pour les ampoules électriques (achat de la majorité du capital de l'entreprise grecque d'ampoules AEE Lamptiron). Cependant bien d'autres firmes germaniques se sont également préoccupées de profiter des avantages consentis par le gouvernement grec au [p. 426] capital étranger. Les secteurs concernés sont particulièrement variés : gisements de lignite, matières plastiques, équipements frigorifiques, argenterie inoxydable, bas nylon, établissements touristiques ...

Le dynamisme allemand contraste avec le déclin relatif du capital britannique. Encore que fort dans certains secteurs (celui des services d'utilité publique notamment), celui-ci a perdu un bon nombre de ses positions anciennes. C'est la répétition au titre des affaires du recul relatif subi en matière politique par les Britanniques, les deux mouvements étant évidemment liés.

Le capital français a montré une assez forte activité en Grèce au cours des dernières années. On doit mentionner avant tout le contrat pour l'établissement d'une fabrique d'aluminium passé par le gouvernement grec le 27 août 1960 avec l'entreprise Péchiney et divers partenaires. Nous reviendrons plus loin sur ce projet qui a suscité de très vives critiques et oppositions. Au titre du capital français, mentionnons aussi la part de Saint-Gobain (40\%) dans le capital de la Société pour l'Industrie Chimique de la Grèce du Nord. Signalons également l'intervention de [p. la Société Le Nickel dans l'exploitation du gisement de nickel de Larymna. Comme opération de moindre importance, notons l'accord entre la firme d'optique Les Frères 
Lissac et l'entreprise grecque P. Marinopoulos, accord tendant à assurer à la seconde le bénéfice des procédés techniques de la première.

Plusieurs autres pays ont acquis des positions à une échelle moindre. Au titre du capital italien, la principale opération a été la création de Pirelli Hellas avec pour premier objectif la création à Patras d'une usine de pneumatiques capable de couvrir la totalité des besoins grecs actuels (coût total de l'opération 11 millions de dollars). On a calculé que cette société (dont $90 \%$ du capital est dans les mains de Pirelli International) vaudrait à la balance commerciale une économie annuelle de 5 millions de dollars. On note aussi la venue dans l'économie grecque de quelques trusts internationaux (Unilever, Philips...), de firmes belges, canadiennes, japonaises, suisses, etc. ... Le comportement des hommes d'affaires s'inspirant volontiers de la conduite de Panurge, on peut penser que ce mouvement ira s'intensifiant de lui-même.

On conçoit aisément que la répartition des secteurs d'activité entre les groupes intéressés ne soit pas allée sans susciter des luttes, les hommes d'affaires faisant souvent appel en une telle conjoncture à l'aide de leur gouvernement respectif. Parmi les sujets de discorde, mentionnons le niveau [p. 427] d'exportation de la bauxite, Péchiney ayant obtenu du gouvernement grec, contre le vœu des groupes allemands, que les ventes de ce minerai à l'étranger fassent l'objet d'une limitation annuelle. Signalons aussi une querelle au titre du plomb tetraéthyle entre l'Ethel Corporation et le groupe de la Banque Commerciale. De telles disputes interviennent fréquemment pour l'attribution des travaux publics: on en a vu surgir par exemple entre la Continental Drilling (États-Unis) et des firmes allemandes.

Un point capital pour l'avenir de la Grèce est l'exploration du sous-sol qui jusqu'alors avait été presque totalement négligée. Des efforts ont été entrepris pour renforcer et développer l'Institut grec pour la recherche géologique mais il s'agit là d'une tâche de longue haleine et dès lors le gouvernement a dû s'en remettre presque entièrement à des organismes étrangers du soin d'effectuer les recherches indispensables. Le point est particulièrement clair pour la prospection pétrolière.

Le premier dispositif d'ensemble adopté à cet égard a été la loi 3.948 de 1957 qui couvre la prospection, la recherche et l'exploitation des hydrocarbures liquides et gazeux. Ce texte établit des conditions juridiques très favorables et précise les termes auxquels le gouvernement est prêt à accorder des concessions en cas de découverte. Le premier contrat signé à ce titre (11 décembre 1959) est allé à la Standard Oil Newjersey qui en a confié l'exécution à une filiale grecque Esso Hellenic Inc. Un autre périmètre a été attribué à la firme américaine W. H. Hunt. La British Petroleum qui travaille sur ce point en coopération avec la Banque Nationale (Compagnie Aitolian) a également pris place dans cet ensemble d'organismes parmi lesquels on trouve la Régie Autonome des Pétroles, l’Institut Français du Pétrole, un organisme d'État roumain... Des études ont été entreprises notamment par des experts allemands et français au sujet de la recherche des gisements gazeux. 


\section{DISCUSSION DES CONTRATS SIGNÉS}

Certains de ces contrats signés au temps du gouvernement Caramanlis ont suscité de très vives protestations de la part de l'opposition qui en a déclaré les termes «scandaleux ». Nous nous bornerons à quelques remarques sur les deux opérations les plus contestées: le contrat Esso-Papas (complexe pétrole-sidérurgie-chimie à Salonique) et le contrat Péchiney (fabrique d'aluminium).

[p. 428]

\section{a) Contrat Esso-Papas.}

Le complexe Papas-Esso dans lequel la Standard Oil New-jersey joue un rôle considérable a rendu célèbre en Grèce le nom de son promoteur américain Tom Papas, homme d'affaires de Boston de descendance hellénique. Ce complexe représente un ensemble d'activités techniquement et financièrement intégrées dont le dessein initial, selon le contrat signé en novembre 1962, s'établissait comme suit (chiffres en dollars) :

\begin{tabular}{|c|c|c|c|c|}
\hline Nature du projet & $\begin{array}{c}\text { Total du } \\
\text { projet }\end{array}$ & Société responsable & $\begin{array}{c}\text { Capital } \\
\text { initial des } \\
\text { sociétés }\end{array}$ & $\begin{array}{l}\text { Capital importé } \\
\text { au } 31 \text { déc. } 63\end{array}$ \\
\hline Raffinerie de pétrole... & 24.000 .000 & Thessaloniki Refinery $\mathrm{C}^{\circ}$ & 6.000 .000 & \multirow{5}{*}{7.000 .000} \\
\hline $\begin{array}{l}\text { Fabrique d'Ammonia- } \\
\text { que liquide........................ }\end{array}$ & 12.000 .000 & $\begin{array}{l}\text { Northern Greece } \\
\text { Ammonia C. }\end{array}$ & 3.000 .000 & \\
\hline Fabrique d'acier............. & 49.000 .000 & Hellenic Steel C ${ }^{\circ}$ & 10.250 .000 & \\
\hline $\begin{array}{l}\text { Activités } \\
\text { Pétrochimique............... }\end{array}$ & 25.100 .000 & $\begin{array}{l}\text { Hellenic Petrochemical } \\
\mathrm{C}^{\circ}\end{array}$ & 6.250 .000 & \\
\hline \multirow[t]{2}{*}{$\begin{array}{l}\text { Tâches administratives } \\
\text { communes....................... }\end{array}$} & 1.000 .000 & Esso-Papas Industrial $C^{\circ}$ & & \\
\hline & 111.100 .000 & - & 25.500 .000 & 7.000 .000 \\
\hline
\end{tabular}

Le point de départ du cycle industriel est la raffinerie de Pétrole (la Grèce disposant déjà de celle d'Aspropyrgos). C'est sur la base des produits et sous-produits de cette unité — dont la capacité annuelle avait été à l'origine fixée à 2.500.000 tonnes - que doit fonctionner l'ensemble du complexe. Le contrat signé entre le gouvernement grec et Tom Papas prévoyait et stipulait que, dans les 90 jours de la validation définitive de l'accord, ce groupe importerait pour le déposer à la Banque de Grèce 25 \% du capital des sociétés. Notons au surplus - et c'est là le type même de la démarche impérialiste - que la Standard Oil est parvenue à se faire reconnaître un investissement de 27 millions de dollars sous la forme de la concession de brevets à utiliser par le groupe - investissement qu'elle pourra donc réexporter en devises libres.

Récemment (mai 1964) ce contrat a fait l'objet d'une révision dans un sens extensif. Le total du projet a été porté à 190 millions de dollars. [p. 429] L’objectif de 
cette augmentation est de permettre l'élargissement des activités initialement prévues (ainsi doublement de la capacité de production d'ammoniaque) et d'adjoindre de nouvelles branches au programme du complexe (ainsi production de soude caustique). C'est dans le cadre de cette opération que se situe le projet Ethyl Corporation déjà mentionné. Autre aspect de la révision : la renonciation par Tom Papas à un certain nombre de droits exclusifs de production d'articles pétrochimiques qu'il avait obtenus lors du premier contrat (il en garde 9 sur 29). Disons enfin que le droit pour l'État grec de désigner les fournisseurs de pétrole brut passe de 10 à 15\% des tonnages traités.

Cette révision a été signée par l'Union du Centre qui, étant alors dans l'opposition, s'était vigoureusement opposée au contrat initial. Sans ironiser sur les fluctuations de la politique, notons un point indiscutable: même si le nouveau gouvernement a obtenu un certain perfectionnement des conditions techniques - perspective qui paraît d'ailleurs loin d'être acquise — il a laissé s'accroître un pouvoir monopolistique qui, à l'échelle grecque, était déjà simplement gigantesque.

L'un des principaux arguments avancés à l'appui du projet est que dans sa forme présente, il doit assurer la création directe ou indirecte de 10.000 emplois dans un pays dont, faute de trouver des conditions de travail adéquates, la main-d'œuvre prend le chemin de l'étranger. Cependant, i1 semble bien qu'en contre-partie de cet apport, le gouvernement ait permis au groupe Esso-Papas de s'assurer des avantages excessifs. On peut reprocher en particulier à ce contrat de fixer des prix trop élevés pour les cessions de combustibles ce qui, compte tenu de son association aux pays du Marché Commun, constituera un handicap supplémentaire pour la Grèce. Déjà exploitée par le groupe Socony-Niarchos (infra), l'économie grecque va l'être encore dans des conditions analogues par l'Esso-Standard. Le Cabinet Papandréou a ainsi consacré la domination quasi totale du marché pétrolier grec par les trusts pétroliers internationaux.

Le contrat Esso-Papas a suscité bien d'autres critiques et appréhensions par suite des facilités de tous ordres consentis par le gouvernement aux promoteurs de l'entreprise. Ainsi l'autorisation donnée au groupe d'emprunter sur les marchés étrangers à un taux de $7 \%$ le complément de capital nécessaire à l'exécution du projet : ce recours à l'emprunt comme source de financement permettra à l'entreprise de réduire considérablement le quantum du bénéfice imposable par inscription au débit du [p. 430] compte d'exploitation des sommes nécessaires au service de la dette. L'État grec aurait été mieux placé sous cet angle s'il avait exigé qu’une fraction plus large du projet soit couverte par des capitaux propres.

En définitive, l'opération Esso-Papas — si du moins elle se réalise complètement, ce que certains mettent en doute - doit apporter au pays d'importants éléments de progrès et de modernisation : elle a le tort de créer, aux mains de très puissants intérêts de l'extérieur, un véritable empire industriel dont on peut redouter que les gouvernants grecs ne soient pas en mesure de contrôler l'activité et le mode de fonctionnement. Il est clair que dans l'esprit des gouvernants — ceux de l'ERE mais aussi ceux de l'EK — le caractère spectaculaire et à divers égards sensationnel du 
projet a primé sur d'autres considérations pourtant essentielles — ainsi celle d'obliger le groupe Esso-Papas à mettre en œuvre l'ensemble du projet dans un délai raisonnable (alors que le délai d'option consenti au titre des industries pétrochimiques, délai qui bloque l'octroi de tout autre permis pour les produits en cause, s'élève à 9 ans).

\section{b) Contrat Péchiney-Niarchos.}

Voyons maintenant le contrat relatif à l'aluminium qui a été le premier des grands investissements industriels réalisés par le capital étranger. La Grèce dispose de larges réserves de bauxite dont l'extraction annuelle lors de la signature du contrat était de l'ordre de 850.000 tonnes (85\% de cette production étant vendu à l'Allemagne de l'Ouest et à l'URSS). Jusqu'alors la Grèce n'avait pu obtenir que les grands trusts étrangers s'intéressent à la création sur son sol d'une industrie de l'aluminium. Le contrat signé le 27 août 1960 traduit un changement de conduite des monopoles à l'égard de ce souhait. Il prévoit la construction d'une usine ayant une capacité minimale de 100.000 tonnes d'alumine et 52.500 d'aluminium. Selon les estimations initiales, le coût du projet devait s'élever à 75.000 .000 de dollars (55 pour les bâtiments et l'équipement, 20 au titre du fonds de roulement). En dehors de l'avantage proprement industriel du projet, le gouvernement attendait, du seul fait des sommes nécessaires à la mise en œuvre, une entrée de devises de 62.000.000 de dollars.

En vue d'assurer l'exécution de ce projet, une Société anonyme a été constituée à Athènes au capital de 25 millions ainsi réparti : Péchiney et Compader (Compagnie pour l'étude et le développement des échanges commerciaux) : 50\% ; S. Niarchos : 21\% ; Reynolds International Inc. : [p. 431] 17\% ; Organisation de développement industriel : 12\%. Il semble que Niarchos, dont on a déjà souligné les liens étroits avec Caramanlis et le Palais, ait joué un rôle considérable dans la négociation du contrat. La part qui lui est attribuée à titre personnel dans cette entreprise illustre bien en tout cas la puissance politico-financière dont il dispose. Finalement la capacité annuelle de l'usine a été fixée à 200.000 tonnes d'alumine et 62.000 tonnes d'aluminium.

À l'échelle de la Grèce, cet investissement, nous le verrons mieux plus loin, représente également une entreprise de grandeur exceptionnelle. Le gouvernement signataire du contrat l'a présenté comme le facteur d'impulsion de toute une série d'activités ayant pour objet, soit de fabriquer les articles nécessaires à l'industrie de l'aluminium, soit d'en utiliser les produits. Mais l'opposition ne s'est pas laissée convaincre : elle a présenté une critique très sévère du projet. À la suite de la défaite électorale de L'ERE, le gouvernement du Centre a prescrit une enquête et les positions qu'il a prises à l'issue de celle-ci provoquent actuellement des difficultés dans le fonctionnement du contrat.

L'essentiel de la controverse porte sur les conditions dans lesquelles doit être fournie l'électricité dont on sait que l'industrie de l'aluminium est grosse consommatrice (la part de l'énergie dans le coût du produit final étant de 20\%). Le gouvernement grec s'est engagé à vendre le courant nécessaire au prix de 0,10 
drachmes le kilowatt-heure — celui-ci étant facturé 0,90 drachmes aux entreprises industrielles ordinaires et 0,45 à l'entreprise Power qui avant sa nationalisation distribuait l'électricité dans le Grand Athènes. La Power qui disposait de sa propre production était obligée d'acheter en plus des quantités croissantes de courant par suite de l'expansion démesurée de l’agglomération athénienne.

La production nationale étant insuffisante pour faire face aux besoins de l'usine d'aluminium, il fallait que l'établissement de celle-ci s'accompagnât de la construction de nouveaux barrages. Ces barrages, le gouvernement de L'ERE a accepté qu'ils soient édifiés aux frais de la collectivité. Or le prix fixé pour la livraison du courant ne tient pas suffisamment compte des dépenses supportées à ce titre. Il doit donc en résulter une perte pour l'Entreprise publique sans que le Parlement, lors de la discussion du contrat, ait été mis au courant de cette particularité par le Cabinet Caramanlis. Selon le rapport qui vient d'être présenté au Ministère de la Coordination, la perte susceptible de frapper l'Entreprise publique d'Électricité pendant toute la durée du contrat, soit 50 ans, se [p. 432] situe entre 100 et 300 millions de drachmes par an (soit 3,3 à 10 millions de dollars). Le rapport met ouvertement en cause la responsabilité du Directeur Général de l'Entreprise d'Électricité lors de la discussion et de la signature du contrat.

Un point aggrave la situation: la sous-estimation initiale, malgré les avis de l'opposition, des quantités nécessaires à l'usine. Alors que l'on prévoyait 800 millions de kW-heure par an, c'est avec un milliard au moins qu'il faut compter aujourd'hui. Pour apprécier la portée de ce chiffre, il faut savoir qu'il représente environ le tiers de la capacité de production dont disposait à la fin de 1963 l'Entreprise Publique d'Électricité. Le gouvernement Papandréou réclame aujourd'hui un ajustement du tarif de cession du courant électrique mais l'entreprise manifeste la ferme intention d'en rester au contrat signé.

Cette affaire illustre parfaitement le genre d'avantages que les monopoles parviennent à obtenir des gouvernements vis-à-vis desquels ils se trouvent en position de force. Il est possible que des techniciens américains, pas nécessairement désintéressés, aient joué un rôle dans la critique technique du contrat mais, si on les compare aux exigences manifestées par d'autres États au titre d'opération de la même branche, les conditions faites par l'équipe Caramanlis à la Société de l'Aluminium semblent beaucoup trop libérales.

Un autre aspect de l'opération illustre le désavantage subi par la collectivité : la disproportion entre les sommes dépensées par l'État pour la construction des barrages soit au minimum 125 millions de dollars et les décaissements effectués par les groupes privés pour l'édification de l'usine soit au très grand maximum une cinquantaine de millions. Or l'État ne dispose dans le capital que de la seule part souscrite par l'Organisation de Développement Industriel, soit 12\%. Sous cet angle non plus le marché n'est pas équitable pour la puissance publique qui en définitive a fourni le plus gros de l'effort nécessaire à la réalisation du projet et n'obtiendra qu'une bien faible part des profits distribués par l'entreprise. 
La fraction des produits de l'usine cédée à l'extérieur sera distribuée par le réseau Péchiney-Reynolds. On peut envisager qu'à l'aide de subtiles manipulations comptables, dans l'emploi desquelles les monopoles sont passés maîtres, le groupe industriel qui détient la majorité absolue du capital n’arrive à minimiser le bénéfice réalisé en Grèce - ce qui, en réduisant les dividendes touchés par l'État, aurait également pour effet [p. 433] de restreindre la base d'imposition fiscale. La puissance publique perdrait ainsi sur tous les tableaux.

Admettons que le gouvernement grec ait témoigné de plus de fermeté et obtenu de meilleures conditions. Le projet n'en reste pas moins discutable dans une autre perspective essentielle : celle de son opportunité même. L'un des impératifs les plus urgents de l'économie grecque est la création d'emplois productifs : or le nombre maximum de postes de travail que procurera l'usine est de l'ordre de 3 à 4.000. Pour obtenir ce résultat, l'État doit affecter à un seul projet la totalité de la capacité nouvelle d'énergie hydraulique créée durant ces dernières années avec le coût que l'on sait. Autrement dit, l'Entreprise Publique d'Électricité ne pourra accroître ses fournitures au reste de l'économie nationale qu'au prix d'une nouvelle extension de cette capacité (ce qui implique d'autres charges et ne peut intervenir qu'au bout d'un certain délai).

Dans la mesure où l’État était appelé à financer les barrages nécessaires au fonctionnement de l'usine d'aluminium, il pouvait être plus avantageux pour l'économie nationale d'affecter ces ressources — ou même le courant produit par les barrages si de toute manière on les avait édifiés — à l'exécution d'autres projets. La réalisation de tels choix n'a de sens que dans le cadre d'un plan global de mise en valeur des ressources nationales. Or, un tel plan n'existait pas. Notons même que le projet de créer une large industrie de l'aluminium ne figurait pas dans le catalogue indicatif présenté comme un premier plan par l'Administration Caramanlis. Cette observation suggère que l'un des traits fondamentaux de l'industrialisation réalisée par appel au capital étranger est de faire dépendre la structure industrielle du pays non d'un système cohérent de priorités établi par référence à l'avantage collectif mais des calculs et manœuvres du capital monopoliste à la recherche du profit maximal.

\section{CAPITAL ÉTRANGER ET AVANTAGE NATIONAL}

Dans les discours dont ils ne sont pas avares, les dirigeants gouvernementaux, hier ceux de l'ERE et aujourd'hui ceux de l'EK, déclarent volontiers que la Grèce se trouve à la veille d'une révolution industrielle, une révolution dont les structures économiques et sociales du pays sortiront entièrement modifiées. Ces déclarations surestiment sans nul doute la portée des modestes transformations en cours de réalisation. Mais surtout elles oublient de préciser le genre d'industrialisation qui est en [p. 434] train de s'accomplir : elles omettent en particulier d'indiquer les centres de décision d'où part l'impulsion industrielle et les modalités selon lesquelles s'effectuera le partage des résultats. 
Voyons d'abord la place relative des opérations de la loi 2687 dans l'ensemble de la structure industrielle du pays. À première vue, le chiffre total des autorisations données au 31 décembre 1963, soit 400 millions, ne semble pas très considérable et il est vrai que plusieurs commentateurs estiment que le dispositif créé en 1953 pour stimuler la venue des capitaux étrangers n'a atteint que très imparfaitement son but. La perspective se modifie toutefois si l'on prend en considération la faiblesse de l'implantation industrielle nationale.

Cette faiblesse a été mise en évidence au lendemain de la signature du contrat Esso-Papas par le Ministre de la coordination d'alors Papaligouras. Selon lui — mais ces chiffres, vu la faiblesse de la comptabilité nationale grecque, appellent bien des réserves - le total du capital investi à cette date dans l'industrie s'élevait à 623 millions de dollars, la position nette des 447 premières firmes nationales s'établissant autour de 220 millions. On voit donc que le contrat Esso-Papas, tel que prévu à l'origine, représentait à lui seul la moitié du capital des 447 plus grandes entreprises de la Grèce tandis qu'aujourd'hui, avec 190 millions, il tend à se rapprocher du chiffre même de ce capital. Comparé aux moyens investis dans ces 447 affaires, le total des autorisations accordées à fin décembre 1963 - total qui ne cesse d'augmenter — prend évidemment une plus grande portée que si on l'examine isolément.

On ne connaît pas la proportion dans laquelle les autorisations données seront effectivement employées. De même, il n'est pas possible de savoir jusqu'à quel point les efforts du gouvernement pour attirer le capital étranger dans le pays seront couronnés de succès. Le fait est que le gouvernement souhaite amplifier l'entrée de ce capital et s'emploie, de son mieux, à l'encourager. Il est donc nécessaire d'examiner les conséquences socio-politiques d'une industrialisation réalisée selon ce schéma. Voici celles qui, sous l’angle de notre étude, présentent la plus grande importance.

\section{a) Prise de possession de l'appareil industriel.}

La conséquence immédiate de l'opération est de valoir à des groupes d'affaires étrangers une part, de dimensions variables selon les secteurs, [p. 435] dans la propriété ou la gestion de l'appareil industriel national. Cette introduction du capital étranger s'établit par la constitution de nouvelles firmes mais aussi par des prises de participation dans les affaires existantes, les capitalistes étrangers s'intéressant de préférence aux meilleures de celles-ci.

Cette situation affecte normalement le secteur privé, mais il arrive également qu'on la rencontre dans le secteur public économique. C'est ainsi que la première raffinerie de pétrole qui est de propriété étatique a été louée en 1958 pour une période de dix ans à la Compagnie hellénique de raffinage de pétrole dans laquelle se rencontrent Niarchos, la Banque Nationale de Grèce et la Socony Mobil Oil (la Compagnie américaine Hydrocarbon Research tient un rôle important dans la gestion de la raffinerie).

La Socony est ainsi parvenue à prendre le contrôle du marché grec qui lui avait été refusé en 1951 par les hommes politiques du Centre. Sous la pression des critiques de 
l'opposition, le gouvernement Caramanlis a toutefois réservé pour l'État grec le droit de désigner les fournisseurs du pétrole à concurrence de $30 \%$ du tonnage traité. Cette disposition permet d'acheter à l'Union Soviétique certaines quantités de pétrole dont la Grèce acquitte le prix par la fourniture de produits agricoles. Mais la plus large partie du pétrole utilisé dans le pays est fournie par le trust américain et doit être payée en devises libres. À la ponction ainsi opérée sur les ressources de change nationales s'ajoute un autre désavantage : le fait que les prix imposés à la Grèce par le trust pétrolier (prix dits LOP $=$ Lowest posted prices) sont de beaucoup supérieurs aux prix soviétiques.

Autre bénéficiaire de l'opération : l'armateur S. Niarchos qui s'est assuré de la sorte le monopole du transport du pétrole en Grèce et pratique des tarifs sensiblement plus élevés que les taux courants.

Le résultat de ces manœuvres - aggravées par la propension de l'État à taxer lourdement la production pétrolière - est que l'industrie grecque paie plus cher son combustible qu'avant la mise en service de la raffinerie étatique. Selon les dirigeants des deux plus grandes cimenteries du pays, il en découlerait une surcharge de un dollar par tonne de ciment - cette surcharge compromettant l'exportation de ce produit sur les marchés du Moyen-Orient. Signalons toutefois que le gouvernement Papandréou vient de procéder à une réduction assez substantielle du prix des produits lourds livrés par la Raffinerie.

[p. 436] La compagnie de gestion, il est vrai, tire de substantiels profits de son activité. En vue d'éviter toute imposition à ce titre, l'armateur Niarchos a mis sa participation au compte de ses Chantiers Navals qui sont déficitaires parce qu'ils réparent les navires de la flotte de leur propriétaire à des taux très bas. Il s'agit là de l'un de ces jeux d'écriture - transfert accompli avec l'accord du gouvernement Caramanlis - par lesquels les grands capitalistes parviennent à se défaire de l'obligation fiscale.

L'État grec, nous l'avons vu, fait une place importante à des conseillers étrangers, notamment dans l'ordre de la recherche géologique. Au titre de l'étude des problèmes énergétiques, il a confié plusieurs études à la firme américaine Nappen ainsi qu'à l'Ebasco qui est une filiale de la Banque Morgan, (situation qui selon certains expliquerait la dureté des attaques contre l'opération Péchiney dans laquelle les intérêts américains sont minoritaires). L'Entreprise Publique d'Électricité a été organisée avec le concours de techniciens américains qui ont ainsi pris une part dans les choix énergétiques dont l'importance capitale pour le destin du pays n'a pas besoin d'être soulignée.

$\mathrm{Au}$ niveau du secteur privé le capital étranger a de nombreuses façons de s'introduire dans les secteurs qui l'intéressent : citons notamment l'octroi d'un prêt que l'on transforme par la suite en une participation au capital (éventualité qui a des chances de se produire si l'entreprise éprouve des difficultés de remboursement). Dans certains cas, l'opération ne coûte plus grand chose au capital étranger : ainsi, concession de l'usage de brevets ou octroi d'une assistance technique L'obligation pour un pays pauvre d'acquitter des redevances au titre d'éléments incorporels — qui, 
en bien des cas, ont déjà rapporté des fortunes à leurs propriétaires — illustre à merveille le caractère parasitaire du système capitaliste. L'exploitation est à son comble quand le groupe étranger arrive à se faire octroyer une part dans le capital sur la base de tels apports (supra contrat Esso-Papas).

\section{b) Obstacles à la planification économique.}

L’industrialisation par le capital étranger a le tort de placer le développement économique du pays sous la dépendance de centres de décision dont le comportement échappe totalement au contrôle des autorités gouvernementales. Qu'il s'agisse de la décision initiale d'investir ou de la série successive de décisions qui déterminent le niveau et la [p. 437] nature de l'activité exercée, toutes ces déterminations sont prises de l'extérieur ou inspirées par les groupes extérieurs. Les critères utilisés à cet effet expriment en premier lieu les intérêts du groupe étranger dans son ensemble et, s'ils coïncident avec l'intérêt national, c'est simplement par chance et non par vocation.

On dira peut-être que le gouvernement du pays a la possibilité d'influer sur le comportement des investisseurs étrangers, en premier lieu par l'établissement d'un plan systématique de développement et par le refus de tous les projets qui ne s'insèrent pas dans le dessein global. Encore faudrait-il, pour que cette éventualité soit réalisable, que le gouvernement soit politiquement autonome à l'égard des pays intéressés et qu'il n'éprouve pas de difficultés à équilibrer la balance des paiements. De plus, tout dépend de la taille du groupe étranger en cause : et l'on peut certes s'interroger sur la marge de manœuvre à la disposition d'un petit pays en proie à des difficultés financières vis-à-vis de firmes monopolistes qui, telle la Standard Oil N.J., ont un chiffre d'affaires plusieurs fois supérieur au total de ses propres encaissements.

Pour ces grands monopoles, l'installation dans le petit pays est simplement un élément d'une stratégie d'ensemble conçu à l'échelle internationale et parfois planétaire. Aujourd'hui, les monopoles américains entreprennent systématiquement la conquête de l'espace économique du Marché Commun: dans cette perspective, l'implantation en Grèce peut leur sembler un procédé utile pour parfaire et consolider cette pénétration. Mais les circonstances peuvent changer et altérer les stratégies des monopoles. Et, de toute manière, ce n'est probablement pas la meilleure façon d'industrialiser la Grèce que de placer cette croissance sous la dépendance d'un tel mobile.

En définitive, il est contradictoire de se réclamer de la planification, si du moins l'on donne au terme un contenu authentique, et de miser sur l'arrivée massive du capital étranger. Sans proscrire nécessairement ou intégralement le recours au capital extérieur, la réalisation d'une véritable planification exige que ce recours soit exercé de manière strictement sélective (ainsi limitation de son implantation à des branches déterminées et à des régions définies préalablement à l'octroi de toute autorisation). Il faudrait également interdire que le capital étranger puisse détenir la majorité dans une entreprise reposant sur l'exploitation des ressources naturelles du pays - la collectivité étant fondée à exiger le traditionnel 51\% en échange du droit d'effectuer cette exploitation. 
[p. 438] Ce sont là les principaux instruments disponibles - ce qui ne veut pas dire que dans l'état du rapport des forces ils soient effectivement applicables — pour tenter d'empêcher que le déroulement de la vie économique nationale ne soit placé sous le contrôle de stratégies extérieures.

\section{c) Entraves au progrès social.}

L'appel systématique au capital étranger paraît difficilement compatible avec la volonté de promouvoir le progrès social. Cette volonté, le gouvernement grec d'aujourd'hui ne cesse de la proclamer. Or, elle implique la suppression des défauts qui constituent justement l'un des facteurs essentiels de l'attrait que les étrangers éprouvent pour la Grèce et sur lesquels le gouvernement lui-même insiste dans sa propagande auprès des milieux étrangers.

Cette contradiction est manifeste en termes de condition ouvrière. Les autorités admettent la nécessité de l'améliorer ne serait-ce que pour conserver les travailleurs qualifiés dans le pays mais, en même temps, il est clair que le bon marché de la maind'œuvre constitue un motif de préférence pour l'investissement en Grèce. Il en va de même de la présence à la tête des organes centraux du syndicalisme d'hommes dévoués aux intérêts du capital : elle est fâcheuse pour la qualité du mouvement syndical mais précieuse pour les investisseurs étrangers. Soit encore le régime fiscal qui se caractérise par un manque absolu d'équité : il serait certes désirable d'exiger une contribution plus importante des couches riches ou aisées du pays. Mais l'expérience établit qu'un tel projet est difficile à réaliser si, au même moment, les autorités créent une sorte de paradis fiscal pour les intérêts étrangers ou considérés comme tels (cas des navires placés sous pavillon grec).

Sans doute les monopoles ont-ils d'autres raisons de s'installer dans un pays ainsi présence d'un grand marché de consommation ou existence d'un niveau technologique très élevé (Allemagne, Grande-Bretagne...) — que le bon marché de la main-d'œuvre ou le caractère favorable du régime fiscal. Mais, en l'état actuel des choses, ce sont des considérations de cet ordre que la Grèce peut avancer pour susciter la venue de capitaux étrangers. Il y a d'autres facteurs certes (ainsi valeur de la position géographique de la Grèce à l'égard des marchés du Moyen-Orient) mais en une large mesure c'est par les défauts relevés dans ses structures et pratiques sociales que ce pays constitue un pôle d'attraction [p. 439] pour les capitalistes étrangers. Et, dès lors, tout effort important pour réduire ces imperfections risque de diminuer cet attrait.

En d'autres termes, le souci de promouvoir le progrès social sous toutes ses formes n'est pas pleinement compatible avec l'appel massif au capital étranger. Sans doute la pratique est-elle moins schématique et moins rigide que la formulation abstraite. Cependant au niveau même des comportements concrets cette contradiction, quoique susceptible d'atténuations, reste un trait de la situation. 


\section{d) Prélèvement sur les ressources nationales.}

Un facteur risque d'ailleurs d'aggraver la situation : l'ampleur des prélèvements que les capitalistes étrangers ont l'habitude de prélever sur les ressources nationales au titre des services rendus et des risques assumés. Les gouvernements essaient de se défendre contre une telle propension en stipulant des taux maxima au titre du transfert des profits vers l'étranger. Ces mesures, qui ont une certaine valeur à l'égard des petites et moyennes entreprises, sont dépourvues de portée à l'égard du capital monopoliste qui, par le jeu des relations financières et commerciales qu'il entretient avec le reste du monde, a la faculté de déplacer le centre géographique de réalisation du profit et, par là, de frustrer l'économie nationale d'une partie des bénéfices lui revenant.

Le gouvernement grec est très favorable aux firmes étrangères qui s'engagent à exporter une large part de la production réalisée dans le, pays. Mais s'il lui est possible de contrôler les quantités exportées, il n'est pas en son pouvoir de déterminer ou simplement de surveiller de près le prix auquel s'effectue l'opération. Pour une entreprise à ramifications internationales, il est facile de sortir le produit du pays à un prix inférieur au prix de vente final et de récupérer la différence à l'étranger en l'un des points quelconques du réseau de distribution. N'oublions pas que l'interpénétration des monopoles offre à cet égard des possibilités de manœuvre discrète que les profanes ignorent et que les services gouvernementaux du pays où s'effectue la production ne soupçonnent pas toujours. À la charge que fait peser le rapatriement des profits au taux officiel admis par les autorités peut se substituer ou s'ajouter le danger qu'une partie plus ou moins large du bénéfice réalisé soit exportée de manière entièrement invisible. Dans l'ensemble, le risque est plus grand au titre des produits bruts ou semi-bruts qu'à celui des articles destinés à la consommation finale.

[p. 440]

\section{e) Stagnation du secteur ancien.}

L'industrialisation du pays par recours massif au capital extérieur risque de provoquer la séparation de l'appareil industriel en deux ensembles de qualité différente et même peut-on dire d'âge technologique différent. D'un côté, le secteur auquel s'intéresse d'une manière ou d'une autre le capital étranger et qui sera moderne, bien organisé, efficace ; de l'autre, un secteur arriéré, peu productif, incapable d'aller de l'avant. Au sommet de la hiérarchie les complexes Esso-Papas ou PéchineyReynolds, au bas de celle-ci une poussière de fabriques de dimensions minuscules à équipement primitif et gestion rudimentaire.

À première vue, la raison de cette discordance paraît être l'ampleur des moyens dont dispose le capital étranger. Mais un second facteur risque de l'aggraver: l'obligation où se trouvent souvent les autorités de consacrer une large part de leurs ressources à la création de l'infrastructure nécessaire aux activités des grandes entreprises étrangères. Et, dès lors, il leur est impossible d'aider, en même temps, le secteur en retard à se moderniser. Les appuis que dans ces conditions l'État peut 
donner à celui-ci sont, en grande partie, de portée négative (ainsi niveau très élevé de protection douanière) : or les concours de cette sorte sont susceptibles de prolonger et d'aggraver le mal qu'il s'agirait de guérir.

Dans la mesure où les branches occupées par le secteur traditionnel ne comptent pas parmi celles qui intéressent au premier chef les capitalistes étrangers, on peut aisément concevoir que la présence du secteur moderne ne porte pas atteinte ou ne porte que modérément atteinte au secteur ancien. Cette remarque a une portée spécialement grande dans le cas où le capital s'installe dans le pays en vue de conquérir plus facilement des marchés de l'étranger. Dès lors il est possible qu'en bien des cas l'association au Marché Commun constitue pour les firmes du secteur ancien soumises à la concurrence internationale un danger plus grand que la constitution d'un secteur moderne dans le pays même.

\section{f) Pouvoir corrupteur du capital étranger.}

Nous voudrions souligner enfin, sur la base de l'expérience universelle, le pouvoir corrupteur du capital étranger et spécialement du capital monopoliste. Deux séries de démarches habituelles du capitalisme étranger méritent à cet égard d'être signalées.

[p. 441] La première est l'utilisation de l'argent pour obtenir des autorités responsables l'octroi et le maintien des privilèges sollicités. Le procédé est également employé quand il s'agit d'obtenir de ces autorités, en cours d'exécution du contrat, qu'elles acquiescent à des pratiques contestables ou ferment les yeux sur des entorses aux engagements pris. Pour les capitalistes étrangers de tels débours qui, selon les cas, s'effectuent sous une forme plus ou moins subtile, ne représentent qu'un élément du compte d'exploitation. Dans les pays pauvres, cette propension à l'achat des consciences contribue à accentuer la dégradation des mœurs politico-administratives.

Au surplus, dans la mesure où l'opinion tend nécessairement à grossir ces phénomènes, il en résulte une accentuation du discrédit naturel qui frappe les politiciens. Même si toutes les rumeurs qui ont circulé à propos de la signature des plus gros contrats n'étaient pas fondées, on ne saurait dire qu'elles n'ont pas eu de résultats fâcheux quant au jugement porté par les citoyens sur la valeur civique de l'appareil gouvernemental (Couronne comprise).

Ce pouvoir corrupteur s'exerce d'une seconde manière qui est de lier la fortune et la position d'un certain nombre d'hommes d'affaires du pays aux entreprises du capital étranger. Chacun sait en Grèce qu'un certain nombre de banquiers et d'industriels sont strictement au service de groupes étrangers dont ils attendent un élargissement de leur situation et une augmentation de leurs bénéfices. On peut légitimement douter qu'en cas de conflit entre l'intérêt de ces groupes et celui du pays - l'activité des monopoles étrangers suscitant continuellement de tels conflits - ces hommes se prononcent et agissent en faveur de l'intérêt national.

L'établissement de ces liaisons a une importance considérable pour la vie du pays dans la mesure où les hommes d'affaires nationaux en relation ou au service du capital étranger tendent presque nécessairement à se faire les partisans et les avocats 
des États dont relève ce capital. Ainsi deviennent-ils des membres actifs de clans étrangers qui s'efforcent d'orienter la politique du pays dans le sens souhaité par les puissances protectrices. Le clan britannique, jadis si fort, attirait les banquiers, commerçants ou armateurs en rapports étroits avec la Cité de Londres. Aujourd'hui le clan américain s'enrichit de tous ceux auxquels la pénétration américaine en Grèce procure des bénéfices ou vaut un accroissement du champ d'action de leurs affaires. Et il est à peine besoin de dire que ces hom-[p. 442] mes trouvent parfaitement légitime la propension des autorités américaines à traiter la Grèce comme un pays vassal.

Ces deux aspects du pouvoir corrupteur du capitalisme étranger sont également graves mais, à tout prendre, le second est plus redoutable que le premier car il met en cause l'aptitude même de la classe dirigeante à mener une politique conforme à l'intérêt du pays tout entier.

\section{CAPITAL ÉTRANGER ET SERVICES D'UTILITÉ PUBLIQUE}

\section{$\underline{\text { Retour à la table des matières }}$}

Ces services constituaient avant la seconde guerre mondiale l'un des secteurs de prédilection du capital étranger, spécialement du capital britannique. Encore que le début d'industrialisation du pays ait un peu réduit l'importance relative de ces branches, leur exploitation, qui s'effectue normalement par concession des autorités publiques, assure des positions solides aux firmes bénéficiaires des contrats et leur vaut de substantiels avantages.

Examinons d'abord le cas des quatre entreprises d'utilité publique contrôlées par la Société britannique Power (qui s'est installée en Grèce dès 1926). Il s'agit des deux sociétés HEAP (production et distribution d'électricité dans la région athénienne), de la société HEM (transports urbains - trolleybus d'Athènes) et de la société EHS (Chemin de fer électrique Le Pirée-Athènes-Kifissia et trolleybus du Pirée).

Dans le cadre de sa politique de rachat de toute entreprise privée de production et de distribution de courant électrique, l'Entreprise Publique d'Électricité a décidé en 1961 de reprendre le groupe HEAP qui disposait de deux centrales thermiques (l'une au Phalère et l'autre au Pirée). Bien que le capital engagé ait déjà été plusieurs fois amorti, la société Power s'est montrée intransigeante quant aux conditions de 1'opération. Non seulement elle a demandé une indemnisation élevée mais, de plus, elle a exigé que le montant de celle-ci soit acquitté en devises libres. À la suite de négociations menées pour le compte de la Power par un avocat qui est ordinairement le conseiller juridique du Palais, la société britannique a obtenu pleine satisfaction. Ce n'est qu'après la conclusion de l'accord que l'on a su que l'entreprise devait au fisc plus de 350 millions de drachmes d'impôts arriérés et que, dès lors, l’État grec aurait pu légitimement la mettre en faillite. 
Durant la même période, la société HEM a obtenu un prêt d'État de [p. 443] 70 millions de drachmes pour le renouvellement de son matériel roulant. Elle a reçu également d'autres avantages tels que l'exploitation monopolistique de nouvelle lignes de transports urbains, l'exemption de la taxe de 2 drachmes par trajet de véhicule qui était destinée à alimenter le fonds de retraite du personnel et la réduction de moitié du taux de la cotisation patronale à la sécurité sociale. Ajoutons que les autorités se montrent en général compréhensives à l'égard des hausses de tarif pratiquées par la société.

Parmi les autres entreprises d'utilité publique sous contrôle étranger, nous signalerons le cas de la société des eaux (OULEN) dont le capital initial de l'ordre de 2,5 millions de drachmes égale à peine le traitement annuellement versé à son Directeur général américain Charles Booth (qui est un général de réserve dans l'armée des États-Unis). Plusieurs des étrangers qui figurent dans le conseil d'administration de l'entreprise (parmi lesquels le général américain Van Fleet qui organisa l'armée grecque durant la guerre civile) touchent aussi des rémunérations substantielles.

La société s'occupe uniquement de la distribution de l'eau et laisse à l'État grec le soin de construire les aqueducs et barrages nécessaires. Les autorités pourvoient à ces dépenses par une taxe spéciale de 30 \% du revenu de tous les immeubles du Grand Athènes. L'OULEN réalise des profits importants en facturant ses services aux usagers à des taux fort élevés (notamment au titre de l'installation et de la location des compteurs). Jusqu'à maintenant, elle est parvenue à écarter toute opération de rachat et de constitution d'un service municipal des eaux.

La présence de telles sociétés dans l'économie grecque constitue sans nul doute un véritable anachronisme dont la persistance illustre la faiblesse de la marge de manœuvre du gouvernement vis-à-vis du capital étranger.

\section{LA ROUTE DE LA SERVITUDE}

\section{$\underline{\text { Retour à la table des matières }}$}

Une phrase du dernier rapport de l'OCDE sur la Grèce éclaire parfaitement la situation « ... la poursuite et l'accentuation de l'expansion et le maintien de l'équilibre financier du pays, paraissent désormais intimement liés aux mouvements des capitaux étrangers, publics et privés ${ }^{1}$. [p. 444] Or il n'est pas difficile, sur la base des études faites en cette section, de mettre en évidence les facteurs de la situation.

Le point de départ en est l'assistance fournie par les États-Unis à la Grèce de 1947 à 1962. Dans la mesure où elle a été consacrée au financement d'investissements publics, cette aide a permis de réaliser des travaux utiles au pays. Mais elle a aussi

\footnotetext{
Rapport 1964, p. 34.
} 
rendu possible à la Grèce de vivre au-dessus de ses moyens actuels. En même temps elle a facilité la prise d'habitudes de consommation par les classes aisées qui ne correspondent pas aux possibilités réelles de l'économie grecque livrée à ses seules ressources (ainsi accroissement rapide du parc d'automobiles de tourisme). Par ailleurs, sous l'angle de la balance des paiements, cette aide en dollars a permis à la Grèce d'adopter un jeu relativement libéral en matière d'échanges internationaux.

L'aide ayant cessé et les gouvernants repoussant ouvertement l'éventualité de l'austérité, il n'y avait d'autre solution que de procurer à l'économie par d'autres procédés les moyens qui venaient ainsi à lui faire défaut. L'entrée des capitaux étrangers au titre des investissements directs ou des prêts aux entreprises privées est l'un de ces procédés sur lequel nous venons de donner de longues explications. Le second est le recours à l'emprunt par l'État et les entreprises publiques : nous en avons dit quelques mots chemin faisant, mais il faut en donner maintenant une vue plus précise ${ }^{1}$.

Avant d'entrer dans le vif du sujet, nous devons signaler la réalisation d'opérations déjà évoquées dans le chapitre préliminaire : la reprise par la Grèce du service des emprunts d'avant-guerre dans des conditions certes bien différentes pour les emprunts étrangers et les emprunts internes - reprise qui contraste avec l'impossibilité pour la Grèce d'obtenir le remboursement des prêts consentis de force aux troupes d'occupation (Allemagne, Italie,...) et qui s'élèvent à 300 millions de dollars. Cette opération, dont on peut certes discuter la légitimité morale était en réalité imposée à la Grèce par sa position actuelle sur le marché financier international : voulant emprunter à nouveau, elle devait donner l'image, aux yeux des porteurs de la dette étrangère du moins, du parfait débiteur qui, après avoir réparé les malheurs subis, s'empresse de reprendre l'exécution de ses engagements. Il y avait d'ailleurs à cette [p. 445] démarche une raison encore plus impérative: le fait que certains pays (spécialement la Grande-Bretagne) et diverses institutions agissant sur la pression des premiers (en particulier la Banque Internationale pour la Reconstruction) se refusaient à prendre en considération toute nouvelle demande tant que la situation ancienne n'aurait pas été apurée.

Des accords ont déjà été signés à ce titre avec les gouvernements américain et britannique. Le principe en est que le gouvernement grec se reconnaît débiteur du montant de la dette et s'engage à en reprendre le service sans avoir, en principe, à acquitter les intérêts arriérés. Toutefois une petite fraction de ceux-ci a été capitalisée et ajoutée au principal. Les estimations diffèrent sur l'ampleur totale que prendra cette dette une fois les arrangements pris avec tous les pays créditeurs pour l'ensemble des emprunts en cause. Les uns parlent de 200 millions de dollars mais d'autres notamment l'Attaché financier américain - sur la base d'une documentation qui parait sérieuse, articulent le chiffre de 250.

1 Le seul tableau complet de la dette publique grecque que nous ayons pu trouver figure dans une note de l'Ambassade des États-Unis à Athènes en date du 27 avril 1964 (A-1082 Unclassified). 
Ces arrangements couvrent à la fois les porteurs étrangers et grecs de ces emprunts. Pour les Grecs qui résident sur le territoire national le règlement sera effectué en drachmes ce qui diminuera d'autant la charge de l'opération pour la balance des paiements. On estime que les Grecs résidents détiendraient environ 40\% des titres. Soulignons au passage que le gouvernement s'est également reconnu débiteur des emprunts internes d'avant-guerre mais seulement à concurrence de 5\% du nominal. L'accroissement de la dette publique actuelle qui en résulte est donc modeste : environ 16 millions de dollars.

Voyons maintenant la nouvelle dette extérieure, c'est-à-dire celle qui est née depuis la fin de la seconde guerre mondiale (partie utilisée et non encore remboursée). Au 31 décembre 1963, cette dette s'élevait à 198,5 millions auxquels il convient d'ajouter les sommes dues à des organismes étrangers par les entreprises publiques grecques soit 33,5 millions. Le total de la nouvelle dette publique vis-à-vis de l'extérieur atteignait donc le chiffre de 232 millions de dollars. On voit donc que la reconnaissance de la dette ancienne a eu pratiquement pour effet de doubler les engagements publics de la Grèce à l'égard du reste du monde. Ceux-ci à la fin de l'année 1963 se situaient donc autour de 450-460 millions (430 si la dette ancienne n'est que de 200 millions, 480 si elle se monte à 250).

On sait que le service d'une telle dette (intérêt et remboursement) [p. 446] impose au pays une double série d'efforts : prélèvements sur les ressources budgétaires de la contre-valeur en monnaie nationale des sommes dues ; prélèvement sur les ressources de change pour le transfert de ces sommes à l'étranger. Dans le cas qui nous occupe ici, les conséquences de cette dette sur la balance des paiements sont réduites par le fait qu'une partie en est réglable en monnaie nationale : au titre de l'ancienne dette, la fraction des titres possédés par des Grecs résidents, au titre de la nouvelle dette la fraction correspondant à des avances américaines remboursables en monnaie nationale (supra), soit 92 millions. Si l'on .admet, sans que nous ayons eu la faculté de vérifier la validité de cette supposition, que les Grecs résidents ont en mains 40\% de la dette .ancienne, la dette extérieure réglable en devises était au 31 décembre 1963 de l'ordre de 275 millions de dollars (avec la possibilité d'une variation en plus ou en moins d'une quinzaine de millions selon le niveau finalement atteint par l'ancienne dette).

Les engagements souscrits par des entreprises privées au titre de la loi 2687 n'imposent pas à l'État d'effort de trésorerie. Par contre, sous l'angle de la balance des paiements, celui-ci doit être prêt à assumer les obligations contractées au titre du rapatriement du capital et du transfert des bénéfices et intérêts. On sait qu'au 31 décembre 1963 le total des entrées effectives de capitaux n'était encore que de l'ordre de 100 millions de dollars : dès lors la charge pour la balance des paiements des engagements déjà souscrits reste dans des limites modestes.

Enfin, il ne sera pas inutile d'indiquer ici le total de la dette publique grecque (ancienne et nouvelle, interne et externe) au 31 décembre 1963. Cette dette s'établissait comme suit : 


\begin{tabular}{|c|c|c|c|}
\hline & Dette ancienne & Dette nouvelle & Total \\
\hline 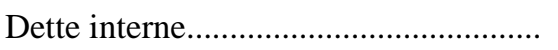 & 16,5 & 357,5 & 374 \\
\hline 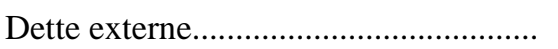 & $225(*)$ & 198,5 & 423,5 \\
\hline \multirow[t]{2}{*}{ Dette des corporations publiques.......... } & - & $(33,5)$ & - \\
\hline & 241,5 & 556,0 & 797,5 \\
\hline
\end{tabular}

$(*)$ Estimation moyenne entre les deux évaluations extrêmes en circulation.

[p. 447]

La dette publique totale de l'État grec proprement dit était donc en définitive de 800 millions de dollars.

Revenons maintenant sur la dette externe (dette des corporations publiques incluses). Le point important à l'époque la plus récente est l'accélération et l'amplification de l'endettement. Au 31 décembre 1963, le total de 232 millions représentant les utilisations effectives était déjà manifestement dépassé si l'on considère les crédits ouverts ou sur le point de l'être et non encore employés : un ensemble de 62 millions de dollars de prêts accordés à des titres divers par des organismes américains un prêt de l'État allemand de 50 millions affecté au projet Mégalopolis la première tranche débloquée sur le prêt du Marché Commun, soit 23 millions. À eux trois, ces éléments représentaient déjà 135 millions. Or, durant l'année 1964, de nouveaux crédits ont été obtenus de diverses sources étrangères. Dès lors, il est nécessaire d'évaluer le poids actuel et futur de cette dette pour le pays.

Au titre du prélèvement budgétaire, on estime que le service total de la dette (interne et externe) pour 1964 exigera 7\% des ressources budgétaires ordinaires au 31 décembre 1963 (contre 4,7\% à fin 1961). Mais c'est surtout l'aspect «balance des paiements » qui nous intéresse ici, c'est-à-dire le pourcentage des recettes courantes (exportations, services...) nécessaire pour régler le service de la dette externe. On estime qu'en 1964 ce pourcentage s'élèvera à 5\% pour la dette publique et à 3\% pour les engagements privés, soit en tout $8 \%$.

Ces pourcentages, tant pour les recettes budgétaires que pour les ressources de change semblent appelés à augmenter sensiblement dans un proche avenir. Et ceci pour deux raisons. D'une part en raison des charges croissantes qui vont résulter des emprunts déjà effectués et des entrées de capitaux déjà faites : l'un des facteurs de cet alourdissement sera l'amortissement de divers prêts américains et allemands dont jusqu'à présent le remboursement n'a pas encore commencé en raison de la période de grâce initialement obtenue par les autorités grecques. Un autre facteur sera l'accroissement des charges entraînées par le remboursement final de la dette ancienne. La seconde raison d'augmentation du poids relatif de la dette est que le gouvernement entend poursuivre à un rythme massif l'obtention de capitaux étrangers. Dès lors, de nouvelles charges vont s'ajouter sans cesse aux anciennes. 
Il n'est pas douteux que le service de la dette grecque va être dans les années à venir un élément d'importance croissante dans le budget [p. 448] et dans la balance des paiements. Cet élément prend un poids exceptionnellement grave dans les finances d'un pays quand le gouvernement est tenu de contracter de nouvelles dettes pour assurer le service des anciennes. Divers experts, qui ne semblent pas montrer un pessimisme excessif estiment que, compte tenu des habitudes de consommation prises (spécialement dans l'ordre de produits étrangers) le gouvernement grec sera contraint, à plus ou moins brève échéance, de procéder de la sorte.

Si elle n'est pas encore alarmante, la situation est déjà préoccupante. La politique financière internationale de la Grèce accroît sans cesse davantage la dépendance du pays à l'égard des États et groupes d'affaires étrangers. Le point le plus sérieux est que, compte tenu de ses options de base - et sous cet angle l'EK ne diffère pas beaucoup de l'ERE - le gouvernement grec n'est pas en mesure d'agir autrement.

La mise en mouvement de l'engrenage est déjà relativement ancienne Il faut remonter en fait en 1953, date à laquelle le gouvernement, sur l'impulsion de S. Markézinis, a choisi de jouer le jeu du marché international. Cette préférence excluait la réalisation d'une politique d'austérité nationale. Et dès lors la Grèce était vouée à rechercher, sous une forme quelconque, un financement croissant par l'étranger.

En principe, ce choix résultait d'une libre détermination du gouvernement hellénique et rien n'interdit de penser qu'il eut pu faire choix d'une autre route. On peut toutefois se demander si la constellation des influences politiques d'alors, nationales et étrangères, laissait une telle marge de manœuvre aux autorités responsables. Plusieurs estiment que dès 1945 — c'est-à-dire à l'époque où il devint évident que les vieilles structures du pouvoir allaient reprendre intégralement le contrôle du pays — la partie était effectivement terminée.

Sans entreprendre la tâche, intellectuellement excitante mais politiquement vaine, de remonter le cours de l'histoire, disons que ces derniers nous paraissent, en gros, avoir raison. On aurait peut-être pu, en 1953, limiter l'acceptation des règles du jeu international — ce jeu si cruel pour les pays pauvres. Mais il était déjà trop tard pour renverser totalement ou même substantiellement le courant. L'histoire, a dit un homme politique français, ne repasse pas les mêmes plats. 
[p. 449]

\section{CONCLUSION}

$\underline{\text { Retour à la table des matières }}$

NOUS VOUDRIONS, en terminant, souligner quelques-uns des traits majeurs qui se dégagent de l'étude entreprise. L'objet de cette récapitulation est évidemment de présenter un raccourci synthétique de l'expérience politique grecque durant cet aprèsguerre. Cependant nous souhaiterions mettre en évidence certains schémas ou catégories de portée générale et, comme tels, susceptibles de faciliter l'élaboration proprement théorique.

Nous reprendrons à cet effet trois points : la qualité de l'appareil gouvernemental au sens large du terme; la valeur immédiate et future de la politique économique suivie au cours de la dernière décennie ; la nature des problèmes à résoudre pour faire de la Grèce une société moderne.

L'examen de telles questions ne saurait être effectué sur une base purement objective. Les analyses de cet ordre sont inévitablement affectées par les choix moraux et les préférences idéologiques de leurs auteurs. Sans éviter de prendre parti sur les options en présence, nous essaierons de ne pas verser dans des constructions idéales en oubliant la réalité sociale qu'il s'agit d'interpréter.

\section{QUALITÉ DE L'APPAREIL GOUVERNEMENTAL}

À première vue ce sont les partis qui dominent la scène politique de la Grèce et orientent le fonctionnement de l'appareil gouvernemental tout entier. Ainsi s'explique l'ampleur des développements que nous leur avons consacrés en cet ouvrage. Mais, sur la base des observations faites tout au long de ce livre, il faut immédiatement tempérer cette proposition de deux réserves.

[p. 450] La première vise à rappeler que les partis d'aujourd'hui ressemblent bien davantage aux groupes parlementaires de type traditionnel qu'à des formations bureaucratisées de style moderne. À l'exception de L'EDA, la stabilité de ces organismes n'apparaît nullement assurée. La constitution de L'ERE et, plus encore, celle de l’EK a dépendu de considérations assez largement fortuites. Ces partis 
représentent en fait des constellations de personnalités et des combinaisons de courants, les unes et les autres pouvant, sous l'effet de circonstances différentes de celles qui ont provoqué leur rassemblement actuel, donner lieu à des regroupements différents. Parmi les circonstances capables de mettre en péril l'unité présente, mentionnons les disputes susceptibles de s'instituer à propos de la succession ou du remplacement des leaders en exercice - étant entendu que l'éclatement de l'une des deux grandes formations diminuerait probablement la propension de l'autre à sauvegarder sa cohésion. Il est également possible que l'adoption d'un système de proportionnelle pure pour les élections au Parlement renforce les tendances centrifuges à l'intérieur de chacune des organisations rivales.

Cette permanence de formes partisanes encore bien proches des modèles du XIX ${ }^{\mathrm{e}}$ siècle — et à cet égard la comparaison, mutatis mutandis bien entendu, avec la situation italienne d'avant la première guerre mondiale, ne manque pas de légitimité - n'est pas le résultat du hasard ou de la propension naturelle des Grecs à l'indiscipline et à l'instabilité. Cette perpétuation des formules anciennes de la politique trouve pour l'essentiel sa raison d'être dans la structure socio-économique du pays qui commence à peine d'acquérir les traits de la société industrielle.

La seconde réserve tend à rappeler que les partis ne sont pas les acteurs exclusifs ni vraisemblablement les acteurs principaux, si du moins l'on raisonne en termes de pouvoir effectif, du jeu politique. En se limitant à l'étude des contestations partisanes on négligerait des éléments essentiels, et parfois strictement déterminants, de l'action étatique. Certes les partis forment le gouvernement du pays mais il s'agit du gouvernement officiel, celui de la vitrine constitutionnelle. S'il est une évidence de la politique grecque, c'est que le gouvernement est loin d'être la seule force qui commande ou essaie de commander. C'est là une propriété capitale de la situation dont il convient de mentionner les facteurs.

Durant toute la période étudiée, la Grèce, conformément à une vieille tradition, a été sous le contrôle des puissances étrangères. On exprime [p. 451] exactement la réalité en disant qu'en certaines périodes ces puissances ont joué le rôle d'un supergouvernement. Nous entendons par là qu'aucune des grandes décisions qui commandent la vie nationale n'a pu être prise sans leur assentiment et que leur voix a été prépondérante dans le choix des dispositifs politico-économiques qui commandent le destin du pays. Après le forfait de la Grande-Bretagne, c'est l'Amérique qui a pris en mains les rênes de l'appareil gouvernemental grec et l'on sait que les Américains ont l'habitude, sur n'importe quel problème, de se croire détenteurs de la solution optimale. Aujourd'hui, les États-Unis, dont les forces ne sont certes pas inépuisables, tendent à laisser à l'Allemagne une partie des opérations d'assistance et de contrôle. On ne risque guère de se tromper en pronostiquant que la seconde n'acceptera pas toujours de tenir le rôle de brillant second dans le sillage et conformément aux vœux des premiers.

Les dirigeants américains s'étonnent et parfois s'indignent qu'on les taxe de comportements impérialistes. En vérité, à moins d'ignorer les réalités élémentaires de notre temps, l'impérialisme américain qui, selon les cas, fait preuve aussi bien de 
pusillanimité que d'esprit millénariste, est le phénomène capital des relations internationales en cette seconde moitié du $\mathrm{XX}^{\mathrm{e}}$ siècle. Selon un processus classique, les États-Unis s'efforcent de conquérir à la fois les esprits et les marchés : cependant leurs moyens, tant intellectuels que matériels, ne sont finalement pas à la mesure de leurs ambitions. Et dès lors il est possible que dans un avenir plus ou moins proche certaines puissances retrouvent une partie des positions dont la poussée américaine les a privées.

Il y a toujours eu en Grèce des clans de l'étranger. Les auteurs qui aiment les réminiscences historiques disent que déjà du temps de Démosthène il y avait à Athènes un parti macédonien. Aujourd'hui, c'est le parti américain qui est le plus actif de ces clans pour lesquels la politique nationale ne se conçoit que dans le sillage d'une puissance protectrice et, disons-le carrément, d'un suzerain. Les promoteurs et défenseurs de ce pacte de suzeraineté en attendent une garantie de l'ordre social établi et l'octroi d'un certain nombre d'avantages individuels.

Un second élément a également réduit au cours de la période étudiée la liberté de manœuvre du gouvernement officiel: l'existence aux mains de la Couronne de facultés politiques assumées avec le concours du clan royal et en liaison avec l'activité des puissances étrangères. Et le fait que, contrairement à Georges II qui savait ce qu'il voulait et était capable [p. 452] de décider par lui-même, le défunt Roi Paul ait été une personnalité plutôt flottante, ne change pas grand chose à l'affaire. À côté des hommes il y a la structure de pouvoir qui les anime et les oriente. En Grèce, la Monarchie n'est pas symbole d'unité nationale mais garante d'un certain ordre social et d'une certaine allégeance internationale : ce qui explique que tant d'hommes politiquement républicains mais socialement conservateurs se soient ralliés à la cause royale.

Cette évaluation, admettons-le, ne cadre pas, au moins en première analyse, avec l'idée que l'on pourrait se faire de la monarchie grecque d'après son comportement externe. Les fastes royaux de la dynastie des Glücksburg évoquent davantage les festivités des petites Cours allemandes du $\mathrm{XIX}^{\mathrm{e}}$ siècle que les cérémonies des grandes monarchies traditionnelles. Mais ce tableau change si, au lieu de juger la Couronne grecque d'après les standards de Buckingham ou de Versailles, l'on prend pour terme de comparaison les monarchies balkaniques de l'entre-deux-guerres. Pour celles-ci, la pauvreté du cérémonial et du décor n'empêchait pas l'exercice d'une action dirigeante par le monarque ou son entourage. En faisant remonter la dynastie danoise, qui est en réalité une dynastie germanique, sur le trône grec, les Britanniques ont introduit dans les institutions publiques de la Grèce un facteur de blocage socio-politique dont on aurait bien tort de sous-estimer la portée.

Mentionnons enfin une troisième source d'amoindrissement des facultés du gouvernement officiel : la présence dans l'appareil gouvernemental de secteurs qui ne lui font pas totalement ou exclusivement allégeance soit parce qu'ils s'arrogent le droit de conduire à leur guise les affaires dont ils sont chargés soit parce qu'ils sont liés au super-gouvernement on au gouvernement parallèle. Nous avons souligné à plusieurs reprises la médiocrité de l’appareil administratif grec encore conditionné par les 
relations de clientèle et rapports de famille. Cependant il est un secteur relativement facile à moderniser, au moins sous l'angle des procédés techniques : c'est celui des forces de l'ordre (armée et corps de sécurité). L'on voit ainsi des États dans lesquels les services de programmation sont dotés de moyens primitifs mais où les organismes de police ont un équipement impeccable. L'instituteur manque de livres mais la gendarmerie dispose de tous les instruments nécessaires à la répression.

En l'absence d'un contrôle politique rigoureux, les exécutants de la force publique ont toujours tendance à s'ériger en juges de leurs propres activités et à se constituer en unités autonomes obéissant à leurs propres [p. 453] règles ou critères d'appréciation. On emploie parfois l'expression de sous-gouvernement pour désigner une telle propension et, encore qu'un peu forte, cette appellation ne manque pas de vraisemblance. Cette tendance est encore plus marquée dans le cas d'un décalage technique manifeste entre le niveau d'organisation des forces de sécurité et celui de la société toute entière. Il n'est à cet égard que d'évoquer l'ampleur et l'intensité du contrôle politique exercé sur les citoyens par la police au temps de la guerre civile et longtemps encore après la fin de celle-ci. Certes la police agissait dans le cadre de directives générales de l'autorité gouvernementale ou, plus exactement peut-être, était couverte par de telles consignes. Mais ce qu'elle faisait effectivement de son pouvoir — qu'il s'agisse de la persécution de certains ou du ménagement d'autres échappait en une large mesure au contrôle supérieur.

Il est dès lors légitime d'avancer qu'en donnant à la police par l'institution du certificat de civisme la faculté légale d'ouvrir des " casiers politiques » à une échelle massive, le gouvernement créait les conditions d'un renforcement du sousgouvernement policier (lui-même en rapports directs, au titre de certains de ses secteurs, avec les services secrets du super-gouvernement). Sur ces bases, la police servait le gouvernement certes mais, en une large mesure, elle s'en servait (en particulier octroi par le second à la première de tous les engins nécessaires à l'exercice d'une pression morale ou d'une violence physique).

Il faut encore évoquer à cet égard l'affaire Lambrakis dont l'instruction provoqua l'arrestation de plusieurs officiers du corps de la Gendarmerie (un général, trois colonels, un lieutenant) sous l'accusation d'avoir participé à la préparation de la manifestation et, plusieurs disent, au montage du scénario qui devait aboutir à l'assassinat du député. L'opinion grecque vit dans cette affaire un cas typique de la propension des forces de l'ordre à s'ériger en juge de l'activité politique des citoyens et, à la limite, en instrument de liquidation physique des opposants. Il est douteux que Caramanlis lui-même ait trempé dans le complot mais il portait la responsabilité d'avoir mis en place les hommes qui devaient le réaliser. Au moment où ces lignes sont écrites, l'affaire Lambrakis, qui doit passer devant un jury, n'a pas encore été jugée mais elle a déjà eu des conséquences politiques très importantes.

Le gouvernement Caramanlis n'a d'ailleurs pas eu le monopole des affaires douteuses: parmi celles survenues sous le gouvernement Papagos, on peut citer le procès livré à des officiers aviateurs pour d'obscures [p. 454] accusations de sabotage. Il s'agissait en réalité d'une sorte de règlement de compte tendant à écarter 
de l'Aviation Royale des officiers de tendances libérales (l'éloignement des officiers républicains ayant été moins poussé dans l'Aviation que dans les autres armes). À l'audience, les officiers inculpés alléguèrent qu'ils avaient été torturés et leurs dires furent confirmés par des médecins. Ils furent condamnés mais amnistiés par un décret-loi 4337 du 12 décembre 1955. Le gouvernement de l'Union du Centre leur a rendu le droit à pension.

Si l'on considère maintenant le cas des militaires dans son ensemble, il est douteux que le gouvernement officiel ait eu beaucoup d'emprise sur les forces armées dont, au cours de la période examinée, les deux pôles d'allégeance ont été la Monarchie et l'OTAN. Depuis l'écrasement de la guerre civile, l'armée grecque s'est attribuée la mission de défendre le pays contre toute infiltration communiste, ce qui l'a conduite notamment, les militaires ayant peu le sens du ridicule en politique, à accepter pour argent comptant les propositions et interprétations de la soviétologie. Et c'est dans la mesure où le gouvernement officiel témoignait lui-même d'un anti-communisme militant que le sous-gouvernement militaire lui a donné son soutien. Le fait que C. Papandréou ait choisi pour Ministre de la Défense un homme comme P. Garoufalias — dont l'attachement au Roi et à l'OTAN est exemplaire — illustre la faiblesse de la marge de manœuvre du gouvernement officiel vis-à-vis de l'établissement militaire.

Telles sont les trois séries de facteurs qui, depuis la fin de la seconde guerre mondiale, ont érodé et érodent encore les facultés de choix et de commandement des hommes élus par le peuple pour assumer la charge de gouverner le pays. La situation se serait peut-être transformée au profit des représentants officiels si le monde politique grec de cette politique avait produit un leader de qualité exceptionnelle capable, sinon d'écarter l'intervention des forces extra-constitutionnelles, du moins de discuter à égalité avec les représentants de celles-ci. On sait que ce n'a pas été le cas.

De cette médiocrité, la manière dont a été traitée l'affaire de Chypre apporte un témoignage éclatant. Dans une récente déclaration du Journal de Genève ${ }^{1}$ l'actuel leader de L'ERE, P. Canellopoulos, a expliqué par les nécessités de la " situation » l'obligation devant laquelle s'est trouvée la Grèce en 1959 d'accepter le régime des accords de Zurich [p. 455] "régime au fond contraire à la logique » mais dont l'acceptation fut dictée par le souci de tout faire pour maintenir l'unité de l'alliance atlantique. En réalité, compte tenu de l'incapacité où se trouvait la Grande-Bretagne de bloquer le mouvement de résistance dans 1'Île, rien n'obligeait les gouvernants de l'époque à accepter le régime de Zurich sinon le fait que les États-Unis, probablement d'accord avec la Couronne (toujours soucieuse des intérêts anglais), voulaient qu'il en soit ainsi.

Il ne serait certes pas sans signification d'établir un parallèle entre le sort réservé à la minorité turque de Chypre par les accords de Zurich et celui fait à la minorité d'origine européenne d'Algérie par les Accords d'Évian. Il y a un monde entre les avantages concédés aux Turcs sur la pression des autorités américaines et celles négociées par le gouvernement français au profit de ses ressortissants. Le dispositif

28 octobre 1964, p. 1. 
d'Évian n'aurait certainement pas été signé si le Général de Gaulle avait témoigné en ce domaine des exigences que manifesta le gouvernement turc avec l'appui de ses alliés de l'OTAN et qu'accepta le gouvernement Caramanlis.

Les déclarations de Canellopoulos au Journal de Genève établissent sans équivoque que dans l'esprit des gouvernants grecs de l'époque, la lutte pour la sauvegarde de l'hellénisme devait être subordonnée au maintien du dispositif de protection militaire de l'ordre social existant. On le savait déjà mais il est important que ce point ait été publiquement admis par l'actuel leader de la Droite.

Sans porter, faute de recul, un jugement définitif sur la période la plus récente, il ne semble pas que le gouvernement du Centre ait de lui-même repoussé avec assez d'énergie - celle que l'on met à défendre les causes nationales — les tentatives américaines pour imposer, au besoin sous une forme déguisée, un partage de 1'Île au profit des Turcs. Il est important de noter que durant toutes les négociations de l'été 1964 l'homme politique grec en vedette a été P. Garoufalias et non le Ministre des Affaires Étrangères, S. Costopoulos.

Il est possible que les fluctuations et vacillations de la politique officielle grecque - fruit de la propension à accepter la dépendance internationale — aient aliéné l'allégeance de nombreux chypriotes à la mère-patrie. Mais cette incapacité à affronter avec courage, lucidité et continuité les grands problèmes du pays s'est aussi manifestée avec beaucoup d'acuité dans le domaine de la politique économique.

[p. 456]

\section{VALEUR DE LA POLITIQUE ÉCONOMIQUE}

Retour à la table des matières

L'action économique gouvernementale présente en Grèce une signification politique exceptionnelle. On peut la caractériser, de manière brève mais adéquate, en disant qu'elle est essentiellement une politique de facilité. Au plan des résultats actuels, elle a permis l'institution dans un pays foncièrement pauvre de certains traits de la société de consommation au profit des couches aisées de la population. En termes de situation à plus long terme, le maintien et le développement de ces avantages impliquent une dépendance internationale croissante. La glorification constante de cette situation par les hommes de l'ERE d'abord, ceux de l'EK ensuite, signifie que la classe politique grecque ou bien ignore tout de la rigueur des engrenages économiques ou sacrifie consciemment l'avenir du pays à la perception de dividendes électoraux.

La Grèce, nous l'avons noté dans le chapitre préliminaire, a toujours été sous la dépendance de l'économie internationale. Actuellement, réserve faite de l'amélioration survenue pour quelques produits alimentaires (spécialement le blé) elle lui est soumise plus que jamais. Le plus simple pour établir ce phénomène est de partir de ce document irrécusable que constitue la balance des paiements. Voir 
(annexe III, pp. 490-491), selon le dernier rapport de l'OCDE pour la Grèce, l'évolution de cette balance de 1953 à 1963 (en millions de dollars) ${ }^{1}$.

Le point de départ de la situation, celui qui commande tous les autres, est le déficit croissant de la balance commerciale (dont on prévoit qu'il atteindra 500 millions de dollars en 1964). Il est à peine besoin de souligner l'importance que revêt la diminution de 1953 à 1960 du pourcentage de couverture des exportations par les importations.

Cependant cette constatation déjà grave s'alourdit encore si l'on considère la composition présente des importations et exportations - l'accent étant mis ici sur les dernières années parce qu'elles font suite à une pé-[p. 457] riode durant laquelle le gouvernement a disposé de sommes relativement importantes au titre de la modernisation. Voici, toujours selon les mêmes sources, la distribution des importations par groupes de produits (en pourcentage du total) :

\begin{tabular}{|c|c|c|c|c|}
\hline Groupes de produits & 1960 & 1961 & 1962 & 1963 \\
\hline 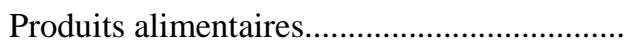 & 19 & 18 & 14 & 19 \\
\hline 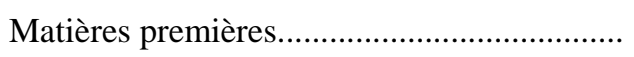 & 26 & 25 & 25 & 23 \\
\hline 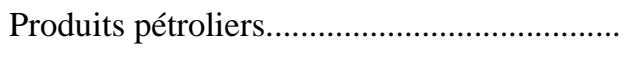 & 10 & 8 & 8 & 7 \\
\hline 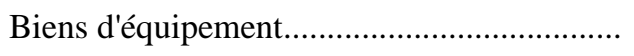 & 16 & 18 & 22 & 19 \\
\hline 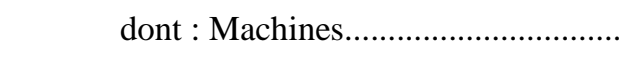 & (13) & (14) & $(16)$ & (15) \\
\hline Matériel des transports............. & (3) & $(4)$ & $(6)$ & (4) \\
\hline Biens de consommation durable........................ & 29 & 31 & 31 & 32 \\
\hline Total & 100 & 100 & 100 & 100 \\
\hline
\end{tabular}

En première analyse, la part des articles de consommation atteint en moyenne la moitié des importations totales. Ce pourcentage laisse tout de même une place assez importante aux matières premières et équipements divers. La situation comporterait donc un élément favorable si une partie de ces articles était utilisée à la fabrication des biens destinés à l'exportation. Or, il n'en est rien comme le montre la structure des exportations au cours des dernières années :

1 Nous devons toutefois signaler que les pourcentages de couverture des importations par les exportations fournis par le Statistical Yearbook of Greece 1963, p. 226, sont sensiblement plus bas que ceux mentionnés dans le tableau de l'OCDE, sans que nous ayons pu établir s'il s'agit de discordances de fond ou de décalages dus à des différences dans la distribution des données. Ayant retenu les estimations de l'OCDE pour des raisons de commodité administrative (concordance exacte du tableau avec nos catégories de travail) nous nous bornons à signaler que l'adoption des pourcentages du Yearbook — du moins ceux qui résultent expressément des chiffres de la p. 226 aurait simplement eu pour effet d'alourdir assez sensiblement les observations faites. 


\begin{tabular}{|c|c|c|c|c|}
\hline Groupes de produits & 1960 & 1961 & 1962 & 1963 \\
\hline 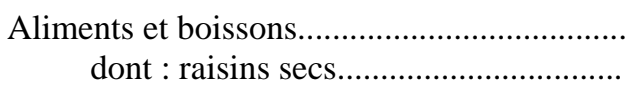 & $\begin{array}{c}27 \\
(13)\end{array}$ & $\begin{array}{c}26 \\
(12)\end{array}$ & $\begin{array}{c}29 \\
(12)\end{array}$ & $\begin{array}{c}24 \\
(11)\end{array}$ \\
\hline 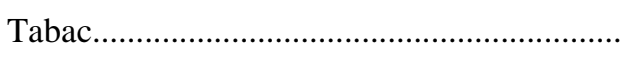 & 35 & 35 & 28 & 43 \\
\hline Coton & 9 & 12 & 16 & 12 \\
\hline Matières premières....................................... & 11 & 11 & 9 & 8 \\
\hline 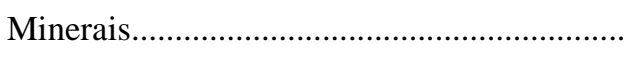 & 9 & 6 & 6 & 5 \\
\hline 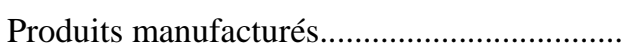 & 4 & 3 & 5 & 3 \\
\hline 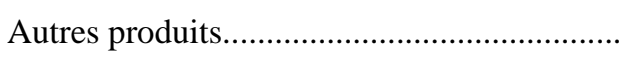 & 5 & 7 & 7 & 5 \\
\hline Total..... & 100 & 100 & 100 & 100 \\
\hline
\end{tabular}

[p. 458] On voit donc que la part de l'agriculture dans les exportations grecques se situe autour de $75 \%$ (71\% en 1960, 79\% en 1963). Si l'on ajoute à ces chiffres les matières premières et minerais, la part du secteur dit primaire dans les ventes extérieures est de l'ordre de $90 \%$, la place des produits manufacturés étant insignifiante et ne montrant aucune tendance à s'élever.

Certes les productions primaires exportées, ainsi que les activités liées au tourisme et à la marine marchande, exigent une certaine quantité des matières et équipements achetés à l'étranger (combustibles, tracteurs, engrais...). Mais, sur la base de ces chiffres, on peut avancer que jusqu'à présent la plus grande partie des biens acquis à l'étranger sous d'autres rubriques que les articles de consommation a, en fait, été utilisée pour la consommation propre de la population grecque. Ce qui revient à dire que de tous les biens matériels produits dans le pays à l'aide de ressources nationales ou étrangères, la Grèce n'exporte que le surplus des produits agricoles non consommés sur place - des produits offerts sur les marchés mondiaux par de nombreux concurrents. Et le fait que deux produits seulement, tabac et coton, représentent en moyenne $45 \%$ du total des exportations suffit à établir la fragilité de la situation.

Jusqu'à maintenant la Grèce a pu faire face à la situation grâce à d'autres sources de devises étrangères que les exportations. En gros celles-ci sont de deux ordres :

$1 \%$ Recettes effectuées au titre des éléments invisibles. La balance de ceux-ci connaît un accroissement spectaculaire au cours de la période étudiées. Passant de 84,4 à 356,4, l'excédent de la balance fait plus que quadrupler en 11 ans. En 1962 et 1963, la balance des invisibles procure au pays des ressources supérieures au total des exportations. Le pourcentage des importations couvert de la sorte ne cesse de croître. Or les recettes effectuées à ce titre dépendent de trois éléments : le tourisme, les transports (essentiellement la marine marchande) et les remises des émigrants. Voici leur évolution depuis 1953 (en millions de dollars), le poste divers incluant plusieurs séries d'entrée de devises (dépenses des missions étrangères, infrastructure de l'OTAN, Télécommunications...) : 
[p. 459]

\begin{tabular}{lcccc|ccr}
\hline Années & Tourisme & Transport & $\begin{array}{c}\text { Remise } \\
\text { des } \\
\text { émigrants }\end{array}$ & Divers & $\begin{array}{c}\text { Total des } \\
\text { recettes }\end{array}$ & Dépenses & Balance \\
\hline 1953 & 22,7 & 22,8 & 45,6 & 16,7 & 107,8 & 23,4 & 84,4 \\
1954 & 25,3 & 28,2 & 47,0 & 23,7 & 124,2 & 30,1 & 94,1 \\
1955 & 29,1 & 35,5 & 50,7 & 38,6 & 153,9 & 36,0 & 117,9 \\
1956 & 31,2 & 48,3 & 60,9 & 42,2 & 182,6 & 39,3 & 143,3 \\
1957 & 41,5 & 66,6 & 75,0 & 52,6 & 235,7 & 49,7 & 186,0 \\
1958 & 36,2 & 60,3 & 76,7 & 44,4 & 217,6 & 47,7 & 169,9 \\
1959 & 41,7 & 60,3 & 88,6 & 46,6 & 237,2 & 54,9 & 182,3 \\
1960 & 49,3 & 76,5 & 90,4 & 57,0 & 273,2 & 65,5 & 207,7 \\
1961 & 62,5 & 102,1 & 98,3 & 56,7 & 319,6 & 76,2 & 243,4 \\
1962 & 76,0 & 107,7 & 117,2 & 78,3 & 379,2 & 87,6 & 291,6 \\
1963 & 95,4 & 125,3 & 128,5 & 105,1 & 454,3 & 97,9 & 356,4 \\
\hline
\end{tabular}

Chacun des trois postes-clés de la balance des paiements comporte pour le pays des contre-parties ou servitudes considérables. Au titre du tourisme, l'État a dû entreprendre de lourds travaux d'infrastructure, les bénéfices ultérieurs de l'opération faisant ensuite l'objet, selon la formule habituelle, d'une distribution privée. Pour la marine marchande, le gouvernement grec n'en a obtenu le rapatriement partiel qu'au prix de concessions lourdes et humiliantes, ces mesures aboutissant à créer une catégorie particulière de citoyens que nous avons qualifiés de "Grecs conditionnels » et qui se livrent à un chantage permanent sur les autorités. Reste enfin le poste « remise des émigrants »: il exprime l'incapacité du pays d'utiliser lui-même son capital le plus précieux.

La deuxième caractéristique de ces recettes, si connue, qu'il suffira de la mentionner, est leur extrême sensibilité à la conjoncture internationale.

$2 \%$ Entrées de capitaux étrangers publics et privés à des titres divers (assistance, investissements directs, emprunts...). Nous en avons suffisamment parlé dans le chapitre XII pour qu'il soit nécessaire de commenter ici les lignes du tableau qui leur sont consacrées. Comme les précédentes, les ressources acquises à ce titre sont étroitement dépendantes de la conjoncture internationale et, singulièrement, de la prospérité des pays dans lesquels elles trouvent leur origine.

Au total, si on l'envisage dans ses caractéristiques et conséquences principales, la politique économique de la Grèce s'est traduite par une aug-[p. 460] mentation des facultés de consommation du pays - une augmentation qui, fort inégalement répartie d'ailleurs selon les groupes sociaux, a absorbé la plus large part des ressources extérieures qui ont pu être mobilisées à des titres divers. C'est là le phénomène que trop de dirigeants responsables et de commentateurs nationaux ou étrangers qualifient de prospérité sans précédent. Il s'agit en réalité d'un immense château de cartes qui 
repose sur une base particulièrement fragile, plus exactement sur une base dont le contrôle échappe presque entièrement aux gouvernants et dépend, pour l'essentiel, de l'état de la conjoncture internationale.

Athènes, cette capitale mégalocéphale, est le principal bénéficiaire du mouvement. De récentes statistiques ont mis en évidence que la propension à l'épargne y est sensiblement plus petite que dans les régions moins favorisées du pays. Le fait, qui ressort en particulier des calculs effectués par la Chase Manhattan Bank, établit clairement le tort que peut causer à la croissance nationale l'incitation à la consommation qui se développe aujourd'hui dans les pays économiquement arriérés du monde capitaliste - incitation qui trouve en une large mesure son origine dans les efforts accomplis par les pays les plus avancés pour élargir leurs marchés à tout prix.

Dans sa Géographie Humaine de la Grèce que nous avons utilisée à de nombreuses reprises, B. Kayser souligne que l'agglomération-capitale constitue avant tout, quant à son fonctionnement interne, un centre de consommation et il poursuit : « ainsi progresse, se développe et s'enrichit Athènes, dont l'expansion est une réalité fragile, certes, parce que ne reposant pas sur les bases sûres de la production, mais concrète $"{ }^{1}$. Ces lignes situent correctement la position d'Athènes mais aujourd'hui tout ce qui brille en Grèce relève de la même pratique.

Naturellement, on relève dans ce pays les signes habituels de la société opulente : ainsi croissance du nombre des automobiles qui se fait à un rythme rapide. Mentionnons aussi la spéculation foncière qui tient en particulier au fait qu'en Grèce l'état de propriétaire foncier, vis-à-vis duquel le fisc a bien des indulgences, est particulièrement lucratif. Un autre facteur de hausse des terrains est la pression de la demande étrangère qui s'exerce avec une force particulière sur le littoral (ainsi sur la soixantaine de kilomètres qui va d'Athènes au Cap Sounion) et dans certaines îles. Selon des informations concordantes, les prix immobiliers [p. 461] à Mykonos — île très fréquentée par les touristes — seraient aujourd'hui 20 à 30 fois plus élevés qu'il y a quelques années.

Il est clair que toute cette politique économique a pour caractéristique essentielle de suivre la pente de la plus grande facilité. Dans son principe même, elle représente une sorte de " fuite en avant », c'est-à-dire de report sur l'avenir — un avenir que l'on déclare brillant — du soin de faire face à tous les engagements que l'on souscrit aujourd'hui. Les difficultés commencent quand, une source de recettes venant à faire défaut, il devient indispensable de trouver dans les délais les plus rapides des éléments de remplacement. Ainsi s'explique la course à l'endettement étranger course assez difficile car il y a dans le monde tant de candidats emprunteurs pour si peu de préteurs éventuels - qui caractérise aujourd’hui l'économie publique et privée de la Grèce.

Op. cit., pp. 123-125. 
On pourrait être tenté d'expliquer l'association au Marché Commun par la volonté de précipiter l'évolution des structures socio-économiques en faisant planer sur les éléments attardés la menace d'une disparition à plus ou moins brève échéance. Ce serait une fois encore se réfugier dans l'avenir puisque l'on attendrait de l'opération que la prise en considération des menaces futures constitue pour les intéressés une incitation décisive à moderniser leur outillage technique et leurs méthodes commerciales.

Il est possible que ce pari soit intervenu comme aussi a dû jouer un rôle l'espoir de trouver chez les Six des marchés privilégiés pour quelques produits méditerranéens et les ressources financières indispensables à la poursuite de l'expérience en cours. Sous ce second aspect, l'opération perdait beaucoup de son attrait dès lors qu'après la Grèce, la Turquie obtenait également un régime d'association au Marché Commun à des conditions que sur divers points les Grecs ont jugé supérieures à celles dont ils bénéficient. Il semble que l'adhésion de la Turquie — dont les produits exportables de base sont en une large mesure les mêmes que ceux de la Grèce et dont les besoins de capitaux sont encore plus grands - ait constitué une déception pour de nombreux milieux grecs.

Actuellement le problème du Marché Commun suscite un malaise sérieux dans les milieux dirigeants grecs, ceux-ci redoutant que la Commission de la CEE ne les considère comme une sorte de lointaine province déshéritée et difficile à intégrer au grand circuit des échanges commerciaux. La déception vient de ce que durant la première année de fonctionnement de l'accord, le déficit commercial entre la Grèce et [p. 462] les Six pays s'est aggravé. Un autre motif de mécontentement est le retard mis par la Commission à envisager le problème de l'harmonisation des politiques agricoles de la Grèce et de ses partenaires. Cependant la position gouvernementale reste que la mise en application de l'accord doit être poursuivie.

On ne saurait certes juger le fonctionnement d'un accord aussi complexe sur une seule année d'application. Il semble toutefois possible de pronostiquer que l'association vaudra aux Grecs bien moins d'avantages et beaucoup plus de dangers que les promoteurs de l'opération ne l'ont dit et que ses défenseurs actuels ne sont prêts à l'admettre. Certains milieux grecs, assez sceptiques sur les chances de succès de l'opération, souhaitent néanmoins que l'expérience soit poursuivie durant quelques années, leur idée étant qu'il convient de ne laisser passer aucune chance. D'autres souhaiteraient une amputation immédiate. À divers égards, l'adhésion donnée par la Turquie qui a certainement réduit l'intérêt de l'association pour la Grèce rend plus difficile à celle-ci de s'éloigner de la Communauté.

Nous avons raisonné jusqu'ici comme si, disposant de ressources internationales, la Grèce avait librement décidé de les affecter à l'édification d'une société de consommation. Cette manière de présenter les choses suppose implicitement que le gouvernement grec aurait pu choisir pour le pays un autre cours de développement sans perdre pour autant le bénéfice de l'aide apportée. Cependant, rien n'est moins certain. Une politique d'austérité aurait inévitablement mis en cause les intérêts commerciaux des puissances dispensatrices de l'aide. Or la tendance naturelle des 
pays capitalistes, même quand ils ne lient pas expressément l'ouverture de crédit à l'achat de biens produits chez eux, est de considérer que l'octroi d'une assistance doit entraîner chez le bénéficiaire une attitude compréhensive à l'égard de ces biens.

En d'autres termes, la réception d'une aide sous ses diverses formes et l'acceptation des règles de la société de consommation n'étaient pas, vu la sujétion politico-militaire de la Grèce, deux positions dissociables. Acceptant l'assistance, la Grèce devait s'en tenir aux conceptions et pratiques économiques des puissances dispensatrices de l'aide. On doit dès lors se demander si, au prix des servitudes et des périls que comporte la formule adoptée, la Grèce est susceptible de procéder à une certaine modernisation socio-économique.

[p. 463]

\section{NATURE DES PROBLÈMES À RÉSOUDRE}

$\underline{\text { Retour à la table des matières }}$

Réserve faite de l'Île de Chypre, la Grèce se trouve désormais libérée du souci de faire coïncider son territoire avec la zone d'expansion de l'Hellénisme. Dans un récent discours, G. Papandréou a certes évoqué la «tragédie » de l'Épire du Nord mais en l'état actuel des relations internationales, ce n'est plus une question d'actualité. Le pays est donc en mesure de consacrer toutes ses énergies au développement économique qui, en définitive, commande lui-même tant d’évolutions dans l'ordre politique et social. Il s'agit pour lui de réaliser une croissance qui soit à la fois accélérée et harmonisée. Or, si une ambition de cet ordre comporte nécessairement des difficultés considérables, la Grèce est préservée ou libérée de plusieurs des handicaps qui compromettent gravement l'avenir d'autres pays en retard. C'est dire que, moyennant un effort adéquat, elle serait probablement en mesure d'obtenir, relativement vite, des résultats appréciables.

L'un des principaux avantages de la Grèce à ce propos est d'avoir dès maintenant une situation démographique de pays développé. Le taux de natalité qui se situait encore entre 25 et $30 \%$ o durant les années trente a considérablement baissé depuis la fin de la seconde guerre mondiale: à partir de 1951, ce taux est demeuré en permanence au-dessous de 20\%. Bien que le taux de mortalité ait également beaucoup diminué (aux alentours de 7\%o depuis 1950), l'augmentation naturelle de la population reste modérée Cette situation contraste avec celle de la Turquie qui se situe dans la zone de démographie dite explosive avec un accroissement annuel de l'ordre de 3\%. Si l'on raisonne en termes d'équilibre politique international dans l'Europe du Sud-Est, la faiblesse de ce rythme d'expansion démographique n'est pas sans poser des problèmes mais, du strict point de vue de la croissance, cette situation ne peut, surtout au départ, que faciliter l'action des autorités. 
Dans l'ordre de l'éducation, la situation sans être bonne est certes moins préoccupante que celle de tant d'autres pays. D'après le recensement de 1961, le taux national d'analphabétisme ne serait plus que d'environ 20\% (10\% à Athènes, 30\% en Thrace). Même si l'on tient compte d'une certaine propension à l'insincérité, ces taux signifient que le pays est en train d'éliminer l'analphabétisme. Par ailleurs, la Grèce [p. 464] dispose dans ses universités et écoles supérieures d'une jeunesse de grande qualité dont il serait très facile d'accroître les effectifs si le pays était en mesure, ce qui n'a pas été le cas jusqu'à présent, de lui assurer des débouchés honorables.

Le point le plus grave est que la Grèce ait jusqu'ici perdu tant de ses élites intellectuelles au profit des pays étrangers. Il en résulte que le gouvernement doit, en plusieurs domaines, faire appel à des experts extérieurs avec le risque que l'on sait, alors que nombre de ses ressortissants travaillent au service d'États ou groupes économiques à l'étranger. L'une des raisons de cette situation est que beaucoup de jeunes Grecs, ne trouvant pas dans le pays des facilités adéquates d'enseignement supérieur, s'en vont les chercher à l'étranger dont ensuite une large proportion ne revient pas. En 1961, le pourcentage des sujets grecs en cours d'études à l'extérieur de la Grèce était de l'ordre de 8.800, soit environ le quart de l'effectif total des élèves des établissements grecs d'enseignement supérieur. Sur ce chiffre, le pourcentage des étudiants en sciences et techniques était de 58,8\%, celui des étudiants de lettres et sciences sociales de 41,2\%. Voici les pays d'accueil : Autriche, 2.450 étudiants; Allemagne, 2.130 ; Italie, 1.420 ; États-Unis, 1.200 ; France, 600 ; Suisse, 500 ; divers, 500.

À long terme, il n'y a d'autre solution à ce problème qu'un élargissement et une rénovation de l'enseignement supérieur. À cet égard, le gouvernement Papandréou envisage d'effectuer des efforts considérables dont les premiers éléments ont déjà été mis en œuvre : il semble que le Premier Ministre, déjà responsable autour de 1930 d'une importante amélioration de l'enseignement primaire, considère que pour la Grèce l'homme constitue la meilleure ressource et le plus sûr investissement. C'est poser là le problème dans les meilleurs termes concevables. Mais une telle entreprise ne saurait donner de résultats à court terme.

En vue de satisfaire les besoins immédiats en personnel scientifique et technique de haute qualité et en professeurs de premier plan, on vient de mettre au point un plan-pilote qui prévoit le rapatriement à titre temporaire d'un nombre limité de chercheurs scientifiques grecs travaillant à l'étranger. Ces derniers sont invités à venir en Grèce au bénéfice d'un contrat avec le Gouvernement à l'expiration duquel ils seront laissés libres de rester dans le pays ou de retourner à l'étranger. Un tel plan atteindrait pleinement son objectif si une forte proportion [p. 465] des chercheurs abordés à cet effet acceptaient de rentrer en Grèce et d'y demeurer par la suite. Ce serait un test bien plus important de la vitalité du pays que l'édification d'une usine par une quelconque société américaine soucieuse d'inonder le Marché Commun d'une production réalisée à bas prix.

Cependant tout l'effort entrepris au titre de l'élévation du niveau scientifique et technique serait finalement vain si la Grèce ne parvenait pas à reprendre l'entière 
maîtrise de son appareil économique. Le système actuel est certes susceptible de produire des résultats. Mais il présente plusieurs vices fondamentaux. Il constitue un pari sur la bonne tenue de la conjoncture internationale : une crise grave frapperait la vie économique et sociale de la Grèce sur tous les plans sans que le Gouvernement ait la moindre ligne de repli. D'un autre côté, la croissance par appel au capital étranger suppose le maintien des bonnes dispositions des capitalistes de l'extérieur à l'égard de la Grèce: la marge de manœuvre politique du gouvernement se trouve ainsi considérablement restreinte et les nombreux privilèges que celui-ci accorde sans cesse pour développer ces bonnes dispositions en sont le témoignage. Enfin, le système adopté, quoiqu'on en écrive, fait de la recherche du profit par le capital monopoliste le principe de l'industrialisation du pays.

Sur la route où le gouvernement de la Droite l'avait engagée, la Grèce semblait inévitablement vouée à un développement économique de type colonial — un développement ayant certains traits communs avec celui d'une principauté de Monaco à grande échelle. Ce genre d'asservissement vaut aux couches bénéficiaires des dividendes parfois substantiels mais il ôte au pays l'essentiel de sa souveraineté et, plus simplement, de sa dignité. Le fait que pour tant d'étrangers le symbole de la Grèce soit aujourd'hui celui des « Enfants du Pirée » illustre bien le point où mène inexorablement la pente de la facilité. Le gouvernement du Centre avait manifesté l'intention d'assurer le redressement du pays et il a pris à cet effet de nombreuses initiatives de valeur, Mais, sur le fond, il a gardé les mêmes options que son prédécesseur et se trouve prisonnier des mêmes forces.

Dans l'état actuel des choses, la Grèce semble vouée à la condition d'un peuple dominé et exploité par l'étranger. On ne saurait envisager un renversement du courant sans un sursaut politique national, un sursaut assez fort pour susciter une révision radicale des pratiques suivies. Il est clair que les conditions d'un tel sursaut ne sont pas réunies aujour-[p. 466] d'hui. Mais si la vie se rit souvent des prédictions optimistes, il arrive aussi qu'elle bouleverse les estimations pessimistes. C'est en tout cas du peuple et du peuple seul que l'on peut attendre ou espérer la poussée libératrice. 
[p. 467]

\section{LEXIQUE DES PARTIS POLITIQUES GRECS}

$\underline{\text { Retour à la table des matières }}$

1. Parti Agraire (Agroticon Comma). - Se présente pour la première fois sous cette dénomination, après la guerre, aux élections de 1950 dans trois circonscriptions (Trikala, Peli, Evros) avec 11 candidats; il n'obtient aucun siège. Aux élections précédentes (1946), son chef, Apostolos Pagoutsos avait participé à la coalition électorale de l'Union des Partis Agraires en qualité de secrétaire général. Il agissait alors en tant que cadre du Parti Agraire de Grèce d'Alexandre Mylonas, qui faisait partie de l'Union. Aux élections de 1951, le Parti Agraire ne présente pas de candidats comme tel, mais son chef figure dans les listes du Parti Libéral. Aux élections de 1952, le parti réapparaît en présentant un candidat (A. Pagoutsos) dans une circonscription (Trikala). Aux élections de 1956, son chef figure sur les listes de l'Union Démocratique. En 1958, on le trouve sur celles de l'Union Progressiste Agricole Démocratique. Aux élections de 1961, il fait partie de l'Union du Centre à laquelle il a donné son adhésion.

2. Parti Agraire de Grèce (Agroticon Comma Ellados). — A été constitué le 14 septembre 1945, avec, pour chef, Alexandre Mylonas. Il groupait les cadres de différents partis agraires d'avant-guerre (Agraire, Agraire Démocratique, Agraire Socialiste). Il a participé aux élections de 1946 dans l'Union des Partis Agraires.

3. Parti Agraire Démocratique (Agroticon Dimokraticon Comma). - N'a jamais participé comme tel aux élections d'après-guerre, mais a fait partie de l'Union des Partis Agraires, aux élections de 1946.

4. Parti Agraire Démocratique de Grèce (Agroticon Dimokraticon Comma Ellados). — N'a jamais participé comme tel aux élections d'après-guerre, mais a fait partie de l'Union des Partis Agraires aux élections de 1946.

5. Parti Agraire et Ouvrier (Agroticon Kai Ergaticon Comma). - Ayant pour chef Alexandre Baltadzis, il constitue le prolongement du Rassemblement des Agriculteurs et Travailleurs (voir sous 11). Il participa aux élections de 1956, dans la coalition électorale de l'Union Démocratique et obtint 7 sièges. Aux élections de 1958, il fit partie de la coalition [p. 468] électorale de l'Union 
Progressiste Agricole Démocratique et reçut 6 sièges. Après la création de l'Union du Centre (septembre 1961) dont il fut l'un des éléments constitutifs, ce parti a cessé d'exister en tant que formation autonome.

6. Parti Agraire National Progressiste (Agroticon Ethnicon Proodefticon Comma). - Ayant pour chef Alexandre Mylonas, il constitue le prolongement du Parti Agraire de Grèce (voir sous 2). Il participa aux élections de 1950, dans le Front des Agriculteurs et Travailleurs.

7. Groupes Agraires du Parti Agraire et Ouvrier (Agroticai Omadai Tou Agroticou Kai Ergaticou Commatos). - Participèrent aux élections de 1946 dans la coalition de l'Union des Partis Agraires.

8. Parti Agraire Populaire (Laïcon Agroticon Comma). - Ayant comme chef Georges Pamboucas, il se présenta aux élections de 1946 dans la coalition de l'Union des Nationalistes. Il s'agissait d'un parti de caractère local (Corinthie) et occasionnel. Par la suite, ce parti disparut en tant que tel et son chef adhéra au Nouveau Parti, dans les listes duquel il figurait aux élections de 1950. Aux élections de 1951 et de 1952, G. Pamboucas se présente sur les listes du Rassemblement Hellénique et aux élections de 1956 et 1958, sur celles de l’Union Nationale Radicale.

9. Parti Agrarien Indépendant (Anexartiton Agroticon Comma). - Ayant pour chefs Alexandre Catsoulidis et Charilaos Costopoulos, il se présenta une seule fois aux élections, en 1950, sans obtenir de siège parlementaire et disparut par la suite. Il avait un caractère purement local (Messinie), ses deux chefs et uniques candidats étant d'anciens cadres du Parti Libéral.

10. Parti Agrarien Indépendant de Grèce (Anexartiton Agroticon Comma Ellados). - De caractère purement local (Achaïe) ne se présenta qu'une seule fois aux élections de 1950 et n'obtint aucun siège.

11. Rassemblement des Agriculteurs et Travailleurs (Synagermos Agroton Kai Ergazoenon) SAE). - Avec pour chef Alexandre Baltadzis, il se présenta pour la première fois aux élections en 1950, dans la coalition électorale du Front des Agriculteurs et Travailleurs. Aux élections de 1951, il présenta des candidats dans 8 circonscriptions de la Thrace et de la Macédoine et obtint un siège au Parlement. En 1952, il présenta des candidats dans trois circonscriptions, sans obtenir de siège parlementaire. À partir de 1956, ce parti apparaît comme Parti Agraire et Ouvrier (voir sous 5).

12. Parti des Automobilistes de Grèce (Comma Aftokinitiston Ellados). - Ayant pour chef Pierre Macaris, il ne se présenta qu'une seule fois aux élections, en 1950, avec une unique liste de 6 candidats à Athènes.

13. Centre Démocratique - Union Agraire Libérale (Dimocraticon Kendron Filelefthera Agrotiki Enossis). — Créé en février 1961 par la fusion des [p. 469] partis Libéral - Démocratique (voir sous 32), Agraire et Ouvrier (voir sous 5) et Nouveau Mouvement Politique (voir sous 49), sous la présidence de G. Papandréou. Ce regroupement fut la première étape vers l'unification des 
formations du Centre qui aboutit en septembre de la même année, à l'Union du Centre (voir sous 85).

14. Parti Chrétien des Grecs Orthodoxes (Christianicon Comma Ellinorthodoxon). - Ayant pour chef Spyridon Coccoris, il prit part aux élections de 1950, dans la coalition électorale du Front Chrétien Travailliste Agraire. Par ailleurs, nous trouvons son chef S. Coccoris, en 1946, sur les listes de la Coalition Chrétienne Orthodoxe des Hellènes et, en 1951, sur les listes du Parti Populiste.

15. Parti Chrétien National de Grèce (Christianicon Ethnicon Comma Ellados). Ayant pour chef Georges Stocas, il se présenta une seule fois aux élections de 1950, dans la coalition électorale du Front Chrétien Travailliste Agraire. Aux élections précédentes (1946), nous trouvons son chef, G. Stocas, dans la Coalition Chrétienne Orthodoxe des Hellènes.

16. Coalition Chrétienne Orthodoxe des Hellènes (Christianiki Orthodoxos Parataxis Ellinon). Se présenta une seule fois aux élections, en 1946, ayant à sa tête, un Comité Directeur. La coalition était composée de divers groupements chrétiens qui, par la suite, se présentèrent sous des étiquettes différentes (voir sous 14, 15, 26 et 62).

17. Parti Chrétien Travailliste Agrarien (Christianicon Ergaticon Agroticon Comma). - Avec, pour chef, Jean Lazaris, il se présenta une seule fois aux élections, en 1950, dans la coalition électorale du Front Chrétien Travailliste Agraire. Aux élections de 1946, son chef, J. Lazaris, figurait sur les listes du Parti National de Grèce.

18. Parti Communiste de Grèce (Commounisticon Comma Ellados). — En 1918 le premier Congrès Socialiste Grec (4 novembre), créa le parti Socialiste Travailliste qui, lors de son deuxième Congrès 5-12 avril 1920, fut transformé en Parti Communiste. Après la libération, le parti Communiste s'abstint de participer aux élections de 1946. Il a été interdit en 1947 et depuis la fin de la rébellion communiste (1949), sa direction se trouve à Bucarest.

19. Démocratie Chrétienne (Christianiki Dimocratia). — Se présenta une seule fois aux élections en 1956 avec une unique liste de deux candidats dans la circonscription de Samos. Son chef, Nicolas Psaroudakis avait figuré comme candidat, aux élections de 1950, sur les listes du Front Chrétien Travailliste Agraire et aux élections de 1951, sur celles de l'Union Nationale Progressiste du Centre.

20. Parti Démocratique du Peuple Travailleur (Dimocraticon Comma Ergazomenou Laou). - Fondé en 1953, il constitue en partie le prolongement du Parti Socialiste-Union de la Démocratie Populaire dit en abrégé Socialiste-ELD, d'après les initiales grecques de l'Union (voir [p. 470] sous 81). En effet, le Parti Démocratique du Peuple Travailleur a été formé par le groupe du Parti Socialiste-ELD qui a suivi son chef, Alexandre Svolos et par l'aile de gauche de l'Union Nationale Progressiste du Centre, qui a suivi Georges Cartalis, après la mort de son chef, le général Plastiras. Il se présenta, sous la direction commune de Svolos et Cartalis, aux élections de 1956, sous le drapeau de la large coalition électorale de l'Union Démocratique et obtint 20 sièges au Parlement. Après la 
mort de ses deux chefs, la direction du Parti a été assumée par Stelios Alamanis (30 septembre 1957). Aux élections de 1958 le parti Démocratique du Peuple Travailleur participa à la coalition électorale de l'Union Progressiste Agricole Démocratique et obtint 1 siège au Parlement. En 1961, son chef, S. Alamanis, adhère à l'Union du Centre.

21. Parti Démocratique Progressiste (Proodefticon Dimocraticon Comma. - Il apparut sur la scène politique aux élections de 1950. Son chef, Emmanuel Tsouderos, collabora électoralement avec le général Plastiras, sous le drapeau de l'Union Nationale Progressiste du Centre (voir sous 91). Le 14 juillet 1951 il quitte l'EPEK avec 16 députés et adhère au Parti Libéral sous le drapeau duquel il se présente aux élections de septembre 1951. Par la suite, il adhère au Rassemblement Hellénique et participe sous ce titre aux élections de 1952.

22. Parti Démocratique Réformiste (Dimocraticon Metarithmisticon Comma). — Se présenta une seule fois aux élections, en 1958. Son chef, Thémistoclis Ketseas, collabora électoralement à la coalition de l'Union du Parti Populiste. Il n'obtint aucun siège au Parlement.

23. Parti Démocratique Socialiste (Dimocraticon Socialisticon Comma). — Fondé par Georges Papandréou en 1935, il participa après la guerre aux élections de 1946 et obtint 27 sièges. Par la suite, le parti changea de nom et s'intitula Parti de Georges Papandréou (voir sous 54).

24. Parti d'Égalité Sociale Chrétienne (Comma Christianikis Issopolitias). Participa une seule fois aux élections en 1950, sous la direction d'un Comité Directeur. Il présenta sans succès deux candidats dans une circonscription électorale.

25. Groupe Politique Embros (Politiki Omas Embros). — Se présenta aux élections de 1946 sous le drapeau de la coalition des Nationalistes.

26. Parti de la Force Chrétienne Orthodoxe des Hellènes (Comma Christianorthodoxou Dynameos Ellinon). - Se présenta aux élections de 1950, dans la coalition électorale du Front Chrétien Travailliste Agraire. Son chef, Minas Soldatos, figurait aux élections de 1946 sur les listes de la Coalition Chrétienne Orthodoxe des Hellènes.

27. Gauche Démocratique Unifiée (Eniaia Dimocratiki Aristera) (EDA). Elle a été créée en août 1951, avant les élections du 9 septembre. Elle constitue la troisième tentative de regroupement des forces de Gauche, [p. 471] après l'interdiction du PC, les deux premières ayant été le Front Démocratique et le Rassemblement Démocratique (voir sous 67). L'EDA a été formée par les partis ou groupements suivants : a) le Rassemblement Démocratique (voir sous 67), b) le Parti socialiste de J. Passalidis voir sous 78), c) le Parti des Libéraux de Gauche (voir sous 35), d) le Parti Radical de Michel Kyrkos (voir sous 65), e) un groupe du Parti de l'Union des Démocrates de Gauche (voir sous 86), sous la direction de E. Papachristos et J. Cocorelis qui formèrent un parti unifié. L'EDA participa aux élections de 1951 et obtint 10 sièges. Aux élections de 1952, elle ne réussit pas à avoir de représentation parlementaire. En 1956, elle participa aux élections, collaborant avec d'autres partis bourgeois dans une sorte de front 
populaire, l'Union Démocratique, et obtint 18 sièges. En 1958, elle se présente seule aux élections et réussit à obtenir 79 sièges, devenant ainsi le deuxième parti au sein du Parlement grec. Pendant la législature, un certain nombre de députés suivirent Elie Tsirimocos, qui crée l'Union Démocratique (voir sous 87), (à ne pas confondre avec la coalition frontiste de 1956 qui portait le même nom). Une autre fraction de députés de l'EDA, pour des raisons de tactique parlementaire, forme le Nouveau Mouvement Agraire (voir sous 48). Aux élections de 1961, après l'échec des tentatives pour la création d'un front populaire, l'EDA se présente aux élections avec le Parti National Agraire (voir sous 38) sous la dénomination de Front Pandémocratique Agraire de Grèce. La coalition obtint 24 sièges. Aux élections de 1963 et 1964, elle se présente seule et obtient respectivement 28 et 22 sièges.

28. Parti des «Hites" de la Résistance Nationale (Comma Hiton Ethnikis Antistasseos). - Créé après la libération par les éléments d'un groupe de résistance « $\mathrm{x}$ ». Les partisans de l'organisation " $\mathrm{x}$ » étant d'après la phonétique grecque, surnommés «Hites», on a nommé ainsi le parti. Le groupe de résistance était commandé par le Colonel G. Grivas. Ce parti, de tendance de Droite, participa aux élections de 1946 avec Constantin Efstathopoulos comme chef. Il présenta sans succès 5 candidats dans deux circonscriptions.

29. Parti Indépendant Agricole (Anexartiton Georgicon Comma). - Ayant pour chef Tilemachos Baltsavias, il participa une seule fois aux élections, en 1950. De caractère purement local, il présenta sans succès deux candidats dans la circonscription de Céphalonie.

30. Parti Indépendant des Artisans et Professionnels de Grèce (Anexartiton Epaguelmatoviotechnicon Comma Ellados). — Participa une fois aux élections, en 1950. Son chef était Nicolas Trighatzis. Il présenta des candidats dans la circonscription d'Athènes et obtint 42 voix. De caractère plutôt folklorique, il faisait la joie des halles d'Athènes en période pré-électorale.

31. Parti Libéral (Comma Fileleftheron). — Fondé par Éleuthère Venizélos. C'est un des plus anciens partis de Grèce. Après la guerre, le parti se [p. 472] scinda en plusieurs fractions qui suivirent soit le fils soit l'un ou l'autre des lieutenants d'E. Venizélos. La fraction « légitimiste » suivit l'héritier politique d'E. Venizélos, Themistocle Sophoulis qui se présenta aux élections de 1946 et obtint 48 sièges au Parlement. Après la mort de Sophoulis, en 1949, Sophocle Venizélos fut proclamé chef du parti (voir sous 34). Sous sa présidence, le parti Libéral participa aux élections de 1950 (56 sièges) et aux élections de 1951 (57 sièges). En 1952, il se présenta en collaboration électorale avec l'Union Nationale Progressiste du Centre (voir sous 91) et le Parti Socialiste-ELD (voir sous 81) et obtint 30 sièges.

En mai 1953, G. Papandréou revint au Parti Libéral et fut nommé Chef de celui-ci conjointement avec S. Venizelos. En avril 1954, S. Venizelos décida d'abandonner la politique et Georges Papandréou fut nommé chef du parti. Sous sa présidence, le Parti Libéral participa aux élections de 1956 et obtint 26 sièges. Après cette date, S. Venizélos étant revenu sur sa décision d'abandonner la 
politique qui n'avait jamais été effective (voir sous 88), reprit la direction du Parti Libéral, conjointement avec G. Papandréou en mars 1957. Aux élections de 1958, sous cette double présidence, le parti obtint 36 sièges au Parlement. Par la suite, il se scinda à nouveau en 3 partis (voir sous 32 et 49). À fin septembre 1961, le Parti Libéral, sous la présidence de S. Venizélos, adhéra à l'Union du Centre (voir sous 85).

32. Parti Libéral Démocratique (Fileleftheron Dimocraticon Comma). — Créé par G. Papandréou après la scission du Parti Libéral en 1958 (voir sous 31), cette formation n'eut qu'un rôle temporaire et aboutit à la création de l'Union du Centre (voir sous 85).

33. Parti Libéral Nationaliste (Comma Ethnicon Fileleftheron). - Créé par Stilianos Gonatas, après la guerre, il groupait des éléments du Parti Libéral d'avant-guerre qui s'étaient éloignés de ce dernier à propos de la question du retour de la dynastie. Il s'allia avec la Droite aux élections de 1946 et obtint 34 sièges. Le 19 janvier 1950, S. Gonatas demanda sa réintégration dans le parti Libéral ; cette proposition fut acceptée le 24 janvier par le Comité directeur du Parti Libéral et ainsi S. Gonatas participa aux élections de mars 1950 sous le drapeau Libéral. Il se retira de la politique en 1951 après avoir été exclu de la liste libérale d'Athènes sur la pression de G. Melas.

34. Parti Libéral Venizeliste (Comma Venizelicon Fileleftheron). — Fondé par Sophocle Venizélos après la guerre, il participa aux élections de 1946 et obtint 31 sièges. Il était lui aussi l'un des produits de la « guerre de succession » livrée au titre de l'héritage politique d'Éleuthère Venizélos. S. Venizélos a été réintégré dans le Parti Libéral en octobre 1947 et proclamé chef du parti après la mort de Sophoulis (voir sous 31).

35. Parti des Libéraux de Gauche (Comma Aristeron Fileleftheron). - Ayant à sa tête Neocosmos Grigoriadis, il groupait des éléments de gauche du [p. 473] Parti Libéral. Il fut un des éléments qui reconstituèrent la Gauche après l'interdiction du Parti Communiste Grec. En 1950, en alliance avec l'Union des Démocrates de Gauche (voir sous 86) et le Parti Socialiste-ELD (voir sous 81), il constitua le Front Démocratique, qui obtint 18 sièges. En 1951, N. Grigoriadis participe à la création de la Gauche Démocratique Unifiée (voir sous 27). Il quitta cette dernière peu après et ne réapparut plus sur la scène politique.

36. Parti des Libéraux Indépendants (Comma Anexartiton Fileleftheron). Formation occasionnelle, fondée par Georges Melas, cadre du Parti Libéral en signe de protestation contre la réintégration de S. Gonatas dans le Parti Libéral, elle présenta sans succès des candidats dans deux circonscriptions (Athènes, Le Pirée) aux élections de 1950. Le groupe retourna au Parti Libéral, sur les listes duquel G. Melas figura comme candidat aux élections de 1951.

37. Parti des Libéraux Progressistes du Centre (Comma Proodefticon Fileleftheron Kendrou). - Créé par le Général Plastiras, il était en grande partie formé par des éléments libéraux de Centre-Gauche. Il collabora lors des élections de 1950, avec le Parti Démocratique Progressiste (voir sous 21) dans une coalition appelée Union Nationale Progressiste du Centre (voir sous 91) et obtint 45 sièges. Après 
ces élections, le parti du général garda le nom d'Union Nationale Progressiste du Centre.

38. Parti National Agraire (Ethnicon Agroticon Comma). - Créé avant les élections de 1961 avec des hommes de Centre-Gauche désireux de collaborer avec L'EDA et des éléments de celle-ci (voir sous 27), il se présente à ces élections dans une coalition EDA - Parti National Agraire appelée Front Pandémocratique Agraire de Grèce, et obtint 2 sièges. Par suite de l'hésitation de la Gauche à laisser ses militants ruraux travailler dans le parti, celui-ci n'a pas effectué de percée dans les campagnes et se trouve actuellement en veilleuse.

39. Parti National Agraire de "Hites» (Ethnicon Agroticon Comma Hiton). Ayant pour chef Georges Grivas, il constitue le prolongement du Parti des " Hites » de la Résistance Nationale (voir sous 28 ; il participa aux élections de 1950 et présenta des candidats dans 20 circonscriptions électorales, sans obtenir de siège. Par la suite, son chef, G. Grivas, adhéra au Parti Populiste, sur les listes duquel il figura aux élections de 1951. Après son retour de Chypre, où il fut le chef de l'EDAKA (Organisation Nationale de Libération de Chypre), le Général Grivas fonda à la veille des élections de 1961 le Mouvement de Reconstitution Nationale (voir sous 69).

40. Parti National Byzantin de Grèce (Ethnicon Byzantinon Comma Ellados). Son chef était Michel Angelopoulos «prétendant au trône de Byzance ». Il se présenta régulièrement aux élections d'après-guerre, jusqu'à sa mort, pour la plus grande joie des habitants de Salonique. Son insuccès politique n’affecta en rien sa popularité, et certaines de ses [p. 474] réunions " politiques » égalaient en assistance celles des plus grands partis.

41. Parti National de Grèce (Ethnicon Comma Ellados). — Fondé après la guerre par Napoléon Zervas qui avait dirigé pendant l'occupation, les troupes de l'EDES, organisation de résistance opposée à l'EAM mais qui s'est toujours réclamée de la République. Il se présenta aux élections de 1946 et obtint 20 sièges. Aux élections de 1950, il obtint 7 sièges. Par la suite, son chef figura sur les listes du Parti Libéral, aux élections de 1951, et se présenta comme candidat isolé de la circonscription de Arta, en 1952. La force de ce parti était principalement localisée dans la Grèce du Nord-Ouest, où le général Zervas tenait ses quartiers pendant l'occupation.

42. Parti National Démocratique (Ethnicodimocraticon Comma). - Ayant pour chef Byron Jovanof, se présenta une seule fois aux élections en 1950 dans une unique circonscription, sans succès.

43. Parti National Indépendant des Invalides et Victimes de Guerre (Ethnicon Anexartiton Comma Anapiron Kai Thymaton Polemou). — Il participa une seule fois aux élections de 1950, en présentant sans succès deux candidats dans deux circonscriptions. Son chef, Georges Georgandas, figurait en 1946 sur les listes du Parti National de Grèce.

44. Parti National Panhellénique (Panellinion Ethnicon Comma). — Ayant à sa tête Alexandre Sakellariou, il participa aux élections de 1946, dans la coalition des 
Nationalistes. Lors des élections de 1950, A. Sakellariou se présenta au peuple à la tête d'une formation appelée Parti Panhellénique (voir sous 53).

45. Parti National Populiste (Ethnicon Laïcon Comma). — Fondé par Pierre Mavromichalis, l'un des dirigeants du Parti Populiste (voir sous 56), il participa sans succès aux élections de 1950, dans une coalition appelée Front du Peuple Travailleur. Son chef, P. Mavromichalis qui figurait sur les listes du Parti Populiste en 1946 et 1958 se présenta comme candidat isolé en 1952.

46. Parti National Unioniste (Ethnicon Enoticon Comma). — Fondé par Panayotis Canellopoulos, en 1935, il participa pour la première fois aux élections en 1946, en collaboration avec d'autres partis dans l'Union Politique Nationale et obtint 7 sièges. Aux élections de 1950, il participa à une coalition électorale appelée Front de Reconstitution Nationale, et obtint également 7 sièges. En novembre 1950, Canellopoulos fonda avec St. Stephanopoulos le Parti Populiste Unioniste (voir 59). Par la suite, en août 1951, P. Canellopoulos adhéra au Rassemblement Hellénique (voir sous 68) et fut l'un des lieutenants du Maréchal Papagos. Aux élections de 1956, il collabora électoralement avec l'Union Nationale Radicale (voir sous 92), qui succéda au Rassemblement Hellénique après la mort du Maréchal Papagos ; aux élections de 1958, il se pré-[p. 475] senta comme chef, conjointement avec C. Tsaldaris, du Parti Populiste (voir sous 56), après quoi il rejoignit l'Union Nationale Radicale, sur les listes de laquelle il figura comme candidat aux élections de 1961.

47. Parti des Nationalistes (Comma Ethnicofronon). — Fondé par Théodore Tourcovassilis, il était essentiellement de caractère régional (localisé dans le Péloponnèse et, plus spécialement dans le Centre et l'Est de celui-ci). Aux élections de 1946, en collaboration avec le Parti Agraire Populiste et sous l'étiquette d'Union des Nationalistes, il présenta des candidats dans 5 circonscriptions du Péloponnèse et obtint 9 sièges. Aux élections de 1950, il collabora avec le Parti de la Renaissance Hellénique dans une coalition appelée Front Politique Indépendant qui obtint 16 sièges. En 1951, Th. Tourcovassilis se présenta comme candidat Populiste et en 1952 comme candidat isolé sans succès. En 1956, le parti des Nationalistes présenta une liste indépendante en Arcadie, également sans succès. Aux élections de 1958, Tourcovassilis participa à l'Union du Parti Populiste. Finalement, en septembre 1961, il adhère à l'Union du Centre. Lors des élections de 1963, il déclara qu'il se retire de la politique.

48. Nouveau Mouvement Agraire (Nea Agrotiki Kinissis). - Cette formation politique parlementaire fut créée temporairement par un groupe de députés ayant collaboré avec l'EDA et ayant été élus sur ses listes, après les élections de 1958, pour des raisons de tactique politique (essai de renforcement de l'influence du parti dans les campagnes et peut-être aussi volonté de rassurer l'opinion centriste en divisant apparemment les effectifs du parti). Ce groupe, ferment du Parti National Agraire, ne participa jamais en tant que parti à des élections, ayant été dissous peu de temps après sa création.

49. Nouveau Mouvement Politique (Nea Politiki Kinissis). - Formation parlementaire constituée en novembre 1958, après la scission du Parti Libéral 
(voir sous 31) par un groupe de dix députés libéraux. Dirigée par un Comité, elle avait pour porte-parole Athanassiadis-Novas. Elle participa à la création de l’Union du Centre (voir sous 85).

50. Nouveau Parti (Neon Comma). — Son chef, Spyridon Markézinis, cadre du Parti Populiste, sous le drapeau duquel il se présenta aux élections de 1946, créa le Nouveau Parti le 10 février 1947 auquel adhérèrent 18 députés populistes. Il participa aux élections de 1950 et obtint un siège parlementaire. Par la suite, en août 1951, le NP a été dissout et S. Markézinis adhéra au Rassemblement Hellénique (voir sous 68).

51. Nouveau Parti Social (Neokinonicon Comma). — Dirigé par Spyridon Botsaris, il participa une seule fois aux élections, en 1950, en collaboration avec le Parti Socialiste Chrétien de Grèce (voir sous 80 ), dans la coalition électorale de l'Union Politique Chrétienne. La coalition présenta sans succès des candidats dans 3 circonscriptions.

52. Parti Ouvrier et Artisan de Grèce (Ergatoepaguelmaticon Comma Ella-[p. 476] dis). - Participa uniquement aux élections de 1950, sans succès, sous la direction d'un Comité Directeur.

53. Parti Panhellénique (Panellinion Comma). — En fait, il constitue le même parti que le Parti National Panhellénique (voir sous 44) présidé par A. Sakellariou. Il participa aux élections de 1950, dans la coalition du Front de la Reconstitution Nationale.

54. Parti de Georges Papandréou (Comma Georgiou Papandréou). — Prolongement du Parti Démocratique Socialiste (voir sous 23) qui changea de nom en prenant celui de son Chef. Il participa aux élections de 1950 et obtint 35 sièges parlementaires. Aux élections de 1951 il n'obtint aucun siège. Aux élections de 1952, G. Papandréou collabora électoralement avec le Rassemblement Hellénique du Maréchal Papagos (voir sous 68) non pas en tant que Chef de parti mais comme personnalité politique indépendante. Élu député, il se détacha du Rassemblement Hellénique et rentra dans le Parti Libéral, dont il fut nommé chef (voir sous 31).

55. Parti Patriotique de Réservistes (Patrioticon Comma Efedron). - Participa une seule fois aux élections, en 1946, sous la direction d'un Comité Directeur. Il présenta des candidats sans succès dans une seule circonscription (Athènes).

56. Parti Populiste (Laïcon Comma). — C'est le plus ancien de tous les partis ayant survécu à la deuxième guerre mondiale. Il a été créé en 1902 par Démètre Gounaris. Son dernier chef Panayotis Tsaldaris étant mort deux mois avant la dictature du 4 août 1936, le Parti reste jusqu'en 1946 sous la direction d'un Comité de cinq membres. Il participa aux élections de 1946 ayant formé, avec d'autres partis, la Coalition de Nationalistes, favorables au retour de la dynastie, qui emporta 206 sièges, dont 156 revenaient au Parti Populiste. Après les élections, Constantin Tsaldaris fut proclamé chef du parti. Aux élections de 1950 quoiqu'en recul notable, il demeurait toujours le plus important avec 62 sièges. Après la création du Rassemblement Hellénique (voir sous 68), le Parti Populiste perdit la majeure partie de ses cadres et de ses électeurs. Aux élections du 9 
septembre 1951, il obtint 2 sièges parlementaires. Aux élections de 1952, la défaite fut totale. De 475.000 voix qu'il avait recueillies en 1946, il tomba à 16.700. Un signe caractéristique de sa désagrégation fut le fait que le parti qui, lors des trois premières élections d'après-guerre était l'un des rares à couvrir de ses listes la totalité du territoire, ne se présenta en 1952 que dans 4 circonscriptions sur les 99 prévues par la loi électorale en vigueur pour ces élections. En 1956, le Parti Populiste participa avec les partis de Centre-Gauche à cette sorte de « front populaire » que fut l'Union Démocratique et obtint 3 sièges parlementaires. En 1958 le Parti Populiste tenta de, réunir un certain nombre de ses anciens cadres dispersés, et forma une coalition électorale nommée Union du Parti Populiste qui obtint aux élections du 11 mai, 4 sièges dont 2 pour le parti. À partir de 1961, il ne participa plus aux élections.

[p. 477]

57. Parti Populiste Progressiste (Laïcon Proodefticon Comma). — Participa une seule fois aux élections en 1950 dans la coalition électorale du Front de Reconstitution Nationale. Son chef, Nicolas Papadopoulos figura, aux élections suivantes, sur les listes du Parti Libéral.

58. Parti Populiste Social (Laïcon Kinonicon Comma). — Son chef, Stéphane Stephanopoulos fut l'un des dirigeants du Parti Populiste. Il quitta ce dernier en novembre 1950 pour former le Parti Populiste Unioniste (voir sous 59). En 1951, il adhéra au Rassemblement Hellénique. Alors qu'il passait pour le Dauphin du Maréchal Papagos, la charge de Premier Ministre fut attribuée par la Couronne à C. Caramanlis. St. Stephanopoulos recréa alors le Parti Populiste Social qui participa aux élections de 1956 sans obtenir de siège. En 1958, il participa à l'Union du Parti Populiste et obtint 2 sièges aux élections du 11 mai. En septembre 1961, le parti adhéra à l'Union du Centre dont il fut l'un des fondateurs (voir sous 85 ).

59. Parti Populiste Unioniste (Laïcon Enoticon Comma). — Résulta de l'Union du Parti National Unioniste et d'un groupe de 27 députés qui quittèrent le parti Populiste en novembre 1950 avec à leur tête St. Stephanopoulos. P. Canellopoulos et St. Stephanopoulos furent conjointement les chefs du Parti Populiste Unioniste qui disposait de 34 députés au Parlement. En août 1951, le parti fut dissout et ses chefs adhérèrent au Rassemblement Hellénique.

60. Parti des Principes de Jean Metaxas (Comma Archon Ioannou Metaxa). - C'est le nom que prit la liste indépendante de Constantin Maniadakis, qui participa aux élections de 1956 dans la circonscription de Corinthe. C. Maniadakis avait été membre du parti du dictateur Jean Metaxas et son ministre de la Police. Par la suite, C. Maniadakis adhéra à l'Union Nationale Radicale.

61. Parti Progressiste (Proodefticon Comma). — Fondé par Spyridon Markézinis en février 1955 après son départ du Rassemblement Hellénique en 1954, il participa aux élections de 1956, sans obtenir de siège parlementaire. Aux élections de 1958, le parti obtint 2 sièges et à celles de 1961, pour lesquelles il collabora électoralement avec l'Union du Centre, le parti eut 16 sièges parlementaires. En 
1963 il se présenta seul aux élections et obtint 2 sièges parlementaires et en 1964, en collaboration avec l'Union Nationale Radicale, il en eut 7.

62. Parti Progressiste Chrétien (Christianicon Proodefticon Comma). — Dirigé par M. Constantin Lykiardopoulos, il participa une seule fois aux élections, en 1950, sans obtenir de siège parlementaire.

63. Parti Progressiste Ouvrier-Technicien (Proodefticon Ergatotechnicon Comma). - Il a été fondé par Pafsanias Catsotas, cadre libéral qui s'est présenté de 1950, 1951, 1952 aux élections sous le drapeau de ce parti. Devenu Maire d'Athènes par la suite, $P$. Catsotas ne se présenta pas [p. 478] aux élections législatives de 1956 et 1958. Il fonda ensuite le Parti Progressiste Ouvrier-Technicien qui ne participa jamais aux élections en tant que tel, ayant adhéré en septembre 1961 à l'Union du Centre sous le drapeau de laquelle P. Catsotas entra au Parlement.

64. Parti de la Propriété Urbaine et Rurale (Asticon Kai Agroticon Comma Idioktissias). - Dirigé par Achille Antonopoulos, il ne participa qu'une seule fois aux élections, en 1946 en présentant sans succès des candidats dans deux circonscriptions. Par la suite, son chef fit acte de candidature aux élections au titre du Parti National de Grèce (1950) et du Parti Populiste (1951). En 1952, il brigua un siège à titre isolé.

65. Parti Radical (Rizospasticon Comma). - Dirigé par Michel Kyrkos, il ne se présenta jamais aux élections en tant que tel. Kyrkos prit part à la création de la Gauche Démocratique Unifiée (EDA) en août 1951 (voir sous 27) et se présenta comme candidat sous le drapeau de celle-ci aux élections de 1951 et 1952.

66. Parti Radical (Rizospasticon Comma). - Fondé par Constantin Rendis qui fut l'un des cadres importants d'abord du Parti Libéral et ensuite de l'Union Progressiste du Centre. Après la mort du général Plastiras, il quitta l'Union Nationale Progressiste du Centre et fonda le Parti Radical. Ce dernier ne se présenta jamais aux élections en tant que tel, mais son chef participa aux élections de 1958, comme personnalité politique indépendante dans la coalition électorale de l'Union Progressiste Agricole Démocratique.

67. Rassemblement Démocratique (Dimocraticos Synagermos). — Créé à l'occasion des élections municipales d'avril 1951, il ne participa jamais aux élections législatives en tant que tel, mais fut une étape importante vers l'unification de la Gauche et la création de la Gauche Démocratique Unifiée (EDA). En effet, après les élections communales et par suite des succès remportés par la formule, les partisans de la Gauche parvinrent à désintégrer le groupe parlementaire des députés ayant été élus sous le drapeau du Front Démocratique en 1950. C'est ainsi que 5 députés du groupe parlementaire du Front Démocratique (L. Karamaounas, Ch. Thymogiannis, F. Chatzibeis, A. Bitakis et D. Christakos), déclarèrent le 5 juillet 1951 qu'ils en constituaient un autre sous le nom de Rassemblement Démocratique. À la veille des élections législatives du 9 septembre 1951, le Rassemblement Démocratique forma, avec d'autres groupements de Gauche, la Gauche Démocratique Unifiée (EDA) (voir sous 27).

68. Rassemblement Hellénique (Ellinicos Synagermos). — Créé par le Maréchal Papagos, il absorba la majeure partie des effectifs, cadres et électeurs, du Parti 
Populiste (voir sous 56) et reçut l'adhésion du Nouveau Parti (voir sous 50) ainsi que du Parti Populiste Unioniste (voir sous 59). Après les élections de 1951, le Rassemblement reçut l'adhésion d'un certain nombre des cadres du Centre. Aux élections de 1951, il obtint la majorité relative avec 114 sièges parlementaires. Aux élections de [p. 479] 1952, il emporta 247 sièges et fut ainsi le premier parti qui, après la guerre, obtint la majorité absolue au Parlement. Après la mort du Maréchal Papagos, survenue en 1955, le parti fut dissout et la majeure partie de ses cadres et électeurs suivirent Constantin Caramanlis qui fonda l'Union Nationale Radicale (voir sous 92).

69. Mouvement de Reconstitution Nationale (Kinissis Ethnikis Anadimiourgias). Il fut fondé par le général Georges Grivas, en novembre 1960 après son retour victorieux de Chypre. Le Chef du Parti Libéral, S. Venizelos, lui céda alors ses 15 députés, lui-même n'y adhérant pas et gardant le titre de chef et le sceau du Parti Libéral. Avec trois autres députés de provenance diverse, Grivas constitua un groupe parlementaire de 18 députés, lui-même ne siégeant pas à la Chambre. Le Général tenta en vain de procéder à un vaste regroupement des cadres « irréprochables » de diverses tendances politiques, pour renverser C. Caramanlis et faire de nouvelles élections. L'opération ayant échoué, il décida de ne pas participer aux élections de 1961 et de dissoudre le Mouvement de Reconstitution Nationale.

70. Parti de Reconstruction (Comma Anasygrotisseos). - Il participa une seule fois aux élections législatives en 1946, dans la coalition des Nationalistes.

71. Parti Réformiste (Metarithmisticon Comma). — Fondé en 1942 par Apostolos Alexandris ancien cadre Libéral, il participa aux élections de 1946, dans la Coalition des Nationalistes et obtint 5 sièges au Parlement. Son Chef s'étant retiré de la politique en 1950 , le parti fut dissout.

72. Parti de la Renaissance Hellénique (Comma Ellinikis Anagenisseos). — Il fut fondé par Constantin Cotzias, ancien Maire d'Athènes et Constantin Maniadakis (voir sous 60). Il participa une seule fois aux élections, en 1950, dans le Front Politique Indépendant qui obtint 16 sièges au Parlement.

73. Mouvement de Renouvellement Politique (Kinissis Politikis Ananeosseos). Fondé par Georges Varvoutis cadre du Parti Libéral, il participa une seule fois aux élections en 1950 en collaboration avec le Parti des Travailleurs de Grèce. Ces deux partis présentèrent sans succès des candidats dans 7 circonscriptions. M. Varvoutis a été candidat du Parti Libéral (aux élections de 1946, 1951, 1952, 1956).

74. Parti de la Résistance Nationale de Grèce (Comma Ethnikis Andistasseos Ellados). - Fondé par Antoine Fosteridis (l'un des chefs de la Résistance en Grèce du Nord pendant l'Occupation), il participa une seule fois aux élections en 1950. Il présenta des candidats dans 9 circonscriptions du Nord de la Grèce (Thrace et Macédoine), sans succès. Par la suite, son chef, Fosteridis, fut successivement candidat sur les listes du Parti Populiste, du Rassemblement Hellénique et du Parti Progressiste. 
[p. 480]

75. Parti des Royalistes (Comma Vassilofronon). - Participa une seule fois aux élections en 1946 dans la Coalition des Nationalistes.

76. Mouvement du Salut National (Kinissis Ethnikis Sotirias). — Participa une seule fois aux élections en 1950 dans la coalition électorale du Front National du Peuple Travailleur, sans obtenir de sièges parlementaires. Par la suite, son chef, Basile Papadakis figura comme candidat sur les listes du Parti de Georges Papandreou (1951).

77. Parti Social de Grèce (Kinonicon Comma Ellados). — Participa une seule fois aux élections en 1946 sous la direction d'un Comité Directeur. Il présenta sans succès un candidat.

78. Parti Socialiste (Socialisticon Comma). — Dirigé par J. Passalidis, il ne participa jamais aux élections en tant que tel, mais il fut l'un des fondateurs essentiels de la Gauche Démocratique Unifiée, dont J. Passalidis devint le Président.

79. Parti Socialiste Archives du Marxisme (Socialisticon-Archion marxisticon Comma). - Groupe du Parti Communiste grec qui s'en sépara avant la guerre pour des divergences ayant trait à la tactique. Ce groupe envisageait de former d'abord des cadres marxistes et d'éduquer la base, avant d'envisager le passage à l'action pour la conquête du pouvoir. Il tirait son nom de la revue qu'il publiait avant la guerre Archives du Marxisme. Il se présenta une seule fois aux élections en 1951 avec deux candidats, sans succès.

80. Parti Socialiste Chrétien de Grèce (Christianicon Socialisticon Comma Ellados). - Il participa une seule fois aux élections en 1950 en collaboration électorale avec le Nouveau Parti Social, sous le nom d'Union Politique Chrétienne. L'Union présenta sans succès des candidats dans 3 circonscriptions.

81. Parti Socialiste - Union de la Démocratie Populaire (Socialisticon CommaEnossis Laïkis Dimocratias) (Parti Socialiste-ELD). - Il fut fondé en janvier 1946 après de longues tractations pour essayer de réunir tous les groupes et personnalités socialistes d'avant-guerre. Il engloba notamment le Parti Socialiste, l'Union de la Démocratie Populaire, fondée par E. Tsirimocos pendant l'Occupation, le Parti Socialiste Révolutionnaire, une fraction du Parti Socialiste Unifié, l'Union Travailliste Socialiste, ainsi que diverses personnalités socialistes, telles que Alexandre Svolos, professeur à l'Université d'Athènes. A. Svolos fut élu président du parti et E. Tsirimocos, secrétaire. Par ailleurs, il fut reconnu comme le seul parti socialiste grec au Congrès international socialiste de Bournemouth, en novembre 1946. Aux élections de 1946, il s'abstint, ainsi que tous les partis de Gauche. En 1950, il collabora électoralement avec d'autres partis de Gauche et d'Extrême-Gauche, au sein du Front Démocratique qui obtint 18 sièges. Aux élections de 1951, il ne réussit pas à obtenir de siège. Aux élections de 1951 qu'il affronta en collaboration avec les [p. 481] partis du Centre, il n'obtint pas non plus de représentation parlementaire. Par la suite, le parti éclata, A. Svolos ayant fondé avec G. Cartalis ; le Parti Démocratique du 
Peuple Travailleur (voir sous 20) ; E. Tsirimocos collabora avec l'EDA jusqu'à la création, par lui, de l'Union Démocratique (voir sous 87).

82. Parti du Tiers État (Comma Tritis Catastasseos). — Fondé par Alexandre Vamvetsos, il participa aux élections de 1950 sans obtenir de siège.

83. Parti des Travailleurs de Grèce (Comma Ergazomenon Ellados). — Fondé par Jean Bérnitsas, cadre du Parti Populiste il participa une seule fois aux élections, en 1950, présentant sans succès des candidats dans 14 circonscriptions en son nom propre et dans 7 autres en collaboration avec le Mouvement du Renouvellement Politique.

84. Parti Travailliste de Grèce (Ergaticon Comma Ellados). — Son chef fut Aristide Dimitratos qui, aux élections de 1946, présenta une liste locale indépendante dans la circonscription de Céphalonie, liste dite des Nationaux Royalistes. Cette liste ayant obtenu la deuxième place dans la circonscription, A. Dimitratos obtint un siège. Celui-ci participa aux élections de 1950 comme chef du Parti Travailliste de Grèce, sans obtenir de siège au Parlement, par la suite, A. Dimitratos adhéra successivement au Parti Populiste et à l'Union Nationale Radicale.

85. Union du Centre (Enossis Kendrou) (EK). — Elle a été créée le 19 septembre 1961. Au Centre Démocratique - Union Agraire Libérale (voir sous 13) sont venus s'ajouter, en août 1961, l'Union Démocratique d’E. Tsirimocos (voir sous 87) et en septembre, le Parti Libéral (voir sous 31), l'Union Nationale Progressiste du Centre (voir sous 91), le Parti Progressiste Ouvrier-Technicien (voir sous 63), le Parti Populiste Social (voir sous 58) et le Parti des Nationalistes (voir sous 47). L'Union du Centre fut placée sous la présidence de G. Papandreou et prit la forme d'un parti et non pas d'une coalition de partis. Aux élections de 1961, elle emporta 85 sièges et devint ainsi le deuxième parti à la Chambre. Le parti emporta les élections de 1963 avec la majorité relative, 136 sièges, et les élections de 1964 avec la majorité absolue de la Chambre, 173 sièges.

86. Union des Démocrates de Gauche (Enossis Dimocraticon Aristeron). — Dirigée par Jean Sophianopoulos, l'Union s'abstint aux élections de 1946. Elle se présenta à celles de 1950 en collaboration avec d'autres partis de Gauche, dans le cadre du Front Démocratique, qui obtint 18 sièges au Parlement. Elle participa à la création de la Gauche Démocratique Unifiée.

87. Union Démocratique (Dimocratiki Enossis). — S'étant séparé du Parti Socialiste-ELD (voir sous 81), Elie Tsirimocos collabora électoralement avec la Gauche Démocratique Unifiée (EDA) aux élections de 1958. Quelque temps après, il se sépara de cette dernière, suivi par quelques dé-[p. 482] putés avec lesquels il fonda l'Union Démocratique. Celle-ci adhéra à l’Union du Centre en août 1961.

88. Union Libérale Démocratique (Filelefthera Dimocratiki Enossis). — Fondée par S. Vénizélos après l'abandon par ce dernier de la direction du Parti Libéral à G. Papandréou, elle participa aux élections de 1956 et obtint 43 sièges au Parlement. Après quoi, Vénizélos et Papandréou s'étant de nouveau mis d'accord, l’Union 
Libérale Démocratique fut réincorporée dans le Parti Libéral, qui fut placé sous la double présidence de Vénizélas et Papandréou.

89. Union des Libéraux et Combattants Nationaux (Enossis Fileleftheron Kai Ethnicon Agoniston). - Le chef du parti, M. Tsarlabas, se présenta aux élections en 1946 sous le drapeau du Parti National de Grèce, en 1951 sous le drapeau de l'EPEK, en 1952 comme candidat isolé et en 1958 sous le drapeau Libéral. En 1961, il se présenta comme chef de l'Union de Libéraux et Combattants Nationaux. Ce parti présenta sans succès deux candidats aux circonscriptions de Leucade et de Prévéza.

90 Parti de l'Union Nationale (Comma Ethnikis Enosseos). — Ce parti, dont le chef fut Démètre Papapolyzos, participa une seule fois aux élections en 1946 par la présentation sans succès d'un candidat.

91. Union Nationale Progressiste du Centre (Ethniki Proodeftiki Enossis Kendrou) (EPEK). - Ce nom fut d'abord utilisé pour désigner la coalition des Libéraux Progressistes du Centre et du Parti Démocratique Progressiste (voir sous 37 et 21) aux élections de 1950. Il servit ensuite, juillet 1951, à appeler le parti du Général Plastiras. Aux élections de 1951, il emporta 74 sièges, devenant le deuxième parti à la Chambre. En 1952, l'EPEK et le Parti Libéral qui s'étaient associés électoralement obtinrent 51 sièges. Après la mort du Général Plastiras, Savvas Papapolitis prit la direction du parti. Aux élections de 1956, participant à l'Union Démocratique, l'EPEK obtint 15 sièges. En 1958, elle obtient un siège à Chios où N. Zorbas est élu dans la coalition PADE. En septembre 1961, l'Union Nationale Progressiste du Centre adhère à l'Union du Centre (voir sous 85).

92. Union Nationale Radicale (Ethniki Rizospastiki Enossis) (ERE). — Après la mort du Maréchal Papagos, survenue en 1955, la majeure partie du Rassemblement Hellénique suivit Constantin Caramanlis qui fonda l'Union Radicale le 4 janvier 1956. Ce parti détint la majorité absolue de la Chambre de 1956 à 1963 et, par conséquent, le pouvoir. Aux élections de 1956, il obtint 165 sièges au Parlement, à celles de 1958, 171 sièges et aux élections de 1961, 176 sièges. Il a été battu, pour la première fois depuis sa création, aux élections de 1963 obtenant 132 sièges. Après cette défaite, son chef C. Caramanlis abandonna la direction du parti et fut remplacé par P. Canellopoulos. Aux élections de 1964, L’ERE obtint 101 sièges et détient la deuxième place dans la Chambre.

[p. 483]

93. Union Patriotique (Patriotiki Enossis). - Elle a pris part une seule fois aux élections, en 1946, faisant partie de la Coalition des Nationalistes.

94. Union Républicaine (Dimocratiki Enossis). - Elle participa une seule fois aux élections, en 1946, en collaboration avec les Partis Libéral Vénizéliste, Démocratique Socialiste et National Unioniste.

95. Union Sociale Radicale (Kinoniki Rizospastiki Enossis). - Elle prit part une seule fois aux élections, en 1946, faisant partie de la Coalition des Nationalistes. 
[p. 484]

\section{TABLEAU \\ DES COALITIONS ÉLECTORALES}

$\underline{\text { Retour à la table des matières }}$

1946

I. Coalition des Nationalistes (Inomeni Parataxis Ethnicofronon). Partis ${ }^{\text {os }}$ : 56, 33, 71, 44, 93, 75, 70, 95, 25.

II. Union Politique Nationale (Ethniki Politiki Enossis).

Partis $n^{\text {os }}: 34,23,46,94$.

III. Union des Nationalistes (Enossis Ethnicofronon). Partis $n^{\text {os }} 47,8$.

IV. Union des Partis Agraires (Enossis Agroticon Commaton). Partis $n^{\text {os }}: 2,4,3,7$.

1950 I. Union Nationale Progressiste du Centre (Ethniki Proodeftiki Enossis Kendrou) (EPEK).

Partis $\mathrm{n}^{\text {os }}:$ 37, 21.

II. Front Démocratique (Dimocratiki Parataxis) (DP).

Partis $\mathrm{n}^{\text {os }}: 86,81,35$.

III. Front Politique Indépendant (Politiki Anexartitos Parataxis) (PAP).

Partis ${ }^{\text {os }}: 72,47$.

IV. Front de Reconstitution Nationale (Metopon Ethnikis Anadimiourgias) (MEA). Partis $n^{\text {os }}: 46,57,53$.

V. Front des Agriculteurs et Travailleurs (Parataxis Agroton Kai Ergazomenon (PAE).

Partis $n^{\text {os }}: 11,6$.

VI. Front National du Peuple Travailleur (Ethniki Parataxis Ergazomenou Laou) (EPEL).

Partis $\mathrm{n}^{\text {os }}: 45,82,84,76$.

VII. Coopération des Partis : Travailleurs de Grèce et Mouvement de Renouvellement Politique (Symbraxis Commaton: Ergazomenon Ellados Kai Kinissis Politikis Ananeosseos).

Partis n ${ }^{\text {os }} 83,73$. 
VIII. Front Chrétien Travailliste Agraire (Christianiki Ergatiki Agrotiki Parataxis). Partis $\mathrm{n}^{\text {os }}: 17,14,26,15,62$.

[p. 485]

IX. Union Politique Chrétienne (Christianiki Politiki Enossis). Partis ${ }^{\text {os }}: 80,51$.

I. Union des Partis : EPEK, Libéral, Socialiste-ELD (Enossis Commaton : EPEK, Fileleftheron, Socialisticon-ELD). Partis $n^{\text {os }}: 91,31,81$.

I. Union Démocratique (Dimocratiki Enossis) (DE). Partis $\mathrm{n}^{\mathrm{os}}:$ 88, 31, 20, 27, 91, 5, 56.

I. Union Progressiste Agraire Démocratique (Proodeftiki Agrotiki Dimocratiki Enossis) (PADE). Partis n ${ }^{\text {os: }}$ 61, 91, 5, 20.

II. Union du Parti Populiste (Enossis Laïcou Commatos) (ELK). Partis $\mathrm{n}^{\mathrm{os}}:$ 56, 58, 47, 71, 22.

1961

I. Coalition de l'Union du Centre et du Parti Progressiste (Synaspismos Enosseos Kendrou Kai Proodefticou Commatos).

Partis $\mathrm{n}^{\mathrm{os}}: 85,61$.

II. Front Pandémocratique Agraire de Grèce (Pandimocraticon Agroticon Metopon Ellados) (PAME).

Partis $\mathrm{n}^{\text {os }}: 27,38$.

I. Coalition de l'Union Nationale Radicale et du Parti Progressiste (Synaspismos tis Ethnikis Rizospastikis Enosseos Kai Tou Proodefticou Commatos).

Partis $\mathrm{n}^{\mathrm{os}}:$ 92, 61. 
[p. 486] ANNEXE I

$\underline{\text { Retour à la table des matières }}$

ÉVOLUTION DE LA FORCE PARLEMENTAIRE DES DIVERSES TENDANCES

\begin{tabular}{|c|c|c|c|c|c|c|c|c|c|c|}
\hline $\begin{array}{l}\text { Partis ayant obtenu } \\
\text { une représentation parlementaire }\end{array}$ & 1946 & & 1950 & & 1951 & & 1952 & & 1956 & \\
\hline 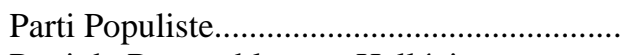 & & 156 & & 62 & & 2 & & - & & 3 \\
\hline Parti du Rassemblement Hellénique.............. & & - & & - & & 114 & & 247 & & - \\
\hline Parti de l'Union Nationale Radicale.............. & & - & & - & & - & & - & & 165 \\
\hline Union des Nationalistes.................................. & & 9 & & - & & - & & - & & - \\
\hline Front Politique Indépendant............................ & & - & & 16 & & - & & - & & - \\
\hline Parti National Unioniste................................... & & 7 & & - & & - & & - & & - \\
\hline Front de Reconstitution National................... & & - & & 7 & & - & & - & & - \\
\hline Parti Populiste Social..................................... & & - & & - & & - & & - & & - \\
\hline Nouveau Parti-Parti Progressiste.................... & & - & & 1 & & - & & - & & - \\
\hline 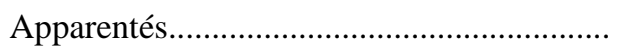 & & 11 & & - & & - & & - & & - \\
\hline Nombre total des Sièges de la Droite & $(51,6 \%)$ & 183 & $(34,4 \%)$ & 86 & $(44,95 \%)$ & 116 & $(82,3 \%)$ & 247 & $(56 \%)$ & 168 \\
\hline Parti Réformiste............................................ & & 5 & & - & & - & & - & & - \\
\hline Parti National de Grèce................................... & & 20 & & 7 & & - & & - & & - \\
\hline Parti Libéral National .......................................... & & 34 & & - & & - & & - & & - \\
\hline Nombre total des Sièges du Centre droit & $(16,9 \%)$ & 59 & $(2,8 \%)$ & 7 & - & - & - & - & - & - \\
\hline 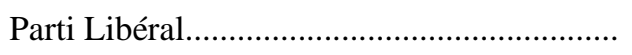 & & 48 & & 56 & & 57 & & 26 & & 26 \\
\hline Parti Libéral Vénizéliste ................................ & & 31 & & - & & - & & - & & - \\
\hline Union Libérale Démocratique........................ & & - & & - & & - & & - & & 43 \\
\hline Parti Démocratique Socialiste......................... & & 27 & & - & & - & & - & & - \\
\hline Parti de G. Papandréou.................................... & & - & & 35 & & - & & - & & - \\
\hline Union Nationale Progressiste du Centre........ & & - & & 45 & & 74 & & 25 & & 15 \\
\hline Union du Centre........................................... & & - & & - & & - & & - & & - \\
\hline Apparentés...……………………………... & & 3 & & - & & - & & - & & - \\
\hline Nombre total des Sièges du Centre & $(30,79 \%)$ & 109 & $(54,4 \%)$ & 136 & $(50,78 \%)$ & 131 & $(17 \%)$ & 51 & $(\mathbf{2 8} \%)$ & 84 \\
\hline
\end{tabular}




\begin{tabular}{|c|c|c|c|c|c|c|c|c|c|c|}
\hline $\begin{array}{l}\text { (suite) Partis ayant obtenu } \\
\text { une représentation parlementaire }\end{array}$ & 1946 & & 1950 & & \multicolumn{2}{|l|}{1951} & 1952 & \multicolumn{3}{|c|}{1956} \\
\hline Parti Agraire de Grèce.................................... & & 1 & & - & & - & & - & & - \\
\hline Front des Agriculteurs et Travailleurs........... & & - & & 3 & & - & & - & & - \\
\hline Rassemblement des Agriculteurs et Travailleurs & & - & & - & & 1 & & - & & - \\
\hline Parti Démocratique du Peuple Travailleur... & & - & & - & & - & & - & & 20 \\
\hline Parti Agraire-Ouvrier....................................... & & - & & - & & - & & - & & 7 \\
\hline Nombre total des Sièges du Centre-Gauche & $(0,28 \%)$ & 1 & $(1,2 \%)$ & 3 & $(0,38 \%)$ & 1 & - & - & $(9 \%)$ & 27 \\
\hline Front Démocratique........................................ & & - & & 18 & & - & - & - & & - \\
\hline Gauche Démocratique Unifiée........................ & & - & & - & & 10 & - & - & & 18 \\
\hline Parti National Agraire ................................... & & - & & - & & - & - & - & & - \\
\hline Nombre total des Sièges de la Gauche & - & - & $(7,2 \%)$ & 18 & $(3,87 \%)$ & 10 & - & - & $(6 \%)$ & 18 \\
\hline 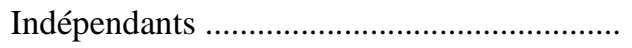 & & 2 & & - & & - & 2 & - & & - \\
\hline Nombre Total des Sièges.................. & & 354 & & 250 & & 258 & & 300 & & 300 \\
\hline
\end{tabular}




\section{[p. 487] ANNEXE I (suite) \\ ÉVOLUTION DE LA FORCE PARLEMENTAIRE DES DIVERSES TENDANCES}

\begin{tabular}{|c|c|c|c|c|c|c|c|c|}
\hline $\begin{array}{l}\text { Partis ayant obtenu } \\
\text { une représentation parlementaire }\end{array}$ & 1958 & & 1961 & & 1963 & & 1964 & \\
\hline 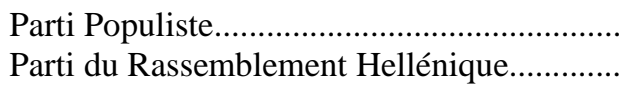 & & 2 & & - & & - & & - \\
\hline Parti de l'Union Nationale Radicale.............. & & 171 & & 176 & & 132 & & 100 \\
\hline Union des Nationalistes................................... & & - & & - & & - & & - \\
\hline Front Politique Indépendant............................. & & - & & - & & - & & - \\
\hline Parti National Unioniste.................................. & & - & & - & & - & & - \\
\hline Front de Reconstitution National................... & & - & & - & & - & & - \\
\hline Parti Populiste Social...................................... & & 2 & & - & & - & & - \\
\hline Nouveau Parti-Parti Progressiste................... & & 2 & & 15 & & 2 & & 7 \\
\hline 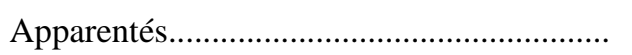 & & - & & - & & - & & - \\
\hline Nombre total des Sièges de la Droite & (59\%) & 177 & $(63.66 \%)$ & 191 & $(44,67 \%)$ & 134 & $(35,7 \%)$ & 107 \\
\hline 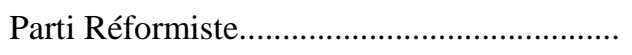 & & - & & - & & - & & - \\
\hline Parti National de Grèce..................................... & & - & & - & & - & & - \\
\hline Parti Libéral National ..................................... & & - & & - & & - & & - \\
\hline Nombre total des Sièges du Centre droit & & - & & - & & - & & - \\
\hline 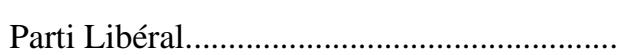 & & 36 & & - & & - & & - \\
\hline Parti Libéral Vénizéliste ................................ & & & & - & & - & & - \\
\hline Union Libérale Démocratique......................... & & & & - & & - & & - \\
\hline Parti Démocratique Socialiste........................ & & & & - & & - & & - \\
\hline Parti de G. Papandréou..................................... & & & & - & & - & & - \\
\hline Union Nationale Progressiste du Centre....... & & 1 & & - & & - & & - \\
\hline Union du Centre.............................................. & & - & & 85 & & 138 & & 171 \\
\hline Apparentés...…………………………….. & & - & & - & & - & & - \\
\hline
\end{tabular}




\begin{tabular}{|c|c|c|c|c|c|c|c|c|}
\hline Nombre total des Sièges du Centre & $(12,33 \%)$ & 37 & $(28,33 \%)$ & 85 & $(46 \%)$ & 138 & $(57 \%)$ & 171 \\
\hline $\begin{array}{l}\text { (suite) Partis ayant obtenu } \\
\text { une représentation parlementaire }\end{array}$ & 1958 & & 1961 & & 1963 & & 1964 & \\
\hline Parti Agraire de Grèce...................................... & & - & & - & & - & & - \\
\hline Front des Agriculteurs et Travailleurs........... & & - & & - & & - & & - \\
\hline Rassemblement des Agriculteurs et Travailleurs & & - & & - & & - & & - \\
\hline Parti Démocratique du Peuple Travailleur... & & 1 & & - & & - & & - \\
\hline Parti Agraire-Ouvrier......................................... & & 6 & & - & & - & & - \\
\hline Nombre total des Sièges du Centre-Gauche & $(2,33 \%)$ & 7 & & - & & - & & - \\
\hline 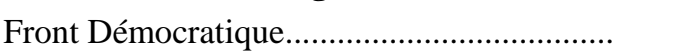 & & - & & - & & - & & - \\
\hline Gauche Démocratique Unifiée........................ & & 79 & & 22 & & 28 & & 22 \\
\hline Parti National Agraire ..................................... & & - & & 3 & & - & & - \\
\hline Nombre total des Sièges de la Gauche & $(26,63 \%)$ & 79 & $(8 \%)$ & 24 & $(9,33 \%)$ & 28 & $(7,3 \%)$ & 22 \\
\hline 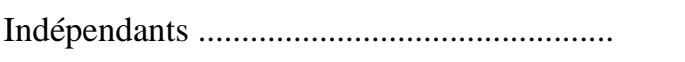 & & - & & - & & - & & - \\
\hline Nombre Total des Sièges.................. & & 300 & & 300 & & 300 & & 300 \\
\hline
\end{tabular}


[p. 488]

\section{ANNEXE II}

$\underline{\text { Retour à la table des matières }}$

\section{Projets de lois soumis par L'EDA au cours de la période 1956-1961}

1. Pour l'augmentation des pensions des mutilés de guerre.

2. Pour l'augmentation des salaires et des pensions.

3. Pour la protection de la production agricole grecque.

4. Pour l'augmentation des salaires des fonctionnaires civils et militaires.

5. Pour la ratification de la convention $n^{\circ} 103$ de l'OIT relative à la protection de la maternité.

6. Pour la proclamation de la fin de la rébellion.

7. Pour le règlement de certains emprunts agricoles.

8. Pour l'allocation d'une pension aux agriculteurs, en cas de vieillesse, d'incapacité de travail et de décès.

9. Pour l'établissement d'une liaison entre les importations étrangères et l'exportation des produits grecs.

10. Pour l'abrogation de la validité de la résolution 3/1946 (relative aux mesures d'exceptions).

11. Pour le contrôle du licenciement des travailleurs.

12. Pour l'abrogation de l'institution de la déportation administrative.

13. Pour la mise en liberté des condamnés sous condition.

14. Pour la modification de certaines clauses de la loi 3289/1955 concernant le règlement des différends collectifs du travail.

15. Pour l'abrogation de la loi obligatoire 375/1936.

16. Pour la modification de la loi 2348/1953 relative au traitement des feuilles de tabac. 
17. Pour l'abrogation de la contribution scolaire et paroissiale.

18 Pour la modification de la loi 3850/1958 relative au recrutement de l'armée.

19. Pour la ratification des résultats du recensement du 7 avril 1951 et la modification de l'article 32 du décret royal du 10-12 avril 1958 concernant la codification des dispositions en vigueur pour l'élection des députés.

20. Pour l'abrogation des mesures d'exception, l'amnistie et la levée des conséquences de l'application des mesures d'exception.

21. Pour l'octroi de facilités de paiements et la diminution des impôts et des charges sur les dettes antérieures.

[p. 489]

22. Pour la dénonciation de l'accord entre l'État et la Compagnie des Eaux.

23. Pour la modification du code des communes et des municipalités concernant les revenus des municipalités et des communes.

24. Pour la reconnaissance de l'Organisation de la Résistance Nationale et la prise de mesures de protection pour ses membres.

Ces 24 projets peuvent être classés de la façon suivante :

\begin{tabular}{|c|c|c|c|}
\hline \multicolumn{3}{|c|}{ Projets d'ordre politique } & 8 \\
\hline " & $»$ & social & 7 \\
\hline$\gg$ & $»$ & financier & 4 \\
\hline$»$ & $»$ & économique & 4 \\
\hline$»$ & $»$ & militaire & 1 \\
\hline
\end{tabular}


[p. 490-491]

\section{ANNEXE III : Balance des paiements}

$\underline{\text { Retour à la table des matières }}$

Importations CIF

Exportations FOB

Balance commerciale

Pourcentage Exp./Imp.

Invisibles

\section{Recettes}

Paiements

Balance des invisibles

Pourcentage invisibles nets/Imp.

Transferts de capitaux (net)

Balance avant aide

Aide américaine

Indemnités de guerre

Erreurs et omissions

Balance des paiements

Achats et ventes d'or dans le pays

et transfert au stock régulateur

Variations des réserves

(augmentation : - ; diminution :)

Variations des disponibilités des

banques commerciales

(augmentation :-)

Réserves officielles en or et en

devises

120,6

$-$

-

$-$

-

$-$

$-$

-

$-2,7$

161,7 207,6

223,5

250,5

269,9

277,9

Crédits des fournisseurs (solde fin de période)

$7,3 \quad 16,1$

16,1

28,9

53,5

$87,3 \quad 105,6 \quad 101,1$

108,9

114,9

146,7

169,9 
[p.492, sans texte p. 493 à 505]

APPENDICE STATISTIQUE

$\underline{\text { Retour à la table des matières }}$

\section{ÉLECTIONS DU 31 MARS 1946}

\begin{tabular}{|c|c|c|c|c|c|c|}
\hline Partis & Chefs de Partis & Voix & $\begin{array}{l}\text { Pourcentage } \\
\text { des voix }\end{array}$ & Sièges & $\begin{array}{l}\text { Nombre de } \\
\text { circonscriptions }\end{array}$ & $\begin{array}{c}\text { Nombre de } \\
\text { candidats }\end{array}$ \\
\hline Coalition des Nationalistes & & 610.995 & 55,12 & $(206)(*)$ & 38 & 354 \\
\hline \multirow{3}{*}{ 1. Parti Populiste...…………………………….......... } & MAVROMICHALIS Pierre & & & & & \\
\hline & THÉOTOKIS Jean & & & 156 & & \\
\hline & TSALDARIS Constantin & & & & & \\
\hline 2. Parti Libéral Nationaliste........................................... & GONATAS Stilianos & & & 34 & & \\
\hline 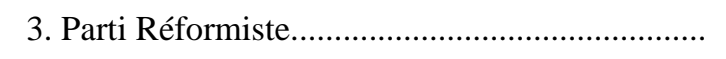 & ÀLEXANDRIS Apostolos & & & 5 & & \\
\hline 4. Parti National Panhellénique................................... & SAKELLARIOU Alexandre & & & 0 & & \\
\hline 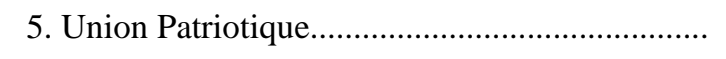 & & & & 0 & & \\
\hline 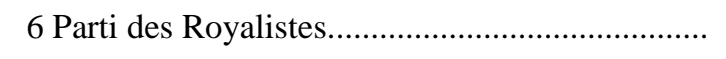 & & & & 0 & & \\
\hline 7. Parti de Reconstruction............................................ & & & & 0 & & \\
\hline 8. Union Sociale Radicale............................................ & & & & 0 & & \\
\hline 9. Groupe politique Embros......................................... & & & & 0 & & \\
\hline Apparentés à la coalition.......................................... & & & & 11 & & \\
\hline Union Politique Nationale & & 213.721 & 19,28 & (68) & 37 & 340 \\
\hline 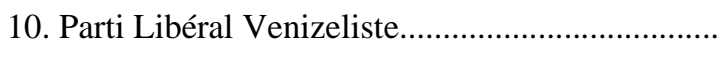 & VÉNIZÉLOS Sophocle & & & 31 & & \\
\hline 11. Parti Démocratique Socialiste.................................... & PAPANDRÉOU Georges & & & 27 & & \\
\hline 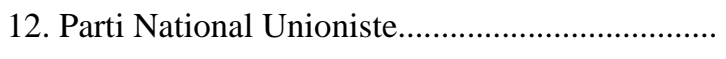 & CANELLOPOULOS Panayotis & & & 7 & & \\
\hline 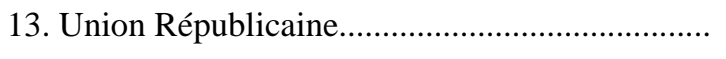 & & & & 0 & & \\
\hline 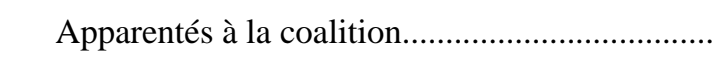 & & & & 3 & & \\
\hline 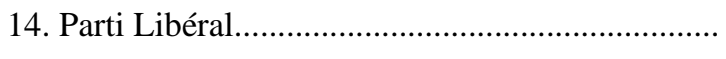 & SOPHOULIS Thémistocle & 159.525 & 14,39 & 48 & 34 & 287 \\
\hline $\begin{array}{l}\text { 15. Parti National de Grèce (de la Résistance } \\
\text { Nationale)........... }\end{array}$ & ZÉRVAS Napoléon & 66.027 & 5,96 & 20 & 20 & 190 \\
\hline
\end{tabular}




\begin{tabular}{|c|c|c|c|c|c|c|}
\hline Partis (suite) & Chefs de Partis & Voix & $\begin{array}{l}\text { Pourcentage } \\
\text { des voix }\end{array}$ & Sièges & $\begin{array}{l}\text { Nombre de } \\
\text { circonscriptions }\end{array}$ & $\begin{array}{l}\text { Nombre de } \\
\text { candidats }\end{array}$ \\
\hline Union des Nationalistes & & 32.538 & 2,94 & (9) & 5 & 40 \\
\hline 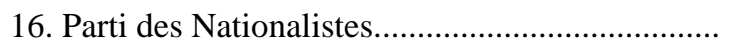 & TOURCOVASSILIS Théodore & & & 9 & & \\
\hline 17. Parti Agraire Populaire......................................... & PAMBOUCAS Georges & & & 0 & & \\
\hline Union des Partis Agraires & & 7.447 & 0,67 & (1) & 5 & 40 \\
\hline 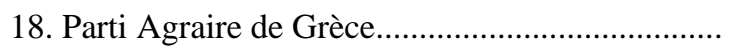 & MYLONAS Alexandre & & & 1 & & \\
\hline 19. Parti Agraire Démocratique de Grèce................. & & & & 0 & & \\
\hline 20. Parti Agraire Démocratique................................... & & & & 0 & & \\
\hline 21. Groupes Agraires du Parti Agraire et Ouvrier.... & & & & & & \\
\hline 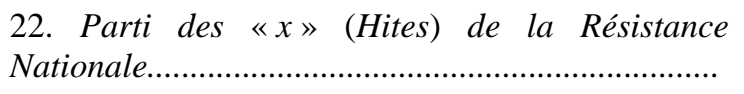 & EFSTATHOPOULOS C. & 1.848 & 0,17 & 0 & 2 & 15 \\
\hline 23. Parti de la Propriété Urbaine et Rurale.............. & ANTONOPOULOS A. & 1.114 & 0,10 & 0 & 2 & 22 \\
\hline 24. Coalition Chrétienne Orthodoxe des Hellènes... & Comité Directeur & 298 & 0,03 & 0 & 2 & 14 \\
\hline 25. Parti Patriotique des Réservistes.......................... & Comité Directeur & 63 & 0,01 & 0 & 1 & 2 \\
\hline 26. Parti de l'Union Nationale.................................... & PAPAPOLYSOS D. & 15 & 0,00 & 0 & 1 & 1 \\
\hline 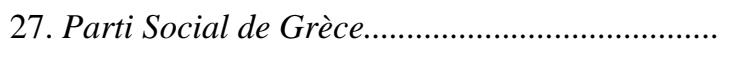 & Comité Directeur & 13 & 0,00 & 0 & 1 & 1 \\
\hline 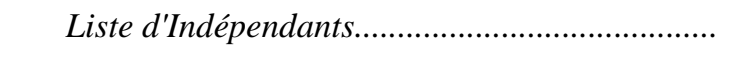 & & 12.036 & 1,08 & 2 & & 25 \\
\hline \multirow[t]{2}{*}{ 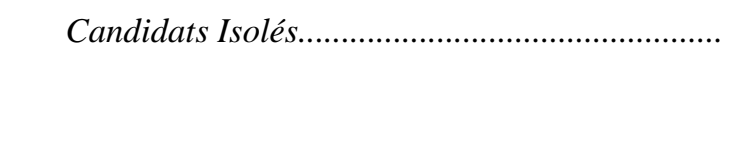 } & & 2.833 & 0,25 & 0 & & 209 \\
\hline & & 1.108 .473 & 100 & 354 & & 1.540 \\
\hline
\end{tabular}

$(*)$ Les nombres entre parenthèses représentent des totaux dont le détail se trouve immédiatement dessous. 


\section{ÉLECTIONS DU 5 MARS 1950}

\begin{tabular}{|c|c|c|c|c|c|c|}
\hline Partis & Chefs de Partis & Voix & $\begin{array}{l}\text { Pourcentage } \\
\text { des voix }\end{array}$ & Sièges & $\begin{array}{l}\text { Nombre de } \\
\text { circonscriptions }\end{array}$ & $\begin{array}{l}\text { Nombre de } \\
\text { candidats }\end{array}$ \\
\hline 1. Parti Populiste & TSALDARIS Constantin & 317.512 & 18,80 & 62 & 39 & 250 \\
\hline 2. Parti Libéral & VÉNIZÉLOS Sophocle & 291.083 & 17,24 & 56 & 39 & 250 \\
\hline $\begin{array}{c}\text { Union Nationale Progressiste } \\
\text { du Centre (EPER) }\end{array}$ & & 277.739 & 16,44 & 45 & 39 & 249 \\
\hline 3. Parti des Libéraux - progressiste du centre & PLASTRAS Nicolas & & & & & \\
\hline 4. Parti Démocratique Progressiste & TOUDÉROS Emmanuel & & & & & \\
\hline 5. Parti de Georges Papandréou & PAPANDRÉOU Georges & 180.185 & 10,67 & 35 & 38 & 247 \\
\hline Front Démocratique & & 163.824 & 9,70 & 18 & 26 & 141 \\
\hline $\begin{array}{l}\text { 6. Union des Démocrates de Gauche } \\
\text { 7. Parti Socialiste-Union Démocratique Populaire } \\
\text { 8. Parti des Libéraux de Gauche }\end{array}$ & $\begin{array}{l}\text { SOFIANOPOULOS Jean } \\
\text { SVOLOS Alexandre } \\
\text { GRIGORIADIS Neocosmos }\end{array}$ & & & & & \\
\hline Front Politique Indépendant & & 137.618 & 8,15 & 16 & 37 & 241 \\
\hline 9. Parti de la Renaissance Hellénique & COTZIAS C., MANIADAKIS C. & & & & & \\
\hline 10. Parti des Nationalistes & TOURCOASSILIS Théodore & & & & & \\
\hline Front de Reconstitution Nationale & & 88.979 & 5,27 & 7 & 29 & 205 \\
\hline 11. Parti National Unioniste & CANELLOPOULOS Panayotis & & & & & \\
\hline 12. Parti Populiste Progressiste & PAPADOPOULOS Nicolaos & & & & & \\
\hline 13. Parti Panhellénique & SAKELLARIOU Alexandre & & & & & \\
\hline 14 Parti National de Grèce & ZÉRVAS Napoléon & 61.575 & 3,65 & 7 & 33 & 198 \\
\hline Front des Agriculteurs et Travailleurs & & 44.308 & 2,62 & 3 & 24 & 155 \\
\hline 15. Rassemblement des Agriculteurs et travailleurs & BALTADZIS Alexandre & & & & & \\
\hline 16. Parti Agraire National Progressiste & MYLONAS Alexandre & & & & & \\
\hline 17. Nouveau Parti & MARKÉZINIS Spyridon & 42.157 & 2,50 & 1 & 20 & 127 \\
\hline
\end{tabular}




\begin{tabular}{|c|c|c|c|c|c|c|}
\hline Partis (suite) & Chefs de Partis & Voix & $\begin{array}{l}\text { Pourcentage } \\
\text { des voix }\end{array}$ & Sièges & $\begin{array}{l}\text { Nombre de } \\
\text { circonscriptions }\end{array}$ & $\begin{array}{c}\text { Nombre de } \\
\text { candidats }\end{array}$ \\
\hline Front National du Peuple Travailleur & & 26.925 & 1,59 & 0 & 23 & 153 \\
\hline 18. Parti National Populiste & MAVROMICHALIS Pierre & & & & & \\
\hline 19. Parti du Tiers État & VAMVÉTSOS Alexandre & & & & & \\
\hline 20. Parti Travailliste de Grèce & DIMITRATOS Aristidis & & & & & \\
\hline 21. Mouvement du Salut National & PAPADAKIS Basile & & & & & \\
\hline 22. Parti National Agraire de « $x »$ (Hites) & GRIVAS Georges & 14.256 & 0,84 & 0 & 20 & 106 \\
\hline 23. Parti des travailleurs de Grèce $(*)$ & BÉRNITAS Jean & 9.132 & 0,54 & 0 & 14 & 85 \\
\hline 24. Parti de Résistance Nationale de Grèce & FOSTÉRIDIS Antoine & 8.260 & 0,49 & 0 & 9 & 52 \\
\hline $\begin{array}{l}\text { Coopération des : } \\
23 \text { Parti des Travailleurs de Grèce * }\end{array}$ & BERNITSAS Jean & 8.127 & 0,48 & 0 & 7 & 45 \\
\hline 25. Mouvement de Renouvellement Politique & VARVOUTIS Georges & & & & & \\
\hline 26. Parti des Libéraux Indépendants & MÉLAS Georges & 3.089 & 0,18 & 0 & 2 & 21 \\
\hline 27. Parti Agraire & PAGOUTSOS Apostolos & 2.191 & 0,13 & 0 & 3 & 11 \\
\hline Front Chrétien Travailliste Agraire & & 1.027 & 0,06 & 0 & 4 & 37 \\
\hline 28. Parti Chrétien Travailliste Agrarien & LAZARIS Jean & & & & & \\
\hline 29. Parti Chrétien des Grecs Orthodoxes & COCORIS Spyridou & & & & & \\
\hline $\begin{array}{l}\text { 30. Parti de la Force Chrétienne Orthodoxe } \\
\text { des Hellènes }\end{array}$ & SOLDATOS Minos & & & & & \\
\hline 31. Parti Chrétien National de Grèce & STOCAS Georges & & & & & \\
\hline 32. Parti Progressiste Chrétien & LYKIARDOPOULOS Constantin & & & & & \\
\hline Union Politique Chrétienne & & 429 & 0,03 & 0 & 3 & 16 \\
\hline 33. Parti Socialiste Chrétien de la Grèce & Comité Directeur & & & & & \\
\hline 34. Nouveau Parti Social & BOTSARIS Spyridon & & & & & \\
\hline 35. Parti des Automobilistes de Grèce & MACARIS Pierre & 157 & 0,01 & 0 & 1 & 6 \\
\hline 36. Parti Agrarien Indépendant & COSTOPOULOS CH. CATSOULADIS A. & 146 & 0,01 & 0 & 1 & 2 \\
\hline
\end{tabular}




\begin{tabular}{|c|c|c|c|c|c|c|}
\hline Partis (suite) & Chefs de Partis & Voix & $\begin{array}{l}\text { Pourcentage } \\
\text { des voix }\end{array}$ & Sièges & $\begin{array}{l}\text { Nombre de } \\
\text { circonscriptions }\end{array}$ & $\begin{array}{l}\text { Nombre de } \\
\text { candidats }\end{array}$ \\
\hline $\begin{array}{l}\text { 37. Parti National Indépendant des Invalides } \\
\text { et Victimes de la Guerre de Grèce }\end{array}$ & GEORGANDAS Georges & 145 & 0,01 & 0 & 2 & 8 \\
\hline 38. Parti des Ouvriers et Artisans de Grèce & Comité Directeur & 97 & 0,01 & 0 & 1 & 5 \\
\hline 39. Parti Indépendant Agricole & BALTSAVIAS Tilémachos & 63 & 0,00 & 0 & 1 & 2 \\
\hline 40. Parti d'Égalité Sociale Chrétienne & Comité Directeur & 62 & 0,00 & 0 & 1 & 2 \\
\hline 41. Parti Agrarien Indépendant de Grèce & & 42 & 0,00 & 0 & 1 & 2 \\
\hline $\begin{array}{l}\text { 42. Parti Indépendant des Artisans et } \\
\text { Professionnels de Grèce }\end{array}$ & TRIGHATZIS Nicolas & 42 & 0,00 & 0 & 1 & 6 \\
\hline 43. Parti National Byzantin de Grèce & ANGÉLOPOULOS Michel & 20 & 0,00 & 0 & 1 & 2 \\
\hline 44. Parti National Démocratique & JOVANOF Byron & 12 & 0,00 & 0 & 1 & 2 \\
\hline Listes d'Indépendants & & 2.979 & 0,18 & 0 & & 33 \\
\hline \multirow[t]{2}{*}{ Candidats isolés } & & 6.742 & 0,40 & 0 & & 383 \\
\hline & & 1.688 .923 & 100 & 250 & & 3.042 \\
\hline
\end{tabular}

(*) Le Parti des Travailleurs de Grèce s'est présenté selon les circonscriptions de manière isolée ou en coalition avec le mouvement de Renouvellement Politique. 


\section{ÉLECTIONS DU 9 SEPTEMBRE 1951}

\begin{tabular}{|c|c|c|c|c|c|c|}
\hline Partis & Chefs de Partis & Voix & $\begin{array}{l}\text { Pourcentage } \\
\text { des voix }\end{array}$ & Sièges & $\begin{array}{l}\text { Nombre de } \\
\text { circonscriptions }\end{array}$ & $\begin{array}{l}\text { Nombre de } \\
\text { candidats }\end{array}$ \\
\hline 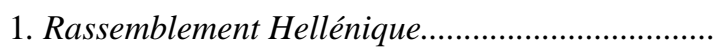 & PAPAGOS Alexandre & 624.316 & 36,53 & 114 & 41 & 329 \\
\hline 2. Union Nationale Progressiste du Centre.............. & PLASTIRAS Nicolas & 401.379 & 23,49 & 74 & 40 & 319 \\
\hline 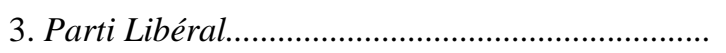 & VÉNIZÉLOS Sophocle & 325.390 & 19,04 & 57 & 41 & 324 \\
\hline 4. Gauche Démocratique Unifiée.............................. & Comité Directeur & 189.640 & 10,57 & 10 & 41 & 215 \\
\hline 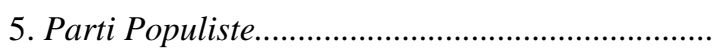 & TSALDARIS Constantin & 113.876 & 6,66 & 2 & 40 & 293 \\
\hline 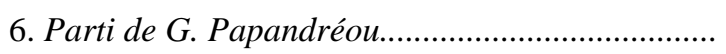 & PAPANDRÉOU Georges & 35.810 & 2,10 & 0 & 19 & 128 \\
\hline 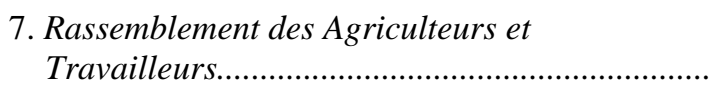 & BALTADZIS Alexandre & 21.009 & 1,23 & 1 & 8 & 41 \\
\hline 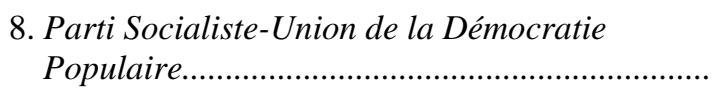 & SVOLOS Alexandre & 3.912 & 0,23 & 0 & 11 & 60 \\
\hline 9. Parti Socialiste Archives du Marxisme................. & Comité Directeur & 53 & 0,00 & 0 & 2 & 2 \\
\hline 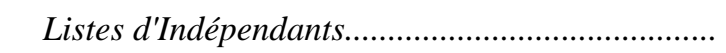 & & 1.554 & 0,09 & 0 & 1 & 2 \\
\hline \multirow[t]{2}{*}{ 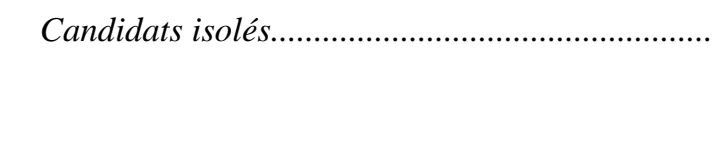 } & & 965 & 0,06 & 0 & 29 & 168 \\
\hline & & 1.708 .904 & 100,00 & 258 & & 1.881 \\
\hline
\end{tabular}




\section{ÉLECTIONS DU 16 NOVEMBRE 1952}

\begin{tabular}{|c|c|c|c|c|c|c|}
\hline Partis & Chefs de Partis & Voix & $\begin{array}{l}\text { Pourcentage } \\
\text { des voix }\end{array}$ & Sièges & $\begin{array}{c}\text { Nombre de } \\
\text { circonscriptions }\end{array}$ & $\begin{array}{c}\text { Nombre de } \\
\text { candidats }\end{array}$ \\
\hline \multirow[t]{2}{*}{ 1. Rassemblement Hellénique....................................... } & PAPAGOS Alexandre & 783.541 & 49,22 & 247 & 99 & 300 \\
\hline & & 544.834 & 34,22 & 51 & 84 & 273 \\
\hline \multicolumn{7}{|l|}{ Union des Partis } \\
\hline 2. Union Nationale Progressiste du Centre............... & PLASTIRAS Nicolas & & & & & \\
\hline 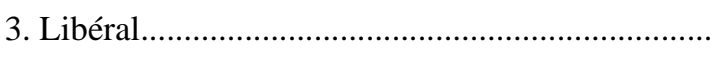 & VÉNIZÉLOS Sophocle & & & & & \\
\hline 4. Socialiste Union de Démocratie Populaire........... & SVOLOS Alexandre & & & & & \\
\hline 5. Gauche Démocratique Unifiée.............................. & PASSALDIS Jean & 152.011 & 9,55 & 0 & 59 & 189 \\
\hline 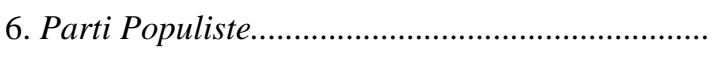 & TSALDARIS Constantin & 16.767 & 1,05 & 0 & 4 & 8 \\
\hline 7. Rassemblement des Agriculteurs et Travailleurs & BALTADZIS Alexandre & 10.431 & 0,66 & 0 & 3 & 8 \\
\hline 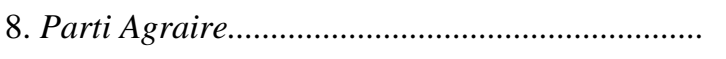 & PAGOUTSOS Apostolos & 691 & 0,04 & 0 & 1 & 1 \\
\hline 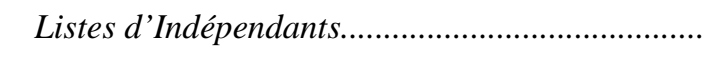 & & 56.679 & 3,57 & 2 & 14 & 50 \\
\hline \multirow[t]{2}{*}{ 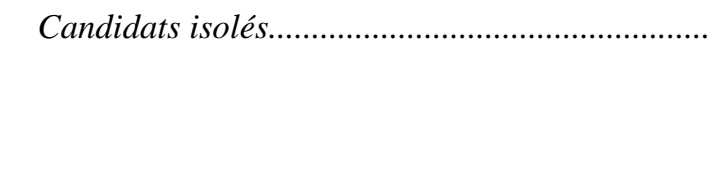 } & & 26.853 & 1,69 & 0 & 71 & 216 \\
\hline & & 1.591.807 & 100,00 & 300 & & 1.045 \\
\hline
\end{tabular}




\section{ÉLECTIONS DU 19 FÉVRIER 1956}

\begin{tabular}{|c|c|c|c|c|c|c|}
\hline Partis & Chefs de Partis & Voix & $\begin{array}{l}\text { Pourcentage } \\
\text { des voix }\end{array}$ & Sièges & $\begin{array}{l}\text { Nombre de } \\
\text { circonscriptions }\end{array}$ & $\begin{array}{l}\text { Nombre de } \\
\text { candidats }\end{array}$ \\
\hline 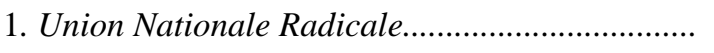 & CARAMANLIS Constantin & 1.594 .112 & 47,38 & 165 & 41 & 299 \\
\hline Union Démocratique & & 1.620 .007 & 48,15 & $(132)^{*}$ & 41 & 300 \\
\hline 2. Union Libérale Démocratique............................. & VÉNIZÉLOS Sophocle & & & 43 & & \\
\hline 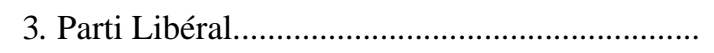 & PAPANDRÉOU Georges & & & 26 & & \\
\hline 4. Parti Démocratique du Peuple Travailleur....... & SVOLOS A.-CARTALIS G. & & & 20 & & \\
\hline 5. Gauche Démocratique Unifiée........................... & PASSALDIS Jean & & & 18 & & \\
\hline 6. Union Nationale Progressiste du Centre........... & PAPAPOLITIS Savvas & & & 15 & & \\
\hline 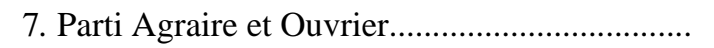 & BALTADZIZ Alexandre & & & 7 & & \\
\hline 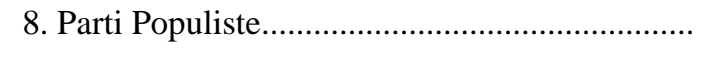 & TSALDARIS Constantin & & & 3 & & \\
\hline 9. Parti Progressiste............................................ & MARKÉZINIS Spyridon & 74.545 & 2,22 & 0 & 34 & 250 \\
\hline 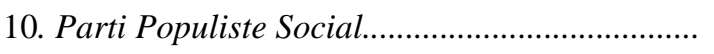 & STÉPHANOPOULOS Stéphanos & 29.375 & 0,88 & 0 & 1 & 8 \\
\hline 11. Parti des Principes de Jean Métaxas................. & MANIADAKIS Constantin & 3.963 & 0,11 & 0 & 1 & 1 \\
\hline 12. Parti de la Démocratie Chrétienne.................... & PSAROUDAKIS Nicolas & 449 & 0,01 & 0 & 1 & 2 \\
\hline 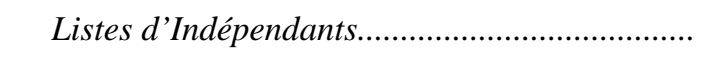 & & 31.022 & 0,92 & 3 & 5 & 24 \\
\hline \multirow[t]{2}{*}{ 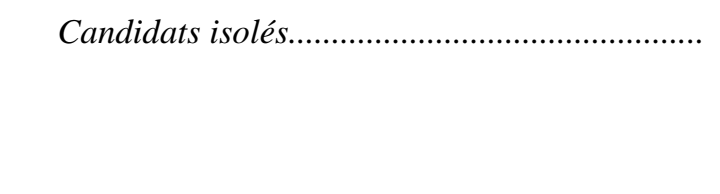 } & & 10.888 & 0,33 & 0 & 25 & 98 \\
\hline & & 3.364.361 & 100,00 & 300 & & 981 \\
\hline
\end{tabular}

(*) Ce nombre entre parenthèses représente le total dont les détails se trouvent immédiatement dessous. 


\section{ÉLECTIONS DU 11 MAI 1958}

\begin{tabular}{|c|c|c|c|c|c|c|}
\hline Partis & Chefs de Partis & Voix & $\begin{array}{l}\text { Pourcentage } \\
\text { des voix }\end{array}$ & Sièges & $\begin{array}{c}\text { Nombre de } \\
\text { circonscriptions }\end{array}$ & $\begin{array}{c}\text { Nombre de } \\
\text { candidats }\end{array}$ \\
\hline 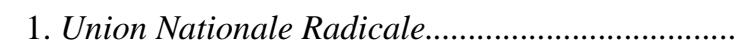 & CARAMANLIS Constantin & 1.583 .885 & 41,17 & 171 & 55 & 300 \\
\hline 2. Gauche Démocratique Unifiée............................... & PASSALIDIS Jean & 939.902 & 24,43 & 79 & 55 & 300 \\
\hline 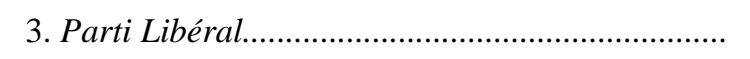 & VÉNIZÉLOS S.-PAPANDRÉOU G. & 795.445 & 20,68 & 36 & 55 & 300 \\
\hline Union Progressiste Agraire Démocratique & MARKÉZINIS Spyridon & 408.787 & 10,62 & 10 & 54 & 292 \\
\hline 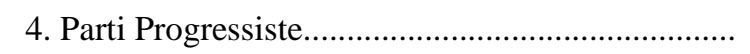 & PAPAPOLITIS Savvas & & & & & \\
\hline 5. Union Nationale Progressiste du Centre............... & BALTADZIS Alexandre & & & & & \\
\hline 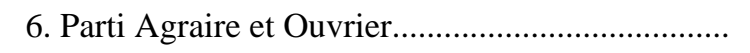 & ALAMANIS Stélios & & & & & \\
\hline \multicolumn{7}{|l|}{ 7. Parti Démocratique du Peuple Travailleur............ } \\
\hline Union du Parti Populiste & & 113.358 & 2,94 & 4 & 29 & 169 \\
\hline 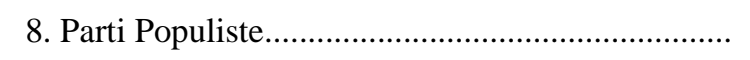 & TSALDARIS C. CANELLOPOULOS P. & & & & & \\
\hline 9. Parti Populiste Social................................................ & STÉPHANOPOULOS St. & & & & & \\
\hline 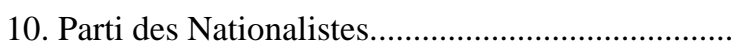 & TOURCOVASSILIS Théodore & & & & & \\
\hline 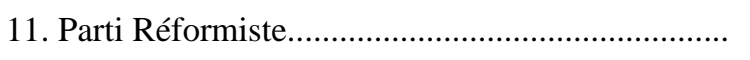 & COTZAMANIS Sotirios & & & & & \\
\hline 12. Parti Démocratique Réformiste.............................. & KÉTSÉAS Thémistocle & & & & & \\
\hline 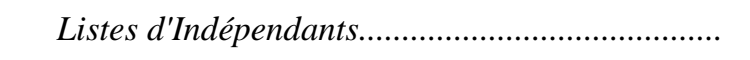 & & 4.009 & 0,10 & 0 & 5 & 12 \\
\hline \multirow[t]{2}{*}{ 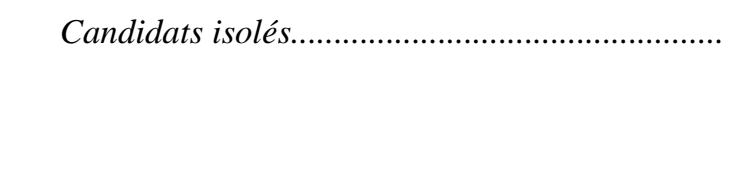 } & & 2.399 & 0,06 & 0 & 26 & 110 \\
\hline & & 2.847.785 & 100,00 & 300 & & 1.483 \\
\hline
\end{tabular}




\section{ÉLECTIONS DU 29 OCTOBRE 1961}

\begin{tabular}{|c|c|c|c|c|c|c|}
\hline Partis & Chefs de Partis & Voix & $\begin{array}{l}\text { Pourcentage } \\
\text { des voix }\end{array}$ & Sièges & $\begin{array}{c}\text { Nombre de } \\
\text { circonscriptions }\end{array}$ & $\begin{array}{c}\text { Nombre de } \\
\text { candidats }\end{array}$ \\
\hline 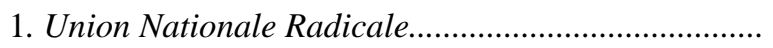 & CARAMANLIS Constantin & 2.347 .824 & 50,81 & 176 & 55 & 300 \\
\hline Coalition électorale des & & 1.555 .442 & 33,66 & 100 & 55 & 300 \\
\hline 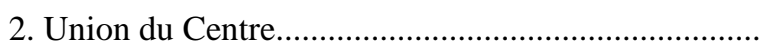 & PAPANDRÉOU Georges & & & & & \\
\hline 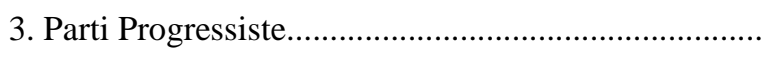 & MARKÉZINIS Spyridon & & & & & \\
\hline Front Pandémocratique Agraire de Grèce & & 675.867 & 14,63 & 24 & 55 & 300 \\
\hline 4. Gauche Démocratique Unifiée..................................... & PASSALIDIS Jean & & & & & \\
\hline 5. Parti National Agraire................................................ & & & & & & \\
\hline 6. Union de Libéraux et Combattants Nationaux.......... & TSARLABAS Marcos & & & 0 & 2 & 2 \\
\hline & & 41.550 & 0,90 & & & \\
\hline \multirow[t]{2}{*}{ 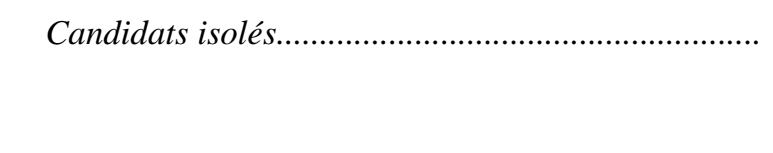 } & & & & 0 & 28 & 93 \\
\hline & & 4.620 .683 & 100,00 & 300 & & 995 \\
\hline
\end{tabular}




\section{ÉLECTIONS DU 3 NOVEMBRE 1963}

\begin{tabular}{|c|c|c|c|c|c|c|}
\hline Partis & Chefs de Partis & Voix & $\begin{array}{l}\text { Pourcentage } \\
\text { des voix }\end{array}$ & Sièges & $\begin{array}{c}\text { Nombre de } \\
\text { circonscriptions }\end{array}$ & $\begin{array}{c}\text { Nombre } \\
\text { de } \\
\text { candidats }\end{array}$ \\
\hline 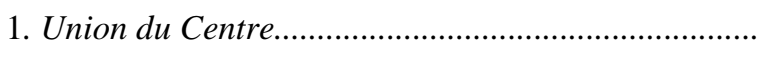 & PAPANDRÉOU Georges & 1.962 .079 & 42,04 & 138 & 55 & \\
\hline 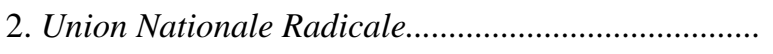 & CARAMANLIS Constantin & 1.837.377 & 39,37 & 132 & 55 & \\
\hline 3. Gauche Démocratique Unifiée................................... & PASSALLIDIS Jean & 669.267 & 14,34 & 28 & 54 & \\
\hline 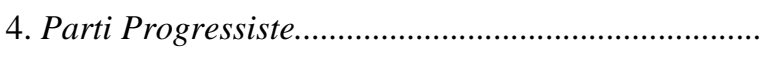 & MARKÉZINIS Spyridon & 173.981 & 3,73 & 2 & 51 & \\
\hline \multirow[t]{2}{*}{ 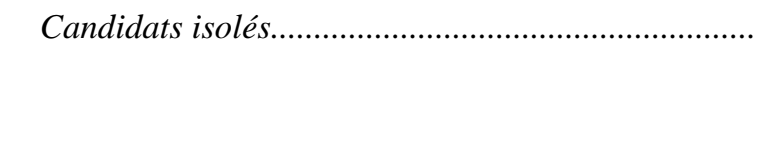 } & & 24.472 & 0,52 & 0 & & \\
\hline & & 4.667.176 & 100,00 & 300 & & \\
\hline
\end{tabular}




\section{ÉLECTIONS DU 16 FÉVRIER 1964}

\begin{tabular}{|c|c|c|c|c|c|c|}
\hline Partis & Chefs de Partis & Voix & $\begin{array}{l}\text { Pourcentage } \\
\text { des voix }\end{array}$ & Sièges & $\begin{array}{l}\text { Nombre de } \\
\text { circonscriptions }\end{array}$ & $\begin{array}{c}\text { Nombre } \\
\text { de } \\
\text { candidats }\end{array}$ \\
\hline 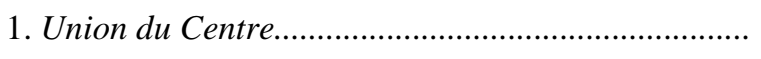 & PAPANDRÉOU Georges & 2.424 .477 & 52,72 & 171 & 55 & \\
\hline Coalition de l' & & 1.621 .546 & 35,26 & 107 & 55 & \\
\hline 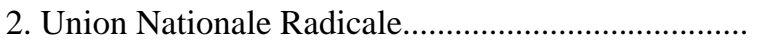 & CANELLOPOULOS Panayotis & & & & & \\
\hline 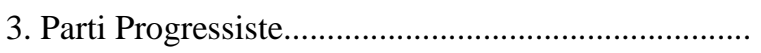 & MARKÉNIS Spyridon & & & & & \\
\hline 4. Gauche Démocratique Unifiée...................................... & PASSALIDIS Jean & 542.865 & 11,80 & 22 & 31 & \\
\hline \multirow[t]{2}{*}{ 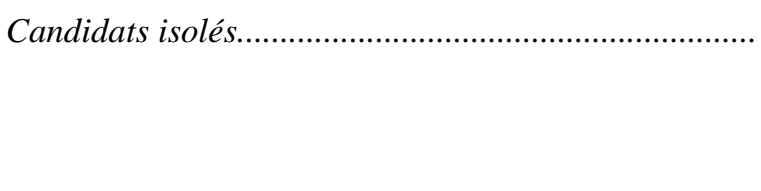 } & & 9.951 & 0,22 & 0 & & \\
\hline & & 4.598 .839 & 100,00 & 300 & & \\
\hline
\end{tabular}


[p. 506 à 510]

\section{INDEX DES NOMS GRECS CITÉS}

Retour à la table des matières

Alantzis V.

Alexandris A.

Alamanis S.

Ambatiélos T.

Andréadis (Stratis C.)

Angélopoulos (frères)

Angélopoulos $\mathrm{M}$.

Antonopoulos A.

Apostolidis A.

Athanassiadis C. et P.

Athanassiadis-Bodossakis Th.

Athanassiadis-Novas G.

Averof E.

Bacatsélos G.

Baltadzis A.

Baltsavias T.

Béloyiannis $\mathrm{N}$.

Bérnitsas J.

Bitakis A.

Botsaris S.

Boutos J.

Brillakis A..

Cafandaris G.

Canellopoulos A.

Canellopoulos L.

Canellopoulos P.
Capsalis Th.

Caramanlis C.

Caramaounas L.

Caranis (entreprise)

Caréla (entreprise)

Caroussos

Cartalis G.

Cassimatis G.

Catsambas Ch.

Catsotas P.

Catsoulidis A.

Chandris G. 370.

Chatzibeis F.

Choïdas

Christacos D.

Chrysostome (Sa Béatitude)

Cladakis G.

Cocas P.

Coccoris S.

Cocorellis J.

Colettis G.

Coliyannis C.

Colocotronis Th.

Constantin XII *

Constantin XIII *

Numérotation en suivant celle des rois de Byzance. 
Coracas M.

Costopoulos Ch.

Costopoulos S.

Cotzamanis S.

Cotzias C.

Coutsoumaris G.

Déliyiannis Th.

Démértzis C.

Dimitratos A.

Diomodis A.

Dovas C.

Dracos G.

Eftaxias L.

Efstatopoulos C.

Eliopoulos S.

Ephremidis -B.

Fix

Fostéridis A.

Fostiropoulos S.

Frangistas G.

Frédérika (Reine)

Garoufalias P.

Gennimatas J.

Georgacopoulos C.

Georgantas G.

Georges I ${ }^{\mathrm{er}}$.

Numérotation en suivant celle des rois de Byzance.
Georges II

Glézos M.

Glücksburg

Gonatas S.

Goulandris S.

Gounaris D.

Grammatidis Ch.

Grigoriadis N.

Grivas G.

Hanotis G.V .

Héliopoulos E.

Helmis D.

Iliopoulos S.

Ilion I.

Jovanof B.

Kétséas Th.

Kioussopoulos D.

Kitsikis D.

Kitsikis N.

Kyrkos L.

Kyrkos M.

Ladopoulos G.

Lambrakis Ch.

Lambrakis G.

Lazaris J.

Livanos S.

Loumakis K. 
Lycourézos P.

Lykiardopoulos C.

Macarios Mgr

Macaris P.

Macris Ph.

Macris $\mathrm{T}$.

Malcotsis S.

Maniadakis C.

Marinopoulos P.

Mariolis D.

Marlkézinis S.

Mavrocordatos A.

Mavromichalis P.

Mavromichalis S.

Mavros G.

Maximos D.

Mélas G.

Mercouri M.

Mercouris S.

Métaxas J.

Mitsotakis C.

Mylonas A.

Néphéloudis V.

Niarchos S.

Nomicos P.

Onassis A.

Othon $\mathrm{I}^{\mathrm{er}}$

Pagoutsos A.
Pamboucas C.

Pangalos Th.

Papachristos E

Papadakis B.

Papadopoulos N.

Papagos A.

Papalassis A.

Papaligouras P.

Papanastasiou A.

Papandréou A.

Papandréou G.

Papanicolaou A.

Papapolitis S.

Papapolyzos D.

Papas T.

Papastratos

Paraskévopoulos J.

Parcalidis D.

Passalidis J.

Paul I ${ }^{\mathrm{er}}$

Pentzopoulos D.

Pipinellis $\mathrm{P}$.

Plastiras N.

Plytas G.

Porphyroyennis N.

Potamianos Ch.

Poulitsas P.

Protopapadakis A.

Psaroudakis N.

Pyromaglou K. 
Rallis J.

Rallis G.

Rendis C.

Rodopoulos C.

Sakellariou A.

Sakellariou V.

Sakellariou

Scalistiris D.

Soldatos M.

Sophianopoulos J.

Sophie (princesse)

Sophoulis Th.

Sourambas (frères)

Spiliopoulos G.

Stavrianos L.S.

Stassinopoulos H. et N.

Stéphanopoulos St.

Stocas G.

Stratis D.

Stratos A.

Svolos A.

Svoronos N.G.

Théodorakis $\mathrm{M}$.

Théotokis J.

Théotokis G.

Théotokis S.

Thymogiannis Ch.

Toumbas J.

Tourcovassilis Th.

Trézos E.
Tricoupis Ch.

Trighatzis N.

Tsaldaris C.

Tsaldaris P.

Tsarlabas M.

Tsatsos A.

Tsirimocos E.

Tsoudéros E.

Typaldos

Vamvétsos A.

Varvoutis G.

Vélidis C.

Vélios S.

Vénizélos E.

Vénizélos S.

Vérnicos

Vgénopoulos $\mathrm{T}$.

Vlachou H.

Xydis S.G.

Zachariadis N.

Zaïmis A.

Zervas N.

Zigdis J.

Zographos H.

Zographos Z.

Zolotas X.

Zorbas N 
[p. 511à 521]

\section{appendice cartographique * FORCE ÉLECTORALE \\ DES PRINCIPAUX PARTIS}

$\underline{\text { Retour à la table des matières }}$

Les pourcentages de voix qu'expriment les cartes de cet appendice ont été calculés sur le nombre des électeurs ayant voté. 
[p.512, sans texte, p. 513]

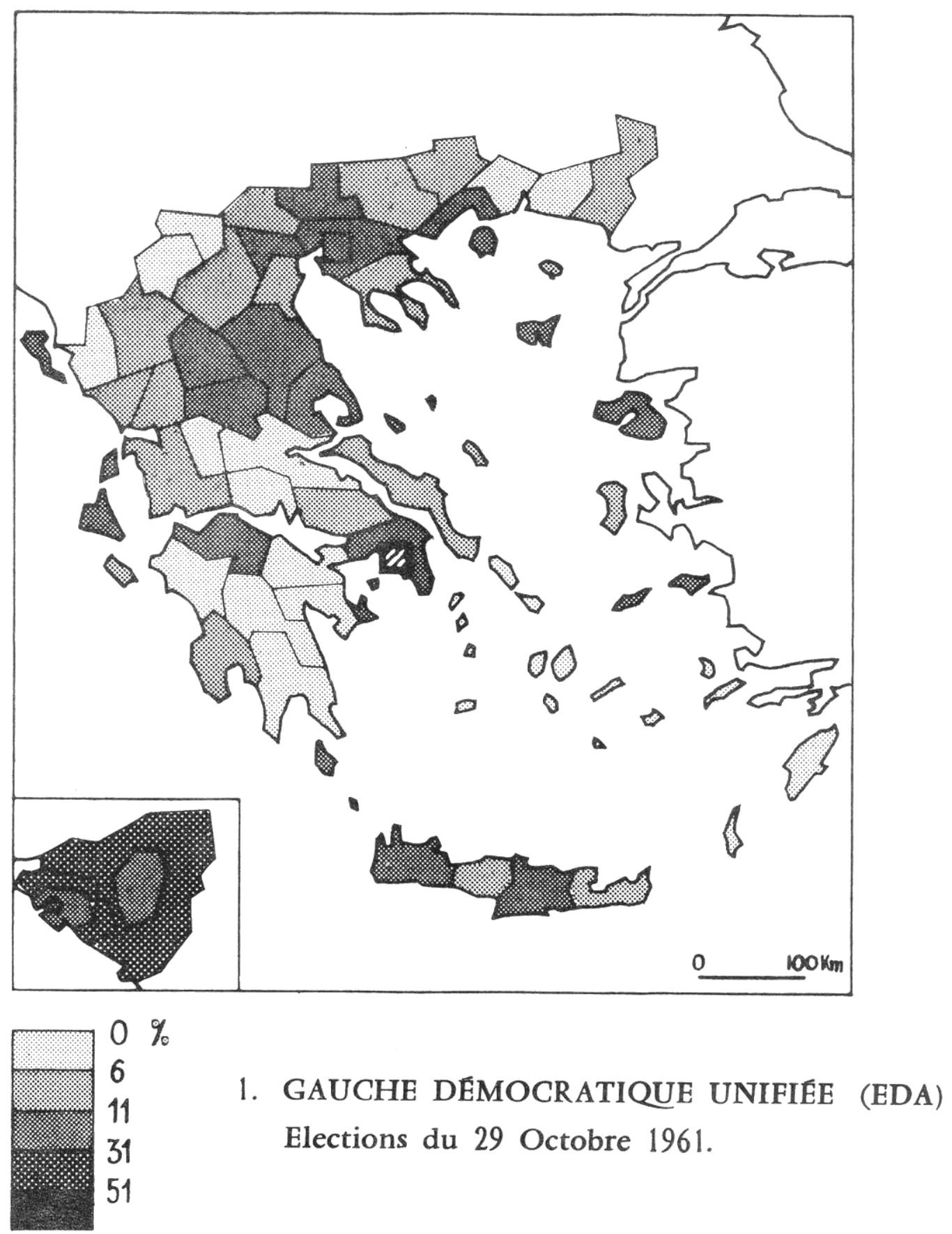




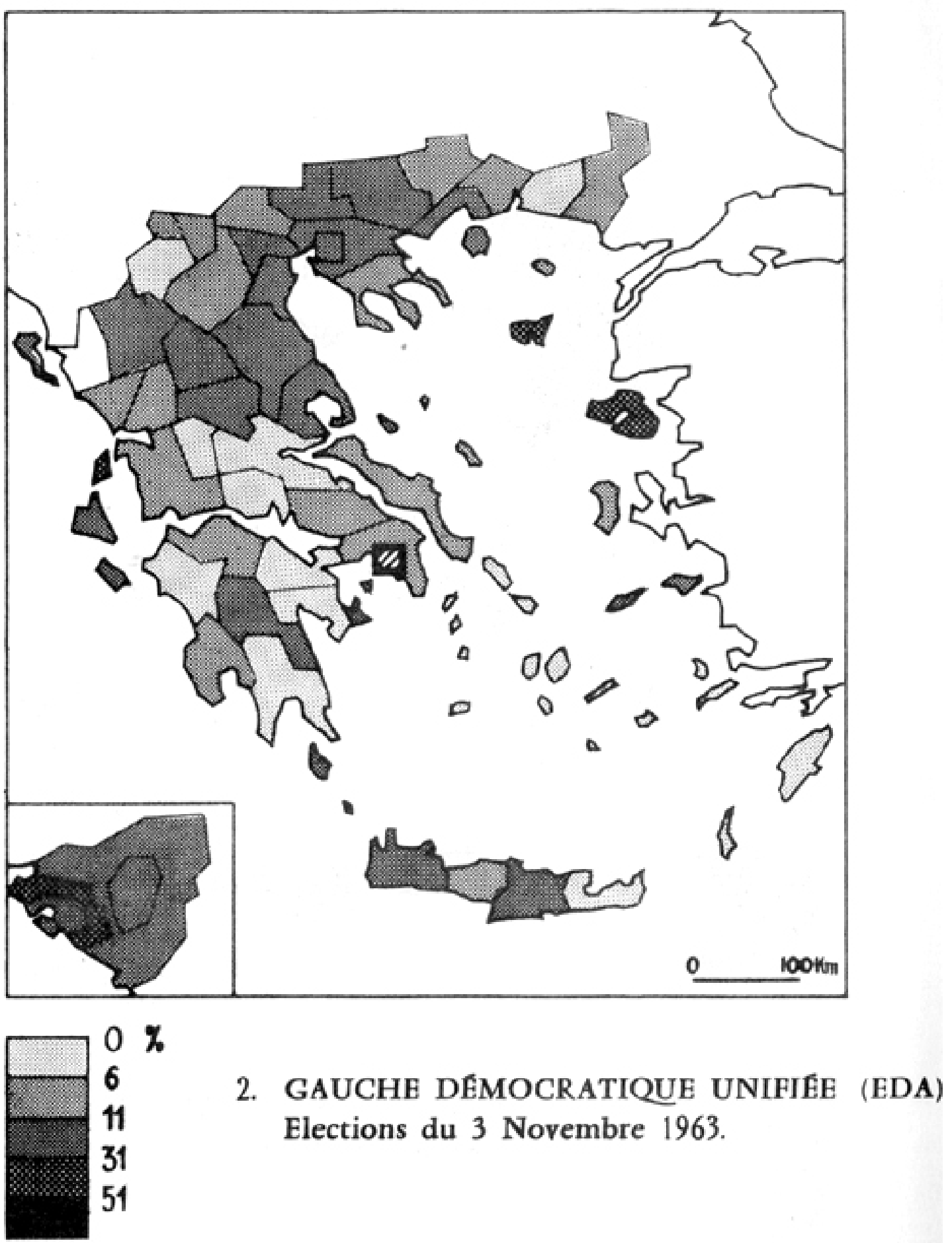




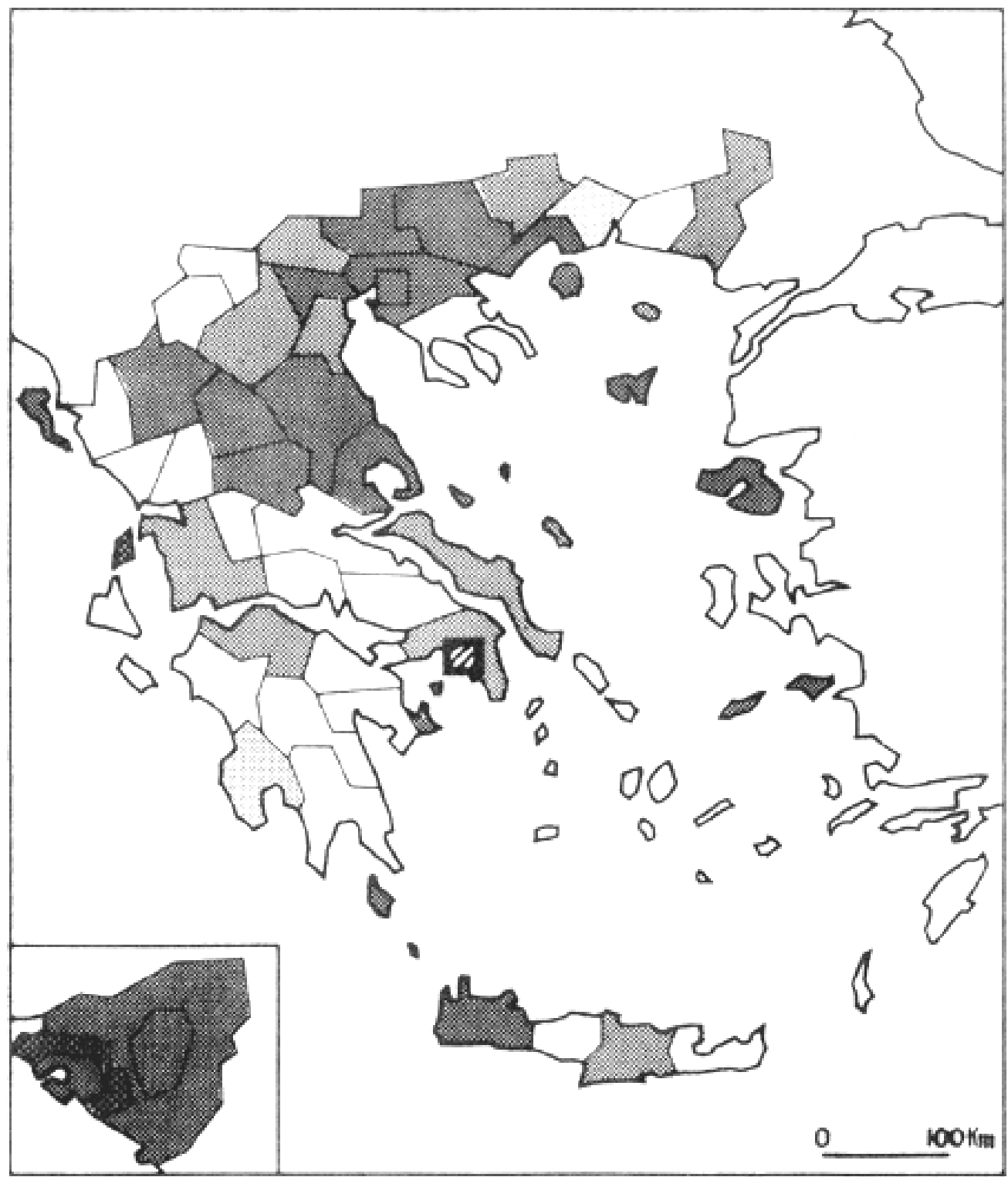

$0 \%$
6
11
31
51

\section{GAUCHE DEMOCRATIQUE UNIFIEE (EDA) Elections du 16 Février 1964.}




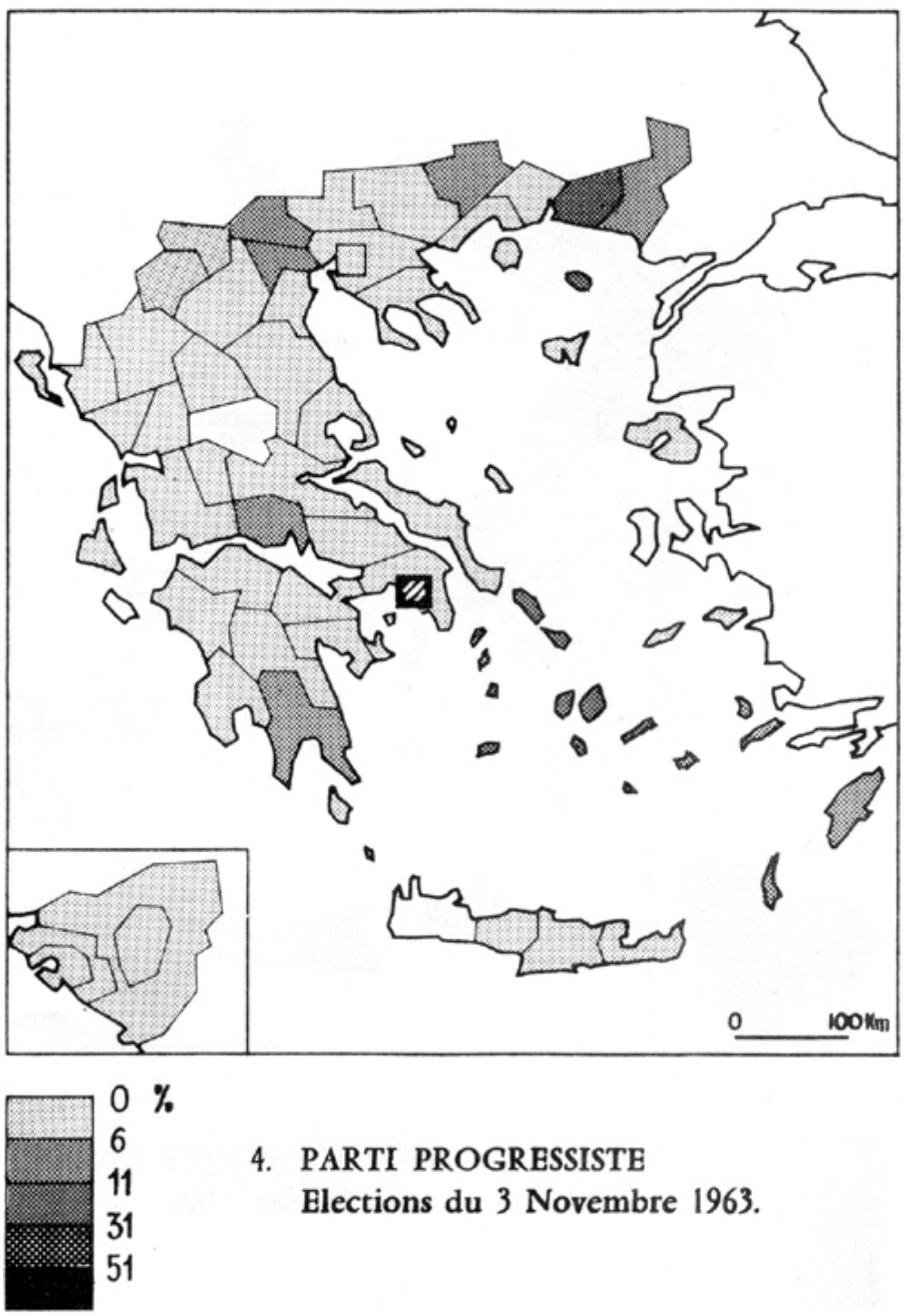




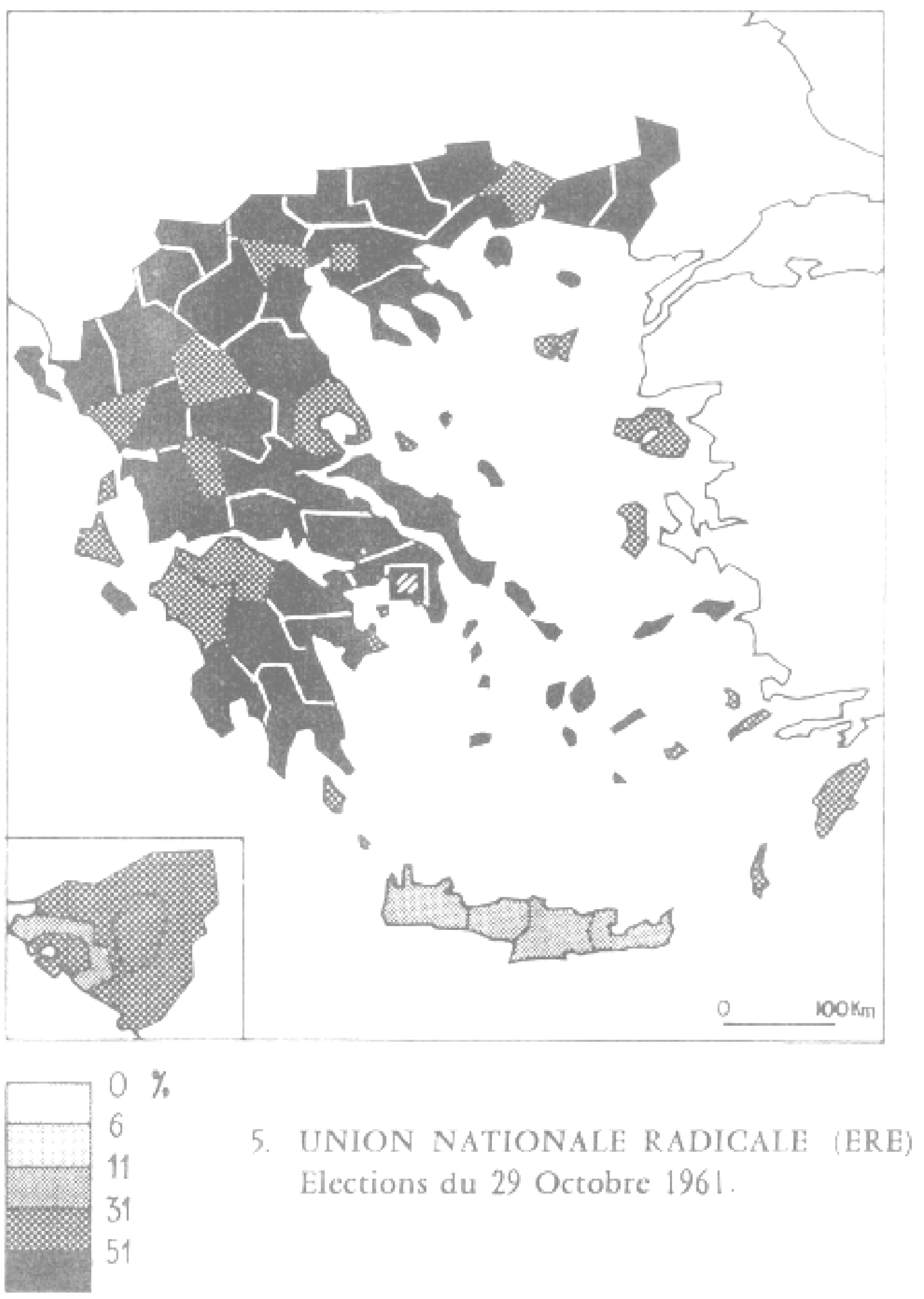



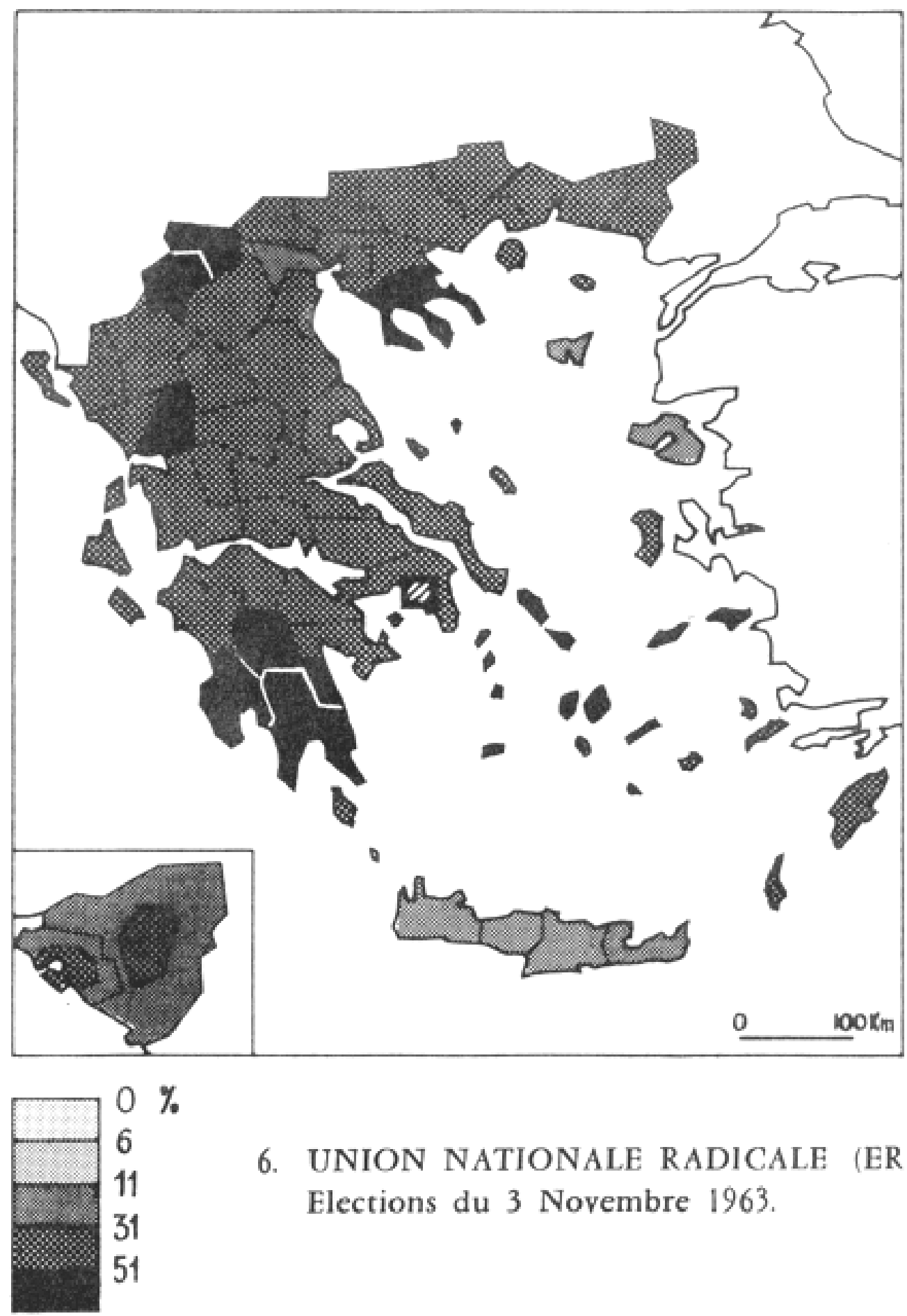

6. UNION NATIONALE RADICALE (ERE) Elections du 3 Novembre 1963. 

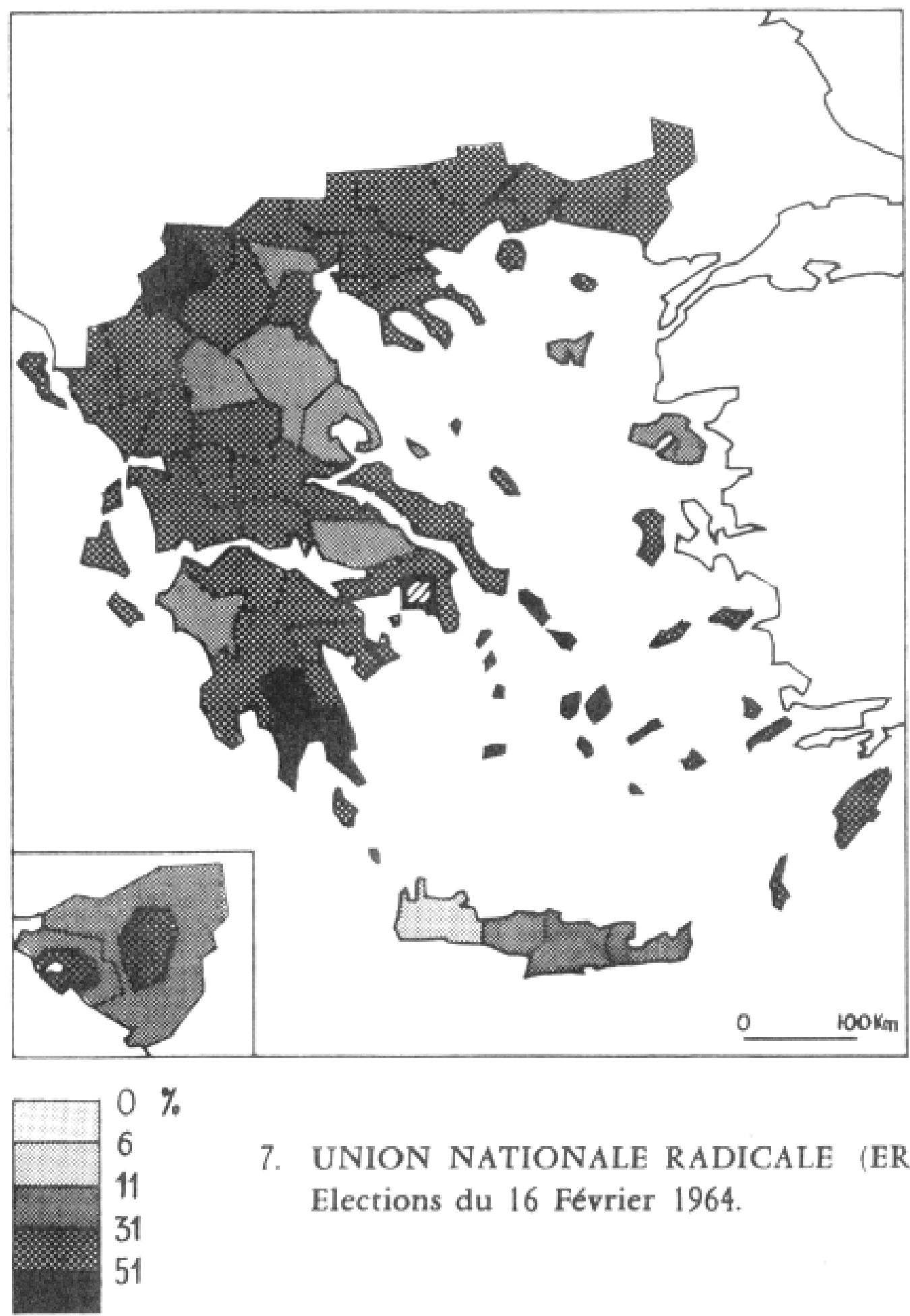

7. UNION NATIONALE RADICALE (ERE) Elections du 16 Février 1964. 


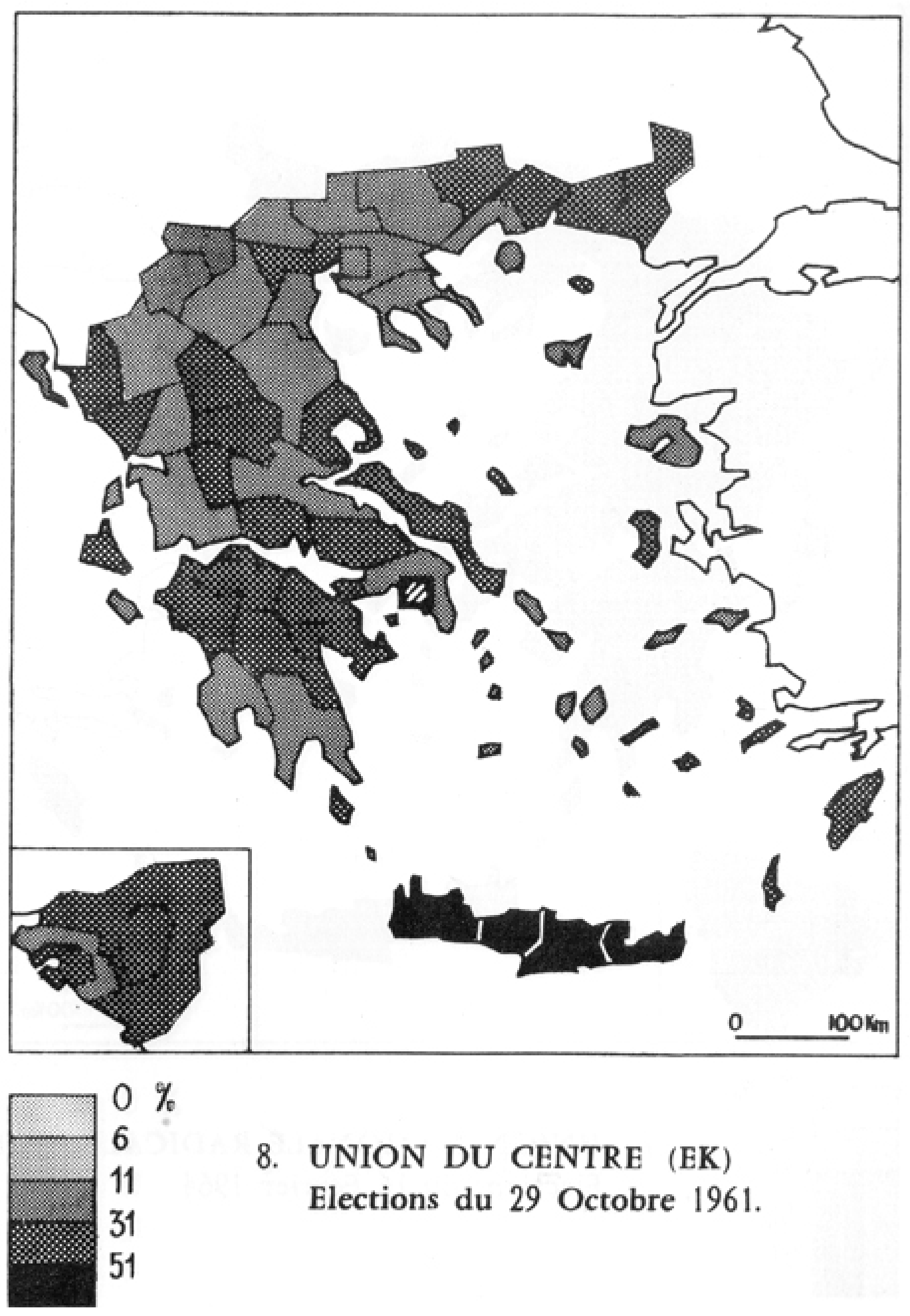




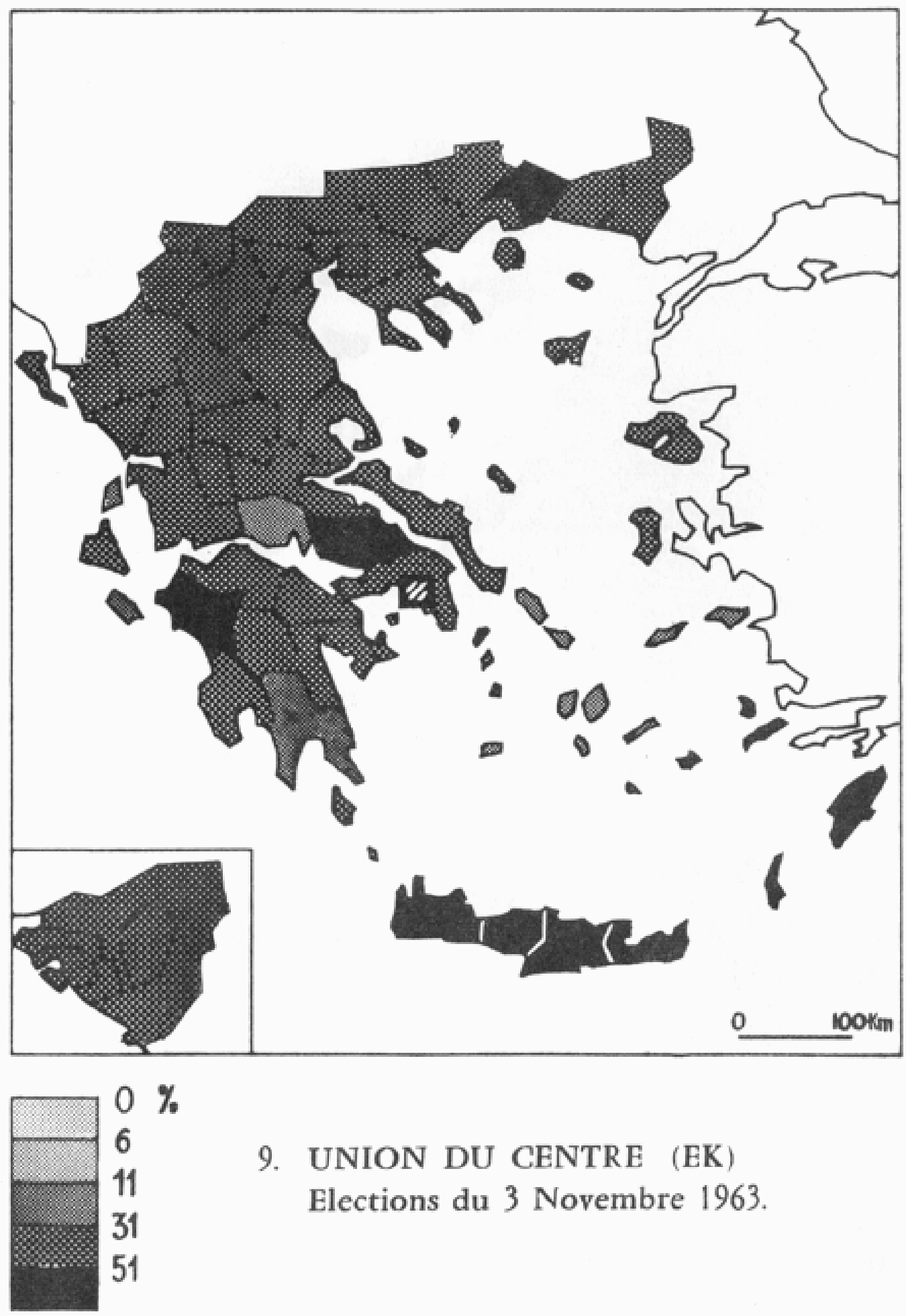




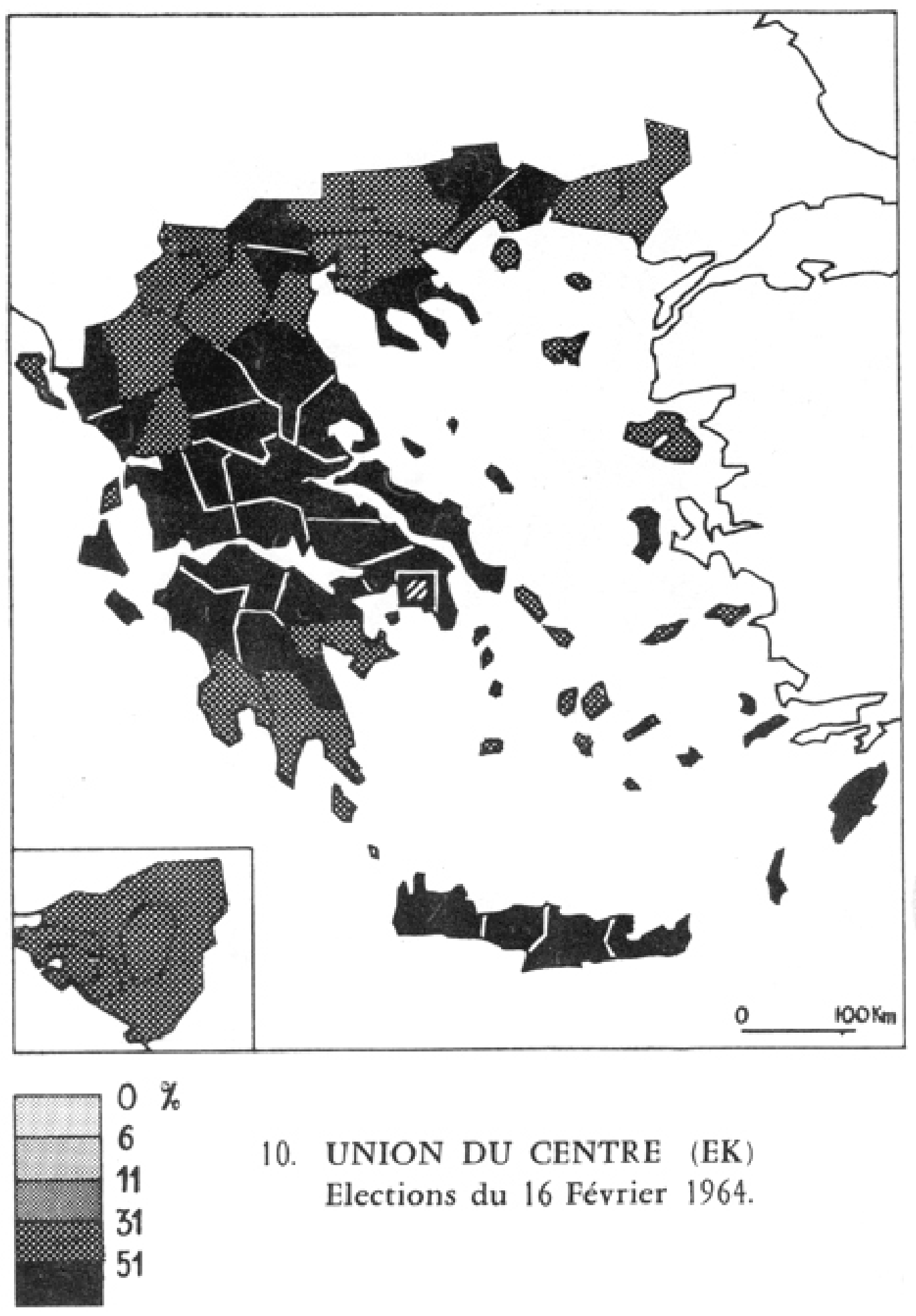


CIRCONSCRIPTIONS ÉLECTORALES ACTUELLES DE LA GRÈCE

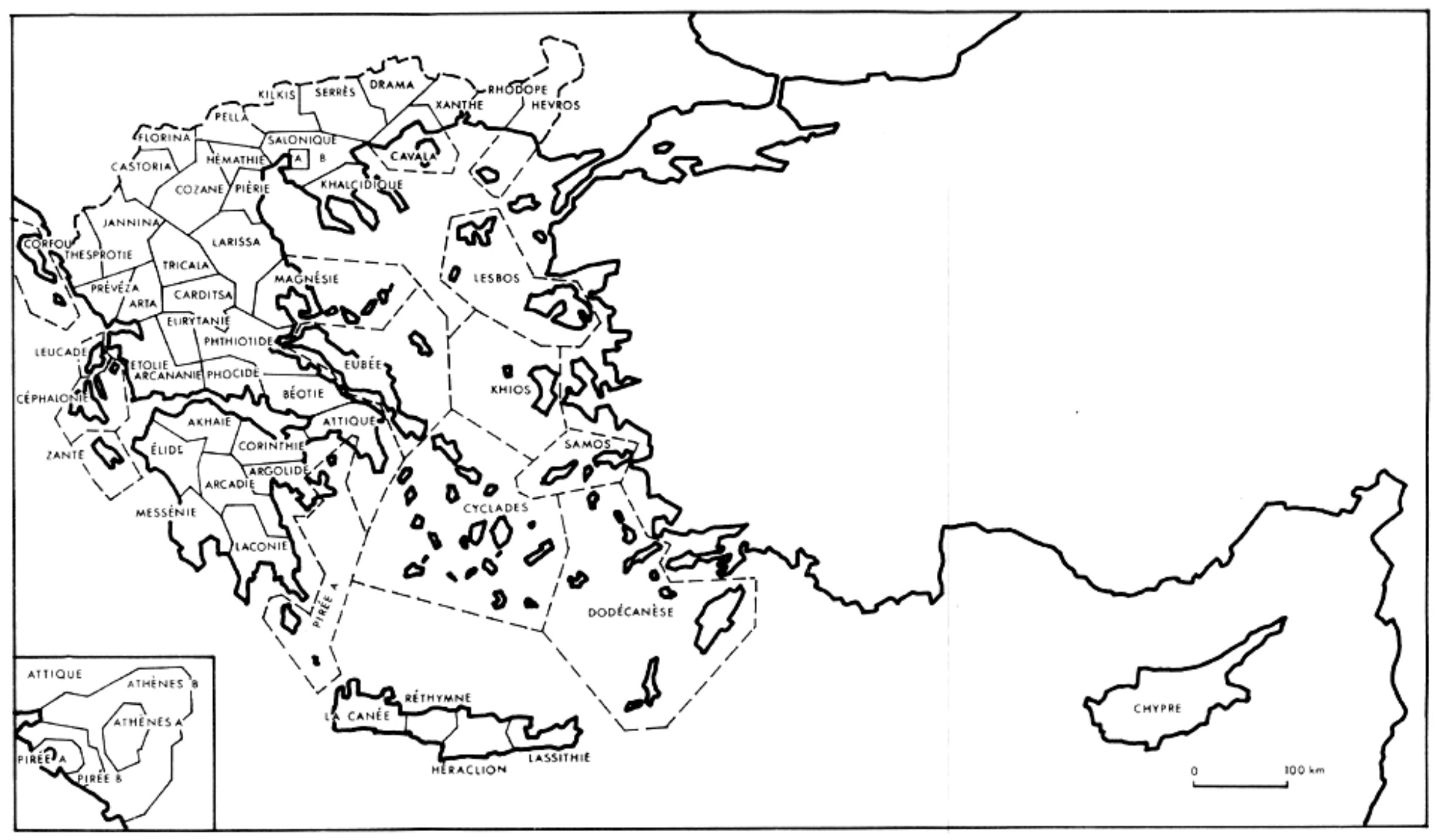

